\title{
WestVirginiaUniversity
}

THE RESEARCH REPOSITORY @ WVU

Graduate Theses, Dissertations, and Problem Reports

2016

\section{Load testing and recommended repairs for dailey branch bridges - milepost 1.4 to 5.8}

\author{
Luis Carlos Parra-Luckert
}

Follow this and additional works at: https://researchrepository.wvu.edu/etd

\section{Recommended Citation}

Parra-Luckert, Luis Carlos, "Load testing and recommended repairs for dailey branch bridges - milepost 1.4 to 5.8" (2016). Graduate Theses, Dissertations, and Problem Reports. 3985.

https://researchrepository.wvu.edu/etd/3985

This Problem/Project Report is protected by copyright and/or related rights. It has been brought to you by the The Research Repository @WVU with permission from the rights-holder(s). You are free to use this Problem/Project Report in any way that is permitted by the copyright and related rights legislation that applies to your use. For other uses you must obtain permission from the rights-holder(s) directly, unless additional rights are indicated by a Creative Commons license in the record and/ or on the work itself. This Problem/Project Report has been accepted for inclusion in WVU Graduate Theses, Dissertations, and Problem Reports collection by an authorized administrator of The Research Repository @ WVU. For more information, please contact researchrepository@mail.wvu.edu. 


\title{
Load Testing and Recommended Repairs for Dailey Branch Bridges - Milepost 1.4 to 5.8
}

\author{
Luis Carlos Parra-Luckert
}

\author{
A problem report submitted to \\ The College of Engineering and Mineral Resources at \\ West Virginia University in partial fulfillment of the \\ requirements for the degree of \\ Master of Science \\ In \\ Civil Engineering
}
Hota V.S. GangaRao, Ph.D., P.E., Chair Udaya Halabe, Ph.D. Mark Skidmore
Department of Civil and Environmental Engineering

\author{
Morgantown, West Virginia \\ 2016
}

Keywords: Strengthening, Timber, GFRP, Wraps, Epoxy, Railroads, Bridges Copyright 2016 Luis Carlos Parra-Luckert 


\section{ABSTRACT \\ Load Testing and Recommended Repairs for Dailey Branch Bridges - Milepost 1.4 to 5.8}

\section{Luis Carlos Parra-Luckert}

The West Virginia Department of Transportation State Rail Authority sponsored a study to evaluate the condition of the railroad bridges on the Dailey Branch in Elkins, WV. The evaluations included field inspections, load rating, load testing, and a repair plan. A total of 2 steel bridges and 3 timber bridges were part of the study. The repair plan focused on identifying deteriorated timber bridge members for potential Glass Fiber Reinforced Polymer (GFRP) wrap repair. Information on dimensions and deterioration was gathered through field inspections. A timber specialist determined the species and grade of the timber bridges, finding most members to be Select Structural lumber of Southern Pine species. A preliminary analysis was performed to ensure that the bridges would withstand a hi-rail dump truck and a locomotive during load testing. A total of 76 strain gages were installed on all 5 bridges to record bending, shear, and axial compression data.

Steel Bridge 1.4 is a 2 span steel through-girder bridge with spans of roughly $98 \mathrm{feet}$, and the measured field strains correlated well to those predicted through load rating analysis. The other steel bridge, Bridge 5.8, had field measurements of about 1.5 times lower than theoretical predictions, likely due to the contribution of the track structure on the $20^{\prime}$ span. The field measured strains for the timber bridges were always less than theory for bending and shear, typically by a factor of about 2 , due to the extra stiffness added through composite action between the ties and track together with the stringers, as evident through the shifting of the neutral axis. Field compression strains in the posts were typically higher than predicted, except for two cases, which are most likely due to the section losses in the instrumented posts and uneven bearing conditions.

All bridges were load rated using AREMA standard Cooper E 80, a 286K freight railcar, and GP 38 locomotive with the analysis assumptions verified during the field load testing process. Under normal rating conditions, the bridges do not meet Cooper $\mathrm{E} 80$ rating, but they can safely carry all other equipment. Recommendations for maintenance were made for the steel bridges. A cost-benefit analysis on timber bridge repair was used to recommend stringers to be replaced, and substructure members to be wrapped with GFRP, and filled with resin and bulk filler. 


\section{ACKNOWLEDGEMENTS}

I wish to thank Dr. Hota GangaRao for giving me the opportunity to perform research in the field of structural engineering and composite materials under his mentorship and guidance. I had the opportunity to grow, both academically and professionally, as a student and a researcher thanks to his lectures and advice. Through his constructive criticism and patience, I was able to develop confidence, which then allowed me to accomplish my goal of obtaining a graduate degree in civil engineering. I would like to thank Mark Skidmore for all of his technical advice and guidance. Mark's support in the computer lab, the engineering lab, and the field made it possible for this work to be completed. His wisdom was of very high value during my stay at West Virginia University. I would also like to thank Dr. Udaya B. Halabe for all the knowledge shared through his coursework and graduate student organization.

I appreciate the funding provided by the West Virginia State Rail Authority through WVU-CFC, if it was not for their support I would have not achieved any of this work. I also appreciate Jerry Nestor for assisting with all of the laboratory work, as well as teaching me the skills necessary to perform laboratory testing. Many fellow graduate students provided me with laboratory and computer assistance for which I am very thankful for. Thus, I would like to thank Anudeep Paraitham, Kumar Karri, Piyush Soti, and Praveen Majjigapu.

Finally, I am endlessly appreciative of my entire family who has always supported me throughout my life and career. I am ultimately able to pursue and obtain my Master's Degree from West Virginia University thanks to all of the sacrifices my grandparents, parents, and other relatives have made. 


\section{Table of Contents}

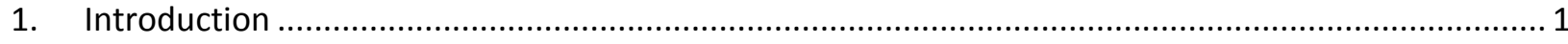

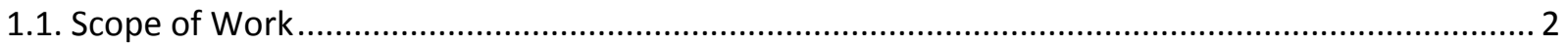

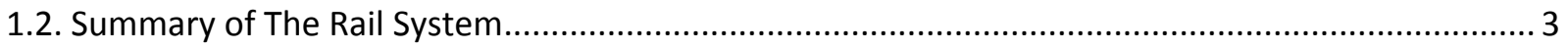

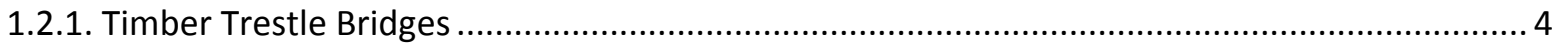

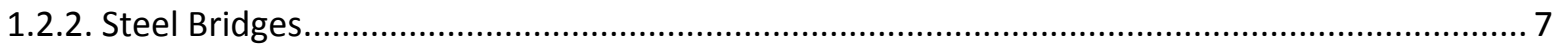

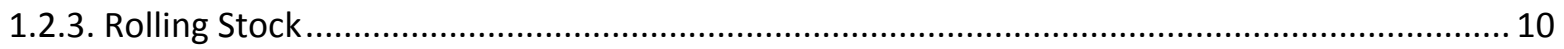

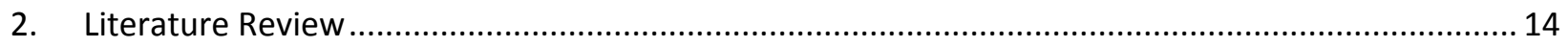

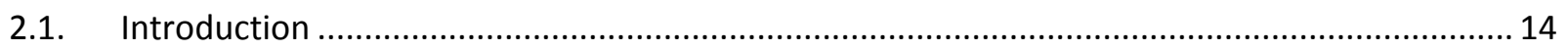

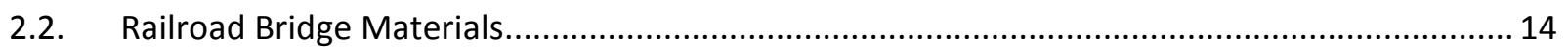

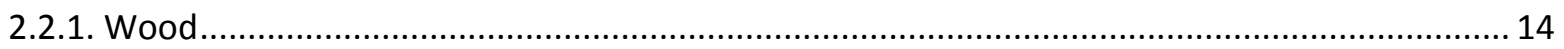

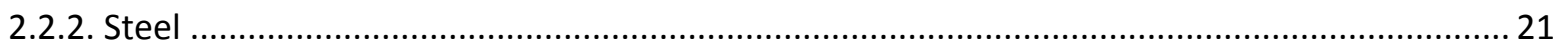

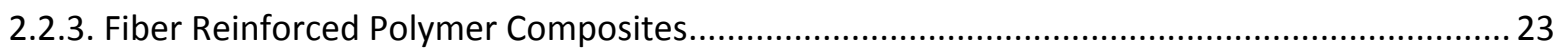

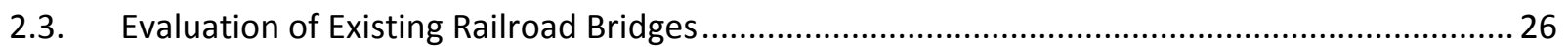

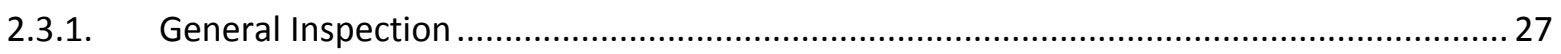

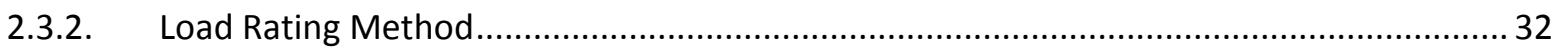

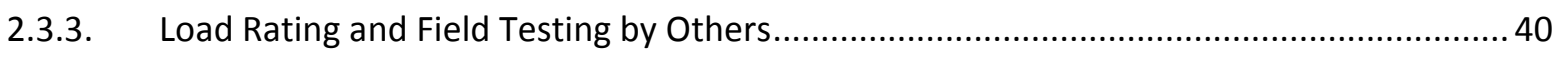

2.4. Rehabilitation of Timber Structures using FRP Composites ............................................... 49

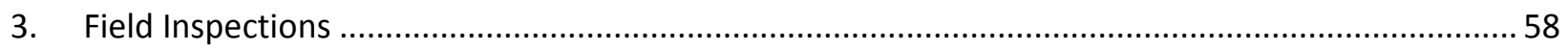

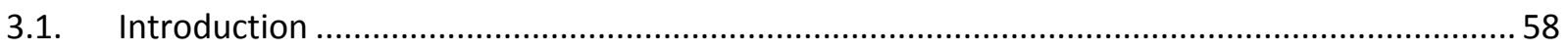

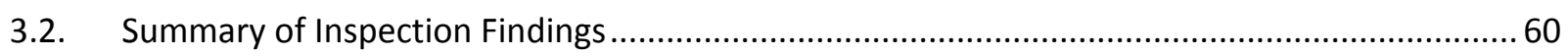

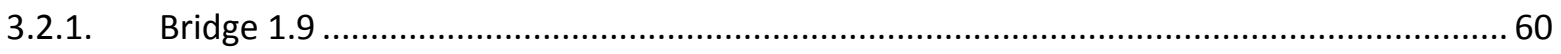

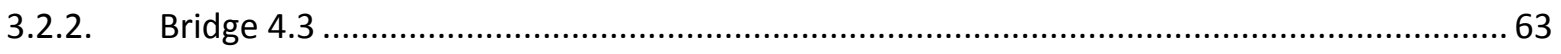

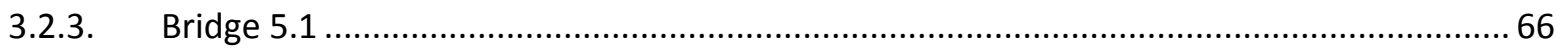

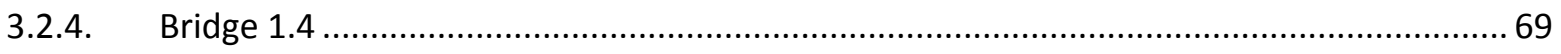

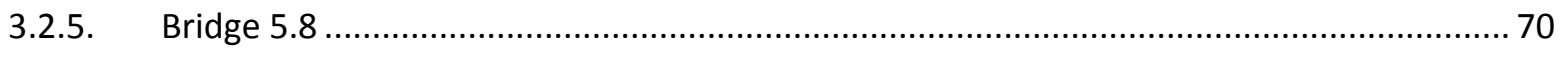




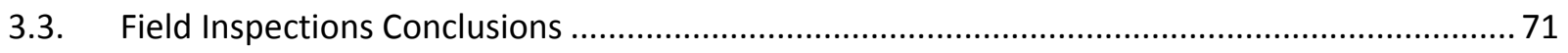

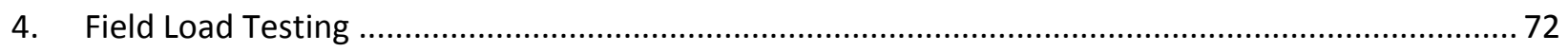

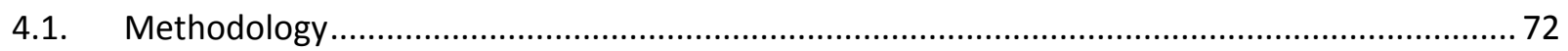

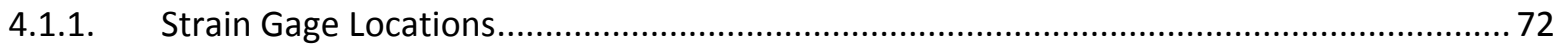

4.1.2. Axle Weights and Spacing - Dailey Checks ................................................................ 74

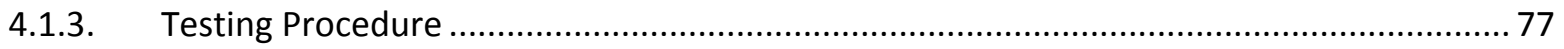

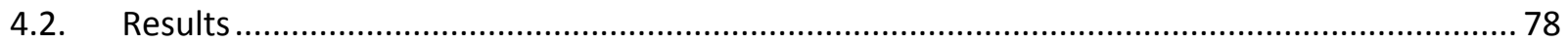

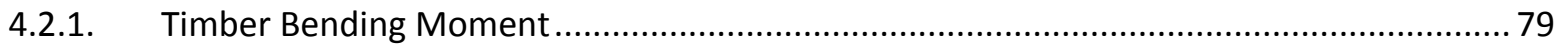

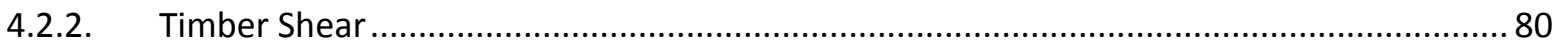

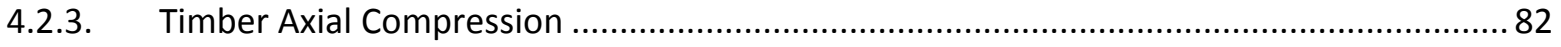

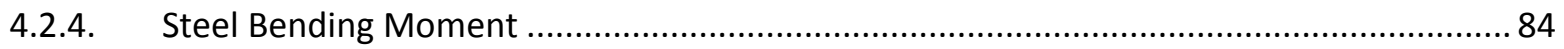

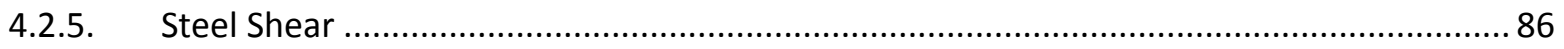

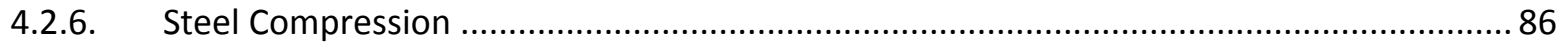

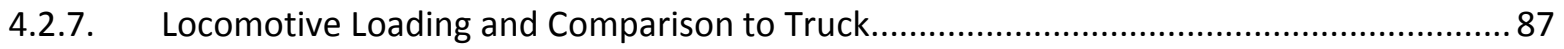

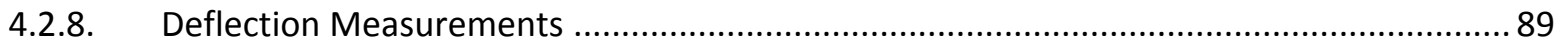

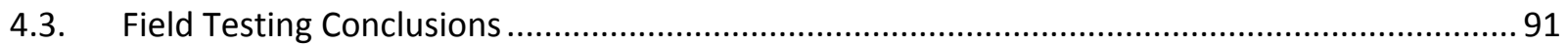

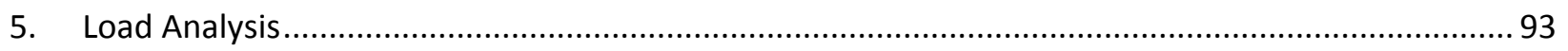

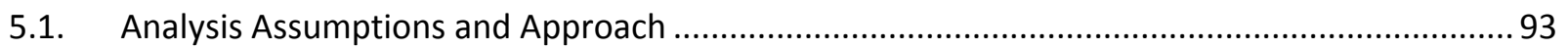

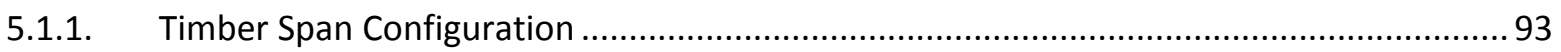

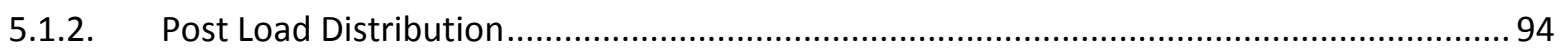

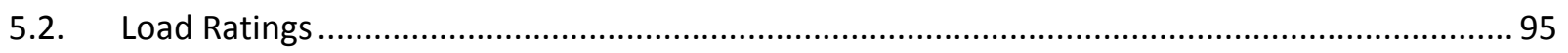

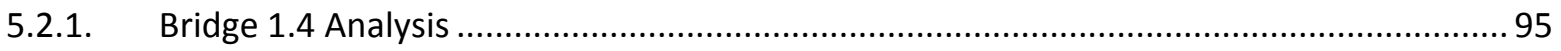

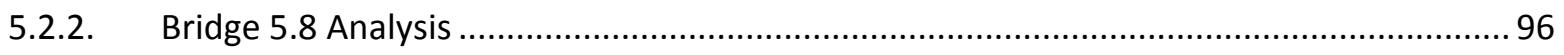

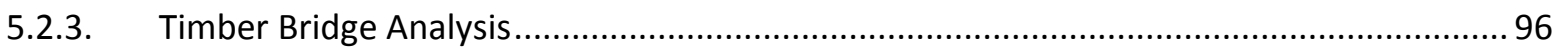

5.3. Analysis of Timber Bridges Using More Complex Models ................................................. 97

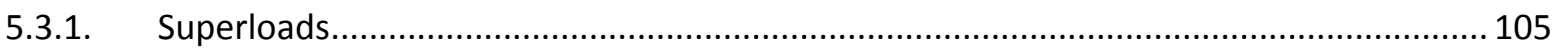




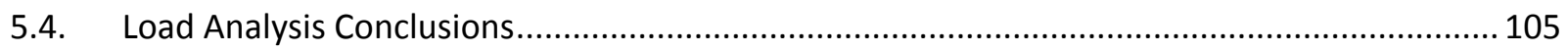

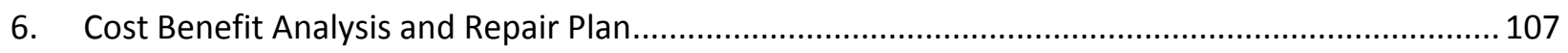

6.1. Cost Benefit Analysis for Timber Bridge Rehabilitation ................................................... 107

6.2. Rehabilitation Summary of Timber Structures …....................................................... 108

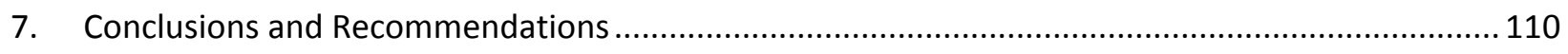

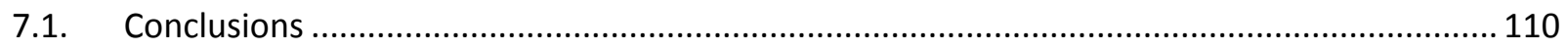

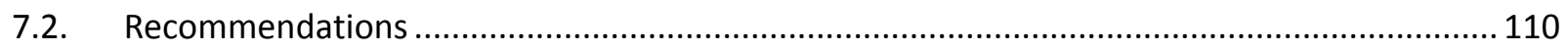

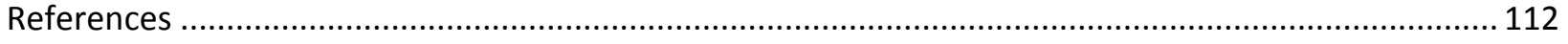

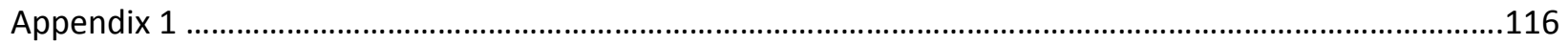

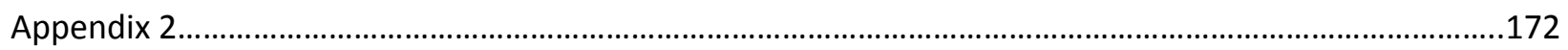




\section{LIST OF FIGURES}

Figure 1 - Timber Stringer Rehabilitation using GFRP (Abhari, 2007)................................................... 2

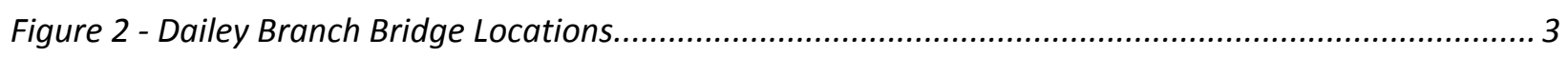

Figure 3 - Typical Cross Section of Timber Frame Bents ................................................................... 4

Figure 4 - Floor Plan for Open-Deck Trestles, Semi-Continuous Design (AREMA, 2014)........................... 5

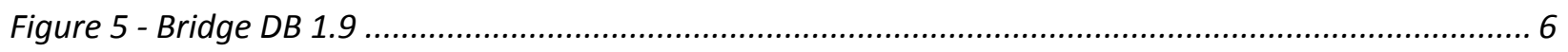

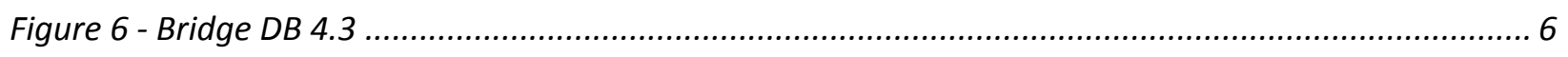

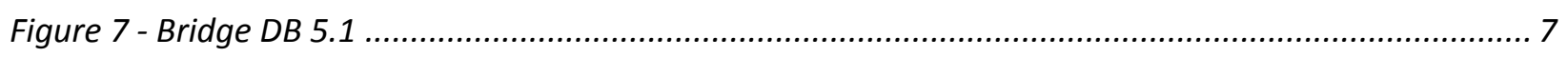

Figure 8 - Old Truss Bridge Replaced by Bridge 1.4. Source: Collection of the Western Maryland Railway

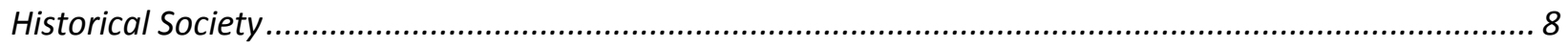

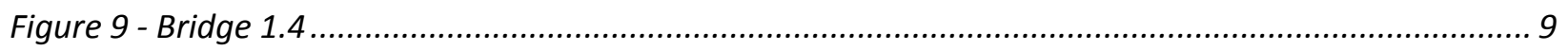

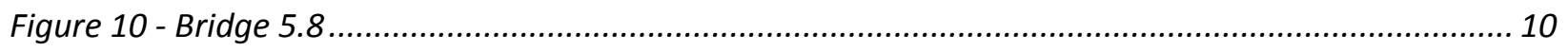

Figure 11 - 2-8-0 Steam Locomotive (Anderson, 2012) (top) Cooper E 80 Loading and Axle Spacing

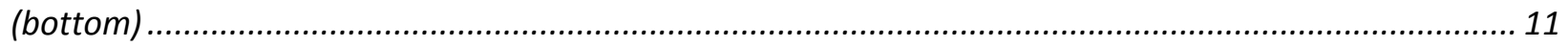

Figure 12 - 286K Freight Railcar Axle Loading …........................................................................... 11

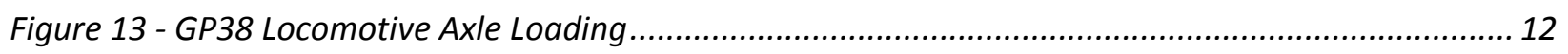

Figure 14 - WM \#82 Locomotive Axle Loading............................................................................... 12

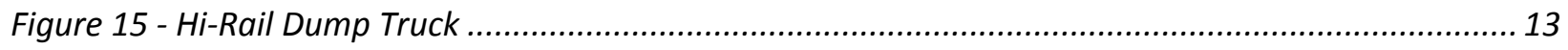

Figure 16 - Wood Log Cross Section (Meriam-Webster, 2006) ........................................................... 15

Figure 17 - (A) Quartersawn and (B) Plainsawn (Wood Handbook, 2010) ............................................ 15

Figure 18 - Principal Axes of Wood Properties..................................................................................... 16

Figure 19 - Cross Section of Pressure Treated Wood Logs (Wood Handbook, 2010).............................. 20

Figure 20 - Upper Left- carpenter ant attack. Upper Right- termite attack. Lower Left- beetle attack.

Lower Right -powder-post beetle attack (Forest Products Laboratory, 2010)..........................................21

Figure 21 - Fiber Orientation Effects on Tensile Strength (Davidson, n.d.) ............................................24

Figure 22 - Typical Deck Girder Bridge (AREMA, 2014).................................................................... 31

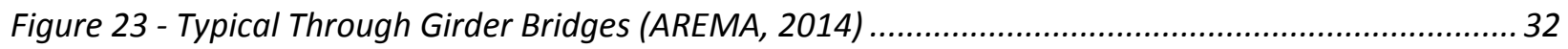

Figure 24 - Equivalent Cooper E Load of a 286 Kip Rail Car (Westbrook Associated Engineers, E80 Pluss

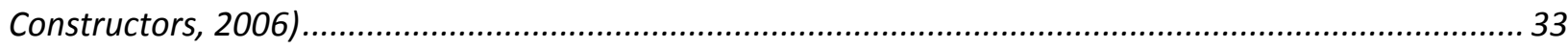

Figure 25 - Comparison between Predicted and Empirical Deflection Values (Wipf et al, 2000) .............. 42

Figure 26 - Semi-continuous beam model (top), and extended semi-continuous chord model (bottom). . 44

Figure 27 - Strain Data Comparison for Bending Strain @ Midspan (Kara, 2011)....................................48 
Figure 28 - Comparison Between FEM and AREMA Load Rating Values

Figure 29 - Manually cracked timber column specimens with FRP wrapping (units in $\mathrm{mm}$ ) (Zhang, Song, Gu, \& Tang, 2012) 51

Figure 30 - Schematic of Specimens and Repair Technique Using GFRP Wet-Wrap Sheets (Hagos, 2001) 52 Figure 31 - Strain Distribution in Piles Before and After Rehabilitation for Train Speed of 2 mph (Abhari, 2007) 54

Figure 32 - Repair and Instrumentation of Specimens, all dimensions in inches (Gómez \& Svecova, 2008) 55

Figure 33 - Results from Bending Test on Repaired Stringers (Gómez \& Svecova, 2008)........................ 56

Figure 34 - Approach Condition: North (left) and South (left) ...........................................................6 61

Figure 35 - North Backwall West End (left) and East End (right) ....................................................... 61

Figure 36 - Rot Span 1 Stringer 1 over Bent 2 (left) and Span 3 Stringer 2 (second stringer from the top

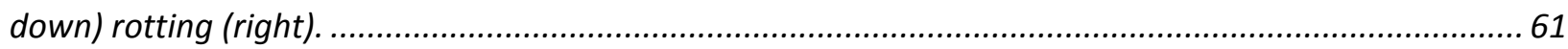

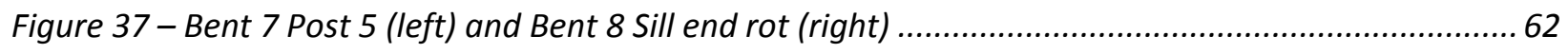

Figure 38 - East Tower Brace 4 rot/split (left) and West Tower Brace 1 split (right)...............................62

Figure 39 - Bent 6 Sway Brace split/rot (left) and West Tower Brace 4 splice (right)............................. 63

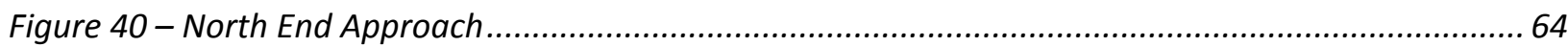

Figure 41 - South Backwall and South West Wingwall heart rot (left). North Backwall West End heart rot (right) 64

Figure 42 - Span 1 Stringer 1 end rot over Bent 1 (left) and Span 1 Stringers 1 \& 2 end rot over Bent 1(right). 65

Figure 43 - Bent 3 Corbel 2 rot (left) and Bent 3 Post 5 heart rot (right).................................................6 65

Figure 44 - Bent 2 Post 1 heart rot (left) and Bent 4 Blocks \& Sills rot (right)........................................66

Figure 45 - North Approach Condition (left) and South Approach Condition (right). .............................67

Figure 46 - South Retaining Wall \& West Wingwall (left) and North East Wingwall heart rot (right).......67

Figure 47 - Span 3 \& 4 Stringer 8 highly rotted (left) and Span 1 Stringer 1 East face fruiting bodies (right).

Figure 48 - Bent 5 Post 3 heart rot (left) and Bent 3 Sill end rot (right)............................................... 68

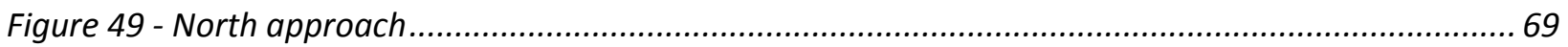

Figure 50 - Corrosion in angle of girder (left) and corrosion in gusset plate \& web stiffeners (right) ........ 70

Figure 51 - Map cracking in north abutment (left) and pier (right) ..................................................... 70

Figure 52 - Bracing corrosion (left) and bend in web stiffener (right)................................................ 71 
Figure 53 - Strain Gage Identification According to Purpose and Location ........................................... 73

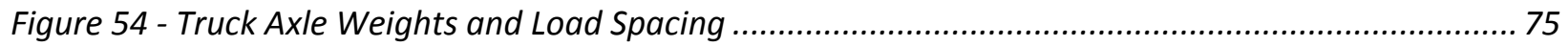

Figure 55 - Bending Strain and Axle Location Versus Time (Bridge 5.8 Truck Test 3) ............................. 76

Figure 56 - Bending Strain and Axle Location Versus Time (Bridge 1.4 Train Test 2) ............................. 77

Figure 57 - WM 82 Locomotive Testing on Bridge 1.9 After Dump Truck Testing ................................... 77

Figure 58 - Timber Stringer Bending Strain (Bridge 5.1, Truck Test 2) ................................................. 80

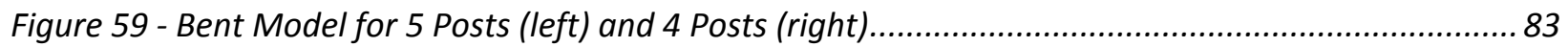

Figure 60 - 3D RISA Model of Bridge 1.4 Span 1 with Cooper E 80 Load .............................................. 85

Figure 61 - Location of Strain Gages for Axial Compression Strain (Gage $3=$ outside, Gage $4=$ inside).... 87

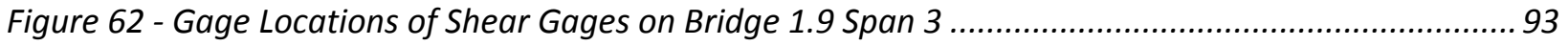

Figure 63 - Shear Microstrain Response of Timber Stringers (Bridge 1.9, WM82 Test 2)........................ 94

Figure 64 - Properties To Determine Load Distribution to Posts Using AREMA Design Aids .....................95

Figure 65 - Bridge 4.3 RISA models for (a) semi continuous, (b) full semi continuous, and (c) parabolic

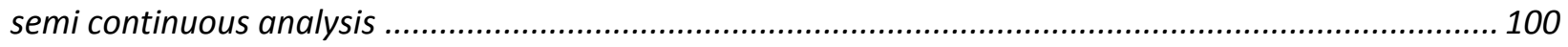

Figure 66 - Comparison Between Models and AREMA Predicted Values for Bending Moment ............... 101

Figure 67 - Comparison Between Models and AREMA Predicted Values for Deflection.......................... 102

Figure 68 - Comparison to Gutkowski Deflection Data ....................................................................... 103

Figure 69 - Comparison to Dailey Moment Data ............................................................................... 104 


\section{LIST OF TABLES}

Table 1 - Bridge Number and Components. 5

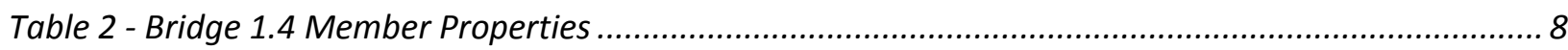

Table 3 - Starting and Ending Points of Cover Plates Along Girders ..................................................... 9

Table 4 - AREMA Yield and Ultimate Stress Values for Existing Railroad Bridge Materials (AREMA, 2014) 22

Table 5 - Advantages and Disadvantages of Thermosets and Thermoplastics ..................................... 26

Table 6 - Component Weights for Dead Load Stress Computations (AREMA, 2014)............................... 35

Table 7 - Allowable Unit Stresses for Stress Graded Lumber - Railroad Loading (Visual Grading) (AREMA,

2014)

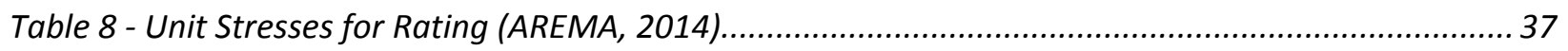

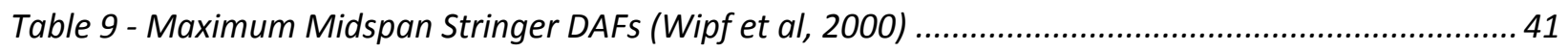

Table 10 - Predicted Field E Values Using SylvaTest Ultrasonic Testing Device (Gutkowski, 2001)............ 43

Table 11 - Comparison of Field to Predicted Deflection Values, Bridge 101 (Gutskowski, 2001) ............... 45

Table 12 - Comparison of Deflection Between Field and Analytical Model Values, Bridge 32.35

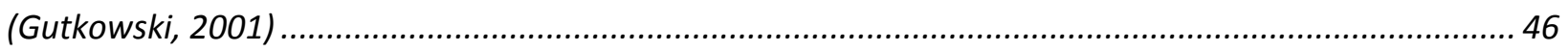

Table 13 - Differen Repair Techniques and Results From Testing ....................................................... 49

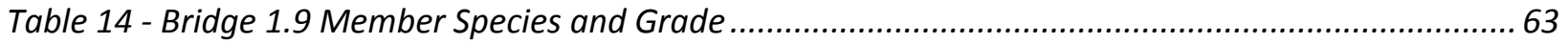

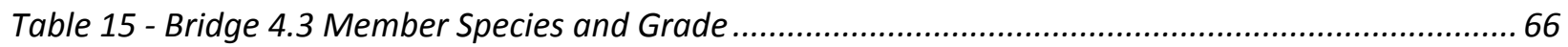

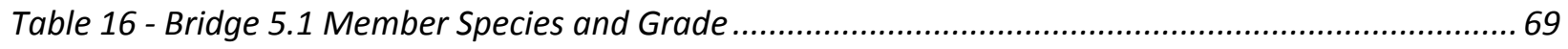

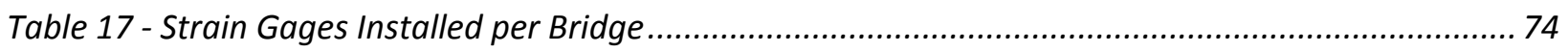

Table 18 - Field Measured Bending Strains in Timber Stringers (microstrain) ........................................ 79

Table 19 - Field Measured Shear Strains in Timber Stringers (microstrain) ............................................ 81

Table 20 - Field Measured Axial Compression Strains in Timber Posts (microstrain) ............................... 82

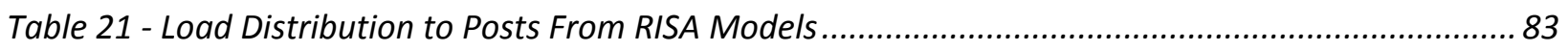

Table 22 - Field Measured Bending Strains in Steel Bridges (microstrain)............................................ 84

Table 23 - Field Measured Shear Strains in Steel Bridges (microstrain) .................................................. 86

Table 24 - Field Measured Compression Strain in Steel Angles (microstrain).........................................87

Table 25 - Field Measured Strains in Steel Bridges with WM 82 Locomotive Loading (microstrain).......... 88

Table 26 - Field Measured Strains in Timber Bridges with WM 82 Locomotive Loading (microstrain) .......89

Table 27 - Timber Bridge Deflection Measurements (inches) ............................................................... 90

Table 28 - Steel Bridge Deflection Measurements and Predicted Values (inches)...................................90 
Table 29 - Bridge 1.4 Load Ratings

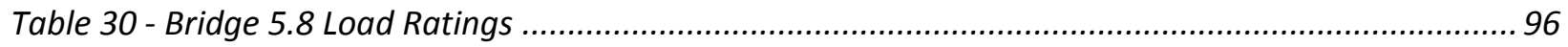

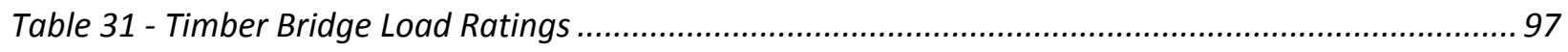

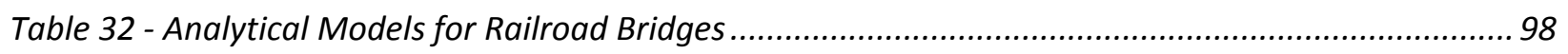

Table 33 - Comparison of Cooper E Ratings for Bridge 4.3 Span 1 Among 3 Different Models for Bending

Moment

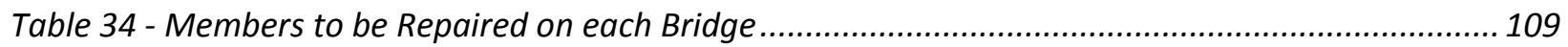

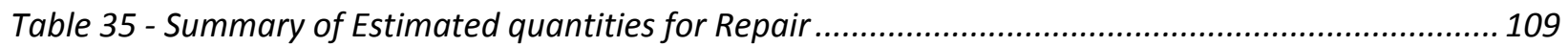




\section{Introduction}

The importance of timber in the history of bridge construction is said to date back to several thousand years. The first human made timber bridge is assumed to have been built by a Neolithic human who felled a tree across a chasm with a hand-fashioned stone axe circa 15,000 B.C. (Eby, 1986). Timber bridges later became key components in the United States railway infrastructure, bridging gaps over rivers, ravines, roads, and other obstacles. Timber bridges represent approximately 7 percent of the 576,874 bridges listed in the National Bridge Inventory (Duwadi \& Ritter, 1997). In the railroad system alone, there are about 35,000 timber bridges in service today, many of which are over 50 years old (Mee, McCown, Davids, \& Nejikovsky, 1994). Railroads usually run through very rural areas of the United States, sometimes populated with dense vegetation along narrow waterways and the access locations for maintenance are very poor. When timber is poorly maintained, and exposed to harsh environments over long periods of time, decay is very prominent. The most common type of Timber Bridge used in railroad industry is the trestle bridge, a bridge with short spans supported by rigid timber frames usually referred to as bents. These timber trestle bridges are usually struck and covered by debris which is dragged downstream by the rivers and creeks usually being crossed. In states like West Virginia, flash flooding is a very common occurrence, thus generating large areas of splash zone in the timber leading to massive decay or rot. Wood being a naturally occurring composite material, also exposes it to biological attacks such as termites and fungi. While accounting for all these factors of structural deterioration, timber structures are weakened and in need for repair. In today's tight budgetary constraints, bridge replacement is not feasible. Therefore, innovative and economic repair approaches are still being developed by the engineering community. A very common rehabilitation procedure, still being tested, is the use of fiber reinforced polymer (FRP) composite wraps to strengthen deteriorated structures. Man-made composite materials are those composed of at least two components, one being the reinforcing agent (fiber) providing the strength, and is the matrix (polymer) where the reinforcing is embedded. The composite wrap acts by wrapping the reinforcing fibers, previously impregnated with the polymer, around or along a member. Once the polymer (resin) cures, it holds the wrap in place and the fibers begin to act as reinforcement together with the member. The use of FRP composites also allows for in-situ rehabilitation of in service bridges, which allows the bridge to remain in service through the rehabilitation process in many occasions. Laboratory experiments previously performed by WVU-CFC (Smith, 2004) helped conclude that using Glass-FRP composite materials, to repair as well as strengthen previously failed beams, allows the recovery of $55-60 \%$ of the initial strength (Figure 1). 


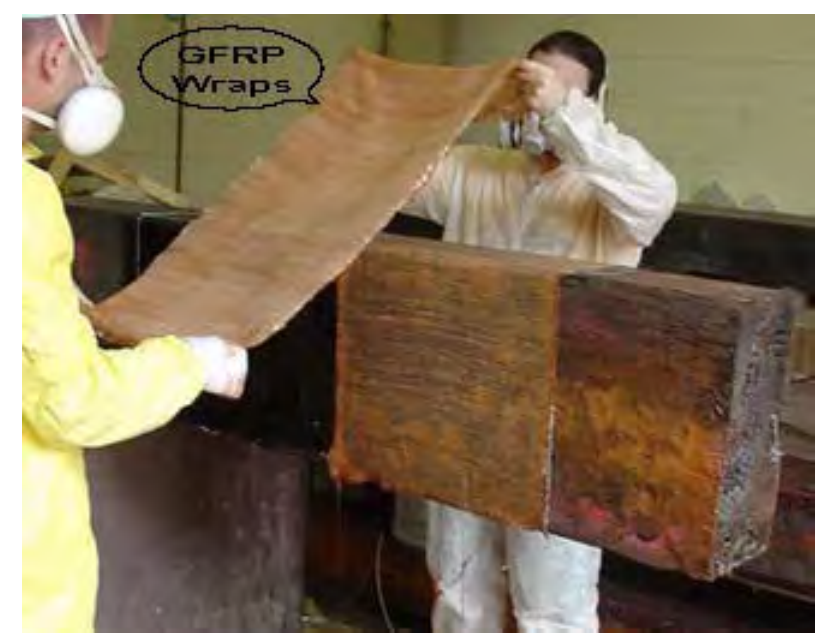

Figure 1 - Timber Stringer Rehabilitation using GFRP (Abhari, 2007)

A review of the literature on railway bridge analysis for both the steel and timber bridges helped develop models to better predict the response of the Dailey Branch bridges to axle live loading. In addition, modeling of timber trestle railroad bridges is covered in this report.

\subsection{Scope of Work}

This report aims to develop different models to better predict the response of existing railroad timber bridges, with decayed members, under train live loads and then load rate the bridges. Subsequently, efficient repair techniques using FRP composites are developed. The work performed during this study is summarized herein as follows.

- Chapter 1: Summary of the Dailey Branch rail system including the bridges found in the line and load vehicles to be used for analysis.

- Chapter 2: Literature review of the behavior and different analysis models of both timber and steel railroad bridges, and a discussion of the different modern FRP wrap repair techniques for deteriorated timber bridges.

- Chapter 3: Methodology and summary of the field inspections of the five bridges.

- Chapter 4: Discussion of field testing procedure and results compared to expected values.

- Chapter 5: Summary of the load rating analysis with a discussion of the different modeling techniques.

- Chapter 6: Summary of the repair plan and cost/benefit analysis.

Two sets of CAD drawings were developed, one for inspection and recommending glass FRP (GFRP) wrap repairs for the timber bridges, and another for inspection and maintenance of the steel bridges. The 
$C A D$ drawings and the calculation details showing individual load ratings for each bridge are included in the appendix section of this report.

\subsection{Summary of The Rail System}

This report will focus on three railroad timber trestle bridges and two steel girder bridges of varying span lengths along the Dailey Branch line, with emphasis on the timber trestles. The Dailey Branch railroad short line is a small section of the West Virginia Central Railroad (WVCR), a railroad owned by the West Virginia State Rail Authority (WVSRA). The previous operator of this line was CSX Transportation, Inc. (CSXT), a line originally built in 1891 by Henry G. Davis under the West Virginia Central and Pittsburg Railway (Clarke, 2003). The five railroad bridges can be located between milepost 0.0 and milepost 6.2 running from the Elkins towards Beverly, WV. The milepost number along the Dailey Branch line increases as the railroad continues South of Elkins. The three timber structures can be found in mileposts 1.9, 4.3 and 5.1, while the steel bridges start at mileposts 1.4 and 5.8, as shown in

\section{Figure 2.}

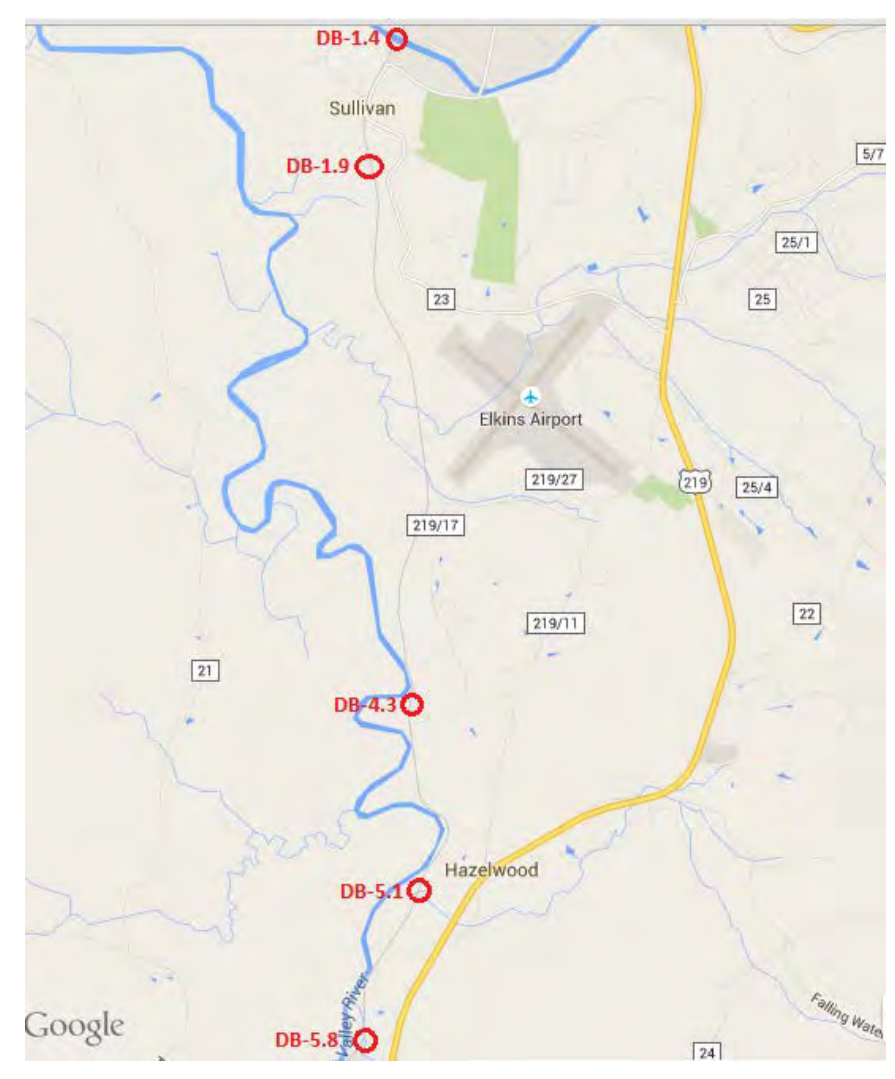

Figure 2 - Dailey Branch Bridge Locations 


\subsubsection{Timber Trestle Bridges}

All three timber structures covered in this report are very similar in superstructure design, but vary in length and substructure design. Figure 3 shows a typical cross section of the trestles. All bridges are of a similar open deck design, meaning that the railroad ties are supported by the timber stringers, thus transferring the load directly to the stringers with no ballast present. The rails are anchored to the ties using deck anchors, while the ties are held in place using tie spacers. A 4 ply chord system is used which is identical to what is shown in AREMA manual 2014 Chapter 7 Appendix 2 for recommended practice plans (Figure 4), where the stringers are semi-continuous over the caps (cross beams). This semicontinuous design consists of a set of four stingers under each rail where stringers 1 and 3 are continuous over spans 2 and 3, but stringers 2 and 4 are continuous over spans 1 and 2 (Figure 4). Corbels are present below stringers in some of the bents of bridge 1.9, and 4.3 (Table 1). The substructure design consists of timber frame bents as shown in Figure 3 of this report, with the exception of no corbels between the cap and stringers in some interior bents.

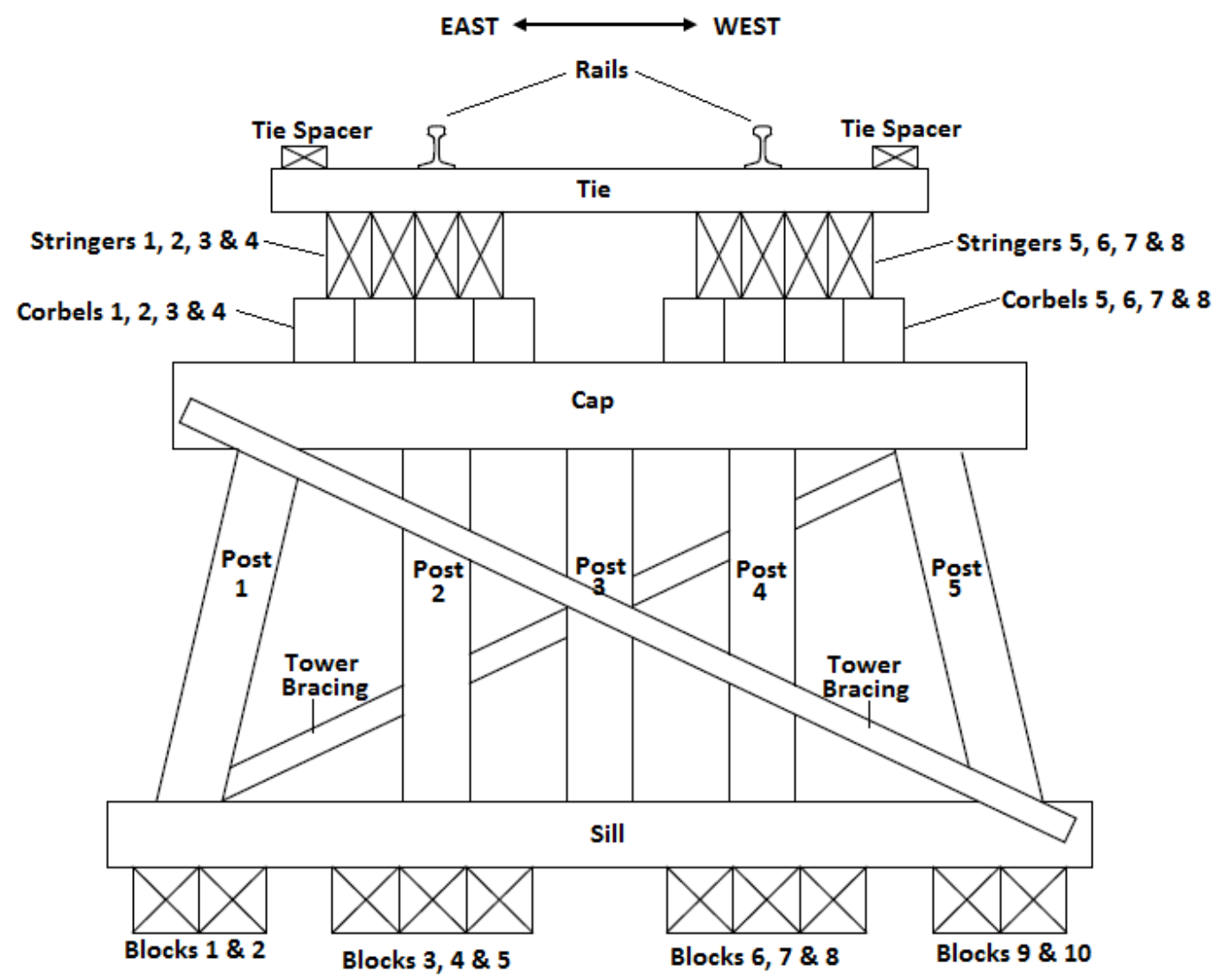

Figure 3 - Typical Cross Section of Timber Frame Bents 


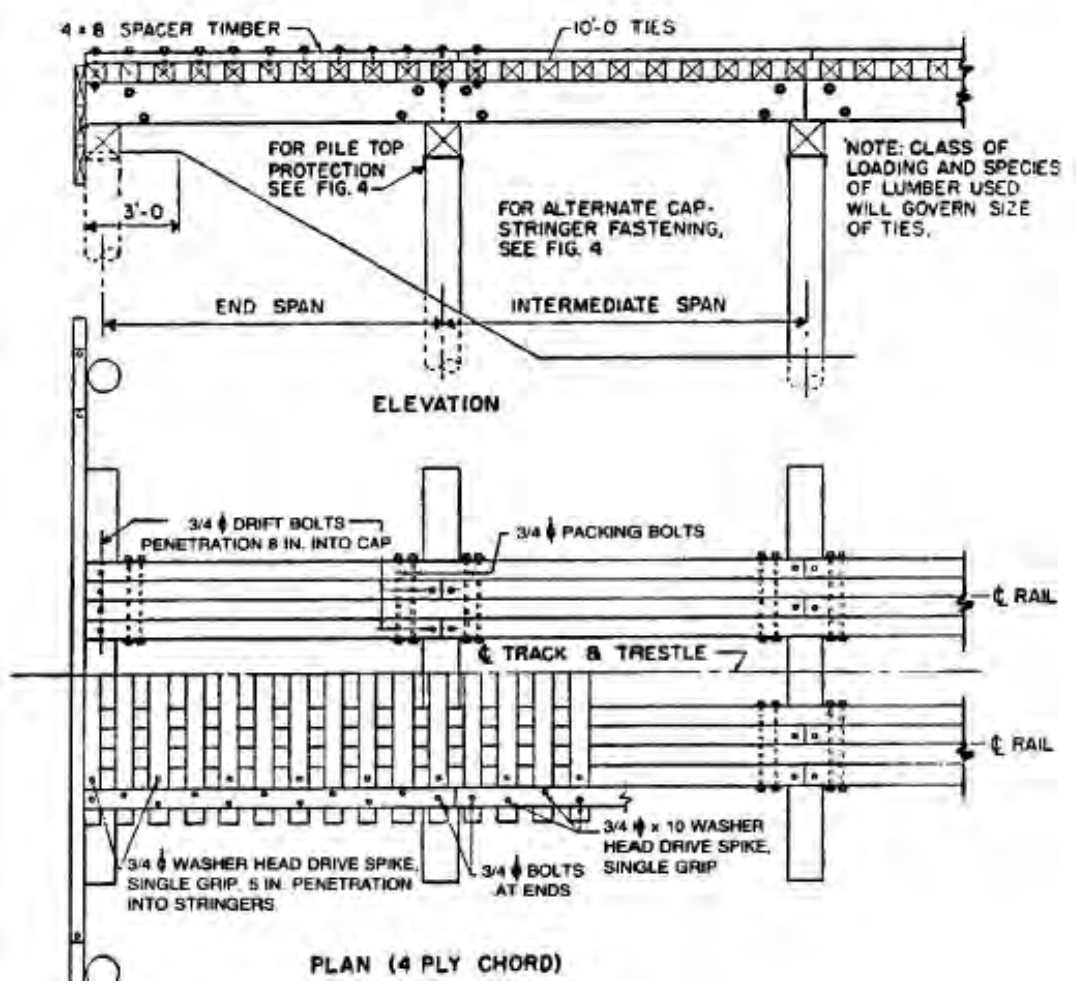

Figure 4 - Floor Plan for Open-Deck Trestles, Semi-Continuous Design (AREMA, 2014)

Table 1 - Bridge Number and Components

\begin{tabular}{|c|c|c|c|}
\hline Bridge \# & 1.9 & \multicolumn{1}{c}{4.3} & 5.1 \\
\hline Total Span Length & $88^{\prime}$ & $32^{\prime}-5^{\prime \prime}$ & $81^{\prime}$ \\
\cline { 2 - 4 } Number of Bents & 10 & 4 & 8 \\
\cline { 2 - 4 } Min. Span Length & $7^{\prime}-3.5^{\prime \prime}$ & $9^{\prime}-2^{\prime \prime}$ & $10^{\prime}-0.88^{\prime \prime}$ \\
\cline { 2 - 4 } Max Span Length & $12^{\prime}-1.5^{\prime \prime}$ & $11^{\prime}-10^{\prime \prime}$ & $12^{\prime}-1.75^{\prime \prime}$ \\
\cline { 2 - 4 } $\begin{array}{c}\text { Corbels } \\
\text { Tower Bracing } \\
\text { Sway Bracing }\end{array}$ & Yes & Yes & No \\
\cline { 2 - 4 } & Yes & Yes & Yes \\
\cline { 2 - 4 } & & No & No \\
\hline
\end{tabular}

\subsubsection{Bridge 1.9}

This timber trestle bridge has an 89' overall length divided into 9 spans averaging about 10' in length.

Bridge 1.9 has a total of 2 abutments and 8 timber-bent frames. The 4 interior bents are also braced together using tower braces. Interior bents have also been braced against sway (sway braces). Figure 5 shows the East face bridge 1.9, found in milepost 1.9 spanning over an unknown stream. 


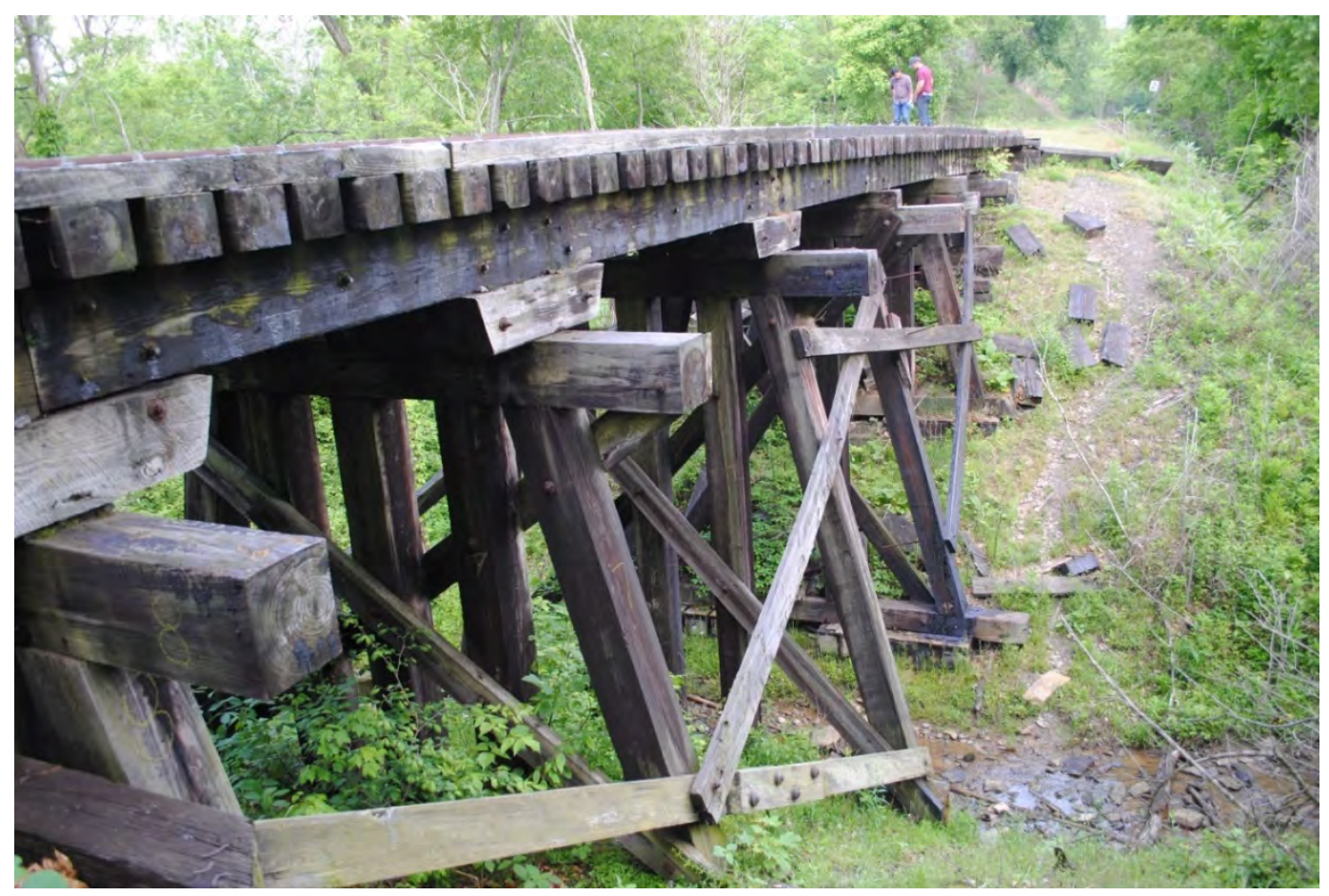

Figure 5 - Bridge DB 1.9

\subsubsection{Bridge 4.3}

This timber trestle bridge has a $34.5^{\prime}$ overall length divided into three $11^{\prime}-5^{\prime \prime}, 11^{\prime}-10^{\prime \prime}$, and 9'-2" spans. Bridge 4.3 has a total of two abutments and 2 timber bent frames as shown in Figure 6. Interior bents have also been braced against sway (sway braces). It can be found in milepost 4.3 spanning over Crouches Creek.

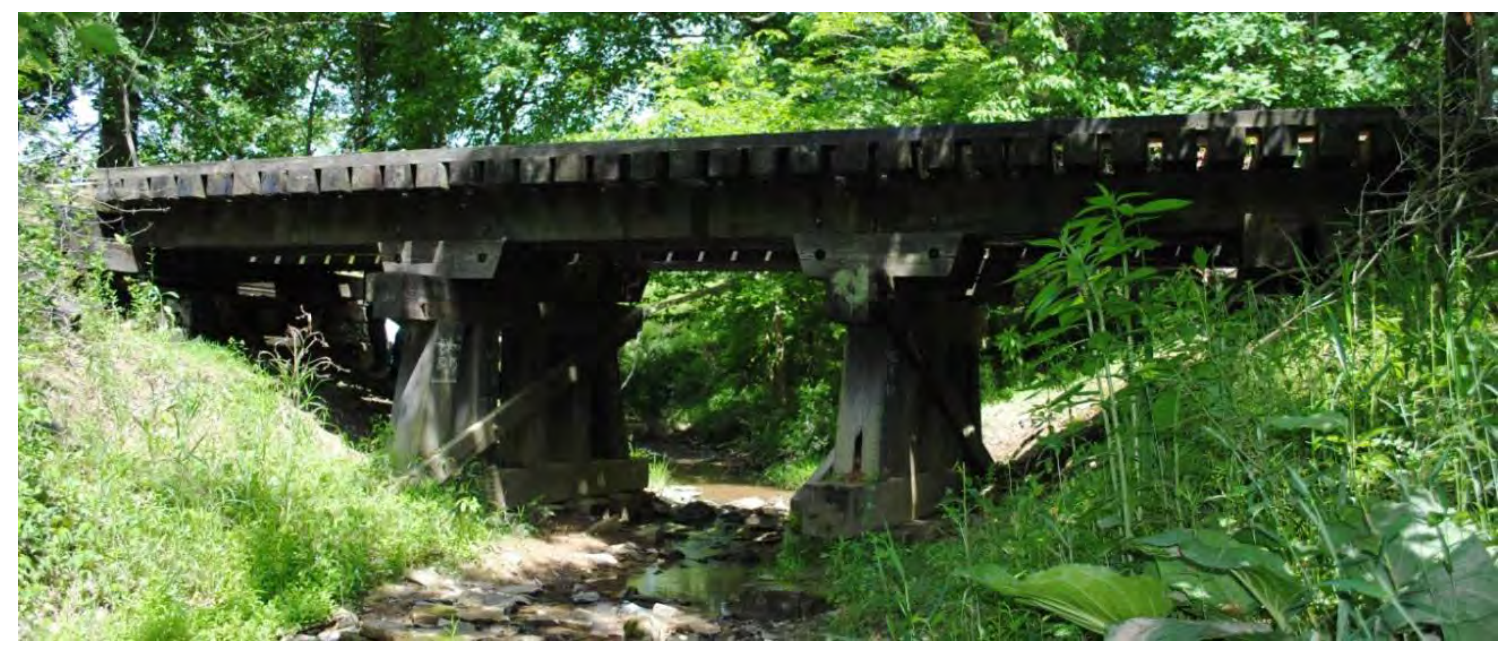

Figure 6 - Bridge DB 4.3 


\subsubsection{Bridge 5.1}

This timber trestle bridge has an $81^{\prime}$ overall length divided into span lengths ranging from $10^{\prime}$ to $12^{\prime} 1.75^{\prime \prime}$. Bridge 5.1 has a total of two abutments and 6 bent frames. Interior bents have also been braced against sway (sway braces). It can be found in milepost 4.3 spanning over Kings Run as shown in Figure 7. The interior bents of bridge 5.1 are skewed up to $9 \%$ in reference to the stream alignment.

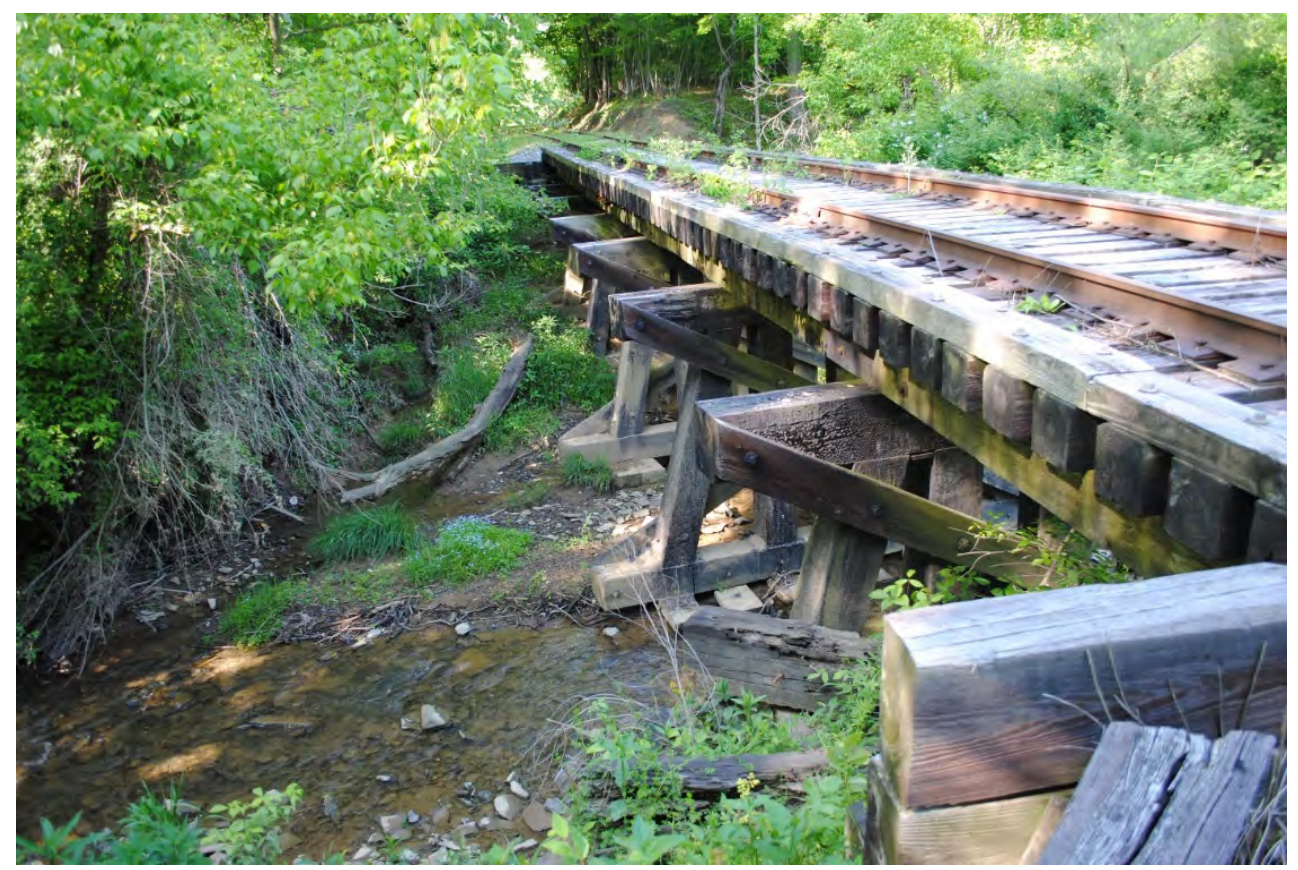

Figure 7 - Bridge DB 5.1

\subsubsection{Steel Bridges}

The first and last two bridges on the Dailey Branch line are open deck steel bridges composed of steel stringers and steel cross beams, supporting the railroad over different water streams. The main members of both bridges are built-up plate girders, which are fracture critical.

\subsubsection{Bridge 1.4}

Bridge 1.4 was originally built in 1891 (opened on August 27) as a 3-span bridge, where the end spans were typical deck girder superstructures and the middle span a truss bridge as show in Figure 8 (Clarke, 2003). This bridge was later replaced with the current 2-span through girder bridge, which according to the WVSRA has plans dating back to 1886 and had been originally used for the Piedmont and Cumberland Railroad (PCR) over the Baltimore and Ohio Railroad (B\&O). The old pier structures of the 3- 
span truss bridge are still present in the river and are now non-load bearing structures under spans 1 and 2 of the current bridge as can be seen in Figure 9.

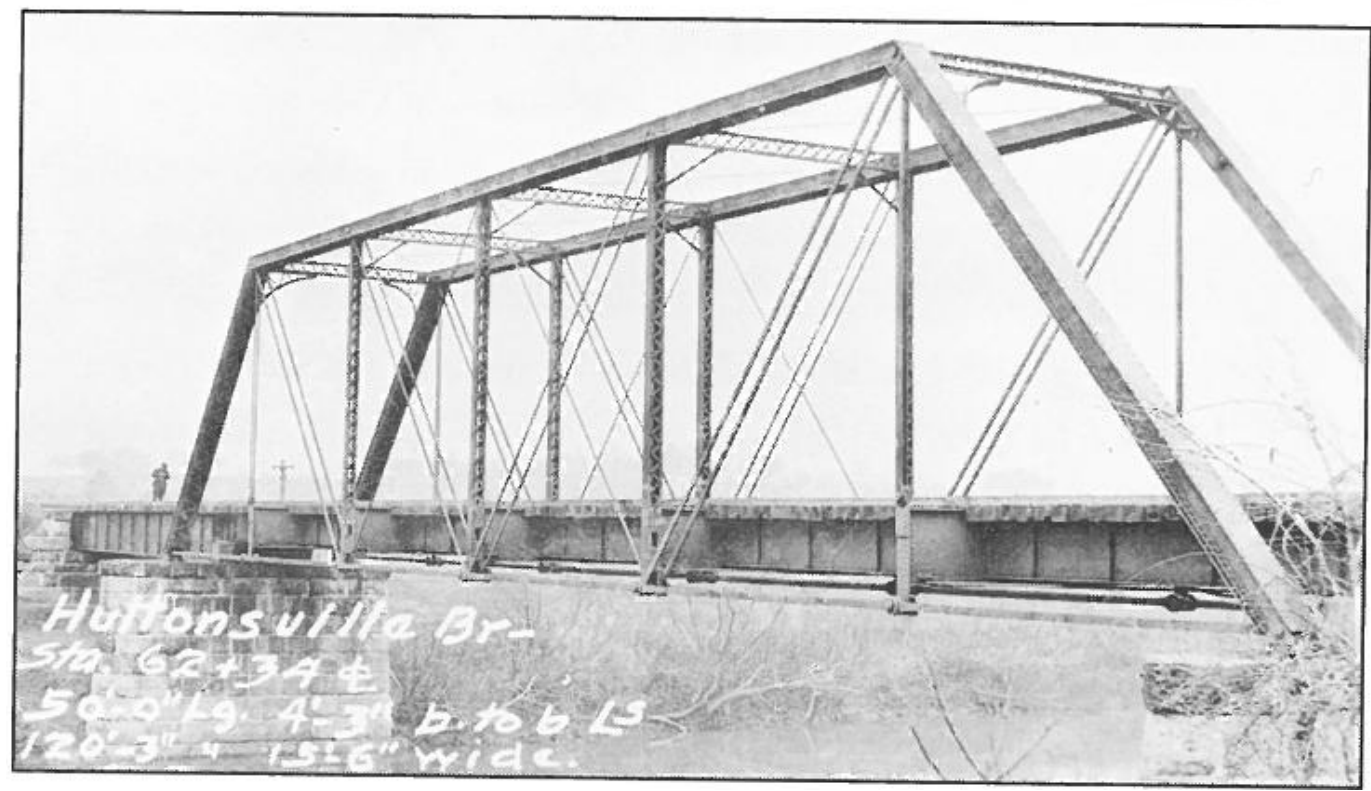

Figure 8 - Old Truss Bridge Replaced by Bridge 1.4. Source: Collection of the Western Maryland Railway Historical Society

The current bridge is a typical through Girder Bridge as defined in the AREMA manual, having an open deck design. It is a 2-span simply supported bridge, with rocker bearings on the North end of each span, and pinned bearings on the South end of each span. Span 1 is $98^{\prime}-8^{\prime \prime}$ feet long, and span 2 is $97^{\prime}-2.5^{\prime \prime}$ feet long. Table 2 shows a summary of the member dimensions of the superstructure for bridge 1.4, and Figure 9 below shows a view of bridge 1.4 from the north abutment looking south.

Table 2 - Bridge 1.4 Member Properties

\begin{tabular}{|l|c|c|c|c|}
\cline { 2 - 5 } \multicolumn{1}{c|}{} & \multicolumn{2}{c|}{ Girders } & \multirow{2}{*}{ Floorbeam } & \multirow{2}{*}{ Stringers } \\
\cline { 2 - 5 } \multicolumn{1}{c|}{} & Span 1 & Span 2 & & \\
\hline Span Length & $97^{\prime}-0^{\prime \prime}$ & $95^{\prime}-7^{\prime \prime}$ & $16^{\prime}-0^{\prime \prime}$ & $11^{\prime}-3^{\prime \prime}$ \\
\hline Depth & $9^{\prime}-9.85^{\prime \prime}$ & $9^{\prime}-9.85^{\prime \prime}$ & $2^{\prime}-2.875^{\prime \prime}$ & $1^{\prime}-8^{\prime \prime}$ \\
\hline Thickness of Web & $0.459^{\prime \prime}$ & $0.459^{\prime \prime}$ & $0.62^{\prime \prime}$ & $0.5^{\prime \prime}$ \\
\hline Width of Flange & $1^{\prime}-6^{\prime \prime}$ & $1^{\prime}-6^{\prime \prime}$ & $1^{\prime}-2^{\prime \prime}$ & $6.15^{\prime \prime}$ \\
\hline Thickness of Flange & $2.49 "$ & $2.49^{\prime \prime}$ & $0.793^{\prime \prime}$ & $0.8^{\prime \prime}$ \\
\hline
\end{tabular}



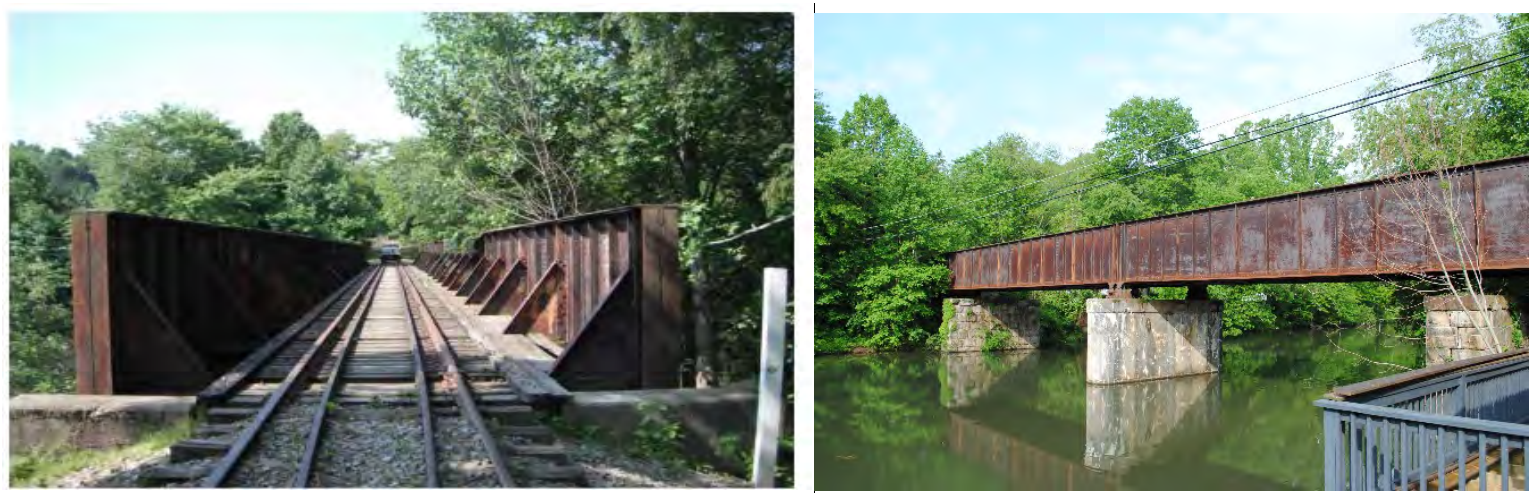

Figure 9 - Bridge 1.4

The main through girders are two built up I-beams with a 114.25 inches high and 0.375 -inch-thick web plates. The flanges consist of 0.6875 -inch-thick angles with 8-inch-long legs. Three top and bottom cover plates are present in the girders, all three with a thickness of 0.5625 inches and a width of 18.25 inches. The first top cover plate runs the entire length of the girders, and the length of the remaining 2 top cover plates and 3 bottom cover plates are shown in Table 3.

Table 3 - Starting and Ending Points of Cover Plates Along Girders

\begin{tabular}{|c|c|c|c|c|c|c|}
\hline \multirow{2}{*}{ Span } & \multirow{2}{*}{ Girder } & \multicolumn{2}{|c|}{ Top Cover Plates } & \multicolumn{3}{c|}{ Bottom Cover Plates } \\
\cline { 3 - 7 } & & $\mathbf{2}$ & $\mathbf{3}$ & $\mathbf{1}$ & $\mathbf{2}$ & $\mathbf{3}$ \\
\hline \multirow{2}{*}{$\mathbf{1}$} & $\mathbf{1}$ & $17^{\prime}$ to $79^{\prime}-5 "$ & $24^{\prime}$ to $72^{\prime}-5^{\prime \prime}$ & $10^{\prime}$ to $86^{\prime}-4 "$ & $17^{\prime \prime}$ to $79^{\prime}-5 "$ & $24^{\prime \prime}$ to $71^{\prime}-10^{\prime \prime}$ \\
\cline { 2 - 7 } & $\mathbf{2}$ & $17^{\prime}$ to $79^{\prime}-5 "$ & $24^{\prime}$ to $72^{\prime}-5^{\prime \prime}$ & $10^{\prime}$ to $86^{\prime}-4 "$ & $17^{\prime \prime}$ to $79^{\prime}-5 "$ & $24^{\prime \prime}$ to $71^{\prime}-10^{\prime \prime}$ \\
\hline \multirow{2}{*}{$\mathbf{2}$} & $\mathbf{1}$ & $14^{\prime}-11^{\prime \prime}$ to $76^{\prime}-11^{\prime \prime}$ & $21^{\prime}-10^{\prime \prime}$ to $70^{\prime}-4^{\prime \prime}$ & $8^{\prime}$ to $84^{\prime}-3^{\prime \prime}$ & $14^{\prime}-11^{\prime \prime}$ to $77^{\prime}-2^{\prime \prime}$ & $22^{\prime}$ to $70^{\prime}-5^{\prime \prime}$ \\
\cline { 2 - 7 } & $\mathbf{2}$ & $17^{\prime}-10^{\prime \prime}$ to $80^{\prime}$ & $24^{\prime}-8 "$ to $73^{\prime}$ & $10^{\prime}-4 "$ to $87^{\prime}-2 "$ & $17^{\prime}-10^{\prime \prime}$ to $80^{\prime}$ & $24^{\prime}-8^{\prime \prime}$ to $73^{\prime}-3 "$ \\
\hline
\end{tabular}

Floor beams run transverse to the girders riveted to the insides of their web plates, with a depth of 26.875 inches. Two rolled steel stringers run parallel to the girders and between floor beams with a depth of 20 inches. The AISC Historic Database has a few sections that closely match the dimensions of the stringers, thus section $\$ 20 \times 64.8$ is used due to it having the smallest strong axis moment of inertia. All substructures consist of concrete abutments and one concrete pier at mid span for Bridge 1.4.

\subsubsection{Bridge 5.8}

Bridge 5.8 is the shortest span structure in the Dailey Branch line, spanning over Dodson Run creek with two $20 \mathrm{ft}$ long built-up plate girders, and $30 \mathrm{1} / 2$ inches in depth. It is a simply supported one-span structure, resting on plate bearings on masonry abutments at both ends. Unlike bridge 1.4, this bridge 
does not have other load carrying members (floor beams and stringers), making the girders fracture critical. Figure 10 below shows the West face of bridge 5.8 .

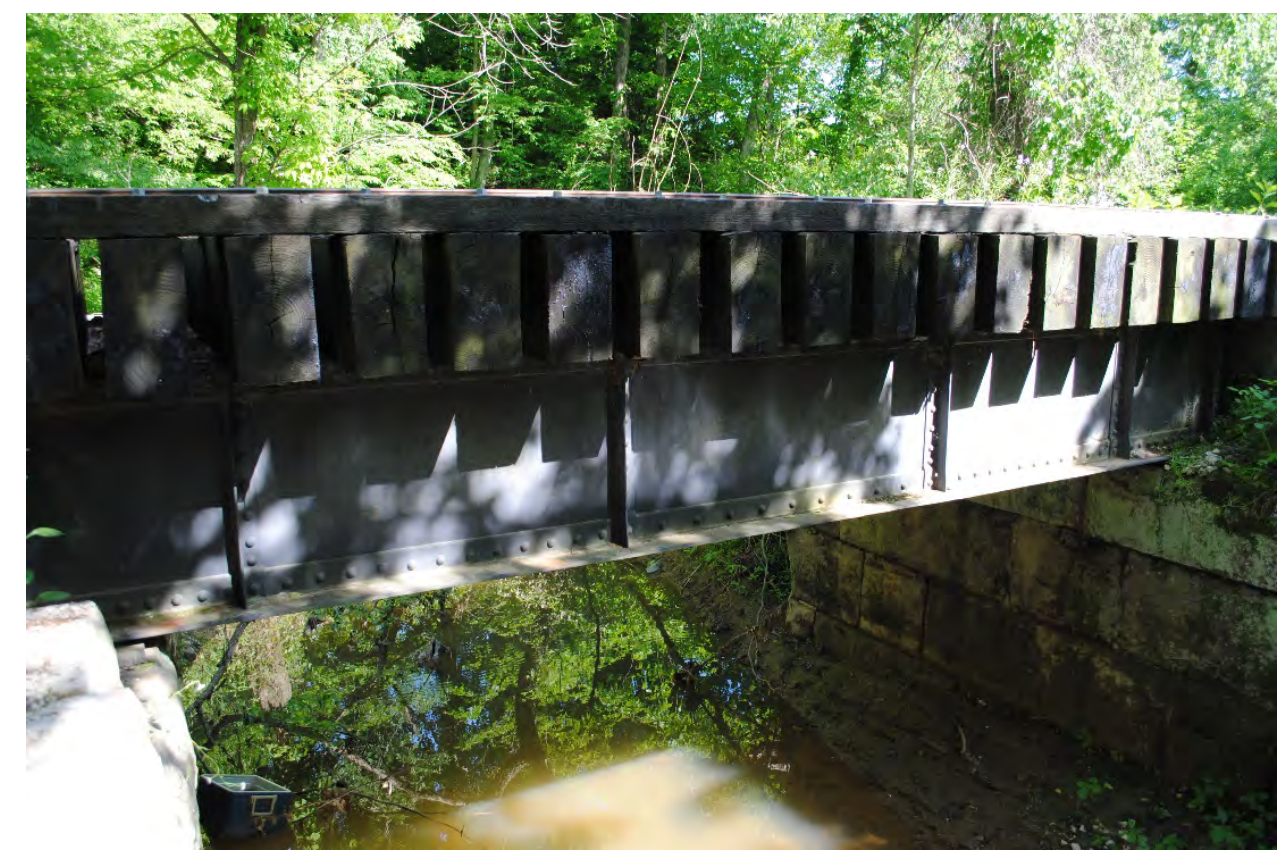

Figure 10 - Bridge 5.8

\subsubsection{Rolling Stock}

The common practice in railroad engineering is to rate a bridge in terms of its Cooper E rating (Figure 11). This is similar to the rating of highway bridges in terms of HS rating. So long as the stresses generated by the expected live load is lower than the capacity, the rolling stock can safely cross the bridge. In this case, a 286 kips rail car (Figure 12), and a GP38 locomotive (Figure 13) were also evaluated as they will be the primary rolling stock used on this line. During the field load test, two other rail vehicles were used to gather strain data. These two other vehicles provided by WVSRA were a hi-rail dump truck, and the West Maryland 82 locomotive. A description of each of these loads is given below.

\subsubsection{Cooper E 80}

Theodore Cooper developed a loading system for the rating of railroad bridges by simulating a locomotive followed by a set of cars with a given axle loading and spacing. The number 80 is proportional to the standard Cooper E 10 first developed, which was based on a 2-8-0 steam locomotive as shown in Figure 11. In the case of a Cooper E 80, you simply multiply the standard Cooper E 10 by a factor of 8. A Cooper E 80 is a common rating for steel railroad bridges, having a load of 80 kips per axle $(80,000 \mathrm{lb})$. Due to heavier load trains been built over the years, a more common rating of $\mathrm{E} 100$ or 
higher can be encountered in the design spectrum. Not all axles carry the same load nor are they spaced equally. The following figure (Figure 11) best describes the distribution in axle loading, and spacing among axles for a Cooper E 80 vehicle.

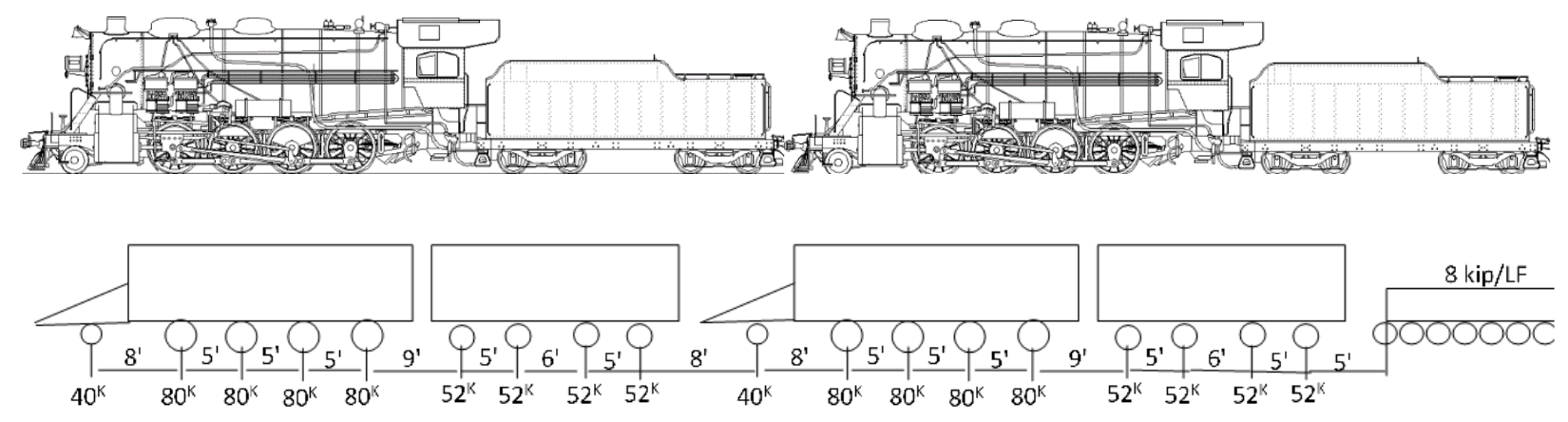

Figure 11 - 2-8-0 Steam Locomotive (Anderson, 2012) (top) Cooper E 80 Loading and Axle Spacing (bottom)

\subsubsection{Hopper Car (286k)}

The WVDOT-SRA asked for the evaluation of a $286,000 \mathrm{lb}$. hopper car as this was expected to be used to haul materials along this line. The axle spacing and loads per axle are shown in the figure below (Figure 12).

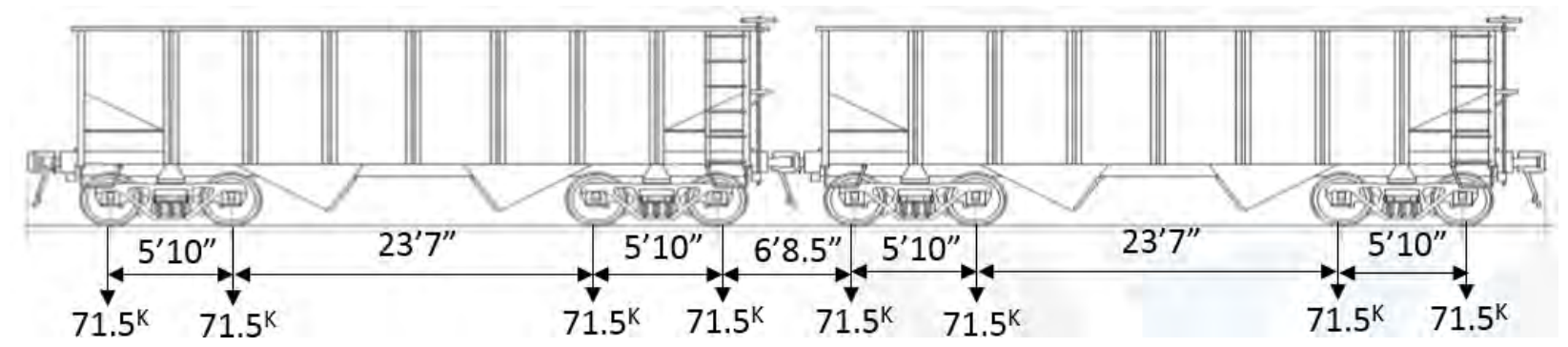

Figure 12 - 286K Freight Railcar Axle Loading. Drawn by Lochner, 2012

\subsubsection{GP38 Locomotive}

This is one type of locomotive currently on the local rail line. It is very important that all the structures on the Dailey Branch line meet the load rating for this 250 kips car locomotive. The following figure will show the axle spacing for this vehicle (Figure 13). 


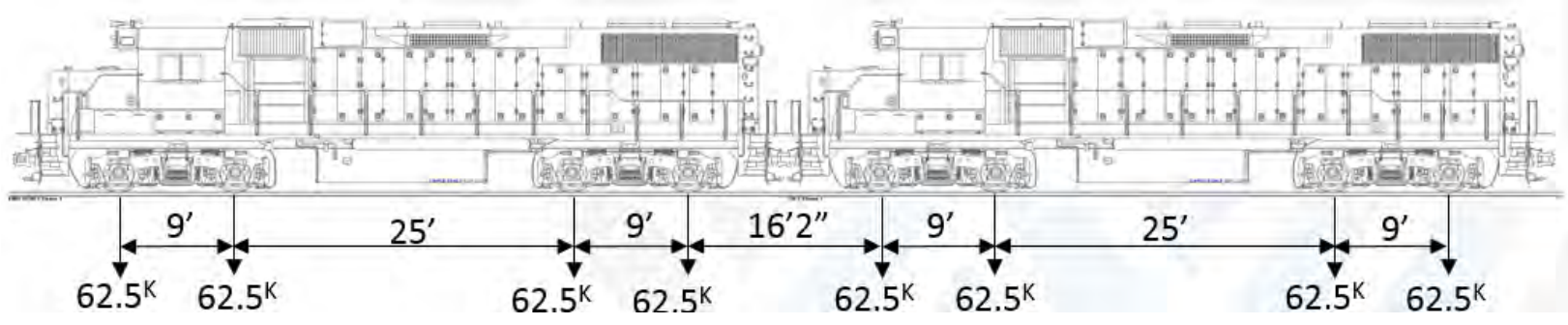

Figure 13 - GP38 Locomotive Axle Loading. Drawn by Elby, 2016

\subsubsection{WM \#82 Locomotive}

The Western Maryland 82 (WM 82) was built by General Motors Electro-Motive Division (EMD) as one of their 59 Branch Line 2 series (BL2) model in October of 1948. This locomotive now belongs to the WVSRA and is located in Elkins, WV. The WM 82 was used during the load testing procedure for strain data acqusition under such live load. The BL2 series lead the way for the latter series of General Purpose (GP) locomotives. Figure 14 shows the axle loading and axle spacing fo the WM \#82. Weights were taken from the Diesel Shop's online database (http://www.thedieselshop.us/Data\%20EMD\%20BL2.HTML).

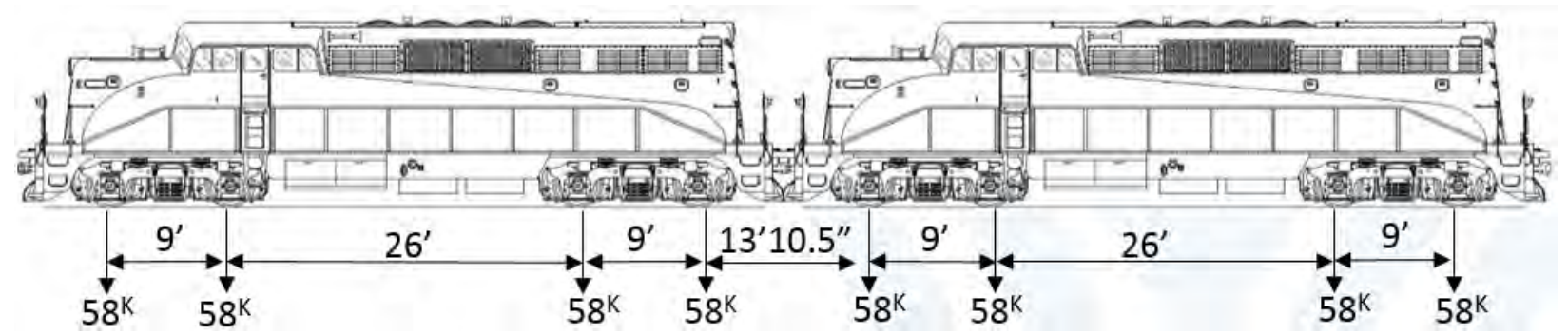

Figure 14 - WM \#82 Locomotive Axle Loading. Drawn by Anderson, 2016

\subsubsection{Hi-Rail Dump Truck}

Due to potential decay in the timber structures, a hi-rail dump truck loaded with gravel lower in axle load than a 286 kip rail car was recommended for load testing the bridges in order to be conservative during the loading procedure. When the dump truck went from the road onto the tracks, a front and rear rail gear was lowered onto the rails, where the front rubber tires axle was lifted up the, but the rear rubber tires remained on the tracks. Photo sensors and strain gages helped determine the center of gravity of the rear axle where the rubber tires and rail gear came into contact with the tracks. The front rail gear carried all of the weight for the front axle. Figure 15 below shows the respective axle weight distribution and axle spacing. 


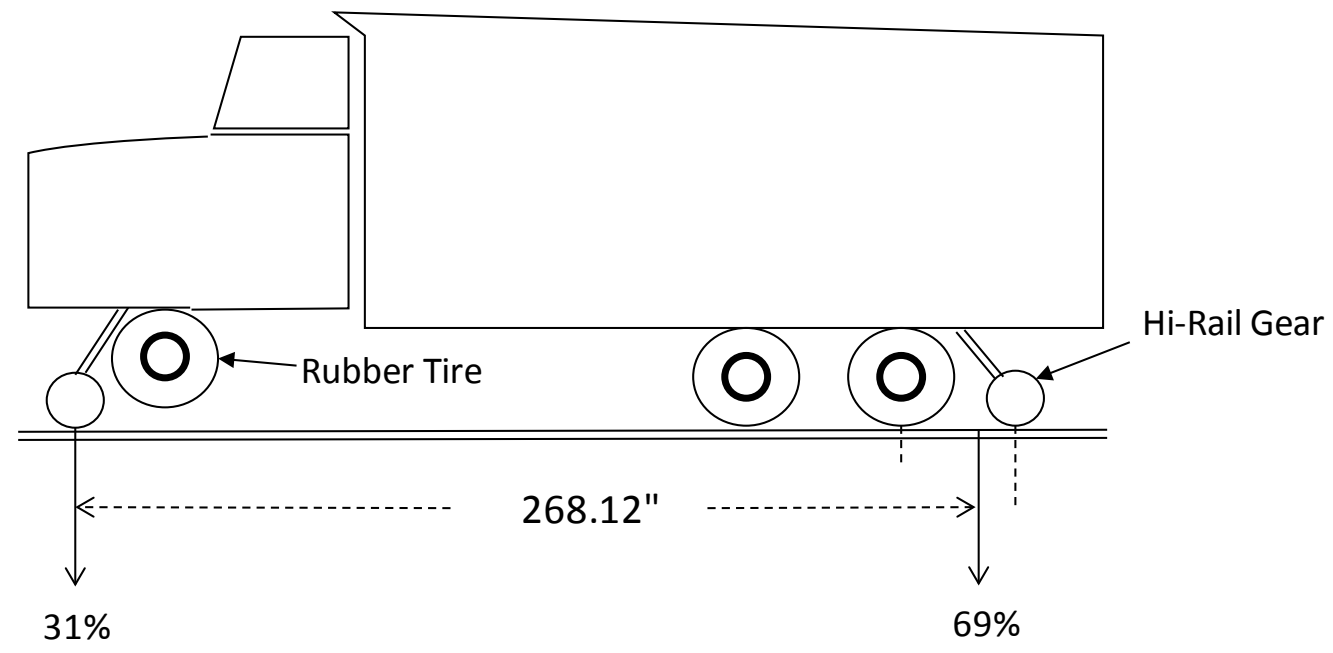

Figure 15 - Hi-Rail Dump Truck 


\section{Literature Review}

\subsection{Introduction}

This critical review of literature on steel and timber trestle bridges covers different aspects of design, analysis, and rehabilitation. The American Railway Engineering and Maintenance-of-way Association (AREMA) has standardized design, rating, and inspection of all railroad components (AREMA, 2014). Various research studies have provided a better understanding of the behavior of steel and timber bridges and innovative schemes of rehabilitation through the use of FRP composites. The focus of this chapter will be on the properties and performance of timber, steel, and FRP composites in the construction and rehabilitation of railway bridge components.

\subsection{Railroad Bridge Materials}

This section covers the material properties used for railroad bridge construction and rehabilitation. Railroads have used timber for bridge construction due to its availability and ease of manufacture (sawing and finishing) since the earliest railroads were built. Historically, bridges were constructed using the locally available lumber, which in West Virginia consisted of red oak, yellow poplar and other hardwoods as these materials were widely harvested in the early 1900's. Timber trestles in many rail lines through the United States were often originally built as temporary structures in order to reach certain areas unreachable due to water ways, ravines, and other obstacles. As the train weights and traffic volumes increased, many timber bridges were replaced with steel, but many timber bridges are still in service today, primarily on short line railroads. Most of the timber railroad bridges that are still in service today are either in good condition, in need of repair, or have been rehabilitated. Some of the rehabilitation techniques on existing timber bridges include the use of FRP composites.

A more in depth discussion about the characteristics of timber, steel, and FRP composites as railroad bridge materials is covered in the next subsections.

\subsubsection{Wood}

The chemical composition of wood is comprised of lignin (phenolic substance) and carbohydrate (cellulose and hemicellulose). These two complex, polymeric materials account for about $18-35 \%$ and $65-75 \%$ of wood respectively (Petersen, 1984). Wood can be classified into two major groups, hardwoods and softwoods. Softwood is the most common type of timber used for structural purposes, and major species currently used for timber bridges is Southern Pine (Jackson, Howard, \& Hammett, 2001). Types of softwoods include Southern Pine, Hemlock, Spruce and Douglas Fir, and common 
hardwoods are Walnut, Oak, and Ash (Forest Products Laboratory, 2010). The cross-section of the tree is very similar for both hardwoods and softwood species, which can be seen in Figure 16.

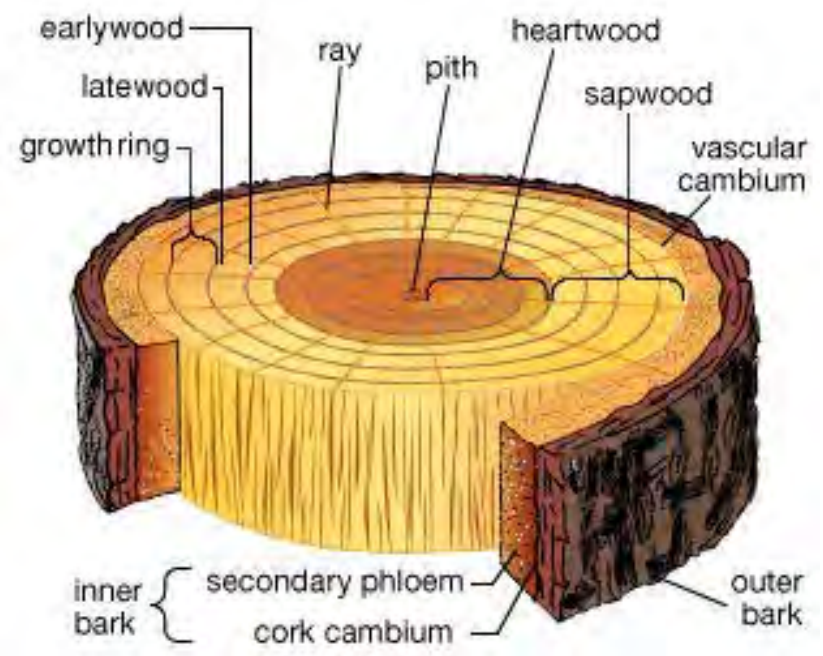

Figure 16 - Wood Log Cross Section (Meriam-Webster, 2006)

Logs cut into dimensional lumber, which depends on the size of the final product intended from each log. There are two ways of sawing wood into boards: plainsawn and quartersawn (Wood Handbook, 2010). Plainsawn boards are cut tangentially to the growth rings, and quartersawn boards are cut radially from the pith towards the outer bark. The two types of cuts described herein can be seen in Figure 17.

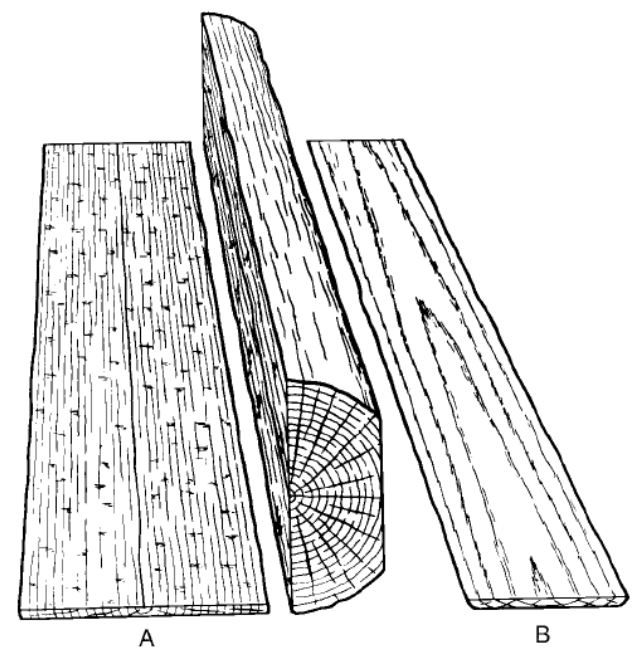

Figure 17 - (A) Quartersawn and (B) Plainsawn (Wood Handbook, 2010) 
Quartersawn and plainsawn boards are used for different applications, and their properties are affected mainly by their different shrinkage patterns.

\subsubsection{Mechanical Properties of Stress Graded Lumber}

The direction of the grain (or fiber) is very important in determining the mechanical properties of wooden members. Timber is an orthotropic and nonhomogeneous material, meaning its mechanical properties are different in the radial, longitudinal, and tangential direction. The different planes where the mechanical properties of wood differ are shown in Figure 18. For example, compression strength of timber is higher parallel to the grain of wood (longitudinal direction) than perpendicular to the grain of wood (radial or tangential direction).

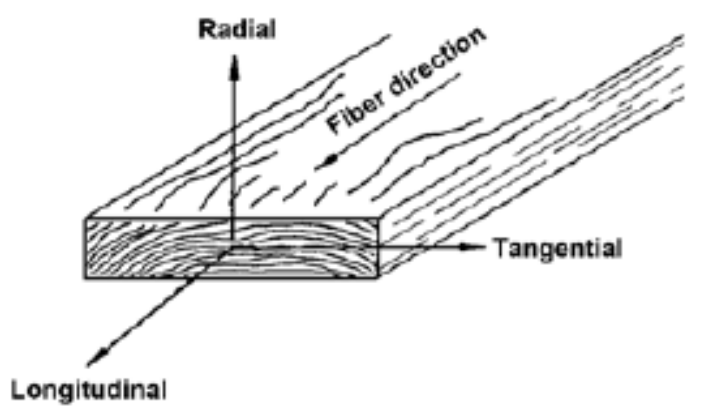

Figure 18 - Principal Axes of Wood Properties

The fiber direction does not always run parallel to the longitudinal axis of the timber member for two reasons: 1) board was cut at an angle from the longitudinal axis of the log, and 2) grain (fiber) in the log has a natural slope. The higher the slope of the grain in relation to the axial direction of the board, the weaker the strength of the board will be in the axial direction. Many other growth properties of the tree unrelated to manufacturing processes of timber can weaken the mechanical properties of wood. Knots, branch off-shoot of living trees, are found in many timber products. The Wood Handbook (2010) gives a good description of how knots affect the mechanical properties of wood:

(a) Clear wood is displaced by a knot, (b) fibers around a knot are distorted, resulting in cross grain, (c) discontinuity of wood fiber leads to stress concentrations, and (d) checking often occurs around the knots during drying.

The density of wood is another strength factor, with higher density wood having higher strength values. Density of wood is typically determined by "the rings per unit length on the cross section and the percentage of latewood" (Forest Products Laboratory, 2010). 
A grading process is used by the lumber industry to classify timber members and group them into groups based on their strength among species, referred to as stress grades. Two identical pieces of lumber of the same species, free of any defect, should contain similar strength properties within a given statistical range as per ASTM guidelines. The grade of any given piece of lumber is dependent on features that can weaken the member, which vary in type, size, quantity and location in the member. Some of these features are part of a living tree including the slope of grain, knots, pitch pockets, and density. Other features affecting the grade occur during the manufacturing process of wood products when the moisture content of lumber decreases due to drying processes, leading to shrinkage. Such features include checks, splits, shakes, and dimensional changes. Visual grading was the first process developed to standardize the stress grade of all lumber being manufactured for structural design, and is still commonly used today (Forest Products Laboratory, 2010). Several agencies exist for grading of specific timber species, including the Southern Pine Inspection Bureau (SPIB) for Southern Pine and the Grading Rule Specifications for Northeast Lumber Manufacturers Association (NeLMA) for eastern hardwoods, including Red Oak.

Generally, not only is lumber grouped by species and growth characteristics, but also by size. Lumber sizes are classified by their thickness as follows:

Board Lumber - Thickness less than 2 inches (nominal), typically non-structural

Dimensional Lumber - Thickness of 2 inches and more, but less than 5 inches (nominal), most commonly used in the building trades

Timbers - Thickness (least dimension) of 5 inches or more, used for larger members

Graded timbers for most species are also divided into two sub groups which are "Beams and Stringers", where bending stresses govern the design, and "Posts and Timbers", primarily resisting axial stresses. Due to the size of timbers, they are typically cut from the center of the log, therefore most of the members will be composed of heartwood. The grade assignment for timbers intended to be used as beams and stringers may be more stringent than the posts and timbers. A beam with many edge knots may be assigned a lower grade than if the same lumber was used as post. This is due to the fact that edge knots are more detrimental to the strength of a member under bending stresses than it is under axial stresses. In spite of edge knots, not all timber is graded with knots in mind as Southern Pine timbers are not graded with regard to its final intended stress use (Ritter, 1992). 
Strength and elastic properties are assigned for each grade and these properties can be found in several publications, including the American Wood Council's National Design Specifications (NDS) supplement and the AREMA manual. The reference design values provided in the NDS supplement are bending stress $(\mathrm{Fb})$, tension parallel to grain $(\mathrm{Ft})$, shear parallel to grain $(\mathrm{Fv})$, compression perpendicular to grain $\left(\mathrm{FC}_{\mathrm{E}}\right)$, compression parallel to grain $(\mathrm{Fc})$, and modulus of elasticity $\left(\mathrm{E}\right.$ and $\left.\mathrm{E}_{\mathrm{min}}\right)$. Strength and elasticity design values for wood are determined by testing as per ASTM D 2555 and ASTM D 245. ASTM D 2555 is a procedure for establishing clear wood strength values through testing of small samples of unseasoned wood. ASTM D 245 is then applied to the experimental values of clear wood specimens to provide design values for timbers of larger dimensions and growth characteristics. The values are based on ASTM D 2555 procedures, which can be summarized as follows:

The ultimate stress is based on the 5-percent exclusion limit for the sample of small, clear specimens. This value is established from a statistical analysis and indicates that out of all clear wood samples tested, 95 percent would be expected to fail at or above the 5-percent exclusion limit, while less than 5 percent would be expected to fail below the limit. (Ritter, 1992)

From the ultimate stress values obtained by testing small clear samples to failure, only the lowest stress values represented by $5 \%$ of the samples are considered by ASTM D 2555 . The 5 -percent exclusion limit provides a high factor of safety for design, because only the lowest stress values obtained from testing are considered. Stress grades provide another factor of safety when assigning design values using ASTM 245.

An individual piece of lumber will often have several characteristics that affect a particular strength property. The characteristic that gives the lowest strength ratio is used to derive the estimated strength. Strength ratio values vary for lumber grades, depending on the maximum number and location of strength-reducing characteristics permitted for the grade. For example, high-strength grades have higher strength ratios because they have more restrictive requirements on the number, type, and location of defects. Lower grades are less restrictive on strength-reducing characteristics and have lower strength ratios. (Ritter, 1992)

Strength ratios are used to determine the value of visually graded lumber in relation to its clear wood specimen value per ASTM D 2555. Strength ratios are determined depending on the strength reducing 
characteristic found. When knots or shakes are present, the cross sectional area of the wood is reduced by the size of these defects and its strength is calculated, which is then divided by the strength of a clear wood specimen. For other defects like slope of grain, the ratios are determined experimentally. A strength ratio of 0.75 for bending stress would provide a lower value for the desired stress grade, thus providing a factor of safety in design. While most of the strength values are based on the $5 \%$ limit, the elastic modulus (E) is based on the average. This is due to its use when calculating deflection, a serviceability limit that would not result in catastrophic failure of the structure. However, the NDS also lists $E_{\min }$ for stability (buckling) checks of members, which are strength limits that can cause catastrophic failure. NDS Appendix D defines $E_{\min }$ as "an approximate $5 \%$ lower exclusion value on pure bending modulus of elasticity, plus a 1.66 factor of safety". The formula used to calculate $E_{\min }$ is:

$$
E_{\text {min }}=E[1-1.645 * \operatorname{COV}] 1.03 / 1.66
$$

The value for coefficient of variation for visually graded sawn lumber is 0.25 as specified in Appendix $F$ of the NDS manual. The multiplier factor of 1.03 is used to transform the value of $E$ into a pure bending young's modulus (E includes both bending and shear effects). The divider, "1.66" is an added factor of safety (American Wood Council, 2014). The NDS also has various adjustment factors to the reference design values to account for various environmental (moisture, temperature, etc.) and loading effects (flat use, load duration, etc.) that a timber member may see in its lifetime. These values are applied based on a particular application for timber on a case-by-case basis. Adjustment factors, the $5 \%$ exclusion limit for ultimate stress values, and average of modulus of elasticity values build safety factors into the design of timber bridges, which provides more confidence in Chapters 4 and 5 when comparing live load stresses and strains to the bridge load rating capacity.

The AREMA manual generally has the same allowable strengths as the NDS supplement, with the allowable AREMA loads reduced by 0.9 to account for the dead load duration factor $\left(C_{D}\right)$ as the other NDS adjustment factors are already accounted for in the AREMA published values. The only exception is the allowable horizontal shear stress of Southern Pine, which is based on tests conducted by the Association of American Railroads. The AREMA manual also does not include the $E_{\min }$ values as buckling is accounted for with minimum standardize bracing requirement for railroad bridges.

The NDS supplement does not provide design values for the modulus of rigidity (G, shear modulus), but the Wood Handbook provides a table of ratios of $G$ with respect to $E_{L}$ (elastic modulus along the longitudinal axis), which allows for the calculation of $\mathrm{G}$ in different planes. Averaging the longitudinal 
shear plane ratios $\left(G_{L R} / E_{L}\right.$ and $\left.G_{L T} / E_{L}\right)$ of three Southern Pine species (Longleaf, Loblolly and Slash) gives a $G_{L} / E_{L}$ ratio for the Southern Pine group of 0.067 , which is the ratio used to calculate predicted shear strain in section 4.2.2 of this report. For comparison, ASTM D 2555 section 4.3 .3 specifies a modulus of rigidity for clear wood as 0.069 times the value of $\mathrm{E}$.

\subsubsection{External Agents Affecting the Mechanical Properties of Wood}

Preservative chemicals are necessary for the preservation of timber structures over their service life in exposed environments. There are two main groups of treatment preservatives, waterborne and oil-type preservatives. Creosote (oil-type) preservatives applied to wood do not affect its strength, and historically have been the primary preservative for railroad structures. Most chemicals used in waterborne preservatives will react with wood, thus affecting its mechanical properties. The preservative is most commonly applied by vacuuming the air out of a chamber containing the wood, filling the chamber with the preservative and then, applying constant pressure to force the preservative into the wood. The extra preservative in the wood from is later removed via a vacuum (Forest Products Laboratory, 2010).

The extent of penetration and retention of a preservative chemical in wood highly affects its effectiveness in preservation. Sapwood is easily penetrated when compared to the heartwood, which usually goes untreated due to the shallow reach of preservative penetration. Figure 19 shows an example of preservative penetration in a wood log. The untreated area (red arrows) is more vulnerable to biological attacks than the treated area (black arrows), which can be verified with findings from the inspections in section 3.2 where timber posts and some stringer are rotted in the core.

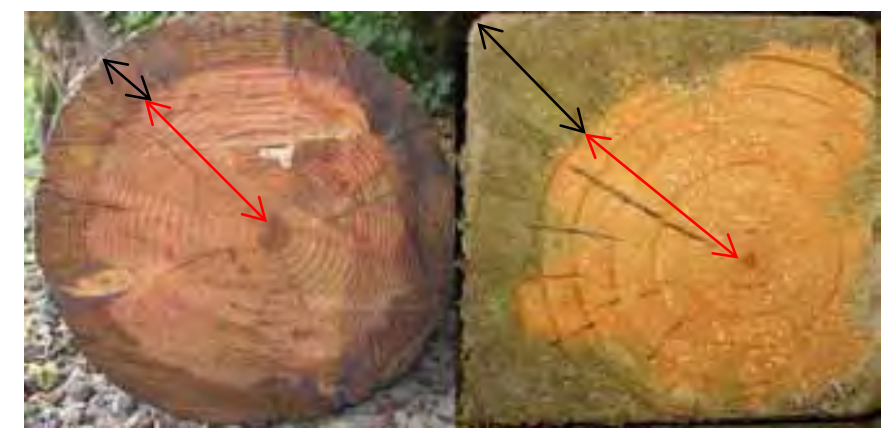

Figure 19 - Cross Section of Pressure Treated Wood Logs (Wood Handbook, 2010)

Biological attacks to wood include fungi, insects, and bacteria. Fungi attacks wood in form of rot or decay, and depending in the type of wood species and fungi, it attacks sapwood or heartwood (heartwood rot or heart rot). Fruiting bodies in wood products are a sign of surface decay. High levels of 
rot can be classified into two groups, the names of which are also indicative of their appearance, brown and white rot (caused by different fungi). Rotting fungi can make wood crack across the grain, shrink, easily crush, and often feel spongy. A less harmful, but very common rot is called soft rot, and it is defined as:

- Soft rot: it is caused by fungi related to the molds rather than those responsible for brown and white rot. Soft rot is relatively shallow, primarily affecting the outer surface of wood; the affected wood is greatly degraded and often soft when wet, but immediately beneath the zone of rot, the wood may be firm (Forest Products Laboratory, 2010).

Insects can also attack wood and leave small tunnels trough the cross section of wood products. Insects attacking wood include beetles, termites, carpenter ants, and carpenter bees. Figure 20 shows wood attacked by different insects.
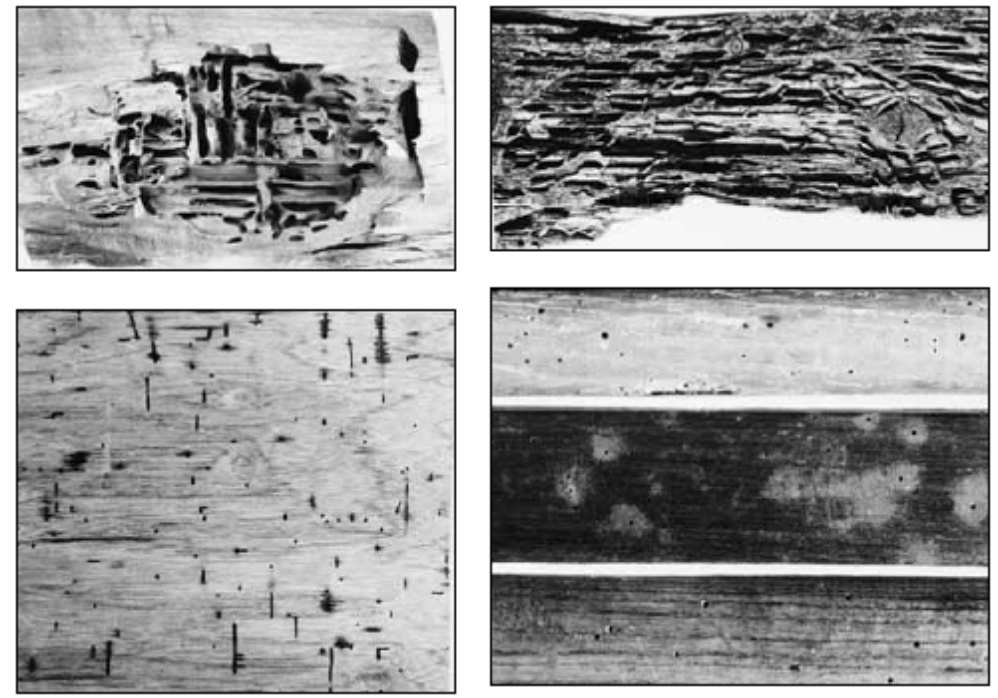

Figure 20 - Upper Left- carpenter ant attack. Upper Right- termite attack. Lower Left- beetle attack. Lower Right -powder-post beetle attack (Forest Products Laboratory, 2010).

Bacteria may also attack wood that remains wet for long periods of time, and is detectable via a very foul odor. Bacteria do not have prominent effects on the strength of wood as fungi and insects may have, but together with fungi, it may accelerate decay.

\subsubsection{Steel}

Steel is very commonly used on railroad bridges, but it is crucial to understand the different types and properties of steel. The type of steel depends on the manufacturing processes, which varied based on the year of construction. For many years, wrought iron was the material of choice for both railroad 
tracks and railroad bridges. It was not until the late 1800s, when the Bessemer steel process was improved, that steel slowly began to replace wrought iron in the railroad industry (both tracks and bridges) (Bowman \& Piskorowski, 2004). The type of connections in a steel bridge can help determine an approximated time of construction. Rivets were first used to connect steel members in bridges until the 1960s, when welding and high strength bolts completely replaced riveting in new construction (Vermes, 2011).

Steel railroad bridges built until 1910 were generally designed to meet cooper ratings of E-40 to E-50, but today's heavier loads have rating requirements to E-80 and up to E-100. During the early years of railroad construction, contracts to build bridges were either based on a fixed price or on the price per pound of steel. Fixed priced contracts generated economic solutions where members in the bridge had just enough material to meet minimum design requirements. On the other hand, price per pound of steel construction usually generated bridges with more material than the required minimum for design for members and connections (Uppal, 2005).

When records of design and construction of existing structures are not available, values for allowable stresses and elastic properties can be estimated via AISC specifications and AREMA recommended practice. The best method is to take sections of steel from the bridge and fail them in the lab to determine their strength. However, semi-destructive testing is often not practical as it is difficult to do without damaging the bridge while ensuring that the samples are representative of the entire structure.

\subsubsection{Mechanical Properties of Steel}

AREMA's (2014) recommended practice establishes yield and ultimate stress values for existing metal railroad structures, and these values are available in Table 4.

Table 4 - AREMA Yield and Ultimate Stress Values for Existing Railroad Bridge Materials (AREMA, 2014)

\begin{tabular}{|l|c|c|}
\cline { 2 - 3 } \multicolumn{1}{c|}{} & fy (psi) & fu (psi) \\
\hline Wrought Iron & 25,000 & 45,000 \\
\hline Bessemer Steel & 30,000 & 50,000 \\
\hline Open-Hearth Steel & 30,000 & 60,000 \\
\hline Silicon Steel & 45,000 & 62,000 \\
\hline Nickel Steel & 50,000 & 90,000 \\
\hline
\end{tabular}

The open-hearth steel making process became more popular than the Bessemer process mainly to the fact that it could eliminate phosphorus from the ore bath, which allowed for a wider variety of iron ores 
to be used with varying phosphorous contents. Even though the Bessemer process was more economical, it was bound to a more restrictive set of ores with limited phosphorous contents, but the open-hearth process allowed for a wider variety of ores available in America to be exploited along with steel scrap. The Open-hearth process also allowed for higher temperatures to be reached, making it possible for entrapped slag to be removed along with impurities, thus generating a more consistent and higher quality steel (Fruehan, 1998). Table 4 lists different steels and their allowable stress values, where Bessemer and Open-Hearth steels are considered carbon steels, and Silicon and Nickel steels are alloy steels. Alloy steels have a higher percentage of silicon or nickel, thus changing the physical properties of carbon steel and enhancing certain mechanical properties.

AREMA also recommends using a Young's modulus (modulus of elasticity, E) value of 29,000 ksi, a Poisson's ratio of 0.3 , and a modulus of rigidity (shear modulus, $\mathrm{G}$ ) of 11,200 ksi. Based on mechanics of materials formula, $G=E / 2(1+v)$, the modulus of rigidity of steel is calculated to be $11,154 \mathrm{ksi}$. For comparison, Section 6B.5.2.1 of the AASHTO Manual for Bridge Evaluation (2014) recommends using a minimum yield of 26,000 psi for highway bridges built prior to 1905 and 30,000 psi for highway bridges built between 1905 and 1936. The higher yield stresses recommended by AREMA reflect the higher weight of railroad vehicles, thus the initial requirement for higher strength steel.

\subsubsection{Fiber Reinforced Polymer Composites}

Fiber Reinforced Polymer (FRP) composites are gaining acceptance in the infrastructure area, especially when strengthening and retrofitting existing structures (Jain \& Lee, 2012). FRP composites are a combination of two distinct elements, a fiber and a matrix, that are combined to create a final product with properties that are the best fit for the application. Thus, it is important to choose a fiber-resin combination that suits the needs of the structure, including strength, ease of installation and durability. Both the fiber and the matrix contribute to the mechanical properties of the final composite product, thus it is important to understand how each of these elements affects the final properties. P. K. Mallick's (2007) textbook on fiber-reinforced composites covers the topics of materials, mechanics and performance of composite materials, and is the primary reference in the following sections.

\subsubsection{Fibers}

The main constituent in composite materials is fiber, carrying the majority of the load imposed. Properties such as diameter, density, tensile modulus, tensile strength, strain-to-failure, coefficient of thermal expansion, electrical conductivity, and cost are the major factors compared when choosing among different fiber materials. 
Fibers are manufactured as small filaments with diameters averaging around 10 nanometers $\left(1^{-8}\right.$ meters). These filaments have to be bundled together for practicality, and they can be bundled together in a twisted (yarn) or untwisted (strand) manner. The strands or yarns of fiber can then be assembled as:

a. - Chopped strands (continuous strands chopped into lengths ranging between 3.2 and $12.7 \mathrm{~mm}$ ).

b. - Continuous strand roving.

c. - Woven roving (continuous roving woven in two mutually perpendicular directions)

d. - Fabrics

The orientation of the strands or yarns in a polymeric matrix lamina will depend on its structural use, so it is crucial to understand the different loading directions a lamina will experience. Figure 21 shows how the fiber orientation in a lamina under tensile stress affects the tensile strength of the composite.

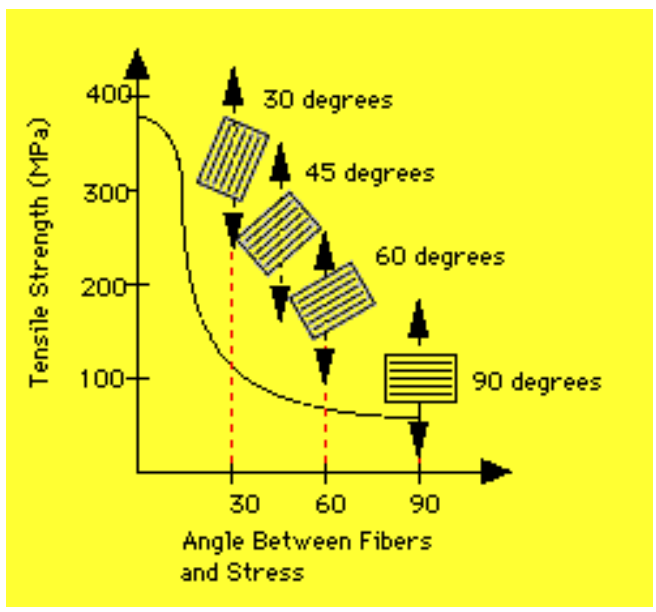

Figure 21 - Fiber Orientation Effects on Tensile Strength (Davidson, n.d.)

Laminas with different fiber orientations are assembled as a laminate in order to resist different directions of loading. Fibers can be made of different materials such as glass, carbon, aramid, boron and natural fibers. For repair of timber, glass is the most appropriate fiber as it is low cost and has similar mechanical properties to wood. The different properties of glass fiber will be discussed in the next subsection.

\subsection{Glass Fibers}

Most glass fibers are produced by mixing silicates, soda, clay, limestone into a molten glass batch which is extruded through platinum alloy bushings that contain orifices ranging from 0.76 to $2.03 \mathrm{~mm}$, finally forming thin filaments ranging from 3 to $35 \mu \mathrm{m}$. In order to efficiently bind glass filaments into strands preventing abrasion among glass filaments, the fibers are coated with sizing (binders) that provide 
lubrication, protection and coupling, and aid in the bonding of the matrix (Donaldson \& Miracle, 2001). There are many types of glass fibers available depending on their final purpose, these different classes are designated by the first letter of a glass type fiber. Two major groups make up the different classifications of glass fibers, general-purpose and special-purpose glass fibers. General purpose fibers are the most commonly used in structural applications, and are designated with the letter $\mathrm{E}$ (E-glass), which stands for low electrical conductivity. E-glass fibers were originally developed for use in electrical applications as insulators for electrical wiring, but it's now a common reinforcement in fiber composite materials (AZoM.com, 2013). Special purpose glass fibers include ECR-, D, S-, and A-glass fibers.

The main difference among fibers, including other non-glass fibers like carbon, boron, and aramid, is their mechanical properties. The advantages of glass fiber are low cost per weight, high resistance to chemical or galvanic corrosion, excellent electrical insulation properties, high tensile strength, and high strain-to-failure. Some disadvantages of glass are low tensile modulus, high density when compared to other materials, and a relatively high coefficient of thermal expansion. Many mechanical properties of glass fiber can be enhanced or counteracted by the matrix used to obtain the final composite material. For example, the coefficient of thermal expansion of the fiber in an FRP laminate might be negative in a specific direction while it may be positive for the matrix in use. Different types of matrices and their properties are discussed next.

\subsubsection{Matrix}

The material holding the reinforcement (fibers) together in a composite material is the matrix. The different types of matrices available include polymeric, metallic, and ceramic materials. Polymers are the most commonly used matrix for structural applications, and are divided into two groups, thermoplastics and thermosets.

\subsection{Thermoplastic and Thermoset Resins}

In thermoplastics, molecules are linked together through secondary bonds, and through the application of heat the bonds break and can be reshaped into a new form upon cooling. This process can be repeated many times do to the weak secondary bonds found in thermoplastics. Thermosets have a different bond configuration where rigid cross-links that can be shaped upon curing, but once cured, the bonds cannot be reshaped through the application of heat. Some common thermoplastic resins are Polyether ether ketone (PEEK), Polyphenylene sulfide (PPS), Polysulfone, and others. Commonly used thermoset resins are Epoxy, Polyester, Vinyl Ester, Cyanate Ester, Phenolic, and many others. Common examples of thermoplastics are PVC pipes, Teflon non-stick cookware, Styrofoam cups, microwave safe 
containers, and many other household objects. Common examples of thermosets include epoxy glues, billiard balls, roller coaster and skateboard wheels, condoms, hoses, and paints. Table 5 shows some of the advantages and disadvantages of thermosets and thermoplastics. Thermosets are the most commonly used resins for the matrix component in fiber reinforced polymer composites.

Table 5 - Advantages and Disadvantages of Thermosets and Thermoplastics

\begin{tabular}{|c|c|c|}
\hline & Advantages & Disadvantages \\
\hline Thermoset & $\begin{array}{c}\text { Thermal Stability } \\
\text { Chemical Resistance } \\
\text { Low Creep } \\
\text { Low Stress Relaxation }\end{array}$ & $\begin{array}{l}\text { Limited Storage Life } \\
\text { Long Fabrication Time } \\
\text { Low Strain-to-Failure } \\
\text { Low Impact Strength }\end{array}$ \\
\hline Thermoplastic & $\begin{array}{l}\text { High Impact Strength } \\
\text { High Fracture } \\
\text { Resistance } \\
\text { High Strain-to-Failure } \\
\text { Unlimited Shelf Life } \\
\text { Postformability }\end{array}$ & $\begin{array}{l}\text { Low Creep Resistance } \\
\text { Low Thermal Stability } \\
\text { Low Heat Resistance }\end{array}$ \\
\hline
\end{tabular}

FRP composites can be applied in the field via wet lay-up to repair concrete or timber members. For these applications, a primer is used to enhance the bond between the FRP and the underlying substrate. The type of primer used depends on expected strength of the composite, the substrate material and the resultant bond capacity needed. Laosiriphong (2000) performed research at WVU-CFC on the development and evaluation of glass fiber reinforced composite creosote-treated wood crossties, and found that a phenolic (thermoset) resin together with glass fabric performed best compared to other resins when bonded to creosote treated wood crossties. Laosiriphong used a primer/resin combination of Phenol Resorcinol Formaldehyde/Resorcinol Formaldehyde together with a phenolic compatible glass fabric.

To better understand the behavior of existing railroad bridges, the next section will cover reports on the evaluation and load testing of existing railway bridges.

\subsection{Evaluation of Existing Railroad Bridges}

Repairing a railroad bridge with FRP composites requires an evaluation of the bridge, including inspections, load rating and field testing. 
Evaluation of existing railroad bridges is very important due to two factors: (1) age of the existing railroad bridges connecting the nationwide railway network, and (2) the increase in train car axle loads due to increased freight loads by the industry. The age of the bridges shown in a study by Nowak (2012) which found that about $59 \%$ of railway bridges on main lines in Nebraska and lowa were built between 1900 and 1950, and 6\% dating as far back as late 1800s. Another study sponsored by PennDOT and the U.S. DOT Federal Highway Administration on short-line railroad bridges in the state of Pennsylvania surveyed 1,184 bridges, with many steel bridges dating back to late 1800 s and early 1900 s, and timber trestles having a median year-built date of 1949 (Laman \& Guyer, 2010). As our railroad structures have aged, railway freight car gross weights have increased by about $70 \%$ over the past 40 years. 1990s freight rail cars of $263,000 \mathrm{lb}$ are now a standard of $286,000 \mathrm{lb}$, and we are now even seeing car loads with gross weights of $315,000 \mathrm{lb}$. Today's design capacity of railroad bridges is double what they were in the early 1900s (Unsworth, 2003). Plans may provide the age and design capacity of the structure, but a thorough field inspection helps detect deviations from the plan that may affect the structural response of the bridge, together with deterioration findings, and replaced members. A proper inspection report helps determine the current carrying capacity of existing timber bridges to withstand today's ever increasing railroad loads. Standardize inspection procedures including detection and recording of decay, and standard inspection reporting can provide the engineer with enough information to assign new load ratings to existing structures.

\subsubsection{General Inspection}

The inspection process of timber and steel bridges follow material-specific procedures. The AREMA manual recommended practice provides information on the conditions to report, and how to record findings for the inspection of railroad bridges. Inspections of any structure are best completed using a formalized method, including an 1) initial pre-inspection data gathering phase to find out general information, 2) a thorough visual inspection in the field and 3) standardized reporting, as outlined below (Ritter, 1992).

1. Pre-inspection evaluation: any existing document with information of construction date, design drawings, as-built drawings, loading history, maintenance, and previous inspection reports should be reviewed in order to familiarize with the structure and potential areas of deterioration. A thorough pre-inspection evaluation helps the inspector perform a more effective field inspection. A third party consultant provided yearly inspection reports to WVSRA 
dating back to 2011 up to 2013 on the Dailey Branch bridges, and these were available to WVU for reference.

2. Field inspection: The track condition should be noted both at the approaches and throughout the length of the bridge, checking for alignment, condition of track rails, position of rail in reference to the center line of the stringer chords, bearing on ballast, and proper amount of ballast. The ties condition should be inspected, recording the size, spacing, uniformity of bearing, and deterioration. Areas susceptible to decay are usually near connections and locations where mechanical damage has created an opening for water to collect. The most common mechanical damage is induced by loading timber bridges above the designed capacity over long periods of time, which may induce shear or bending cracks visible in the side faces of beams and stringers. Another sign of overloading are crushed surfaces where stringer ends bear on beams, or beams bear on posts. Foundation settlement is another cause of mechanical damage, affecting proper load distribution among adjacent members, and proper bearing of substructure members. Component inspection is necessary when deterioration is identified; the location of the component and the extent of rust or rot need to be noted. Substructure components usually experience decay due to contact with soil and fluctuating water elevations. Debris may also impact bridge components due to stream channel overflow, including components both in the superstructure and substructure. Locations where members connect such as cap/column joints, bracing bolts, backwall/wingwall intersections are highly susceptible to deterioration. The superstructure components are inspected last, looking for locations where water and debris tend to be trapped. Non-structural components, such as tie spacers, need to also be inspected for decay. Section 3.2 of this report was performed following recommendations from this section.

3. Reports and records: for each individual bridge, the inspector shall record the bridge number, name of nearest station, lowest mile-post number, Global Position System (GPS) location, age and type of structure, total length of spans, height of spans, and number of spans. Per AREMA, all bridge components and spans along the length of the bridge shall be numbered in increasing order in the direction that the mile posts increase. Transverse members, such as stringers and posts, shall be numbered in increasing order from left to right when looking from bent number 1 towards the last numbered bent. A summary of inspection findings including strength reducing factors that may lower the capacity of the bridge needs to be documented. Drawings, pictures, and sketches depicting the location and extent of deterioration need to be included with the 
inspection report, as provided in Appendix 2. Dimensions and quantities need to be verified and updated if any discrepancies between as-built drawings and the current condition of the structure exist. Recommendations need to be provided in the report with respect to repair, replacement, capacity reduction, or closure of the bridge and bridge components. An inspection report should provide means of determining a cost-benefit analysis for future work on the inspected structure.

AREMA recommends that a periodic inspection is completed on all bridges at least once a year. Periodic inspections help track any change in the structural condition of the bridge through its service life, and any major findings are noted for further investigations. AREMA further recommends special inspections when periodic inspections demand further investigation, when determining the current capacity rating of the bridge, when preparing repair plans, and whenever fracture-critical members (FCMs) are encountered specifically in steel structures. Emergency inspections are special inspections in situations where a bridge undergoes an event that may have affected its capacity to resist design loads. These events can be floods, derailments, collisions, fires, and earthquakes. (AREMA, 2014). The load rating procedure in chapter 4 falls under the category of special inspections, since it provides further information regarding the bridge current load carrying capacity.

\subsubsection{Specific Inspection Needs for Timber Raillroad Bridges}

All timber members in any location of a bridge need to be visually inspected for cross grain, and for any sign of failure due to shear, bending or bearing. Signs of failure are usually due to overstressed members, natural defects in wood and uneven bearing conditions. Such signs can be seen as significant cracks across or along members, and crushed wood at bearing areas. It is also important to note whether the timber member is treated or untreated. A timber expert assisted the inspection crew in locating and recording defects in the wood, such as cross grain, to then determine the structural grade of timber as shown in section 2.3.

On open-deck bridges, the condition of the anchorage of ties, guard timber and tie spacers should be noted. All stringers should be checked for any deterioration and natural defects, recording the location, type and size. The dimensions of each stringer, number of stringers per chord, and whether they are packed or spaced within the chord system should be noted. The bearing condition of the stringers on each bent need to be checked; including number of shims where used, uneven bearing among stringers in a chord, and any crushed surfaces due to bearing stress. 
The substructure should be inspected last, recording the number of posts in each bent, their dimensions, the spacing among posts, and if they are braced. The bearing conditions of the corbels (if present) on the cap beams, the cap beams on the posts, and the posts on the sills or blocking should be noted. Any deterioration found on all substructure members including lateral and longitudinal bracing should be noted. The wingwall and backwall components should be examined in a similar fashion. "Sketches, drawings, and photographs are invaluable for illustrating inspection results and should be used freely to locate, identify, and clarify the condition of the bridge components" (Ritter, 1992). A set of drawings including sketches and photographs is included in this report in Appendix 2 in order to provide clear and thorough information regarding inspection findings.

\subsubsection{Specific Inspection Needs for Steel Bridges}

Corrosion can appear in any member of a steel bridge, and any loss of section from corrosion needs to be noted including the location and extent of rust and section loss. Areas where dirt and water can collect, such as bearings and flanges, need to be checked for corrosion or potential future rust. Areas needing spot painting or repainting are locations for future rust to develop, thus recommendations for repainting are important for the longevity of the structure. Locations of expected higher stress should be inspected for cracks and signs of local buckling. For steel bridges, AREMA recommends the inspection to focus on the following items.

- Anchors, bearings, and bridge seats: Type of bearing of superstructure on masonry below. Condition of expansion bearings, rollers, or rockers including proper functioning, cleanliness, correct positioning, and bearing.

- Expansion: The condition of the masonry at support bearings, abutment and piers, looking for apparent movement from original position.

- Straightness and alignment of members: whether the girders, beams, and stringers have any bends or kinks, and condition of alignment.

- Cracks and breaks: record any cracks and breaks in stringer connection angles, flange angles, ends of cover plates, and lateral bracing.

- $\quad$ Rivets, bolts, pin holes and nuts: record any loose rivets, corrosion heads of rivets, and wear of rivet holes.

- Corrosion: Any corrosion should be noted, including the size, location of corrosion in member, and location of corrosion in the bridge. Any loss of cross section due to corrosion should be recorded. Collection of rust at bearing locations and at bottom of stiffeners. 
- Paint and cleanliness: the condition of the paint throughout the bridge including areas in need of spot painting. Note areas were dirt and debris collect on any surface.

For rating purposes, inspection findings should be taken into consideration, including any additional dead load or fixed loads since the structure was originally built. Loss of section due to corrosion should be measured as best possible in the field. All bracing that reduces the unbraced length of compression members are to be noted. Special attention needs to be paid when inspecting fracture-critical members, which are defined by AREMA as "tension members or tension components of members whose failure would be expected to result in collapse of the bridge or inability of the bridge to perform its design function". When inspecting typical steel railway bridges, AREMA suggests a standardize nomenclature for each bridge component as shown in Figure 22 for deck girder bridges and Figure 23 for through girder bridges.

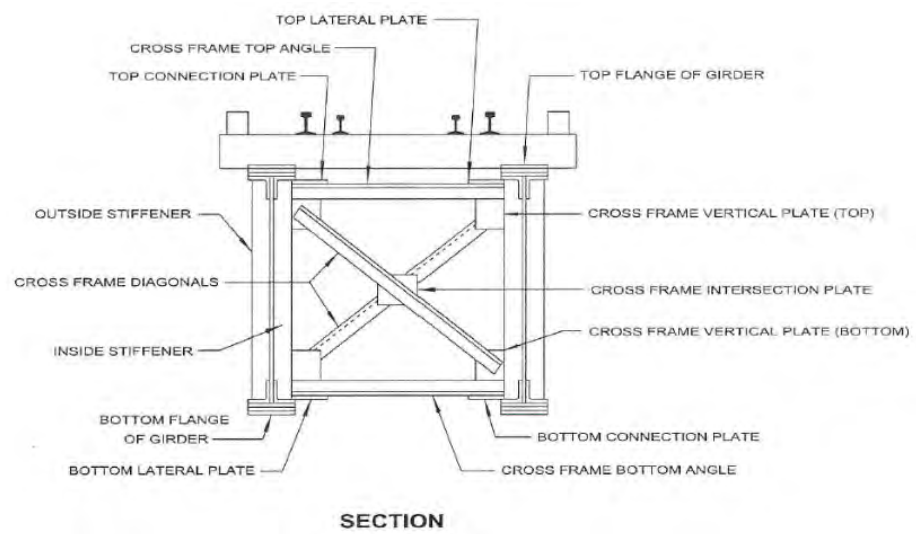

Figure 22 - Typical Deck Girder Bridge (AREMA, 2014) 

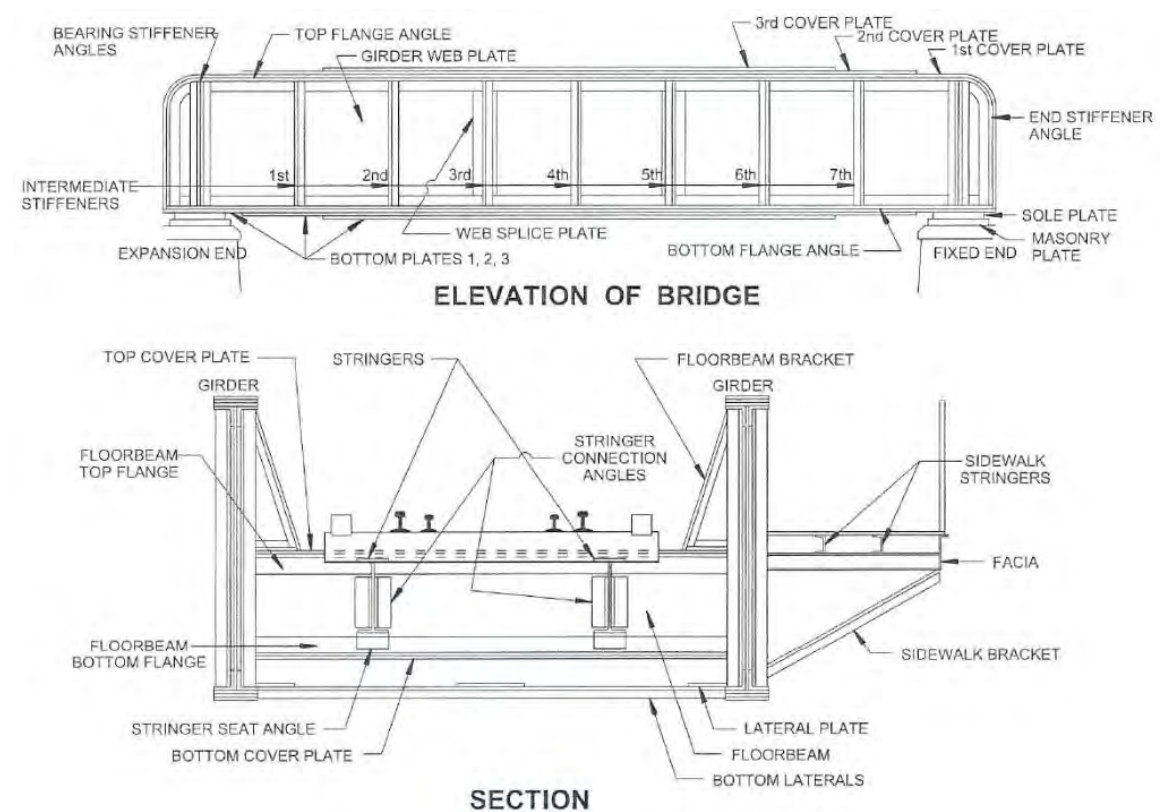

Figure 23 - Typical Through Girder Bridges (AREMA, 2014)

\subsubsection{Load Rating Method}

The standard rating for railroad bridges is Cooper E 80, thus the live load stress used for rating factor calculations shall be that of a Cooper E 80 locomotive. The rating factor is calculated in the same manner as highway bridges: 1) determine the allowable capacity of a given member on the bridge, 2) subtract the dead load effects, and 3 ) divide by the live load stresses. The rating factor (RF) formula is:

$$
R F=\frac{\text { Allowable Unit Stress } \text { Normal }- \text { Dead Load Stress }}{\text { Live Load Stress } \text { L } 80}
$$

If the rating factor is less than 1 , then the member is unable to support the Cooper $\mathrm{E} 80$ standard. A rating factor greater or equal to 1 meets the Cooper E 80 standard. The next step is to determine the Cooper $\mathrm{E}$ rating value, which is calculated by multiplying the rating factor by 80 .

$$
\text { Cooper E Rating }=80 *(R F)
$$

For example, a rating factor of 0.75 , is equal to a Cooper $E 60$ rating. If the load rating of the bridge is sufficient to carry the expected live load throughout its service life, the bridge can be deemed safe. In order to compare live load stresses to the Cooper E rating, they must be converted to equivalent Cooper E loads. A standard live load that most railroad bridges need to meet is that of a 286 kip rail car. The equivalent Cooper E load of a 286 kip rail car is calculated as follows: 
Equivalent Cooper E Load $_{286 K}=\left(\frac{\text { Live Load StresS }_{286 K}}{\text { Live Load StresS }_{E} 80}\right) * 80$

All the formulas in this section were used to compute the load rating of bridges 1.4 and 5.8 in Appendix 1. Figure 24 shows the bending moment exerted on a simple span bridge by a 286 kip rail car and its equivalent Cooper E load.

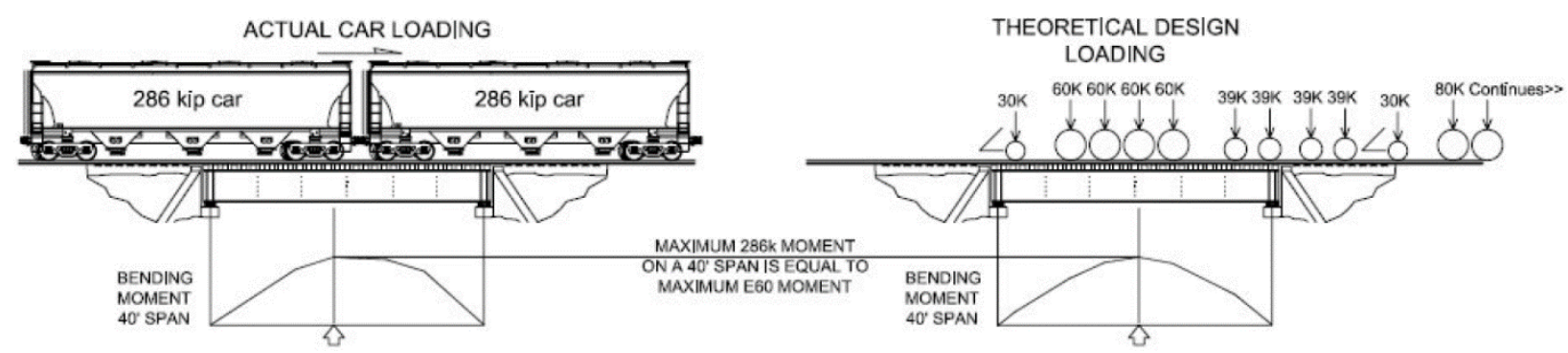

Figure 24 - Equivalent Cooper E Load of a 286 Kip Rail Car (Westbrook Associated Engineers, E80 Pluss Constructors, 2006)

In a similar fashion, equivalent Cooper E loads can be calculated for any other live load expected on the bridge during its service life.

When rating both steel and timber railroad bridges two different ratings are assigned to the structure. Steel bridges use a Normal and Maximum rating, while timber bridges are rated for Regularly Assigned Equipment or Locomotives and Equipment or Locomotives Not Regularly Assigned. Although AREMA does not formally define regularly and not-regularly assigned equipment or locomotives, in practice they are treated the same as normal and maximum. Normal rating is the load level that can be carried by an existing structure for its expected service life. Maximum rating is the load level that the structure can support at infrequent intervals, thus recognizing that loads inducing stresses higher than design values may be imposed on a structure for a limited time, similar to oversized loads on highway bridges (AREMA, 2014). These two different rating conditions have not always been part of the standard rating specifications. In 1994, AREMA Committee 15 decided to add normal ratings to the provisions, reasoning that the increase of many heavy axle loads of cars in a single train had changed the load effects on bridges, particularly with respect to fatigue life. In earlier years, heavy steam engines pulled relatively lighter weight cars, but the advent of several powerful diesel-electric locomotives coupled together to pull unit-trains of coal and other commodities increased the axle loads of the rail cars. This provision helped maintain the expected service life of the bridge under increasing axle loads. Ratings higher than normal can be assigned, but a reduction in service life needs to be assessed, as long as serviceability limits are met (Conway, 2001). 
Although the overall rating procedure is the same for both timber and steel, there are some material specific provisions as discussed in the next two sections.

\subsubsection{Timber Bridge Specific Rules}

The superstructure of timber bridges is commonly configured as a set of 3 or more stringers assembled into a chord where the stringers are packed in a staggered manner (semi-continuous) as shown in Figure 4 of chapter 1 . When designed, stringers should be placed such that the track loads are equally distributed to each stringer in a chord. As per AREMA Chapter 7, Section 3.1.5, the chord should be analyzed as a partially continuous span computed from the average of continuous and simple span analysis. The span length used for calculating simple span bending stresses on stringers should be the clear distance from face to face of supports plus 6 inches. For continuous span bending, the middle (intermediate) support is set at the center of bearing. Horizontal shear stress on stringers should be calculated at a distance $d(\mathrm{~d}=$ height of stringer) away from the face of the support. Any loads within distance $d$ from the face of the support should be neglected. The following formula is provided by AREMA for shear stress calculations of rectangular sections.

$$
S=\frac{3 V}{2 b h}
$$

Where $S$ is the maximum unit shear stress in pounds per square inch (psi), $V$ is the maximum shear in pounds (lb), $b$ is the width of the stringer in inches, and $h$ is the height of the stringer in inches. This formula is derived from the following mechanics of materials shear stress formula:

$$
\tau=\frac{Q V}{I b}
$$

Where $\tau$ is the unit shear stress in psi, $Q$ is the first moment of area of the stringer in cubic inches $\left(\mathrm{in}^{3}\right)$, and $I$ is the moment of inertia of the stringer in inches to the fourth power $\left(\mathrm{in}^{4}\right)$. The above mechanics of materials formula for shear stress $(\tau)$ can then be reduced to the AREMA maximum unit shear stress $(S)$ formula for rectangular timber stringers.

When computing stresses in the substructure of a bridge, the spacing between bents shall be considered as the center-to-center distance of the cap beams. The AREMA manual provides design pile aids with an approximate analysis for the determination of load distribution among piles in a bent. The parameters used by these tables to determine load distribution are cap beam dimensions, chord (set of stringers) width, pile spacing, and the effective pile length. 
All bridge components including the deck, tracks, and other fixed loads shall be considered when determining the dead load on the bridge. AREMA provides component weights for dead load stress computations, and they are shown in Table 6.

Table 6 - Component Weights for Dead Load Stress Computations (AREMA, 2014).

\begin{tabular}{|l|l|}
\hline \multicolumn{1}{|c|}{ COMPONENT } & \multicolumn{1}{c|}{ WEIGHT } \\
\hline Track, rails, inside guard rails, and fastenings & $200 \mathrm{lb}$ per linear foot track \\
\hline Ballast, including track ties & $120 \mathrm{lb}$ per cubic foot \\
\hline Timber & $60 \mathrm{lb}$ per cubic foot \\
\hline Protective coverings & Actual weight \\
\hline
\end{tabular}

AREMA Chapter 7 Section 3.1.9 states that the impact factor for wood is not well established for railroad bridges, but the allowable stresses provided in AREMA have taken impact into account, thus engineers do not need to include impact for timber structures.

The AASHTO LRFD 2012 Bridge Design Specifications 6th Edition - Article 3.6.2.3 on wood components also states that the "dynamic load allowance (IM) need not be applied to wood components". A study by Abhari (2007) on the rehabilitation of timber railroad bridges performed under static and dynamic (2 and $15 \mathrm{mph}$ ) field load tests with an 80 ton locomotive, concluded that no dynamic impact allowance was evident.

The AREMA manual provides tables with allowable unit stresses for stress-graded lumber specific for railroad loading, in accordance with ASTM 245. The design values found in the tables are for a moisture content of wood over $19 \%$. Several grades and size classifications for each species are provided by different grading agencies, and the process for grading was through visual inspection. The values provided in the tables are in part based on testing of full-scale Douglas-Fir and Southern Yellow Pine stringers conducted at Texas A\&M University. The different allowable stress values for the species studied in this project can be found in Table 7. 
Table 7 - Allowable Unit Stresses for Stress Graded Lumber - Railroad Loading (Visual Grading) (AREMA, 2014)

\begin{tabular}{|c|c|c|c|c|c|c|c|c|}
\hline \multirow[b]{2}{*}{ Grade } & \multirow{2}{*}{$\begin{array}{c}\text { Size } \\
\text { Classification }\end{array}$} & \multicolumn{6}{|c|}{ Railroad values wet conditions (over $19 \% \mathrm{MC}$ ) } & \multirow{2}{*}{$\begin{array}{c}\text { Grading } \\
\text { Agency } \\
\text { Rules }\end{array}$} \\
\hline & & $\begin{array}{l}F_{b} \\
\text { psi }\end{array}$ & $\begin{array}{l}F_{t} \\
\text { psi }\end{array}$ & $\begin{array}{l}F_{v} \\
\text { psi }\end{array}$ & $\begin{array}{l}F_{c_{\perp}} \\
\text { psi }\end{array}$ & $\begin{array}{l}\mathbf{F}_{\mathrm{c}} \\
\mathrm{psi}\end{array}$ & $\begin{array}{l}\text { E } \\
\text { ksi }\end{array}$ & \\
\hline \multicolumn{9}{|c|}{ Southern Pine } \\
\hline Select Struct. & \multirow{3}{*}{$\begin{array}{l}5 " \times 5 " \text { and } \\
\text { larger }\end{array}$} & 1350 & 900 & 150 & 340 & 855 & 1500 & \multirow{3}{*}{ SPIB } \\
\hline No. 1 & & 1215 & 810 & 150 & 340 & 745 & 1500 & \\
\hline No. 2 & & 765 & 495 & 150 & 340 & 475 & 1200 & \\
\hline \multicolumn{9}{|c|}{ Red Oak } \\
\hline Select Struct. & Beams and & 1215 & 720 & 140 & 495 & 675 & 1200 & \multirow{4}{*}{ NELMA } \\
\hline No. 1 & Stringers & 1035 & 495 & 140 & 495 & 575 & 1200 & \\
\hline Select Struct. & \multirow{2}{*}{$\begin{array}{l}\text { Posts and } \\
\text { Timbers }\end{array}$} & 1125 & 765 & 140 & 495 & 715 & 1200 & \\
\hline No. 1 & & 900 & 610 & 140 & 495 & 635 & 1200 & \\
\hline
\end{tabular}

An adjustment to the allowable bending stress, $F_{b}$, value has to be made if the depth of the member exceeds 12 inches. When this occurs, $F_{b}$ shall be multiplied by a size factor, calculated as

$$
C_{r}=\left(\frac{12}{d}\right)^{1 / 9}
$$

The size factor, $C_{r}$, applies to members under the NDS classifications of Beams \& Stringers, Posts \& Timbers, and Southern Pine sections 5" and wider (American Wood Council, 2014).

The allowable stresses are multiplied by different factors for Regularly Assigned Equipment or Locomotives and Equipment or Locomotives Not Regularly Assigned ratings, as shown in Table 8. The values for unit stress, $k$, can be extracted from Table 7 . The timber stringers for all the bridges in this study have a depth not greater than 16 inches, thus the depth factor referenced in Table 8 will always be equal to 1 for unit stresses calculations. 
Table 8 - Unit Stresses for Rating (AREMA, 2014)

\begin{tabular}{|c|c|c|c|}
\hline & Description & $\begin{array}{c}\text { Equipment or } \\
\text { Locomotives Not } \\
\text { Regularly Assigned }\end{array}$ & $\begin{array}{c}\text { Regularly Assigned } \\
\text { Equipment or } \\
\text { Locomotives }\end{array}$ \\
\hline$f=$ & unit stress in extreme fiber in bending, in pounds per square inch & $1.3 \mathrm{kF}_{\mathrm{h}}$ & $1.1 \mathrm{kF}_{\mathrm{h}}$ \\
\hline All of & her unit stresses & $1.3 \mathrm{k}$ & $1.1 \mathrm{k}$ \\
\hline $\mathrm{E}=$ & modulus of elasticity, in thousands of pounds per square inch & \multicolumn{2}{|c|}{ As shown in Table XX } \\
\hline $\begin{array}{l}\text { wher } \\
k=\end{array}$ & \multicolumn{3}{|c|}{$\begin{array}{l}\text { Unit Stress for Structural Lumber Subject to Railway Loading, Section 2.5, Allowable Unit Stresses for Stress- } \\
\text { Graded Lumber. }\end{array}$} \\
\hline & \multicolumn{3}{|l|}{$0.81 \frac{H^{2}+143}{H^{2}+88}$} \\
\hline & \multicolumn{3}{|c|}{ where: $\quad H$ is the depth of the beam. For $H$ of 16 inches or less, $F_{h}=1$ may be used. } \\
\hline
\end{tabular}

\subsubsection{Steel Bridge Specific Rules}

The dead load stress calculations for steel bridges shall include all bridge components including the track, ties, walkways, and any other fixed loads. As with the timber bridges, the track rails, inside guard rails, and their rail fastenings are assumed to be $200 \mathrm{lb}$ per linear foot for each track per AREMA.

The live load stresses have to be computed for a standard Cooper E load, and for the vehicles expected on the line. The bending moment and shear forces need to account for dynamic impact effects. AREMA specifies an impact factor for two different cases, one is for span lengths less than 80 feet, and the other one for span lengths greater or equal to 80 feet. These two impact factors are calculated as follows:

$$
L<80 \mathrm{ft}: \mathrm{Im}=40-\frac{3 L^{2}}{1600} \quad L \geq 80 \mathrm{ft}: \mathrm{Im}=16+\frac{600}{L-30}
$$

$L=$ span length in feet

A reduction to the impact factor is to be made for train speeds below $60 \mathrm{mph}$. The reduction factor to be multiplied to the impact effect is calculated using the following formula:

$$
1-\frac{0.8}{2500}(60-S)^{2} \geq 0.2
$$

$\mathrm{S}=$ speed of train in $\mathrm{mph}$

Impact load due to the rocking effect ( $\mathrm{RE}$ ) of the train needs to be calculated and factored into the live load forces as well. The RE factor shall be calculated as " $20 \%$ of the wheel load without impact, acting 
downward on one rail and upward on the other" (AREMA, 2014). Centrifugal forces shall also be considered only when horizontal curvature of the track is present.

AREMA Chapter 15 Section 7.3.3.2b specifies fatigue evaluations are not necessary for bridges that will carry less than 5 million gross tons per year and do not have details for any bridge with an allowable stress range lower than the detail corresponding to Category D found in the AREMA manual, as it is later referenced in section 5.2.1 load rating of bridge 1.4. The commentary section of the AREMA manual further explains the reasoning behind not performing a fatigue evaluation:

For lines carrying low volumes of traffic, fatigue is generally not a problem. For a bridge carrying less than 5 million gross tons per annum throughout its existing and projected life, fatigue check is waived for usual mixed traffic. The term "usual mixed traffic" refers to normal North American equipment and is intended to exclude solid unit train traffic and unusual heavy loads such as heavy molten metal cars or heavy transformers in frequent service (AREMA, 2014).

It also stated in the manual that the project engineer may decide to waive fatigue requirements for lines that have carried and are carrying up to 15 million gross tons per year. The allowable stress values for normal and maximum rating are calculated differently per AREMA. Normal allowable bending stress is determined for both tension and compression in extreme fibers of flexural members. For tension in extreme fibers of rolled shapes, girders and built-up sections, the allowable bending stress is:

$$
F_{b+N}=0.55 F_{y}
$$

For compression in the extreme fibers of flexural members that are rolled beams or welded built-up members, the allowable stress is the larger of the following two formulas:

$$
F_{b-N}=0.55 F_{y}-\frac{0.55\left(F_{y}\right)^{2}}{6.3 \pi^{2} E}\left(\frac{l}{r_{y}}\right)^{2} \text { or } \frac{0.131 \pi E}{(l d \sqrt{1+\pi}) / A_{f}} \text {, but not to exceed } 0.55 F_{y}
$$

$I$ = distance between points of lateral supports for the compression flange, inches.

$r_{y}=$ minimum radius of gyration of the compression flange and that portion of the web area on the compression side of the axis of bending, about an axis in the plane of the web, inch.

$A_{f}=$ area of the smaller flange excluding any portion of the web, inch ${ }^{2}$.

$\mathrm{d}=$ overall depth of the member, inches. 
For compression in the extreme fibers of riveted or bolted built-up flexural members, the allowable stress is:

$$
F_{b-N}=0.55 F_{y}-\frac{0.55 F_{y}^{2}}{6.3 \pi^{2} E}\left(\frac{l}{r_{y}}\right)^{2}
$$

The lesser of $\mathrm{F}_{\mathrm{b}+\mathrm{N}}$ and $\mathrm{F}_{\mathrm{b}-\mathrm{N}}$ will control the allowable bending stress under normal rating, $\mathrm{F}_{\mathrm{bN}}$. For shear in the webs of rolled beams and plate girders, the allowable shear stress is:

$$
F_{v N}=0.35 F_{y}
$$

Maximum allowable bending stresses are also calculated for both the tension and compression extreme fiber of flexural members. For tensions in the extreme fibers of rolled shapes, riders, and built-up sections, the allowable bending stress is:

$$
F_{b+M}=0.8 F_{y}
$$

For compression in the extreme fibers of welded built-up or rolled beam flexural members, the allowable bending stress is the larger of the following two formulas:

$$
F_{b-M}=0.8 F_{y}-\frac{0.8 F_{y}{ }^{2}}{1.8 \times 10^{9}}\left(l / r_{y}\right)^{2} \text { or }\left(\frac{0.8 F_{y}}{0.55 F_{y}}\right) \frac{10,500,000}{l d / A_{f}} \text {, but not to exceed } 0.8 F_{y}
$$

For compression in the extreme fibers of riveted or bolted built-up flexural members, the allowable bending stress is:

$$
F_{b-M}=0.8 F_{y}-\frac{0.8 F_{y}^{2}}{1.8 \times 10^{9}}\left(l / r_{y}\right)^{2}
$$

The lesser of $F_{b+M}$ and $F_{b-M}$ will control the allowable bending stress under maximum rating, $F_{b M}$. For shear in the webs of rolled beams and plate girders, the allowable shear stress is:

$$
F_{v M}=0.6 F_{y}
$$

The rating factors and Cooper E ratings are computed as shown previously. All of the formulas shown in this section can be found in Appendix 1 for the computation of allowable stress for bridges 1.4 and 5.8, and their respective load rating capacity in sections 5.2.1 and 5.2.2. 


\subsubsection{Load Rating and Field Testing by Others}

Given the lack of as-built design data and analysis assumptions, field testing is often completed to provide additional information on the performance of the structure. AREMA Chapter 15 Section 7.2.4.3 states that instrumentation may be used to determine in-situ strains and displacements, but must be used as a supplement to qualified inspections.

Due to the staggered (semi-continuous) stringer configuration of the superstructure, different models have been developed to analyze and rate timber railroad bridges. The Wisconsin DOT (2006) sponsored a study where 20 timber pile trestle bridges, 3 steel plate girder bridges, and 1 concrete slab bridge on the Wisconsin railroad system were evaluated to assess the impact of the weight increase of railcars. The timber bridges were 40-60 years old, and the steel and concrete bridges were $80-120$ years old. It is noted in this study that AREMA recommends rating the timber bridges using the average of results from a simple span and a continuous span analysis, but a simple span analysis was performed for both timber and steel bridges in order to obtain conservative results. Six open deck trestles rated below the desired E 80 standard under bending and shear, with only one ballasted deck trestle rating slightly above. All seven timber trestles didn't meet the E 80 standard for pile rating and about half of the structures rated above a 286-kip rail car loading. Prior to performing the load test covered in chapter 4 a preliminary analysis using worst span case scenarios, such as simple span for bending and continuous for shear, in order to provide a margin of safety when testing. This approach is similar to the Wisconsin DOT's method for load rating.

Wipf et al (2000) took the analysis procedure further, by creating a model to calculate deflections that could be compared to results from field testing. The model assumed the chords of stringers to be one single beam per span, combining the properties of the stringers into one single beam. Support conditions were analyzed both as simply supported and continuously supported. The axle loads were applied directly to the beam and no impact factor was considered. The bridge to be modeled and load tested consisted of an 11-span open-deck packed chord timber trestle built 60+ years ago in D'Hanis, Texas. The north chord had recently been replaced with glue laminated (glulam) beams, and the south chord remained the original Douglas-Fir Larch with a recently added "helper" stringer (a fifth stringer on the outside of the chord) in Spans 1 through 4. The bridge was instrumented with displacement transducers, accelerometers, and rail load circuits in Span 2 (south chord includes extra helper stringer) and span 8 (no extra helper stringer, original 4 rough sawn stringers). The displacement transducers were located at midspan and near the cap beams on each stringer of each chord in order to measure 
both the absolute and relative displacement of the stringers. Several train speeds were tested in order to determine the dynamic amplification factor (DAF) by dividing the maximum dynamic deflection induced by speeds of 24,48 , and $64 \mathrm{~km} / \mathrm{hr}$ by the maximum static deflection which was obtained by rolling the train over the bridge at crawl speed. The determination of DAFs would help improve analytical models, if considerable impact is shown. Table 9 shows the different DAF values obtained from absolute and relative deflection empirical data. Absolute deflection is the total deflection at midspan including support movement. Relative deflection is calculated by subtracting the average of the stringer deflection right at both supports from the midspan deflection. The authors concluded that for the south chord, the DAF decreased as the train velocity increased. When comparing south chord values between spans 2 and 8, the extra helper stringer in span 2 should be taken into account. It is also important to keep in mind that the north chord is composed of newer glulam stringers compared to rough sawn lumber in the south chord.

Table 9 - Maximum Midspan Stringer DAFs (Wipf et al, 2000)

\begin{tabular}{ccccccccc}
\hline & \multicolumn{4}{c}{ Absolute DAF } & \multicolumn{3}{c}{ Relative DAF } \\
\cline { 2 - 9 } \begin{tabular}{c} 
Test Train $\begin{array}{c}\text { Velocity } \\
(\mathrm{km} / \mathrm{h})\end{array}$ \\
\cline { 2 - 9 }
\end{tabular} & \multicolumn{2}{c}{ Span 2 } & \multicolumn{2}{c}{ Span 8} & \multicolumn{2}{c}{ Span 2 } & \multicolumn{2}{c}{ Span 8 } \\
\cline { 2 - 9 } & $\begin{array}{l}\text { North } \\
\text { Chord }\end{array}$ & $\begin{array}{l}\text { South } \\
\text { Chord }\end{array}$ & $\begin{array}{l}\text { North } \\
\text { Chord }\end{array}$ & $\begin{array}{l}\text { South } \\
\text { Chord }\end{array}$ & $\begin{array}{l}\text { North } \\
\text { Chord }\end{array}$ & $\begin{array}{l}\text { South } \\
\text { Chord }\end{array}$ & $\begin{array}{l}\text { North } \\
\text { Chord }\end{array}$ & $\begin{array}{l}\text { South } \\
\text { Chord }\end{array}$ \\
\hline 24 & 1.00 & 1.02 & 1.05 & 1.01 & 1.00 & 1.05 & 1.00 & 1.00 \\
\hline 48 & 1.11 & 1.21 & 1.09 & 1.03 & 1.15 & 1.05 & 1.07 & 1.01 \\
\hline 64 & 1.16 & 1.15 & 1.04 & 1.03 & 1.22 & 1.06 & 1.14 & 1.07 \\
\hline
\end{tabular}

The DAF values in Table 9 show that no impact is present for speeds below $24 \mathrm{~km} / \mathrm{h}(15 \mathrm{mph})$ as assumed during load testing and load rating in Sections 4.2 and 5.2 respectively. Field deflection values from testing were also compared to results from both simple span and continuous span models. The comparison between predicted and field values was made using stringer 5 of the north chord at span 8 , and it can be seen in Figure 25. 


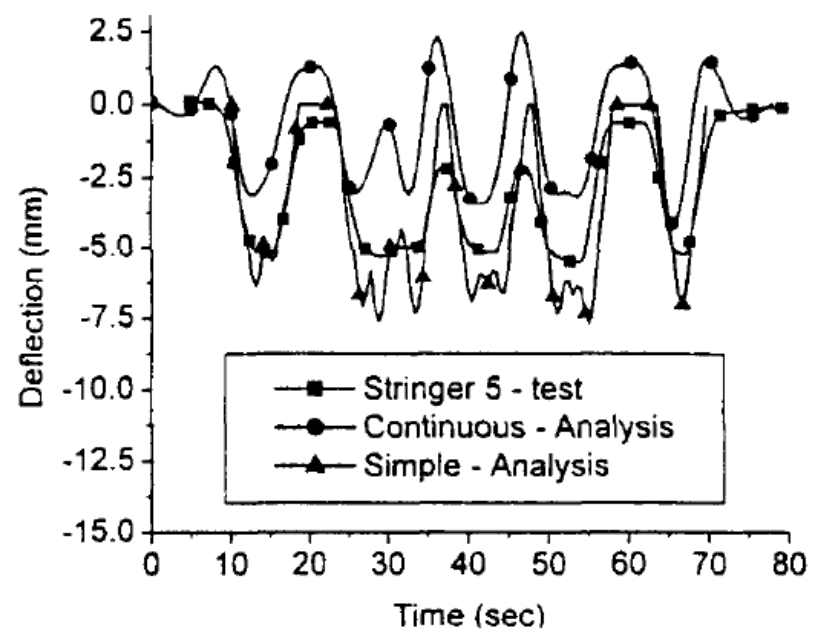

Figure 25 - Comparison between Predicted and Empirical Deflection Values (Wipf et al, 2000)

Figure 25 obtained from the original report shows the continuous analysis data as the upper bound trend line, with the simple analysis data being the lower bound trend line. The field test data happens to fall in between the continuous and simple analysis data trend lines for almost every data point. Field tests results for bending and shear strain in Section 4.2.1 validate the assumption that semi-continuous timber bridges behave has both simple and continuous spans as found by Wipf et al.

Gutkowski (2001) expanded more on Wipf's analysis approach by including three more models in the investigation of three timber stringer trestle bridges with semi-continuous (staggered) design. In a similar way to Wipf et al, Gutkowski combined stringer properties in some of the simpler models. The material properties of the stringers, cap beams, and piles were evaluated in the field using a nondestructive assessment technique. It was first determined by inspection that all the timber in all three structures was Douglas-fir treated with Pentachlorophenol. Very few defects, such as knots, slope of grain, and checks along the grain were found in the members. An ultrasonic instrument, SylvaTest, measuring the propagation speed of ultrasonic waves between two piezo-electric transducers was used to determine the $\mathrm{E}$ value of individual timbers. The system used had an upper and lower limit, any values falling outside of these limits could be predicted with a formula for the linear relationship between propagation wave speed and predicted E. Table 10 shows the predicted $\mathrm{E}$ value for the 160 stringers (Ply Locations), 27 cap beams (Cap Locations), and 12 piles, along with their respective minimum and maximum values for the timber members found in all three bridges in the study. 
Table 10 - Predicted Field E Values Using SylvaTest Ultrasonic Testing Device (Gutkowski, 2001)

\begin{tabular}{|c|c|c|c|c|}
\hline $\begin{array}{c}\text { All } \\
\text { Members } \\
\text { Tested }\end{array}$ & $\begin{array}{c}\text { Population } \\
\text { Descriptor }\end{array}$ & $\begin{array}{c}\text { Measured } \\
\mathrm{E} \\
(\mathrm{psi})\end{array}$ & $\begin{array}{c}\text { Lower Limit } \\
\text { Extrapolated } \\
\mathrm{E}\end{array}$ & $\begin{array}{c}\text { Combined Population } \\
\mathrm{E}\end{array}$ \\
\hline Ply & $\mathrm{psi})$ & $(\mathrm{psi})$ \\
Locations & $\mathrm{N}$ & 137 & 23 & 160 \\
& Mean & $2.05 \times 10^{6}$ & $1.60 \times 10^{6}$ & $2.04 \times 10^{6}$ \\
& Minimum & $1.77 \times 10^{6}$ & $1.13 \times 10^{6}$ & $1.13 \times 10^{6}$ \\
& Maximum & $2.15 \times 10^{6}$ & $1.77 \times 10^{6}$ & $2.49 \times 10^{6}$ \\
& St.Dev. & $1.16 \times 10^{5}$ & $1.35 \times 10^{5}$ & $2.38 \times 10^{5}$ \\
& COV & .057 & .084 & .117 \\
\hline Cap & $\mathrm{N}$ & 18 & 9 & 27 \\
& Mean & $2.02 \times 10^{6}$ & $1.31 \times 10^{6}$ & $1.78 \times 10^{6}$ \\
& Minimum & $1.83 \times 10^{6}$ & $8.92 \times 10^{5}$ & $8.92 \times 10^{5}$ \\
& Maximum & $2.15 \times 10^{6}$ & $1.74 \times 10^{6}$ & $2.23 \times 10^{6}$ \\
& St.Dev. & $1.08 \times 10^{5}$ & $3.06 \times 10^{5}$ & $3.93 \times 10^{5}$ \\
& COV & .053 & .234 & .221 \\
\hline Piles & $\mathrm{N}$ & 7 & 5 & 12 \\
& Mean & $1.92 \times 10^{6}$ & $1.51 \times 10^{6}$ & $1.75 \times 10^{6}$ \\
& Minimum & $1.77 \times 10^{6}$ & $1.24 \times 10^{6}$ & $1.24 \times 10^{6}$ \\
& Maximum & $2.15 \times 10^{6}$ & $1.73 \times 10^{6}$ & $2.19 \times 10^{6}$ \\
& St.Dev. & $1.44 \times 10^{5}$ & $1.91 \times 10^{5}$ & $2.67 \times 10^{5}$ \\
& COV & .075 & .126 & .152 \\
\hline
\end{tabular}

The maximum and minimum values of $E$ found in table 7-2-9 of the 2014 AREMA manual is $1.7 \times 10^{6}$ and $1.6 \times 10^{6}$ psi respectively, which applies to stringers, cap beams, and piles. The maximum and minimum values of $E$, for the stringers alone in the three bridges covered in Table 10, are $2.49 \times 10^{6}$ and $1.13 \times 10^{6}$ respectively. Not only are field values for each individual stringer different from each other, but they also differ in range from those values provided in the AREMA manual. Knowing the $E$ value of each individual stringer-ply in a chord helped input actual field mechanical values where possible in the analytical models. The shortest bridge was a 3-span 3-ply packed chord trestle with 40 feet in length, and the longest bridge was approximately 465 feet long containing 31 spans with 4-ply spaced chords. Several models were generated by applying different boundary conditions and continuity assumptions at each bent. The different models were:

a. Pinned single span beam model: each span is represented as a simply supported beam, and the stringers in a chord are represented as one beam with an $E$ value of the average of each stringer in the chord.

b. Continuous beam model: one continuous beam spanning across all spans supported by pinned supports at each bent. The same approach regarding average E values was taken as in model (a). 
c. Semi-continuous beam model: two subsystems of two-span continuous beams, where one subsystem begins as a simple span (span 1) while the adjacent subsystem is continuous over the first two spans (spans 1 and 2), thus representing the staggered ply design as shown in Figure 26 (top). These two adjacent beams are connected at mid span of each span using a pin connected axial element with a high EA value and a negligible El value. Every bent is represented as pinned supports. The same approach regarding average E values was taken as in models (a) and (b), depending on the chord being represented in each subsystem.

d. Extended semi-continuous chord model: each ply in a chord is represented by its own two-span continuous subsystem, same approach as model (c), but representing each stringer in a chord instead of just two subsystems per chord as shown in Figure 26 (bottom). E values are assigned to each individual member as determined from non-destructive testing. A disadvantage of this model was that the live load distribution among stringers is unknown.

e. Fixed end beam model: similar to model (a) with the only difference being at the supports, where no rotation was allowed (fixed supports). The single line model represented the total number of stringers in a span as done with models (a) and (b).
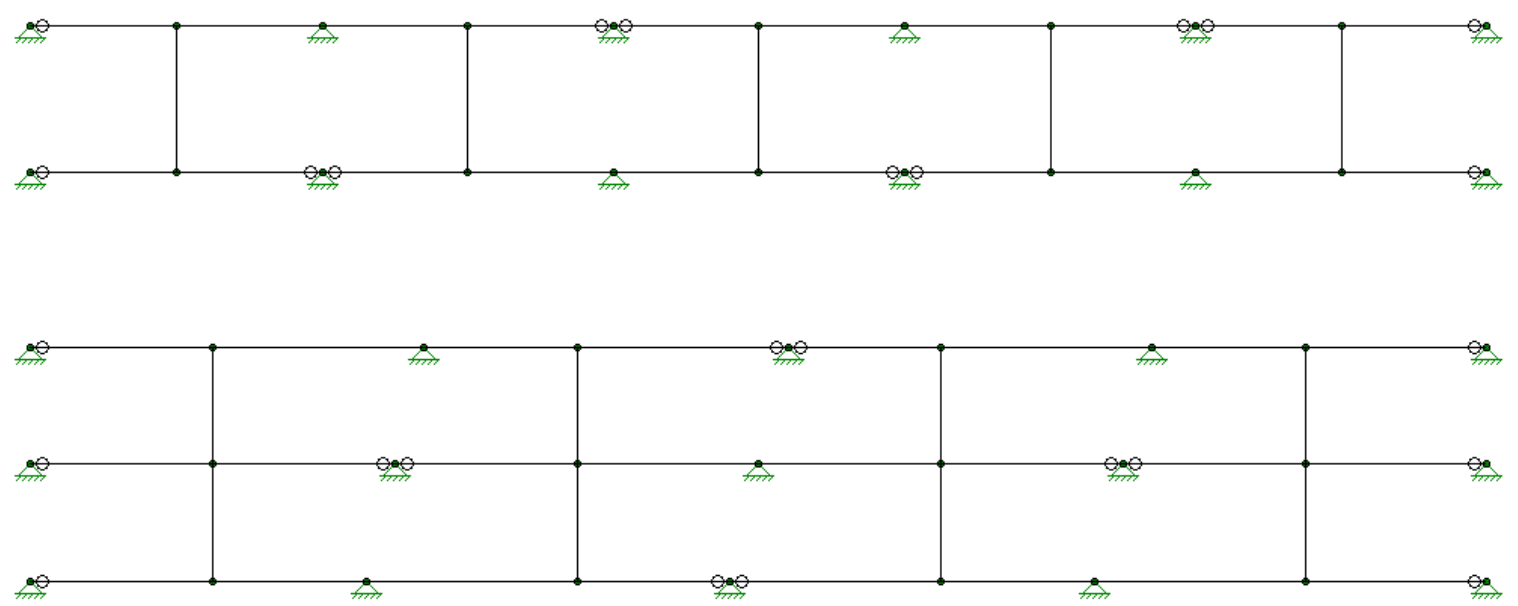

Figure 26 - Semi-continuous beam model (top), and extended semi-continuous chord model (bottom).

The deflection values predicted by analyzing each model under the vehicular load was compared to the field data obtained from displacement transducers (LVDTs), extensometers (strain gages), optical surveying equipment, and accelerometers. In Table 11 the calculated deflections using some of the analytical models were compared to static loading of a locomotive and 2 rail cars used in the field for testing Bridge 101 (3-span bridge). Since the models did not account for support motions, the net 
deflection was measured in the field as well as the deflection relative to the ground, but only the net deflections were compared to the models.

Table 11 - Comparison of Field to Predicted Deflection Values, Bridge 101 (Gutskowski, 2001)

\begin{tabular}{|c|c|c|c|}
\hline & \multicolumn{3}{|c|}{ Mid-span Deflection } \\
\hline & \multirow{2}{*}{$\begin{array}{c}\text { Span } 1 \\
\text { (inches) }\end{array}$} & \multirow{2}{*}{$\begin{array}{l}\text { Span } 2 \\
\text { (inches) }\end{array}$} & \multirow{2}{*}{$\begin{array}{r}\text { Span } 3 \\
\text { (inches) }\end{array}$} \\
\hline Models & & & \\
\hline \multicolumn{4}{|l|}{ 11@I } \\
\hline Fixed Model & 0.0491 & -0.0022 & -0.0114 \\
\hline Continuous Model & 0.1376 & -0.0456 & -0.0163 \\
\hline Semi-continuous Model Hinge at $D^{* *}$ & 0.1414 & -0.0719 & -0.0459 \\
\hline $\begin{array}{l}\text { Semi-continuous Model Hinge at } \\
\mathrm{G}^{* * *}\end{array}$ & 0.2032 & 0.0021 & -0.0266 \\
\hline Single Span Model & 0.1964 & -0.0208 & -0.0463 \\
\hline Displaced Chord Field Data & & -0.021 & \\
\hline \multicolumn{4}{|l|}{$11 @ \mathrm{~F}$} \\
\hline Fixed Model & -0.0012 & 0.0574 & -0.0012 \\
\hline Continuous Model & -0.0588 & 0.1304 & -0.0578 \\
\hline Semi-continuous Model Hinge at $D^{* *}$ & -0.0675 & 0.1597 & -0.0136 \\
\hline $\begin{array}{l}\text { Semi-continuous Model Hinge at } \\
\qquad \mathrm{G}^{* * *}\end{array}$ & -0.0148 & 0.1748 & -0.0710 \\
\hline Single Span Model & -0.0143 & 0.2295 & -0.0137 \\
\hline Displaced Chord Field Data & & 0.150 & \\
\hline \multicolumn{4}{|l|}{$11 @ \mathrm{C}$} \\
\hline Fixed Model & -0.0119 & -0.0022 & 0.0471 \\
\hline Continuous Model & -0.0126 & -0.0449 & 0.1332 \\
\hline Semi-continuous Model Hinge at $D^{* *}$ & -0.0263 & 0.0022 & 0.1869 \\
\hline Semi-continuous Model Hinge at & & & \\
\hline $\mathrm{G}^{* * *}$ & -0.0499 & -0.0766 & 0.1448 \\
\hline Single Span Model & -0.0483 & -0.0208 & 0.1886 \\
\hline Displaced Chord Field Data & & -0.021 & \\
\hline
\end{tabular}

The left column labeled "Models" contains four different loading positions of the $1^{\text {st }}$ (and sometimes $1^{\text {st }}$ and $2^{\text {nd }}$ ) axle of the locomotive in different locations of the bridge (locations J, K, L, and O). Models on the left column labeled single span, continuous, and fixed (models $a, b$ and e) are as mentioned earlier. The two semi-continuous models with hinges at $D$ and $G(D=$ support between spans 1 and $2, G=$ support between spans 2 and 3), consist of 2 continuous spans with 1 simple span modeled as single beams. The semi-continuous model mentioned in Figure 26 (top) was analyzed and compared to results from load tests on Bridge 32.35 (465 ft long bridge) and the results are shown in Table 12 below. 
Table 12 - Comparison of Deflection Between Field and Analytical Model Values, Bridge 32.35

(Gutkowski, 2001)

\begin{tabular}{|c|c|c|c|c|c|}
\hline & \multicolumn{2}{|r|}{ Predicted } & Mid-span & \multicolumn{2}{|l|}{ Deflection } \\
\hline & \multirow{2}{*}{$\begin{array}{c}\text { Span } 3 \\
\text { (inches) }\end{array}$} & \multirow{2}{*}{$\begin{array}{c}\text { Span } 4 \\
\text { (inches) }\end{array}$} & \multirow{2}{*}{$\begin{array}{c}\text { Span } 5 \\
\text { (inches) }\end{array}$} & \multirow{2}{*}{$\begin{array}{c}\text { Span } 6 \\
\text { (inches) }\end{array}$} & \multirow{2}{*}{$\begin{array}{c}\text { Span } 7 \\
\text { (inches) }\end{array}$} \\
\hline Models & & & & & \\
\hline \multicolumn{6}{|l|}{ 1@J } \\
\hline Continuous Model & 0.0270 & -0.0154 & 0.0739 & -0.0254 & 0.0068 \\
\hline Semi-continuous Model & 0.0463 & -0.0009 & 0.1001 & -0.0204 & 0.0042 \\
\hline Single Span Model & 0.1079 & 0.0492 & 0.1661 & 0.0000 & 0.0000 \\
\hline Mean Field Test Data & & & 0.0953 & -0.0132 & \\
\hline \multicolumn{6}{|l|}{ 1-2@K } \\
\hline Continuous Model & 0.0773 & -0.0294 & 0.0403 & 0.0340 & -0.0103 \\
\hline Semi-continuous Model & 0.1001 & -0.0207 & 0.0642 & 0.0612 & -0.0103 \\
\hline Single Span Model & 0.1619 & 0.0166 & 0.1316 & 0.1316 & 0.0000 \\
\hline Mean Field Test Data & & & & 0.0730 & \\
\hline Mean Field Test Data* & & 0.0330 & 0.0850 & 0.0885 & -0.0060 \\
\hline \multicolumn{6}{|l|}{$1 @ \mathbf{L}$} \\
\hline Continuous Model & 0.0368 & 0.0258 & -0.0151 & 0.0738 & -0.0253 \\
\hline Semi-continuous Model & 0.0676 & 0.0458 & -0.0008 & 0.1001 & -0.0204 \\
\hline Single Span Model & 0.1500 & 0.1079 & 0.0492 & 0.1661 & 0.0000 \\
\hline Mean Field Test Data & & & 0.0070 & 0.1260 & \\
\hline \multicolumn{6}{|l|}{\begin{tabular}{|l|}
$1 @ 0$ \\
\end{tabular}} \\
\hline Continuous Model & 0.0533 & -0.0523 & 0.0991 & -0.0684 & 0.0910 \\
\hline Semi-continuous Model & 0.0609 & -0.0398 & 0.1223 & -0.0523 & 0.1087 \\
\hline Single Span Model & 0.0847 & 0.0000 & 0.1852 & 0.0000 & 0.1568 \\
\hline Mean Field Test Data & & & 0.1200 & & \\
\hline
\end{tabular}

* - Data combined from1-2@I,1-2@K and 1-2@M to illustrate possible responses in spans 4 and 7.

It was concluded that the deflections measured in the field were always between the lower and upper limits of the continuous and simple beam analysis deflections. The semi-continuous model for Bridge 32.35 predicted similar values to the field. Static, rolling, and ramp loads were applied to all 3 bridges in the study during load testing in order to obtain as much data possible regarding different loading conditions, impact, and support motion. The author concluded that support motion due to differential bearing among stringers in a chord on to the cap beams created a load distribution that was difficult to model (small gaps between stringers and cap beams exist in the field). It was also concluded that variability in Young's modulus among all members attributed to the difficulty in determining a load sharing pattern among stringers. Wipf et al's (2000) comparison of models and field values on Figure 14 showed that field deflection data fell between the predicted data of both simple and continuous beam conditions, with a correlation closer to the simple beam analysis. The authors concluded that uneven 
bearing conditions, both at the tie-chord and chord-cap connection, generate a load sharing action where the individual stringers do not act as a unit as originally intended in design. Results from these two studies show that the analysis approach by the Wisconsin DOT in their 2006 study leads to a very conservative results that do not reflect the actual condition of the bridges in the field, even after years of decay. More rigorous analysis, as the semi-continuous model by Gutkowski (2001), helped model the in-situ response of timber trestles closer to field testing values as shown in section 5.3.

The Wisconsin DOT (2006) study also proposed a single beam analysis for steel railroad bridges, which would yield highly conservative results. Kara (2011) from Rutgers University developed a more complete model for the analysis of steel railroad bridges. Kara studied three steel railroad bridges built in 1902, 1911, and 1930 in a thesis titled "Field Testing and Finite Element Analysis for Evaluation of Railroad Bridges". The bridge built in 1930 (Bridge A) is a 77 feet long ballasted deck structure, with the steel deck resting on rolled floor beams, which then transfer the load down to three through plate girders. The middle girder of the middle span (Girder 2, span 2) was analyzed and rated as a simply supported 44.8 foot long beam under a $286 \mathrm{~K}$ railcar live load per AREMA. The $286 \mathrm{k}$ railcar analyzed as a simple beam produced a maximum bending moment of $2338.1 \mathrm{ft}-\mathrm{k}$ at midspan, with a $286 \mathrm{k}$ normal load rating of 79 (assuming each girder carries half of the load per adjacent track). An FEM model including the through girders, floor beams, wood-ties, and rails was analyzed under the same live load. The FEM model predicted a bending moment of $485 \mathrm{ft}-\mathrm{k}$, generating a $286 \mathrm{k}$ normal load rating of 460 , a rating almost 6 times higher than the simple beam analysis. A load test was conducted to verify both the simple beam (AREMA) and the FEM analysis approach. The live load used during testing was a four-axle GP40-PH-2B train, with equal axle loads of 71.05 kips. The strain data obtained from testing was compared to strain data extracted from the FEM model using the GP40-PH-2B train. 


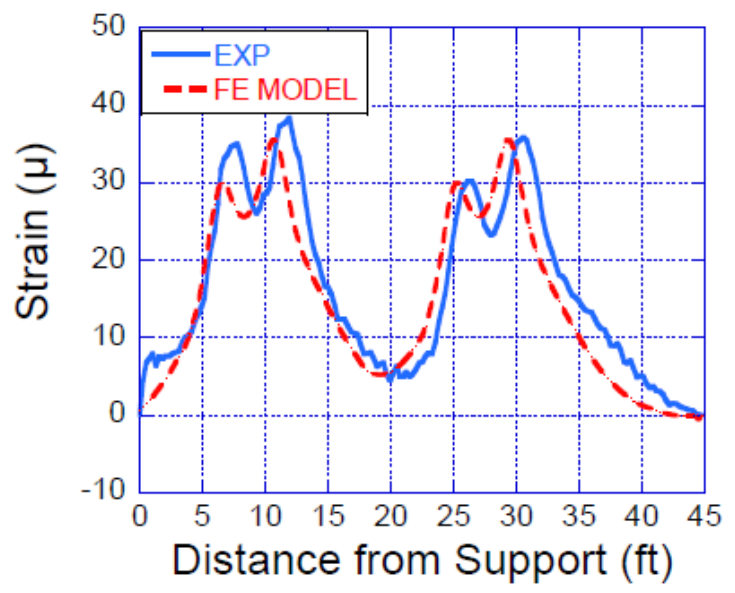

Figure 27 - Strain Data Comparison for Bending Strain@ Midspan (Kara, 2011)

It can be seen in Figure 27 that the FEM model showed a good prediction of the field experimental (EXP) values under live loading. A comparison was also made between the rating values of the single beam analysis and the FE model at four different span locations (including mid-span) as shown in Figure 28.

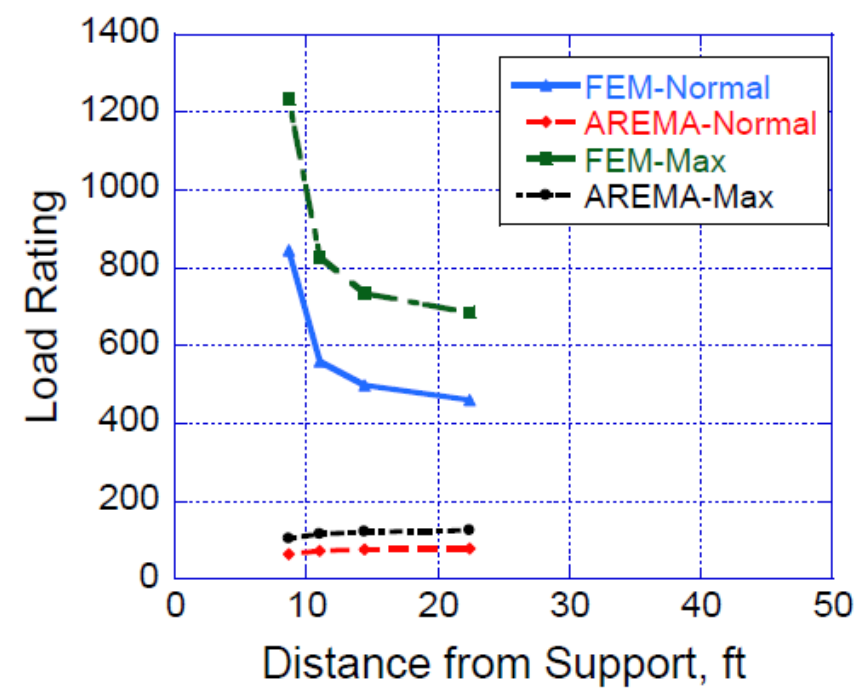

Figure 28 - Comparison between FEM and AREMA Load Rating Values

Kara concluded that the target bridge had more capacity than predicted using AREMA (single beam analysis) specifications approach, and that it can be attributed to the current good condition of the structure. More complex models of both steel and timber structures predict closer values to the measured result from field testing, while the AREMA approach provides a more conservative load rating for design purposes. Once proper stress and strain values can be determined via analysis and testing, the bridge structures can be assigned a proper rating value which will determine the need for a posted 
bridge with lower load capacity, a complete shutdown of the bridge, or a repair plan in order to rehabilitate the bridge's load carrying capacity.

\subsection{Rehabilitation of Timber Structures using FRP Composites}

When repairing timber structures, the type of repair has to be taken into consideration, whether the repair is for a pile, a stringer, or a joint (pile/beam connection). A variety of different rehabilitation schemes to restore the strength loss in deteriorated timber members have been published in the literature, with a focus herein on glass FRP wraps together with epoxy or phenolic filling injections. A review of concentrically and eccentrically axially loaded repaired piles is covered first to grasp a better understanding of the compression and bending behavior of such. Research on the bending and shear behavior of repaired timber stringers is also covered, including previous work from WVU-CFC.

Table 13 shows a comparison of the different studies where FRP repair techniques have been tested in both laboratory settings and in the field, comparing the different strength and stiffness increase among them.

Table 13 - Different Repair Techniques and Results From Testing

\begin{tabular}{|c|c|c|c|c|c|c|c|}
\hline Study & Member & Testing Type & $\begin{array}{c}\text { Repair } \\
\text { Technique }\end{array}$ & $\begin{array}{c}\text { Value } \\
\text { Monitored }\end{array}$ & $\begin{array}{l}\text { Control } \\
\text { Value }\end{array}$ & $\begin{array}{l}\text { Repair } \\
\text { Effects }\end{array}$ & Failure Mode \\
\hline \multirow{3}{*}{ Mohammadi } & \multirow{3}{*}{ Pile } & \multirow{3}{*}{$\begin{array}{l}\text { Lab - } \\
\text { Axial } \\
\text { Compression }\end{array}$} & \multirow{3}{*}{ GFRP + Fill } & \multirow{3}{*}{$\begin{array}{c}\text { Axial } \\
\text { Strength }\end{array}$} & \multirow{3}{*}{$\begin{array}{c}59-73 \\
\text { kips }\end{array}$} & $\begin{array}{l}177.7 \text { kips, } \\
95 \text { kips }\end{array}$ & \\
\hline & & & & & & $\begin{array}{l}122.5 \text { kips, } \\
171.2 \text { kips }\end{array}$ & \\
\hline & & & & & & 133.1 kips & \\
\hline \multirow{2}{*}{ Zhang } & \multirow{2}{*}{ Pile } & \multirow{2}{*}{$\begin{array}{l}\text { Lab - } \\
\text { Axial } \\
\text { Compression }\end{array}$} & CFRP & \multirow{2}{*}{$\begin{array}{c}\text { Axial } \\
\text { Strength }\end{array}$} & \multirow{2}{*}{$\begin{array}{c}33.27 \\
\text { kips }\end{array}$} & $\begin{array}{l}20 \% \\
\text { increase }\end{array}$ & Crushing \& Buckling \\
\hline & & & BFRP & & & $\begin{array}{l}27 \% \\
\text { increase }\end{array}$ & \\
\hline Hago & Pile & $\begin{array}{l}\text { Lab - } \\
\text { Axial } \\
\text { Compression }\end{array}$ & GFRP + Fill & $\begin{array}{c}\text { Axial } \\
\text { Strength }\end{array}$ & $\begin{array}{l}41.36 \\
\text { kips }\end{array}$ & 225.5 kips & \\
\hline Abhari & Pile & $\begin{array}{l}\text { Field - } \\
\text { Axial } \\
\text { Compression }\end{array}$ & GFRP + Fill & $\begin{array}{c}\text { Axial } \\
\text { Compressive } \\
\text { Strain }\end{array}$ & & $\begin{array}{l}32 \% \text { reduced } \\
\text { strain }\end{array}$ & \\
\hline Gomez & Beam & $\begin{array}{l}\text { Lab - } \\
\text { 3-Point } \\
\text { Bending }\end{array}$ & GFRP & $\begin{array}{c}\text { Bending } \\
\text { Stiffness (EI) }\end{array}$ & & $\begin{array}{l}21.7 \text { to } 77.4 \\
\% \text { increase }\end{array}$ & Horizontal Shear \\
\hline \multirow{3}{*}{ King } & \multirow{3}{*}{ Beam } & \multirow{2}{*}{$\begin{array}{l}\text { Lab - } \\
\text { 4-Point } \\
\text { Bending }\end{array}$} & \multirow{2}{*}{ GFRP } & $\begin{array}{c}\text { Maximum } \\
\text { Load } \\
\text { (Bending) }\end{array}$ & & $\begin{array}{l}55 \%, 60 \% \\
\text { regained }\end{array}$ & Bending Cracks \\
\hline & & & & $\begin{array}{l}\text { Maximum } \\
\text { Load (Shear) }\end{array}$ & & $\begin{array}{l}30 \%, 107 \% \\
\text { regained }\end{array}$ & Horizontal Shear \\
\hline & & $\begin{array}{l}\text { Field - } \\
\text { Train Load }\end{array}$ & GFRP & $\begin{array}{l}\text { Vertical } \\
\text { Deflection }\end{array}$ & & $\begin{array}{l}44 \% \text { reduced } \\
\text { deflection }\end{array}$ & \\
\hline
\end{tabular}


All of the methods for pile repair in Table 13 involve both a fill material for the cavities left behind by rot and an FRP wrap system. Glass FRP wrap is the main fiber material employed in these repair techniques, including some carbon and basalt wrap testing. In laboratory testing increases of $20 \%$ up to $138 \%$ were achieved, and field load tests showed decreases in axial strain up to $32 \%$. One technique developed by Mohammadi (2014) looked at three different methods of pile repair in the lab under eccentric axial compression. Five southern yellow pine specimens with an average length of 204 inches were tested. The damaged section was represented by removing 1 to 2 inches of the outer surface of the pile for a length of 16 inches. All involved wrapping the damaged section with GFRP wrap, but three different filler materials were used; (1) resin only, 2) grout only and 3) resin and aggregate. The Timber Design and Construction Manual (2002) specifies an axial allowable compression strength of 1200 psi for Southern Pine graded in accordance with ASTM D25, and for the five specimens tested design capacities ranging from 59 kips to 73 kips (the highest allowable stress value provided by AREMA is 990 psi for Dense Select Structural Grade). The maximum axial load taken by the two specimens repaired by FRP and resin is 177.7 and 95 kips, showing failure cracks at one of the ends and the repaired section. The two specimens repaired using FRP and grout experienced a maximum axial load of 122.5 and 171.2 kips. One of these specimen failed 12 inches away from the repaired section, and the other specimen (damaged and repaired at one of the ends) failed about 80 inches away near mid length. FRP, resin and aggregate showed a maximum axial load of 133.1 kips, failing away from the repaired section, but showing some damage to the FRP jacket. From the limited testing, the author concluded in the study that resin might be more effective filling small voids, while grout is recommended for filling bigger voids. The low viscosity of the resin simply would work better filling smaller voids were aggregate cannot be used. The resin filled specimens showed damage in different locations, including the repaired section, when failed. The grout and resin-aggregate filled specimens failed outside of the repaired area, which suggests that repair methods 2 and 3 should have a higher capacity than repair method 1 . Appendix 2 of this report contains the repair plan for the Dailey Branch bridges, where a combination of wrap and filler were used where voids where found, but voids were not big enough for grout to be used. A summary of the repair procedure, including wrap and filler, can be found section 6.2.

Another approach by Zhang (2012) covered, like the piles on the Dailey Branch line, square timber piles using different fiber materials (carbon, glass and basalt) and filling applications for rehabilitation. A total of 17 specimens were tested under axial compression, 2 of them used as undamaged control specimens, 
3 of them damaged by inflicting a longitudinal crack, and the remaining specimens were manually cracked and repaired using different material. The cracks were manually cut through the members with a width of 0.4 inches and length of 59 inches as shown in Figure 29.
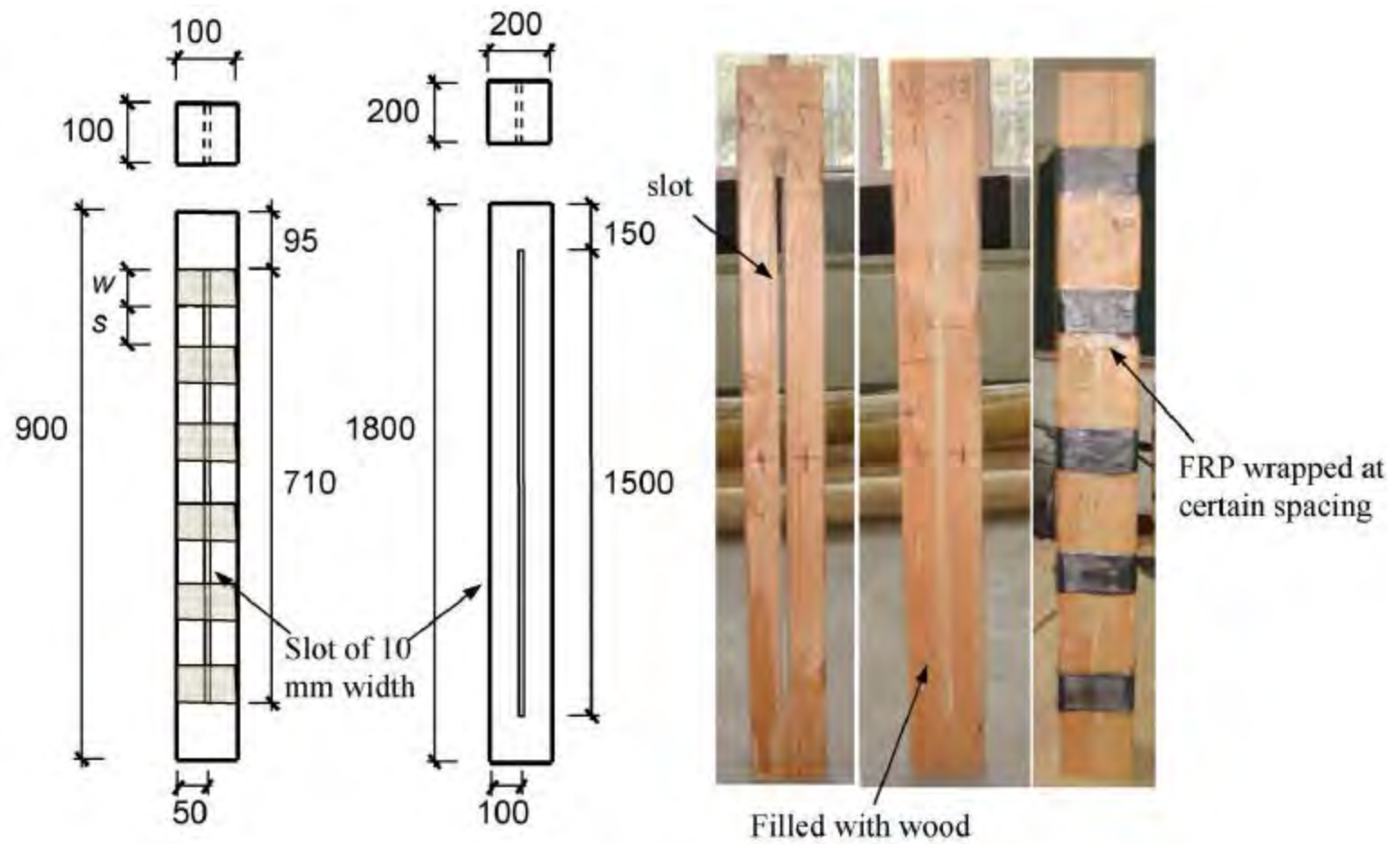

Filled with wood straps and glue

Figure 29 - Manually cracked timber column specimens with FRP wrapping (units in $\mathrm{mm}$ ) (Zhang, Song, Gu, \& Tang, 2012)

Different sections of the retrofitted columns were wrapped along their length at different spacing configurations in order to determine which fiber material and wrap design worked best. Three wrapped specimens remained unfilled, while the remaining wrapped columns had their cracks filled with glue and wood straps. After testing, it was determined that smaller spacing between wrapped sections of the column yielded a more efficient retrofitting effect. It was also shown that the retrofitting effect of the FRP sheets become stable with more than three layers of FRP applied over the full length of the timber columns. The author concluded that applying CFRP at a spacing of 2.35 inches, plus filling the crack, can increase the axial capacity of the cracked column by more than $20 \%$ when compared to the axial capacity of the cracked specimen. The cracked specimen failed at 45.4 kips while the carbon wrapped and filled specimen failed at 55.1 kips. The BFRP wrapped specimens failed at 46.31 and 41.14 kips, compared to the 45.41 kips for the sound control specimen and 33.27 kips for the cracked specimen, thus being able to increase the capacity of the cracked specimen beyond the control level. 
These testing techniques involved the simulation of damage on control piles, so the test results are only compared to control specimens created in the lab. Hagos (2001) was able to test similar repair techniques on in service damaged piles to produce real life scenarios. His research involved the testing of a total of 43 pile specimens in axial compression and 10 specimens in bending. Three different GFRP configurations were tested; a single layer of GFRP wet-wrap, double layers of GFRP wet-wrap, and a prefabricated GFRP shell. Actual decayed timber piles were used in the testing of the control specimens and the repaired specimens. Three different levels of decay were tested throughout the experiment, mildly decayed core, highly decayed core, and man-made void core. Two different diameter piles were also tested, one being an 11.8 inches diameter pile with a reduced damaged core of 7.9 inches in diameter, and the second one having a 7.9 inches diameter and damaged core of 4 inches in diameter. All repaired specimens had a non-shrink cementitious grout shell with a thickness of 2 inches surrounding the damaged core, which was then wrapped using either single or double layers of GFRP wet-wrap, or a GFRP prefabricated shell. Figure 30 shows the schematic of prepared specimen and repair technique using GFRP wet wrap sheets and grout filling.
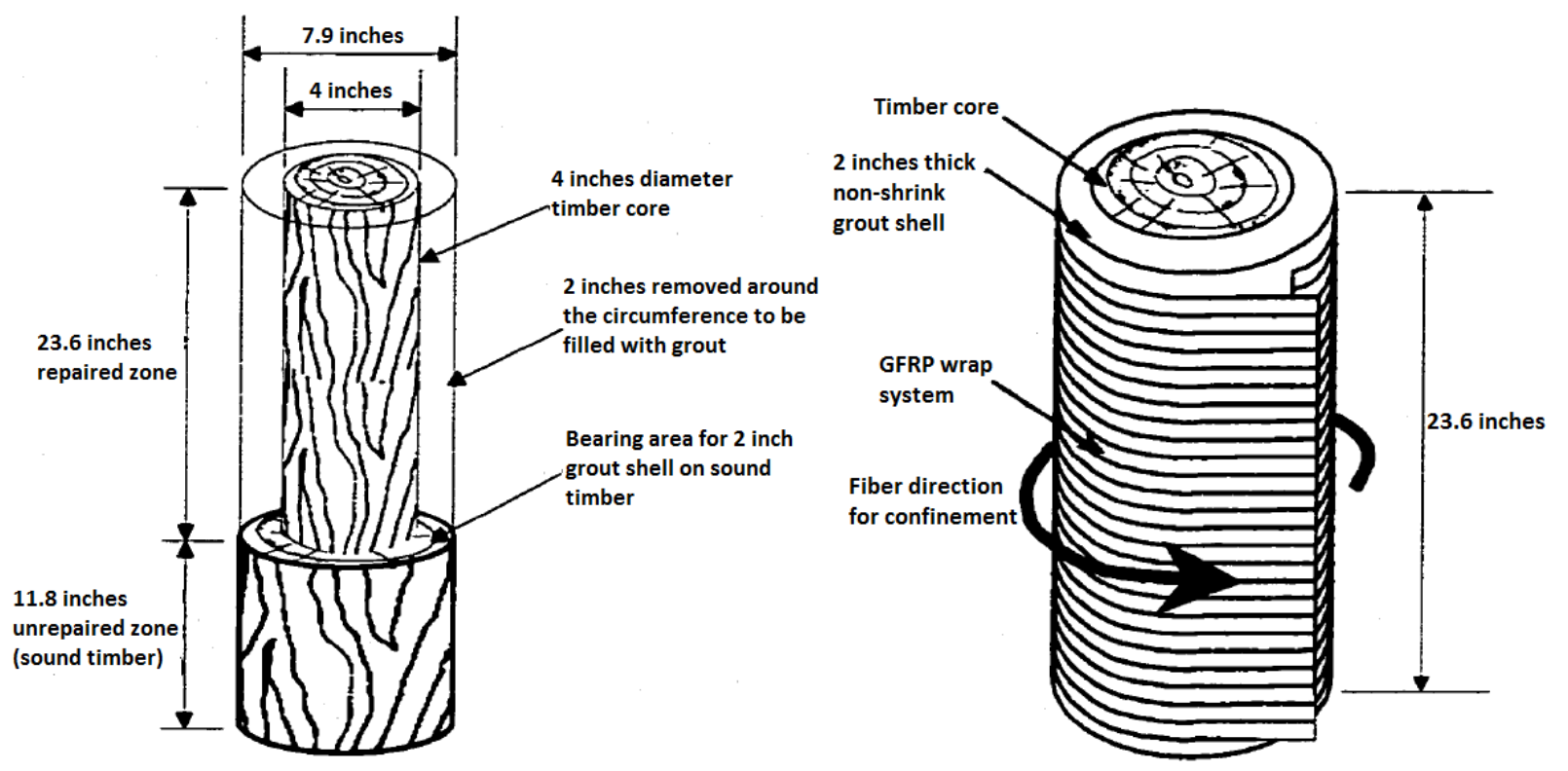

Figure 30 - Schematic of Specimens and Repair Technique Using GFRP Wet-Wrap Sheets (Hagos, 2001)

Form work was used to place the grout filling before wrapping, and in the case of the shell, the GFRP shell was used as formwork for grout filling. For the wrap specimens, an epoxy resin was applied to the grout filling surface after curing in order create proper bonding for the GFRP wrap sheets. The GFRP wraps were saturated with resin after being wrapped around the grout shell and left to cure. After axial compression testing was performed, the data was gathered and analyzed in order to conclude that the 
grouted single layer of GFRP wet-wrap repair option can restore or increase a decayed timber pile's original axial capacity. Heavily decayed timbers (control specimens) tested under axial compression showed an average maximum load of 41.36 kips with a standard deviation of 44.5 kips. Heavily decayed timbers of the same dimensions repaired with one layer of GFRP wet wrap and grout filling showed an average maximum load of 225.5 kips with a standard deviation of 33.5 kips. The remaining two repair techniques, GFRP double-layer and GFRP shell, showed an increase in axial capacity when compared to a single layer, thus being higher performance repair methods. It is not implied that adding more layers beyond 2 layers will continue to proportionally increase axial capacity. The grout used to fill the decayed timber core area showed a higher strength than the bearing area between the grout and the sound timber during axial compression testing. It is recommended to strengthen the timber bearing surface using epoxy impregnation and GFRP confinement, thus avoiding bearing failure in the sound timber. Some of the timber posts in the Dailey Branch line have highly decayed cores similar to the ones studied herein by Hagos, as shown in the findings of section 3.2. A similar wrapping approached is recommended in section 6.2 as the literature deems it an effective approach for rehabilitation of highly deteriorated timbers.

Another wrapping system using glass fiber in a similar fashion to Mohammadi's technique, except for the filler material, was developed and tested by West Virginia University Constructed Facilities Center (WVU-CFC) on in service piles as well, with the advantage of being able to test the repair in the structure in-situ. Abhari's (2007) report covered the repairs of damaged timber trestle structures found on the South Valley Railroad (SBVR) in Moorefield, WV. In 2004, bridge No. 574 was selected for rehabilitation, mainly due to the poor condition of the timber piles. Piles \#2, \#3, and \#4 experienced heart rot and were deemed to have lost $55 \%$ of their cross section. In order to repair the piles in-situ, the repair crew first began by filling the voids in the decayed piles with a phenolic-based adhesive mixed with sawdust. The length of the pile to be filled was wrapped with temporary shrink-wrap in order to prevent any type of spill during the resin flow and curing process. Prior to wrapping the timber piles with GFRP, the surface was pressure washed with water, dried using heavy-duty heaters, and sanded in order to allow better bonding between the GFRP wrap and the timber pile. Uniformity in the pile surface not only provides better bonding, but it also generates uniformity in order to avoid voids. A phenolic based primer was then applied to the surface of the pile to be wrapped in order to provide better bond for the repair system. After the primer cured, the GFRP wrap was soaked in a phenolic formaldehyde adhesive resin and wrapped around the pile with a 3 to 4 inch overlap (3 layers of GFRP wrap). Wax paper was wrapped around the GFRP-repaired section covered by another rubber sheet in order to generate 
uniform pressure on the GFRP layers during curing. A UV protective coating was applied to the wrap after curing. Figure 31 compares microstrain data from the piles being load tested before and after rehabilitation. An 80-ton locomotive was used for load testing at a speed of $2 \mathrm{mph}$. A reduction in strains can be observed in Figure 31 by the rehabilitated piles in comparison with the same piles before rehabilitation.

Before and After Rehabilitation - Pile Load Test

80 Ton Locomotive (SBVR) - 2 mph

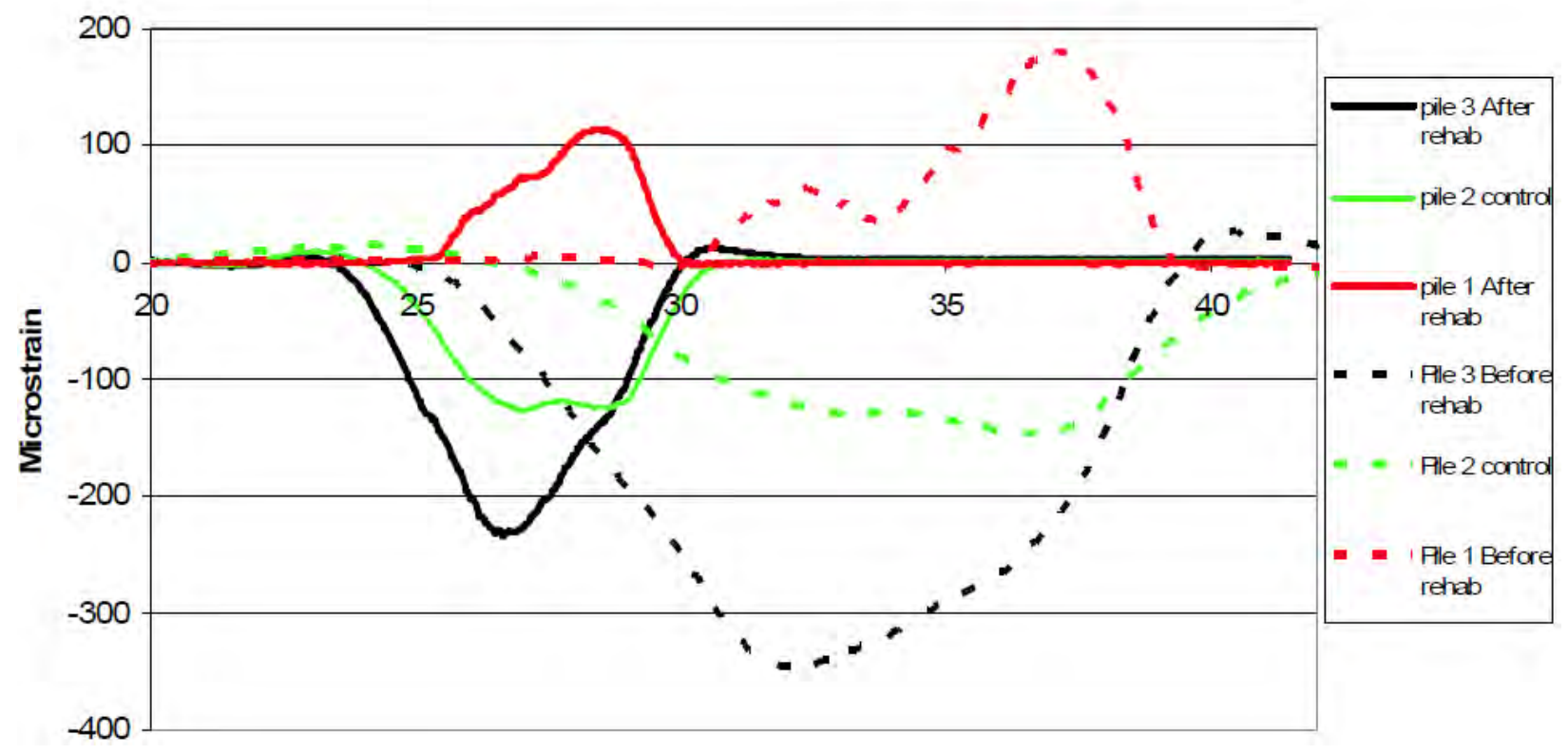

Figure 31 - Strain Distribution in Piles Before and After Rehabilitation for Train Speed of 2 mph (Abhari, 2007)

Data was recorded for a train speed of $15 \mathrm{mph}$, and for static loading with the train at four different positions. When the strain data for the rolling and static tests are averaged for before and after rehabilitation results, a decrease of $31 \%$ and 33\% in strain can be observed for piles 1 and 3 respectively. The maximum strain values were compared among static and rolling load tests, and no dynamic impact was evident for speeds up to $15 \mathrm{mph}$. No impact is consider in the load rating of the timber bridges in section 5.2.3.

Timber beams are wrapped in a different fashion than piles due to the mechanical properties being rehabilitated in the member. When repairing timber stringers in-situ, not all surfaces of the member are visible, which makes it difficult compared to piles when FRP wraps are to be applied on all faces. Depending on the mechanical properties being reinforced/repaired, timber stringers can be wrapped in 
different faces of the beam and in different orientations. Gómez and Svecova's (2008) technical paper covered the results obtained by testing GFRP-repaired split timber stringers of treated Douglas fir species under 3-point bending loads. All 5 stringers tested were originally of select structural grade, but had to graded again due to aging related damages. The new grades left 2 select structural, 2 No. 1, 1 No. 2 stringers, and four reject stringer samples. The stringers were reinforced using glass fabric sheets saturated in an epoxy matrix for both bending and shear. Bending reinforcement consisted of two layers of FRP sheets bonded to the tension face of the stringer. One layer of FRP sheets was placed at 45 degrees around each end of the beam in order to add shear strength. Figure 32 shows the repair scheme of the stringers with its corresponding dimensions.

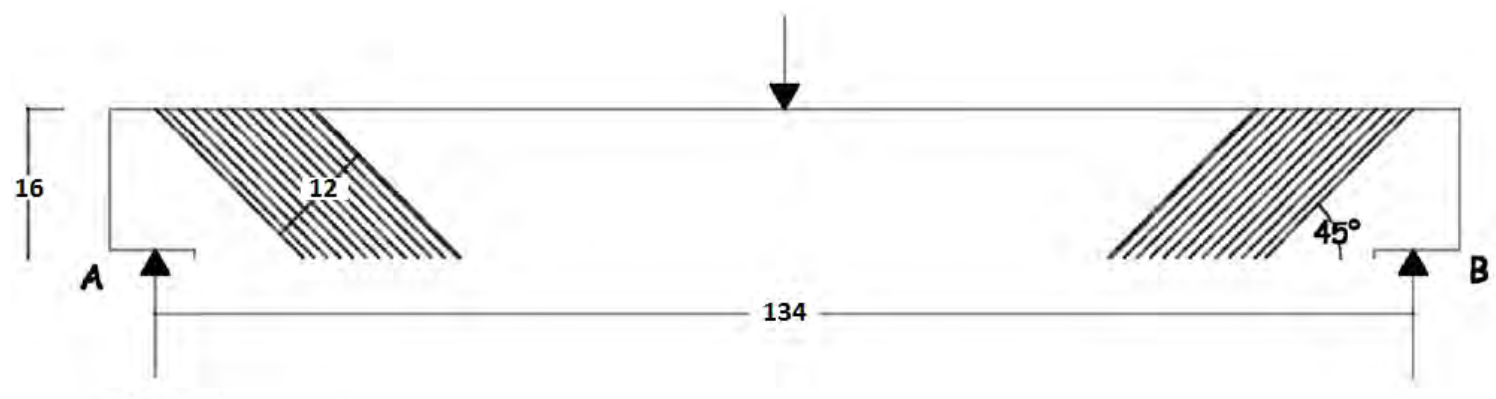

Side 1

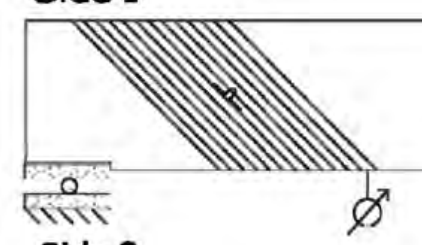

Side 2

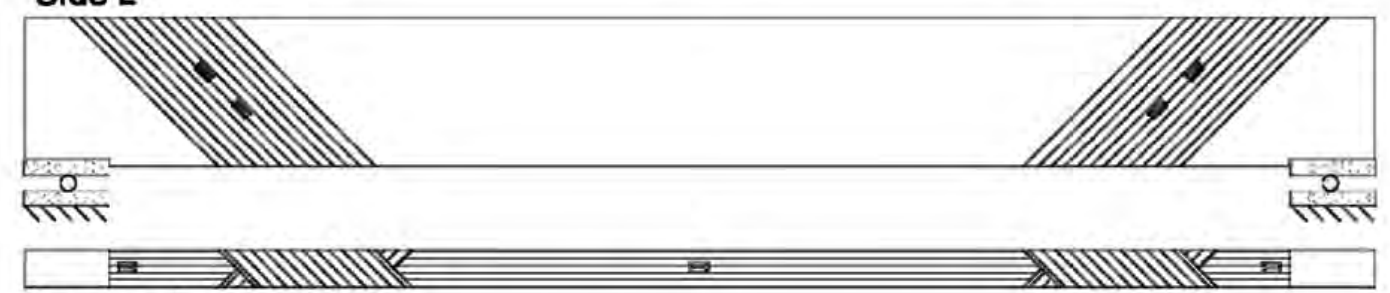

Bottom view

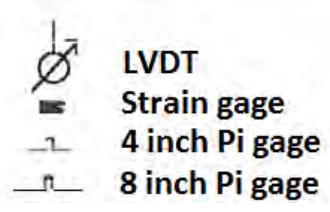

Figure 32 - Repair and Instrumentation of Specimens, all dimensions in inches (Gómez \& Svecova, 2008)

After laboratory testing, it was concluded that the repair system leads to improvements of stiffness by 5.5-52.8\% depending on the amount of damage in the timber beams. Figure 33 shows that for lower grade (No. 2) and below grade (Reject) timber stringers due to splits and deterioration, the repair system can considerably increase their stiffness value from $21.7 \%$ up to $77.4 \%$. The composite 
reinforcement contributed about 18.4 to $42 \%$ of the shear forces prior to slip deformation, and 21.4 to $148.5 \%$ after slip deformation occurred. Slip deformation corresponds to the relative displacement of the two sections of a timber beam above and below a split, which is induced by an applied load reaching the maximum load capacity of the beam. When slip deformation occurred during testing, the FRP shear reinforcing sheets carried the majority of the horizontal shear forces, failing by debonding of shear reinforcement.

\begin{tabular}{|c|c|c|c|c|c|c|c|c|c|}
\hline \multirow[b]{3}{*}{ Sample } & \multirow[b]{3}{*}{ Grade } & \multicolumn{3}{|c|}{ Split } & \multicolumn{3}{|c|}{ EI } & \multirow[b]{3}{*}{$\begin{array}{l}P_{\max } \\
(\mathrm{kN})\end{array}$} & \multirow[b]{3}{*}{$\begin{array}{c}\text { Failure } \\
\text { mode }\end{array}$} \\
\hline & & \multicolumn{2}{|r|}{ Length } & \multirow{2}{*}{$\begin{array}{l}\text { Distance } \\
\text { from top } \\
(\mathrm{mm})\end{array}$} & \multirow[b]{2}{*}{$\begin{array}{c}\text { Original } \\
\left(\mathrm{N} \mathrm{mm}^{2}\right) 10^{9}\end{array}$} & \multirow[b]{2}{*}{$\begin{array}{c}\text { New } \\
\left(\mathrm{N} \mathrm{mm}^{2}\right) 10^{9}\end{array}$} & \multirow[b]{2}{*}{$\begin{array}{c}\text { Improv. } \\
(\%)\end{array}$} & & \\
\hline & & A & $(\mathrm{mm}){ }^{B}$ & & & & & & \\
\hline Y2-203 & SS & - & - & - & 4,327 & 4,830 & 11.6 & 156.5 & Bearing \\
\hline Y2-205 & ss & - & - & - & 4,844 & 4,929 & 1.8 & 151.1 & Bearing \\
\hline Y2-201 & $1^{\circ}$ & - & - & - & 3,923 & 4,012 & 2.3 & 127 & Flexure \\
\hline Y2-202 & $1^{\circ}$ & - & 320 & 210 & 4,178 & 4,454 & 6.6 & 119.6 & Bearing \\
\hline Y2-204 & $2^{\circ}$ & - & 600 & 205 & 4,642 & 5,650 & 21.7 & 131.9 & Shear \\
\hline Y1-206 & Reject & - & 1,540 & 220 & 2,246 & 3,985 & 77.4 & 130.1 & Shear \\
\hline Y1-207 & Reject & 875 & 880 & $215^{\mathrm{a}}, 180^{\mathrm{b}}$ & 2,636 & 3,997 & 51.6 & 129.8 & Shear (A) \\
\hline Y2-208 & Reject & - & 2,000 & 305 & 2,546 & 3,831 & 50.5 & 130.4 & Bearing \\
\hline Y2-209 & Reject & - & 1,200 & 205 & 2,695 & 4,386 & 62.7 & 134.1 & Shear \\
\hline
\end{tabular}

${ }^{\mathrm{a}}$ End A

${ }^{\mathrm{b}}$ End B.

Figure 33 - Results from Bending Test on Repaired Stringers (Gómez \& Svecova, 2008)

West Virginia University Constructed Facilities Center performed both laboratory and field testing on timber stringers to further develop a technique that can apply to in-situ rehabilitation projects. King (2007) conducted laboratory bending and shear testing of GFRP repaired timber stringers. King used GFRP composite fabric in combination with a phenolic resin (the fiber-resin combination was selected from previous research performed at WVU-CFC on different resin-substrate combinations). Three layers of wrap applied using the wet lay-up process was determined to be appropriate for both bending and shear repair. Prior to repairing the stringers, all specimens were tested to failure in order to obtained experimental mechanical properties (control values). The failed specimens were then repaired to test how much of the original mechanical properties could be rehabilitated. The bending specimens were wrapped in a U-shape (leaving the top surface of the stringer unwrapped) at the center 24" of the 12' stringer, where the largest bending stresses would be concentrated. The shear specimens were wrapped for 30 " on both ends in a U-shape lay-up. Four-point loading tests were performed on both bending and shear specimens until failure was reached. King concluded that the repaired bending specimens regained $55-60 \%$ of their carrying capacity when compared to the control testing values. Even though 
the repaired stringers failed at a lower load, the failure strain was higher, thus showing an improvement in ductility. One out of the two shear specimens regained $107 \%$ of its control specimen maximum load after being repaired, thus increasing its original carrying capacity. The other repaired shear specimen regained only $30 \%$ of its original load carrying capacity, which could be due to poor bonding of the fabric to the substrate, or high levels of damage to the control specimen when failed. King concluded that GFRP wrap together with a phenolic resin helps regain load carrying capacity of timber stringers under bending and shear stresses, even after the stringers have been tested to failure. The repair scheme was also applied in-situ in previous work by King, showing that GFRP composite wrap is an effective method of repair for in-service timber railway structures. King wrapped 1 out of 3 stringers in a chord of an existing bridge with GFRP using a phenolic resin. A load test prior and after rehabilitation showed that the average deflection at mid span was reduced by $44 \%$.

The advantage of both West Virginia University Constructed Facilities Center repair techniques for piles and stringers is the ability to repair in service bridges without disrupting rail traffic. Field test results show promising rehabilitation to the timber structures using a combination of glass fiber and phenolics to wrap timber members. A saw dust/resin combination filler provides for a good filler material in the cases where heart rot may be present in piles or stringers. Glass fiber also is more economical than carbon and other fiber material. A thorough inspection of the field conditions of the bridge structures will help determine the best repair approach from the existing FRP wrap options. 


\section{Field Inspections}

\subsection{Introduction}

The purpose of the field inspections is to gather information on member section properties, structure design, wood species, grade of timber, and deterioration of all bridges. The inspection findings are then used to select timber members that are potential candidates for FRP wrap repair. The inspections also helped determine the current capacity of the bridges to withstand loads imposed by the hi-rail dump truck and locomotive used during field load testing.

The inspection for all five railroad bridges on the Dailey Branch line was carried out by 3 representatives of WVU-CFC. The 3 men team used regular hand tools to visually inspect the bridges. Findings reported on the steel bridges include rusted areas, loss of cross section, bent members, paint, and support conditions. None of the findings in the steel bridges were found to have compromising effects on the structural integrity of the bridge, but minor maintenance recommendations were made to extend the service life of the bridge. The findings on the timber bridges include surface rot and heart rot via sounding using a tap hammer. High levels of moisture were determined where muted hammer taps were found, and such findings were identified as softening. Fruiting bodies were found on the surface of some members, which is also an indication of decay. Highly rotted members are recommended for either repair or replacement in the wood structures. Some bracing members were split or spliced, comprising the integrity of the bolts, so recommendations were made for replacement where necessary.

All of the bridges, except for bridge 5.8, have decayed/split ties and low ballast either or both approaches. The rails show rust as well, and in bridge 1.4 some railing joints show cracks. Abutments in the steel bridges are in good condition, showing minor cracks. Abutment components and retaining walls in the timber bridges show significant levels of rot, but are not good candidates for FRP repair. Any members with high levels of rot, not feasible for repair due to field conditions, are not further investigated. Recommendations on replacing rails, ties, ballast, and retaining wall members is left to the discretion of the State Rail Authority.

A set of drawings can be found in the Appendix of this report where the inspection findings are summarized in tables by type of decay, size, and location. The drawings include recommendations for members to be repaired, replaced, or monitored. The timber bridge drawings also include a color coding system for each member in order to easily identify decayed members, members to be repaired with FRP, members with softening, and sound members (red, yellow, green, and brown respectively). The 
steel bridge drawings do not contain color codes because the findings show negligible signs of deterioration; maintenance recommendations are included in the drawings. Information regarding member dimensions, span length, and pictures are included in the set of drawings.

Color coding system:

- RED: Significant deterioration in member, replacement of member is recommended.

- YELLOW: Significant deterioration in member, FRP wrap is recommended.

- GREEN: High moisture noted in member, no repair is needed but monitoring is recommended.

- BROWN: Member in good condition, no repair is needed.

Members recommended for replacement are based on a cost-benefit analysis where repair exceeds the cost of replacement.

Lawrence Osborn, a timber expert in the WVU Division of Forestry and Natural Resources, was asked to determine the species and grade for the timber bridges. All members in the super structure and substructure were found to be Southern Pine, with the exception of 6 Oak posts. Grading was assigned per the Grading Rule Specifications for Southern Pine Timber, and Grading Rules Specifications for NeLMA (WWPA) Timbers for Oak. In order to determine the grade of each member, all surfaces must be visible in order to check for knots, slope of grain issues, splits, and checks, thus the grading is a typical representation of the members originally used and not complete checks on every member. Based on these limitations, the overall structures would likely have graded as select structural when originally constructed. Osborne expressed concern about the inability to see all the members, particularly interior stringers due the chord arrangement and the center of posts due to the limitations of creosote treatments. The species and grade for each member of the substructure is included in the discussion of each bridge in section 3.2. Based on what was visible on the stringers, they were all determined to be Select Structural Southern Pine. The information Osborne provided served as the basis for the allowable strength assignments used in field testing and load rating analyses. Based on this expert analysis, select structural Southern Pine was used for nearly all members in analysis, with the exception of the posts on Bridge 1.9 which were found to be red oak.

When inspecting all the members in both the timber and steel structures, limitations existed which did not allow the crew to visually inspect all members completely as follows.

- The inner 2 stringers in a 4-stringer chord system were only visual inspected on the top and bottom faces of the stringers as the sides are not visible due to the chord layout. 
- The bottoms of members that could not be reached with a ladder were not inspected.

- Bridge 1.4: Most of the floor structure not visible from the track itself and the bottom flange of the plate girder

- Bridge 1.9: Timber stringers in spans 4, 5 and 6 were only inspected from above.

- Buried members could only be inspected where visible. This includes blocking and beams in all abutments, all mud sills, and most blocking.

- Internal decay of timber members was located using hammer sounding and approximate dimensions noted, but further evaluation was not possible at the time without destructive evaluation.

A tape measure and a ruler were used in the inspection to quantify the amount of rot found in different members. For members with visible surface rot, the depth was measured with the ruler to best of the crew's ability, while height and length were measured on visible portions of members to the naked eye. A good example for this type of measurement can be found in the inspection of Bridge 5.1, for the rot on stringer 8 shown in Figure 47. Where heart rot was found in a post by means of tapping the surface with a hammer, the length was determined by tapping the entire height of the post while the cross sectional dimensions were estimated by tapping along the width. In cases like the heart rot found on post 5 of bent 3 on bridge 4.3, as shown in Figure 43, full heart rot is visible. In this case, the dimensions of the rot in the drawings show only 1.5 inches of the outer shell of the post left in order to represent a failed post needing repair.

Inspection findings and grading are summarized for each bridge in the next section.

\subsection{Summary of Inspection Findings}

\subsubsection{Bridge 1.9}

The condition of the track at the approaches is poor due to defective ties and low ballast (Figure 34). On the North approach, the track dips approximately 1 inch, and approximately 2 inches at the south approach. 

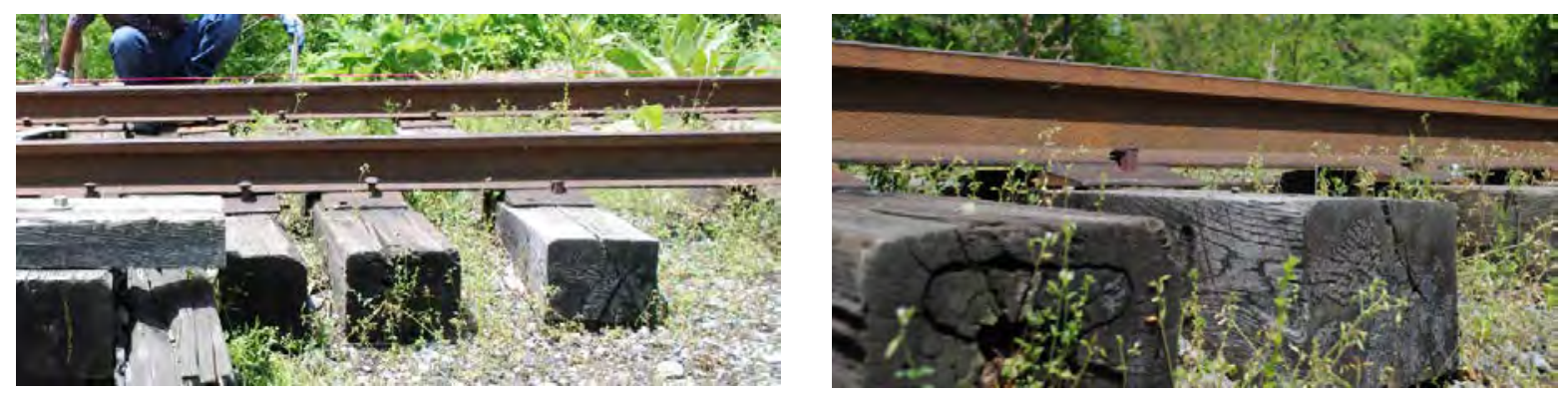

Figure 34 - Approach Condition: North (left) and South (left)

The timber back wall on the north end has full heart rot for the entire length (Figure 35). The north east wingwall exhibits heart rot and it is leaning outward. The south abutment is located between Bent 8 and Bent 9. This backwall exhibits heart rot on the West end for about a third of the member length. The west wingwall timbers have begun to rot.
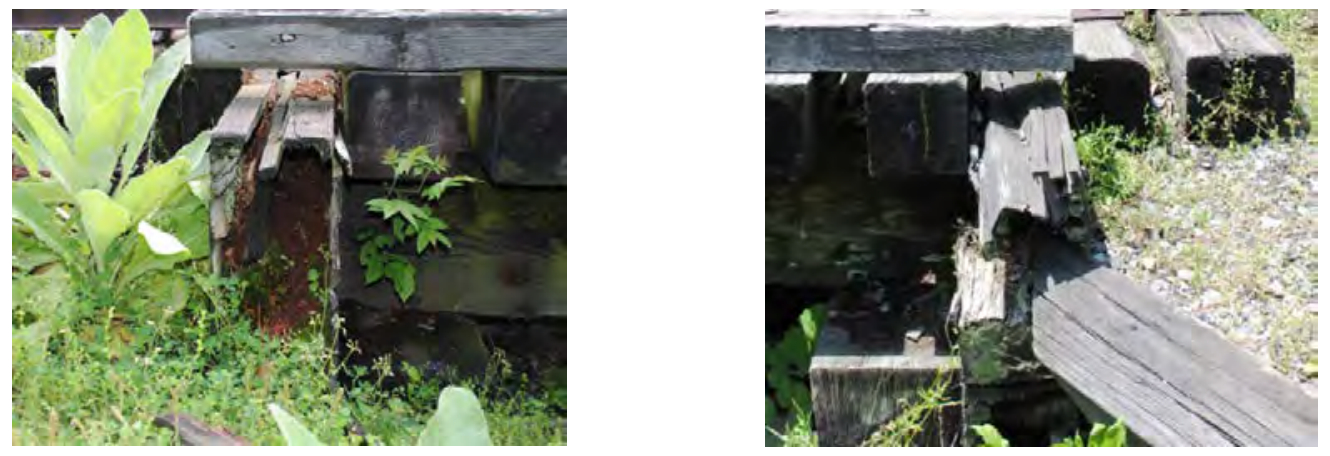

Figure 35 - North Backwall West End (left) and East End (right)

A few stringers showed substantial rot, and some other showed softening when tapped. Span 1, Stringer 1 , has a $2^{\prime \prime} \times 8^{\prime \prime}$ rot with $4^{\prime}$ in length ending over bent 2 (Figure 36 left). Stringer 2 in span 3 and 4 has a 2 2"x8" rot for a length of 17'-6" (Figure 36 right). Span 5 and 6 also show rot in stringers 2, 3 and 4 .

Stringer 3 in spans 4, 5, 8, and 9 shows softening.
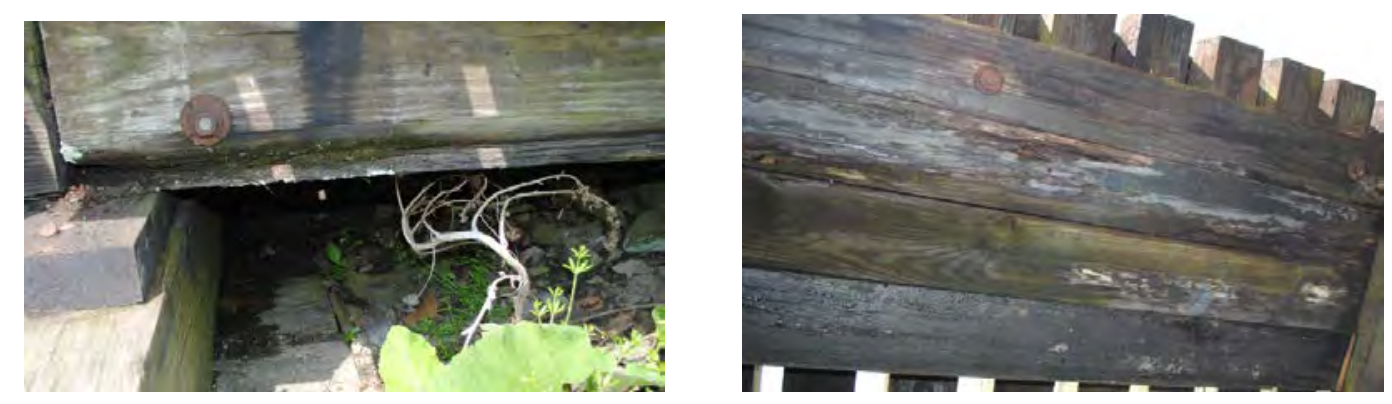

Figure 36 - Rot Span 1 Stringer 1 over Bent 2 (left) and Span 3 Stringer 2 (second stringer from the top down) rotting (right). 
Some posts had visible surface rot, while others sounded hollow indicating heart rot. Posts 2 and 3 from Bent 4 sound hollow from hammer tapping, and post 1 has visible heart rot. Post 3 in bent 6 , and posts 3 and 5 in bent 7 exhibit heart rot from sounding hollow by hammer tapping (Figure 37 left). The sills in bents $3,4,6,7$, and 8 show heart rot. Sills in bent 6,7 , and 8 (Figure 37 right) all have heart rot for more than $2^{\prime}$ in length. Block 5 in both bent 2 and 3, and blocks 1, 2, and 4 in bent 9 have high levels of decay.
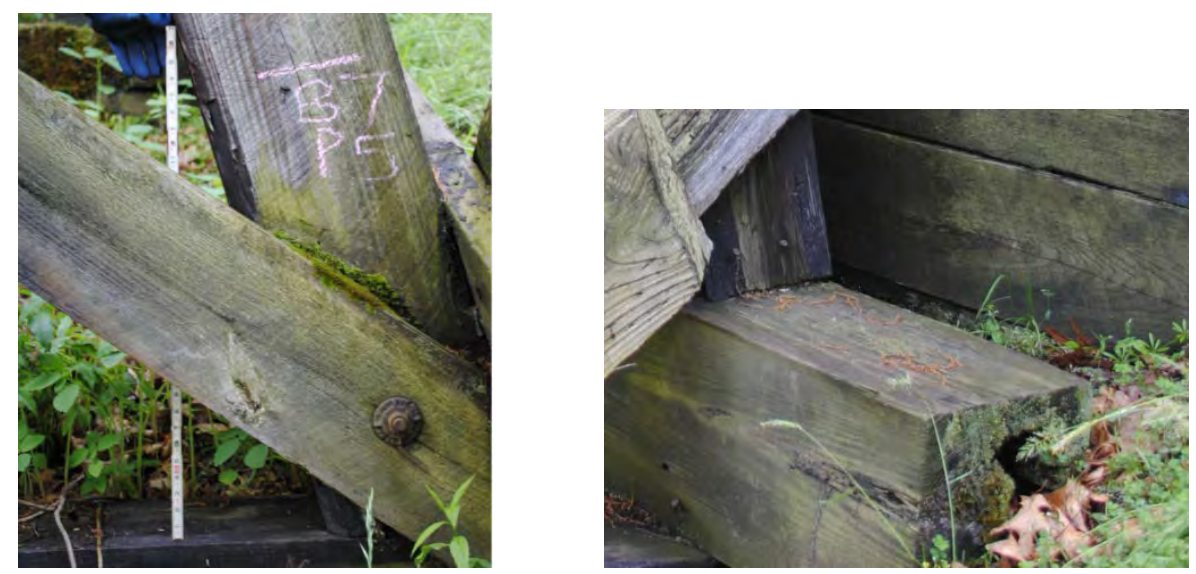

Figure 37 - Bent 7 Post 5 (left) and Bent 8 Sill end rot (right)

The north sway brace on bent 6 has split through the bottom bolt, some rot is noticeable as well (Figure 39 left). On the east side of the bridge, tower brace 3 has visible rot on the surface through the cross section of the member, and tower brace 4 has been spliced and shows rot (Figure 38 left). On the west side of the bridge, tower brace 1 has a large split (Figure 38 right) through the North bolt and tower brace 4 has been spliced (Figure 39 right).
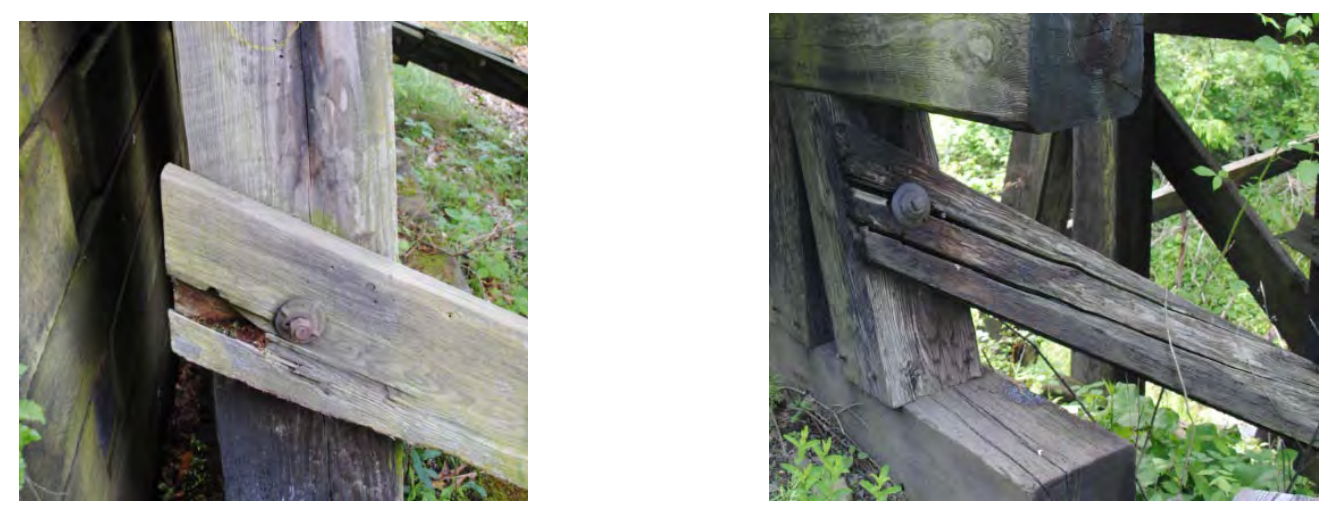

Figure 38 - East Tower Brace 4 rot/split (left) and West Tower Brace 1 split (right) 

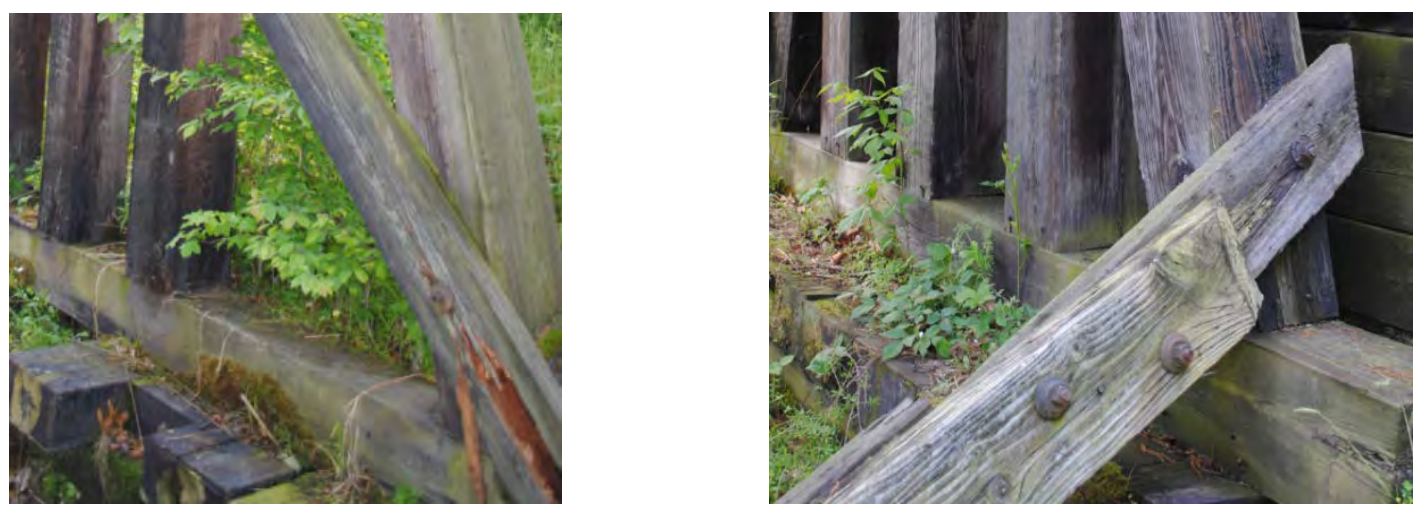

Figure 39 - Bent 6 Sway Brace split/rot (left) and West Tower Brace 4 splice (right)

Table 14 shows the species and grade for all the substructure elements as determined by Lawrence

Osborn during his inspections. Species is either Southern Pine (SP), Oak or N/A - Non-Applicable (nonexistent member). Lawrence graded the members as with SS - Select Structural (SS), Number 1 (No 1) or Below Grade (BG) for members that had damage.

Table 14 - Bridge 1.9 Member Species and Grade

\begin{tabular}{|c|cccccccccc|}
\cline { 2 - 9 } \multicolumn{1}{c|}{ Element } & Bent 1 & Bent 2 & Bent 3 & Bent 4 & Bent 5 & Bent 6 & Bent 7 & Bent 8 & Bent 9 & Bent 10 \\
\hline Cap & SP-SS & SP-SS & SP-No.2 & SP-SS & SP-SS & SP-SS & SP-SS & SP-SS & SP-BG & SP-SS \\
Sill & SP-SS & SP-SS & Oak-No.2 & Oak-SS & SP-SS & SP-BG & SP-SS & SP-SS & SP-SS & SP-BG \\
Post 1 & N/A & N/A & SP-SS & SP-BG & SP-SS & SP-SS & SP-SS & SP-SS & N/A & N/A \\
Post 2 & N/A & N/A & SP-SS & SP-SS & Oak-SS & SP-SS & SP-SS & SP-SS & N/A & N/A \\
Post 3 & N/A & N/A & SP-SS & SP-BG & Oak-SS & SP-BG & SP-BG & SP-SS & N/A & N/A \\
Post 4 & N/A & N/A & SP-SS & SP-SS & SP-SS & SP-BG & SP-SS & SP-BG & N/A & N/A \\
Post 5 & N/A & N/A & SP-SS & N/A & N/A & SP-SS & SP-SS & SP-No.1 & N/A & N/A \\
\hline
\end{tabular}

\subsubsection{Bridge 4.3}

The south approach is in very good shape (sound ties and sufficient ballast) and with no appreciable dip in the rails. The north approach has decayed/missing ties and very low ballast (Figure 40). The two last ties before bent 1 are missing, and 7 ties away from the north approach are not bearing on any ballast. The track dips approximately 1 inch on the North approach, but would defect further with train movement as the track is not resting on several ties/ballast. 4 ties over the bridge structure are decayed. 


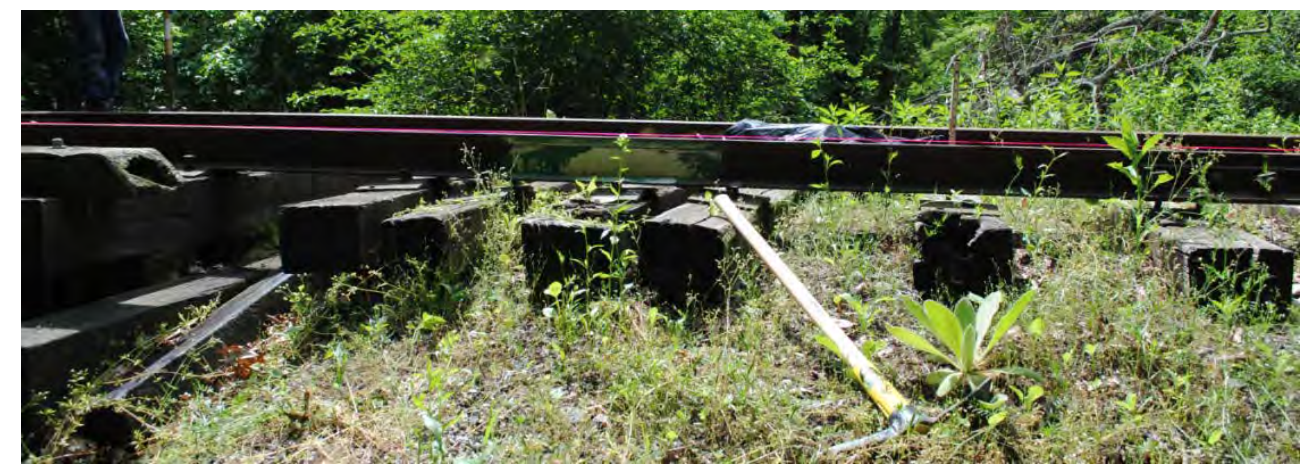

Figure 40- North End Approach

The North timber back wall has full heart rot, while the South back wall is rotten on west end (Figure 41 left). The Northwest wingwall consists of 1 member (Figure 41 right) and the Northeast wingwall is rotting and leaning outward. The Southwest wingwall shows some rot and is leaning outward.
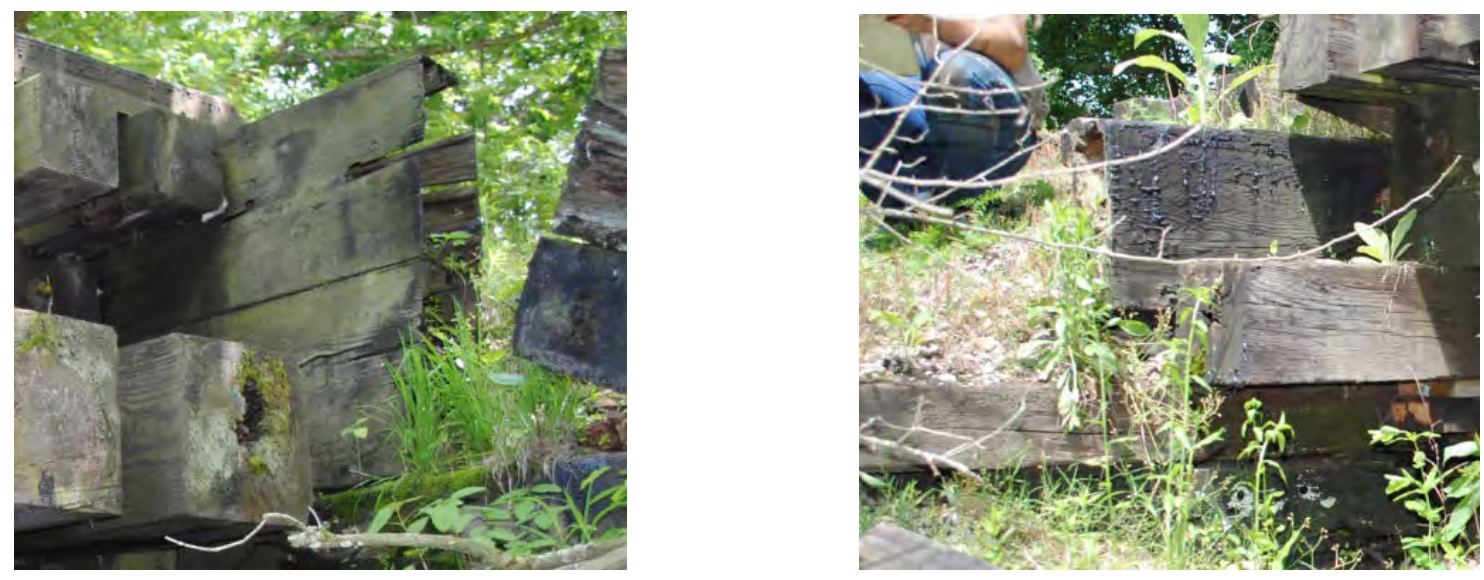

Figure 41 - South Backwall and South West Wingwall heart rot (left). North Backwall West End heart rot (right)

On Span 1, stringers 1, 2, 5, and 8 have end heart rot over bent 1 (Figure 42). Stringers 7 and 8 have heart rot over bent 3 on span 3. 

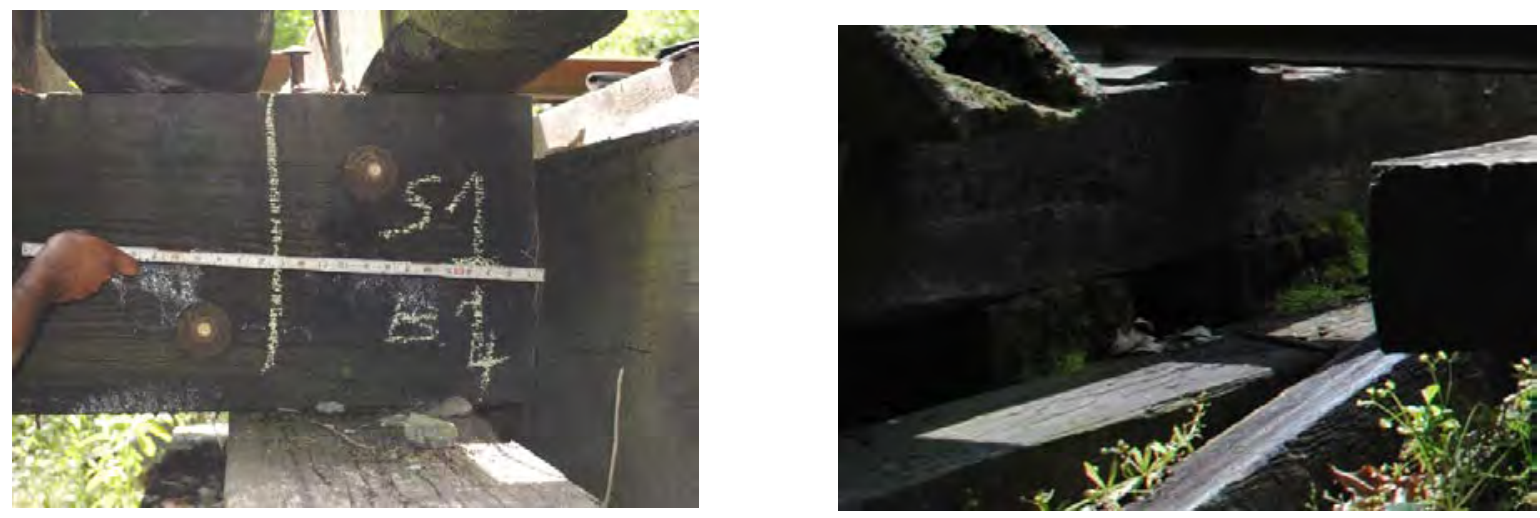

Figure 42 - Span 1 Stringer 1 end rot over Bent 1 (left) and Span 1 Stringers 1 \& 2 end rot over Bent 1(right).

In bent 2, post 1 (Figure 44 left) exhibits heart rot coming through the outer surface of the post estimated to continue for its full height. Posts 2 and 5 were tapped with a regular hammer and were found to be hollow for a length of about 2'. In bent 3, posts 1 and 5 (Figure 43 right) exhibit signs of heart rot either visibly or through hollow soundings for their full height. Bent 1, 2, and 4 have sills that exhibit varying degrees of end rot. The sill on Bent 1 has heart rot for $2^{\prime}$ on the East end. Bent 2 sill shows heart rot on the East end 14" in length. Bent 4 sill and cap beam exhibit heart rot for 4' and 2' respectively. The following blocks exhibit high rot: block 6 in bent 1, block 4 in bent 3, and blocks 4,5 and 6 in bent 4 (Figure 44 right). Mud blocks 2 and 5 in bent 4 are also highly rotted. The corbels in bent 2 show softening (Figure 43 left), specifically corbels 1, 2, 3, and 7. Corbel 2 in bent 3 is highly rotted.
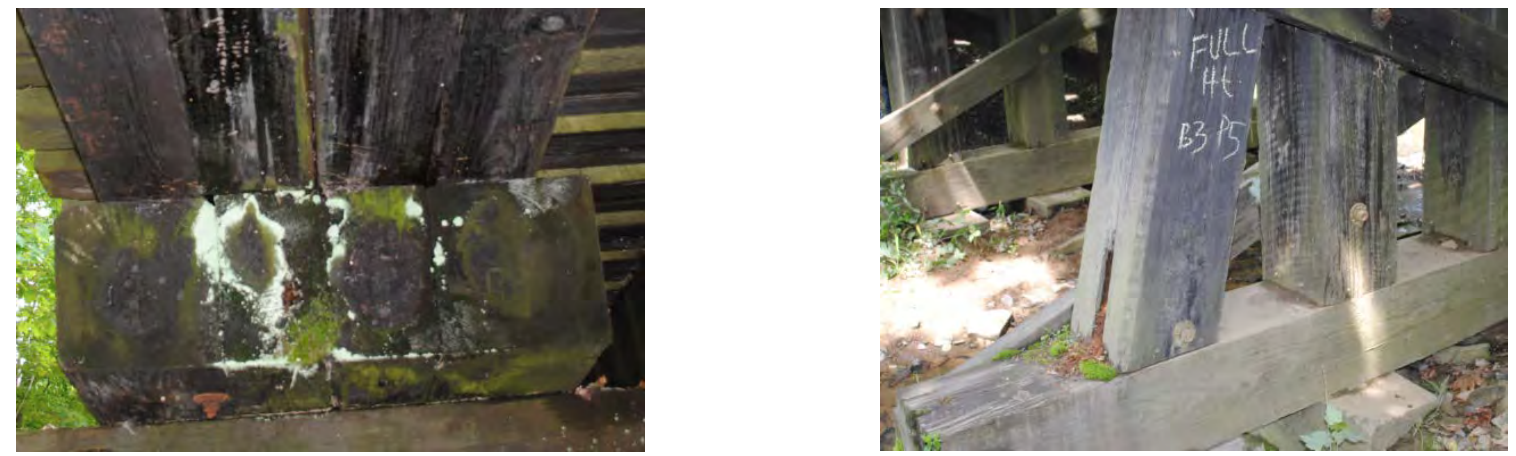

Figure 43 - Bent 3 Corbel 2 rot (left) and Bent 3 Post 5 heart rot (right). 

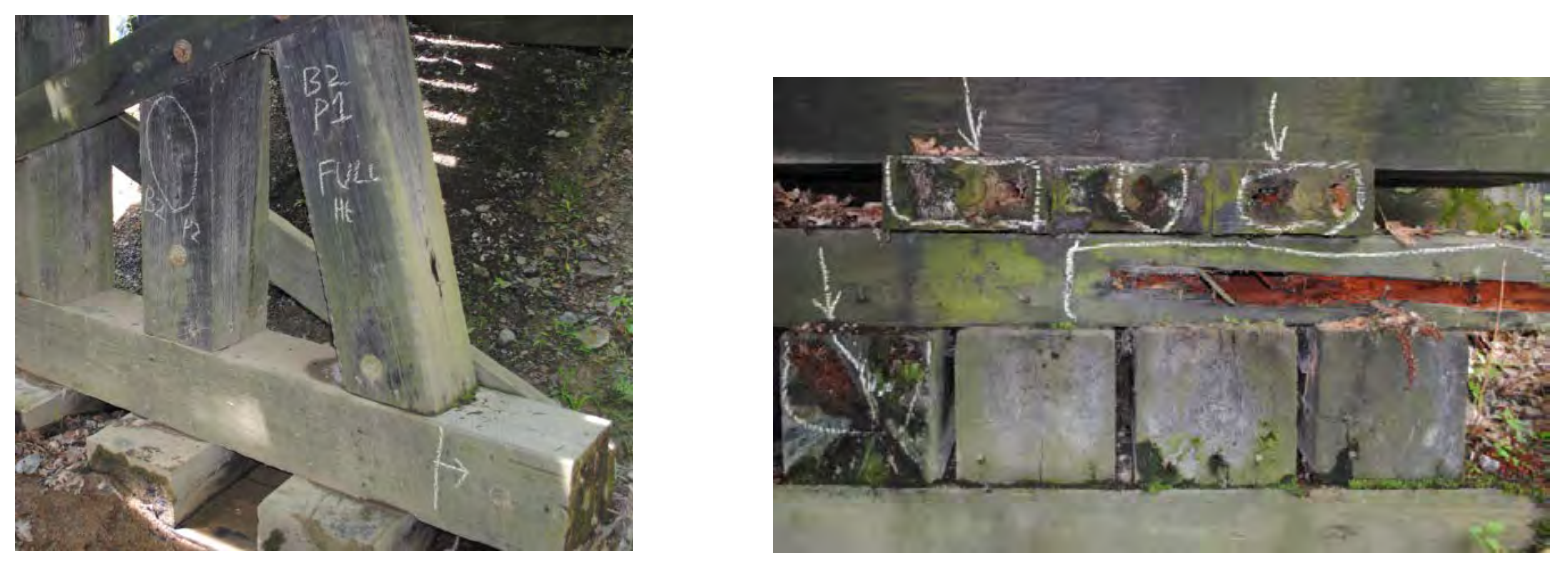

Figure 44 - Bent 2 Post 1 heart rot (left) and Bent 4 Blocks \& Sills rot (right).

The bracing components in bridge 4.3 are in good condition. Table 15 shows the species and grade for all the substructure elements as determined by Osborn during his inspections. Species is either Southern Pine (SP), Oak or N/A - Non-Applicable (nonexistent member). Lawrence graded the members as with SS - Select Structural (SS), Number 1 (No 1) or Below Grade (BG) for members that had damage.

Table 15 - Bridge 4.3 Member Species and Grade

\begin{tabular}{|c|cccc|}
\cline { 2 - 5 } \multicolumn{1}{c|}{ Element } & Bent 1 & Bent 2 & Bent 3 & Bent 4 \\
\hline Cap & Oak-SS & SP-SS & SP-No.1 & SP-BG \\
Sill & SP-BG & SP-BG & SP-SS & SP-BG \\
Post 1 & N/A & SP-BG & SP-SS & N/A \\
Post 2 & N/A & SP-SS & SP-SS & N/A \\
Post 3 & N/A & SP-SS & SP-SS & N/A \\
Post 4 & N/A & SP-No.2 & SP-SS & N/A \\
Post 5 & N/A & SP-SS & SP-BG & N/A \\
\hline
\end{tabular}

\subsubsection{Bridge 5.1}

The North approach has two highly rotted ties with low ballast with a gap of nearly 3 inches between the rail and ballast (Figure 45 left). The rail on the North approach dips by 1.25 inches. Ballast in the South approach is very low; the first two ties are hanging by the rails with no support beneath them, even with a dip in the rails of 1.1875 inches (Figure 45 right). 

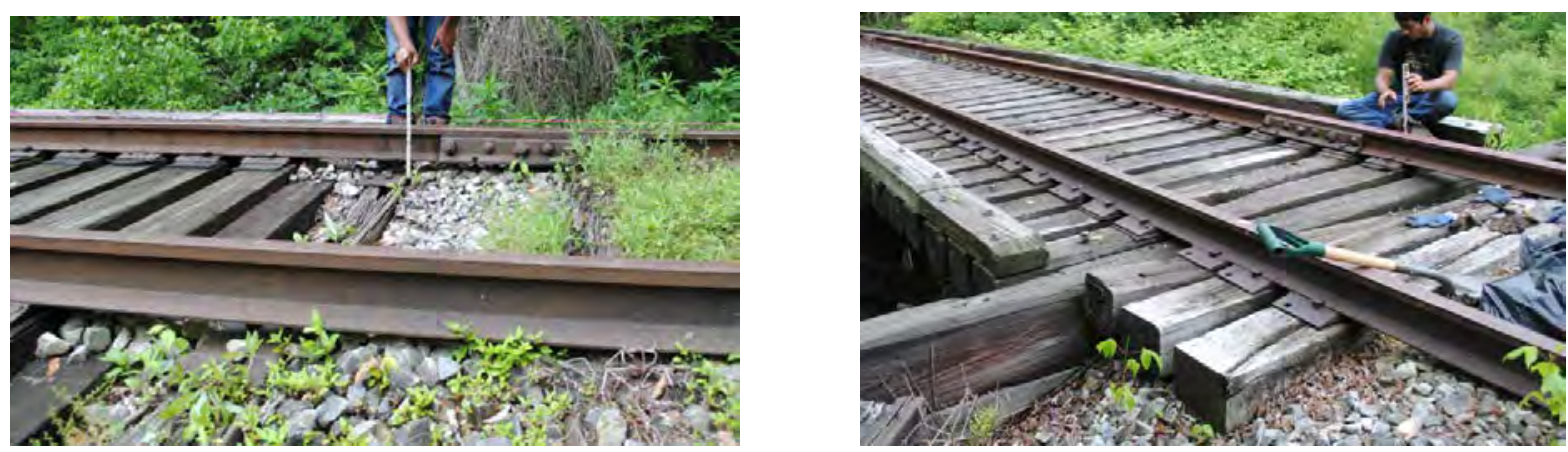

Figure 45 - North Approach Condition (left) and South Approach Condition (right).

The top timber member on the Northeast wingwall is fully rotted (Figure 46 right). The Southwest wingwall shows minor rot. The south retaining wall structure between bents 7 and 8 is leaning outward on the west, and some rot is noticeable on the top west timber members (Figure 46 left).
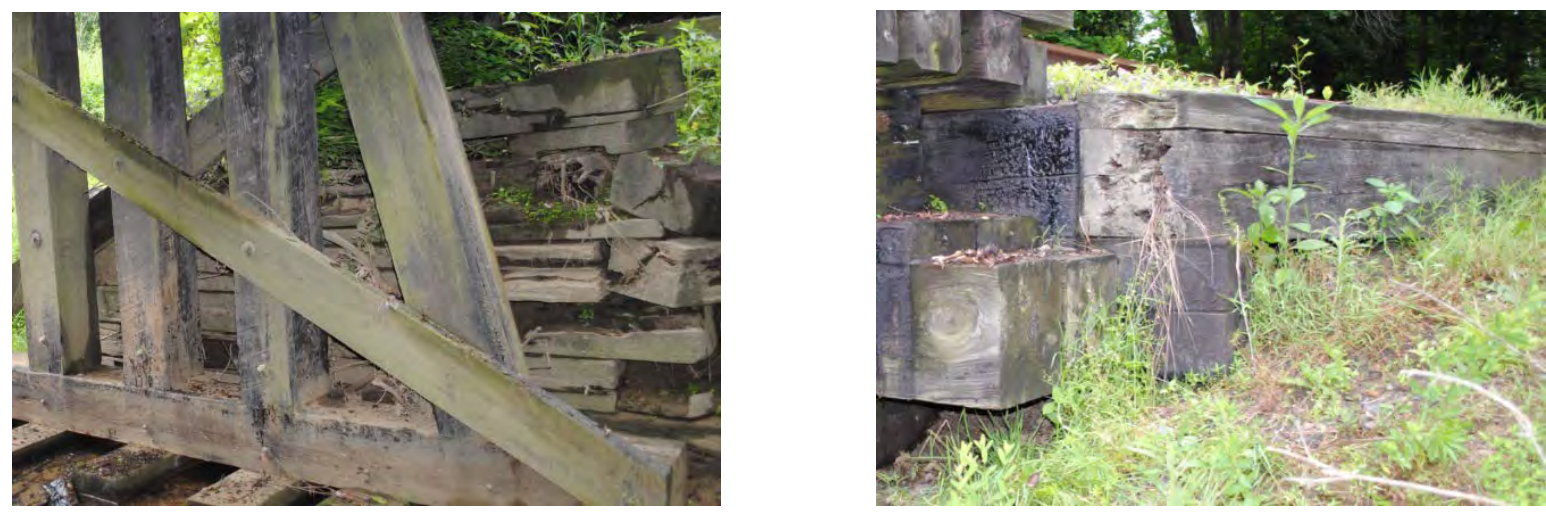

Figure 46 - South Retaining Wall \& West Wingwall (left) and North East Wingwall heart rot (right).

Stringer 1 in span 1 is highly rotted on the East face of the member near bent 1 for $2^{\prime}$ in length and at center span for another $2^{\prime}$, both about $5^{\prime \prime}$ by 2 " in cross section (Figure 47 right). Stringer 4 in span 1 also shows some rot near bent 2, 2" by 4" in cross section for a length of $3^{\prime}$. Stringer 8 in span 3 is highly rotted on the West face, the decayed area being 4 " by 10" in cross section, and as long as $11^{\prime}$ spanning over to span 4 (Figure 47 left). Stringer 6 in span 3 and 4 shows softening. 

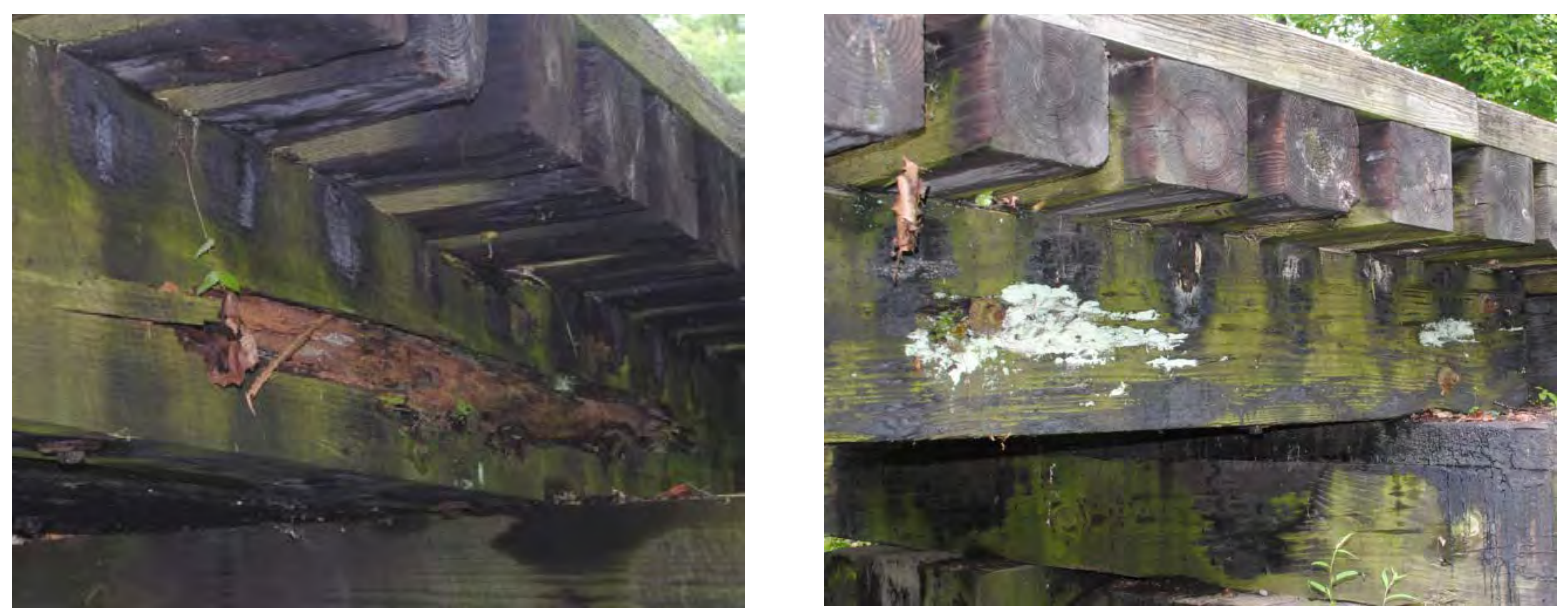

Figure 47 - Span 3 \& 4 Stringer 8 highly rotted (left) and Span 1 Stringer 1 East face fruiting bodies (right).

Flood debris has lodged against the upstream edge of bent 3 and other areas of the bridge. Post 1 in bent 3 has heart rot for the entire length of the member. Post 3 in bent 5 has heart rot near the bottom (Figure 48 left). Post 6 in bent 3 has heart rot present for the entire length of the member. The sill in bent 3 was found to be hollow for the end 4 ' below post 5 using the tapping technique (Figure 48 right). Blocks 5 and 6 in bent 1 are softening and beginning to rot.
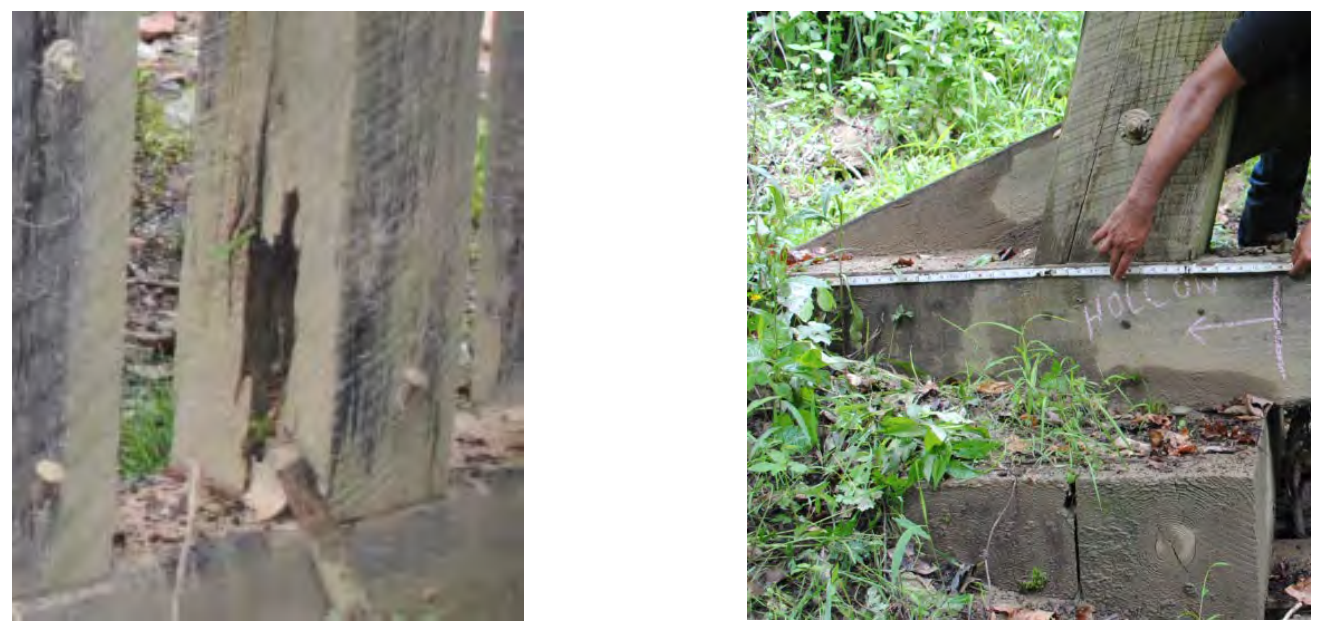

Figure 48 - Bent 5 Post 3 heart rot (left) and Bent 3 Sill end rot (right).

The bracing components in Bridge 5.1 are in good condition. Table 16 shows the species and grade for all the substructure elements as determined by Osborne during his inspections. Species is either Southern Pine (SP), Oak or N/A - Non-Applicable (nonexistent member). Lawrence graded the members as with SS - Select Structural (SS), Number 2 (No 2) or Below Grade (BG) for members that had damage. 
Table 16 - Bridge 5.1 Member Species and Grade

\begin{tabular}{|c|cccccccc|}
\cline { 2 - 8 } \multicolumn{1}{c|}{ Element } & Bent 1 & Bent 2 & Bent 3 & Bent 4 & Bent 5 & Bent 6 & Bent 7 & Bent 8 \\
\hline Cap & SP-SS & SP-SS & SP-No.2 & SP-SS & SP-SS & SP-SS & SP-SS & SP-SS \\
Sill & SP-No.2 & SP-SS & SP-No.2 & SP-SS & SP-SS & SP-SS & SP-SS & Oak-SS \\
Post 1 & N/A & SP-BG & SP-SS & SP-SS & SP-SS & SP-SS & SP-No.2 & N/A \\
Post 2 & N/A & SP-SS & SP-SS & SP-SS & SP-SS & SP-SS & SP-SS & N/A \\
Post 3 & N/A & SP-BG & SP-BG & SP-SS & SP-BG & SP-SS & SP-SS & N/A \\
Post 4 & N/A & SP-SS & SP-BG & SP-SS & SP-SS & SP-SS & SP-SS & N/A \\
Post 5 & N/A & SP-SS & SP-SS & SP-SS & SP-SS & SP-SS & SP-SS & N/A \\
\hline
\end{tabular}

\subsubsection{Bridge 1.4}

Ballast is low near the approaches (Figure 49), and numerous ties show degradation.

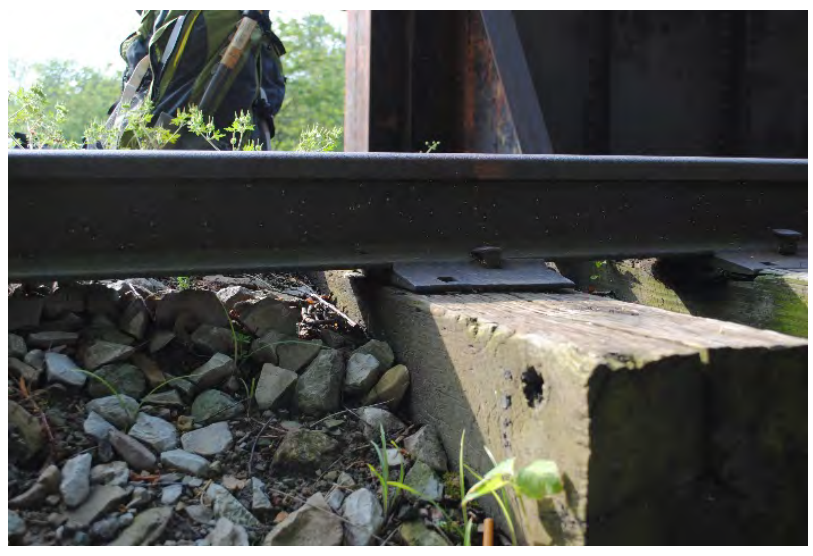

Figure 49 - North approach

Overall, the entire bridge exhibits minor corrosion. Span 1, Girder 2 exhibits corrosion on the bottom flange angles at Northwest end near bearing with losses up to $1 / 4$ " to the interior vertical angle for up to 3 " in height (Figure 50 left). Girder 1 has a bent bottom flange near abutment. Anchor bolts have section loss at the bottom up to $1 / 4$ " loss for $1 / 2$ " in height. The rocker bearings are tilted strongly north, and the anchor bolts in Span 2 are bent. Gusset plate for the longitudinal bracing show corrosion, with corners rusted through in places, but this is not a structural issue as the area around the rivets is in good condition (Figure 50 right). Numerous web stiffeners in the gusset plate have $100 \%$ section loss at the bottom resting on girder flanges, but it does not affect the structural integrity of the girders as the section loss is below the rivets (Figure 50 right). 

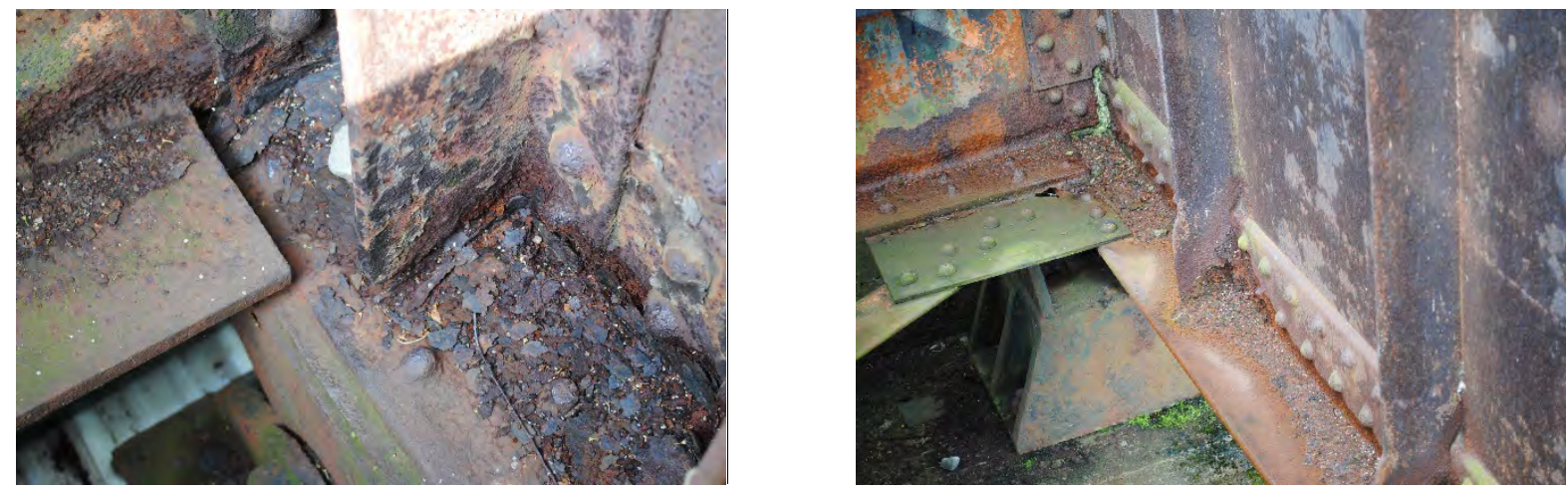

Figure 50 - Corrosion in angle of girder (left) and corrosion in gusset plate \& web stiffeners (right)

Both concrete abutments exhibit map cracking, minor scaling, beam seats have hairline cracks (Figure 51 left). Concrete backwalls exhibits map cracking. Wingwalls are extensions of abutments. All exhibit minor map cracking, and minor delamination. Piers have heavy efflorescence, rust staining from super structure, and the top face has scaling up to 2 inches(Figure 51 right).
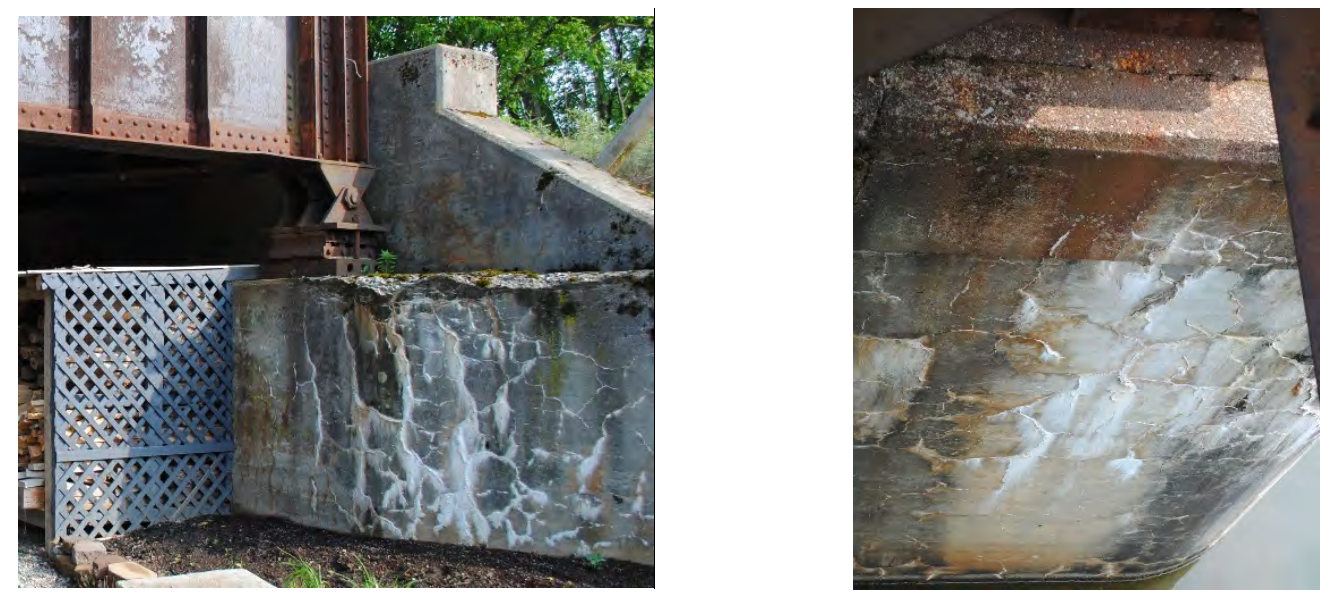

Figure 51 - Map cracking in north abutment (left) and pier (right)

\subsubsection{Bridge 5.8}

Bridge 5.8 is good structural shape with very few signs of decay/corrosion. The most noticeable amount of corrosion was found in the end cross frame bracing (Figure 52 left) on the north end of the bridge. The bearing sole plates also show minor corrosion. Some web stiffeners show a small bend, which is considered nonstructural in nature (Figure 52 right). Some of the mortar in the cut stone abutments is missing or cracked. The west end of the north abutment is missing the top abutment stone (stone has been pushed into creek). Both approaches are in good condition and the timber ties and spacers are in good condition. 

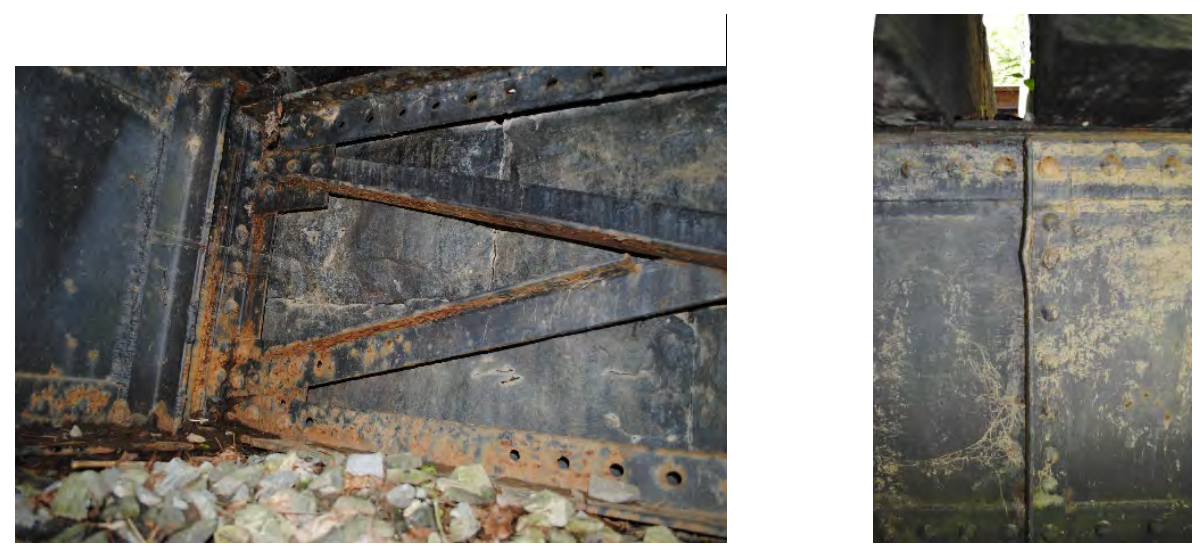

Figure 52 - Bracing corrosion (left) and bend in web stiffener (right)

\subsection{Field Inspections Conclusions}

The WVSRA had provided WVU with previous periodical inspection reports performed by a third party with span lengths, dimensions, and bridge configurations that did not match those found in the field. A common finding in almost all bridges was poor tie conditions due to rot, and poor bearing conditions due to both rot and low ballast at the approaches. Deterioration in the steel bridges was not found to compromise their structural integrity. Many timber stringers to cap beam joints had been shimmed over time with either one or more shims, and in some locations the cap beam was not evenly bearing on all posts in a given bent. Together, the track conditions and poor bearing conditions on post will most likely generate poor and uneven load distribution among all members. A preliminary analysis based on inspections findings should help determine a safe bridge load carrying capacity, but load testing of the bridges would provide a better understanding of the bridge's response to live loads. Load testing may also help detect, verify and quantify the extent of decay in members found via hammer tap sounding and visual inspection. 


\section{Field Load Testing}

\subsection{Methodology}

A field load test with the instrumentation of uniaxial and shear strain gages, linear variable differential transformers (LVDTs) and data acquisition software helped gather data on the response of the bridges due to live loads. The location of the strain gages in the timber bridges were chosen after the field inspections with the intention to attempt to quantify the amount of decay in certain members and to compare their response to other gaged structurally sound members. The bending strain, shear strain and deflection data were then used to verify analysis assumptions used in the different models, and to refine them in order to generate better results, which in most cases predicted conservative values as is expected. The results from the data gathered on the steel bridges confirmed the nominal impact the corrosion and other inspection findings had on the structural integrity of the bridges. The variation in data gather from the timber bridges did not allow for quantification of damage in the individual members, but it did prove the load rating procedure to be conservative due to the higher than expected resistance of the timber members to the applied loads, a conclusion arrived at due the high stiffness in spite of inspection findings.

Two vehicles were used for testing. A hi-rail dump truck was used to load test all five bridges, while a locomotive was used only on bridges 1.4 and 1.9. Data gathered from locomotive loading on the two steel and timber bridges was then used to prorate hi-rail dump truck data on the remaining bridges up to a locomotive loading. The field testing procedure was completed in two days, August $3^{\text {rd }}$ and August $4^{\text {th }}$ of 2015.

\subsubsection{Strain Gage Locations}

A total of 76 strain gages were placed in locations where rating values where needed i.e. horizontal shear strain, bending strain, and compression strain. The following designation was used to identify each individual strain gage. The uniaxial gages used on the steel bridges were either $1 / 8$ or $1 / 4$ of an inch, while 1 or 2 inch gages were used on the timber bridges as a larger area needs to be monitored in order to be representative of the member behavior in timber. Steel is a homogeneous material and monitoring a very small surface area is representative of the member as a whole. Timber is more susceptible to discontinuities along and across the grain, thus a larger area needs to be monitored in order to provide representative data of the entire member. $1 / 4$ inch shear pattern gages were used at all locations where shear strain was monitored. No further manipulation of the data gathered from the 
shear strain gages was needed since the strain gages are designed to provide shear strain data. Figure 53 shows the designation used to identify each individual strain gage.

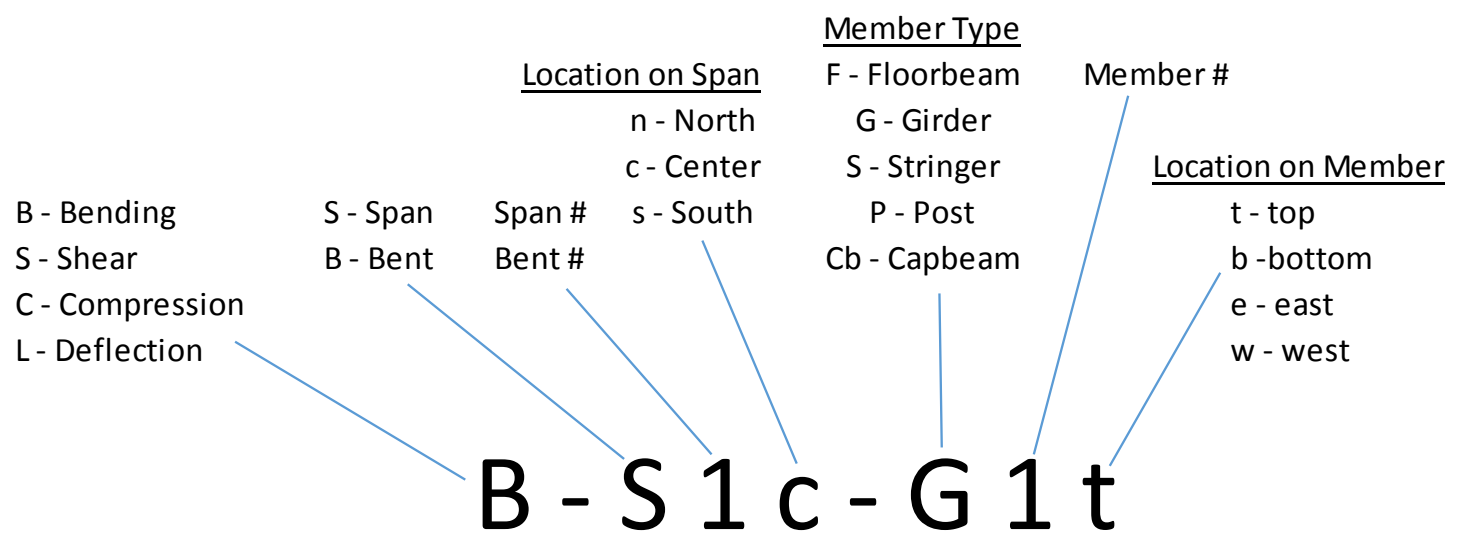

Figure 53 - Strain Gage Identification According to Purpose and Location

Table 17 below shows all the strain gages per bridge from which a strain value was picked for further analysis. Gages marked in red failed to produce reliable data, which was determined by graphing the results and comparing the high variation between data points or the unrealistic values after analysis. Several gages were installed in part to provide enough redundancy in the event of gage failure. Therefore, the 8 failed gages did not affect the outcome of the study. Drawings showing the exact location of the strain gages on all bridges are shown on the appendix section of this report. 
Table 17 - Strain Gages Installed per Bridge

\begin{tabular}{|c|c|c|c|c|c|}
\hline Gage \# & Bridge 1.4 & Bridge 1.9 & Bridge 4.3 & Bridge 5.1 & Bridge 5.8 \\
\hline $\mathbf{1}$ & S-S1n-Fs & S-S1s-S1e & S-S1n-S1e & S-S1s-S1e & S-S1n-G1e \\
\hline $\mathbf{2}$ & S-S1n-G2e & S-S1s-S8w & S-S1n-S4w & S-S1s-S4w & S-S1n-G2w \\
\hline $\mathbf{3}$ & C-S1n-G2e & S-S3s-S1e & S-S1n-S5e & S-S1s-S5e & S-S1o-G1e \\
\hline $\mathbf{4}$ & C-S1n-G2w & S-S3s-S4w & S-S1n-S8w & S-S1s-S8w & S-S1o-G2w \\
\hline $\mathbf{5}$ & S-S1o-G2e & S-S3s-S5e & B-S1c-S2b & C-B3-P1e & B-S1c-G1b \\
\hline $\mathbf{6}$ & B-S1c-G1t & S-S3s-S8w & B-S1c-S3b & C-B3-P3e & B-S1c-G2b \\
\hline $\mathbf{7}$ & B-S1c-G1b & B-B4-Cb & B-S1c-S4b & C-B4-P3e & \\
\hline $\mathbf{8}$ & B-S1c-G2t & C-B4-P1e & B-S1c-S5b & S-S4n-S1e & \\
\hline $\mathbf{9}$ & B-S1c-G2b & C-B4-P3w & B-S1c-S6b & S-S4n-S4w & \\
\hline $\mathbf{1 0}$ & B-S1c-S1c & C-B4-P3n & C-B2-P1 & S-S4n-S5e & \\
\hline $\mathbf{1 1}$ & B-S1c-Fc & B-S5c-S1t & C-B2-P5 & B-S4c-S5b & \\
\hline $\mathbf{1 2}$ & B-S2c-G1t & B-S5c-S4t & S-S2n-S1e & B-S4c-S6b & \\
\hline $\mathbf{1 3}$ & B-S2c-G2t & B-S5c-S5t & S-S2n-S4w & B-S4c-S7b & \\
\hline $\mathbf{1 4}$ & & B-S5c-S8t & S-S2n-S5e & B-S4c-S8b & \\
\hline $\mathbf{1 5}$ & & S-S5s-S1e & S-S2n-S8w & S-S4s-S8w & \\
\hline $\mathbf{1 6}$ & & S-S5s-S8w & B-S2c-S5b & C-B5-P3w & \\
\hline $\mathbf{1 7}$ & & C-B6-P3w & B-S2c-S6b & C-B6-P1e & \\
\hline $\mathbf{1 8}$ & & C-B6-P4w & C-B3-P1 & C-B6-P3w & \\
\hline $\mathbf{1 9}$ & & C-B7-P3e & C-B3-P5 & & \\
\hline $\mathbf{2 0}$ & & C-B7-P5w & & & \\
\hline
\end{tabular}

LVDT sensors were placed in one span of each bridge, where bending strain gages were also located, in order to determine maximum net chord deflections to then be compared to maximum bending strains. In all timber bridges, LVDTs were also placed right next to the face of each support under the desired span in order to calculate net deflections. Deflection values need checking against allowable criteria found in the AREMA manual for Railway Engineering. Photoelectric sensors were used in order to determine axle locations for all the maximum strains obtained during testing.

\subsubsection{Axle Weights and Spacing - Dailey Checks}

Testing was performed in two days with two different axle weights each day for the dump truck. The locomotive was only used for testing on the first day on bridges 1.4 and 1.9. The dump truck had a gross weight of 66.48 kips on day 1 when tested over bridges 1.4 and 1.9, and a gross weight of 69.86 kips on day 2 when tested on the remaining bridges. The dump truck driver provided by the West Virginia Division of Highways was required to unload the gravel from the truck at the end of day 1 , thus having a different gross weight when reloading with gravel on day 2. In order to determine the load distribution 
between the front and rear axles, maximum bending strain data exerted at mid span on bridge 5.8 was compared during the passage of each axle. The data showed that the rear axle carried $69 \%$ of the gross weight of the dump truck, and the distribution of the load to each axle for both days is as show in Figure 54. Strain data from bridge 5.8 was the only reliable source when determining the load distribution because the span length was short enough to allow for only 1 axle to apply loading on the bridge at a time. When the dump truck was loaded onto the rail tracks, the front hi-rail gear lifted the front steering axle off of the track, thus all of the front axle weight was carried by the hi-rail gear. The rear tandem axles being the driving axle remained on the tracks together with the rear hi-rail gear, so the rear axle load was shared among them. Thus, the center of gravity of the rear tandem axles and the hi-rail gear had to be determined in order to measure the actual distance between the front axle and rear axle loads. The data gathered from testing bridge 5.8 can also be used to determine the center of gravity of the rear axles by finding the distance in relation to time of the two highest bending strains. Figure 55 is the plot of the bending strain (red and green lines) at mid span of the girders of bridge 5.8 and the location of each axle (blue line) against elapsed time in seconds for truck test number 3 . Based on the time elapsed between photoelectric sensor readings of the front and rear hi-rail gear, and knowing that the spacing between them is 23 feet, the speed of the truck can be calculated. Then, the time elapsed between the two bending strain peaks (local maximums) can be multiplied by the speed of the truck which results in the location of the center of gravity, 268.12 inches, which is equal to the load spacing.

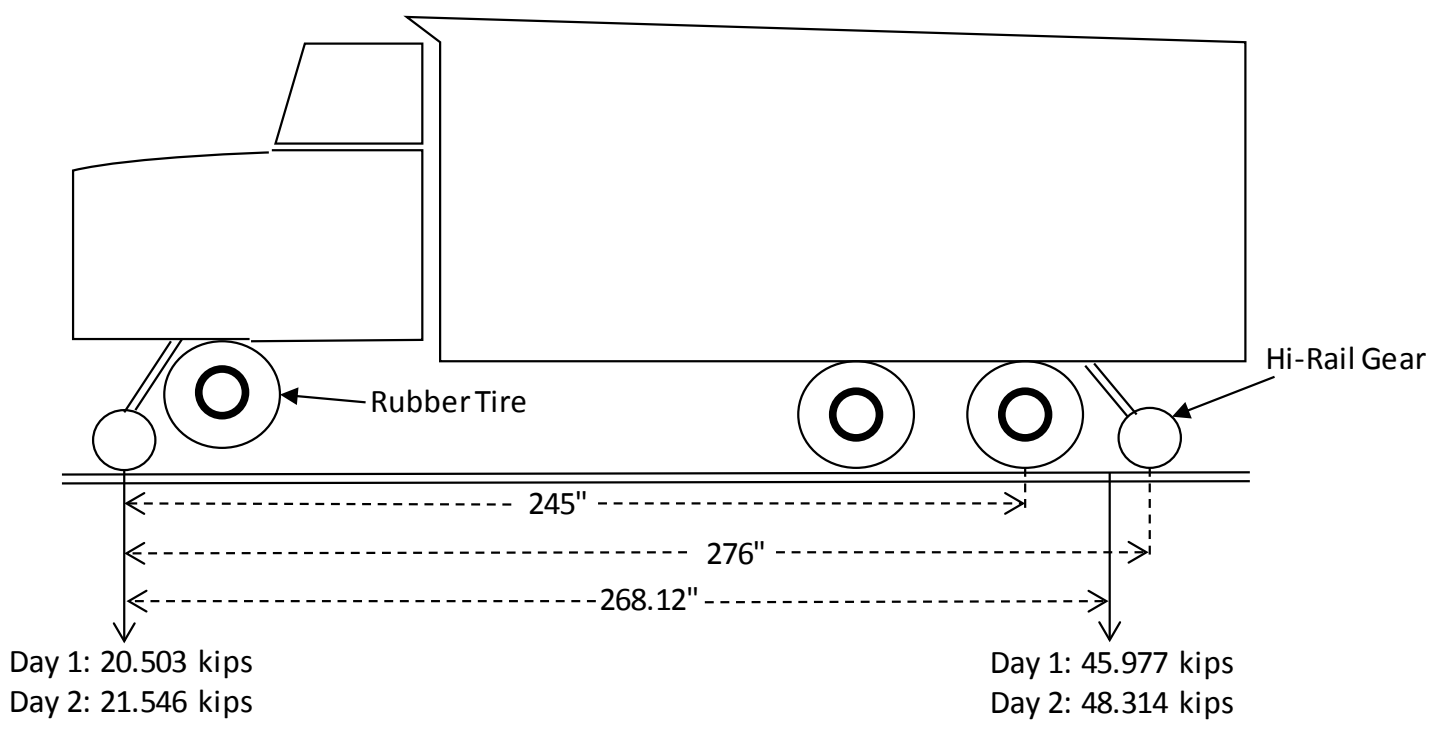

Figure 54 - Truck Axle Weights and Load Spacing 


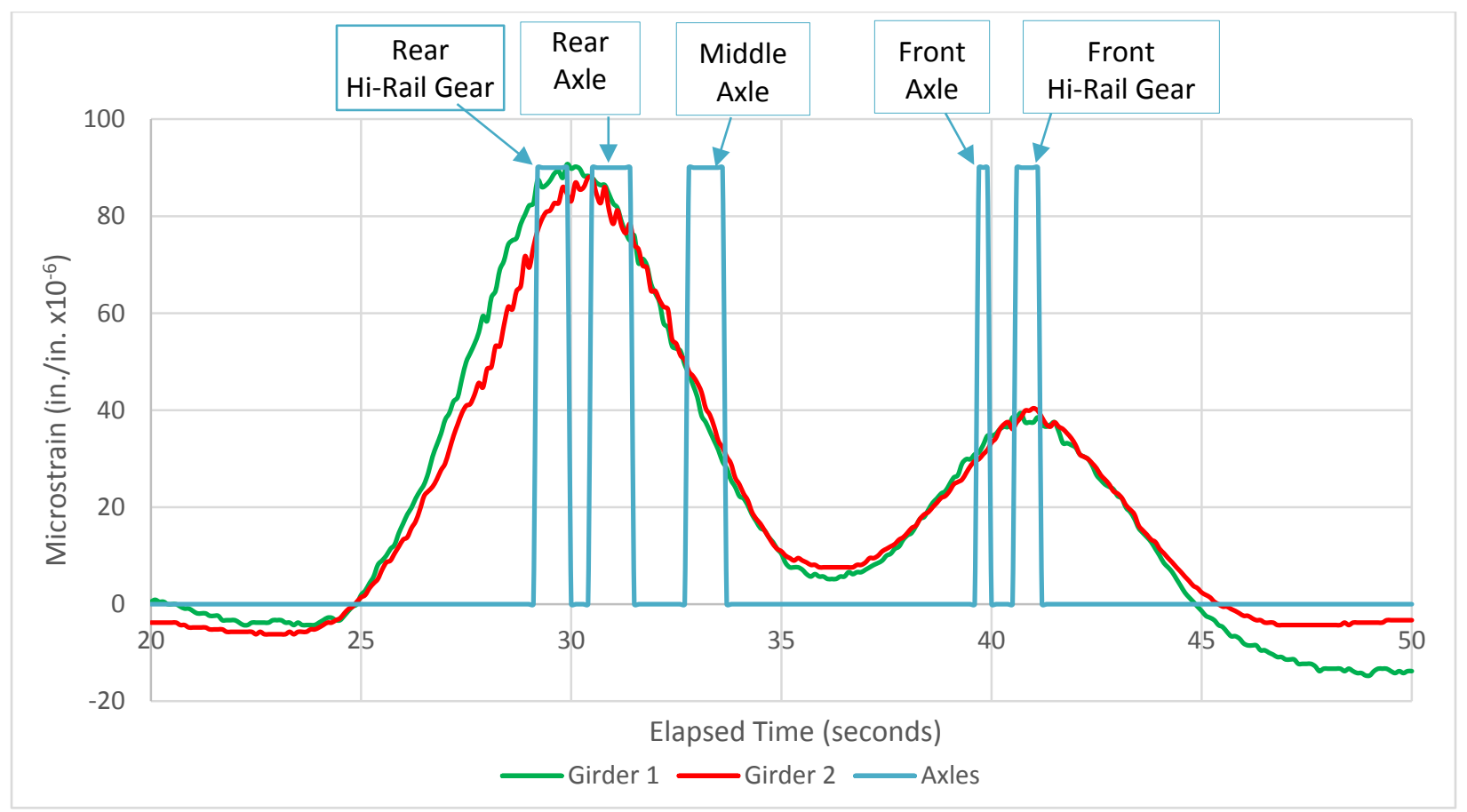

Figure 55 - Bending Strain and Axle Location Versus Time (Bridge 5.8 Truck Test 3)

Figure 55 shows the maximum bending strain (rear axles center of gravity) falling between the rear axle and the rear hi-rail gear, which verifies the assumptions made when determining the spacing between front and rear axle loads.

The locomotive could not be used for load testing of other bridges other than 1.4 and 1.9 for safety reasons. The actual axle weights could not be measured in the field, therefore the axle weights from section 1.2.3.4 where used assuming a gross weight of 230 kips distributed equally to 4 axles. The bending strain data gathered for the WM82 locomotive on bridge 1.4 debunks the assumption that the gross weight is distributed equally to all 4 axles. Figure 56 shows how the bending strain data peaks when the first pair of axles reaches the mid span, and slightly drops as the second pair of axles pass through. The data collected did not provide sufficient information to determine the actual load distribution, thus the assumption of equal distribution of $230 \mathrm{kips}$ is herein applied to field data and theoretical model analysis. 


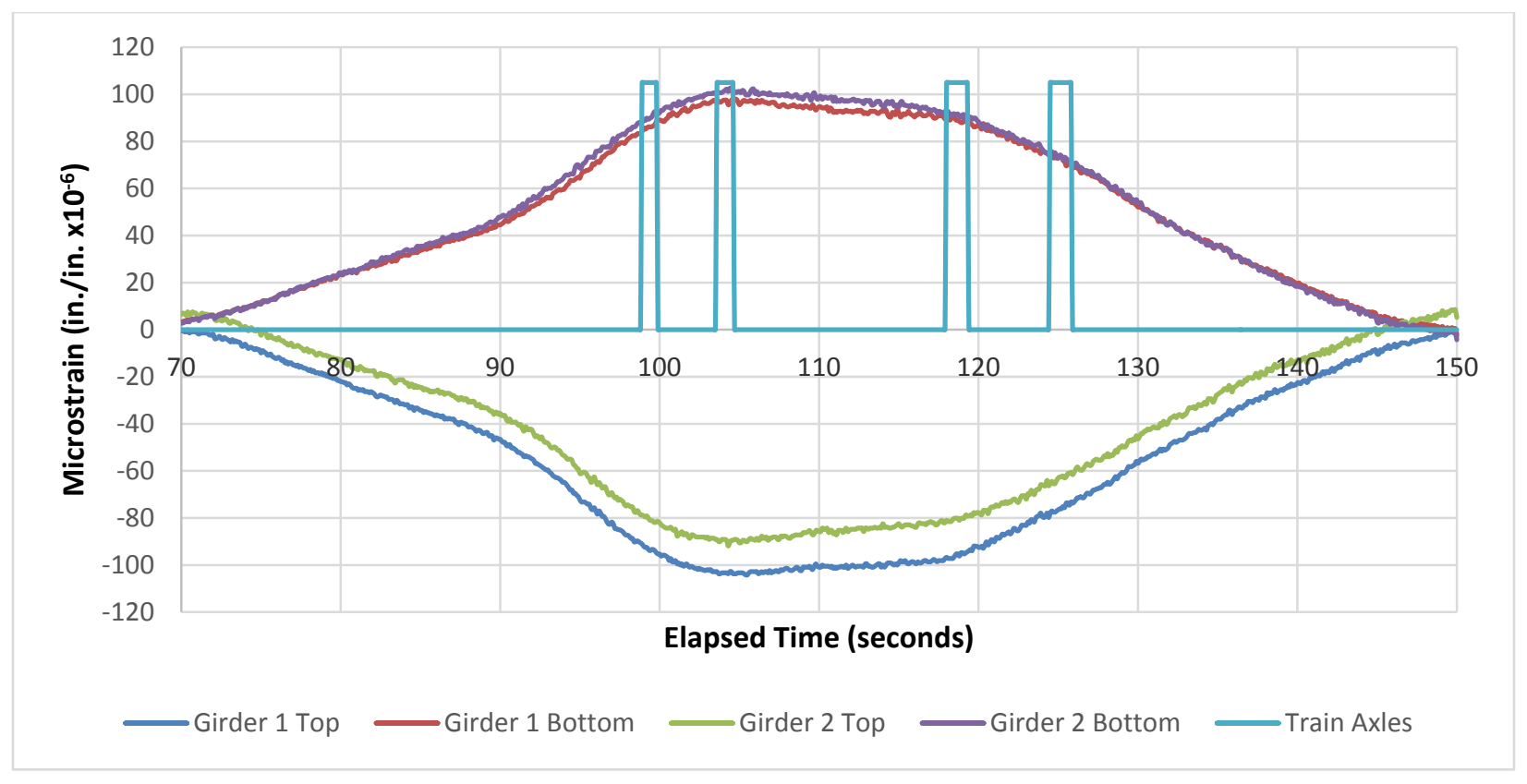

Figure 56 - Bending Strain and Axle Location Versus Time (Bridge 1.4 Train Test 2)

\subsubsection{Testing Procedure}

In order to obtain maximum strain values under each vehicle for all five bridges, both rail vehicles were slowly rolled over the bridges three times for each bridge, slow enough (crawl speed) to reduce any impact effects. The strain values obtained were taken as static loading values in order to compare the results with the theoretical analysis.

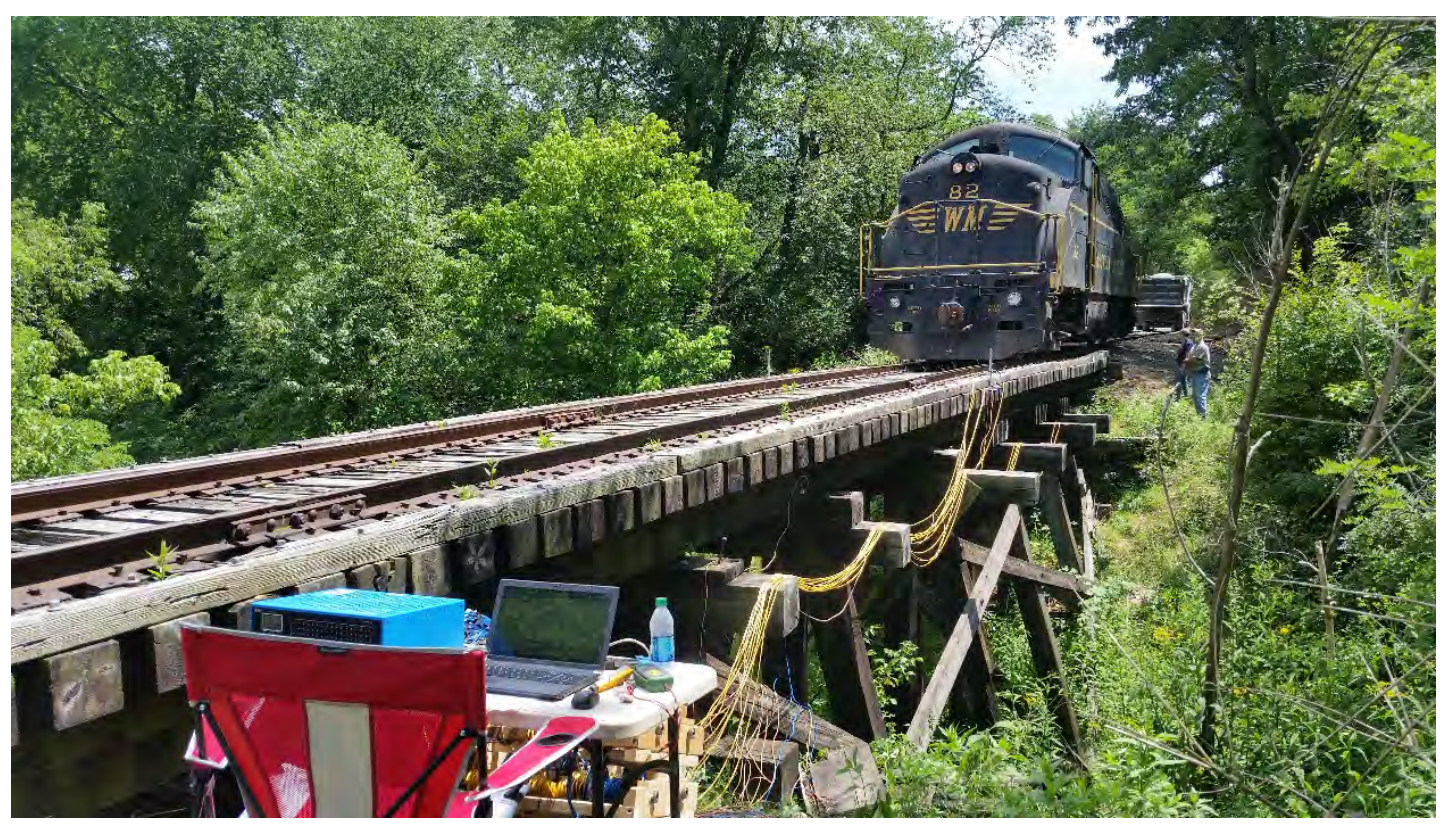

Figure 57 - WM 82 Locomotive Testing on Bridge 1.9 After Dump Truck Testing 
The data acquisition system shown in Figure 57 recorded 10 data points per second for the duration of each test. The same test was ran three times on each bridge, two runs with the vehicle moving in the same direction (North or South) and one run traveling the opposite direction. The dump truck was the first rail vehicle used during testing in order to determine if the structure was sound enough to withstand the locomotive loading. Bridges 1.4 and 1.9 were tested one day 1 with both the locomotive and the dump truck, while the remaining bridges were tested on day 2 only with the dump truck. Dump truck strain values on testing day 2 were prorated to the locomotive values using field data between both vehicles from testing day 1 .

\subsection{Results}

This section summarizes the results for the timber bridges and steel bridges separately, dividing them into individual sections depending on the measurement type such as bending, shear, and axial compression strain. The maximum strain readings for each gage from each run was collected and used to calculate a weighted average. Test runs 1 and 3 generated similar strain readings, while test run 2 tended to be a little off. This is due to the entire bridge structure's response, including bent movement and load sharing through continuity, when the truck or locomotive are at different locations on the bridge. Even though the speeds are low enough to moch static loading, the vehicles are still moving across the bridge during data recording thus deforming the entire structure and chaning its geomtry in different ways as the the load moves in oposite directions. In order to account for this the weighted average was calculated using the data for test run 2 twice as two individual runs.

The field results for each gage were compared to the predicted values using AREMA's recommended approach for semi-continuous design timber bridges as well as material mechanical properties found in the manual for the given species and grade. The predicted values for steel bridge 1.4 were calculated using a 3D model where the stringers, floorbeams, and girders resist the loads as a unit, thus generating output values for all gage locations in one analysis. This approach generated values close to the measured field results. The predicted strain values for the timber bridges were usually higher, thus being on the more conservative side of analysis. This can be due to the assumed modulus of elasticity (E) of $1500 \mathrm{ksi}$, which is most likely a higher value. An example of this is Gutkowski's study covered in the literature review section, where the measured average E value in the field was about $2000 \mathrm{ksi}$, but the highest E value provided in the AREMA manual for Douglas Fir is $1700 \mathrm{ksi}$. The predicted values for steel bridge 5.8 were also conservative with respect to the field measurements. This bridge was modeled 
using simple beam analysis since it is a one span deck girder bridge. Bridge 5.8 and the other timber bridges are small structures in comparison to Bridge 1.4, it being almost 5 times shorter than Bridge 1.4. The sheer size of the through girders on Bridge 1.4 contrinute to the majority of the bridge's strength, thus contributing most of the stiffness to the structure. But in the smaller timber bridges and bridge 5.8, other load carrying members come into play such as the rail and tie spacers. Accounting for this other members in the smaller bridges can help provide less conservative results, but would not be accounted for load rating purposes as the actual stiffness contirbution has not yet been determined.

\subsubsection{Timber Bending Moment}

All bending strain gages were placed on the bottom face of the stringers at midspan, with the exception of bridge 1.9 where the bottom of stringers could not be reached, thus the gages were place on the top face recording negative strain values. Table 18 shows the average maximum field strain generated by the moving hi-rail dump truck for each strain gage. The gage column is color coded to show gages that were placed in members with noted findings through the field inspections (green $=$ softening, red $=$ rot). The field strain values are compared to theoretical values calculated by averaging the bending moment of simple span and continuous span conditions as per AREMA. The theoretical values were generated using RISA models with moving loads. The far right column in Table 18 shows the difference between the theoretical value and the field measured value, where positive values mean over prediction.

Table 18 - Field Measured Bending Strains in Timber Stringers (microstrain)

\begin{tabular}{|c|c|c|c|c|c|c|}
\hline Bridge & Span & Stringer & Gage & $\begin{array}{c}\text { Average } \\
\text { Field } \\
\text { Strain }\end{array}$ & $\begin{array}{l}\text { Theoretical } \\
\text { Microstrain }\end{array}$ & Difference \\
\hline \multirow{4}{*}{1.9} & \multirow{4}{*}{5} & 1 & B-S5c-S1t & -209 & -331 & $59 \%$ \\
\hline & & 4 & B-S5c-S4t & -115 & -331 & $189 \%$ \\
\hline & & 5 & B-S5c-S5t & -101 & -331 & $229 \%$ \\
\hline & & 8 & B-S5c-S8t & -163 & -331 & $103 \%$ \\
\hline \multirow{7}{*}{4.3} & \multirow{5}{*}{1} & 2 & B-S1c-S2b & 149 & 354 & $138 \%$ \\
\hline & & 3 & B-S1c-S3b & 244 & 354 & $45 \%$ \\
\hline & & 4 & B-S1c-S4b & 216 & 354 & $64 \%$ \\
\hline & & 5 & B-S1c-S5b & 224 & 354 & $58 \%$ \\
\hline & & 6 & B-S1c-S6b & 222 & 354 & $59 \%$ \\
\hline & \multirow{2}{*}{2} & 5 & $B-S 2 c-S 5 b$ & 231 & 341 & $47 \%$ \\
\hline & & 6 & B-S2c-S6b & 373 & 341 & $-9 \%$ \\
\hline \multirow{3}{*}{5.1} & \multirow{3}{*}{4} & 5 & B-S4c-S5b & 113 & 339 & $201 \%$ \\
\hline & & 7 & B-S4c-S7b & 288 & 339 & $18 \%$ \\
\hline & & 8 & B-S4c-S8b & 192 & 339 & $76 \%$ \\
\hline
\end{tabular}




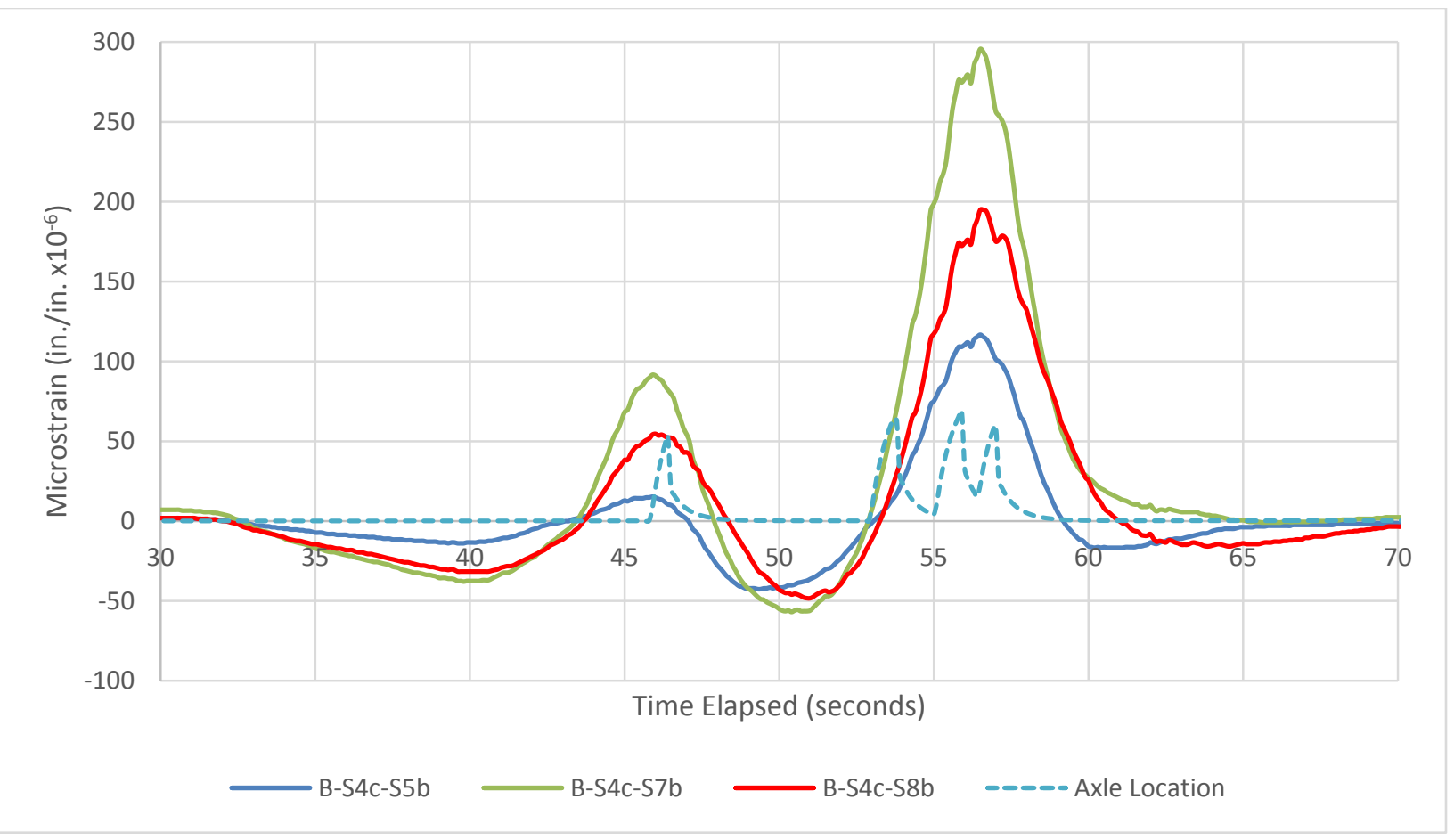

Figure 58 - Timber Stringer Bending Strain (Bridge 5.1, Truck Test 2)

Figure 58 shows the data collected for hi-rail dump truck test number 2 on bridge 5.1 from where the maximum peaks were selected when calculating average field measured values. The dashed lines peak whenever the wheels or rail gear passed through the mid span where the bending strains were being recorded. The average bending microstrain values for the timber bridges are $-147,237$, and 198 for bridge 1.9, 4.3, and 5.1 respectively. For positive bending (bridges $4.3 \& 5.1$ ) the theoretical values overpredicted the field values by an average of $70 \%$. The lower negative strain values for bridge 1.9 suggest that the neutral axis is no at stringers mid depth, but higher up closer to the top of the stringers. This is most likely due to the stiffness contribution of other superstructure components such as the tracks, ties and spacers. The actual stiffness contribution to the stringers from the tracks and other member cannot be accurately calculated, so it should not be accounted for when load rating.

On bridge 5.1, stringer 8 was decayed, but resulted in a strain value 33\% lower than the adjacent stringer 7 which is sound. The amount of variation in strain values within span makes it difficult to quantify the amount of decay in the stringers and the load sharing pattern among them.

\subsubsection{Timber Shear}

The crawl speed tests with the hi-rail dump trucks allow for gathering of data for shear, compression, bending and deflection at the same time. Shear gages were installed 16 inches away from the face of the 
supports at mid depth on the side faces of the stringers in order to obtain the maximum shear strain during testing. 24 shear gages were installed on all 3 timber bridges only on the outer stringers of each chord (stringers $1,4,5$ or 8 ), because the side faces of the remaining stringers were not exposed. Table 19 shows all the maximum average field shear strains gathered for each gage, showing no trend among sound, decayed, similar end span (continuous or simple span near support) stringers.

Table 19 - Field Measured Shear Strains in Timber Stringers (microstrain)

\begin{tabular}{|c|c|c|c|c|c|c|}
\hline Bridge & Span & Stringer & Gage & $\begin{array}{c}\text { Average } \\
\text { Field } \\
\text { Strain }\end{array}$ & $\begin{array}{l}\text { Theoretical } \\
\text { Microstrain }\end{array}$ & Difference \\
\hline \multirow{8}{*}{1.9} & \multirow{2}{*}{1} & 1 & S-S1s-S1e & 18 & 516 & $2851 \%$ \\
\hline & & 8 & S-S1s-S8w & 224 & 516 & $130 \%$ \\
\hline & \multirow{4}{*}{3} & 1 & S-S3s-S1e & 112 & 532 & $376 \%$ \\
\hline & & 4 & S-S3s-S4w & 324 & 532 & $64 \%$ \\
\hline & & 5 & S-S3s-S5e & 55 & 532 & $873 \%$ \\
\hline & & 8 & S-S3s-S8w & 319 & 532 & $67 \%$ \\
\hline & \multirow{2}{*}{5} & 1 & S-S5s-S1e & 281 & 566 & $101 \%$ \\
\hline & & 8 & S-S5s-S8w & 116 & 566 & $390 \%$ \\
\hline \multirow{8}{*}{4.3} & \multirow{4}{*}{1} & 1 & S-S1n-S1e & 233 & 586 & $152 \%$ \\
\hline & & 4 & S-S1n-S4w & 144 & 586 & $308 \%$ \\
\hline & & 5 & S-S1n-S5e & 145 & 586 & $304 \%$ \\
\hline & & 8 & S-S1n-S8w & 362 & 586 & $62 \%$ \\
\hline & \multirow{4}{*}{2} & 1 & S-S2n-S1e & 172 & 646 & $275 \%$ \\
\hline & & 4 & $S-S 2 n-S 4 w$ & 190 & 646 & $240 \%$ \\
\hline & & 5 & S-S2n-S5e & 478 & 646 & $35 \%$ \\
\hline & & 8 & S-S2n-S8w & 394 & 646 & $64 \%$ \\
\hline \multirow{8}{*}{5.1} & \multirow{4}{*}{1} & 1 & S-S1s-S1e & 629 & 575 & $-8 \%$ \\
\hline & & 4 & S-S1s-S4w & 103 & 575 & $456 \%$ \\
\hline & & 5 & S-S1s-S5e & 411 & 575 & $40 \%$ \\
\hline & & 8 & S-S1s-S8w & 547 & 575 & $5 \%$ \\
\hline & \multirow{4}{*}{4} & 1 & S-S4n-S1e & 305 & 674 & $121 \%$ \\
\hline & & 4 & S-S4n-S4w & 227 & 674 & $197 \%$ \\
\hline & & 5 & S-S4n-S5e & 170 & 674 & $296 \%$ \\
\hline & & 8 & S-S4s-S8w & 422 & 673 & $59 \%$ \\
\hline
\end{tabular}

The shear gages recorded negative and positive shear strains, but the direction in which the planes are shearing from each other does not make a difference as the magnitude of strain is all that matters when comparing to shear capacity. The average shear strain for bridge 1.9, 4.3 and 5.1 was 181, 265, and 352 
respectively. The gage on stringer 8 for bridge 5.1 span 4 (gage S-S4S-S8w) was expected to show the highest shear strain, or lower if not able to share any load, due to it being the stringer with the highest level of rot/decay on all bridges as shown in the inspection findings. As with the bending strains, decay could not be properly identified and quantified with load test strain data. The AREMA manual nor the NDS manual provide a shear modulus, so in order to determine the theoretical shear strain values in Table 19, a G/E ratio of 0.067 was assumed as is described in section 2.2.1.a of this report.

\subsubsection{Timber Axial Compression}

Uniaxial strain gages were installed longitudinally on either the west or east face of the posts to collect axial compression strain data in both sound and decayed members. Table 20 shows the average maximum strain sustained by each post from the reactions to the moving hi-rail dump truck at each bent.

Table 20 - Field Measured Axial Compression Strains in Timber Posts (microstrain)

\begin{tabular}{|c|c|c|c|c|c|c|}
\hline Bridge & Bent & Post & Gage & $\begin{array}{c}\text { Average } \\
\text { Field } \\
\text { Strain } \\
\end{array}$ & $\begin{array}{l}\text { Theoretical } \\
\text { Microstrain }\end{array}$ & Difference \\
\hline \multirow{3}{*}{1.9} & \multirow{2}{*}{4} & 1 & C-B4-P1e & -80 & -34 & $-57 \%$ \\
\hline & & 3 & C-B4-P3w & -11 & -74 & $594 \%$ \\
\hline & 7 & 5 & C-B7-P5w & -88 & -35 & $-61 \%$ \\
\hline \multirow{3}{*}{4.3} & \multirow{2}{*}{2} & 1 & C-B2-P1 & -171 & -30 & $-82 \%$ \\
\hline & & 5 & C-B2-P5 & -92 & -30 & $-67 \%$ \\
\hline & 3 & 5 & C-B3-P5 & -53 & -30 & $-44 \%$ \\
\hline \multirow{5}{*}{5.1} & 3 & 3 & C-B3-P3e & -53 & -43 & $-19 \%$ \\
\hline & 4 & 3 & C-B4-P3e & -36 & -43 & $18 \%$ \\
\hline & 5 & 3 & C-B5-P3w & -50 & -43 & $-13 \%$ \\
\hline & \multirow[b]{2}{*}{6} & 1 & C-B6-P1e & -153 & -32 & $-79 \%$ \\
\hline & & 3 & C-B6-P3w & -6 & -44 & $609 \%$ \\
\hline
\end{tabular}

The average strain for all the posts gaged is -72 and the spread of data can be seen in Table 20. The strain values among sound and decayed members do not show a pattern of loss in stiffness or cross section due to decay, thus not allowing to identify and quantify decay as with the bending and shear strain data. The theoretical microstrain values were computed by taking the average reaction in each bent from a simple span and continuous span model of each bridge, and distributing the load to each post accordingly. The load distribution to each post was determined by modeling each bent with their corresponding field dimensions including posts height, spacing, cap beam dimensions in RISA. The 
reaction at each bent was applied to the cap beams as uniformly distributed loads with a width equal to the stringer chords, or corbels if present, which then transferred the load down to the posts. The posts were modeled as six 2 inches wide by 12 inches high members (posts are 12" by 12") to provide proper bearing areas for the cap beam. The cap beams were fixed to the top of the posts, and the posts rest on pin supports. Figure 59 shows the 5 post model and 4 post model from RISA, and the load distributions are summarized in Table 21.
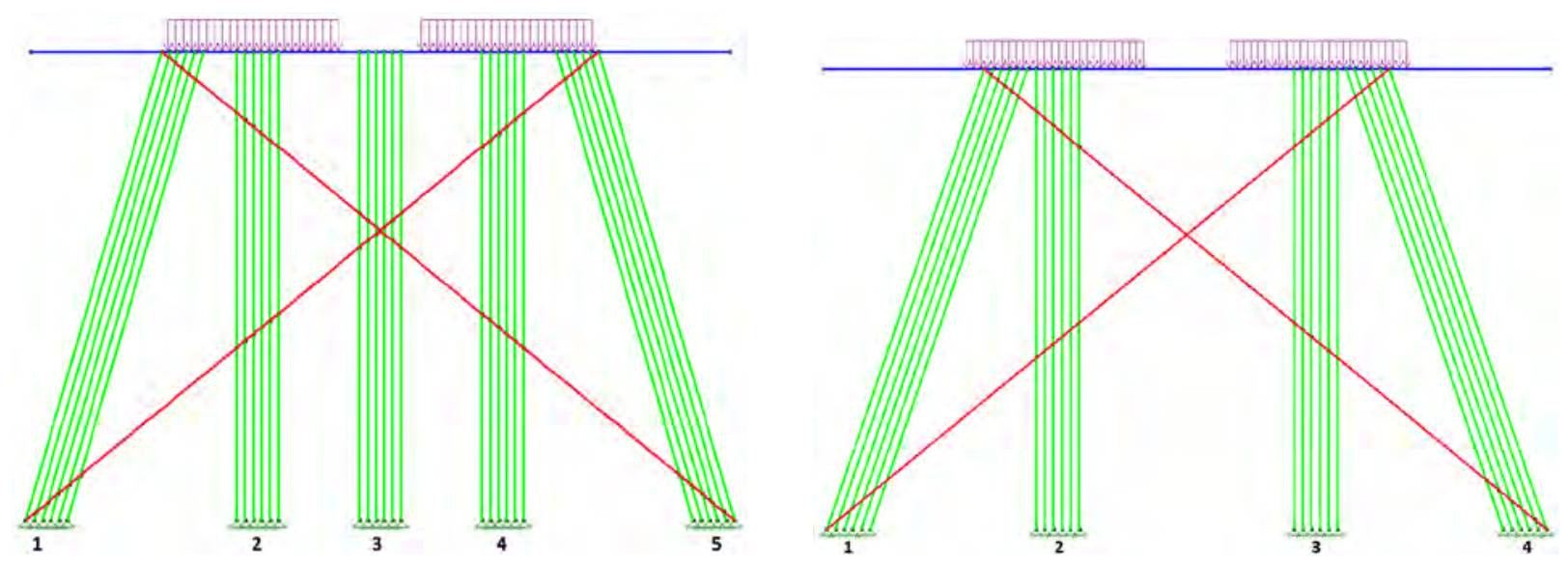

Figure 59 - Bent Model for 5 Posts (left) and 4 Posts (right)

Table 21 - Load Distribution to Posts From RISA Models

\begin{tabular}{|c|c|c|c|c|c|c|}
\hline Bridge & Bent & Post 1 & Post 2 & Post 3 & Post 4 & Post 5 \\
\hline \multirow{2}{*}{1.9} & 4 & $15.8 \%$ & $34.2 \%$ & $34.2 \%$ & $15.8 \%$ & N/A \\
\cline { 2 - 7 } & 7 & $16.1 \%$ & $23.5 \%$ & $20.8 \%$ & $23.5 \%$ & $16.1 \%$ \\
\hline \multirow{3}{*}{4.3} & 2 & $13.6 \%$ & $25.8 \%$ & $21.1 \%$ & $25.8 \%$ & $13.6 \%$ \\
\cline { 2 - 7 } & 3 & $13.2 \%$ & $26.3 \%$ & $20.9 \%$ & $26.3 \%$ & $13.2 \%$ \\
\hline \multirow{3}{*}{5.1} & 3 & $14.0 \%$ & $26.4 \%$ & $19.2 \%$ & $26.4 \%$ & $14.0 \%$ \\
\cline { 2 - 7 } & 4 & $14.2 \%$ & $26.1 \%$ & $19.4 \%$ & $26.1 \%$ & $14.2 \%$ \\
\cline { 2 - 7 } & 5 & $14.4 \%$ & $25.9 \%$ & $19.5 \%$ & $25.9 \%$ & $14.4 \%$ \\
\cline { 2 - 7 } & 6 & $14.5 \%$ & $25.7 \%$ & $19.6 \%$ & $25.7 \%$ & $14.5 \%$ \\
\hline
\end{tabular}

As the height of the posts for bents 3, 4, 5, 6 in bridge 5.1 increases respectively in that order, the load is distributed more evenly among the posts. This is likely due to the taller posts deflect more, thus allowing for a more even bearing of the cap beam on all posts. The average measured field microstrain was -72 , which is higher than the average theoretical strain value of -40 microstrain which can be due to the majority of the gaged posts being decayed, and uneven bearing from the cap onto the posts which was a common finding in the field. The posts on bent 3 and 4 for bridge 5.1 were not decayed and sustained 
an average of -45 microstrain, with a predicted theoretical value of -43 microstrain. This tells us that decay in the posts can possibly be detected using strain data, but the spread of strain value among decayed posts goes from -6 to -171 , thus not providing a base to quantify and identify decayed members. A gage was installed on the north face of post 3 on bent 4 of bridge 1.9 together with a gage on the west face (gage C-B4-P3w) so that potential bending in the posts could be detected during loading. A difference of only 6 microstrain between the two gages showed that the strain data in the posts is only due to axial compression, if bending was occurring one of the gages would read considerably higher strains and could have been the reason of higher strains in Table 21.

The load distribution from Table 21 is fairly close to that provided by AREMA for all the 5 post bents. For 4 post bents, the RISA model should be used. The location of strain gages in the field were first installed to simply compare decayed posts to sound posts, because too many posts were found to have some level of decay. A field test on a bent with posts and other members in good conditions should be performed solely to gather load distribution data, but proper geometry and bearing of cap beam/posts/sill interfaces need be provided.

\subsubsection{Steel Bending Moment}

Uniaxial strain gages were installed at midspan on the top and bottom flanges of span 1 and top flanges of span 2 of bridge 1.4, as well as on the bottom flanges of both girders of bridge 5.8. Gages were also installed near midpsan on a floorbeam and stringer to gather bending strain data. Table 22 shows the average maximum measured field strains for a hi-rail dump truck moving load at crawl speed. The gage for girder 1 on span 2 of bridge 1.4 failed during testing.

Table 22 - Field Measured Bending Strains in Steel Bridges (microstrain)

\begin{tabular}{|c|c|c|c|c|c|c|c|}
\hline Bridge & Span & Member & Location & Gage & $\begin{array}{l}\text { Average } \\
\text { Field Strain }\end{array}$ & $\begin{array}{l}\text { Theoretical } \\
\text { Microstrain }\end{array}$ & Difference \\
\hline \multirow{7}{*}{1.4} & \multirow{6}{*}{1} & Stringer & Bottom & B-S1C-S1C & 49 & 77 & $57 \%$ \\
\hline & & Floorbeam & Bottom & B-S1c-Fc & 72 & 104 & $45 \%$ \\
\hline & & \multirow{2}{*}{ Girder 1} & Top & B-S1c-G1t & -39 & -39 & $0 \%$ \\
\hline & & & Bottom & B-S1c-G1b & 37 & 39 & $7 \%$ \\
\hline & & \multirow{2}{*}{ Girder 2} & Top & B-S1c-G2t & -37 & -39 & $7 \%$ \\
\hline & & & Bottom & B-S1c-G2b & 38 & 39 & $5 \%$ \\
\hline & 2 & Girder 2 & Top & $B-S 2 c-G 2 t$ & -39 & -39 & $1 \%$ \\
\hline \multirow{2}{*}{5.8} & \multirow{2}{*}{1} & Girder 1 & Bottom & B-S1c-G1b & 91 & 141 & $55 \%$ \\
\hline & & Girder 2 & Bottom & B-S1c-G2b & 91 & 141 & $55 \%$ \\
\hline
\end{tabular}


The strain values for the top and bottom flanges of the girders in span 1 of bridge 1.4 shows that the neutral axis for the girders is located at mid depth as the strains are only off by 1 or 2 microstrain. The average bending strain for the girders are 38 and 91 for bridge 1.4 and 5.8 respectively, thus showing that the smaller girders in bridge 5.8 are less stiff. The fact that the neutral axis is located at mid girder depth for bridge 1.4 helps predict better strain values through modeling. Modeling the girders alone as simple beams would generate large conservative theoretical values, so a 3D model including all the floorbeams and stringers was created in RISA 3D as shown in Figure 60. The floorbeams were fixed to the web plates of the girders and the stringers to the webs of the floorbeams. The axle loads were equally divided and applied to the stringers, which then transferred the load onto the floorbeams, and consequently onto the girders. The girders rest on pinned supports on the north end, and roller supports on the south end as they do in the field. The theoretical values predicted the girder bending strains by a difference of 1 microstrain, but were about twice higher for the floorbeam and stringer which is probably due to the girders carrying the majority of the loads in the field.

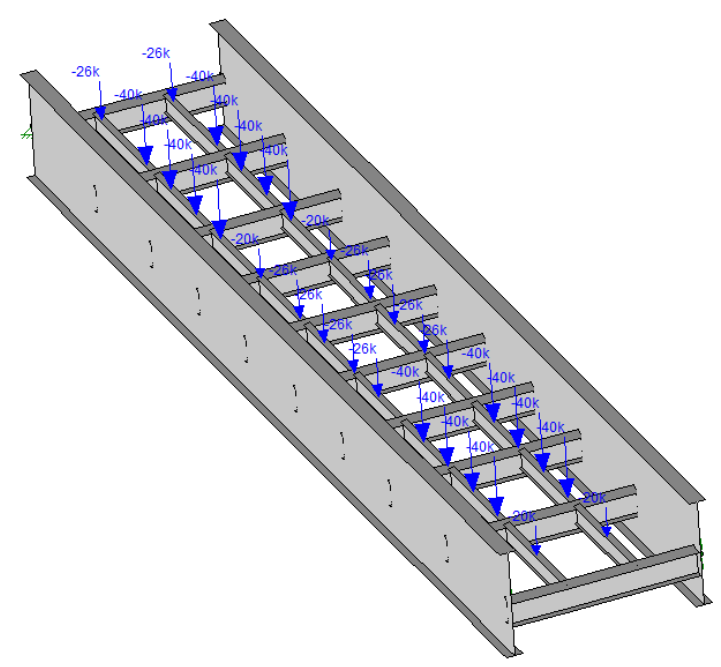

Figure 60 -3D RISA Model of Bridge 1.4 Span 1 with Cooper E 80 Load

The theoretical bending strains for bridge 5.8 were also twice as much as the measured field values. This probably due to the modeling of 5.8 as two simply supported beams, not accounting for the end cross bracing at span ends and the potential contribution of the tracks and larger ties to the smaller size of this bridge. The contribution of the track and other components is ignored during load testing as this approach provides a factor of safety in design. 


\subsubsection{Steel Shear}

During the hi-rail drump truck test of bridge 1.4, strain gages were also installed near the supports of girders and 30 to 36 inches away from the support. Another gage was installed in the first floorbeam right by the north support of bridge 1.4. Table 23 compares measured field shear strains to theoretical shear strain values generated using the 3D model used for bending strain prediction.

Table 23 - Field Measured Shear Strains in Steel Bridges (microstrain)

\begin{tabular}{|c|c|c|c|c|c|c|c|}
\hline & Span & Member & Location & Gage & $\begin{array}{l}\text { Average } \\
\text { Field Strain }\end{array}$ & $\begin{array}{l}\text { Theoretical } \\
\text { Microstrain }\end{array}$ & Difference \\
\hline \multirow[t]{2}{*}{1.4} & \multirow[t]{2}{*}{1} & Floorbeam & $\begin{array}{l}\text { North end, west } \\
\text { side }\end{array}$ & S-S1n-Fs & 69 & 124 & $80 \%$ \\
\hline & & Girder 2 & 36" from North & S-S1o-G2e & 45 & 51 & $13 \%$ \\
\hline \multirow{4}{*}{5.8} & \multirow{4}{*}{1} & Girder 1 & North end & S-S1n-G1e & 112 & 192 & $71 \%$ \\
\hline & & Girder 2 & North end & S-S1n-G2w & 118 & 192 & $63 \%$ \\
\hline & & Girder 1 & $30 "$ from North & S-S1o-G1e & 106 & 165 & $56 \%$ \\
\hline & & Girder 2 & $30 "$ from North & S-S1o-G2w & 116 & 165 & $43 \%$ \\
\hline
\end{tabular}

The theoretical shear strain for the floorbeam is about $80 \%$ higher than the field measure value of 69 microstrain. The RISA model did not include large triangular stiffeners on the ends of each floorbeam connecting them to the girder web plates. The shear gage for the floorbeam was located right below a stiffener which is deeper than the floorbeam web at that location, does contributing to the shear capacity and resulting in lower than predicted strains. The predicted shear strain for the girder was $13 \%$ higher than the measured field value, which accounts to 6 microstrain and does not affect the stress considerably.

The predicted theoretical values for bridge 5.8 are conservative, similar bending strain prediction, thus contribution of track and other members to the stiffness of the girders is again generating lower measured field values. For load rating purposes, approach is good as it provides a factor of safety.

\subsubsection{Steel Compression}

Through field inspections of bridge 1.4, rust was found in both bottom angles that make the bottom flange of girder 2 on span 1 at the north support. One gage was placed on the vertical leg of the outside angle and another on the vertical leg of the inside angle. The outside angle was less corroded compared to the inside angle, so the gages were placed to monitor any difference in strain due to corrosion levels. 
Figure 61 shows the location of the gages and Table 24 shows the average maximum strain recorder when the hi-rail dump truck moved over the support.

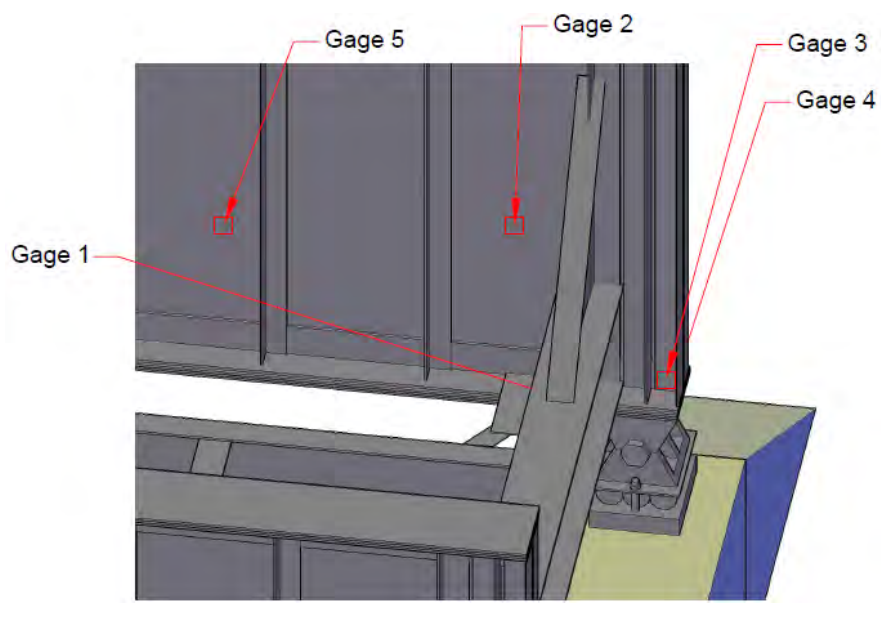

Figure 61 - Location of Strain Gages for Axial Compression Strain (Gage $3=$ outside, Gage $4=$ inside)

Table 24 - Field Measured Compression Strain in Steel Angles (microstrain)

\begin{tabular}{|c|c|c|}
\cline { 2 - 3 } \multicolumn{1}{c|}{} & inside & outside \\
\hline Truck & -73 & -7 \\
\hline Locomotive & -179 & -26 \\
\hline
\end{tabular}

The difference in microstrain show that the girder web plate is bending about the girders longitudinal axis due to the fixed connection between the floorbeam/stiffener and the girder web plate. This information helps verify the fixed connections between members in the 3D model of bridge 1.4. Even if a model could be generated to predict this compression and out of plane bending strains on the web plate, the results would be hard to verify and would be unreliable. Thus, theoretical values were not calculated for this measured field data.

\subsubsection{Locomotive Loading and Comparison to Truck}

The same tests described in the previous section with for bending, shear and compression data were performed using the WM 82 locomotive. Table 25 shows the average maximum strain data of the steel bridges under locomotive loading. Theoretical values have also been calculated using the same models this time with a WM 82 moving load. As expected, all of the strain values for both the field testing and the models are higher than those of a hi-rail dump truck loading. The far right column in Table 25 shows 
the ratio of locomotive strain to truck strain. Table 26 shows the average maximum strain data of the timber bridges under locomotive loading, with values calculated the same way as the values in Table 25 .

Table 25 - Field Measured Strains in Steel Bridges with WM 82 Locomotive Loading (microstrain)

\begin{tabular}{|c|c|c|c|c|c|c|c|c|}
\hline Bridge & Span & Member & Location & Gage & $\begin{array}{c}\text { Average } \\
\text { Field } \\
\text { Strain }\end{array}$ & $\begin{array}{l}\text { Theoretical } \\
\text { Microstrain }\end{array}$ & Difference & $\begin{array}{c}\text { Ratio to } \\
\text { Truck } \\
\text { Strain }\end{array}$ \\
\hline \multirow{7}{*}{ Bending } & \multirow{6}{*}{1} & Stringer & Bottom & B-S1C-S1C & 75 & 69 & $-7 \%$ & 1.53 \\
\hline & & Floorbeam & Bottom & B-S1c-Fc & 138 & 197 & $43 \%$ & 1.93 \\
\hline & & \multirow[b]{2}{*}{ Girder 1} & Top & B-S1c-G1t & -106 & -108 & $2 \%$ & 2.70 \\
\hline & & & Bottom & $\begin{array}{c}\text { B-S1c- } \\
\text { G1b }\end{array}$ & 97 & 108 & $12 \%$ & 2.63 \\
\hline & & \multirow[b]{2}{*}{ Girder 2} & Top & B-S1c-G2t & -95 & -108 & $13 \%$ & 2.58 \\
\hline & & & Bottom & $\begin{array}{c}\text { B-S1c- } \\
\text { G2b }\end{array}$ & 102 & 108 & $6 \%$ & 2.72 \\
\hline & 2 & Girder 2 & Top & B-S2c-G2t & -100 & -106 & $6 \%$ & 2.59 \\
\hline \multirow{2}{*}{ Shear } & \multirow{2}{*}{1} & Floorbeam & $\begin{array}{l}\text { North end, } \\
\text { west side }\end{array}$ & S-S1n-Fs & 135 & 194 & $44 \%$ & 1.96 \\
\hline & & Girder 2 & $\begin{array}{l}36 " \text { from } \\
\text { North }\end{array}$ & $\begin{array}{l}\text { S-S1o- } \\
\text { G2e }\end{array}$ & 128 & 145 & $14 \%$ & 2.83 \\
\hline
\end{tabular}

The average measured locomotive to truck strain ratio for the steel girders is 2.7 and 2.8 for bending and shear respectively. The ratios for the theoretical values are 2.7 and 2.9 respectively, thus accurately being able to prorate the truck measured stains of bridge 5.8 to locomotive strains. The floorbeam has ratios of equal ratios of 1.9 for both field measured and theoretical strains. The shear strain ratio is 1.9 for measured strain and 1.5 for theoretical strains, which is most likely due to not accounting for the triangular stiffeners at both ends of the floorbeam during analysis. The stringers bending strain was measure at the connection with the floorbeam, which in part is connected at the top to the triangular stiffener, thus generating a theoretical locomotive to truck ratio of 0.9 compared to 1.5 measured. 
Table 26 - Field Measured Strains in Timber Bridges with WM 82 Locomotive Loading (microstrain)

\begin{tabular}{|c|c|c|c|c|c|c|c|}
\hline Bridge & Span & Stringer & Gage & $\begin{array}{c}\text { Average } \\
\text { Field } \\
\text { Strain } \\
\end{array}$ & $\begin{array}{l}\text { Theoretical } \\
\text { Microstrain }\end{array}$ & Difference & $\begin{array}{c}\text { Ratio to } \\
\text { Truck } \\
\text { Strain } \\
\end{array}$ \\
\hline \multirow{4}{*}{ Bending } & \multirow{4}{*}{5} & 1 & B-S5c-S1t & -328 & -388 & $18 \%$ & 1.57 \\
\hline & & 4 & B-S5c-S4t & -210 & -388 & $85 \%$ & 1.83 \\
\hline & & 5 & B-S5c-S5t & -219 & -388 & $77 \%$ & 2.18 \\
\hline & & 8 & B-S5c-S8t & -290 & -388 & $34 \%$ & 1.77 \\
\hline \multirow{8}{*}{ Shear } & \multirow{2}{*}{1} & 1 & S-S1s-S1e & 43 & 649 & $1407 \%$ & 2.46 \\
\hline & & 8 & S-S1s-S8w & 392 & 649 & $66 \%$ & 1.75 \\
\hline & \multirow{4}{*}{3} & 1 & S-S3s-S1e & 212 & 698 & $230 \%$ & 1.89 \\
\hline & & 4 & S-S3s-S4w & 665 & 698 & $5 \%$ & 2.05 \\
\hline & & 5 & S-S3s-S5e & 101 & 698 & $592 \%$ & 1.84 \\
\hline & & 8 & S-S3s-S8w & 613 & 698 & $14 \%$ & 1.92 \\
\hline & \multirow{2}{*}{5} & 1 & S-S5s-S1e & 473 & 866 & $83 \%$ & 1.68 \\
\hline & & 8 & S-S5s-S8w & 230 & 866 & $277 \%$ & 1.99 \\
\hline \multirow{3}{*}{$\begin{array}{c}\text { Axial } \\
\text { (Posts) }\end{array}$} & \multirow{2}{*}{4} & 1 & C-B4-P1e & -160 & -57 & $-65 \%$ & 2.00 \\
\hline & & 3 & C-B4-P3w & -31 & -122 & $288 \%$ & 2.95 \\
\hline & 7 & 5 & C-B7-P5w & -218 & -57 & $-74 \%$ & 2.48 \\
\hline
\end{tabular}

Table 26 shows the measured strain for locomotive loading of bridge 1.9 and comparisons to the truck generated strains. The average ratio for timber bridge measured bending, shear, and compression strain are $1.8,1.9$, and 2.5 , and $1.2,1.4$, and 1.7 for theoretical ratios respectively. High variability in decay in the members, and the stiffness contribution of the track are key factors in not been able to estimate proper ratios through modeling.

\subsubsection{Deflection Measurements}

Gross deflection data at midspan of different spans for the timber bridges were obtained during load testing for both the truck and locomotive. The values in Table 27 are gross deflection values which include support movement. The values are scaled to E80 based on the moment ratios, and the AREMA limit of $\mathrm{L} / 250$ is presented as a reference limit. 
Table 27 - Timber Bridge Deflection Measurements (inches)

\begin{tabular}{|c|l|l|l|l|}
\hline \multirow{2}{*}{ Load } & Bridge & Average & $\begin{array}{c}\text { Scaled } \\
\text { to E80 }\end{array}$ & $\begin{array}{c}\text { AREMA } \\
\text { Limit }\end{array}$ \\
\hline \multirow{4}{*}{ Truck } & 1.9 West & 0.151 & 0.232 & 0.425 \\
\cline { 2 - 5 } & 4.3 East & 0.270 & 0.508 & 0.568 \\
\cline { 2 - 5 } & 4.3 West & 0.205 & 0.386 & 0.568 \\
\cline { 2 - 5 } & 5.1 East & 0.199 & 0.358 & 0.536 \\
\cline { 2 - 5 } & 5.1 West & 0.211 & 0.379 & 0.536 \\
\hline \multirow{2}{*}{ WM82 } & 1.9 East & 0.320 & 0.420 & 0.425 \\
\cline { 2 - 6 } & 1.9 West & 0.333 & 0.437 & 0.425 \\
\hline
\end{tabular}

The AREMA limit is based on the net chord deflection, not the gross deflection. However, scaling the gross truck deflection to an E80 equivalent does not exceed the AREMA limits. The scaled values for the WM82 exceed the AREMA limit, but they include support movement which is always higher than the net chord deflection. LVDTs were installed near each support for the span being tested on bridge 1.9 , and after subtracting the support vertical movement from the gross mid span deflections, net chord deflections of 0.016 and 0.059 inches were determined for the truck and locomotive respectively. When these values are scaled to E 80, they are well below the AREMA limit for net chord deflection, thus far exceeding $\mathrm{E} 80$ rating for deflection.

Table 28 shows the measured deflections at mid span for the girders in span 1 of bridge 1.4 and girder 1 of bridge 5.8 (girder two readings erroneous).

Table 28 - Steel Bridge Deflection Measurements and Predicted Values (inches)

\begin{tabular}{|c|c|c|c|c|c|c|}
\hline Load & Member & $\begin{array}{c}\text { Field } \\
\text { Average }\end{array}$ & Predicted & Difference & $\begin{array}{c}\text { Scaled } \\
\text { to E 80 }\end{array}$ & $\begin{array}{c}\text { AREMA } \\
\text { Limit }\end{array}$ \\
\hline \multirow{3}{*}{ Truck } & 1.4 Girder 1 & 0.101 & 0.121 & $20 \%$ & 0.93 & 1.819 \\
\cline { 2 - 7 } & 1.4 Girder 2 & 0.116 & 0.121 & $4 \%$ & 1.07 & 1.819 \\
\cline { 2 - 7 } & 5.8 Girder 1 & 0.042 & 0.045 & $8 \%$ & 0.13 & 0.33 \\
\hline \multirow{2}{*}{ WM82 } & 1.4 Girder 1 & 0.299 & 0.362 & $21 \%$ & 1.00 & 1.819 \\
\cline { 2 - 7 } & 1.4 Girder 2 & 0.344 & 0.362 & $5 \%$ & 1.15 & 1.819 \\
\hline
\end{tabular}

The predicted values over predicted deflections by an average of $12 \%$, with the highest difference being $21 \%$ and lowest $4 \%$. The steel bridge models and assumed steel properties produce considerably accurate results for deflection. The highest recorded deflection when scaled to a Cooper $E 80$ value, is still 0.67 inches (37\%) under the AREMA limit. The deflection of the floorbeam at midspan of span 1 on 
bridge 1.4 was also recorded, with a gross deflection equal to that of the girders which equates to a zero net deflection.

\subsection{Field Testing Conclusions}

For bending, shear and compression in the timber bridges, the field values are less than those predicted via the AREMA analysis methods. The field shear data varies considerably, but has a stable average regardless of the loading condition. The compression data is greater than the AREMA computations, but is acceptable given the excess capacity in the posts. The data shows there is sufficient excess capacity in the bridges as the predicted strains are substantially higher than the average field measurements. The prorated net chord live load deflection was roughly one quarter of the AREMA limits. Taken together, the field data shows that for these structures, the AREMA analysis methods provide a high factor of safety for good members, and a reasonable safety level for damaged members. The field strain data and the analysis approach did not allow to properly quantify and identify the extent of decay in the timber members, so recommendations on repair need to be made based on field inspection findings.

A full 3D frame model with 1D element for Bridge 1.4 should be used for the analysis to properly account for the end conditions of the members. The shear in the floor beams and bending strain in the stringers do not predict well, but the prediction is typically conservative and can be used with confidence. Large triangular stiffeners, as seen in Figure 62, are riveted to the top flange of the floor beams on both ends, and are also riveted to the web plates of the through girders (depth of the triangular stiffener is about half the depth of the girders). These triangular stiffeners add extra stiffness to the floor beams when in bending, and they also carry part of the shear load on the floor beams. Since bending field strain in the stringer was measured at the stringer end where it connects to the floor beam, the triangular stiffeners are also providing extra stiffness to the stringer (the bending response at the connection is difficult to model). 


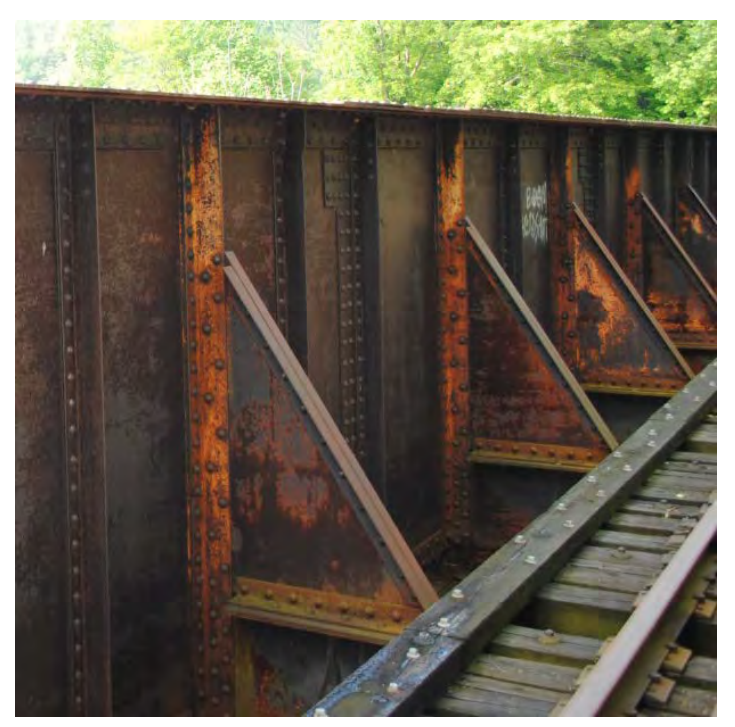

Figure 62 - Triangular Stiffeners on Floor Beam Top Flanges (Bridge 1.4)

The locomotive/truck ratios matched theoretical ratios well for the Bridge 1.4, providing a high degree of confidence in the analysis and field measurements. Bridge 5.8 did not match the finite element analysis data as well, with field measurements lower than those predicted by analysis. Therefore it is indicating that there is excess strength and stiffness in the system due to indeterminacy from connection details. The load capacity of these bridges is well established, and only recommendations for proper maintenance and cleanliness should be made as they have sufficient strength and little corrosion. 


\section{Load Analysis}

A thorough analysis was performed in order to load rate each bridge according to rail road standard known as Cooper E rating. Each structure was also analyzed under the loads of two consecutive coupled 286 kips rail cars, two GP38 locomotives, and two Western Maryland 82 (WM 82) locomotives. The load rating of the timber bridges followed AREMA's recommended approach of semi-continuous analysis. Bridge 1.4 was load rated using a 3D model of the floor beams, stringers and girder together, while bridge 5.8 was modeled trough single beam simple span analysis. All bending, shear, and compression values were obtained through RISA modeling, and load ratings were computed using a spreadsheet as given in Appendix 1.

\subsection{Analysis Assumptions and Approach}

\subsubsection{Timber Span Configuration}

A Wisconsin DOT (2006) study load rated timber bridges with semi-continuous design assuming simple span analysis. AREMA recommends otherwise by computing the average of both a simple and continuous span analysis for all stresses. Field data helped verify these assumptions in this report. Gages 3 and 5 were installed near simple supports on stringers 1 and 5, and gages 4 and 6 were installed near the middle support of continuous span stringers 4 and 8 for bridge 1.9 as shown in Figure 62 .

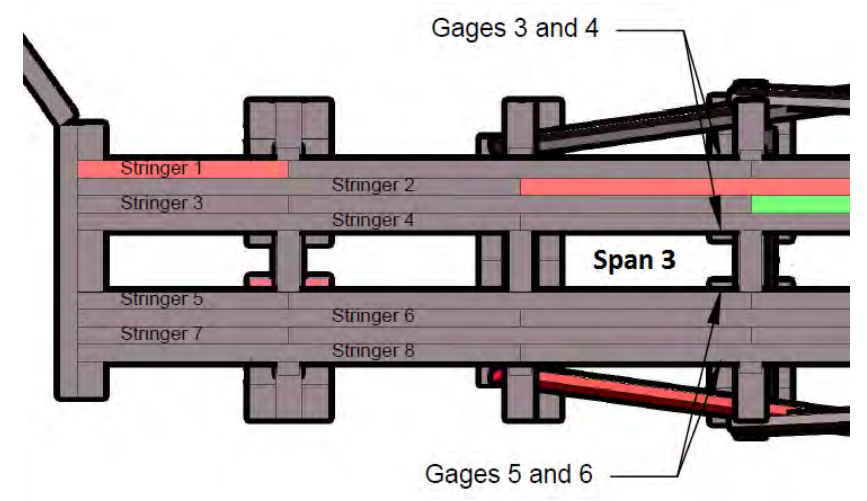

Figure 63 - Shear Gage Location on Bridge 1.9 Span 3 


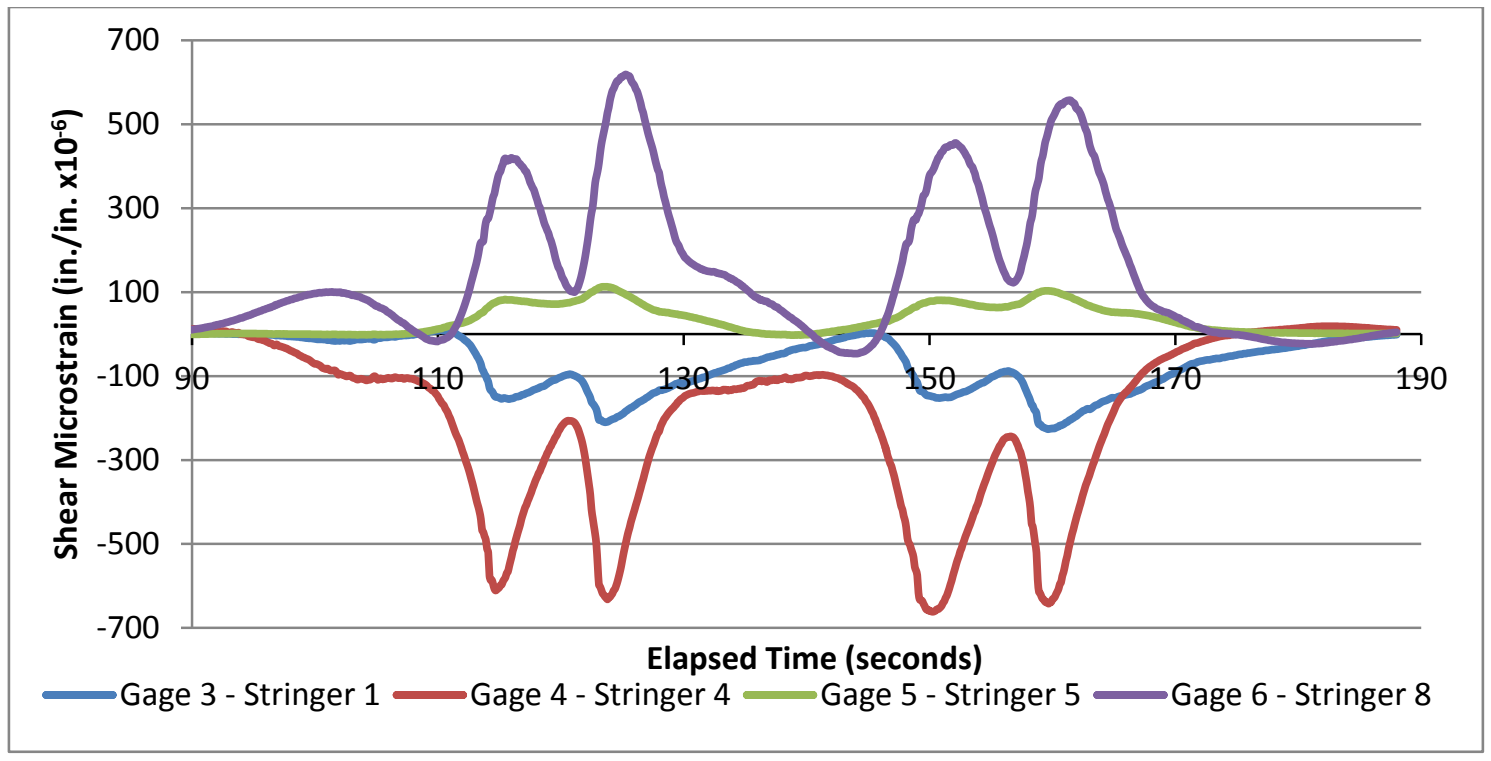

Figure 64 - Shear Microstrain Response of Timber Stringers (Bridge 1.9, WM82 Test 2)

Shear strain data in Figure 63 (gages 3, 4, 5, and 6) shows that shear strain is higher near the middle supports of a continuous span than at the ends of simple spans, which in theory is correct, thus verifying the AREMA assumption for semi-continuous analysis.

\subsubsection{Post Load Distribution}

Section A3.2 of AREMA 2014 manual provides pile design aids that closely match the load distribution to the posts determined in section 4.2 .3 of this report for 5 post bent. When dealing with the 4 post bents in bridge 1.9, the spacing of the posts does not match the aids provided in AREMA. Therefore, RISA derived distributions should be used. Figure 64 shows the parameters needed to calculate the load distribution using AREMA's pile design aids. 


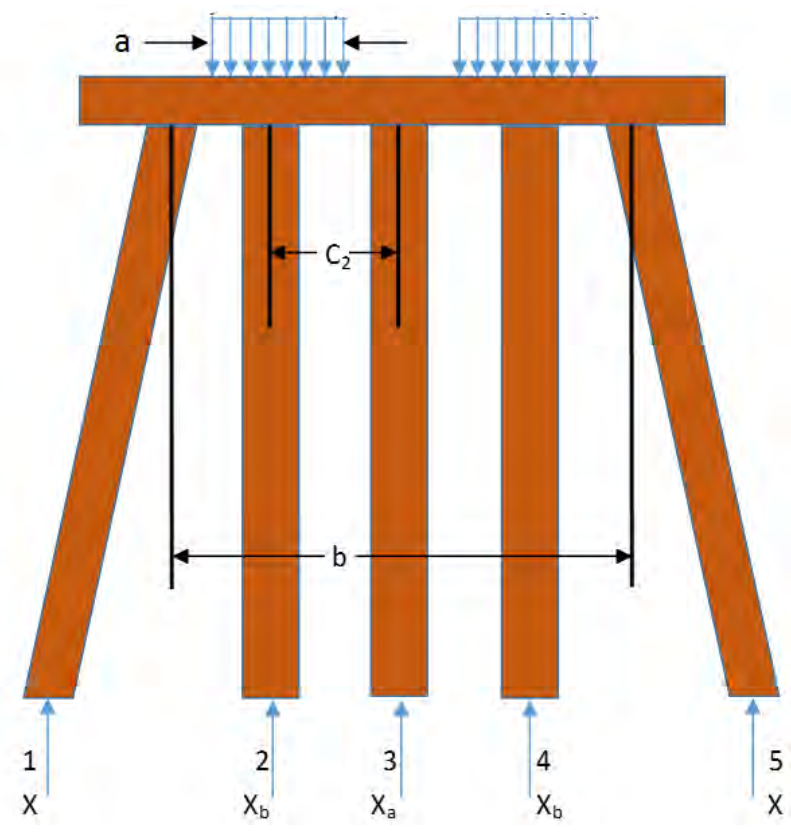

Figure 65 - Properties to Determine Load Distribution to Posts Using AREMA Design Aids

\subsection{Load Ratings}

Based on the field inspections and testing, load rating was completed using AREMA procedures for all bridges. The full calculations are included in appendix 1 for all bridges. The load rating capacity is the Cooper E rating structural capacity limit for the bridges, which needs to be higher than the equivalent Cooper E load expected on the bridges.

\subsubsection{Bridge 1.4 Analysis}

Bridge 1.4 was load rated using the 3D model shown in Figure 60 of Section 4.2.4 of this report. Fatigue ratings did not need to be assigned to the steel bridges as per AREMA, because the expected traffic on the line is less than 5 million gross tons per year. Also, no details on the steel bridges were found to be less than fatigue Category $D$, thus fatigue ratings are not necessary.

Table 29 - Bridge 1.4 Load Ratings

\begin{tabular}{|c|l|c|c|c|c|c|}
\hline \multirow{2}{*}{ Member } & \multirow{2}{*}{ Type } & \multicolumn{2}{|c|}{ Cooper E Rating Capacity } & \multicolumn{3}{|c|}{ Equivalent Cooper E Load } \\
\cline { 3 - 7 } & & Normal & Maximum & $286 k$ & GP38 & WM82 \\
\hline \multirow{2}{*}{ Stringers } & Bending & E 74 & E 108.9 & E 61.9 & E 48.6 & E 45.1 \\
\cline { 2 - 7 } & Horz. Shear & E 80 & E 138.7 & E 60.7 & E 42.2 & E 39.2 \\
\hline \multirow{2}{*}{ Floorbeams } & Bending & E 69.6 & E103.1 & E 59.4 & E 34.2 & E 32.1 \\
\cline { 2 - 7 } & Horz. Shear & E 102.2 & E 177.8 & E 60.1 & E 34.8 & E 32.3 \\
\hline $\begin{array}{c}\text { Plate } \\
\text { Girders }\end{array}$ & Bending & E 84.8 & E 132.2 & E 51.7 & E 34 & E 32.1 \\
\cline { 2 - 7 } & Horz. Shear & E 110 & E 196.5 & E 47.2 & E 34.2 & E 32.3 \\
\hline
\end{tabular}


Even though the floor beams and the stringers do not rate as E80 under bending, the rating does meet all of the equivalent loads expected on the bridge, which is the targeted live load capacity.

\subsubsection{Bridge 5.8 Analysis}

Bridge 5.8 was load rated using simple beam analysis. The simplicity of design compared to bridge 1.4 makes it easier to model the response of this bridge, but the approach is still slightly conservative as shown in the field testing results.

Table 30 - Bridge 5.8 Load Ratings

\begin{tabular}{|c|c|c|c|c|c|}
\hline DB 5.8 & \multicolumn{2}{|c|}{ Cooper E Rating } & \multicolumn{3}{|c|}{ Equivalent Cooper E Load } \\
\hline Load Effect & Normal & Maximum & $286 \mathrm{k}$ & GP38 & WM82 \\
\hline Bending & 73.5 & 113.8 & 60.7 & 33.2 & 30.8 \\
\hline Horz. Shear & 76.8 & 133.7 & 60.8 & 40.3 & 37.4 \\
\hline
\end{tabular}

The normal rating is below $\mathrm{E} 80$ capacity, but the rating well meets the capacity needed for the expected live load on the line. E 80 is only a general standard rating value for main rail road lines, and it does not deem the bridge to be structurally deficient as it meets the expected live load.

\subsubsection{Timber Bridge Analysis}

All timber bridges were analyzed using AREMA recommended semi-continuous design approach. All stringers and posts in each bridge were analyzed and rated individually, and the lowest rated member per bridge was used as the overall bridge rating value. The equivalent Cooper E loads chosen were the maximum generated in each bridge. Table 31 provides a summary of the load ratings for timber bridges along with the equivalent Cooper E loads for a 286 kip rail car, a GP38 locomotive and a WM82 locomotive. 
Table 31 - Timber Bridge Load Ratings

\begin{tabular}{|c|l|c|c|c|c|c|}
\hline \multirow{2}{*}{ Bridge } & \multirow{2}{*}{ Type } & \multicolumn{2}{|c|}{ Cooper E Rating } & \multicolumn{3}{c|}{ Equivalent Cooper E Load } \\
\cline { 3 - 7 } & & Regularly Assigned & Not Regularly Assigned & 286K & GP38 & WM82 \\
\hline \multirow{3}{*}{1.9} & Bending & E 107.9 & E 128.2 & E 78.7 & E 67.5 & E 61.6 \\
\cline { 2 - 7 } & Horz. Shear & E 78 & E 92.8 & E 71.2 & E 62.1 & E 57.6 \\
\cline { 2 - 7 } & Axial (Post) & E 156.4 & E 186 & E 60.3 & E 37.3 & E 34.4 \\
\hline \multirow{3}{*}{4.3} & Bending & E 111.8 & E 132.8 & E 78 & E 67.3 & E 61.8 \\
\cline { 2 - 7 } & Horz. Shear & E 78 & E 92.7 & E 66.7 & E 56 & E 51.8 \\
\cline { 2 - 7 } & Axial (Post) & E 124.9 & E 148.6 & E 59.6 & E 37.5 & E 34.8 \\
\hline \multirow{3}{*}{5.1} & Bending & E 107.9 & E 128.2 & E 74.6 & E 64.9 & E 59.6 \\
\cline { 2 - 7 } & Horz. Shear & E 78.1 & E 92.8 & E 67.2 & E 49.8 & E 46.3 \\
\cline { 2 - 7 } & Axial (Post) & E 207.6 & E 246.4 & E 60.8 & E 36.3 & E 33.6 \\
\hline
\end{tabular}

All timber bridges meet the capacity for the expected live loads, assuming deterioration does not worsen rapidly over time. Recommendations will be made in chapter 6 for the repair or replacement of highly decayed members. The load rating values are also produced by the AREMA method in which the average of simple beam and continuous beam analysis is determined, which provides reliable rating values, but a more detailed analysis can help determine the response and capacity of individual members

\subsection{Analysis of Timber Bridges Using More Complex Models}

Five different models were analyzed for all three timber bridges on the Dailey Branch line in order to determine the best rating approach. Deflection and moment values for three new modeling approaches were compared to the AREMA method (average of simple and continuous span analysis results). For all models one 4-stringer chord system was modeled since both chords are symmetrical about the center line of the bridge. The simple and continuous span models (AREMA method) have span lengths as established in the AREMA manual for stress calculations. The other three more complex models have equal span lengths as the continuous span model. The members in all five models have equal height which is the height of the timber stringers in the field. The members in the simple and continuous span models are represented by four elements packed parallel to each other along the length of the spans. Each element has equal dimensions to a single timber stringer in the field. The semi continuous model has 2 members where each member is represented by 2 elements. Both the full semi and parabolic full semi continuous models have 4 members where each member is represented by 1 element. The supports for all 5 models are represented by pinned supports. The properties for the members are those 
for Select Structural Grade Southern Pine species. The major differences among the 5 models can be seen on Table 32.

Table 32 - Analytical Models for Railroad Bridges

\begin{tabular}{|c|c|c|c|c|c|}
\hline Model Type & Continuous & Simple & $\begin{array}{c}\text { Semi } \\
\text { Continuous }\end{array}$ & $\begin{array}{l}\text { Full Semi } \\
\text { Continuous }\end{array}$ & $\begin{array}{c}\text { Parabolic Full } \\
\text { Semi Continuous }\end{array}$ \\
\hline $\begin{array}{l}\text { Elements per } \\
\text { span }\end{array}$ & 1 & 1 & 2 & 4 & 4 \\
\hline End Conditions & Fixed & Hinged & $\begin{array}{l}\text { Hinged and } \\
\text { Fixed }\end{array}$ & Hinged and Fixed & Hinged and Fixed \\
\hline $\begin{array}{c}\text { Connecting } \\
\text { bolts }\end{array}$ & No & No & Yes & Yes & Yes \\
\hline Loads & Centered & Centered & Divided equally & Divided equally & $\begin{array}{c}\text { Parabolic } \\
\text { distribution }\end{array}$ \\
\hline $\begin{array}{c}\text { Model } \\
\text { Complexity per } \\
\text { span }\end{array}$ & $1 \mathrm{E}$ value & $1 \mathrm{E}$ value, 2 hinges & $\begin{array}{l}2 \mathrm{E} \text { values, } 2 \text { hinges, } 1 \\
\text { transverse member, } 1 \\
\text { transverse release }\end{array}$ & $\begin{array}{l}4 \text { E values, } 4 \text { hinges, } 3 \\
\text { transverse members, } 3 \\
\text { transverse releases }\end{array}$ & $\begin{array}{l}4 \text { E values, } 4 \text { hinges, } 3 \\
\text { transverse members, } 3 \\
\text { transverse releases }\end{array}$ \\
\hline $\begin{array}{l}\text { Outputs per } \\
\text { 4-stringer chord }\end{array}$ & 1 & 1 & 2 & 4 & 4 \\
\hline
\end{tabular}

The first 2 models, simple and continuous, are averaged together into one model referenced as "AREMA". This is done following the AREMA recommendation to average the results of a simple span and a continuous span analysis together to produce results for a semi-continuous design (AREMA, 2014). Below is a list describing the 4 final models used for analysis and comparison with measured field values.

1. AREMA: for the continuous span analysis, one single member spans across all spans in a bridge with no releases at the supports, thus loading in one span affects all adjacent spans. The simple span analysis has one member per span, with hinges applied to both ends of each span, thus loading in one span does not affect adjacent spans. For both simple and continuous models, the individual $\mathrm{E}$ values per span for each stringer in the field are to be averaged to generate one value to be assigned to each span. Force and deflection values resulting from the simple and continuous span analysis are then averaged together to provide one value. 
2. Semi Continuous: Two parallel members, with a stringer spacing equal to the width of two elements, are continuous over two spans, every other span as shown in Figure 65 (a). At the end spans, one member will be a simple span, while the other parallel member will be continuous over the next span. This staggered two-span continuous system represents the actual bridge design. The moment of inertia is such that both elements acting together as one member. Hinges are located at both ends of each two-span continuous member. The E values for each stringer per span in the field that are continuous over the same two spans are to be averaged to form one value per member in the model. All spans have a cross member at mid span connecting the parallel set of stringers. The connecting member represents the bolts running through all four stringers at mid height and at mid span in the field. The properties assigned (assumed) to this member are of infinite axial stiffness (EA) and negligible bending stiffness (EI) in order to only transfer shear among the two subsystems. Torsional releases have been applied to the connecting member in order to allow rotation of the stringers at mid spans. Both dead and live loads are divided in half and applied equally to each line at the centerline.

3. Full Semi Continuous: This model represents each member in a 4-stringer chord system, where members 1 and 3 are continuous over the same two spans, and members 2 and 4 are continuous over the same two spans. One member is equal to one element. At one end span members 1 and 3 are simply supported, while members 2 and 4 are simply supported on the opposite end span as shown in Figure 65 (b). This end span condition generates a staggered twospan continuous design with hinges at the ends of the continuous spans. All members have a spacing equal to the width of one element. The $E$ value for each individual stringer per span in the field is to be assigned to its corresponding member in the model. A connecting member is located at mid-span of each span with equal properties to the one used for the semi continuous model. The connecting member is connected to all four members through nodes, with torsional releases in between each member, thus allowing the stringers to rotate freely at mid span. Both dead loads and live loads are divided equally into four and applied to each member at the centerline.

4. Parabolic Full Semi Continuous: This model is equal to the full semi continuous model in all aspects expect for the application of the live load. The live load distribution to each stringer was determined through AREMA 2014 Chapter 7 Appendix 1 Section A1.2, and it was determined that stringers $1,2,3$, and 4 carry $21.42 \%, 24.89 \%, 26.28 \%$, and $27.41 \%$ of the wheel load (half the axle load) respectively. This parabolic distribution of the load is shown in Figure 65(c). 

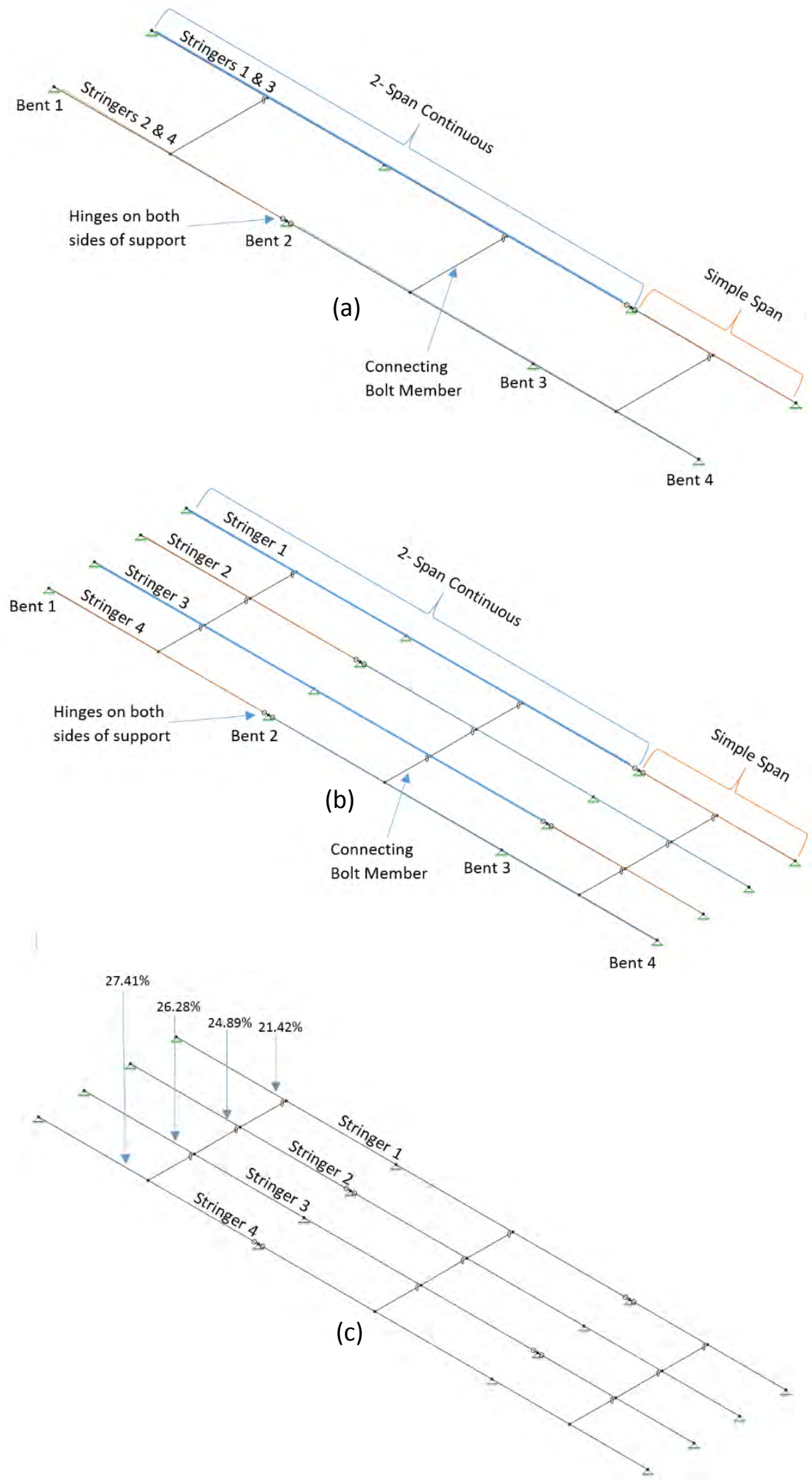

Figure 66 - Bridge 4.3 RISA models for (a) semi continuous, (b) full semi continuous, and (c) parabolic semi continuous analysis 
A uniformly distributed load (dead load) was applied to the entire length of the stringer for all models. The deflection and bending moment values from all 4 models were compared to the AREMA recommended procedure values. For the parabolic and full semi continuous models, the results for each of the 4 stringers on one given span were averaged to provide one value. Stringers for the semi continuous model, the average of the two sets of stringers per span were used. This was completed for all 19 spans, and the percent difference was calculated using the AREMA method as a baseline. The bending moment comparisons are shown in Figure 66 for each span. The comparison shows that the semi, full and parabolic models generally predict a smaller moment than AREMA does. Thus the AREMA method is a more conservative estimate for calculating the strength of the bridge, though using this comparison there is no way to measure its accuracy as there is no comparison to field data. The comparison also shows that the full and parabolic models predict nearly the same values, thus there is no advantage of using the parabolic load distribution if the results are averaged across the stringers. Figure 67 shows similar trends for the deflection predictions, as well.

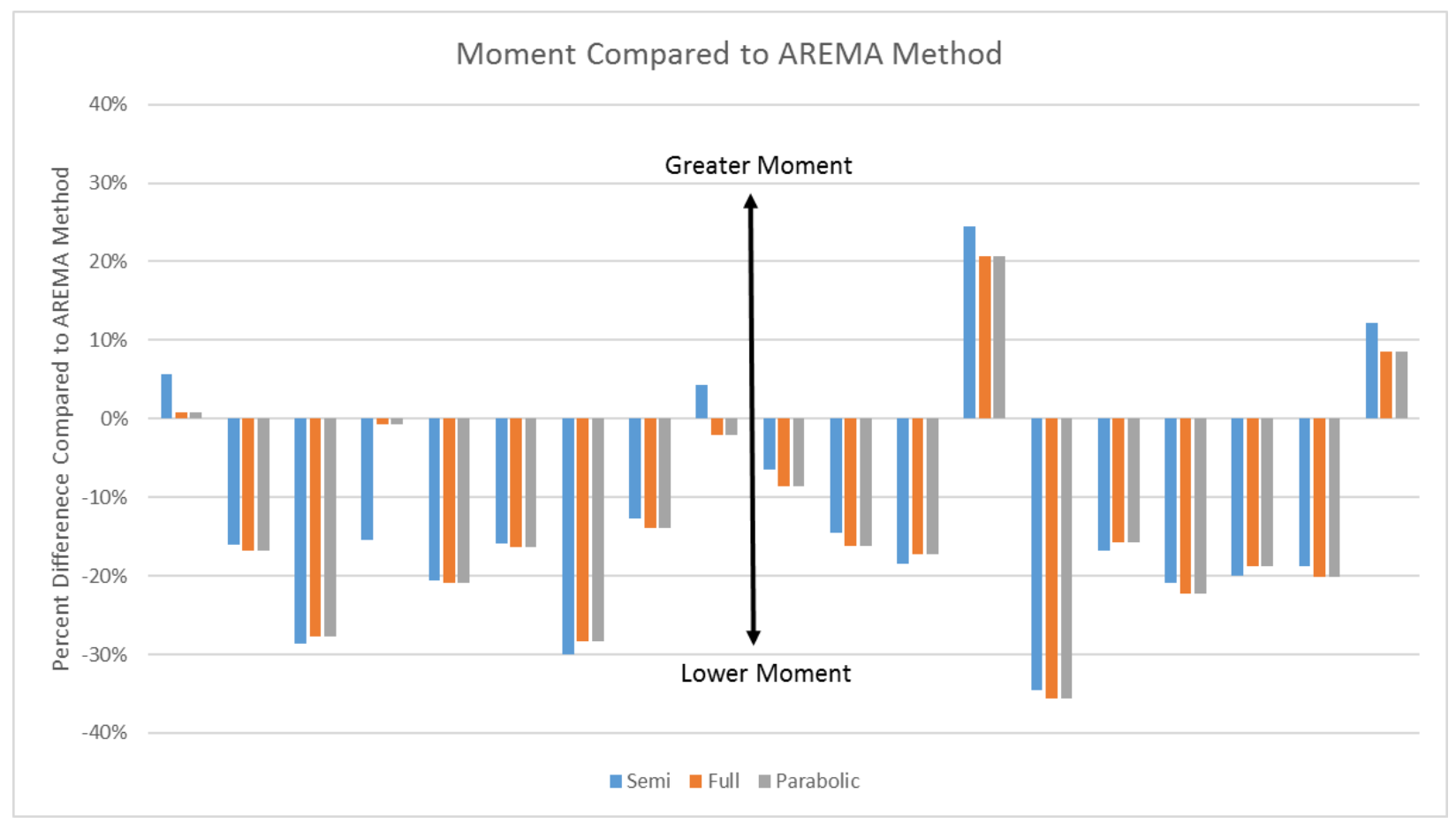

Figure 67 - Comparison between Models and AREMA Predicted Values for Bending Moment 


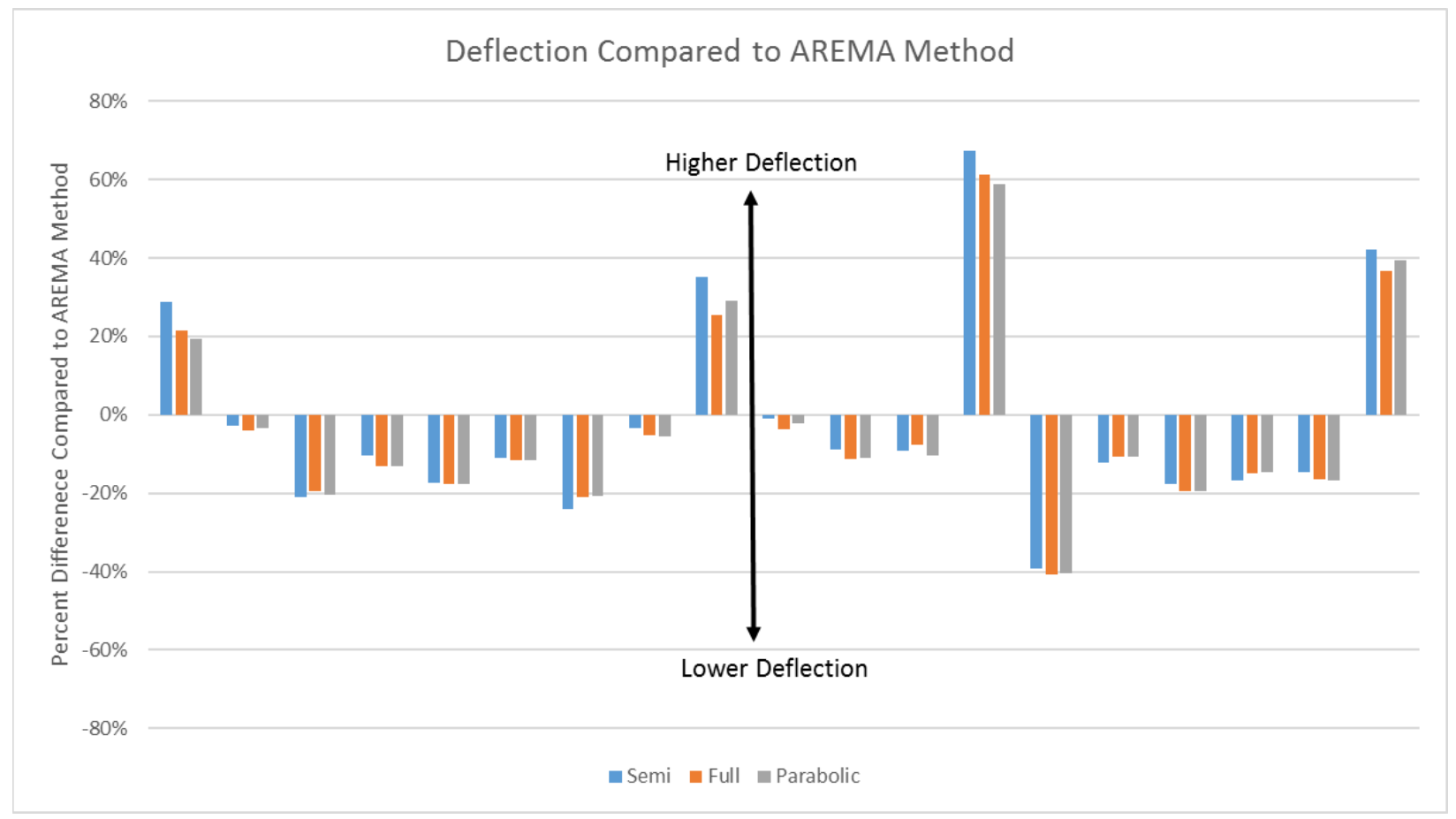

Figure 68 - Comparison between Models and AREMA Predicted Values for Deflection

To determine the accuracy of different models with AREMA results, model data comparisons with field data is needed. Gutkowski's study of timber stringers in Texas provides deflection data points for comparison, whereas the microstrain readings from the truck testing on Dailey Branch can be used to assess the bending moments. Figure 68 shows that the AREMA method predicted greater deflections than measured in the field for 3 of the 4 cases, while the other models split evenly. The AREMA method had an overall average error of about $15 \%$, while the other models had an average error of $11-12 \%$. This suggests that the AREMA model is conservative, i.e. it predicts greater deflections than measured, but with the limited deflection data, no firm conclusions can be made at this stage. 


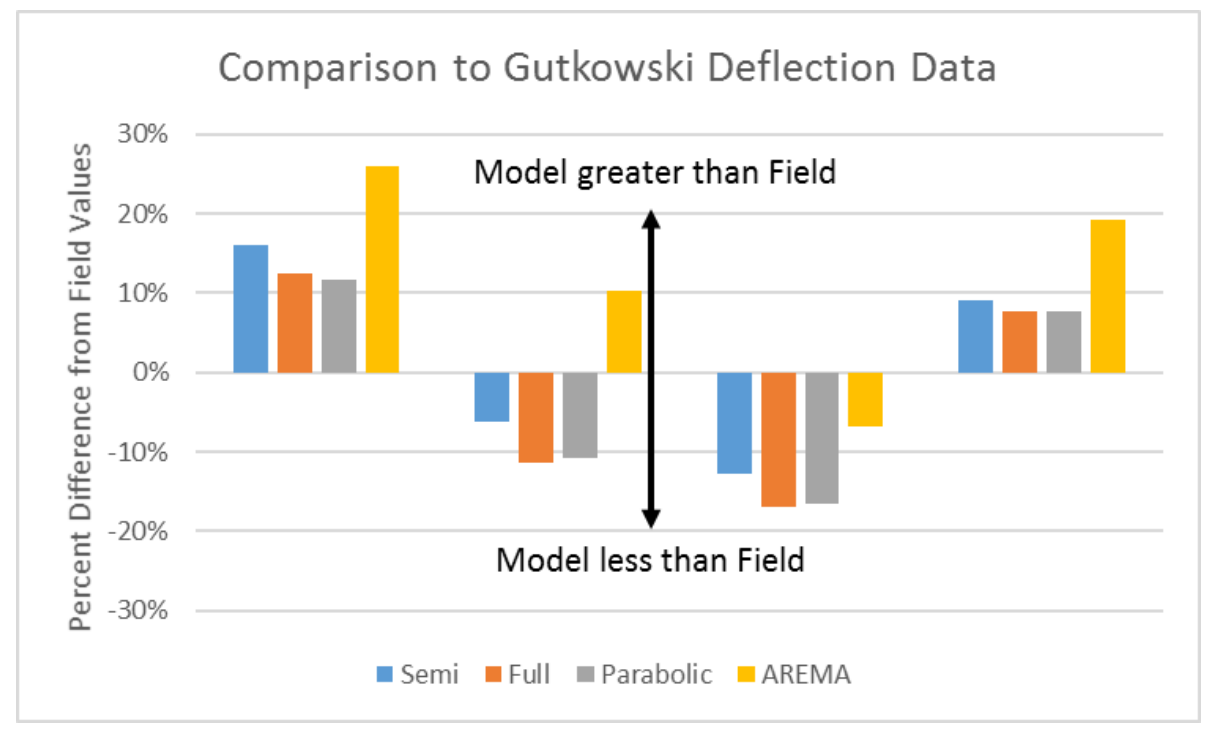

Figure 69 - Comparison to Gutkowski Deflection Data

In terms of the moment predictions, data collected from the Dailey Branch bridges during the truck load testing was compared to each of the 4 models. As shown in Figure 69, the models predict that the moment will be greater than the field measurement for each span except for a single span where the models slightly under predicted. The AREMA method tended to over-predict the moment with the highest value being around $94 \%$ on average. The semi continuous model was off by $87 \%$ while the full and parabolic were off by $80 \%$. On average the semi, full semi, and parabolic full semi continuous models predict values closer to the field measurements when compared to the AREMA approach by $7 \%$, $14 \%$, and $14 \%$ respectively. In other words, the parabolic model being $14 \%$ closer to the field value means an average difference of about 24 microstrain when compared to the AREMA approach. 


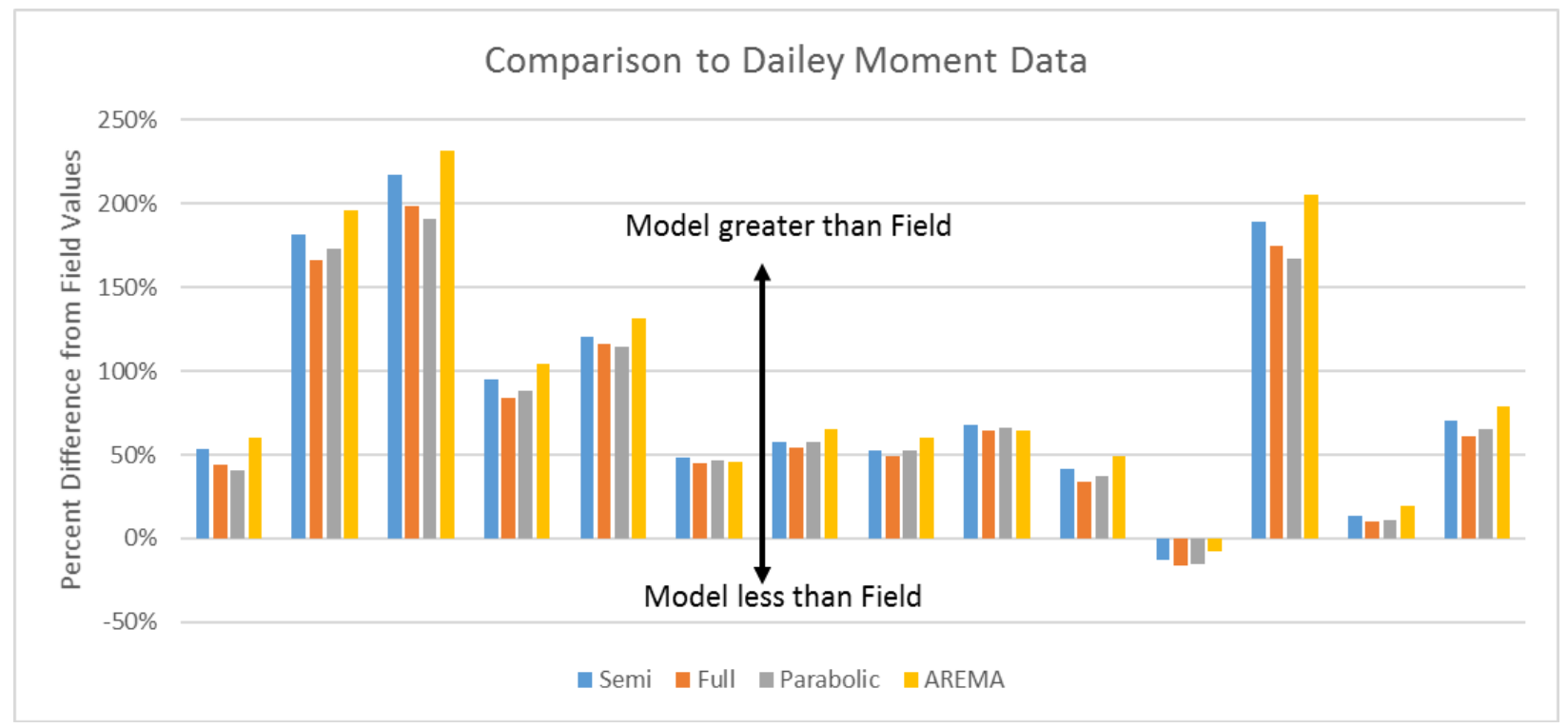

Figure 70 - Comparison to Dailey Moment Data

These results tend to suggest that a different model should be used in place of the AREMA model, and needs more field data for further configuration. In addition, as models get complex, additional variables are added to input into the analysis such as individual E values per stringer, degrees of freedom for each extra member (including transverse members that are non-existent using AREMA approach). In order to obtained individual $E$ values for each stringer on each span, a thorough field assessment needs to be performed as Gutkowski (2001) showed on his research of timber trestle railroad bridges. The connecting bolt member at mid span of each span needs to be properly connected to each stringer including end releases in order to represent field results. The lateral load distribution among stringers has also not being determined and properly studied, so the choice to model the loads as parabolic or uniform is still not clearly based on field analysis. All models, except the simple and continuous analysis for the AREMA approach, are difficult to verify via hand calculations. Being able to verify the simple and continuous span models by hand is an advantage.

The AREMA average approach provides more conservative values, thus recommended for load rating as it always provides a factor of safety in case an individual stringer happens to be overly stressed compared to other stringers in the same span. The semi continuous model is less complex than the full and parabolic models, and provides less conservative values that come closer to the field response of the bridges, thus it can be recommended when performing load tests in the field. The semi continuous model also provides the engineer with less room for mistakes compared to the more complex values since less input provided from the field, such as E values. 


\subsubsection{Superloads}

The complex models provide an advantage if there is a situation where a bridge is going to be subjected to extremely high loads, similar to superloads on highway bridges. In this case, the complex models can provide ratings for each individual member, and not just for the stringer on average. This does require a thorough field assessment of timber railroad bridges and it can be performed obtaining accurate $E$ values for each stringer and ensuring there is no signs of decay. As shown in Table 33, the bending moment from Cooper $\mathrm{E}$ ratings are assigned using three different approaches for bridge 4.3 span 1. Even when using the same $E$ modulus for each member, the ratings between members can vary considerably, as the values in red signify individual members that have an E rating lower than the AREMA calculation for the stringer as a whole.

Table 33 - Comparison of Cooper E Ratings for Bridge 4.3 Span 1 Among 3 Different Models for Bending Moment

\begin{tabular}{|c|c|c|c|c|c|c|}
\hline \multirow{2}{*}{ Stringer } & \multicolumn{3}{|c|}{ Normal } & \multicolumn{3}{c|}{ Maximum } \\
\cline { 2 - 7 } & AREMA & Full & Parabolic & AREMA & Full & Parabolic \\
\hline 1 & E 111.8 & E 116.1 & E 125.1 & E 132.8 & E 137.9 & E 148.6 \\
\hline 2 & E 111.8 & E 131.8 & E 134.2 & E 132.8 & E 156.3 & E 159.2 \\
\hline 3 & E 111.8 & E 99.2 & E 96.2 & E 132.8 & E 117.9 & E 114.4 \\
\hline 4 & E 111.8 & E 114.4 & E 106.6 & E 132.8 & E 135.8 & E 126.6 \\
\hline
\end{tabular}

An engineer can choose to perform a more in depth analysis of each individual stringer using the full semi-continuous models when an individual stinger may provide a lower rating (like stringer 3 in Table 33), and when that specific stringer is highly decayed.

\subsection{Load Analysis Conclusions}

AREMA's method will always provide conservative load ratings using a more simple analysis approach, which can also be verified by hand most occasions. The semi-continuous model is less complex than the remaining models, where average $E$ values per span are sufficient to perform analysis. It also provides more accurate predictions than AREMA's method. Therefore, AREMA's method can be recommended for load rating, while the semi-continuous method can be used when predicting field load testing results.

The more complex full semi-continuous and parabolic full semi-continuous models are more accurate than the other two approaches, but actual field measured $E$ values have to be obtained for each stringer in order for the models to have high accuracy. If using field measured E values, these models can predict 
more accurate field responses to live loads and also produce individual rating values for each stringer. These two models are recommended if individual stringers are to be studied.

The field testing results and the load analysis models were not able to locate, quantify, and predict decay in the timber bridges. A repair plan has to be prepared based on inspection findings alone. 


\section{Cost Benefit Analysis and Repair Plan}

A repair plan for the timber bridges was prepared based on field inspection findings, field testing data and a cost benefit analysis on repair versus replacement. After the field inspection, load testing and analysis of the steel bridges, recommendations for maintenance only were made due to the low levels of corrosion in the steel and the overall strength of the steel bridges. A set of drawings for the timber bridges can be found in the Appendix XX section including summary of inspection, inspection findings, bridge dimensions, repair and replacement recommendations, and summary of materials needed for rehabilitation. Another set of drawings has also been included for steel bridges summarizing inspection findings and recommendations for proper maintenance.

As shown in Chapter 4, the load testing analysis did not provide a basis from which deterioration could be identified and quantified in each member properly. Measured strain values were usually higher than those predicted assuming no deterioration, thus members with softening should be monitored to make sure their condition does not affect their structural integrity. The amount of rot in decayed members was estimated, so non-destructive testing techniques should be employed for the amount of decay to be properly recorded. Members with high levels of surface rot or heart rot shall be replaced or repaired for reasons of safety.

\subsection{Cost Benefit Analysis for Timber Bridge Rehabilitation}

A simple cost benefit evaluation was conducted to compare the feasibility between replacing or repairing the decayed members in the timber bridges. The WVSRA provided WVU-CFC with a quote for timber members that the WVDOT-SRA had received in the 2015 year with a stringer $\left(8^{\prime \prime} \times 16^{\prime \prime} \times 24^{\prime}\right)$ costing $\$ 663.75$. The prevailing wages by the West Virginia Division of Labor for Heavy and Highway Construction Rates is $\$ 25.92$ per hour with $\$ 16.30$ fringe benefits for 2015 for a Class II laborer, which covers the majority of labor duties in all counties. The laborer foreman falls under Class I for an hourly rate of $\$ 26.95$ with $\$ 16.30$ fringe benefits, and the work includes handling creosote and creosoted materials, and working with and handling epoxy materials. Both Class I and II laborers will be needed for FRP railroad repair work. Work related to railroads falls under the Heavy Construction category under the West Virginia Division of Labor.

Based on the WVU-CFC pile wrapping project completed on the SBVR in 2010, the material and supply costs averaged $\$ 3.38$ per square foot. The entire stringer would need wrapped to prevent stress concentrations and maintain constant dimensions along the section. Regardless of whether the stringer 
is replaced or wrapped, it would have to be removed from the structure, as wrapping requires access to all sides of the stringer which is not possible when they are on the bridge. It is assumed that after the stringer is removed, it would take approximately 4 hours total to wrap the pile, including surface preparation work (sanding, rounding edges, filling voids), applying primer, wrapping with at least 2 layers of GFRP, applying protective coatings and installing shims on the other stringers to bring them to the same dimensions as the wrapped stringer. Labor rates are based on Engineering Scientists average salary at WVU along with 3 graduate students, which was the typical crew used to rehab the SBVR piles. Thus the material costs would be $\$ 324$, and the labor costs (including fringe benefits) would be $\$ 368$, totaling $\$ 693$ to wrap a stringer. This does not include costs incurred by the WVDOT-SRA, which is assumed to be needed to help remove/replace the members with extra laborers paid prevailing wages. The cost to repair a stringer with FRP is about $\$ 30$ higher than replacement, so replacement is recommended.

The substructure members are great candidates for repair for many reasons. The substructure members do not need to be removed from the structure in order to wrap it, thus removing the need of temporary shoring that would also be needed if the member was to be replaced. Wrapping does not require heavy machinery that would otherwise require an operator at a higher hourly rate than FRP wrap installers. The railroad line can also remain in service for the duration of the repair since no member will be removed at any given time. Unlike the stringers, wrapping of posts does not require wrapping the entire member. Since non-bearing areas would be wrapped, the geometry of the structure would always remain the same (no shims needed). Posts have all four sides uncovered, and bracing can be removed without any damage to the structures integrity and placed back once wrapping is done. Therefore, all substructure members in need of repair will be recommended for GFRP wrap repair and non-load bearing structures like bracing will be replaced.

\subsection{Rehabilitation Summary of Timber Structures}

Replacement is recommended for stringers based on the cost-benefit analysis that deems the repair cost to be higher when comparing material, labor and machinery costs. The blocking and bracing are also recommended for replacement, blocking due to having to excavate and shim non repaired blocking to meet geometry, and the braces due to cracking at bolt locations where wrapping would not prevent bolt tearing. It is recommended to wrap the posts and sills, as these members are easily wrapped in-situ as done in previous projects by WVU-CFC (cap beam/post joint wrapping). A summary of the number of 
members to be repaired on each structure along with the percent of these members in the structure are presented in Table 34.

Table 34 - Members to be Repaired on each Bridge

\begin{tabular}{|c|c|c|c|c|}
\hline Bridge & Stringers & Posts/Sills & Blocking & Bracing \\
\hline 1.9 & $5(12 \%)$ & $11(32 \%)$ & $5(6 \%)$ & $4(36 \%)$ \\
\hline 4.3 & $6(37 \%)$ & $8(44 \%)$ & $9(30 \%)$ & 0 \\
\hline 5.1 & $4(12 \%)$ & $4(11 \%)$ & 0 & 0 \\
\hline
\end{tabular}

A phenolic-based adhesive mixed with sawdust would be used as filler material for the voids to be filled in posts where heart rot and surface rot has decayed the core of the timber. This filler material was used in the field by Abhari (2007), a successful rehabilitation approach for railroad timber piles in-situ. This combination of sawdust and resin is referred to as bulk material in Table 35 along with the estimated total quantities of GFRP wrap.

Table 35 - Summary of Estimated quantities for Repair

\begin{tabular}{|c|c|c|c|}
\hline Item & Description & Units & Quantity \\
\hline 1 & Glass Fiber Fabric (per layer) & $\mathrm{ft}^{2}$ & 325 \\
\hline 2 & Bulk Filler & gallons & 302 \\
\hline
\end{tabular}

The set of drawings for the timber and steel bridges can be found in the Appendix including all recommendations for repair and maintenance in detail. 


\section{Conclusions and Recommendations}

\subsection{Conclusions}

After summarizing the findings, analyzing the load tests results, and assigning final load ratings to the bridges, the following conclusions are drawn:

- The approaches for all bridges had poor ballast conditions, several ties were highly decayed or had lost bearing underneath, and a few tie spacers showed heart rot.

- The steel bridges were found to be in good condition, with a few locations of minimum rust in bridge 1.4 .

- The timber bridges were in poor condition due to neglect over the years, retaining debris between ties and other pockets in the structure. Softening was found in a few stringers, but only a few had significant rot. The substructure members were in the worst condition, several posts showed both surface and heart rot. Blocking showed rot in many locations. This is most like due to fluctuating water levels that allow for moisture to vary, rot resulting in wood.

- Field testing results showed that analysis and load rating procedures set forth by AREMA are conservative for timber bridges and accurate for steel bridges.

- The spread and randomness in the timber strain data does not allow for decay to be determined or quantified via analysis.

- Not all bridges met the E 80 rating standard under normal rating conditions, but safely met the ratings for the expected vehicles in the line.

- The load distribution among posts set by AREMA is reliable as it was verified through RISA modeling, except for cases like Bent 4 in bridge 1.9 where the middle post seemed to be missing, thus AREMA pile design aids do not provide load distribution information on such case.

- More complex timber bridge models predicted values closer to those during load testing, and the AREMA approach proved safe for load rating.

- A repair plan and cost benefit analysis suggests to repair posts and sills with FRP wrap, and to replace stringers that are highly decayed.

\subsection{Recommendations}

- Non-destructive testing (NDT) should be employed in order to detect the actual extent of rot in timber members where heart rot is detected from sounding or fruiting bodies are present. 
Members with softening should be monitored with NDT equipment so that rot can be detected when it occurs (if it occurs).

- If the full semi continuous and parabolic full semi continuous models are to be analyzed, equipment capable of reading the modulus of elasticity for all timber stringers in the field should be used (recommended for smaller structures with fewer spans).

- Strain gages should be installed in all stringers in one given span, where no decay is present, in order to determine the load distribution among stringers.

- Strain gages should be installed in all posts in a given bent, where little to no decay is present and even bearing is provided among the posts, in order to determine the actual load distribution among posts or piles.

- Large steel structures like bridge 1.4 should be analyzed using 3D models where actual end strain conditions among connecting members (Girder/Floorbem and Floorbeam/Stringer) are used in order to provide more accurate results.

- Spot painting and rust removal, together with periodic maintenance shall help prolong the service life of bridge 1.4 . 


\section{References}

AASHTO. (2014). Manual for Bridge Evaluation . American Association of State Highway and Transportation Officials (AASHTO).

Abhari, R. S. (2007). Rehabilitation of Timber Railroad Bridges Using Glass Fiber Reinforced Polymer Composite. West Virginia University, Civil and Environmental Engineering. Morgantown: West Virginia University.

Administration, U. D. (2015, November 05). Prefrabricated Steel Bridge Systems: Final Report . Retrieved from U.S. Department of Transportation Federal Highway Administration: http://www.fhwa.dot.gov/bridge/prefab/psbsreport03.cfm

American Wood Council. (2014). National Design Specification (NDS) for Wood Construction 2015 Edition. Leesburg: American Wood Council.

Anderson, W. (2012). Will Anderson's Train Art. Retrieved from http://trainweb.org/willstrainart/Train_Art_files/Steam_line/RDGI10/IM1.htm

AREMA. (2014). Manual for Railway Engineering. Lanham: AREMA.

AZoM.com. (2013, June 11). www.azom.com. Retrieved from AZO Materials: http://www.azom.com/article.aspx?ArticleID=764

Bowman, M. D., \& Piskorowski, A. M. (2004). Evaluation and Repair of Wrought Iron and Steel Structures in Indiana. West Lafayette: Purdue University.

Clarke, A. R. (2003). The West Virginia Central and Pittsburg Railway: A Western Maryland Predecessor. TLC Publishing.

Conway, W. B. (2001). Practical Application of the Rating Rules. New Orleans: Modjeski and Masters, Inc.

Corporation, Alaska Railroad. (n.d.). Timber Trestle Bridges in Alaska Railroad History. Anchorage: Alaska Railroad Corporation.

Crook, W. J. (1927). Alloy Steels and Their Uses. Journal of Chemical Education, 4(5), 583.

Donaldson, S. L., \& Miracle, D. B. (2001). ASM Handbook - Composites (10 ed., Vol. 21). ASM International. 
Duwadi, S. R., \& Ritter, M. A. (1997, Winter). Timber Bridges in The United States. Retrieved from http://www.fhwa.dot.gov: http://www.fhwa.dot.gov/publications/publicroads/97winter/p97wi32.cfm

Eby, R. (1986). Timber \& glulam as structural materials, general history. Engineered Timber Workshop, (p. 15). Portland, OR.

Fisher, D. A. (1963). The Epic of Steel. New York: Harper \& Row.

Forest Products Laboratory. (2010). Wood Handbook - Wood as an Engineering Material. Madison: Forest Products Laboratory, United States Department of Agriculture Forest Service.

Fruehan, R. J. (1998). The Making, Shaping and Treating of Steel: Steelmaking and Refining (11 ed., Vol. 2). Pittsburgh: The AISE Steel Foundation.

Gillett, H. W. (1926). High Silicon Structural Steel. Department of Commerce, Bureu of Standards.

Gómez, S., \& Svecova, D. (2008, April 1). Behavior of Split Timber Stringers Reinforced with External GFRP Sheets. Journal of Composites for Construction, 12, 202-211. doi:10.1061/(ASCE)10900268(2008)12:2(202)

Gutkowski, R. M. (2001). Field Load Tests of Open-Deck Timber Trestle Railroad Bridges. Fort Collins: Colorado State University.

Hagos, M. W. (2001). Repair of Heavily Decayed Timber Piles Using Glass Fiber Reinforced Polymers (GFRP) and Cementitious Grout. Civil and Geological Engineering. Winnipeg: University of Manitoba.

Jackson, G., Howard, J., \& Hammett, A. L. (2001). Use and Production of Solid Sawn Timbers in the United States. Forest Products Journal, 51, 24-25.

Jain, R., \& Lee, L. (2012). Fiber Reinforced Polymer (FRP) Composites for Infrastructure Applications. Springer.

Kara, O. E. (2011). Field Testing and Finite Element Analysis for Evaluation of Railroad Bridges. Civil and Environmental Engineering. New Brunswick: Rutgers, The State University of New Jersey.

Laman, J. A., \& Guyer, R. C. (2010). Condition Assessment of Short-line Railroad Bridges in Pennsylvania . University Park: Commonwealth of Pennsylvania Department of Transportation. 
Mallick, P. K. (2007). Fiber-Reinforce Composites: Materials, Manufacturing, and Design (3rd ed.). Boca Raton, FL: CRC Press.

Mee, B., McCown, B., Davids, G. A., \& Nejikovsky, B. (1994). Overview of Railroad Bridges and Assessment of Methods to Monitor Railroad Bridge Integrity. United States Department of Transportation Federal Railroad Administration.

Mohammadi, A., Gull, J. H., Taghinezhad, R., \& Azizinamini, A. (2014). Assessment and Evaluation of Timber Piles Used in Nebraska for Retrofit and Rating. Florida International University, Civil and Environmental Engineering. Miami, FL: Florida International University.

Petersen, R. C. (1984). http://www.fpl.fs.fed.us/documnts/pdf1984/pette84a.pdf.

Ritter, M. A. (1992). Timber Bridges Design, Construction, Inspection, and Maintenance. Washington DC: United States Department of Agriculture, Forest Service.

Saafi, M., \& Asa, E. (2010). Extending the Service Life of Electric Distribution and Transmission Wooden Poles Using a Wet Layup FRP Composite Strengthening System. Journal of Performance of Constructed Facilities, 24, 409-416. doi:10.1061/(ASCE)CF.1943-5509.0000117

Simcoe, C. R. (2014, July 1). Metallurgy Lane: The History of Alloy Steels: Part I. Advanced Materials \& Processes (ASM International), 172(7), 34-35.

Smith, A. W. (2004). Rehabilitation of Timber Railroad Bridges Using Glass Fiber Reinforced Polymer Composite Wraps. Civil and Environmental Engineering. Morgantown: West Virginia University.

Terry Wipf, M. R. (2000, April 3-5). Evaluation and Field Load Testing of Timber Railroad Bridge. Transportation Research Record, 327-330.

The Colling Croup, Ltd. (2002). Timber Pile Design and Construction Manual. Falls Church: Timber Pile Council, American Wood Preservers Institute.

Unsworth, J. F. (2003). Heavy Axle Load Effects on Fatigue Life of Steel Bridges. Calgary: Canadian Pacific Railway.

Uppal, A. S. (2005). Coping with the Older Railroad Steel Bridges. Edmonton: IMA Infrastructure Engineering Inc. 
Vermes, W. J. (2011). Design and Performance of Riveted Bridge Connections. Akron: Iron and Steel Preservation Conference Newsletter.

Westbrook Associated Engineers, E80 Pluss Constructors. (2006). Impact of Railcar Weight Changes on Bridges of the State of Wisconsin-Owned Railroad System. Madison: Wisconsin Department of Transportation.

Zhang, W., Song, X., Gu, X., \& Tang, H. (2012, June 1). Compressive Behavior of Longitudinally Cracked Timber Columns Retrofitted Using FRP Sheets. Journal of Structural Engineering, 138, 90-98. doi:10.1061/(ASCE)ST.1943-541X.0000423 
Appendix 1 


\section{Bridge DB-1.9}

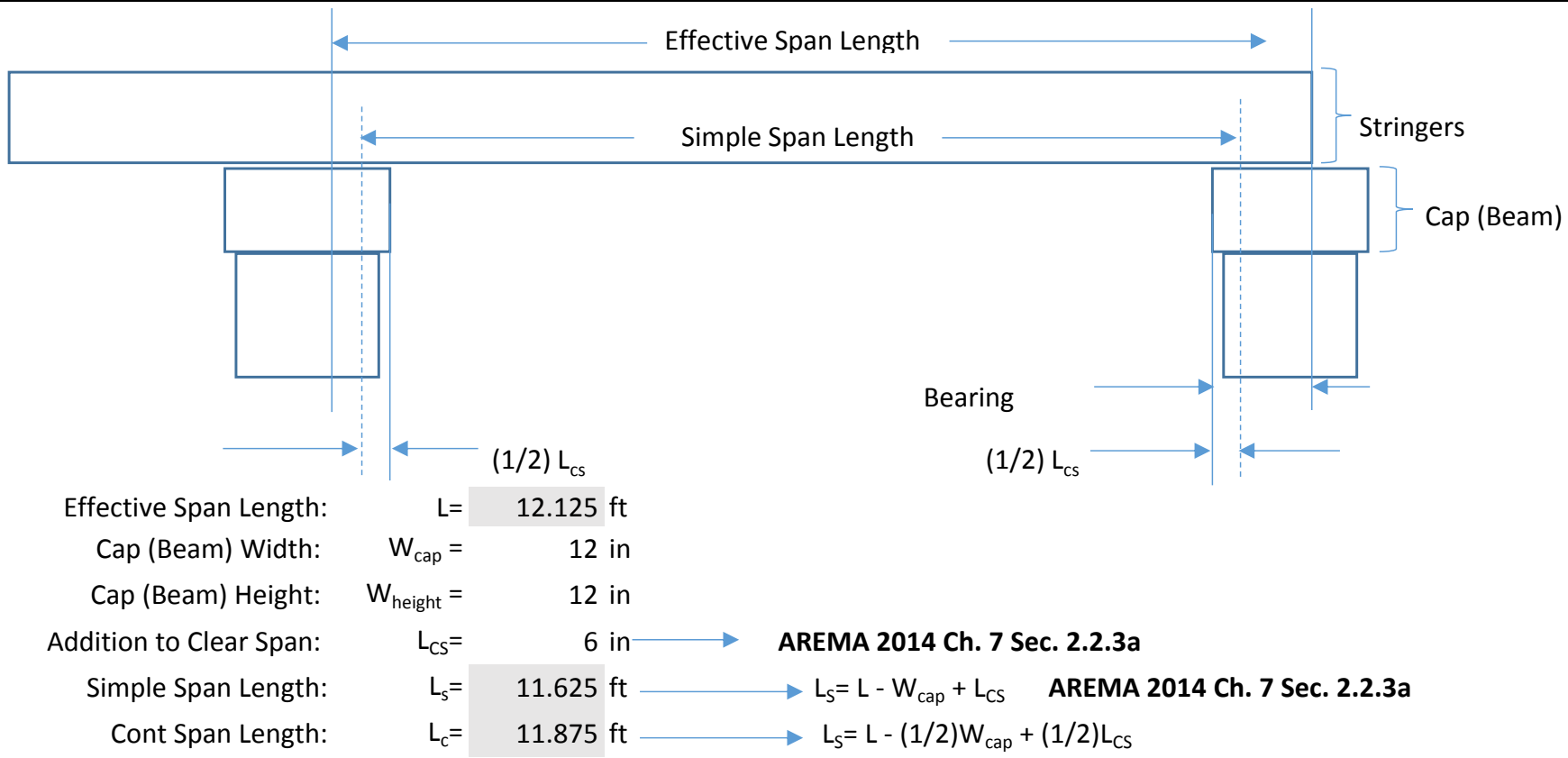

STRINGERS

\begin{tabular}{|c|c|c|c|c|c|c|}
\hline Number of Strigners: & $\mathrm{n}_{\mathrm{S}}=$ & 4 under each rail & & & & \\
\hline Stirnger Width: & $w_{S}=$ & 8 in & $\mathrm{Is}=$ & $w_{s} \cdot h_{s}^{3} / 12$ & & \\
\hline Stringer Height: & $h_{S}=$ & 16 in & & & & \\
\hline Stringer Moment of Inertia: & $\mathrm{I}_{\mathrm{S}}=$ & 2730.667 in $^{4}$ & & & & \\
\hline Stringer Section Modulus: & $\mathrm{S}_{\mathrm{S}}=$ & $341.333 \mathrm{in}^{3}$ & $\rightarrow \mathrm{S}_{\mathrm{S}}=$ & $\mathrm{I}_{\mathrm{S}}$ & $=$ & 2730.667 \\
\hline Stringer Density: & $\gamma_{s}=$ & $60 \mathrm{lb} / \mathrm{ft}^{3}$ & & $\mathrm{~h}_{\mathrm{s}} / 2$ & & $16 / 2$ \\
\hline
\end{tabular}

AREMA Ch.7 Sec. 2.3.2 Dead Load (5lb per foot board = 1"x12"x12" = $60 \mathrm{lb} / \mathrm{ft}^{3}$ )

WOOD SPECIES

Wood Grade: Southern Yellow Pine, Select Structural, $5 \times 5$ AREMA Table 7-2-9

$\begin{array}{rlr}\text { Bending Stress: } & \mathrm{f}_{\mathrm{b}}= & 1350 \mathrm{psi} \\ \text { Shear Stress: } & \mathrm{f}_{\mathrm{v}}= & 150 \mathrm{psi} \\ \text { Modulus of Elasticity: } & \mathrm{E}= & 1500 \mathrm{psi}\end{array}$

TIES

Tie Size and Spacing (actual dimensions as measured in the field)

$\begin{array}{rrrr}\text { Tie width: } & \mathrm{w}_{\mathrm{t}}= & 8 \mathrm{in} \\ \text { Tie height } & \mathrm{h}_{\mathrm{t}}= & 8 \mathrm{in} \\ \text { Tie spacing: } & \mathrm{sp}_{\mathrm{t}}= & 12 \mathrm{in} \\ \text { Tie Length: } & \mathrm{L}_{\mathrm{t}}= & 10 \mathrm{ft} \\ \text { Tie Density: } & \mathrm{V}_{\mathrm{t}}= & 60 \mathrm{lb} / \mathrm{ft}^{3}\end{array}$

AREMA 2.3.2 Dead Load (5lb per foot board = 1"x12"x12" = $60 \mathrm{lb} / \mathrm{ft}^{3}$ )

(Note: Tie Density includes creosote)

ALLOWABLE STRESS FOR STRINGERS

Depth Factor: $\quad h=$

1 if $h \leq 16$ in

AREMA Table 7-3-1

$F_{h}:=\operatorname{DepthFactor}\left(h_{s}\right)=1$ 
for Regularly Assigned Equipment or Locomotives:
$\mathrm{f}_{\mathrm{INC}}=1.1$
Not Regularly Assigned Equipment

$f_{\text {INC }}=1.3$

or Locomotives:

AREMA 7-3.1.14

Allowable Stress for Rating:

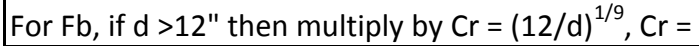

0.968541

Not Regularly Assigned Locomotive Regularly Assigned Locomotive

\begin{tabular}{r|cr|rr|}
\hline Bending Moment: & $\mathrm{Fb}_{\mathrm{n}}=\mathrm{Cr}^{*} \mathrm{f}_{\mathrm{INC}} * \mathrm{f}_{\mathrm{b}} * \mathrm{~F}_{\mathrm{h}}=$ & $1699.7891 \mathrm{psi}$ & $\mathrm{Fb}_{\mathrm{a}}=\mathrm{Cr}^{*} \mathrm{f}_{\mathrm{INC}} * \mathrm{f}_{\mathrm{b}} * \mathrm{~F}_{\mathrm{h}}=$ & $1438.283 \mathrm{psi}$ \\
\hline Horizontal Shear: & $\mathrm{Fv}_{\mathrm{n}}=\cdot \mathrm{f}_{\mathrm{INC}} * \mathrm{f}_{\mathrm{v}}=$ & $195 \mathrm{psi}$ & $\mathrm{Fv}_{\mathrm{a}}=\mathrm{f}_{\mathrm{INC}} * \mathrm{f}_{\mathrm{v}}=$ & $165 \mathrm{psi}$ \\
& & & &
\end{tabular}

AREMA 2014 Ch. 15 Sec. 7.3.1 (Ch. 15 Commentary Sec. 9.7.3.1)

Regularly Assigned (Normal) rating:

.- Normal rating is the load level that can be carried by the existing structure for its expected service life.

Not Regularly Assigned (Maximum) rating:

.- Maximum rating is the load level that the structure can support at infrequent intervals.

\section{DEAD LOADS}

Track rails, inside guide rail \& fastening:

$\mathrm{dl}_{\text {track }}=$

$200 \mathrm{lb} / \mathrm{ft}$

AREMA 2.3.2 Dead Load

Ties: $\quad \mathrm{dl}_{\text {ties }}=\mathrm{w}_{\mathrm{t}} * \mathrm{~h}_{\mathrm{t}} * \mathrm{~L}_{\mathrm{t}} * \mathrm{\gamma}_{\mathrm{t}} / \mathrm{sp}_{\mathrm{t}}=$ $\underline{8 * 8 * 10 * 60}=$

$266.7 \mathrm{lb} / \mathrm{ft}$

$12 * 12$

Guard Timber: $\mathrm{dl}_{\mathrm{gt}}=2 * 4 \mathrm{in} * 8 \mathrm{in} * \gamma_{\mathrm{t}}=2 * 4 * 8 * 60 / 144=$

$26.7 \mathrm{lb} / \mathrm{ft}$

Stringers: $\quad \mathrm{dl}_{\mathrm{s}}=\mathrm{w}_{\mathrm{s}} * \mathrm{~h}_{\mathrm{s}}{ }^{*} \gamma_{\mathrm{s}}{ }^{*} \mathrm{n}_{\mathrm{s}} * 2=8 * 16 * 60 * 4 * 2 / 144=\quad 426.667 \mathrm{lb} / \mathrm{ft}$

Total DL: $\mathrm{W}_{\mathrm{DL}}=\mathrm{dl}_{\text {track }}+\mathrm{dl}_{\text {ties }}+\mathrm{dl}_{\mathrm{gt}}+\mathrm{dl}_{\mathrm{s}}=200+266.7+26.7+426.667=920 \mathrm{lb} / \mathrm{ft} \quad$ timber= $5 \mathrm{lb}$ per $\mathrm{ft}$ board measure

\section{LIVE LOADS}

Cooper E 80 Load (loads shown are for each axle)

AREMA 7-2.3.3 Live Load

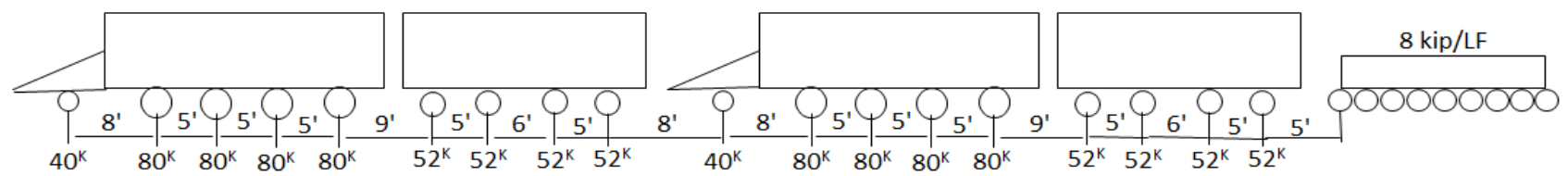

${ }^{*}$ All other Cooper ratings are proportional to the Cooper $E 10$ loading by a certain value. i.e.Cooper E 80 is a Cooper E 10 times 8 , meaning all axle loads are to be multiplied times 8.

\section{COMPUTATION OF STRESSES}

AREMA 7-3.1.5

\section{AREMA 2014 Ch. 7 Sec. 3.1.5c}

Continuity occurring in stringers. Where the support under a rail consists of three or more stringers assembled as a chord, or otherwise acting in unison, and extending over two spans with staggered joints, a partially continuous beam action may be assumed to exist, and the computations may be made for stringers based on the average stress as determined from single beam analysis and that for a fully continuous condition.

\section{AREMA 2014 Ch. 7 Sec. 2.3.8 Impact}

The dynamic increment of load due to the effects of speed, roll and track irregularities is not well established for timber structures. Its total effect is estimated to be less than the increased strength of timber for the short cumulative duration of loading to which railroad bridges are subjected in service, and is taken into consideration in the derivation of allowable working stresses for design.

\section{AASHTO LRFD 2012 Bridge Design Specifications 6th Edition - Article 3.6.2.3 Wood Components}

Dynamic load allowance (IM) need not be applied to wood components.

\section{Moment Ratings}


Single beam moments:

Dead Load Moment:

$$
\mathrm{M}_{\mathrm{DL} \_ \text {Simp }}=\text { Moment }(\mathrm{RISA} \text { input })=\quad 15.54 \mathrm{ft} \cdot \mathrm{kips}
$$

Live Load Moment:

$$
\mathrm{M}_{\mathrm{LL} \_ \text {Simp }}=\text { Moment }(\mathrm{RISA} \text { input })=\quad 296.667 \mathrm{ft} \cdot \mathrm{kips} \quad(\text { Cooper } \mathrm{E} 80 \text { Load })
$$

Two-span continuous beam moments:

DL Moment:

$$
\mathrm{M}_{\mathrm{DL} \_ \text {Cont }}=\text { Moment2 }(\mathrm{RISA} \text { input })=\quad 6.53 \mathrm{ft} \cdot \mathrm{kips}
$$

Live Load Moment:

$$
\left.\mathrm{M}_{\mathrm{LL} \_ \text {Cont }}=\text { Moment2 (RISA input }\right)=\quad 172.211 \mathrm{ft} \cdot \mathrm{kips} \quad \text { (Cooper E } 80 \text { Load) }
$$

Average bending Moments:

$$
\begin{array}{ll}
M_{D L}=\frac{M_{D L_{-} \operatorname{Simp}}+M_{D L_{-} \text {Cont }}}{2}= & 11.034 \mathrm{ft} \cdot \mathrm{kips} \\
M_{L L}=\frac{M_{L L_{-} \operatorname{Simp}}+M_{L L_{-} \text {Cont }}}{2}= & 234.439 \mathrm{ft} \cdot \mathrm{kips}
\end{array}
$$

Bending moments and stresses per stringer:

$$
\begin{aligned}
& M_{D L \_S t r}=\frac{M_{D L}}{2 n_{S}}=\quad 1.379 \mathrm{ft} \cdot \mathrm{kips} \quad \mathrm{n}_{\mathrm{s}}=\text { number of stringers under one rail } \\
& f_{D L}=\frac{M_{D L} L_{-} t r}{S_{S}}=\quad 48 \mathrm{psi} \quad \mathrm{S}_{\mathrm{s}}=\text { Stringer Section Modulus }=341.333 \mathrm{in}^{3} \\
& M_{L L \_S t r}=\frac{M_{L L}}{2 n_{S}}=\quad 29.305 \mathrm{ft} \cdot \mathrm{kips} \\
& f_{L L}=\frac{M_{L L} S t r}{S_{S}}=\quad 1030 \mathrm{psi}
\end{aligned}
$$

\section{MOMENT RATINGS}

$\begin{array}{cccc}\mathrm{Fb}_{\mathrm{a}}=\text { allowable bending stress for regularly assigned locomotives }= & 1438 & \text { psi } & \text { AREMA 2014 Table 7-2-9 } \\ \mathrm{Fb}_{\mathrm{n}}=\text { allowable bending stress for locomotives not regularly assigned }= & \begin{array}{ll}1700 & \text { psi }\end{array}\end{array}$

\section{Assigned Locomotives}

$$
\operatorname{RFM}_{\mathrm{a}}:=\frac{F b_{a}-f_{D L}}{f_{L L}}=\frac{1438-48}{1030}=\quad 1.35 \quad \text { Cooper } E \text { Rating } \quad E m_{\mathrm{a}}=\operatorname{round}\left(\mathrm{RFM} \mathrm{a}_{\mathrm{a}} \cdot 80\right)=\quad 104
$$

Not-Assigned Locomotives

Cooper E Rating - 107.9

$\mathrm{RFM}_{\mathrm{n}}:=\frac{F b_{n}-f_{D L}}{f_{L L}}=\frac{1700-48}{1030}=\quad 1.603 \quad$ Cooper $E$ Rating $\quad \mathrm{m}_{\mathrm{n}}=\operatorname{round}\left(\mathrm{RFM}_{\mathrm{n}} \cdot 80\right)=$

128

\section{Cooper E Rating - $\mathbf{1 2 8 . 2}$}


AREMA 2.5.9c

In calculating the maximum shear, $\mathrm{V}$, use the following rules:

$1 \mathrm{~V}$ shall be calculated at a distance " $\mathrm{d}$ " away from the face of support equal to the height of the stringer.

2 Neglect all loads within the height of the beam from the face of the support.

3 Moving loads shall be placed such that they produce the maximum value for $V$

4 When a beam spans continuously over one or more supports, continuity shall be considered when calculating $\mathrm{V}$.

5 Take into account any relief to the beam under consideration resulting from the loading being distributed to adjacents parallel beams by flooring or other members of the construction.

$\underline{\text { Single beam Shear }}$

Dead Load Shear:

$$
\left(\text { RISA) } V_{\text {DL_Simp }}=\quad 3.891\right. \text { kips }
$$

Live Load Shear:

$$
\left(\text { RISA) } V_{L_{L} \text { Simp }}=108.6157 \text { kips } \quad \text { (Cooper E } 80\right. \text { Load) }
$$

Shear at stringer depth from face

of support

Two span continuous beam shears:

Dead Load Shear:

$$
\left(\text { RISA) } V_{\text {DL_Cont }}=\quad 4.085\right. \text { kips }
$$

Live Load Shear:

\section{AREMA 2.3.3 Live Load}

$$
\left(\text { RISA) } \mathrm{V}_{\text {LL_Cont: }}=\quad 114.14\right. \text { kips }
$$

(Cooper E 80 Load)

Shear at stringer depth from face

Average Shears: of support

$$
\begin{array}{rr}
\mathrm{V}_{\mathrm{DL}}:=\frac{V_{D L \text { Simp }}+V_{D L_{\text {cont }}}}{2}= & 3.99 \mathrm{kips} \\
\mathrm{V}_{\mathrm{LL}}:=\frac{V_{L L \text { Simp }}+V_{L L \text { Cont }}}{2}= & 111.38 \mathrm{kips}
\end{array}
$$

$$
\begin{aligned}
& \mathrm{Fv}:=\frac{3 \cdot V}{2 \cdot b \cdot h} \\
& V_{D L \_S t r}=\frac{V_{D L}}{2 n_{S}}=\quad 0.498 \mathrm{kips} \\
& f v_{D L}=\frac{3 V_{D L} S t r}{2 w_{S} h_{S}}=\quad 5.8 \mathrm{psi} \\
& V_{L L_{-} S t r}=\frac{V_{L L}}{2 n_{S}}=\quad 13.922 \mathrm{kips} \\
& f v_{L L}=\frac{3 V_{L L} S t r}{2 w_{S} h_{S}}=163 \text { psi }
\end{aligned}
$$

\section{AREMA 2.5.9 Horizontal Shear}

$$
\begin{aligned}
& h_{s}=\text { height of stringer }=16 \text { in } \\
& W_{S}=\text { width of stringer }=8 \text { in } \\
& n_{s}=\text { number of stringers under each rail }=4
\end{aligned}
$$


SHEAR RATINGS:

$\begin{array}{rr}\mathrm{Fv}_{\mathrm{a}}=\text { allowable shear stress for regularly assigned locomotives }= & 165 \mathrm{psi} \\ \mathrm{Fv}_{\mathrm{n}}=\text { allowable shear stress for locomotives not regularly assigned }= & 195 \mathrm{psi}\end{array}$

Assigned Locomotive
$\operatorname{RFV}_{\mathrm{a}}:=\frac{F v_{a}-f v_{D L}}{f v_{L L}}=\frac{165-5.8}{163}=$
0.976
Cooper E Rating
$\mathrm{EV}_{\mathrm{a}}=\operatorname{round}\left(\mathrm{RFV}_{\mathrm{a}} \cdot 80\right)=$
80
Cooper E Rating - 78.0

Non-Assigned Locomotive
$\mathrm{RFV}_{\mathrm{n}}:=\frac{F v_{n}-f v_{D L}}{f v_{L L}}=\frac{195-65.8}{163}=$
1.159
Cooper E Rating
$\mathrm{EV}_{\mathrm{n}}=\operatorname{round}\left(\mathrm{RFV}_{\mathrm{n}} \cdot 80\right)=$
96

\section{Equivalent Cooper E Loadings}

Since shear controls rating, check all special loads for horizontal shear

\section{Load 1 - Covered Hopper Car}

286 K Railcar - Drawn by Lochner, 2012

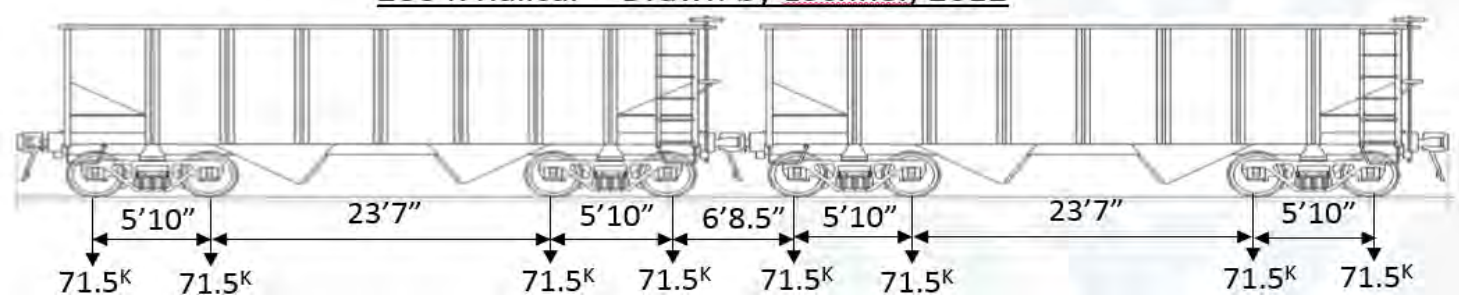

Simple Span Moment

$$
\left.\mathrm{M}_{\text {HP_Simp }}:=\text { Moment(RISA input }\right)=207.797 \mathrm{ft} \cdot \text { kips } \quad \text { (Max M from moving 286K load on } \mathrm{L}_{\mathrm{s}} \text { ) }
$$

Continuous Span Moment

$$
\mathrm{M}_{\text {HP_Cont }}:=\text { Moment2(RISA input)= } 152.363 \mathrm{ft} \cdot \mathrm{kips} \quad \text { (Max +M from moving 286K load on } 2 \text { cont. } L_{c} \text { spans) }
$$

Bending stresses per stringer:

$$
\begin{gathered}
M_{H P}=\frac{M_{H P_{-} S i m p}+M_{H P_{-} C o n t}}{2}=180.080 \mathrm{ft} \cdot \mathrm{kips} \\
M_{H P_{-} S t r}=\frac{M_{H P}}{2 n_{S}}= \\
f_{H P}=\frac{M_{H P \_S t r}}{S_{S}}= \\
M E_{H P}=\frac{80 * M_{H P}}{M_{L L}}=
\end{gathered}
$$




$$
\mathrm{V}_{\mathrm{HP}_{-} \text {Simp }}:=\text { Shear }(\mathrm{RISA} \text { input })=87.45903 \text { kips }
$$

Two continuous spans shear:

$$
\begin{aligned}
& d^{\prime}=\text { Distance from end of beam to stringer depth } \\
& \text { from face of interior support for continuous spans. }
\end{aligned}
$$

$$
\mathrm{V}_{\text {HP_Cont }}:=\mid \text { Shear2(RISA)@ d' } \mid=94.80888 \text { kips }
$$

Shears and horizontal shear stresses per stringer:

$$
\begin{gathered}
V_{H P}=\frac{V_{H P_{-} S i m p}+V_{H P_{-} \text {Cont }}}{2}= \\
V_{H_{-} S_{S t r}}=\frac{V_{H P}}{2 n_{S}}= \\
f v_{H P}=\frac{3 V_{H P \_S t r}}{2 w_{S} h_{S}}= \\
V E_{H P}=\frac{10 * V_{H P}}{V_{L L}}=
\end{gathered}
$$

\section{Load 2 - GP38 Locomotive}

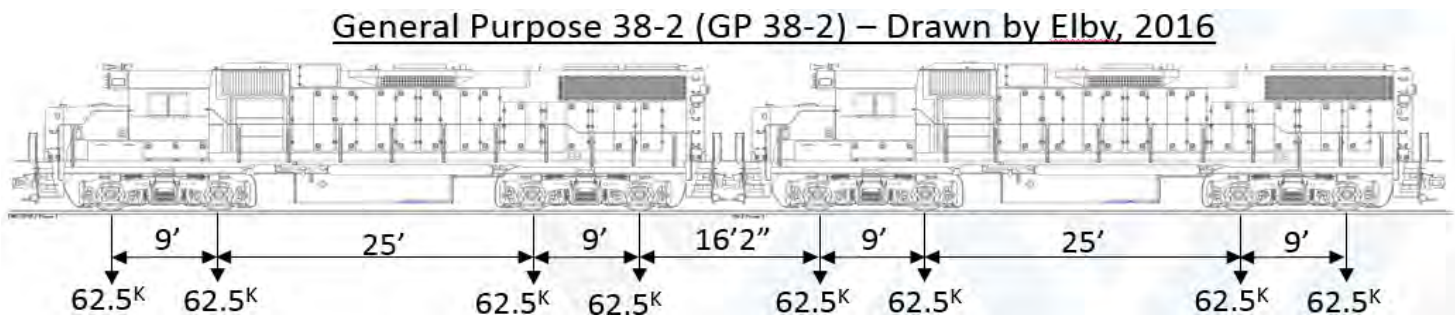

Simple Span Moment

$$
\left.\mathrm{M}_{\mathrm{GP} \_ \text {Simp }}:=\text { Moment(RISA }\right)=180.99 \mathrm{ft} \cdot \mathrm{kips}
$$

Continuous Span Moment

$$
\left.\mathrm{M}_{\mathrm{GP} \_ \text {Cont }}:=\text { Moment2(RISA }\right)=114.381 \mathrm{ft} \cdot \mathrm{kips}
$$

Bending stresses per stringer:

$$
\begin{aligned}
& M_{G P}=\frac{M_{G P \_S i m p}+M_{G P \_C o n t}}{2}=\quad 147.686 \mathrm{ft} \cdot \mathrm{kips} \\
& M_{G P_{-} S t r}=\frac{M_{G P}}{2 n_{S}}=\quad 18.461 \mathrm{ft} \cdot \mathrm{kips} \\
& f_{G P}=\frac{M_{G P \_} S t r}{S_{S}}=\quad 0.649 \mathrm{ksi}
\end{aligned}
$$




$$
M E_{G P}=\frac{10 * M_{G P}}{M_{L L}}=\quad 50.396
$$

\section{Equiv. Cooper E Load - E $\quad 50.4$}

Single span shears:

$$
\left.\mathrm{V}_{\mathrm{GP}_{-} \text {Simp }}:=\text { Shear(RISA input }\right)=\quad 60.28 \text { kips }
$$

Two continuous spans shears:

$$
\mathrm{V}_{\mathrm{GP}_{-} \text {Cont }}:=\mid \text { Shear2(RISA) @ d' } \mid=
$$

63.73 kips

Shears and horizontal shear stresses per stringer:

$$
\begin{array}{cc}
V_{G P}=\frac{V_{G P_{-} S i m p}+V_{G P_{-} \text {Cont }}}{2}= & 62.004 \mathrm{ft} \cdot \mathrm{kips} \\
V_{G P_{-} S t r}=\frac{V_{G P}}{2 n_{S}}= & 7.75 \mathrm{kips} \\
f v_{G P}=\frac{3 V_{G P \_S t r}}{2 w_{S} h_{S}}= & 90.826 \mathrm{psi} \\
V E_{G P}=\frac{10 * V_{G P}}{V_{L L}}= & 44.535
\end{array}
$$
$d^{\prime}=$ Distance from end of beam to stringer depth from face of interior support for continuous spans.

Equiv. Cooper E Load - E $\quad 44.5$

\section{GP38 Load OK}

Load 3 - WM 82 Locomotive

Western Maryland 82 BL2 (WM 82) - Drawn by Anderson, 2016

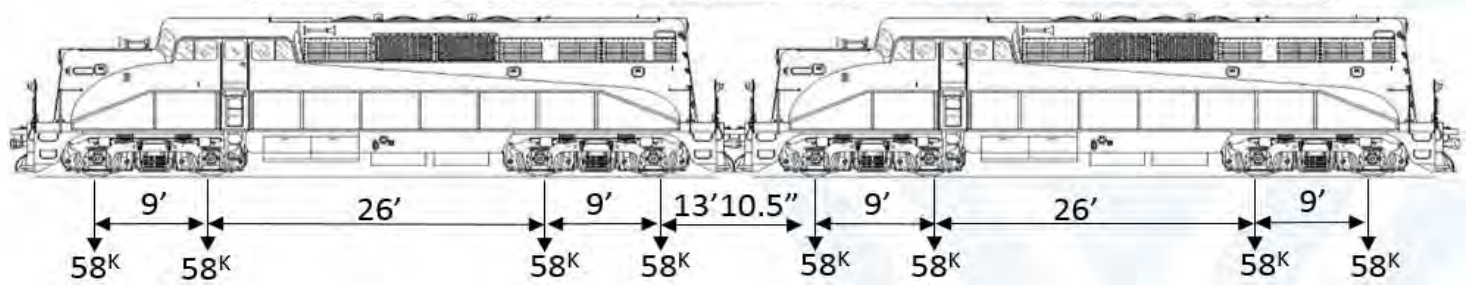

Single Span Moment

$$
\mathrm{M}_{\mathrm{GP}_{-} \text {Simp }}:=\text { Moment }(\mathrm{RISA} \text { input })=168.562 \mathrm{ft} \cdot \mathrm{kips}
$$

Continuous Span Moment

$$
\left.\mathrm{M}_{\mathrm{GP} \_ \text {Cont }}:=\text { Moment2(RISA input }\right)=106.027 \mathrm{ft} \cdot \mathrm{kips}
$$

Bending stresses per stringer: 


$$
\begin{aligned}
& M_{G P}=\frac{M_{G P \_S i m p}+M_{G P_{-} \text {Cont }}}{2}=137.295 \mathrm{ft} \cdot \mathrm{kips} \\
& M_{G P_{-} S t r}=\frac{M_{G P}}{2 n_{S}}=\quad 17.162 \mathrm{ft} \cdot \mathrm{kips} \\
& f_{G P}=\frac{M_{G P}{ }_{S} S t r}{S_{S}}=\quad 0.603 \mathrm{ksi} \\
& M E_{G P}=\frac{10 * M_{G P}}{M_{L L}}=\quad 46.850
\end{aligned}
$$

Single span shears:

$$
\begin{array}{ll}
\left.V_{\text {GP_Simp }}:=\text { Shear(RISA input }\right)=55.93906 \text { kips } & \text { Shear at stringer depth from } \\
\text { support }
\end{array}
$$

Two continuous spans shears:

$$
\mathrm{V}_{\text {GP_Cont }}:=\mid \text { Shear2(RISA)@ d' } \mid=58.8872857 \text { kips }
$$

Shears and horizontal shear stresses per stringer:

$$
\begin{gathered}
V_{G P}=\frac{V_{G P_{-} S i m p}+V_{G P_{-} \text {Cont }}}{2}=57.413 \text { kips } \\
V_{G P_{-} S t r}=\frac{V_{G P}}{2 n_{S}}= \\
f v_{G P}=\frac{3 V_{G P_{-} S t r}}{2 w_{S} h_{S}}= \\
\\
V E_{G P}=\frac{10 * V_{G P}}{V_{L L}}=
\end{gathered}
$$

Equiv. Cooper E Load - E $\quad 41.2$

WM82 Load OK

TIMBER POST OR PILES (Select Structural Southern Pine, Post and Timbers)
(Piles):=
$4 \quad$ Number of Piles per bent
$\mathrm{F}_{\mathrm{C}}=$ $855 \mathrm{psi}$ Allowable Compressive Stress Parallel to Grain
$\mathrm{L}_{\mathrm{u}}=$
$12 \mathrm{ft}$
Unbraced Length - Max Between longitudinal braces

No Reduction in capacity since $L / d \leq 11$, see table $7-2-10$
Apile $:=12 \mathrm{in} \times 12 \mathrm{in}=$
144 in $^{2}$
Area of One 12" Post

Allowable Compressive Stress

AREMA Table 7-3-1 (AREMA 2004 Table 7-2-20 p.7-2-119) 


\begin{tabular}{|l|cc|}
\cline { 2 - 3 } Regularly Assigned Locomotive & $1.1 \mathrm{f}_{\mathrm{c}}=$ & $940.5 \mathrm{psi}$ \\
\hline Not Regularly Assigned Locom. & $1.3 \mathrm{f}_{\mathrm{c}}=$ & $1111.5 \mathrm{psi}$ \\
\hline
\end{tabular}

Live Load Reactions of the track at an interior bent

Highest reaction load taken by an interior bent

$\begin{array}{lr}\text { (LLRXN1):= } & 146.372 \text { kips Live Load Reaction for the } 286 \text { kip hopper car fully loaded } \\ \text { (LLRXN2):= } & 85.5605 \text { kips Live Load Reaction for the GP } 38 \text { Locomotive. } \\ \text { (LLRXN3):= } & 194.16 \text { kips Live Load Reaction for the Copper E } 80 \text { Load } \\ \text { (LLRXN4):= } & 71.097 \text { kips Live Load Reaction for the wm82 Locomotive. }\end{array}$

Dead Load Reactions of the track at an interior bent

DLRXN:= Superstructure + Caps + Posts $=15357$ lb Dead Load Reaction at Interior Support With 15.357 kips Pier Dead Load Added In (Bent 5)

Total Reactions of the track at an interior bent

$\begin{array}{lrl}\text { TLRXN1 }:=\text { LLRXN1 + DLRXN }= & 161.729 \text { kips } & 286 \text { kip rail car, Total reaction per Track } \\ \text { TLRXN2 }:=\text { LLRXN2 + DLRXN }= & 100.9175 \text { kips } & \text { GP } 38 \\ \text { TLRXN3 }:=\text { LLRXN3 + DLRXN }= & 209.521 \text { kips } & \text { Cooper E } 80 \\ \text { TLRXN4 }:=\text { LLRXN4 + DLRXN }= & 86.454 \text { kips } & \text { WM82 }\end{array}$

\section{Percent of the Rail Load Per Pile}

Use the Pile Design Aids Provided by AREMA to get the fraction of the rail reaction that is distributed to each pile For 4 piles use RISA calculated distribution:
(Pile1Fr:=
0.32
Fraction of Rail Load Taken by Outer Pile, (Piles 1 and 4)
(Pile2Fr:=
0.68
Fraction of Rail Load Taken by Inner Pile, (Piles 2 and 3)

\section{Cooper Rating Per Pile}

Since the Pile 2 takes the biggest load, Get the Cooper Rating for It

$$
\text { (MaxPileLd := Pile2Fr·TLRXN1·0.5 = } 55.291 \text { kips) }
$$

Regularly Assigned Locomotive:

$$
\mathrm{CRF}:=\frac{F C-\frac{\text { DLRXN } \cdot 0.5 \cdot P i l e 2 F r}{\text { Apile }}}{\frac{L L R X N 3 \cdot P i l e 2 F r \cdot 0.5}{\text { Apile }}}=\frac{940.5-\frac{15357(0.5) 0.68}{144}}{\frac{194160(0.55) 0.68}{144}}=1.96
$$

$\underline{\text { Rating of Cooper E }} \mathbf{1 5 7}$ (if posts have no deterioration)

Not Regularly Assigned Locomotive:

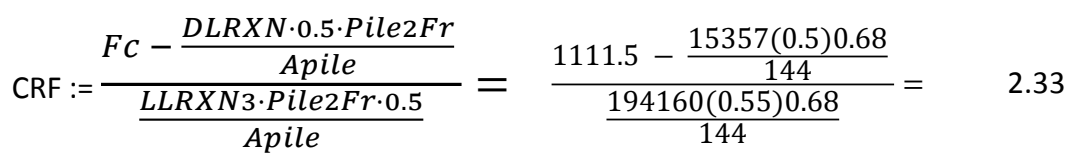

$\underline{\text { Rating of Cooper E }} \underline{\mathbf{1 8 7}}$ (if posts have no deterioration)

\section{Equivalent Cooper Load (ECR) for the 286 kip hopper car}

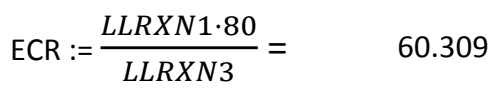


Equivalent Cooper Load for the GP 38 Locomotive

$$
\text { ECR38 }:=\frac{L L R X N 2 \cdot 80}{L L R X N 3}=\quad 35.25288
$$

\section{Equivalent Cooper Load for the WM 82 Locomotive}

$$
\text { ECR9 := } \frac{L L R X N 4 \cdot 80}{L L R X N 3}=29.29359
$$

\begin{tabular}{|c|c|c|c|c|c|}
\hline \multirow{2}{*}{ Type } & \multicolumn{3}{|c|}{ Cooper E Rating Capacity } & \multicolumn{3}{|c|}{ Equivalent Cooper E Load } \\
\cline { 2 - 6 } & $\begin{array}{c}\text { Regularly } \\
\text { Assigned }\end{array}$ & $\begin{array}{c}\text { Not } \\
\text { Regularly }\end{array}$ & \multicolumn{2}{|c|}{$286 \mathrm{k}$} & \multicolumn{2}{c}{ GP38 } & WM82 \\
\hline Bending & 107.9 & 128.2 & 61.5 & 50.4 & 46.9 \\
\hline Horz. Shea & 78.0 & 92.8 & 65.5 & 44.5 & 41.2 \\
\hline Pile (Post) & 157 & 187 & 60.3 & 35.3 & 29.3 \\
\hline
\end{tabular}


Bridge DB-4.3

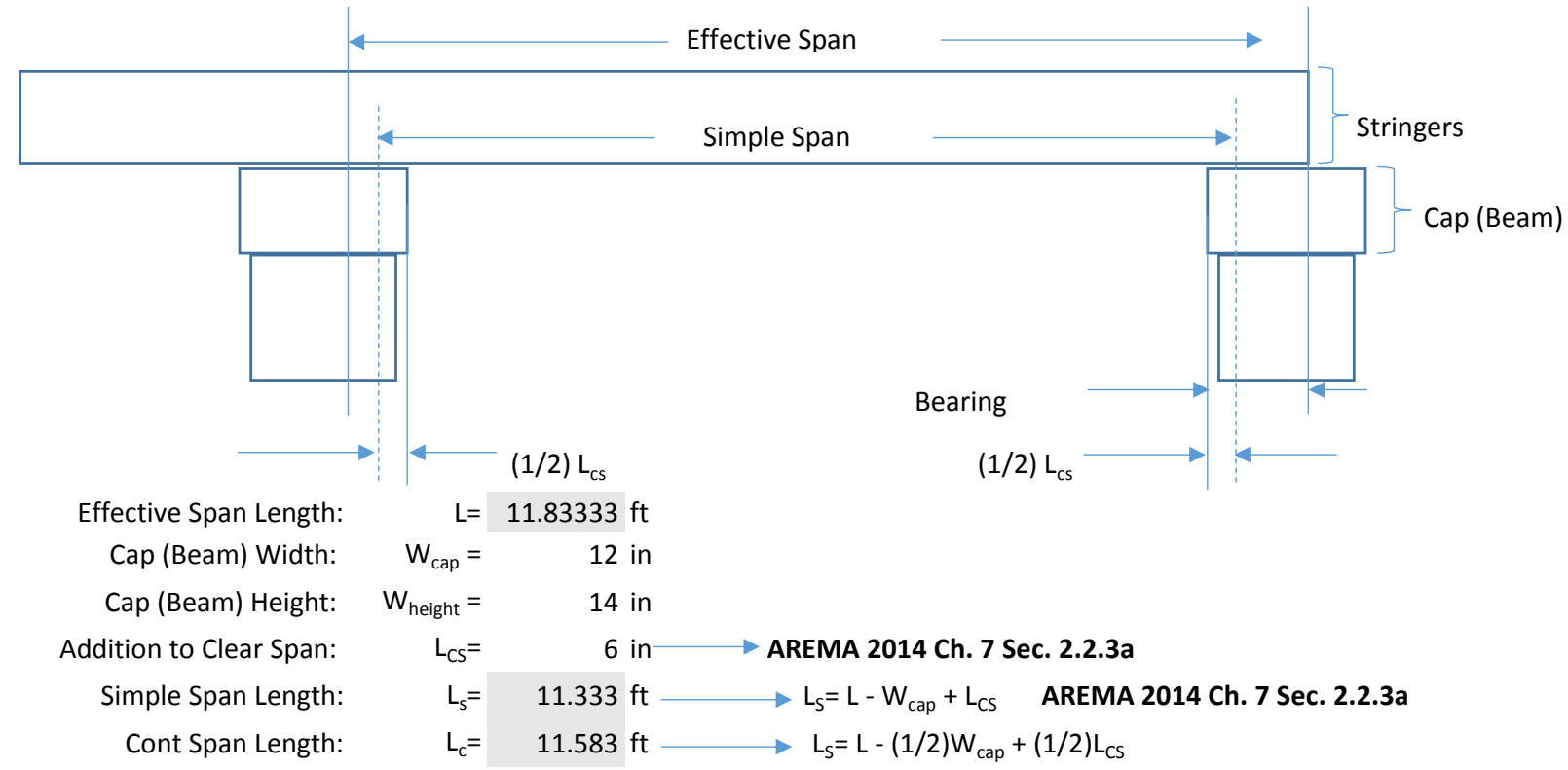

STRINGERS

\begin{tabular}{|c|c|c|c|c|c|c|}
\hline Number of Strigners: & $\mathrm{n}_{\mathrm{s}}=$ & 4 under each rail & & & & \\
\hline Stirnger Width: & $\mathrm{w}_{\mathrm{s}}=$ & 8 in & $\mathrm{Is}=$ & $w_{s} \cdot h_{s}^{3} / 12$ & & \\
\hline Stringer Height: & $h_{s}=$ & 16 in & & & & \\
\hline Stringer Moment of Inertia: & $\mathrm{I}_{\mathrm{S}}=$ & 2730.667 in $^{4}$ & & & & \\
\hline Stringer Section Modulus: & $\mathrm{S}_{\mathrm{S}}=$ & $341.333 \mathrm{in}^{3}$ & $\rightarrow S_{S}=$ & $\mathrm{I}_{\mathrm{S}}$ & $=$ & 2730.667 \\
\hline Stringer Density: & $\gamma_{s}=$ & $60 \mathrm{lb} / \mathrm{ft}^{3}$ & & $h_{s} / 2$ & & $16 / 2$ \\
\hline
\end{tabular}

AREMA Ch.7 Sec. 2.3.2 Dead Load (5lb per foot board = 1"x12"x12" = $60 \mathrm{lb} / \mathrm{ft}^{3}$ )

WOOD SPECIES

Wood Grade: Southern Yellow Pine, Select Structural, 5x5 AREMA Table 7-2-9

$\begin{array}{rlr}\text { Bending Stress: } & \mathrm{f}_{\mathrm{b}}= & 1350 \mathrm{psi} \\ \text { Shear Stress: } & \mathrm{f}_{\mathrm{v}}= & 150 \mathrm{psi} \\ \text { Modulus of Elasticity: } & \mathrm{E}= & 1500 \mathrm{psi}\end{array}$

TIES

Tie Size and Spacing (actual dimensions as measured in the field)

$\begin{array}{rrrr}\text { Tie width: } & \mathrm{w}_{\mathrm{t}}= & 8 \mathrm{in} \\ \text { Tie height } & \mathrm{h}_{\mathrm{t}}= & 8 \mathrm{in} \quad \text { AREMA 2.3.2 Dead Load (5lb per foot board = 1"x12"x12" = 60 lb/f } \\ \text { Tie spacing: } & \mathrm{sp}_{\mathrm{t}}= & 12 \mathrm{in} \\ \text { Tie Length: } & \mathrm{L}_{\mathrm{t}}= & 10 \mathrm{ft} \\ \text { Tie Density: } & \mathrm{V}_{\mathrm{t}}= & 60 \mathrm{lb} / \mathrm{ft}^{3} \\ & & & \text { (Note: Tie Density includes creosote) }\end{array}$

\section{ALLOWABLE STRESS FOR STRINGERS}

$\begin{array}{cc}\text { Depth Factor: } & h= \\ \mathrm{F}_{\mathrm{h}}:=\text { DepthFactor }\left(\mathrm{h}_{\mathrm{s}}\right)= & 1\end{array} \mid \begin{gathered}1 \text { if } \mathrm{h} \leq 16 \mathrm{in} \\ 0.81 \cdot \frac{\mathrm{h}^{2}+143 \mathrm{in}}{\mathrm{h}^{2}+88 \mathrm{in}^{2}} \text { otherwise }\end{gathered}$

Allowable Increase in unit Stress for Regularly Assigned Equipment or Locomotives:
Allowable Increase in unit Stress

$f_{\text {INC }}=1.1 \quad$ for Not Regularly Assigned $\quad f_{\text {INC }}=1.3$

Equipment or Locomotives: 


\begin{tabular}{r|cc|cc|}
\hline Bending Momen: & $\mathrm{Fb}_{\mathrm{n}}=\mathrm{Cr}^{*} \mathrm{f}_{\mathrm{INC}} * \mathrm{f}_{\mathrm{b}} * \mathrm{~F}_{\mathrm{h}}=$ & $1700 \mathrm{psi}$ & $\mathrm{Fb}_{\mathrm{a}}=\mathrm{Cr}^{*} \mathrm{f}_{\mathrm{INC}} * \mathrm{f}_{\mathrm{b}} * \mathrm{~F}_{\mathrm{h}}=$ & $1438 \mathrm{psi}$ \\
\hline Horizontal Shear: & $\mathrm{Fv}_{\mathrm{n}}=\cdot \mathrm{f}_{\mathrm{INC}} * \mathrm{f}_{\mathrm{v}}=$ & $195 \mathrm{psi}$ & $\mathrm{Fv}_{\mathrm{a}}=\mathrm{f}_{\mathrm{INC}} * \mathrm{f}_{\mathrm{v}}=$ & $165 \mathrm{psi}$ \\
& & & & \\
& & & & \\
\hline
\end{tabular}

AREMA 2014 Ch. 15 Sec. 7.3.1 (Ch. 15 Commentary Sec. 9.7.3.1)

Regularly Assigned (Normal) rating:

.- Normal rating is the load level that can be carried by the existing structure for its expected service life.

Not Regularly Assigned (Maximum) rating:

.- Maximum rating is the load level that the structure can support at infrequent intervals.

\section{DEAD LOADS}

\begin{tabular}{|c|c|c|c|}
\hline Track rails, inside guide rail \& fastening & $\mathrm{dl}_{\text {track }}=$ & $200 \mathrm{lb} / \mathrm{ft}$ & AREMA 2.3.2 Dead Load \\
\hline \multirow[t]{2}{*}{ Ties: } & $\underline{8 * 8 * 10 * 60}$ & $266.7 \mathrm{lb} / \mathrm{ft}$ & \\
\hline & $12 * 12$ & & \\
\hline Guard Timber: $\mathrm{dl}_{\mathrm{gt}}=2 * 4 \mathrm{in}^{*} \sin ^{*} \gamma_{\mathrm{t}}=$ & $2 * 4 * 8 * 60 / 144=$ & $26.7 \mathrm{lb} / \mathrm{ft}$ & \\
\hline
\end{tabular}

Stringers: $\quad \mathrm{dl}_{\mathrm{s}}=\mathrm{w}_{\mathrm{s}}{ }^{*} \mathrm{~h}_{\mathrm{s}}{ }^{*} \mathrm{v}_{\mathrm{s}}{ }^{*} \mathrm{n}_{\mathrm{s}} * 2=8 * 16 * 60 * 4 * 2 / 144=426.667 \mathrm{lb} / \mathrm{ft}$

Total DL: $\mathrm{W}_{\mathrm{DL}}=\mathrm{dl}_{\text {track }}+\mathrm{dl}_{\text {ties }}+\mathrm{dl}_{\mathrm{gt}}+\mathrm{dl}_{\mathrm{s}}=200+266.7+26.7+426.667=\quad 920 \mathrm{lb} / \mathrm{ft} \quad$ timber $=5 \mathrm{lb}$ per $\mathrm{ft}$ board measure

\section{LIVE LOADS}

Cooper E 80 Load (loads shown are for each axle)

AREMA 7-2.3.3 Live Load

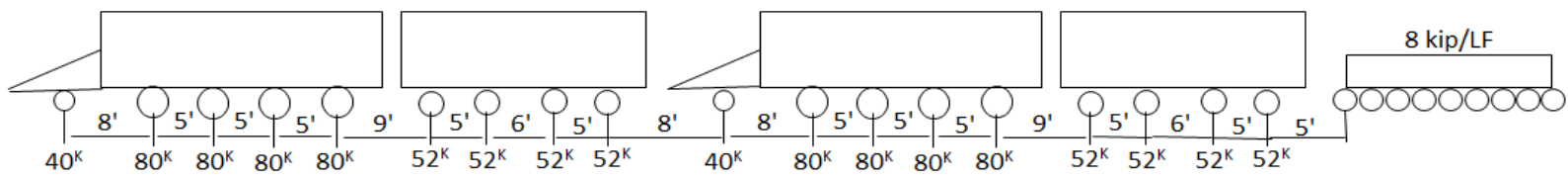

*All other Cooper ratings are proportional to the Cooper E 10 loading by a certain value. i.e.Cooper E 80 is a Cooper E 10 times 8 , meaning all axle loads are to be multiplied times 8.

\section{COMPUTATION OF STRESSES}

AREMA 7-3.1.5

\section{AREMA 2014 Ch. 7 Sec. 3.1.5c}

Continuity occurring in stringers. Where the support under a rail consists of three or more stringers assembled as a chord, or otherwise acting in unison, and extending over two spans with staggered joints, a partially continuous beam action may be assumed to exist, and the computations may be made for stringers based on the average stress as determined from single beam analysis and that for a fully continuous condition.

\section{AREMA 2014 Ch. 7 Sec. 2.3.8 Impact}

The dynamic increment of load due to the effects of speed, roll and track irregularities is not well established for timber structures. Its total effect is estimated to be less than the increased strength of timber for the short cumulative duration of loading to which railroad bridges are subjected in service, and is taken into consideration in the derivation of allowable working stresses for design.

\section{AASHTO LRFD 2012 Bridge Design Specifications 6th Edition - Article 3.6.2.3 Wood Components}

Dynamic load allowance (IM) need not be applied to wood components.

\section{Moment Ratings}

Single beam moments:

Dead Load Moment:

$$
M_{\text {DL_Simp }}=\text { Moment }(\text { RISA input })=\quad 13.71 \mathrm{ft} \cdot \mathrm{kips}
$$

Live Load Moment:

$$
\left.\mathrm{M}_{\mathrm{LL} \_ \text {Simp }}=\text { Moment (RISA input }\right)=254.583 \mathrm{ft} \cdot \mathrm{kips} \quad(\text { Cooper E } 80 \text { Load })
$$


Two-span continuous beam moments:

DL Moment:

$$
\left.\mathrm{M}_{\mathrm{DL} \_ \text {Cont }}=\text { Moment2 (RISA input }\right)=\quad 7.80 \mathrm{ft} \cdot \mathrm{kips}
$$

Live Load Moment:

$$
\mathrm{M}_{\mathrm{LL} \_ \text {Cont }}=\text { Moment2 }(\mathrm{RISA} \text { input })=198.46 \mathrm{ft} \cdot \mathrm{kips} \quad(\text { Cooper } \mathrm{E} 80 \text { Load })
$$

Average bending Moments:

$$
\begin{array}{cr}
M_{D L}=\frac{M_{D L_{-} \operatorname{Simp}}+M_{D L_{-} \text {Cont }}}{2}= & 10.750 \mathrm{ft} \cdot \mathrm{kips} \\
M_{L L}=\frac{M_{L L_{-} \operatorname{Simp}}+M_{L_{L} \text { Cont }}}{2}= & 226.5215 \mathrm{ft} \cdot \mathrm{kips}
\end{array}
$$

Bending moments and stresses per stringer:

$$
\begin{aligned}
& M_{D L_{-} S t r}=\frac{M_{D L}}{2 n_{S}}=\quad 1.344 \mathrm{ft} \cdot \mathrm{kips} \quad \mathrm{n}_{\mathrm{s}}=\text { number of stringers under one rail } \\
& f_{D L}=\frac{M_{D L} S t r}{S_{S}}=\quad 47 \mathrm{psi} \quad \mathrm{S}_{\mathrm{s}}=\text { Stringer Section Modulus } \\
& M_{L L_{-} S t r}=\frac{M_{L L}}{2 n_{S}}=\quad 28.315 \mathrm{ft} \cdot \mathrm{kips} \\
& f_{L L}=\frac{M_{L L} S t r}{S_{S}}=995 \mathrm{psi}
\end{aligned}
$$

\section{MOMENT RATINGS}

$\mathrm{Fb}_{\mathrm{a}}=$ allowable bending stress for regularly assigned locomotives $=\quad 1438$ psi

$\mathrm{Fb}_{\mathrm{n}}=$ allowable bending stress for locomotives not regularly assigned $=1700$ psi

AREMA 2014 Table 7-2-9

Assigned Locomotives

$$
\mathrm{RFM}_{\mathrm{a}}:=\frac{F b_{a}-f_{D L}}{f_{L L}}=\frac{1438-47}{995}=\quad 1.40 \quad \text { Cooper E Rating } \quad \mathrm{m}_{\mathrm{a}}=\operatorname{round}\left(\mathrm{RFM}_{\mathrm{a}} \cdot 80\right)=
$$

Cooper E Rating - 111.8

Not-Assigned Locomotives

$$
\operatorname{RFM}_{\mathrm{n}}:=\frac{F b_{n}-f_{D L}}{f_{L L}}=\frac{1700-47}{995}=1.660 \quad \text { Cooper E Rating } \quad \mathrm{Em}_{\mathrm{n}}=\operatorname{round}\left(\mathrm{RFM}_{\mathrm{n}} \cdot 80\right)=
$$

\section{Cooper E Rating - 132.8}

\section{HORIZONTAL SHEAR RATINGS}

AREMA 2.5.9c

In calculating the maximum shear, $\mathrm{V}$, use the following rules:

$1 \mathrm{~V}$ shall be calculated at a distance " $\mathrm{d}$ " away from the face of support equal to the height of the stringer.

2 Neglect all loads within the height of the beam from the face of the support.

3 Moving loads shall be placed such that they produce the maximum value for $V$

4 When a beam spans continuously over one or more supports, continuity shall be considered when calculating $\mathrm{V}$.

5 Take into account any relief to the beam under consideration resulting from the loading being distributed to adjacents parallel beams by flooring or other members of the construction. 
Single beam Shear

Dead Load Shear:

$$
\mathrm{V}_{\mathrm{DL} \_ \text {Simp }}=(\mathrm{RISA})=3.565 \mathrm{kips}
$$

Live Load Shear:

$\mathrm{V}_{\mathrm{LL} \_ \text {Simp }}=$ Shear $(\mathrm{RISA}) @ \mathrm{~d}^{\prime}=102.3148$ kips

Two span continuous beam shears:

Dead Load Shear:

$$
V_{D L} \text { Cont: }=\mid \text { Shear }(\mathrm{RISA}) \mid @ \mathrm{~d}^{\prime}=\quad 4.609 \text { kips }
$$

Live Load Shear:

$$
\begin{aligned}
V_{\mathrm{LL}_{-} \text {cont: }}= & \mid \text { Shear }(\mathrm{RISA}) \mid @ \mathrm{~d}^{\prime}= \\
& \text { from interior support }
\end{aligned}
$$

120.30 kips

(Cooper E 80 Load)

\section{AREMA 2.3.3 Live Load}

Average Shears:

$$
\begin{array}{rr}
\mathrm{V}_{\mathrm{DL}}:=\frac{V_{D L \text { Simp }}+V_{D L \text { cont }}}{2}= & 4.09 \mathrm{kips} \\
\mathrm{V}_{\mathrm{LL}}:=\frac{V_{L L \text { Simp }}+V_{L L \text { cont }}}{2}= & 111.31 \mathrm{kips}
\end{array}
$$

Shears and horizontal shear stresses per stringer:

$$
\begin{array}{cr}
\mathrm{Fv}:=\frac{3 \cdot V}{2 \cdot b \cdot h} & \\
V_{D L_{-} S t r}=\frac{V_{D L}}{2 n_{S}}= & 0.511 \mathrm{kips} \\
f v_{D L}=\frac{3 V_{D L_{-} S t r}}{2 w_{S} h_{S}}= & 6 \mathrm{psi} \\
V_{L L_{-} S t r}=\frac{V_{L L}}{2 n_{S}}= & 13.913 \mathrm{kips} \\
f v_{L L}=\frac{3 V_{L L_{-} S t r}}{2 w_{S} h_{S}}= & 163 \mathrm{psi}
\end{array}
$$

$d^{\prime}=$ Distance from end of beam to stringer depth from face of support for continuous spans.

(Cooper E 80 Load)

Shear at stringer depth from face

of support from face of support for continuous spans.

\section{SHEAR RATINGS:}

AREMA 2.5.9 Horizontal Shear

$h_{s}=$ height of stringer $=16$ in

$W_{S}=$ width of stringer $=8$ in

\footnotetext{
$\mathrm{Fv}_{\mathrm{a}}=$ allowable shear stress for regularly assigned locomotives $=\quad 165 \mathrm{psi}$ $\mathrm{Fv}_{\mathrm{n}}=$ allowable shear stress for locomotives not regularly assigned $=195 \mathrm{psi}$
}

Assigned Locomotive
$\mathrm{RFV}_{\mathrm{a}}:=\frac{F v_{a}-f v_{D L}}{f v_{L L}}=\frac{165-6}{163}=$
0.975
Cooper E Rating
$E V_{a}=\operatorname{round}\left(\operatorname{RFV}_{\mathrm{a}} \cdot 80\right)=$

80

Non-Assigned Locomotive 

$\mathrm{RFV}_{\mathrm{n}}:=\frac{F v_{n}-f v_{D L}}{f v_{L L}}=\frac{195-6}{163}=$
1.159
Cooper E Rating
$\mathrm{EV}_{\mathrm{n}}=\operatorname{round}\left(\mathrm{RFV}_{\mathrm{n}} \cdot 80\right)=$
96
Cooper E Rating - 92.7

\section{Equivalent Cooper E Loadings}

Load 1 - Covered Hopper Car

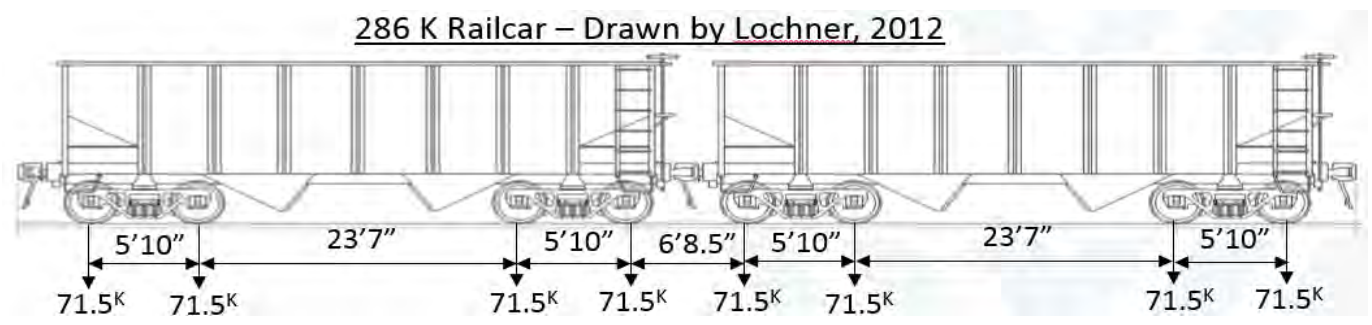

Simple Span Moment

$$
\left.\mathrm{M}_{\text {HP_Simp }}:=\text { Moment(RISA input }\right)=195.135 \mathrm{ft} \cdot \text { kips } \quad \text { (Max M from moving 286K load on } \mathrm{L}_{\mathrm{s}} \text { ) }
$$

Continuous Span Moment

$$
\left.\mathrm{M}_{\text {HP_Cont }}:=\text { Moment2(RISA input }\right)=163.127 \mathrm{ft} \cdot \mathrm{kips} \quad\left(\text { Max }+\mathrm{M} \text { from moving 286K load on cont. } \mathrm{L}_{\mathrm{c}}\right. \text { spans) }
$$

Bending stresses per stringer:

$$
\begin{aligned}
& M_{H P}=\frac{M_{H P_{-} \operatorname{Simp}}+M_{H_{P_{-}} \text {Cont }}}{2}=\quad 179.131 \mathrm{ft} \cdot \mathrm{kips} \\
& M_{H P_{-} S t r}=\frac{M_{H P}}{2 n_{S}}=\quad 22.391 \mathrm{ft} \cdot \mathrm{kips} \\
& f_{H P}=\frac{M_{H P \_} S t r}{S_{S}}=\quad 0.787 \mathrm{ksi} \\
& M E_{H P}=\frac{80 * M_{H P}}{M_{L L}}=\quad 63.263
\end{aligned}
$$

Equiv. Cooper E Load - E $\quad 63.3$

Single span shear:

$$
\mathrm{V}_{\mathrm{HP}_{-} \text {Simp }}:=\text { Shear }(\mathrm{RISA} \text { input })=83.83764 \text { kips } \quad \text { Max V @ d' }
$$

Two continuous spans shear:

$$
\mathrm{V}_{\text {HP_Cont }}:=\mid \text { Shear2(RISA)@ d' } \mid=97.60254 \text { kips }
$$

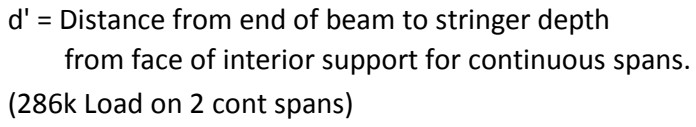

Shears and horizontal shear stresses per stringer:

$$
\begin{aligned}
& V_{H P}=\frac{V_{H P_{-} \operatorname{Simp}}+V_{\text {HP_Cont }}}{2}=90.720 \mathrm{kips} \\
& V_{H P_{-} S t r}=\frac{V_{H P}}{2 n_{S}}=\quad 11.340 \mathrm{kips} \\
& f v_{H P}=\frac{3 V_{H P \_S t r}}{2 w_{S} h_{S}}=\quad 132.891 \mathrm{psi}
\end{aligned}
$$




$$
V E_{H P}=\frac{80 * V_{H P}}{V_{L L}}=\quad 65.204
$$

\section{Hopper Load OK}

Load 2 - GP38 Locomotive

General Purpose 38-2 (GP 38-2) - Drawn by Elbv, 2016

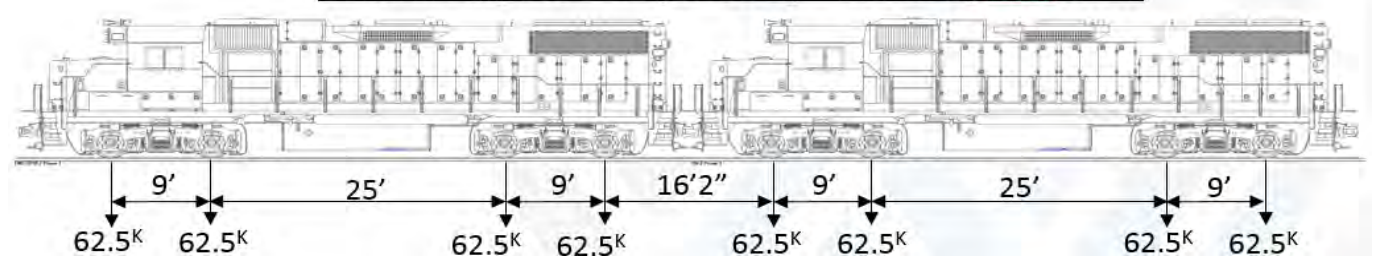

Simple Span Moment

$$
\mathrm{M}_{\mathrm{GP} \_ \text {Simp }}:=\text { Moment }(\mathrm{RISA})=170.247 \mathrm{ft} \cdot \mathrm{kips}
$$

Continuous Span Moment

$$
\left.\mathrm{M}_{\mathrm{GP} \_ \text {Cont }}:=\text { Moment2(RISA }\right)=\quad 140.285 \mathrm{ft} \cdot \mathrm{kips} \quad\left(\mathrm{Max}+\mathrm{M} \text { on } 2 \text { cont. } \mathrm{L}_{\mathrm{c}} \text { spans under GP38 load }\right)
$$

Bending stresses per stringer:

$$
\begin{array}{cc}
M_{G P}=\frac{M_{G P_{-} \operatorname{Simp}}+M_{G P_{-} \text {Cont }}}{2}= & 155.266 \mathrm{ft} \cdot \mathrm{kips} \\
M_{G P_{-} S t r}=\frac{M_{G P}}{2 n_{S}}= & 19.408 \mathrm{ft} \cdot \mathrm{kips} \\
f_{G P}=\frac{M_{G P \_S t r}}{S_{S}}= & 0.682 \mathrm{ksi} \\
M E_{G P}=\frac{80 * M_{G P}}{M_{L L}}= & 54.835
\end{array}
$$

Single span shears:

$$
\left.\mathrm{V}_{\text {GP_Simp }}:=\text { Shear(RISA input }\right)=57.72283 \text { kips }
$$

Max V@ d'

Two continuous spans shears:

$$
\mathrm{V}_{\mathrm{GP}_{-} \text {Cont }}:=\mid \text { Shear(RISA) @ d' } \mid=63.7275 \text { kips }
$$

$d^{\prime}=$ Distance from end of beam to stringer depth from face of interior support for continuous spans.

(286k Load on 2 cont spans)

Shears and horizontal shear stresses per stringer:

$$
\begin{gathered}
V_{G P}=\frac{V_{G P_{-} S i m p}+V_{G P_{-} \text {Cont }}}{2}=\quad 60.725 \mathrm{ft} \cdot \mathrm{kips} \\
V_{G P_{-} S t r}=\frac{V_{G P}}{2 n_{S}}= \\
f v_{G P}=\frac{3 V_{G P \_S t r}}{2 w_{S} h_{S}}=88.59 \mathrm{kips}
\end{gathered}
$$




$$
V E_{G P}=\frac{80 * V_{G P}}{V_{L L}}=\quad 43.645
$$

\section{Load 3 - WM 82 Locomotive}

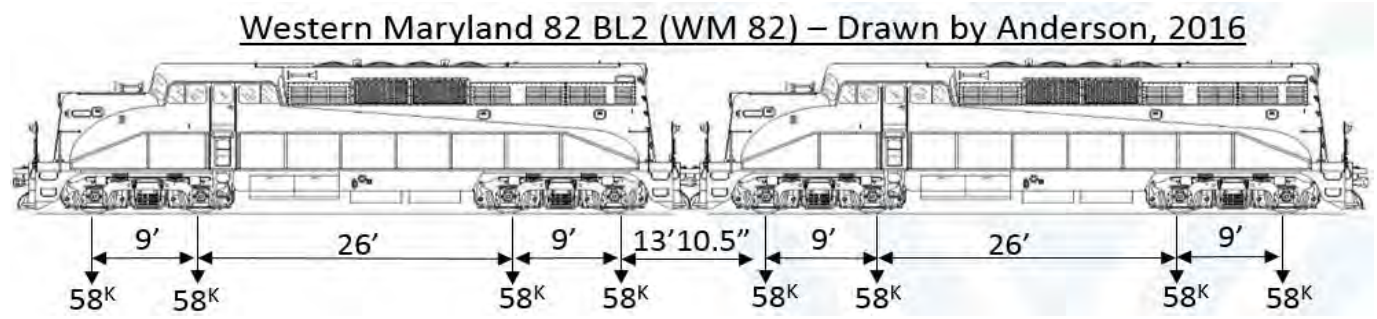

Single Span Moment

$$
M_{G P \_S i m p}:=\text { Moment }(R I S A \text { input })=158.292 \mathrm{ft} \cdot \text { kips }
$$

Continuous Span Moment

$$
\left.\mathrm{M}_{\mathrm{GP} \_ \text {Cont }}:=\text { Moment2(RISA input }\right)=129.651 \mathrm{ft} \cdot \mathrm{kips}
$$

Bending stresses per stringer:

$$
\begin{aligned}
& M_{G P}=\frac{M_{G P \_S i m p}+M_{G P \_C o n t}}{2}=143.972 \mathrm{ft} \cdot \mathrm{kips} \\
& M_{G P_{-} S t r}=\frac{M_{G P}}{2 n_{S}}=\quad 17.996 \mathrm{ft} \cdot \mathrm{kips} \\
& f_{G P}=\frac{M_{G P \_S t r}}{S_{S}}=\quad 0.633 \mathrm{ksi} \\
& M E_{G P}=\frac{80 * M_{G P}}{M_{L L}}=\quad 50.846
\end{aligned}
$$

Single span shears:

$$
\left.\mathrm{V}_{\text {GP_Simp }}:=\text { Shear(RISA input }\right)=53.75251 \text { kips } \quad \text { Shear at stringer depth from support }
$$

Two continuous spans shears:

$$
\mathrm{V}_{\text {GP_Cont }}:=\mid \text { Shear2(RISA)@ d' } \mid=59.26612 \text { kips }
$$


Shears and horizontal shear stresses per stringer:

$$
\begin{gathered}
V_{G P}=\frac{V_{G P_{-} S i m p}+V_{G P_{-} \text {Cont }}}{2}=\quad 56.509 \text { kips } \\
V_{G P_{-} S t r}=\frac{V_{G P}}{2 n_{S}}= \\
f v_{G P}=\frac{3 V_{G P \_} S t r}{2 w_{S} h_{S}}= \\
\\
V E_{G P}=\frac{80 * V_{G P}}{V_{L L}}=
\end{gathered}
$$

\section{WM82 Load OK}

TIMBER POST OR PILES (No. 2 Southern Pine, 5" x 5" and larger)

$\begin{array}{lcl}\text { (Piles): }= & 5 & \text { Number of Piles per bent } \\ \mathrm{F}_{\mathrm{C}}= & 475 \mathrm{psi} & \text { Allowable Compressive Stress Parallel to Grain } \\ \mathrm{L}_{\mathrm{u}}= & 12 \mathrm{ft} & \text { Unbraced Length - Max Between longitudinal braces }\end{array}$

No Reduction in capacity since $L / d \leq 11$, see table $7-2-10$

Apile $:=12$ in $\times 13$ in $=\quad 144$ in $^{2} \quad$ Area of One 12"x12" Post

Allowable Compressive Stress AREMA Table 7-3-1 (AREMA 2004 Table 7-2-20 p.7-2-119)

\begin{tabular}{|l|ll|}
\hline Regularly Assigned Locomotive & $1.1 \mathrm{f}_{\mathrm{c}}=$ & $522.5 \mathrm{psi}$ \\
\hline Not Regularly Assigned Locom. & $1.3 \mathrm{f}_{\mathrm{c}}=$ & $617.5 \mathrm{psi}$ \\
\hline
\end{tabular}

Live Load Reactions of the track at an interior bent

Highest reaction load taken by an interior bent (Bent 2)

$$
\begin{array}{lr}
\text { (LLRXN1):= } & 146.2325 \text { kips Live Load Reaction for the } 286 \text { kip hopper car fully loaded } \\
\text { (LLRXN2):= } & 85.695 \text { kips Live Load Reaction for the GP } 38 \text { Locomotive. } \\
\text { (LLRXN3): }= & 196.28 \text { kips Live Load Reaction for the Copper E } 80 \text { Load } \\
\text { (LLRXN4):= } & 79.525 \text { kips Live Load Reaction for the wm82 Locomotive. }
\end{array}
$$

\section{Dead Load Reactions of the track at an interior bent}

DLRXN:= Superstructure + Caps + Posts $=13228 \mathrm{lb}$ Dead Load Reaction at Interior Support With

$$
\text { 13.22775 kips Pier Dead Load Added In (Bent 2) }
$$

Total Reactions of the track at an interior bent

\begin{tabular}{lll}
\hline TLRXN1 $:=$ LLRXN1 + DLRXN $=$ & 159.4603 kips & 286 kip rail car, Total reaction per Track \\
TLRXN2 $:=$ LLRXN2 + DLRXN $=$ & 98.92275 kips & GP 38 \\
TLRXN3 $:=$ LLRXN3 + DLRXN $=$ & 209.5068 kips & Cooper E 80 \\
TLRXN4 := LLRXN4 + DLRXN $=$ & 92.75275 kips & WM82
\end{tabular}

Percent of the Rail Load Per Pile

Use the Pile Design Aids Provided by AREMA to get the fraction of the rail reaction that is distributed to each pile:

$$
\begin{array}{lll}
\text { (Pile1Fr:= } & 0.31 & \text { Fraction of Rail Load Taken by Outer Pile, (Piles } 1 \text { and 4) } \\
\text { (Pile2Fr:= } & 0.47 & \text { Fraction of Rail Load Taken by Intermediate Pile, (Piles 2 and 3) } \\
\text { (Pile3Fr:= } & 0.22 & \text { Fraction of Rail Load Taken by Inner Pile, (Piles 2 and 3) }
\end{array}
$$


Cooper Rating Per Pile

Since the Pile 2 takes the biggest load, Get the Cooper Rating for It

$$
\text { (MaxPileLd := Pile2Fr·TLRXN1·0.5 = } 37.540 \text { kips) }
$$

Regularly Assigned Locomotive:

$$
\begin{aligned}
& \mathrm{CRF}:=\frac{F c-\frac{D L R X N \cdot 0.5 \cdot P i l e 2 F r}{\text { Apile }}}{\frac{\text { LLRXN3.Pile2Fr.0.5 }}{\text { Apile }}}=\frac{522.5-\frac{13228(0.5) 0.47}{144}}{\frac{196280(0.47) 0.5}{144}}=1.56 \\
& \underline{\text { Rating of Cooper } \mathrm{E}} \underline{\mathbf{1 2 5}} \text { (if posts have no deterioration) }
\end{aligned}
$$

Not Regularly Assigned Locomotive:

$$
\begin{aligned}
& \mathrm{CRF}:=\frac{F c-\frac{D L R X N \cdot 0.5 \cdot P i l e 2 F r}{\text { Apile }}}{\frac{L L R X N 3 \cdot P i l e 2 F r \cdot 0.5}{\text { Apile }}}=\frac{617.5-\frac{13228(0.5) 0.47}{144}}{\frac{196280(0.47) 0.5}{144}}=1.86
\end{aligned}
$$

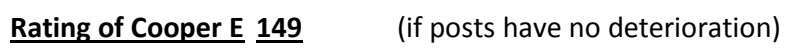

Equivalent Cooper Load (ECR) for the 286 kip hopper car

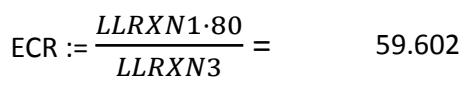

Equivalent Cooper Load for the GP 38 Locomotive

$$
\text { ECR38 : }=\frac{L L R X N 2 \cdot 80}{L L R X N 3}=34.92783
$$

\section{Equivalent Cooper Load for the WM 82 Locomotive}

$$
\text { ECR9 : }=\frac{L L R X N 4 \cdot 80}{L L R X N 3}=\quad 32.41304
$$

\begin{tabular}{|l|c|c|c|c|c|}
\hline \multirow{2}{*}{ Type } & \multicolumn{2}{|c|}{ Cooper E Rating } & \multicolumn{3}{c|}{ Equivalent Cooper E Load } \\
\cline { 2 - 6 } & $\begin{array}{c}\text { Regularly } \\
\text { Assigned }\end{array}$ & $\begin{array}{c}\text { Not } \\
\text { Regularly } \\
\text { Assigned }\end{array}$ & $286 \mathrm{k}$ & GP38 & WM82 \\
\hline Bending & 111.8 & 132.8 & 63.3 & 54.8 & 50.8 \\
\hline Horz. Shea & 78.0 & 92.7 & 65.2 & 43.6 & 40.6 \\
\hline Pile (Post) & 125 & 149 & 59.6 & 34.9 & 32.4 \\
\hline
\end{tabular}


Bridge DB-5.1

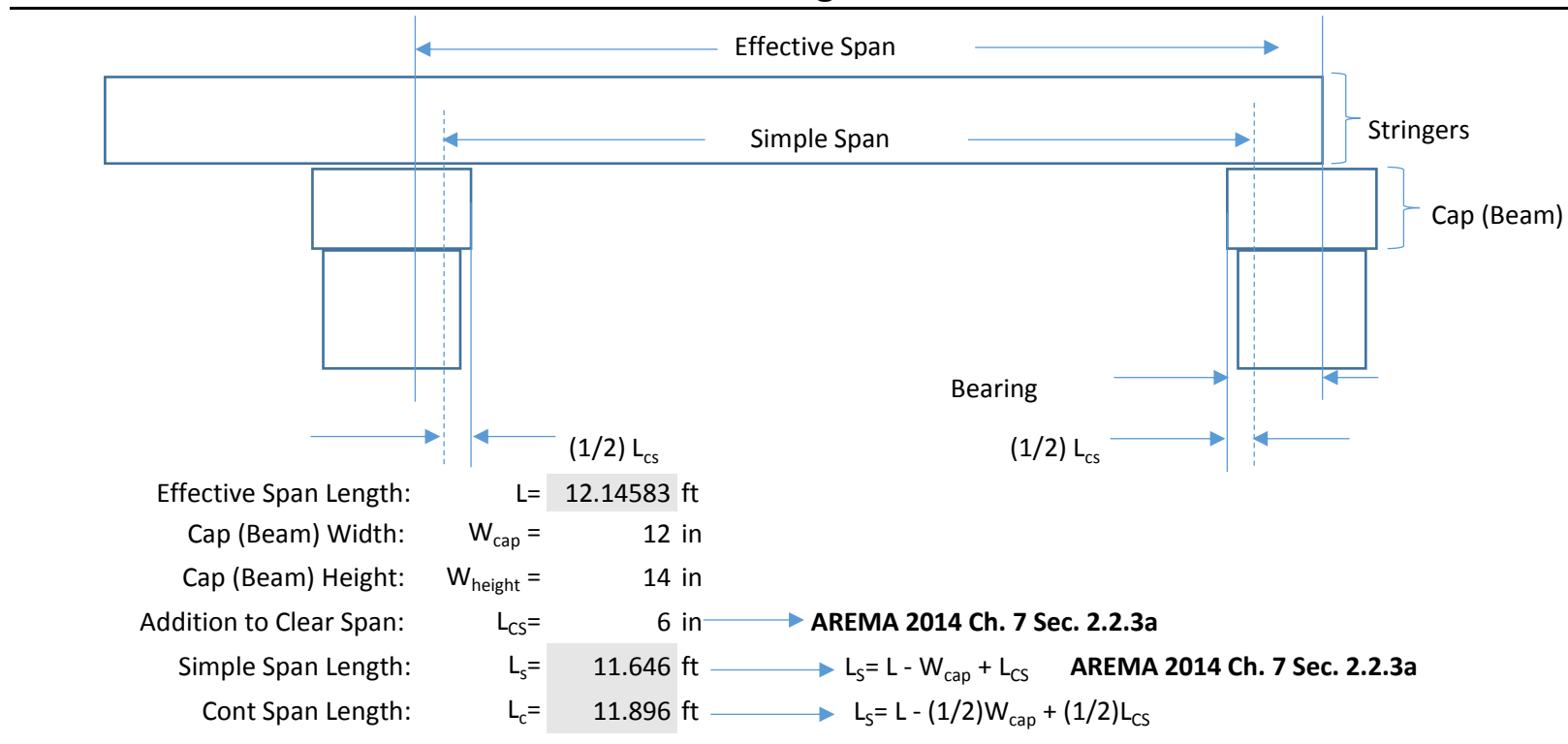

STRINGERS

\begin{tabular}{|c|c|c|c|c|c|}
\hline Number of Strigners: & $\mathrm{n}_{\mathrm{s}}=$ & 4 under each rail & & & \\
\hline Stirnger Width: & $w_{S}=$ & 8 in & $w_{s} \cdot h_{s}^{3} / 12$ & & \\
\hline Stringer Height: & $h_{s}=$ & 16 in & & & \\
\hline Stringer Moment of Inertia: & $\mathrm{I}_{\mathrm{S}}=$ & 2730.667 in $^{4}$ & & & \\
\hline Stringer Section Modulus: & $\mathrm{S}_{\mathrm{S}}=$ & $341.333 \mathrm{in}^{3} \longrightarrow \mathrm{S}_{\mathrm{S}}=$ & $\mathrm{I}_{\mathrm{S}}$ & $=$ & 2730.667 \\
\hline Stringer Density: & $v_{s}=$ & $60 \mathrm{lb} / \mathrm{ft}^{3}$ & $\mathrm{~h}_{\mathrm{s}} / 2$ & & $16 / 2$ \\
\hline
\end{tabular}

AREMA Ch.7 Sec. 2.3.2 Dead Load (5lb per foot board = 1"x12"x12" = $60 \mathrm{lb} / \mathrm{ft}^{3}$ )

WOOD SPECIES

Wood Grade: Southern Yellow Pine, Select Structural, $5 \times 5$ AREMA Table 7-2-9

$\begin{array}{rlr}\text { Bending Stress: } & \mathrm{f}_{\mathrm{b}}= & 1350 \mathrm{psi} \\ \text { Shear Stress: } & \mathrm{f}_{\mathrm{v}}= & 150 \mathrm{psi} \\ \text { Modulus of Elasticity: } & \mathrm{E}= & 1500 \mathrm{psi}\end{array}$

TIES

Tie Size and Spacing (actual dimensions as measured in the field)

\begin{tabular}{|c|c|c|c|}
\hline Tie width: & $w_{t}=$ & 8 in & \\
\hline Tie height & $h_{t}=$ & 8 in & AREMA 2.3.2 Dead Load (5lb per foot board = 1"x12"x12" = $60 \mathrm{lb} / \mathrm{ft}^{3}$ ) \\
\hline Tie spacing: & $\mathrm{sp}_{\mathrm{t}}=$ & 12 in & \\
\hline Tie Length: & $L_{t}=$ & $10 \mathrm{ft}$ & \\
\hline Tie Density: & $\gamma_{t}=$ & $60 \mathrm{lb} / \mathrm{ft}^{3}$ & \\
\hline
\end{tabular}

\section{ALLOWABLE STRESS FOR STRINGERS}

Depth Factor:
$\mathrm{F}_{\mathrm{h}}:=$ DepthFactor $\left(\mathrm{h}_{\mathrm{s}}\right)=$
1 $\quad \begin{gathered}1 \text { if } \mathrm{h} \leq 16 \mathrm{in} \\ 0.81 \cdot \frac{\mathrm{h}^{2}+143 \mathrm{in}}{\mathrm{h}^{2}+88 \mathrm{in}^{2}} \text { otherwise }\end{gathered}$

Allowable Increase in unit Stress for Regularly Assigned Equipment or Locomotives:

$$
f_{\text {INC }}=1.1
$$

Allowable Increase in unit Stress for Not Regularly Assigned $\quad f_{I N C}=1.3$ Equipment or Locomotives: AREMA 7-3.1.14

Allowable Stress for Rating:
For $\mathrm{Fb}$, if $\mathrm{d}>12$ " then multiply by $\mathrm{Cr}=(12 / \mathrm{d})^{1 / 9}, \mathrm{Cr}=0.969$ Not Regularly Assigned Locomotive Regularly Assigned Locomotive

\begin{tabular}{ll|ll}
$\mathrm{Fb}_{\mathrm{n}}=\mathrm{Cr}^{*} \mathrm{f}_{\mathrm{INC}} * \mathrm{f}_{\mathrm{b}} * \mathrm{~F}_{\mathrm{h}}=$ & $1700 \mathrm{psi}$ & $\mathrm{Fb}_{\mathrm{a}}=\mathrm{Cr} * \mathrm{f}_{\mathrm{INC}} * \mathrm{f}_{\mathrm{b}} * \mathrm{~F}_{\mathrm{h}}=$ & $1438 \mathrm{psi}$
\end{tabular}




\begin{tabular}{ll|l|l} 
Horizontal Shear: & $\mathrm{Fv}_{\mathrm{n}}=\cdot \mathrm{f}_{\mathrm{INC}} * \mathrm{f}_{\mathrm{v}}=\quad 195 \mathrm{psi}$ & $\mathrm{Fv}_{\mathrm{a}}=\mathrm{f}_{\mathrm{INC}} * \mathrm{f}_{\mathrm{v}}=\quad 165$ psi \\
\hline
\end{tabular}

AREMA 2014 Ch. 15 Sec. 7.3.1 (Ch. 15 Commentary Sec. 9.7.3.1)

Regularly Assigned (Normal) rating:

.- Normal rating is the load level that can be carried by the existing structure for its expected service life.

Not Regularly Assigned (Maximum) rating:

-- Maximum rating is the load level that the structure can support at infrequent intervals.

\section{DEAD LOADS}

Track rails, inside guide rail \& fastening: $\quad \mathrm{dl}_{\text {track }}=\quad 200 \mathrm{lb} / \mathrm{ft} \quad$ AREMA 2.3.2 Dead Load

Ties: $\quad \mathrm{dl}_{\text {ties }}=\mathrm{w}_{\mathrm{t}}{ }^{*} \mathrm{~h}_{\mathrm{t}}{ }^{*} \mathrm{~L}_{\mathrm{t}}{ }^{*} \mathrm{~V}_{\mathrm{t}} / \mathrm{sp}_{\mathrm{t}}=\underline{8 * 8 * 10 * 60}=266.7 \mathrm{lb} / \mathrm{ft}$

$12 * 12$

Guard Timber: $\mathrm{dl}_{\mathrm{gt}}=2 * 4 \mathrm{in}^{*} 8 \mathrm{in}^{*} \mathrm{Y}_{\mathrm{t}}=\quad 2 * 4 * 8 * 60 / 144=\quad 26.7 \mathrm{lb} / \mathrm{ft}$

Stringers: $\quad \mathrm{dl}_{\mathrm{s}}=\mathrm{w}_{\mathrm{s}}{ }^{*} \mathrm{~h}_{\mathrm{s}}{ }^{*} \gamma_{\mathrm{s}}{ }^{*} \mathrm{n}_{\mathrm{s}}{ }^{*} 2=8 * 16 * 60 * 4 * 2 / 144=426.667 \mathrm{lb} / \mathrm{ft}$

Total DL: $\mathrm{W}_{\mathrm{DL}}=\mathrm{dl}_{\text {track }}+\mathrm{dl}_{\text {ties }}+\mathrm{dl}_{\mathrm{gt}}+\mathrm{dl}_{\mathrm{s}}=200+266.7+26.7+426.667=920 \mathrm{lb} / \mathrm{ft} \quad$ timber= $5 \mathrm{lb}$ per ft board measure

\section{LIVE LOADS}

Cooper E 80 Load (loads shown are for each axle)

AREMA 7-2.3.3 Live Load

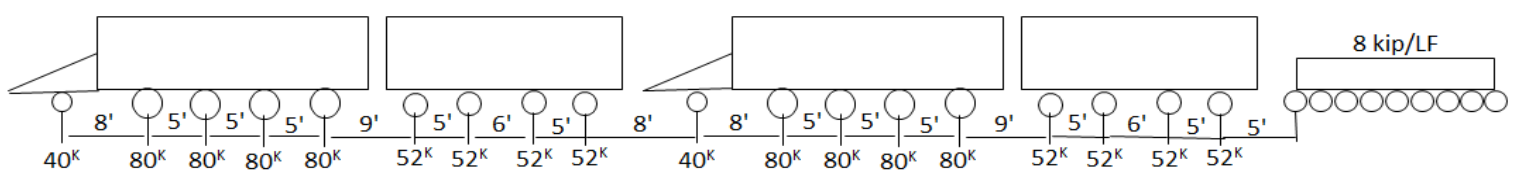

*All other Cooper ratings are proportional to the Cooper 10 loading by a certain value. i.e.Cooper E 80 is a Cooper E 10 times 8 , meaning all axle loads are to be multiplied times 8.

\section{COMPUTATION OF STRESSES}

\section{AREMA 7-3.1.5}

\section{AREMA 2014 Ch. 7 Sec. 3.1.5c}

Continuity occurring in stringers. Where the support under a rail consists of three or more stringers assembled as a chord, or otherwise acting in unison, and extending over two spans with staggered joints, a partially continuous beam action may be assumed to exist, and the computations may be made for stringers based on the average stress as determined from single beam analysis and that for a fully continuous condition.

\section{AREMA 2014 Ch. 7 Sec. 2.3.8 Impact}

The dynamic increment of load due to the effects of speed, roll and track irregularities is not well established for timber structures. Its total effect is estimated to be less than the increased strength of timber for the short cumulative duration of loading to which railroad bridges are subjected in service, and is taken into consideration in the derivation of allowable working stresses for design.

\section{AASHTO LRFD 2012 Bridge Design Specifications 6th Edition - Article 3.6.2.3 Wood Components}

Dynamic load allowance (IM) need not be applied to wood components.

\section{Moment Ratings}

Single beam moments:

Dead Load Moment:

$$
\mathrm{M}_{\mathrm{DL} \_ \text {Simp }}=\text { Moment }(\mathrm{RISA} \text { input })=15.54 \mathrm{ft} \cdot \mathrm{kips}
$$

Live Load Moment:

$$
\left.\mathrm{M}_{\mathrm{LL} \_ \text {Simp }}=\text { Moment (RISA input }\right)=\quad 296.7 \mathrm{ft} \cdot \mathrm{kips} \quad(\text { Cooper } \mathrm{E} 80 \text { Load })
$$

Two-span continuous beam moments:

DL Moment:

$$
\left.\mathrm{M}_{\mathrm{LL} \_ \text {Cont }}=\text { Moment (RISA input }\right)=\quad 6.14 \mathrm{ft} \cdot \text { kips } \quad \mathrm{L}_{\mathrm{c}}=\text { Continuous Span Length }
$$

Live Load Moment:

$$
\left.\mathrm{M}_{\mathrm{LL} \_ \text {Cont }}=\text { Moment (RISA input }\right)=172.477 \mathrm{ft} \cdot \mathrm{kips} \quad \text { (Cooper } \mathrm{E} 80 \text { Load on cont. spans) }
$$


Average bending Moments:

$$
\begin{array}{cc}
M_{D L}=\frac{M_{D L_{-} \text {Simp }}+M_{D L_{-} \text {Cont }}}{2}= & 10.842 \mathrm{ft} \cdot \mathrm{kips} \\
M_{L L}=\frac{M_{L L_{-} \text {Simp }}+M_{\text {LL_Cont }}}{2}= & 234.572 \mathrm{ft} \cdot \mathrm{kips}
\end{array}
$$

Bending moments and stresses per stringer:

$$
\begin{array}{ccc}
M_{D L_{-} S t r}=\frac{M_{D L}}{2 n_{S}}= & 1.355 \mathrm{ft} \cdot \mathrm{kips} & \mathrm{n}_{\mathrm{s}}=\text { number of stringers under one rail } \\
f_{D L}=\frac{M_{D L} S t r}{S_{S}}= & 48 \mathrm{psi} & \mathrm{S}_{\mathrm{s}}=\text { Stringer Section Modulus } \\
M_{L L_{-} S t r}=\frac{M_{L L}}{2 n_{S}}= & 29.322 \mathrm{ft} \cdot \mathrm{kips} & \\
f_{L L}=\frac{M_{L L \_S t r}}{S_{S}}= & 1031 \mathrm{psi}
\end{array}
$$

\section{MOMENT RATINGS}

$\mathrm{Fb}_{\mathrm{a}}=$ allowable bending stress for regularly assigned locomotives $=\quad 1438 \mathrm{psi}$

$\mathrm{Fb}_{\mathrm{n}}=$ allowable bending stress for locomotives not regularly assigned $=1700 \mathrm{psi}$

AREMA 2014 Table 7-2-9

Assigned Locomotives

$$
\begin{gathered}
\mathrm{RFM}_{\mathrm{a}}:=\frac{F b_{a}-f_{D L}}{f_{L L}}=\frac{1438-48}{1031}=1.35 \quad \text { Cooper E Rating } \quad \mathrm{Em}_{\mathrm{a}}=\operatorname{round}\left(\mathrm{RFM}_{\mathrm{a}} \cdot 80\right)= \\
\text { Cooper E Rating }-107.9
\end{gathered}
$$

\section{Cooper E Rating - 107.9}

$$
\begin{array}{r}
\mathrm{RFM}_{\mathrm{n}}:=\frac{F b_{n}-f_{D L}}{f_{L L}}=\frac{1700-48}{1031}=1.603 \quad \text { Cooper } E \text { Rating } \quad \mathrm{Em}_{\mathrm{n}}=\operatorname{round}\left(\mathrm{RFM}_{\mathrm{n}} \cdot 80\right)= \\
\text { Cooper E Rating }-\mathbf{1 2 8 . 2}
\end{array}
$$

\section{Cooper E Rating - 128.2}

\section{HORIZONTAL SHEAR RATINGS}

AREMA 2.5.9c

In calculating the maximum shear, $V$, use the following rules:

$1 \mathrm{~V}$ shall be calculated at a distance " $\mathrm{d}$ " away from the face of support equal to the height of the stringer.

2 Neglect all loads within the height of the beam from the face of the support.

3 Moving loads shall be placed such that they produce the maximum value for $\mathrm{V}$

4 When a beam spans continuously over one or more supports, continuity shall be considered when calculating $\mathrm{V}$.

5 Take into account any relief to the beam under consideration resulting from the loading being distributed to adjacents parallel beams by flooring or other members of the construction.

\section{Single beam Shear}

Dead Load Shear:

$\mathrm{V}_{\text {DL_Simp }}=\operatorname{Shear}(\mathrm{RISA}) @ \mathrm{~d}^{\prime}=\quad 3.891$ kips

Live Load Shear:

$V_{\text {LL_Simp }}=$ Shear $($ RISA $) @ d^{\prime}=108.42$ kips $d^{\prime}=$ Distance from end of beam to stringer depth from face of support for continuous spans.

(Cooper E 80 Load)

Shear at stringer depth from face 
Two span continuous beam shears:

Dead Load Shear:

$$
\mathrm{V}_{\mathrm{DL} \_ \text {Cont: }}=\mid \text { Shear }(\mathrm{RISA}) \mid @ \mathrm{~d}^{\prime}=\quad 3.910 \text { kips } \quad \mathrm{d}^{\prime}=\text { Distance from end of beam to stringer depth }
$$
from face of support for continuous spans.

Live Load Shear:

\section{AREMA 2.3.3 Live Load}

$$
\mathrm{V}_{\mathrm{LL} \_ \text {Cont: }}=\mid \text { Shear }(\mathrm{RISA}) \mid @ \mathrm{~d}^{\prime}=
$$$$
\text { from interior support }
$$

114.04 kips

(Cooper E 80 Load on cont spans)

Average Shears:

$$
\begin{array}{ll}
\mathrm{V}_{\mathrm{DL}}:=\frac{V_{D L \text { Simp }}+V_{D L \text { cont }}}{2}= & 3.90 \mathrm{kips} \\
\mathrm{V}_{\mathrm{LL}}:=\frac{V_{L L \text { Simp }}+V_{L L \text { cont }}}{2}= & 111.23 \mathrm{kips}
\end{array}
$$

Shears and horizontal shear stresses per stringer:

\section{AREMA 2.5.9 Horizontal Shear}

$$
\begin{aligned}
& \mathrm{Fv}:=\frac{3 \cdot V}{2 \cdot b \cdot h} \\
& V_{D L_{-} S t r}=\frac{V_{D L}}{2 n_{S}}=\quad 0.488 \text { kips } \quad \mathrm{h}_{\mathrm{s}}=\text { height of stringer }=16 \mathrm{in} \\
& f v_{D L}=\frac{3 V_{D L_{S} S t r}}{2 w_{S} h_{S}}=\quad 6 \mathrm{psi} \quad \mathrm{W}_{\mathrm{S}}=\text { width } \text { of } \text { stringer }=8 \mathrm{in} \\
& V_{L L_{-} S t r}=\frac{V_{L L}}{2 n_{S}}=\quad 13.904 \text { kips } \\
& f v_{L L}=\frac{3 V_{L L} S t r}{2 w_{S} h_{S}}=\quad 163 \mathrm{psi}
\end{aligned}
$$

SHEAR RATINGS:

$$
\begin{aligned}
\mathrm{Fv}_{\mathrm{a}}=\text { allowable shear stress for regularly assigned locomotives }= & 165 \mathrm{psi} \\
\mathrm{Fv}_{\mathrm{n}}=\text { allowable shear stress for locomotives not regularly assigned }= & 195 \mathrm{psi}
\end{aligned}
$$

Assigned Locomotive
$\operatorname{RFV}_{\mathrm{a}}:=\frac{F v_{a}-f v_{D L}}{f v_{L L}}=\frac{165-6}{163}=$
0.978
Cooper E Rating
$\mathrm{EV}_{\mathrm{a}}=\operatorname{round}\left(\mathrm{RFV}_{\mathrm{a}} \cdot 80\right)=$
Cooper E Rating - 78.2
Non-Assigned Locomotive
$\mathrm{RFV}_{\mathrm{n}}:=\frac{F v_{n}-f v_{D L}}{f v_{L L}}=\frac{195-6}{163}=$
Cooper E Rating
$\mathrm{EV}_{\mathrm{n}}=\operatorname{round}\left(\mathrm{RFV}_{\mathrm{n}} \cdot 80\right)=$
96

\section{Equivalent Cooper E Loadings}

\section{Load 1 - Covered Hopper Car}

286 K Railcar - Drawn by Lochner, 2012

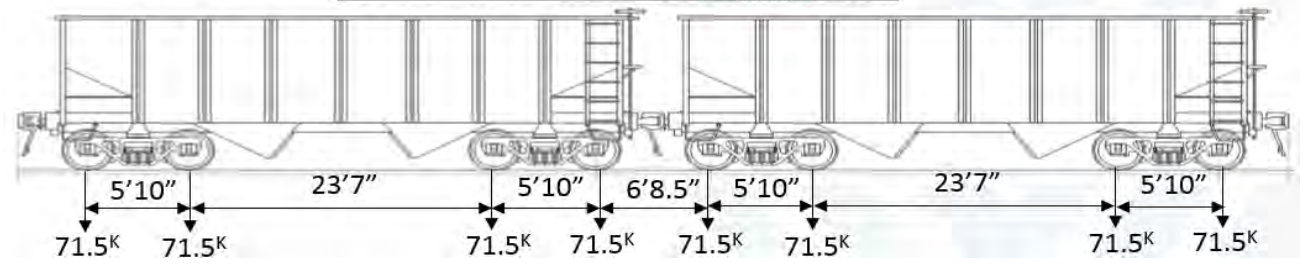

Simple Span Moment 


$$
\mathrm{M}_{\text {HP_Simp }}:=\text { Moment }(\mathrm{RISA} \text { input })=207.052 \mathrm{ft} \cdot \mathrm{kips} \quad\left(\text { Max M from moving 286K load on } \mathrm{L}_{\mathrm{s}}\right)
$$

Continuous Span Moment

$$
\mathrm{M}_{\mathrm{HP} \_ \text {Cont }}:=\text { Moment2(RISA input)= } 154.977 \mathrm{ft} \cdot \text { kips } \quad \text { (Max }+\mathrm{M} \text { from moving 286K load on cont. } \mathrm{L}_{\mathrm{c}} \text { spans) }
$$

Bending stresses per stringer:

$$
\begin{array}{cc}
M_{H P}=\frac{M_{H P_{-} \text {Simp }}+M_{H P_{-} \text {Cont }}}{2}= & 181.015 \mathrm{ft} \cdot \mathrm{kips} \\
M_{H P_{-} S t r}=\frac{M_{H P}}{2 n_{S}}= & 22.627 \mathrm{ft} \cdot \mathrm{kips} \\
f_{H P}=\frac{M_{H P_{-} S t r}}{S_{S}}= & 0.795 \mathrm{ksi} \\
M E_{H P}=\frac{80 * M_{H P}}{M_{L L}}= & 61.734
\end{array}
$$

Single span shear:

$$
\mathrm{V}_{\text {HP_Simp }}:=\text { Shear }(\text { RISA input })=87.34205 \text { kips } \quad \text { Max V @ d' }
$$

Two continuous spans shear:

$$
\mathrm{V}_{\text {HP_Cont }}:=\mid \text { Shear2(RISA)@ d' } \mid=95.69181 \text { kips }
$$

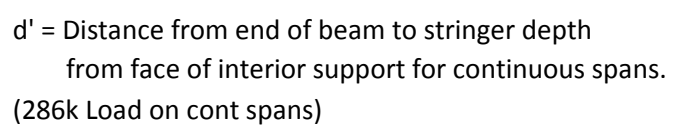

Shears and horizontal shear stresses per stringer:

$$
\begin{aligned}
& V_{H P}=\frac{V_{H P \_S i m p}+V_{H P \_C o n t}}{2}=91.517 \mathrm{kips} \\
& V_{H P_{-} S t r}=\frac{V_{H P}}{2 n_{S}}=\quad 11.440 \mathrm{kips} \\
& f v_{H P}=\frac{3 V_{H P} S t r}{2 w_{S} h_{S}}=\quad 134.058 \mathrm{psi} \\
& V E_{H P}=\frac{80 * V_{H P}}{V_{L L}}=\quad 65.821
\end{aligned}
$$

Equiv. Cooper E Load - E $\quad 65.8$

Hopper Load OK

Load 2 - GP38 Locomotive

General Purpose 38-2 (GP 38-2) - Drawn by Elbv, 2016

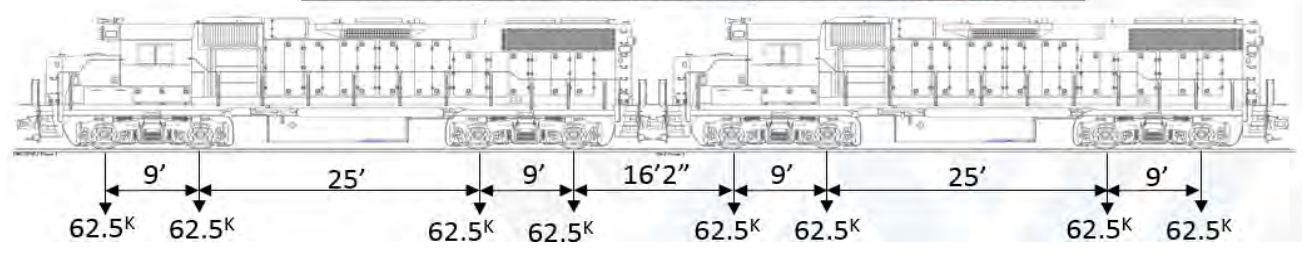

$\underline{\text { Simple Span Moment }}$

$$
\mathrm{M}_{\mathrm{GP} \_ \text {Simp }}:=\text { Moment }(\mathrm{RISA})=180.99 \mathrm{ft} \cdot \mathrm{kips}
$$


Continuous Span Moment

$$
\left.M_{\text {GP_Cont }}:=\text { Moment2(RISA }\right)=\quad 114.339 \mathrm{ft} \cdot \text { kips } \quad\left(\text { Max }+M \text { on } 2 \text { cont. } L_{c} \text { spans under GP38 load }\right)
$$

Bending stresses per stringer:

$$
\begin{array}{cc}
M_{G P}=\frac{M_{G P_{-} S i m p}+M_{G P_{-} \text {Cont }}}{2}= & 147.665 \mathrm{ft} \cdot \mathrm{kips} \\
M_{G P_{-} S t r}=\frac{M_{G P}}{2 n_{S}}= & 18.458 \mathrm{ft} \cdot \mathrm{kips} \\
f_{G P}=\frac{M_{G P_{-} S t r}}{S_{S}}= & 0.649 \mathrm{ksi} \\
M E_{G P}=\frac{80 * M_{G P}}{M_{L L}}= & 50.360
\end{array}
$$

Equiv. Cooper E Load - E $\quad 50.4$

Single span shears:

$$
\left.\mathrm{V}_{\mathrm{GP} \_ \text {Simp }}:=\text { Shear(RISA input }\right)=60.17722 \text { kips } \quad \text { Max V @ d' }
$$

Two continuous spans shears:

$$
\mathrm{V}_{\text {GP_Cont }}:=\mid \text { Shear(RISA) @ d' } \mid=64.53916 \text { kips }
$$

$$
\begin{aligned}
& d^{\prime}=\text { Distance from end of beam to stringer depth } \\
& \text { from face of interior support for continuous spans. }
\end{aligned}
$$

(286k Load on 2 cont spans )

Shears and horizontal shear stresses per stringer:

$$
\begin{aligned}
& V_{G P}=\frac{V_{G P \_S i m p}+V_{G P \_C o n t}}{2}=\quad 62.358 \mathrm{ft} \cdot \mathrm{kips} \\
& V_{G P_{-} S t r}=\frac{V_{G P}}{2 n_{S}}=\quad 7.79 \mathrm{kips} \\
& f v_{G P}=\frac{3 V_{G P} S t r}{2 w_{S} h_{S}}=\quad 91.345 \mathrm{psi} \\
& V E_{G P}=\frac{80 * V_{G P}}{V_{L L}}=\quad 44.849
\end{aligned}
$$

Equiv. Cooper E Load - E $\quad 44.8$

\section{GP38 Load OK}

\section{Load 3 - WM 82 Locomotive}

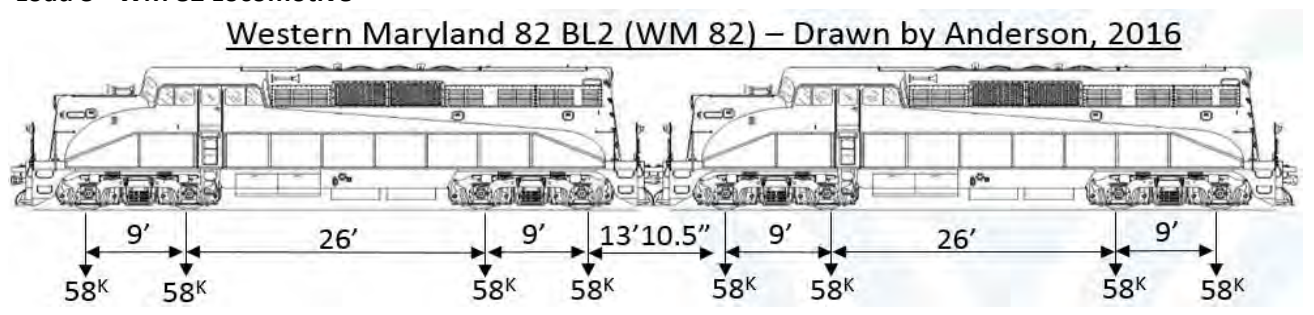

Single Span Moment

$$
\mathrm{M}_{\mathrm{GP} \_ \text {Simp }}:=\text { Moment }(\mathrm{RISA} \text { input })=167.958 \mathrm{ft} \cdot \mathrm{kips}
$$

Continuous Span Moment

$$
\left.\mathrm{M}_{\mathrm{GP}_{-} \text {Cont }}:=\text { Moment2(RISA input }\right)=107.229 \mathrm{ft} \cdot \mathrm{kips}
$$


Bending stresses per stringer:

$$
\begin{array}{cc}
M_{G P}=\frac{M_{G P_{-} S i m p}+M_{G P_{-} C o n t}}{2}= & 137.594 \mathrm{ft} \cdot \mathrm{kips} \\
M_{G P_{S} S t r}=\frac{M_{G P}}{2 n_{S}}= & 17.199 \mathrm{ft} \cdot \mathrm{kips} \\
f_{G P}=\frac{M_{G P \_S t r}}{S_{S}}= & 0.605 \mathrm{ksi} \\
M E_{G P}=\frac{80 * M_{G P}}{M_{L L}}= & 46.926
\end{array}
$$

Equiv. Cooper E Load - E

46.9

Single span shears:

$$
\left.\mathrm{V}_{\text {GP_Simp }}:=\text { Shear(RISA input }\right)=55.84438 \text { kips } \quad \text { Shear at stringer depth from support }
$$

Two continuous spans shears:

$$
\mathrm{V}_{\text {GP_Cont }}:=\mid \text { Shear2(RISA)@ d' } \mid=59.7616 \text { kips }
$$

Shears and horizontal shear stresses per stringer:

$$
\begin{gathered}
V_{G P}=\frac{V_{G P_{-} \text {Simp }}+V_{G P_{-} \text {Cont }}}{2}=\quad 57.803 \mathrm{kips} \\
V_{G P_{-} S t r}=\frac{V_{G P}}{2 n_{S}}= \\
f v_{G P}=\frac{3 V_{G P \_S t r}}{2 w_{S} h_{S}}=\quad 84.672 \mathrm{kips} \\
V E_{G P}=\frac{80 * V_{G P}}{V_{L L}}=
\end{gathered}
$$

TIMBER POST OR PILES (No. 2 Southern Pine, 5" x 5" and larger)

$\begin{array}{lcl}\text { (Piles):= } & 5 & \text { Number of Piles per bent } \\ \mathrm{F}_{\mathrm{C}}= & 475 \mathrm{psi} & \text { Allowable Compressive Stress Parallel to Grain } \\ \mathrm{L}_{\mathrm{u}}= & 12 \mathrm{ft} & \text { Unbraced Length - Max Between longitudinal braces }\end{array}$

No Reduction in capacity since $\mathrm{L} / \mathrm{d} \leq 11$, see table $7-2-10$

Apile $:=12 \mathrm{in} \times 12 \mathrm{in}=\quad 144 \mathrm{in}^{2} \quad$ Area of One 12" Post

Allowable Compressive Stress AREMA Table 7-3-1 (AREMA 2004 Table 7-2-20 p.7-2-119)

\begin{tabular}{|l|ll|}
\hline Regularly Assigned Locomotive & $1.1 \mathrm{f}_{\mathrm{c}}=$ & $522.5 \mathrm{psi}$ \\
\hline Not Regularly Assigned Locom. & $1.3 \mathrm{f}_{\mathrm{c}}=$ & $617.5 \mathrm{psi}$ \\
\hline
\end{tabular}

Live Load Reactions of the track at an interior bent

Highest reaction load taken by an interior bent with weakest post (Bent 7)

(LLRXN1):= 135.7905 kips Live Load Reaction for the 286 kip hopper car fully loaded (LLRXN2):= 83.058 kips Live Load Reaction for the GP 38 Locomotive.

(LLRXN3):= 183.09 kips Live Load Reaction for the Copper E 80 Load

(LLRXN4):= 76.9315 kips Live Load Reaction for the wm82 Locomotive. 


\section{Dead Load Reactions of the track at an interior bent}

DLRXN:= Superstructure + Caps + Posts =

12829 lb Dead Load Reaction at Interior Support With

12.829 kips Pier Dead Load Added In (Bent 7)

Total Reactions of the track at an interior bent

\begin{tabular}{rrll}
\hline TLRXN1 $:=$ LLRXN1 + DLRXN $=$ & 148.6195 kips & 286 kip rail car, Total reaction per Track \\
TLRXN2 $:=$ LLRXN2 + DLRXN $=$ & 95.887 kips & GP 38 \\
TLRXN3 $:=$ LLRXN3 + DLRXN = & 195.9165 kips & Cooper E 80 \\
TLRXN4 := LLRXN4 + DLRXN = & 89.7605 kips & WM82
\end{tabular}

Percent of the Rail Load Per Pile

Use the Pile Design Aids Provided by AREMA to get the fraction of the rail reaction that is distributed to each pile:
$\begin{array}{ll}\text { (Pile1Fr: }= & 0.31 \\ \text { (Pile2Fr: } & 0.47\end{array}$
Fraction of Rail Load Taken by Outer Pile, (Piles 1 and 4)
$\begin{array}{ll}\text { (Pile2Fr:= } & 0.47 \\ \text { (Pile3Fr: }= & 0.22\end{array}$
Fraction of Rail Load Taken by Intermediate Pile, (Piles 2 and 3)

Per Pile

Cooper Rating Per Pile

Since the Pile 1 is of No. 2 grade, while all others are Select Structural, Get the Cooper Rating for It

$$
\text { (MaxPileLd := Pile1Fr·TLRXN1·0.5 = } 22.912 \text { kips })
$$

Regularly Assigned Locomotive:

$$
\begin{aligned}
& \mathrm{CRF}:=\frac{F c-\frac{D L R X N \cdot 0.5 \cdot P i l e 1 F r}{\text { Apile }}}{\frac{L L R X N 3 \cdot \text { Pile1Fr } \cdot 0.5}{\text { Apile }}}=\frac{522.5-\frac{13829(0.5) 0.31}{144}}{\frac{183090(0.31) 0.5}{144}}=2.60
\end{aligned}
$$

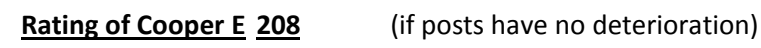

Not Regularly Assigned Locomotive:

$$
\begin{aligned}
& \mathrm{CRF}:=\frac{F C-\frac{\text { DLRXN.0.5.Pile1Fr }}{\text { Apile }}}{\frac{L L R X N 3 \cdot \text { Pile1Fr } \cdot 0.5}{\text { Apile }}}=\quad \frac{617.5-\frac{13829(0.5) 0.31}{144}}{\frac{183090(0.31) 0.5}{144}}=3.08
\end{aligned}
$$

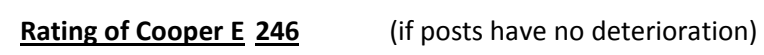

\section{Equivalent Cooper Load (ECR) for the 286 kip hopper car}

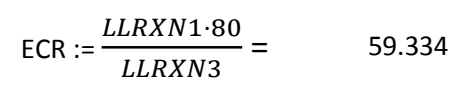

Equivalent Cooper Load for the GP 38 Locomotive

$$
\text { ECR38 : }=\frac{L L R X N 2 \cdot 80}{L L R X N 3}=36.29216
$$

Equivalent Cooper Load for the WM 82 Locomotive

$$
\text { ECR9 : }=\frac{L L R X N 4 \cdot 80}{L L R X N 3}=\quad 33.61518
$$

\begin{tabular}{|c|c|c|c|c|c|}
\hline \multirow{2}{*}{ Type } & \multicolumn{2}{|c|}{ Cooper E Rating } & \multicolumn{3}{c|}{ Equivalent Cooper E Load } \\
\cline { 2 - 6 } & $\begin{array}{c}\text { Regularly } \\
\text { Assigned }\end{array}$ & $\begin{array}{c}\text { Not } \\
\text { Regularly } \\
\text { Assigned }\end{array}$ & $286 \mathrm{k}$ & GP38 & WM82 \\
\hline Bending & 107.9 & 128.2 & 61.7 & 50.4 & 46.9 \\
\hline Horz. Shea & 78.2 & 92.9 & 65.8 & 44.8 & 41.6 \\
\hline Pile (Post) & 207.6 & 246.4 & 59.3 & 36.3 & 33.6 \\
\hline
\end{tabular}




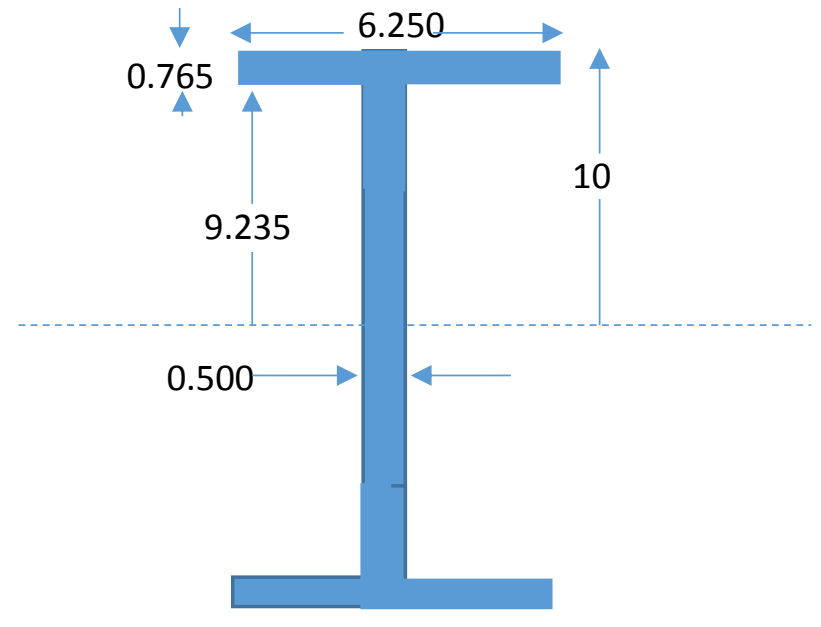

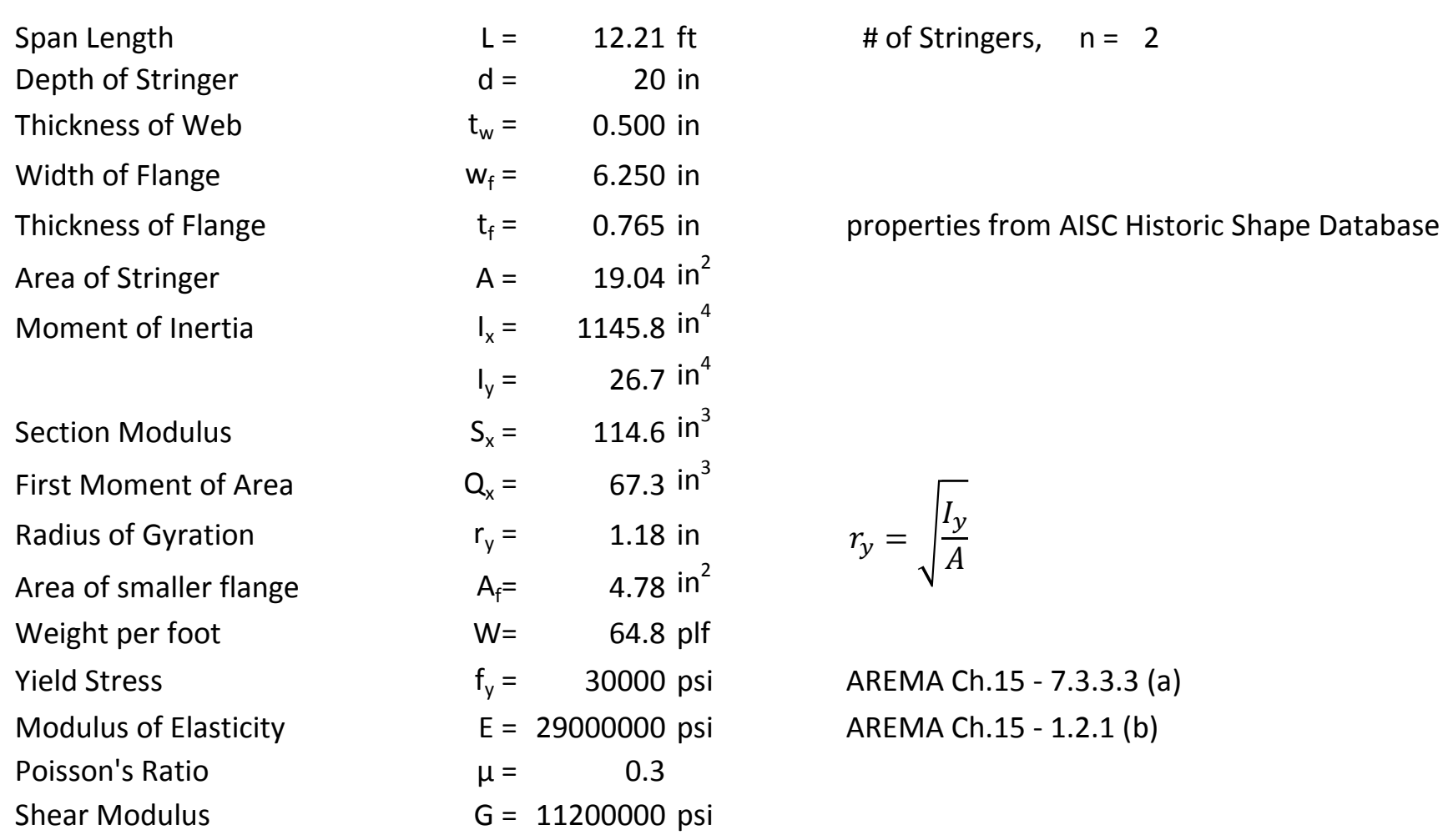

AISC Database

\begin{tabular}{|l|l|}
\hline Designation $\mathrm{S} 20 \times 64.8$ \\
\hline
\end{tabular}

\begin{tabular}{|l|l|}
\hline$A$ & 19.04 \\
\hline$d$ & 20.00 \\
\hline
\end{tabular}

\begin{tabular}{|c|c|}
\hline$A$ & 19.04 \\
\hline$d$ & 20.00 \\
\hline$t_{w}$ & 0.500 \\
\hline$b_{f}$ & 6.250 \\
\hline$t_{f}$ & 0.765 \\
\hline$T$ & 16.912 \\
\hline$k$ & 1.544 \\
\hline$W$ & 64.8 \\
\hline$I_{x}$ & 1145.8 \\
\hline$Z_{x}$ & 134.5 \\
\hline$S_{x}$ & 114.6 \\
\hline$r_{x}$ & 7.76 \\
\hline$I_{y}$ & 26.7 \\
\hline$Z_{y}$ & 14.9 \\
\hline$S_{y}$ & 8.5 \\
\hline$r_{y}$ & 1.18 \\
\hline$J$ & 3.26 \\
\hline$C_{w}$ & 2470 \\
\hline$W_{n o}$ & 30.1 \\
\hline$Q_{w}$ & 67.3 \\
\hline
\end{tabular}

Tie width:

$\begin{aligned} \mathrm{w}_{\mathrm{t}}= & 8 \mathrm{in} \\ \mathrm{h}_{\mathrm{t}}= & 12 \mathrm{in} \\ \mathrm{sp}_{\mathrm{t}}= & 12 \mathrm{in} \\ \mathrm{L}_{\mathrm{t}}= & 10 \mathrm{ft} \\ \mathrm{V}_{\mathrm{t}}= & 60 \mathrm{lb} / \mathrm{ft}^{3}\end{aligned}$

AREMA Ch.7 - 2.3.2 Dead Load (5lb per foot board = 1"x12"x12" = $60 \mathrm{lb} / \mathrm{ft}^{3}$ )

\section{Allowable Stresses}

Normal Rating: AREMA Table 15-1-11

Tension in extreme fibers of rolled shapes, $0.55 \mathrm{~F}_{\mathrm{y}}$

$\mathrm{Fbp}_{\mathrm{n}}: \quad 0.55 \mathrm{~F}_{\mathrm{y}}=16500 \mathrm{psi}$

Compression in extreme fibers of flexural members, larger of

$$
\begin{aligned}
\mathrm{Fbn}_{\mathrm{n}}: 0.55 F_{y}-\frac{0.55\left(F_{y}\right)^{2}}{6.3 \pi^{2} E}\left(\frac{l}{r_{y}}\right)^{2} & \text { or } \frac{0.131 \pi E}{(l d \sqrt{1+\mu}) / A_{f}} \quad \text { but not to exceed } 0.55 \mathrm{~F}_{\mathrm{y}} \\
12268.66 \mathrm{psi} & <\quad 17081.32 \mathrm{psi}
\end{aligned}
$$


$l=$ dist. Between points of lateral support for the compression flange

$\mathrm{Fb}_{\mathrm{n}}: \quad \mathrm{Fbn}_{\mathrm{n}}=16500 \mathrm{psi}$, controls for bending under Normal rating conditions

Shear in webs of rolled beams and plate girders, gross section, $0.35 \mathrm{~F}_{\mathrm{y}}$

$\mathrm{Fv}_{\mathrm{n}}: \quad 0.35 \mathrm{~F}_{\mathrm{y}}=10500 \mathrm{psi}$

Maximum Rating: AREMA Ch.15 - 7.3.3.3 \& Table 15-7-1

Tension in extreme fibers of rolled shapes, $0.8 \mathrm{~F}_{\mathrm{y}}$

$\mathrm{Fbp}_{\mathrm{m}}: \quad 0.8 \mathrm{~F}_{\mathrm{y}}=\quad 24000 \mathrm{psi}$

Compression in extreme fibers of flexural members, larger of

$$
\begin{aligned}
& \mathrm{Fbn}_{\mathrm{m}}: 0.8 F_{y}-\frac{0.8 F_{y}}{1.8 \times 10^{9}}\left(\frac{l}{r_{y}}\right)^{2} \quad \text { or } \quad\left(\frac{0.8 F_{y}}{0.55 F_{y}}\right) \frac{10,500,000}{l d / A_{f}} \quad \text { but not to exceed } 0.8 \mathrm{~F}_{\mathrm{y}} \\
& 23999.79 \mathrm{psi} \quad 24922.43 \text { psi } \\
& \mathrm{Fb}_{\mathrm{m}}: \quad \mathrm{Fbn}_{\mathrm{m}}=\quad 24000 \mathrm{psi}, \text { controls for bending under Maximum rating conditions } \\
& \text { Shear in webs of plate girders and rolled beams, gross section, } 0.75\left(0.8 \mathrm{~F}_{\mathrm{y}}\right) \\
& \mathrm{Fv}_{\mathrm{n}}: 0.75\left(0.8 \mathrm{~F}_{\mathrm{y}}\right)=18000 \mathrm{psi}
\end{aligned}
$$

Allowable Stress for Rating:

\begin{tabular}{|c|c|c|}
\hline & Normal & Maximum \\
\hline Bending Moment: & $16500 \mathrm{psi}$ & $24000 \mathrm{psi}$ \\
\hline Shear: & $10500 \mathrm{psi}$ & $18000 \mathrm{psi}$ \\
\hline
\end{tabular}

AREMA 2014 Ch. 15 Sec. 7.3.1 (Ch. 15 Commentary Sec. 9.7.3.1)

Normal rating:

- Normal rating is the load level that can be carried by the existing structure for its expected service life.

Maximum rating:

- Maximum rating is the load level that the structure can support at infrequent intervals.

\section{DEAD LOADS}

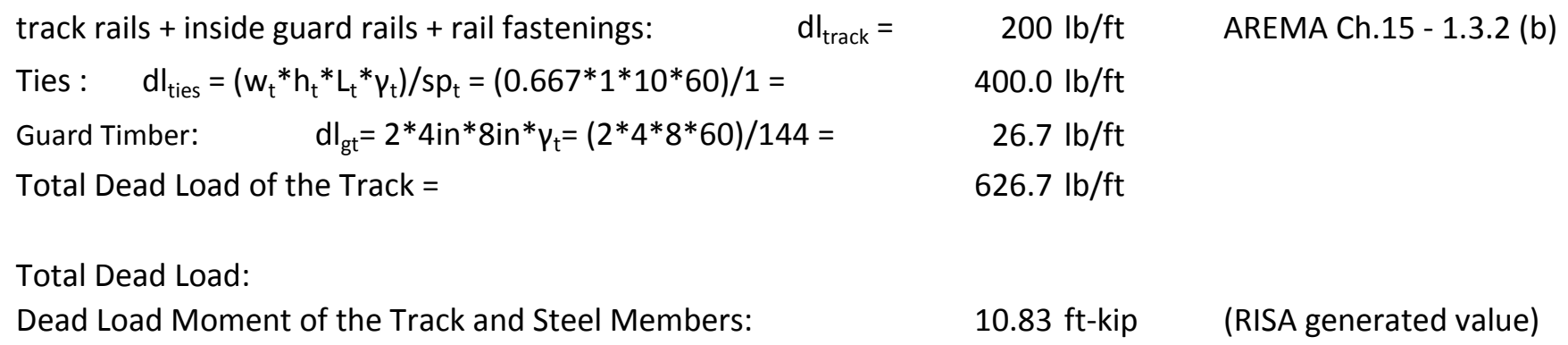

\section{LIVE LOADS}

Live Load Factors

Impact Load: AREMA Ch.15 - 1.3.5c(1)(a)

$\operatorname{Im}=40-3 L^{2} / 1600$, for $L$ less than 80 feet $(L=11.25 \mathrm{ft})$

$\mathrm{Im}=\quad 39.72 \%$

AREMA Ch.7 - 7.3.2.3a (1) : for train speeds below $60 \mathrm{mph}$, the values of the vertical effects of the impact equations shall be multiplied by the factor:

$$
\begin{gathered}
1-\frac{0.8}{2500}(60-S)^{2} \geq 0.2, \quad \text { where } S=\text { speed } \text { in } m p h \\
0.20 \geq 0.2
\end{gathered} \quad \mathrm{~S}=10 \quad \mathrm{mph}
$$

Thus, $\operatorname{Im}=39.72(0.2)=7.94 \%$ 
Rocking Effect: AREMA Ch.15-1.3.5d : impact load due to rocking effect, RE, shall be calculated as $20 \%$ of the wheel load without impact, acting downward on one rail and upward on the other.

$$
\mathrm{RE}=20 \%
$$

Centrifugal Force: AREMA Ch.15 - 1.3.6: Factor applied where horizontal curvature of the track is present. No centrigual forces are acting on this bridge.

Cooper $\mathbf{8 0}$ Load (loads shown are for each axle)

AREMA Ch.15 - 1.3.3a Live Load

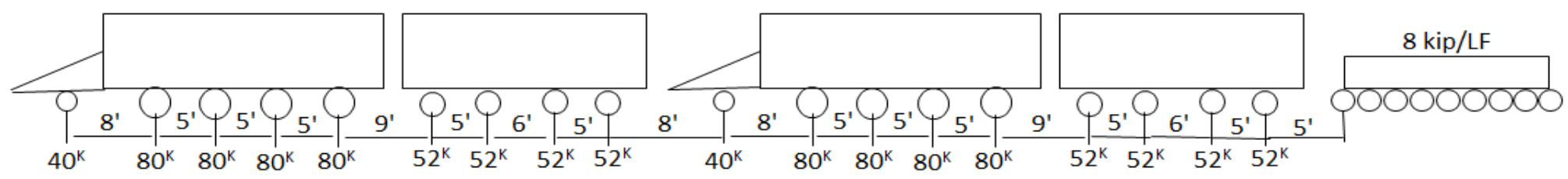

${ }^{*}$ All other Cooper ratings are proportional to the Cooper 10 loading by a certain value. i.e.Cooper E 80 is a Cooper E 10 times 8 , meaning all axle loads are to be multiplied times 8.

\section{COMPUTATION OF STRESSES}

AREMA Ch.15 - 7.3.3.1

All live load beding and shear forces are calculated using a RISA model with moving loads.

\section{Moment Ratings Calculations}

AREMA Ch.15 - 1.2.7b : For calculation of stresses, the length of span for stringers shall be taken as the distance between centers of floorbeams.

$$
L=12.208333 \mathrm{ft}
$$

(Unfactored) $\mathrm{M}_{\mathrm{LL} \_ \text {E80 }}=\quad 128.526 \mathrm{ft}-\mathrm{k} \quad$ (Maximum Moment by a moving load Cooper E80 on 3D model per stringer)

$$
\mathrm{M}_{\mathrm{LL} \_ \text {E80 }}=128.5(1+\mathrm{Im}+\mathrm{RE})=\quad 164.4 \mathrm{ft}-\mathrm{k}
$$

Bending moments and stresses per stringer:

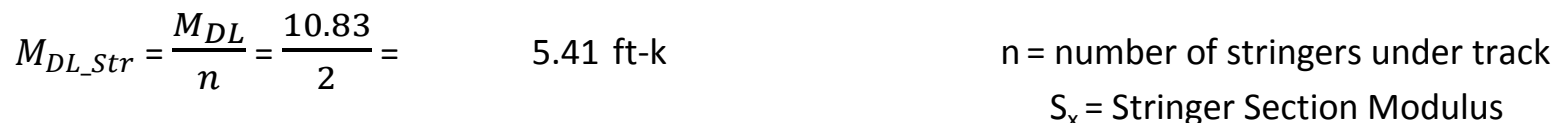

$$
\begin{aligned}
& f_{D L}=\frac{M_{D L} S t r}{S_{x}}=\frac{12 \cdot 5.41}{114.6}=\quad 567 \mathrm{psi} \\
& M_{L L_{-} S t r}=M_{L L_{-} E 80}=\quad 164.44 \mathrm{ft}-\mathrm{k} \\
& f_{L L}=\frac{M_{L L} S t r}{S_{X}}=\frac{12 \cdot 164.44}{114.6}=17219 \mathrm{psi}
\end{aligned}
$$

\section{MOMENT RATINGS}

$$
\begin{gathered}
\mathrm{Fb}_{\mathrm{n}}=\text { allowable bending stress for Normal rating }= \\
\mathrm{Fb}_{\mathrm{m}}=\text { allowable bending stress for Maximum rating }= \\
\begin{array}{c}
\text { Normal Rating } \\
24000
\end{array} \quad \mathrm{psi} \\
\mathrm{psi}
\end{gathered}
$$




$$
\begin{aligned}
\text { (Unfactored) } \mathrm{V}_{\mathrm{LL} \_\mathrm{E} 80} & =\quad 73.869 \mathrm{kip} \\
\mathrm{V}_{\mathrm{LL} E \mathrm{E} 80} & =73.87(1+\mathrm{Im}+\mathrm{RE})=94.51 \quad \mathrm{kip}
\end{aligned}
$$

Shears and shear stresses per stringer:

$$
\begin{aligned}
f_{v}=\frac{V}{\left(D-2 t_{f}\right) t_{w}} & \\
V_{D L_{-} S t r}= & 2.41 \mathrm{kips} \\
f v_{D L}= & 261 \mathrm{psi} \\
V_{L L_{-} S t r}=\frac{V_{L L_{-} E 80}}{n}= & 94.51 \mathrm{kips} \\
f v_{L L}= & 10234 \mathrm{psi}
\end{aligned}
$$

SHEAR RATINGS

$$
\begin{aligned}
& \mathrm{Fv}_{\mathrm{n}}=\text { allowable bending stress for Normal rating }=10500 \text { psi } \\
& \mathrm{Fv}_{\mathrm{m}}=\text { allowable bending stress for Maximum rating }=18000 \text { psi } \\
& \text { Normal Rating } \\
& \mathrm{RF}_{\mathrm{n}}:=\frac{F v_{n}-f_{D L}}{f_{L L}}=\frac{10500-261}{10234}=\quad 1.00 \quad \text { Cooper E Rating: } \quad \mathrm{E}_{\mathrm{n}}=\operatorname{round}\left(\mathrm{RF}_{\mathrm{n}} \cdot 80\right)=\quad 80 \\
& \text { Maximum Rating } \\
& \mathrm{RF}_{\mathrm{m}}:=\frac{F v_{m}-f_{D L}}{f_{L L}}=\frac{18000-261}{10234}=\quad 1.733 \quad \text { Cooper } \mathrm{E} \text { Rating: } \quad \mathrm{E}_{\mathrm{m}}=\operatorname{round}\left(\mathrm{RF}_{\mathrm{m}} \cdot 80\right)=\quad 136 \\
& \text { Cooper E Rating - } 138.7 \\
& \text { Transverse stiffeners are required if the depth of the web exceeds } \\
& t_{w} 2.12 \sqrt{\frac{E}{F_{y}}} \text {, where } \mathrm{t}_{\mathrm{w}} \text { equals the thickness of the web } \\
& (0.586) 2.12 \sqrt{\frac{29,000,000}{30,000}}=32.96 \text { in }>\quad d_{w e b}=20 \text { in } \\
& \text { Therefore, Transverse Stiffeners Not Required. }
\end{aligned}
$$

\section{Equivalent Cooper E Loadings}

\section{Load 1 - Covered Hopper Car}

Gross rail load 286 kips

286 K Railcar - Drawn by Lochner, 2012

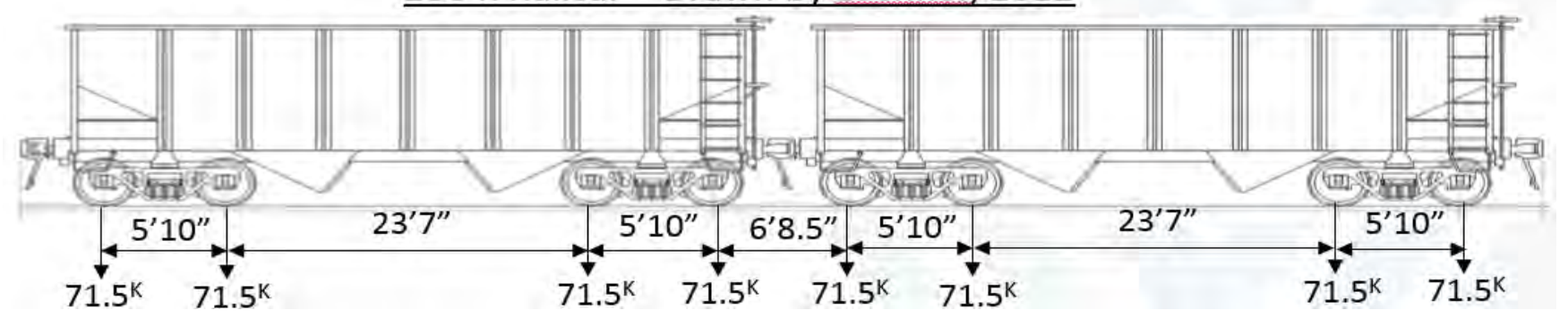


Live Load Moment

All live load beding and shear forces are calculated using a RISA model with moving loads.

$$
\begin{aligned}
\text { (Unfactored) } \mathrm{M}_{\mathrm{LL}_{-} \mathrm{HP}} & =198.792 \mathrm{ft}-\mathrm{k} \\
\mathrm{M}_{\mathrm{LL} \_\mathrm{HP}} & =220.3(1+\mathrm{Im}+\mathrm{RE})=\quad 254 \mathrm{ft}-\mathrm{k}
\end{aligned}
$$

Bending moments and stresses per stringer:

$$
\begin{array}{cc}
M_{L L_{-} S t r}=\frac{M_{L L_{-} H P}}{n}=\frac{254}{2}= & 127.17 \mathrm{ft}-\mathrm{k} \\
f_{L L_{-} H P}=\frac{M_{L_{L} S t r}}{S_{x}}= & 13316 \mathrm{psi} \\
M E_{H P}=\frac{80 * f_{L L_{-} H P}}{f_{L L_{-} E 80}}= & 61.87
\end{array}
$$

$\mathrm{n}=$ number of stringers under track $\mathrm{S}_{\mathrm{x}}=$ Stringer Section Modulus

Live Load Shear

All live load beding and shear forces are calculated using a RISA model with moving loads.

$$
\begin{aligned}
\text { (Unfactored) } \mathrm{V}_{\text {LL_HP }} & =112.042 \text { kips } \\
\mathrm{V}_{\text {LL_HP }} & =112.04(1+\mathrm{Im}+\mathrm{RE})=\quad 143 \mathrm{kips}
\end{aligned}
$$

Shears and shear stresses per stringer:

$$
\begin{array}{cc}
V_{L L_{-} S t r}=\frac{V_{L L_{-} H P}}{n}=\frac{143}{2}= & 71.68 \mathrm{kips} \\
f v_{L_{-} H P}=\frac{V_{L_{L} S t r}}{\left(D-2 t_{f}\right) t_{W}}= & 7761.3 \mathrm{psi} \\
V E_{H P}=\frac{80 * f v_{L_{L} H P}}{f v_{L L_{-} E 80}}= & 60.67
\end{array}
$$

\section{Load 2 - GP38 Locomotive}

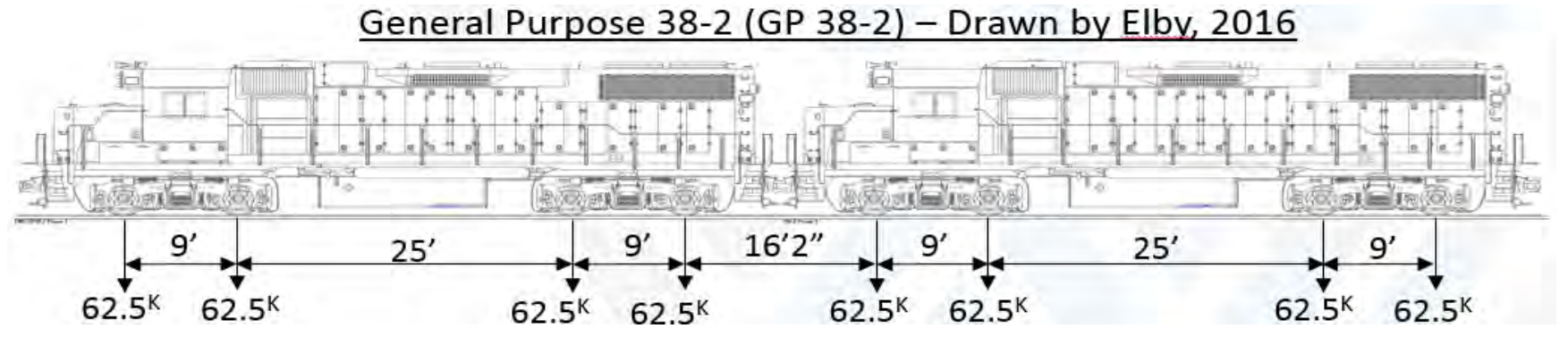

Live Load Moment

All live load beding and shear forces are calculated using a RISA model with moving loads.

(Unfactored) $\mathrm{M}_{\mathrm{LL} \_\mathrm{GP}}=\quad 156.216 \mathrm{ft}-\mathrm{k}$

$$
M_{\text {LL_GP }}=156.22(1+I m+R E)=\quad 200 \mathrm{ft}-\mathrm{k} \quad 11.25 \mathrm{ft}
$$

Bending moments and stresses per stringer:

$$
\begin{array}{rr}
M_{L L_{-} S t r}=\frac{M_{L L_{-} G P}}{n}=\frac{200}{2}= & 99.93 \mathrm{ft}-\mathrm{k} \\
f_{L L_{-} G P}=\frac{M_{L L_{-} S t r}}{S_{x}}= & 10464 \mathrm{psi}
\end{array}
$$




$$
M E_{G P}=\frac{80 * f_{L L_{-} G P}}{f_{L L_{-} E 80}}=
$$

Live Load Shear

All live load beding and shear forces are calculated using a RISA model with moving loads.

$$
\begin{aligned}
\text { (Unfactored) } \mathrm{V}_{\mathrm{LL}_{-} \mathrm{GP}} & =77.986 \text { kips } \\
\mathrm{V}_{\mathrm{LL}_{-} \mathrm{GP}} & =77.99(1+\mathrm{Im}+\mathrm{RE})=\quad 100 \mathrm{kips}
\end{aligned}
$$

Shears and shear stresses per stringer:

$$
\begin{aligned}
V_{L L_{-} S t r} & =\frac{V_{L L_{-} G P}}{n}=\frac{100}{2}= \\
f v_{L L_{-} G P} & =\frac{V_{L L_{-} S t r}}{\left(D-2 t_{f}\right) t_{w}}=540.89 \mathrm{kips} \\
V E_{G P} & =\frac{80 * f v_{L L_{-} G P}}{f v_{L L_{-} E 80}}=42.192 \mathrm{psi}
\end{aligned}
$$

\section{Load 3 - WM 82 Locomotive}

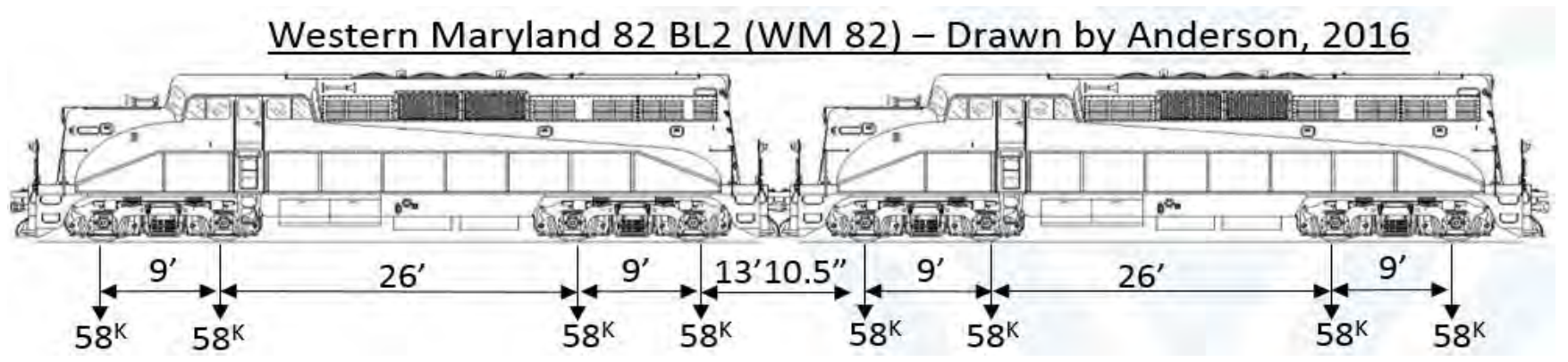

Live Load Moment

All live load beding and shear forces are calculated using a RISA model with moving loads.

$$
\begin{aligned}
\text { (Unfactored) } \mathrm{M}_{\mathrm{LL}-W M} & =144.994 \mathrm{ft}-\mathrm{k} \\
\mathrm{M}_{\mathrm{LL} \_\mathrm{WM}} & =144.99(1+\mathrm{Im}+\mathrm{RE})=\quad 186 \mathrm{ft}-\mathrm{k}
\end{aligned}
$$

Bending moments and stresses per stringer:

$$
\begin{array}{cc}
M_{L L \_S t r}=\frac{M_{L L \_} W M}{n}=\frac{186}{2}= & 92.76 \mathrm{ft}-\mathrm{k} \\
f_{L L_{-} W M}=\frac{M_{L L \_S t r}}{S_{X}}= & 9713 \mathrm{psi} \\
M E_{W M}=\frac{80 * f_{L L \_} W M}{f_{L L_{-} E 80}}= & 45.13
\end{array}
$$

$\mathrm{n}=$ number of stringers under track $\mathrm{S}_{\mathrm{x}}=$ Stringer Section Modulus

Live Load Shear

All live load beding and shear forces are calculated using a RISA model with moving loads.
(Unfactored) $\mathrm{V}_{\mathrm{LL} \_\mathrm{WM}}=$
72.37 kips
$V_{\text {LL_WM }}=72.37(1+\operatorname{Im}+R E)=$
93 kips
$L=\quad 11.25 \mathrm{ft}$ 
Shears and shear stresses per stringer:

$$
\begin{gathered}
V_{L_{L_{-} S t r}}=\frac{V_{L L_{-} W M}}{n}=\frac{93}{2}=46.30 \mathrm{kips} \\
f v_{L_{-} W M}=\frac{V_{L L_{-} S t r}}{\left(D-2 t_{f}\right) t_{w}}=5013.165 \mathrm{psi} \\
V E_{W M}=\frac{80 * f v_{L L \_W M}}{f v_{L L_{-} E 80}}=
\end{gathered}
$$

Equiv. Cooper E Load - E 39.2

\begin{tabular}{|l|c|c|c|c|c|}
\hline \multicolumn{1}{|c|}{ DB 1.4 } & \multicolumn{2}{|c|}{ Cooper E Rating } & \multicolumn{3}{c|}{ Equivalent Cooper E Load } \\
\hline & & & & \\
\cline { 1 - 3 } Load Effect & Normal & Maximum & $286 \mathrm{k}$ & GP38 & WM82 \\
\hline Bending & 74.0 & 108.9 & 61.9 & 48.6 & 45.1 \\
\hline Horz. Shear & 80.0 & 138.7 & 60.7 & 42.2 & 39.2 \\
\hline
\end{tabular}




\section{FLOORBEAMS}
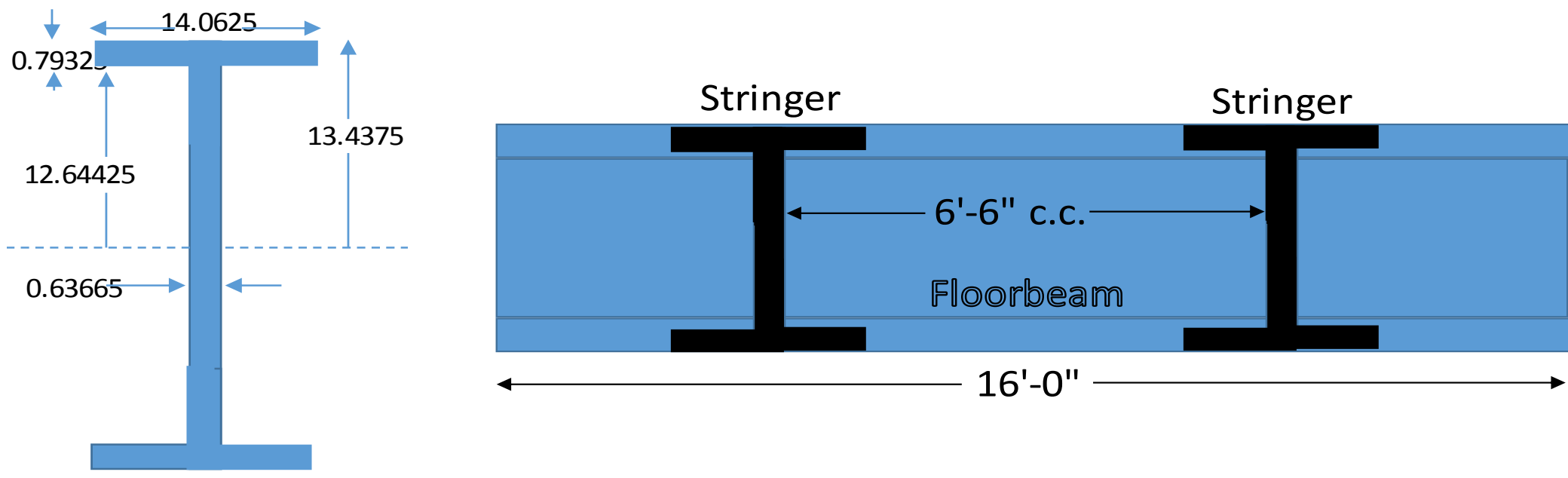

$16+-0 "$

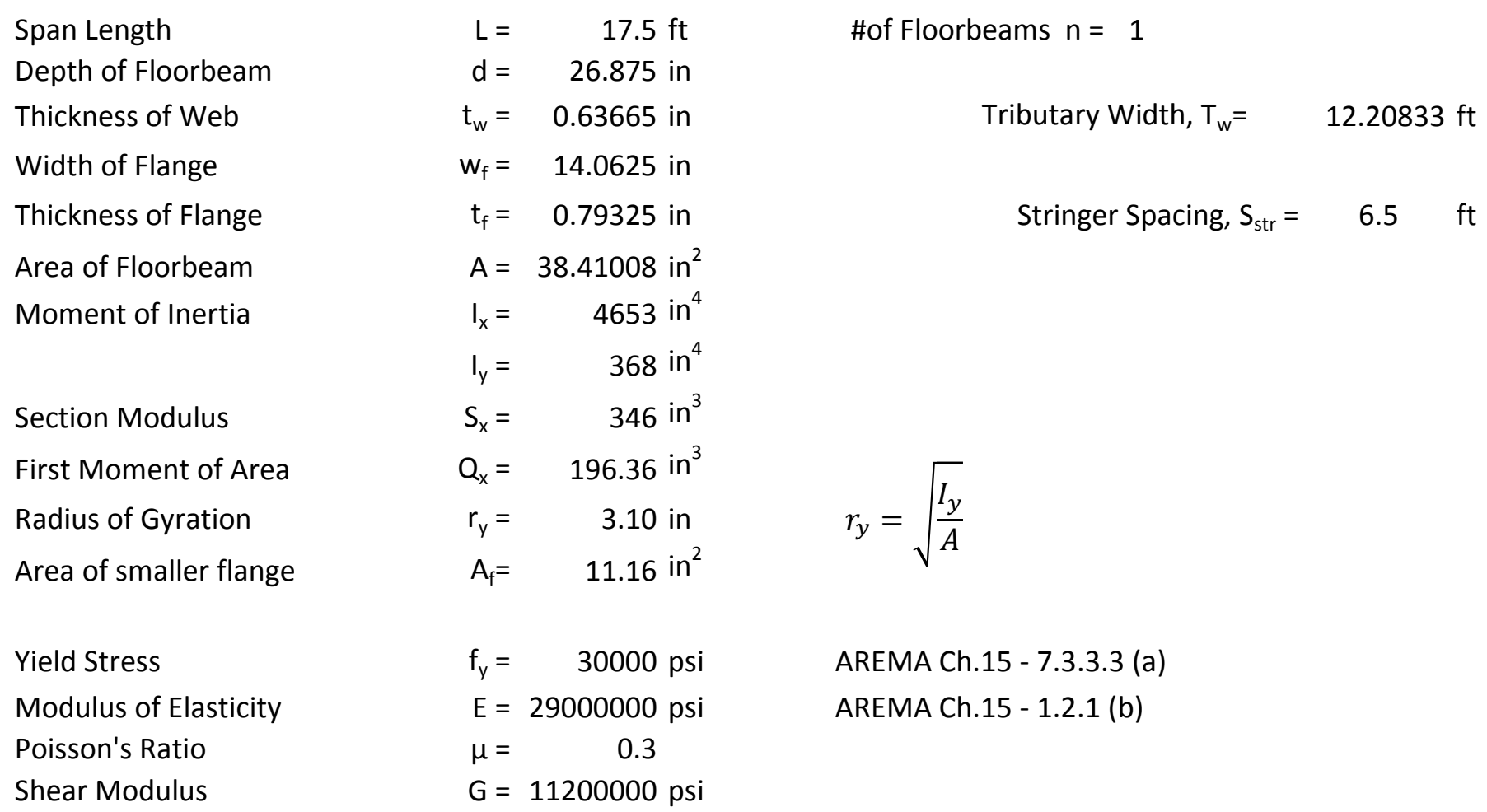

TIES

Tie Size and Spacing (actual dimensions as measured in the field)

$\begin{array}{rrr}\text { Tie width: } & \mathrm{w}_{\mathrm{t}}= & 8 \mathrm{in} \\ \text { Tie height } & \mathrm{h}_{\mathrm{t}}= & 12 \mathrm{in} \\ \text { Tie spacing: } & \mathrm{sp}_{\mathrm{t}}= & 12 \mathrm{in} \\ \text { Tie Length: } & \mathrm{L}_{\mathrm{t}}= & 10 \mathrm{ft} \\ \text { Tie Density: } & \gamma_{\mathrm{t}}= & 60 \mathrm{lb} / \mathrm{ft}^{3}\end{array}$

AREMA Ch.7 - 2.3.2 Dead Load (5lb per foot board = 1"x12"x12" = $60 \mathrm{lb} / \mathrm{ft}^{3}$ )

Allowable Stresses

Normal Rating: AREMA Table 15-1-11

Tension in extreme fibers of rolled shapes, $0.55 \mathrm{~F}_{\mathrm{y}}$

$\mathrm{Fbp}_{\mathrm{n}}: \quad 0.55 \mathrm{~F}_{\mathrm{y}}=\quad 16500 \mathrm{psi}$

Compression in extreme fibers of flexural members, larger of

$$
\begin{gathered}
\mathrm{Fbn}_{\mathrm{n}}: 0.55 F_{y}-\frac{0.55\left(F_{y}\right)^{2}}{6.3 \pi^{2} E}\left(\frac{l}{r_{y}}\right)^{2} \text { or } \frac{0.131 \pi E}{(l d \sqrt{1+\mu}) / A_{f}} \quad \text { but not to exceed } 0.55 \mathrm{~F}_{\mathrm{y}} \\
15237.12 \mathrm{psi} \\
<\quad 20689.61 \mathrm{psi} \text {, the larger of the two exceeds } 0.55 \mathrm{~F}_{\mathrm{y}} \\
l=\text { dist. Between points of lateral support for the compression flange }
\end{gathered}
$$

$\mathrm{Fb}_{\mathrm{n}}: \quad \mathrm{Fbn}_{\mathrm{n}}=16500 \mathrm{psi}$, controls for bending under Normal rating conditions 
Shear in webs of rolled beams and plate girders, gross section, $0.35 \mathrm{~F}_{\mathrm{y}}$

$$
\mathrm{Fv}_{\mathrm{n}}: \quad 0.35 \mathrm{~F}_{\mathrm{y}}=10500 \mathrm{psi}
$$

Maximum Rating: AREMA Ch.15 - 7.3.3.3 \& Table 15-7-1

$$
\begin{aligned}
& \text { Tension in extreme fibers of rolled shapes, } 0.8 \mathrm{~F}_{\mathrm{y}} \\
& \mathrm{Fbp}_{\mathrm{m}}: \quad 0.8 \mathrm{~F}_{\mathrm{y}}=\quad 24000 \mathrm{psi} \\
& \text { Compression in extreme fibers of flexural members, larger of } \\
& \mathrm{Fbn}_{\mathrm{m}}: 0.8 F_{y}-\frac{0.8 F_{y}}{1.8 \times 10^{9}}\left(\frac{l}{r_{y}}\right)^{2} \quad \text { or } \quad\left(\frac{0.8 F_{y}}{0.55 F_{y}}\right) \frac{10,500,000}{l d / A_{f}} \quad \text { but not to exceed } 0.8 \mathrm{~F}_{\mathrm{y}} \\
& 23999.94 \mathrm{psi} \quad 30187.1 \mathrm{psi} \text {, the larger of the two exceeds } 0.8 \mathrm{~F}_{\mathrm{y}} \\
& \mathrm{Fb}_{\mathrm{m}}: \quad \mathrm{Fbn}_{\mathrm{m}}=24000 \text { psi, controls for bending under Maximum rating conditions } \\
& \text { Shear in webs of plate girders and rolled beams, gross section, } 0.75\left(0.8 \mathrm{~F}_{\mathrm{y}}\right) \\
& \mathrm{Fv}_{\mathrm{n}}: 0.75\left(0.8 \mathrm{~F}_{\mathrm{y}}\right)=18000 \mathrm{psi}
\end{aligned}
$$

\begin{tabular}{|c|c|c|}
\hline track rails + inside guard rails + rail fastenings: & $200 \mathrm{lb} / \mathrm{ft}$ & AREMA Ch.15 - 1.3.2 (b) \\
\hline Ties : $\quad \mathrm{dl}_{\text {ties }}=\left(\mathrm{w}_{\mathrm{t}}^{*} \mathrm{~h}_{\mathrm{t}}^{*} \mathrm{~L}_{\mathrm{t}}^{*} \mathrm{~V}_{\mathrm{t}}\right) / \mathrm{s} \mathrm{p}_{\mathrm{t}}=(0.667 * 1 * 10 * 60) / 1=$ & $400.0 \mathrm{lb} / \mathrm{ft}$ & \\
\hline Guard Timber: $\quad \mathrm{dl}_{\mathrm{gt}}=2 * 4 \mathrm{in}^{*} 8 \mathrm{in}^{*} \mathrm{\gamma}_{\mathrm{t}}=(2 * 4 * 8 * 60) / 144=$ & $26.7 \mathrm{lb} / \mathrm{ft}$ & \\
\hline Total Dead Load of the Track $=$ & $626.7 \mathrm{lb} / \mathrm{ft}$ & \\
\hline \multicolumn{3}{|l|}{ Total Dead Load: } \\
\hline Dead Load Moment of the Track and Steel Members: & $25.96 \mathrm{ft}-\mathrm{kip}$ & \\
\hline
\end{tabular}

Allowable Stress for Rating:

\begin{tabular}{|c|c|c|}
\hline \hline & Normal & Maximum \\
\hline Bending Moment: & $16500 \mathrm{psi}$ & $24000 \mathrm{psi}$ \\
\hline Shear: & $10500 \mathrm{psi}$ & $18000 \mathrm{psi}$ \\
\hline
\end{tabular}

AREMA 2014 Ch. 15 Sec. 7.3.1 (Ch. 15 Commentary Sec. 9.7.3.1)

Normal rating:

-- Normal rating is the load level that can be carried by the existing structure for its expected service life.

Maximum rating:

.- Maximum rating is the load level that the structure can support at infrequent intervals.

\section{DEAD LOADS}

\section{LIVE LOADS}

Live Load Factors

Impact Load: AREMA Ch.15 - 1.3.5c(1)(a)

$\operatorname{Im}=40-3 L^{2} / 1600$, for $L$ less than 80 feet $(L=11.25 \mathrm{ft})$

$\operatorname{Im}=\quad 39.43 \%$

AREMA Ch.7 - 7.3.2.3a (1) : for train speeds below $60 \mathrm{mph}$, the values of the vertical effects of the impact equations shall be multiplied by the factor:

$$
\begin{array}{ccc}
1-\frac{0.8}{2500}(60-S)^{2} & \geq 0.2, & \text { where } S=\text { speed } \text { in } \mathrm{mph} \\
0.20 & \geq & 0.2
\end{array} \quad \mathrm{~S}=10 \quad \mathrm{mph}
$$

Thus, $\operatorname{Im}=39.43(0.2)=7.89 \%$

Rocking Effect: AREMA Ch.15 - 1.3.5d : impact load due to rocking effect, RE, shall be calculated as $20 \%$ of the wheel load without impact, acting downward on one rail and upward on the other. 
$\mathrm{RE}=20 \%$

Centrifugal Force: AREMA Ch.15 - 1.3.6: Factor applied where horizontal curvature of the track is present. No centrigual forces are acting on this bridge.

Cooper E 80 Load (loads shown are for each axle)

AREMA Ch.15 - 1.3.3a Live Load

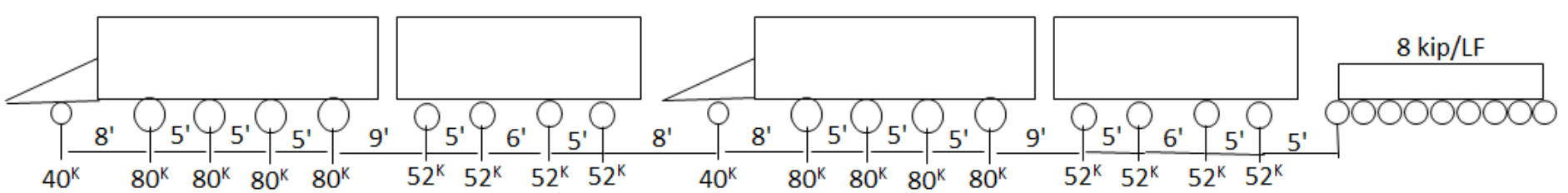

COMPUTATION OF STRESSES

AREMA Ch.15 - 7.3.3.1

All live load beding and shear forces are calculated using a RISA model with moving loads.

Moment Ratings Calculations

AREMA Ch.15 - 1.2.7b : For calculation of stresses, the length of span for floorbeams shall be taken as the distance between centers of girders.

$$
L=\quad 17.5 \mathrm{ft}
$$

(Unfact.) $\mathrm{M}_{\mathrm{LL} \_\mathrm{E} 80}=\quad 404.34 \mathrm{ft}-\mathrm{k}$

$$
M_{L L E 80}=404.34(1+I m+R E)=\quad 517.1 \mathrm{ft}-\mathrm{k}
$$

Bending moments and stresses per floorbeam:

$$
\begin{aligned}
& M_{D L_{-} F B}=\frac{M_{D L}}{n}=25.96 \mathrm{ft}-\mathrm{k} \quad \mathrm{n}=\text { number of floorbeams } \\
& f_{D L}=\frac{M_{D L_{L} F B}}{S_{X}}=900 \mathrm{psi} \\
& M_{L L_{-} F B}=\frac{M_{L L_{-} E 80}}{n}=517.09 \mathrm{ft}-\mathrm{k} \\
& f_{L L}=\frac{M_{L L_{F} F B}}{S_{x}}=17919 \mathrm{psi}
\end{aligned}
$$

MOMENT RATINGS

$$
\begin{aligned}
& \mathrm{Fb}_{\mathrm{n}}=\text { allowable bending stress for Normal rating }=16500 \text { psi } \\
& \mathrm{Fb}_{\mathrm{m}}=\text { allowable bending stress for Maximum rating }=24000 \text { psi } \\
& \text { Normal Rating } \\
& \mathrm{RF}_{\mathrm{n}}:=\frac{F b_{n}-f_{D L}}{f_{L L}}=\frac{16500-900}{17919}=\quad 0.87 \quad \text { Cooper E Rating: } \quad \mathrm{E}_{\mathrm{n}}=\operatorname{round}\left(\mathrm{RF}_{\mathrm{n}} \cdot 10\right)=\quad 69.6 \\
& \text { Maximum Rating } \\
& \mathrm{RF}_{\mathrm{m}}:=\frac{F b_{m}-f_{D L}}{f_{L L}}=\frac{24000-900}{17919}=\quad 1.289 \quad \text { Cooper } E \text { Rating: } \quad \mathrm{E}_{\mathrm{m}}=\operatorname{round}\left(\mathrm{RF}_{\mathrm{m}} \cdot 10\right)=\quad 103.2 \\
& \text { Cooper E Rating - } 103.1
\end{aligned}
$$

\section{Shear Ratings Calculations}

(Unfactored) $\mathrm{V}_{\mathrm{LL} \_ \text {E80 }}=\quad 99.88 \mathrm{kip}$ 


$$
\mathrm{V}_{\mathrm{LL} \_ \text {E80 }}=99.88(1+\mathrm{Im}+\mathrm{RE})=\quad 127.74 \quad \mathrm{kip}
$$

Shears and shear stresses per floorbeam:

$$
\begin{aligned}
f_{v}=\frac{V}{\left(D-2 t_{f}\right) t_{w}} & \\
V_{D L_{-} E 80}= & 5.86 \mathrm{kips} \\
f v_{D L}= & 364 \mathrm{psi} \\
V_{L L_{-} E 80}=\frac{V_{L L_{-} E 80}}{n}= & 127.74 \mathrm{kips} \\
f v_{L L} & =7934 \mathrm{psi}
\end{aligned}
$$

\section{SHEAR RATINGS}

$$
\begin{aligned}
& \mathrm{Fv}_{\mathrm{n}}=\text { allowable bending stress for Normal rating }=10500 \text { psi } \\
& \mathrm{Fv}_{\mathrm{m}}=\text { allowable bending stress for Maximum rating }=18000 \mathrm{psi} \\
& \text { Normal Rating } \\
& \mathrm{RF}_{\mathrm{n}}:=\frac{F v_{n}-f_{D L}}{f_{L L}}=\frac{10500-364}{7934}=1.28 \quad \text { Cooper } \mathrm{E} \text { Rating: } \quad \mathrm{E}_{\mathrm{n}}=\operatorname{round}\left(\mathrm{RF}_{\mathrm{n}} \cdot 80\right)=\quad 104 \\
& \text { Maximum Rating } \\
& \mathrm{RF}_{\mathrm{m}}:=\frac{F v_{m}-f_{D L}}{f_{L L}}=\frac{18000-364}{7934}=2.223 \quad \text { Cooper E Rating: } \quad \mathrm{E}_{\mathrm{m}}=\operatorname{round}\left(\mathrm{RF}_{\mathrm{m}} \cdot 80\right)=\quad 176 \\
& \text { Cooper E Rating - } 177.8
\end{aligned}
$$

$$
\begin{aligned}
& \text { Transverse stiffeners are required if the depth of the web exceeds } \\
& t_{w} 2.12 \sqrt{\frac{E}{F_{y}}} \text {, where } t_{w} \text { equals the thickness of the web } \\
& \text { (0.625) } 2.12 \sqrt{\frac{29,000,000}{30,000}}=41.96 \text { in }>\quad \mathrm{d}_{\text {web }}=26.875 \text { in }
\end{aligned}
$$

Therefore, Transverse Stiffeners Not Required.

\section{Equivalent Cooper E Loadings}

\section{Load 1 - Covered Hopper Car}

Gross rail load 286 kips

$\underline{286 \text { K Railcar - Drawn by Lochner, } 2012}$

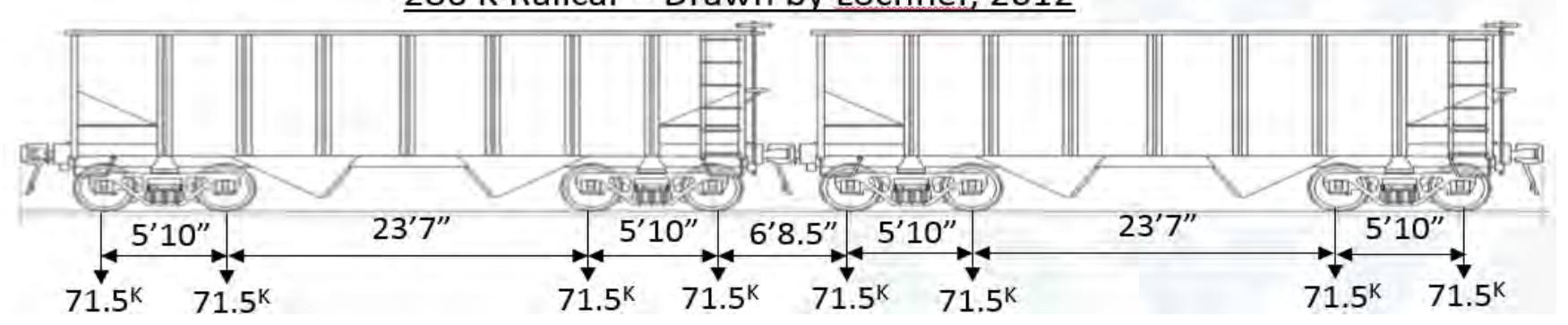


Live Load Moment

All live load beding and shear forces are calculated using a RISA model with moving loads.

(Unfact.) $\mathrm{M}_{\mathrm{LL} \_\mathrm{HP}}=\mathrm{Pa}=\quad 300.42 \mathrm{ft}-\mathrm{k}$

$$
M_{L_{-} H P}=300.42(1+I m+R E)=\quad 384.2 \mathrm{ft}-\mathrm{k} \quad \mathrm{L}=\quad 17.5 \mathrm{ft}
$$

Bending moments and stresses per floorbeam:

$$
\begin{gathered}
M_{L L_{-} F B}=\frac{M_{L L_{-} H P}}{n}=384.20 \mathrm{ft}-\mathrm{k} \\
f_{L L_{-} H P}=\frac{M_{L L_{-} F B}}{S_{X}}=13313 \mathrm{psi} \\
M E_{H P}=\frac{80 * f_{L L_{-} H P}}{f_{L L_{-} E 80}}=59.44
\end{gathered}
$$

$$
\begin{gathered}
n=\text { number of floorbeams } \\
S_{x}=\text { Floorbeam Section Modulus }
\end{gathered}
$$

Equiv. Cooper E Load - E 59.4

Live Load Shear

All live load beding and shear forces are calculated using a RISA model with moving loads.

$$
\begin{aligned}
\text { (Unfactored) } \mathrm{V}_{\text {LL_HP }} & =75.07 \text { kips } \\
& \mathrm{V}_{\text {LL_HP }}=75.07(1+\mathrm{Im}+\mathrm{RE})=\quad 96.0 \mathrm{kips}
\end{aligned}
$$

Shears and shear stresses per floorbeam:

$$
\begin{array}{r}
V_{L L_{-} F B}=\frac{V_{L_{L} H P}}{n}=96.00 \mathrm{kips} \\
f v_{L_{-} H P}=\frac{V_{L L_{-} F B}}{\left(D-2 t_{f}\right) t_{w}}=5962.574 \mathrm{psi} \\
V E_{H P}=\frac{80 * f v_{L L_{-} H P}}{f v_{L L_{-} E 80}}=
\end{array}
$$

Load 2 - GP38 Locomotive

General Purpose 38-2 (GP 38-2) - Drawn by Elbv, 2016

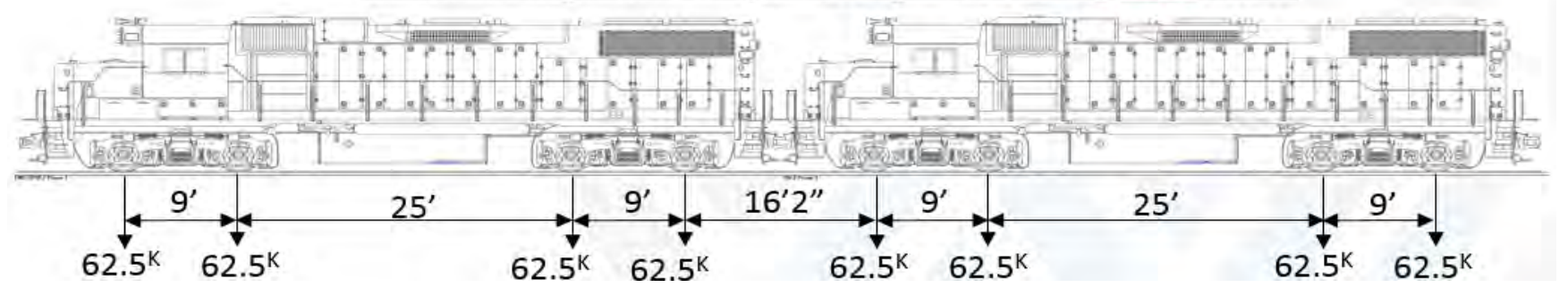

Live Load Moment

All live load beding and shear forces are calculated using a RISA model with moving loads.

RISA 3D model

$$
\begin{aligned}
\text { (Unfact.) } \mathrm{M}_{\mathrm{LL} \_\mathrm{GP}}=\mathrm{Pa} & =172.65 \mathrm{ft}-\mathrm{k} \\
\mathrm{M}_{\mathrm{LL} \_\mathrm{GP}} & =172.65(1+\mathrm{Im}+\mathrm{RE})=\quad 220.8 \mathrm{ft}-\mathrm{k}
\end{aligned}
$$

Bending moments and stresses per floorbeam:

$$
M_{L L_{-} S t r}=\frac{M_{L L} G P}{n}=220.8 \mathrm{ft}-\mathrm{k} \quad \mathrm{n}=\text { number of floorbeams }
$$




$$
\begin{array}{ccc}
f_{L L_{-} G P}=\frac{M_{L L_{-} S t r}}{S_{X}}= & 7651 \mathrm{psi} & \mathrm{S}_{\mathrm{x}}=\text { Floorbeam Section Modulus } \\
M E_{G P}=\frac{80 * f_{L L_{-} G P}}{f_{L L_{-} E 80}}=34.16 & \text { Equiv. Cooper E Load }-\mathbf{E ~ 3 4 . 2}
\end{array}
$$

Live Load Shear

All live load beding and shear forces are calculated using a RISA model with moving loads.

$$
\begin{aligned}
& \text { (Unfactored) } \mathrm{V}_{\mathrm{LL} \_\mathrm{GP}}=\quad 43.44 \text { kips } \\
& V_{L_{-} G P}=43.44(1+I m+R E)=\quad 55.5 \text { kips } \\
& L=\quad 17.5 \mathrm{ft}
\end{aligned}
$$

Shears and shear stresses per floorbeam:

$$
\begin{gathered}
V_{L L_{-} F B}=\frac{V_{L L_{-} G P}}{n}=55.5 \mathrm{kips} \\
f v_{L L_{-} G P}=\frac{V_{L L_{-} F B}}{\left(D-2 t_{f}\right) t_{w}}=3450.294 \mathrm{psi} \\
V E_{G P}=\frac{80 * f v_{L L_{-} G P}}{f v_{L L_{-} E 80}}=34.79
\end{gathered}
$$

\section{Load 3 - WM 82 Locomotive}

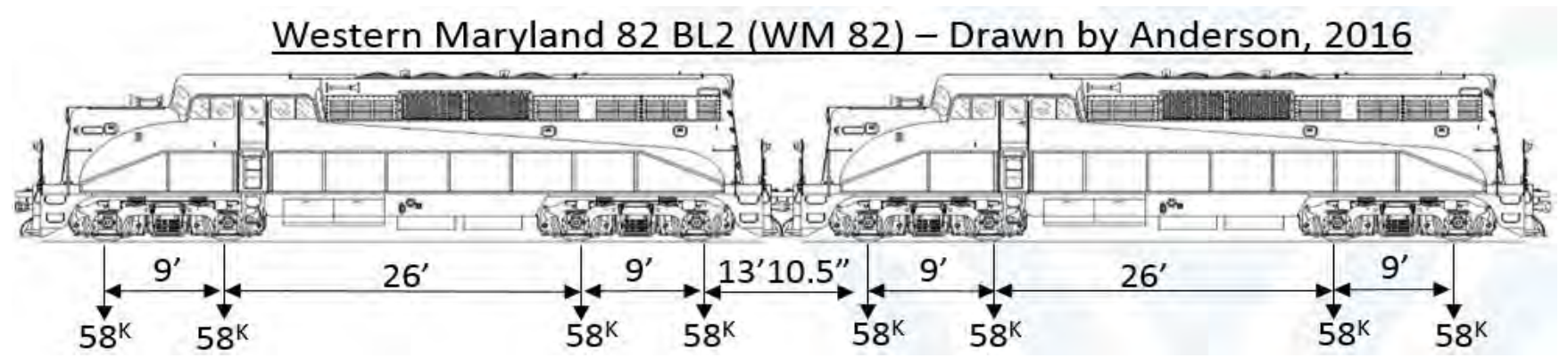

Live Load Moment

All live load beding and shear forces are calculated using a RISA model with moving loads.

RISA 3D model

$$
\begin{aligned}
\text { (Unfact.) } \mathrm{M}_{\mathrm{LL}_{-} W M}=\mathrm{Pa} & =162.44 \mathrm{ft}-\mathrm{k} \\
\mathrm{M}_{\mathrm{LL} \_\mathrm{WM}} & =162.44(1+\mathrm{Im}+\mathrm{RE})=\quad 207.7 \mathrm{ft}-\mathrm{k}
\end{aligned}
$$

Bending moments and stresses per floorbeam:

$$
\begin{array}{cc}
M_{L_{L} W M}=\frac{M_{L L_{-} W M}}{n}= & 207.7 \mathrm{ft}-\mathrm{k} \\
f_{L L_{-} W M}=\frac{M_{L L_{-} W M}}{S_{X}}= & 7199 \mathrm{psi} \\
M E_{W M}=\frac{80 * f_{L L \_W M}}{f_{L L_{-} E 80}}= & 32.14
\end{array}
$$

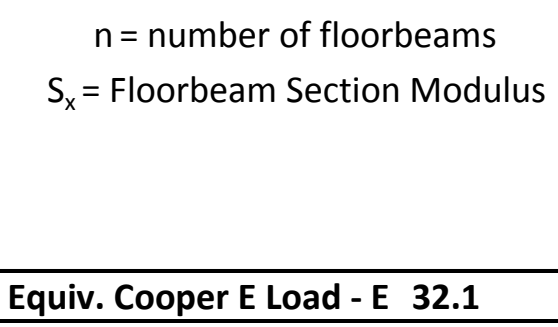

Live Load Shear

All live load beding and shear forces are calculated using a RISA model with moving loads.

$$
\text { (Unfactored) } \mathrm{V}_{\mathrm{LL} \_W M}=\quad 40.32 \text { kips }
$$




$$
V_{\text {LL_WM }}=40.32(1+I m+R E)=\quad 51.6 \text { kips }
$$

Shears and shear stresses per floorbeam:

$$
\begin{gathered}
V_{L L_{-} W M}=\frac{V_{L L_{-} W M}}{n}=51.57 \mathrm{kips} \\
f v_{L L_{-} W M}=\frac{V_{L L_{-} W M}}{\left(D-2 t_{f}\right) t_{W}}=3203.022 \mathrm{psi} \\
V E_{W M}=\frac{80 * f v_{L L_{-} W M}}{f v_{L L_{-} E 80}}=32.30
\end{gathered}
$$

Equiv. Cooper E Load - E 32.3

\begin{tabular}{|l|c|c|c|c|c|}
\hline \multicolumn{1}{|c|}{ DB 1.4 } & \multicolumn{2}{|c|}{ Cooper E Rating } & \multicolumn{3}{c|}{ Equivalent Cooper E Load } \\
\hline & & & \multicolumn{2}{c|}{} \\
\cline { 5 - 6 } Load Effect & Normal & Maximum & $286 \mathrm{k}$ & GP38 & WM82 \\
\hline Bending & 69.6 & 103.1 & 59.4 & 34.2 & 32.1 \\
\hline Horz. Shear & 102.2 & 177.8 & 60.1 & 34.8 & 32.3 \\
\hline
\end{tabular}




\section{THROUGH-GIRDERS}

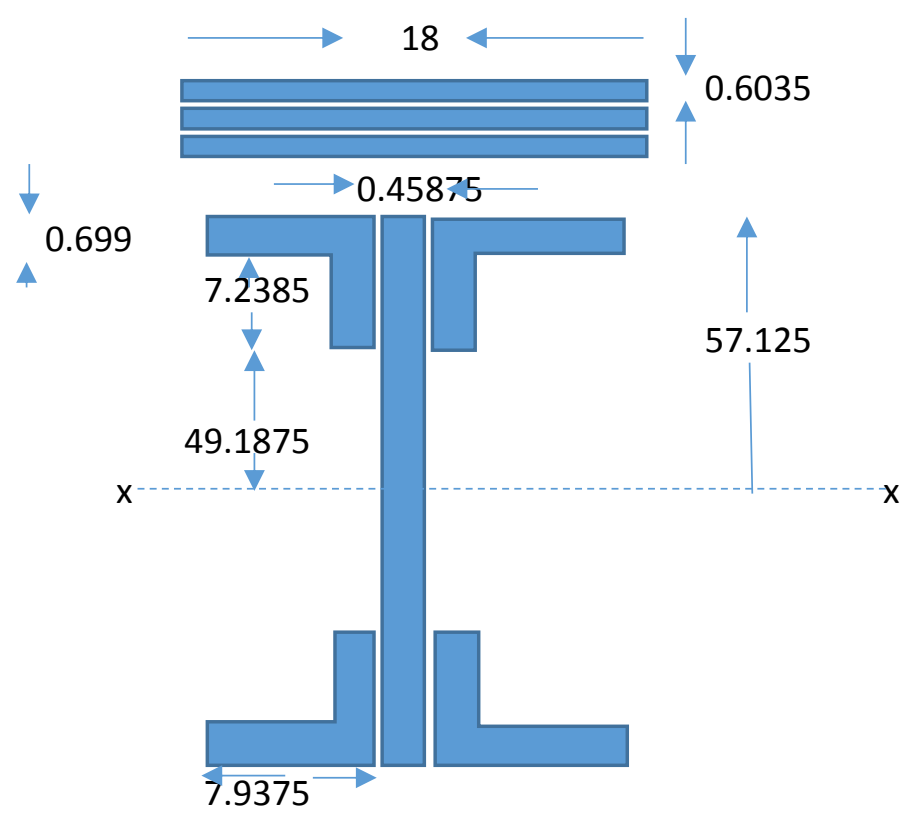

\begin{tabular}{|c|c|c|c|c|c|}
\hline Length of Girder & $\mathrm{L}_{\text {Girder }}=$ & $98.66667 \mathrm{ft}$ & & \multicolumn{2}{|c|}{ \# of Girder } \\
\hline Span Length & $\mathrm{L}=$ & \multicolumn{2}{|c|}{$97.04167 \mathrm{ft}$. AREMA Ch.15-1.2.7b } & $\mathrm{n}=$ & 2 \\
\hline Depth of Girder & $d=$ & \multicolumn{4}{|c|}{117.871 in } \\
\hline Thickness of Web & $t_{w}=$ & \multicolumn{4}{|l|}{0.45875 in } \\
\hline Flange width & $w_{f}=$ & \multicolumn{4}{|l|}{18 in } \\
\hline Flange thickness & $t_{f}=$ & \multicolumn{4}{|l|}{2.5095 in } \\
\hline Area of Girder & $A=$ & \multicolumn{4}{|c|}{$160.0223 \mathrm{in}^{2}, 3$ cover plates top and bottom } \\
\hline Moment of Inertia & $I_{x}=$ & \multicolumn{4}{|c|}{404582 in $^{4}, 3$ cover plates top and bottom } \\
\hline & $I_{y}=$ & \multicolumn{4}{|c|}{2276 in $^{4}, 3$ cover plates top and bottom } \\
\hline Section Modulus & $\mathrm{S}_{\mathrm{x}}=$ & \multicolumn{4}{|c|}{6865 in $^{3}, 3$ cover plates top and bottom } \\
\hline First Moment of Area & $Q_{x}=$ & \multicolumn{4}{|c|}{2536.73 in $^{3}, 1$ cover plate top and bottom } \\
\hline Radius of Gyration & $r_{y}=$ & 3.77 in & \multirow{3}{*}{\multicolumn{3}{|c|}{$r_{y}=\sqrt{\frac{I_{y}}{A}}$}} \\
\hline Cover Plate thickness & $t_{c p}=$ & 0.6035 in & & & \\
\hline Cover Plate Width & $\mathrm{w}_{\mathrm{cp}}=$ & 18 in & & & \\
\hline Number of cover plates, & $\mathrm{n}_{\mathrm{cp}}=$ & 3 & & & \\
\hline Yield Stress & $f_{y}=$ & 30000 psi & \multicolumn{3}{|c|}{ AREMA Ch.15 - 7.3.3.3 (a) } \\
\hline Modulus of Elasticity & $E=$ & 29000000 psi & \multirow{2}{*}{\multicolumn{3}{|c|}{ AREMA Ch.15 - 1.2.1 (b) }} \\
\hline Poisson's Ratio & $\mu=$ & 0.3 & & & \\
\hline Shear Modulus & $\mathrm{G}=$ & 11200000 psi & & & \\
\hline
\end{tabular}

TIES

Tie Size and Spacing (actual dimensions as measured in the field)

$\begin{array}{rrr}\text { Tie width: } & \mathrm{w}_{\mathrm{t}}= & 8 \mathrm{in} \\ \text { Tie height } & \mathrm{h}_{\mathrm{t}}= & 12 \mathrm{in} \\ \text { Tie spacing: } & \mathrm{sp}_{\mathrm{t}}= & 12 \mathrm{in} \\ \text { Tie Length: } & \mathrm{L}_{\mathrm{t}}= & 10 \mathrm{ft} \\ \text { Tie Density: } & \mathrm{\gamma}_{\mathrm{t}}= & 60 \mathrm{lb} / \mathrm{ft}^{3}\end{array}$

AREMA Ch.7 - 2.3.2 Dead Load (5lb per foot board = 1"x12"x12" = $60 \mathrm{lb} / \mathrm{ft}^{3}$ )

Allowable Stresses

Normal Rating: AREMA Table 15-1-11

Tension in extreme fibers of rolled shapes, $0.55 \mathrm{~F}_{\mathrm{y}}$

$\mathrm{Fbp}_{\mathrm{n}}: \quad 0.55 \mathrm{~F}_{\mathrm{y}}=16500 \mathrm{psi}$

Compression in extreme fibers of riveted or bolted built-up flexural members,

$\mathrm{Fbn}_{\mathrm{n}}: 0.55 F_{y}-\frac{0.55\left(F_{y}\right)^{2}}{6.3 \pi^{2} E}\left(\frac{l}{r_{y}}\right)^{2}$ 
16148.24 psi

$l=$ dist. Between points of lateral support for the compression flange $=$

$\mathrm{Fb}_{\mathrm{n}}: \quad \mathrm{Fbn}_{\mathrm{n}}=16148.24 \mathrm{psi}$, controls for bending under Normal rating conditions

Shear in webs of rolled beams and plate girders, gross section, $0.35 \mathrm{~F}_{\mathrm{y}}$

$\mathrm{Fv}_{\mathrm{n}}: \quad 0.35 \mathrm{~F}_{\mathrm{y}}=10500 \mathrm{psi}$

Maximum Rating: AREMA Ch.15 - 7.3.3.3 \& Table 15-7-1

Tension in extreme fibers of rolled shapes, $0.8 \mathrm{~F}_{\mathrm{y}}$

$\mathrm{Fbp}_{\mathrm{m}}: \quad 0.8 \mathrm{~F}_{\mathrm{y}}=\quad 24000 \mathrm{psi}$

Compression in extreme fibers of riveted or bolted built-up flexural members,

$\mathrm{Fbn}_{\mathrm{m}}: 0.8 F_{y}-\frac{0.8 F_{y}}{1.8 \times 10^{9}}\left(\frac{l}{r_{y}}\right)^{2}$

$23999.98 \mathrm{psi}$

$\mathrm{Fb}_{\mathrm{m}}: \quad \mathrm{Fbn}_{\mathrm{m}}=24000 \mathrm{psi}$, controls for bending under Maximum rating conditions

Shear in webs of plate girders and rolled beams, gross section, $0.75\left(0.8 \mathrm{~F}_{\mathrm{y}}\right)$

$\mathrm{Fv}_{\mathrm{n}}: 0.75\left(0.8 \mathrm{~F}_{\mathrm{y}}\right)=18000 \mathrm{psi}$

Allowable Stress for Rating:

\begin{tabular}{|c|c|c|}
\hline & Normal & Maximum \\
\hline Bending Moment: & $16148 \mathrm{psi}$ & $24000 \mathrm{psi}$ \\
\hline Shear: & $10500 \mathrm{psi}$ & $18000 \mathrm{psi}$ \\
\hline
\end{tabular}

\section{AREMA 2014 Ch. 15 Sec. 7.3.1 (Ch. 15 Commentary Sec. 9.7.3.1)}

\section{Normal rating:}

.- Normal rating is the load level that can be carried by the existing structure for its expected service life.

Maximum rating:

.- Maximum rating is the load level that the structure can support at infrequent intervals.

\section{DEAD LOADS}

\begin{tabular}{|c|c|c|}
\hline track rails + inside guard rails + rail fastenings: & $200 \mathrm{lb} / \mathrm{ft}$ & AREMA Ch.15 - 1.3.2 (b) \\
\hline Ties : $\quad \mathrm{dl}_{\text {ties }}=\left(\mathrm{w}_{\mathrm{t}}^{*} \mathrm{~h}_{\mathrm{t}}^{*} \mathrm{~L}_{\mathrm{t}}^{*} \mathrm{Y}_{\mathrm{t}}\right) / \mathrm{s} \mathrm{p}_{\mathrm{t}}=(0.667 * 1 * 10 * 60) / 1=$ & $400.0 \mathrm{lb} / \mathrm{ft}$ & \\
\hline Guard Timber: $\quad \mathrm{dl}_{\mathrm{gt}}=2 * 4 \mathrm{in} * 8 \mathrm{in} * \gamma_{\mathrm{t}}=(2 * 4 * 8 * 60) / 144=$ & $26.7 \mathrm{lb} / \mathrm{ft}$ & \\
\hline Total Dead Load of the Track = & $626.7 \mathrm{lb} / \mathrm{ft}$ & AREMA Table 15-1-5 \\
\hline
\end{tabular}

Total Dead Load:

Dead Load Moment of the Track and Steel Members: $\quad 2421.17 \mathrm{ft}$-kip

\section{LIVE LOADS}

Live Load Factors

Impact Load: AREMA Ch.15 - 1.3.5c(1)(b)

$\operatorname{Im}=16+600 /(L-30)$, for $L$ more than 80 feet $(L=97.5 \mathrm{ft})$

$\mathrm{Im}=\quad 24.95 \%$

AREMA Ch.7 - 7.3.2.3a (1) : for train speeds below $60 \mathrm{mph}$, the values of the vertical effects of the impact equations shall be multiplied by the factor:

$$
\begin{array}{ccc}
1-\frac{0.8}{2500}(60-S)^{2} & \geq 0.2, & \text { where } S=\text { speed } \text { in } m p h \\
0.20 & \geq & 0.2
\end{array}=10 \quad \mathrm{mph}
$$


Thus, $\operatorname{Im}=24.95(0.2)=4.99 \%$

Rocking Effect: AREMA Ch.15 - 1.3.5d : impact load due to rocking effect, RE, shall be calculated as $20 \%$ of the wheel load without impact, acting downward on one rail and upward on the other.

$\mathrm{RE}=20 \%$

Centrifugal Force: AREMA Ch.15 - 1.3.6: Factor applied where horizontal curvature of the track is present. No centrigual forces are acting on this bridge.

Cooper 80 Load (loads shown are for each axle)

AREMA Ch.15 - 1.3.3a Live Load

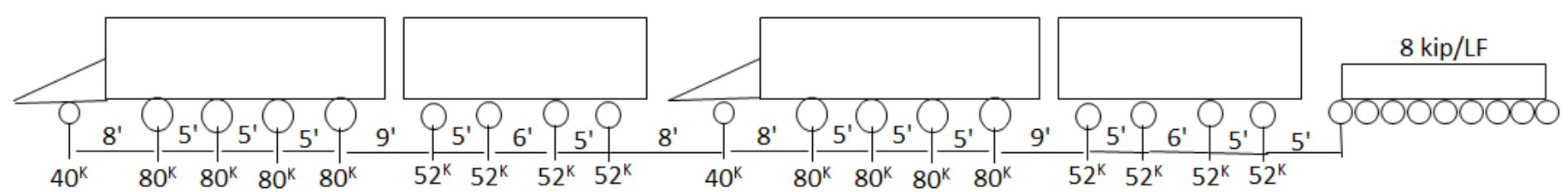

COMPUTATION OF STRESSES

AREMA Ch.15 - 7.3.3.1

All live load beding and shear forces are calculated using a RISA model with moving loads.

\section{Moment Ratings Calculations}

AREMA Ch.15 - 1.2.7b : For calculation of stresses, the length of span for girders shall be taken as the distance between centers of bearings.

$L=97.041667 \mathrm{ft}$

(Unfactored) $\mathrm{M}_{\mathrm{LL} \_E 80}=\quad 12123.308 \mathrm{ft}-\mathrm{k}$

$$
\mathrm{M}_{\mathrm{LL} \_\mathrm{E} 80}=12123(1+\mathrm{Im}+\mathrm{RE})=\quad 15152.9 \mathrm{ft}-\mathrm{k}
$$

Bending moments and stresses per Girder:

$$
\begin{aligned}
& M_{D L_{-} F B}=\frac{M_{D L}}{n}=1210.58 \mathrm{ft}-\mathrm{k} \\
& \mathrm{n}=\text { number of girders for track }=2 \\
& \mathrm{~S}_{\mathrm{x}}=\text { Girder Section Modulus }=\quad 6864.8 \mathrm{in}^{3} \\
& f_{D L}=\frac{M_{D L_{-} F B}}{S_{x}}=2116 \mathrm{psi} \\
& M_{L L_{-} F B}=\frac{M_{L L_{-} E 80}}{n}=7576.46 \mathrm{ft}-\mathrm{k} \\
& f_{L L}=\frac{M_{L L_{-} F B}}{S_{X}}=13244 \mathrm{psi}
\end{aligned}
$$

MOMENT RATINGS

$$
\begin{aligned}
& \mathrm{Fb}_{\mathrm{n}}=\text { allowable bending stress for Normal rating }=16148 \text { psi } \\
& \mathrm{Fb}_{\mathrm{m}}=\text { allowable bending stress for Maximum rating }=24000 \text { psi } \\
& \text { Normal Rating } \\
& \mathrm{RF}_{\mathrm{n}}:=\frac{F b_{n}-f_{D L}}{f_{L L}}=\frac{16148-2116}{13244}=\quad 1.06 \quad \text { Cooper } \mathrm{E} \text { Rating: } \quad \mathrm{E}_{\mathrm{n}}=\operatorname{round}\left(\mathrm{RF}_{\mathrm{n}} \cdot 80\right)=\quad 88 \\
& \text { Maximum Rating } \\
& \mathrm{RF}_{\mathrm{m}}:=\frac{F b_{m}-f_{D L}}{f_{L L}}=\frac{24000-2116}{13244}=\quad 1.652 \quad \text { Cooper } \mathrm{E} \text { Rating: } \quad \mathrm{E}_{\mathrm{m}}=\operatorname{round}\left(\mathrm{RF}_{\mathrm{m}} \cdot 80\right)=\quad 136
\end{aligned}
$$




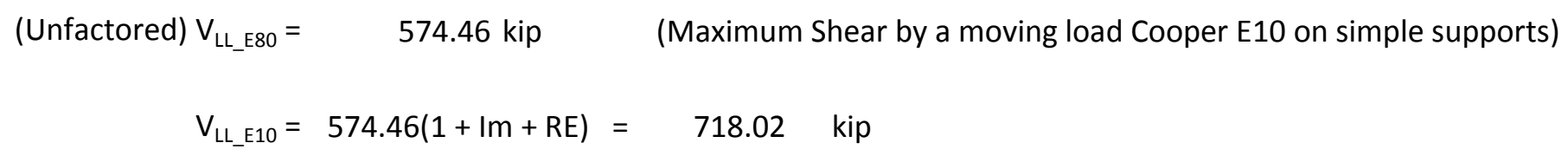

Shears and shear stresses per stringer:

$$
\begin{aligned}
f_{v}=\frac{V}{\left(D-2 t_{f}\right) t_{w}} & \\
V_{D L_{-} E 80} & =50.14 \mathrm{kips} \\
f v_{D L} & =\quad 968 \mathrm{psi} \\
V_{L L_{-} E 80}=\frac{V_{L L_{-} E 80}}{n} & =\quad 359.01 \mathrm{kips} \\
f v_{L L} & =6935 \mathrm{psi}
\end{aligned}
$$

\section{SHEAR RATINGS}

$$
\begin{aligned}
& \mathrm{Fv}_{\mathrm{n}}=\text { allowable bending stress for Normal rating }=10500 \mathrm{psi} \\
& \mathrm{Fv}_{\mathrm{m}}=\text { allowable bending stress for Maximum rating }=18000 \mathrm{psi} \\
& \text { Normal Rating } \\
& \mathrm{RFM}_{\mathrm{n}}:=\frac{F v_{n}-f_{D L}}{f_{L L}}=\frac{10500-968}{6935}=1.37 \quad \text { Cooper E Rating: } \mathrm{Em}_{\mathrm{n}}=\operatorname{round}\left(\mathrm{RFM}_{\mathrm{n}} \cdot 10\right)=\quad 14 \\
& \text { Maximum Rating } \\
& \mathrm{RFM}_{\mathrm{m}}:=\frac{F v_{m}-f_{D L}}{f_{L L}}=\frac{18000-968}{6935}=2.456 \quad \text { Cooper } E \text { Rating: } \mathrm{Em}_{\mathrm{m}}=\operatorname{round}\left(\mathrm{RFM}_{\mathrm{m}} \cdot 10\right)=\quad 25 \\
& \text { Cooper E Rating - } 196.5 \\
& t_{w} 2.12 \sqrt{\frac{E}{F_{y}}} \text {, where } \mathrm{t}_{\mathrm{w}} \text { equals the thickness of the web } \\
& (0.375) 2.12 \sqrt{\frac{29,000,000}{30,000}}=30.24 \text { in }<\quad d_{\text {web }+ \text { Cover Plates }}=116 \text { in } \\
& d=1.95 t_{w} \sqrt{\frac{E}{S}} \quad, \mathrm{~S}=\begin{array}{c}
\text { calculated shear stress in gross section of the web at the } \\
\text { point under consideration, psi. }
\end{array} \\
& S=4093 \text { psi, generated by a } 286 \text { railcar, heaviest load analyzed } \\
& d=1.95(0.375) \sqrt{\frac{29,000,000}{3,758}}=\quad 75 \text { inches }
\end{aligned}
$$




\section{Equivalent Cooper E Loadings}

\section{Load 1 - Covered Hopper Car}

Gross rail load 286 kips

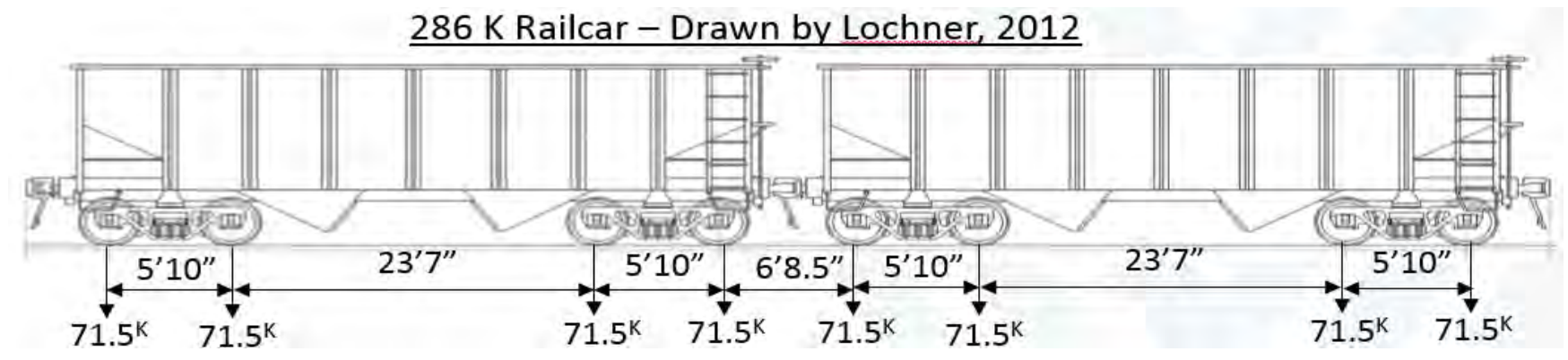

Live Load Moment

All live load beding and shear forces are calculated using a RISA model with moving loads.

$$
\begin{aligned}
\text { (Unfactored) } \mathrm{M}_{\mathrm{LL}_{-} H P} & =7839.882 \mathrm{ft}-\mathrm{k} \\
\mathrm{M}_{\mathrm{LL}_{-} \mathrm{HP}} & =7839.8(1+\mathrm{Im}+\mathrm{RE})=\quad \mathrm{L}=97.0416667 \mathrm{ft}
\end{aligned}
$$

Bending moments and stresses per girder:

$$
\begin{aligned}
& M_{L L_{-} F B}=\frac{M_{L L_{-} H P}}{n}=4899.53 \mathrm{ft}-\mathrm{k} \\
& \mathrm{n}=\text { number of girders for track }=2 \\
& f_{L L_{-} H P}=\frac{M_{L L_{-} F B}}{S_{x}}=8565 \mathrm{psi} \\
& \mathrm{S}_{\mathrm{x}}=\text { Girder Section Modulus }= \\
& 6864.8 \mathrm{in}^{3} \\
& M E_{H P}=\frac{80 * f_{L L_{-} H P}}{f_{L L_{-} E 80}}=
\end{aligned}
$$

Live Load Shear

All live load beding and shear forces are calculated using a RISA model with moving loads.

$$
\begin{aligned}
\text { (Unfactored) } \mathrm{V}_{\text {L__HP }}= & 339.05 \text { kips } \quad \begin{array}{c}
\text { (Maximum Shear by a moving load 286K railcar on simple supports) } \\
\mathrm{L}=97.0416667 \mathrm{ft}
\end{array} \\
\mathrm{V}_{\mathrm{LL} \_\mathrm{HP}}= & 339.05(1+\mathrm{Im}+\mathrm{RE})=\quad 423.8 \mathrm{kips}
\end{aligned}
$$

Shears and shear stresses per girder:

$$
\begin{array}{r}
V_{L L_{-} H P}=\frac{V_{L_{-} H P}}{n}=211.89 \mathrm{kips} \\
f v_{L L_{-} H P}=\frac{V_{L L_{-} H P}}{\left(D-2 t_{f}\right) t_{w}}=4092.828 \mathrm{psi} \\
V E_{H P}=\frac{80 * f v_{L L_{-} H P}}{f v_{L L_{-} E 80}}=47.22
\end{array}
$$

\section{Load 2 - GP38 Locomotive}

General Purpose 38-2 (GP 38-2) - Drawn by Elbv, 2016

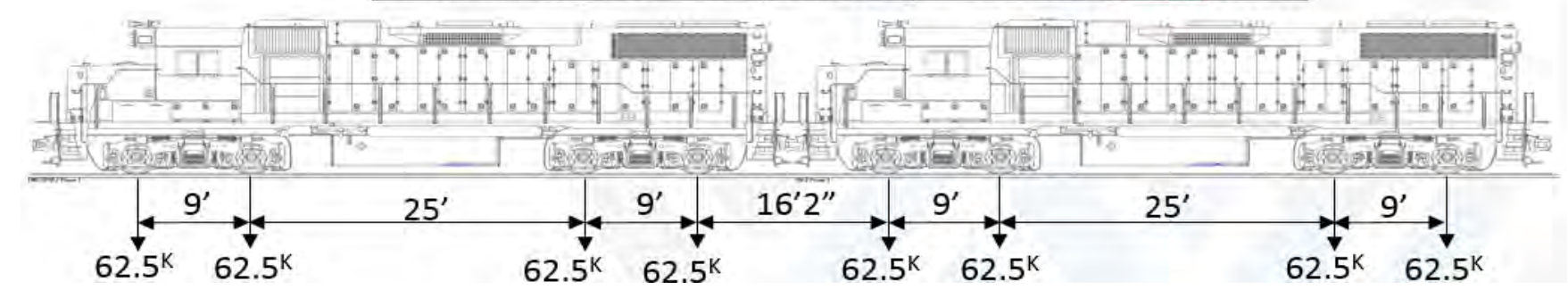


Live Load Moment

All live load beding and shear forces are calculated using a RISA model with moving loads.

(Unfactored) $\mathrm{M}_{\mathrm{LL} \_\mathrm{GP}}=\quad 5147.19 \mathrm{ft}-\mathrm{k}$

$$
M_{L_{-} G P}=5147.2(1+I m+R E)=\quad 6433.5 \mathrm{ft}-\mathrm{k}
$$

Bending moments and stresses per girder:

$$
\begin{aligned}
& M_{L L_{-} S t r}=\frac{M_{L L_{-} G P}}{n}=3216.73 \mathrm{ft}-\mathrm{k} \\
& f_{L L_{-} G P}=\frac{M_{L L} S t r}{S_{x}}=5623 \mathrm{psi} \\
& M E_{G P}=\frac{80 * f_{L L \_G P}}{f_{L L_{-} E 80}}=\quad 33.97
\end{aligned}
$$

Live Load Shear

All live load beding and shear forces are calculated using a RISA model with moving loads.

$$
\begin{aligned}
\text { (Unfactored) } \mathrm{V}_{\mathrm{LL} \_\mathrm{GP}}= & 245.598 \mathrm{kips} \quad \begin{array}{c}
\text { (Maximum Shear by a moving load GP38 on simple supports) } \\
\mathrm{L}=97.0416667 \mathrm{ft}
\end{array} \\
\mathrm{V}_{\mathrm{LL} \_\mathrm{GP}}= & 245.59(1+\mathrm{Im}+\mathrm{RE})=\quad 307.0 \mathrm{kips}
\end{aligned}
$$

Shears and shear stresses per girder:

$$
\begin{gathered}
V_{L L_{-} F B}=\frac{V_{L L_{-} G P}}{n}=153.49 \mathrm{kips} \\
f v_{L_{-} G P}=\frac{V_{L L_{-} F B}}{\left(D-2 t_{f}\right) t_{w}}=2964.726 \mathrm{psi} \\
V E_{G P}=\frac{80 * f v_{L L_{-} G P}}{f v_{L L_{-} E 80}}=34.20
\end{gathered}
$$

Equiv. Cooper E Load - E 34.2

Load 3 - WM 82 Locomotive

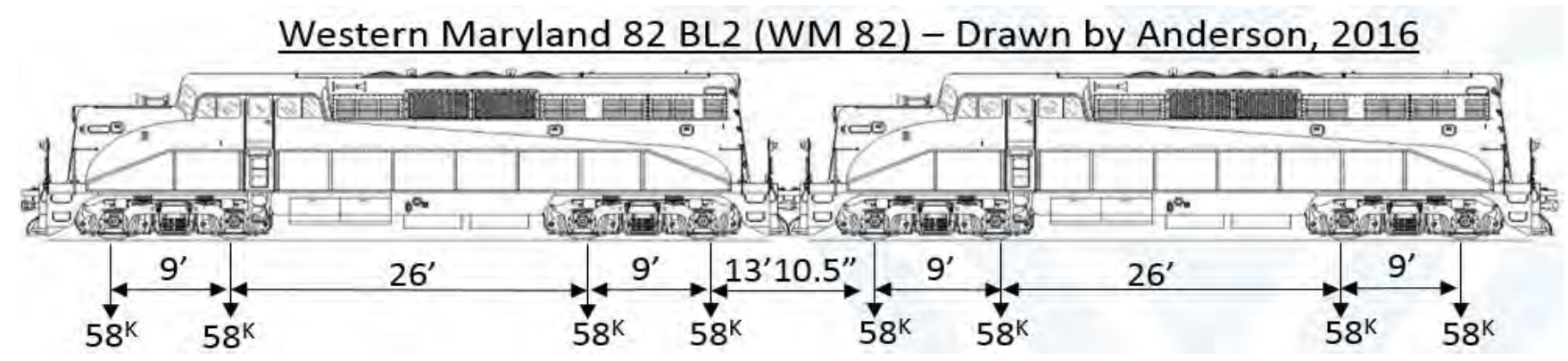

Live Load Moment

All live load beding and shear forces are calculated using a RISA model with moving loads.

(Unfactored) $\mathrm{M}_{\mathrm{LL} \_W M}=\quad 4871.938 \mathrm{ft}-\mathrm{k}$

$$
M_{L_{L} W_{M}}=4871.9(1+I m+R E)=\quad 6089.4 \mathrm{ft}-\mathrm{k}
$$

$L=97.0416667 \mathrm{ft}$

Bending moments and stresses per girder:

$$
\begin{array}{rr}
M_{L L_{-} W M}=\frac{M_{L L_{-} W M}}{n}= & 3044.72 \mathrm{ft}-\mathrm{k} \\
f_{L_{-} W M}=\frac{M_{L_{L} W M}}{S_{x}}= & 5322 \mathrm{psi}
\end{array}
$$

$\mathrm{n}=$ number of girders for track $=2$

$\mathrm{S}_{\mathrm{x}}=$ Girder Section Modulus $=\quad 6864.8 \mathrm{in}^{3}$ 


$$
M E_{W M}=\frac{80 * f_{L L} W M}{f_{L L \_} E 80}=\quad 32.15
$$

Equiv. Cooper E Load - E 32.1

Live Load Shear

All live load beding and shear forces are calculated using a RISA model with moving loads.

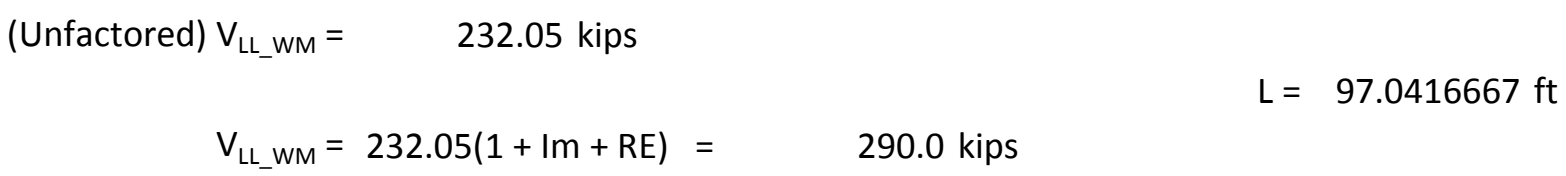

Shears and shear stresses per girder:

$$
\begin{array}{cc}
V_{L L_{-} W M}=\frac{V_{L L_{-} W M}}{n}= & 145.0 \mathrm{kips} \\
f v_{L L_{-} W M}=\frac{V_{L L_{-} W M}}{\left(D-2 t_{f}\right) t_{W}}= & 2801.182 \mathrm{psi} \\
V E_{W M}=\frac{80 * f v_{L L_{-} W M}}{f v_{L L_{-} E 80}}= & 32.32
\end{array}
$$

Equiv. Cooper E Load - E 32.3

\begin{tabular}{|l|c|c|c|c|c|}
\hline \multicolumn{1}{|c|}{ DB 1.4 } & \multicolumn{2}{|c|}{ Cooper E Rating } & \multicolumn{3}{c|}{ Equivalent Cooper E Load } \\
\hline & & & & \\
\cline { 5 - 6 } Load Effect & Normal & Maximum & $286 \mathrm{k}$ & GP38 & WM82 \\
\hline Bending & 84.8 & 132.2 & 51.7 & 34.0 & 32.1 \\
\hline Horz. Shear & 110.0 & 196.5 & 47.2 & 34.2 & 32.3 \\
\hline
\end{tabular}


Bridge DB-5.8

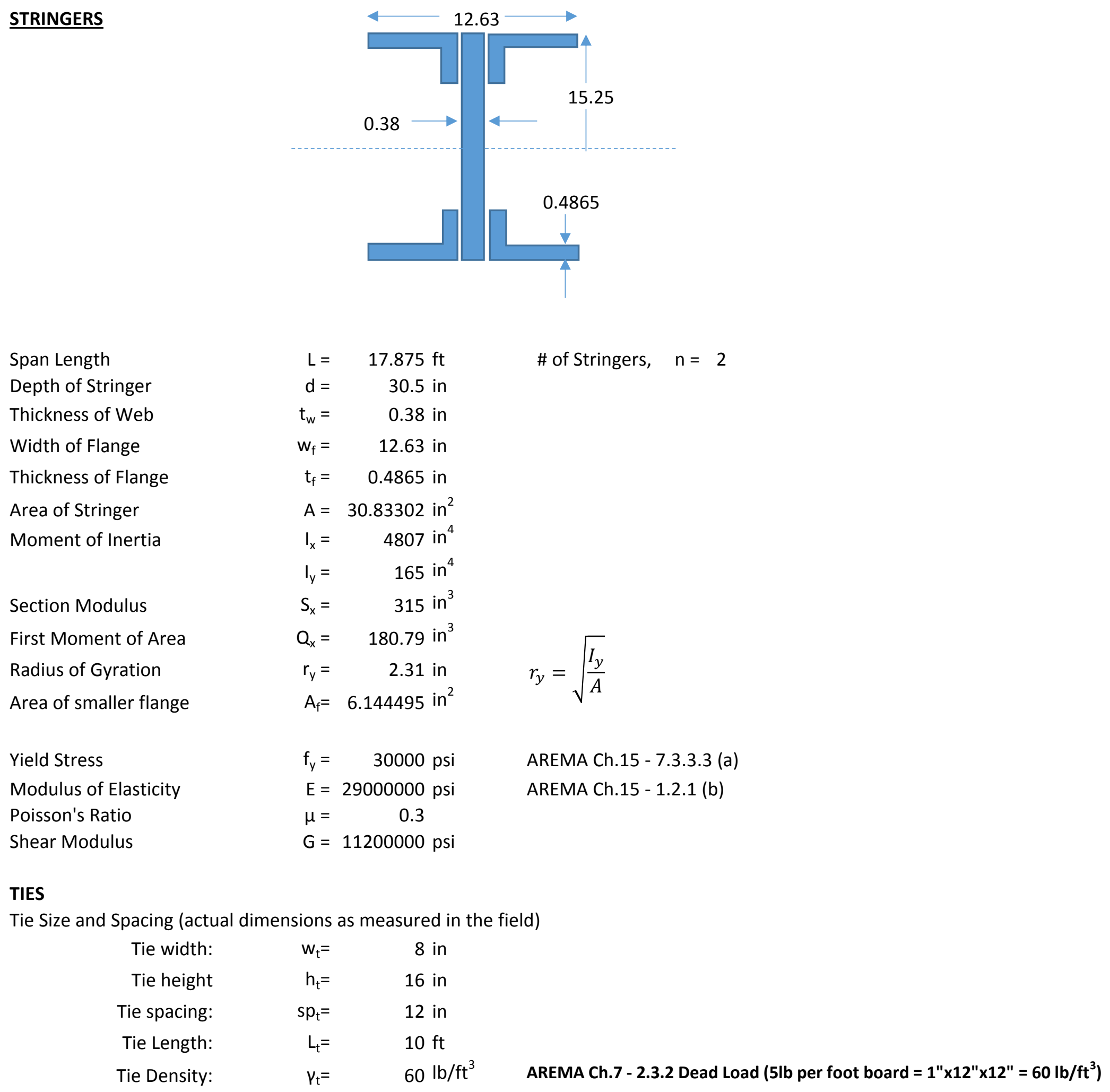

Allowable Stresses

Normal Rating: AREMA Table 15-1-11

Tension in extreme fibers of rolled shapes, $0.55 \mathrm{~F}_{\mathrm{y}}$

$\mathrm{Fbp}_{\mathrm{n}}: \quad 0.55 \mathrm{~F}_{\mathrm{y}}=16500 \mathrm{psi}$

Compression in extreme fibers of riveted or bolted built-up flexural members,

$$
\begin{array}{r}
\mathrm{Fbn}_{\mathrm{n}}: 0.55 F_{y}-\frac{0.55\left(F_{y}\right)^{2}}{6.3 \pi^{2} E}\left(\frac{l}{r_{y}}\right)^{2} \\
15761.37 \mathrm{psi}
\end{array}
$$

$l=$ dist. Between points of lateral support for the compression flange $=$ 
$\mathrm{Fb}_{\mathrm{n}}: \quad \mathrm{Fbn}_{\mathrm{n}}=15761.37 \mathrm{psi}$, controls for bending under Normal rating conditions

Shear in webs of rolled beams and plate girders, gross section, $0.35 \mathrm{~F}_{\mathrm{y}}$

$\mathrm{Fv}_{\mathrm{n}}: \quad 0.35 \mathrm{~F}_{\mathrm{y}}=10500 \mathrm{psi}$

Maximum Rating: AREMA Ch.15 - 7.3.3.3 \& Table 15-7-1

Tension in extreme fibers of rolled shapes, $0.8 \mathrm{~F}_{\mathrm{y}}$

$\mathrm{Fbp}_{\mathrm{m}}: \quad 0.8 \mathrm{~F}_{\mathrm{y}}=24000 \mathrm{psi}$

Compression in extreme fibers of riveted or bolted built-up flexural members,

$\mathrm{Fbn}_{\mathrm{m}}: 0.8 F_{y}-\frac{0.8 F_{y}}{1.8 \times 10^{9}}\left(\frac{l}{r_{y}}\right)^{2}$

23999.96 psi

$\mathrm{Fb}_{\mathrm{m}}: \quad \mathrm{Fbn}_{\mathrm{m}}=24000$ psi, controls for bending under Maximum rating conditions

Shear in webs of plate girders and rolled beams, gross section, $0.75\left(0.8 \mathrm{~F}_{\mathrm{y}}\right)$

$\mathrm{Fv}_{\mathrm{n}}: 0.75\left(0.8 \mathrm{~F}_{\mathrm{y}}\right)=18000 \mathrm{psi}$

Allowable Stress for Rating:

\begin{tabular}{|c|c|c|}
\hline \hline & Normal & Maximum \\
\hline Bending Moment: & $15761 \mathrm{psi}$ & $24000 \mathrm{psi}$ \\
\hline Shear: & $10500 \mathrm{psi}$ & $18000 \mathrm{psi}$ \\
\hline
\end{tabular}

AREMA 2014 Ch. 15 Sec. 7.3.1 (Ch. 15 Commentary Sec. 9.7.3.1)

Normal rating:

.- Normal rating is the load level that can be carried by the existing structure for its expected service life.

Maximum rating:

.- Maximum rating is the load level that the structure can support at infrequent intervals.

\section{DEAD LOADS}

\begin{tabular}{|c|c|c|c|c|}
\hline track rails + inside gu & uard rails + rail fastenings: & $200 \mathrm{lb} / \mathrm{ft}$ & AREMA Ch.15 - 1.3 .2 (b & \\
\hline Ties: $\quad d_{\text {ties }}=\left(w_{t}^{*} h_{t}^{*}\right.$ & $\left.* \mathrm{~L}_{\mathrm{t}}^{*} \gamma_{\mathrm{t}}\right) / \mathrm{sp}_{\mathrm{t}}=\left(0.667 * 1.333^{*} 10 * 60\right) / 1=$ & $533.3 \mathrm{lb} / \mathrm{ft}$ & & 1.333333 \\
\hline Guard Timber: & $\mathrm{dl}_{\mathrm{gt}}=2 * 4 \mathrm{in}^{*} \operatorname{8in}^{*} \gamma_{\mathrm{t}}=(2 * 4 * 8 * 60) / 144=$ & $26.7 \mathrm{lb} / \mathrm{ft}$ & & \\
\hline Stringers: & $\mathrm{dl}_{\mathrm{s}}=\mathrm{nA} \nu_{\mathrm{s}}=2 * 28.4 *\left(490 \mathrm{lb} / \mathrm{ft}^{3}\right) / 144=$ & $209.8 \mathrm{lb} / \mathrm{ft}$ & AREMA Table 15-1-5 & \\
\hline Total Dead Load: & $\mathrm{W}_{\mathrm{DL}}=\mathrm{dl}_{\mathrm{track}}+\mathrm{dl}_{\text {ties }}+\mathrm{dl}_{\mathrm{gt}}+\mathrm{dl}_{\mathrm{s}}=$ & $969.8 \mathrm{lb} / \mathrm{ft}$ & & \\
\hline Dead Load Moment: & $M_{D L}=W_{D L} L^{2} / 8=969.8(17.875)^{2} / 8=$ & $38734.7 \mathrm{ft}-\mathrm{lb}$ & $38.73 \mathrm{ft}-\mathrm{kip}$ & \\
\hline
\end{tabular}

\section{LIVE LOADS}

Live Load Factors

Impact Load: AREMA Ch.15-1.3.5c(1)(a)

$\operatorname{Im}=40-3 L^{2} / 1600$, for $L$ less than 80 feet $(L=17.875 \mathrm{ft})$

$\operatorname{Im}=\quad 39.40 \%$

AREMA Ch.7 - 7.3.2.3a (1) : for train speeds below $60 \mathrm{mph}$, the values of the vertical effects of the impact equations shall be multiplied by the factor:

$\begin{aligned} 1-\frac{0.8}{2500}(60-S)^{2} & \geq 0.2, \quad \text { where } S=\text { speed } \text { in } m p h \quad S=10 \quad \mathrm{mph} \\ 0.20 & \geq 0.2\end{aligned}$ 
Thus, $\operatorname{Im}=39.40(0.35)=7.88 \%$

Rocking Effect: AREMA Ch.15 - 1.3.5d : impact load due to rocking effect, RE, shall be calculated as $20 \%$ of the wheel load without impact, acting downward on one rail and upward on the other.

$\mathrm{RE}=20 \%$

Centrifugal Force: AREMA Ch.15 - 1.3.6: Factor applied where horizontal curvature of the track is present. No centrigual forces are acting on this bridge.

Cooper E 80 Load (loads shown are for each axle)

AREMA Ch.15 - 1.3.3a Live Load

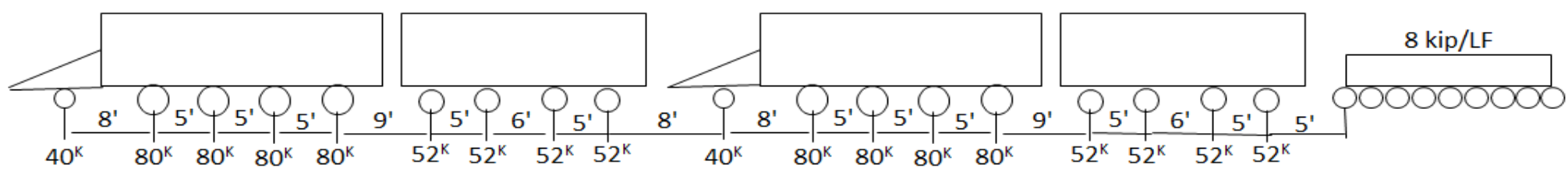

*All other Cooper ratings are proportional to the Cooper E 10 loading by a certain value. i.e.Cooper E 80 is a Cooper E 10 times 8 , meaning all axle loads are to be multiplied times 8.

\section{COMPUTATION OF STRESSES}

AREMA Ch.15 - 7.3.3.1

All live load beding and shear forces are calculated using a RISA model with moving loads.

\section{Moment Ratings Calculations}

AREMA Ch.15 - 1.2.7b : For calculation of stresses, the length of span for stringers shall be taken as the distance between centers of floorbeams.

$$
L=17.875 \mathrm{ft}
$$

(Unfactored) $\mathrm{M}_{\mathrm{LL} \_ \text {E80 }}=\quad 671.666 \mathrm{ft}-\mathrm{k} \quad$ (Maximum Moment by a moving load Cooper E80 on simple supports)

$$
M_{L_{-} E 80}=671.66(1+I m+R E)=\quad 858.9 \mathrm{ft}-\mathrm{k}
$$

Bending moments and stresses per stringer:

$$
\begin{aligned}
& M_{D L} S t r=\frac{M_{D L}}{n}=\frac{38.73}{2}=\quad 19.37 \mathrm{ft}-\mathrm{k} \quad \mathrm{n}=\text { number of stringers under track }=2 \\
& \mathrm{~S}_{\mathrm{x}}=\text { Stringer Section Modulus }=\quad 315.21 \mathrm{in}^{3} \\
& f_{D L}=\frac{M_{D L \_} S t r}{S_{x}}=737 \mathrm{psi} \\
& M_{L L_{-} S t r}=\frac{M_{L L_{-} E 80}}{n}=\frac{859}{2}=\quad 429.46 \mathrm{ft}-\mathrm{k} \\
& f_{L L}=\frac{M_{L L} S t r}{S_{X}}=16350 \mathrm{psi}
\end{aligned}
$$

\section{MOMENT RATINGS}

$$
\begin{aligned}
& \mathrm{Fb}_{\mathrm{n}}=\text { allowable bending stress for Normal rating }=15761 \text { psi } \\
& \mathrm{Fb}_{\mathrm{m}}=\text { allowable bending stress for Maximum rating }=24000 \text { psi } \\
& \text { Normal Rating } \\
& \mathrm{RF}_{\mathrm{n}}:=\frac{F b_{n}-f_{D L}}{f_{L L}}=\frac{15761-737}{16350}=0.92 \quad \text { Cooper } E \text { Rating: } \mathrm{E}_{\mathrm{n}}=\operatorname{round}\left(\mathrm{RF}_{\mathrm{n}} \cdot 80\right)=72
\end{aligned}
$$




$$
\begin{gathered}
\mathrm{RF}_{\mathrm{m}}:=\frac{F b_{m}-f_{D L}}{f_{L L}}=\frac{24000-737}{16350}=1.423 \quad \text { Cooper } \mathrm{E} \text { Rating: } \mathrm{E}_{\mathrm{m}}=\operatorname{round}\left(\mathrm{RF}_{\mathrm{m}} \cdot 80\right)=112 \\
\text { Cooper } \mathrm{E} \text { Rating }-\mathbf{1 1 3 . 8}
\end{gathered}
$$

\section{$\underline{\text { Shear Ratings Calculations }}$}

$$
\begin{aligned}
\text { (Unfactored) } \mathrm{V}_{\mathrm{LL}_{-} \mathrm{E} 80} & =184.988 \mathrm{kip} \quad \text { (Maximum Shear by a moving load Cooper E80 on simple supports) } \\
\mathrm{V}_{\mathrm{LL} \_\mathrm{E} 80} & =24.8(1+\mathrm{Im}+\mathrm{RE})=\quad 236.56 \mathrm{kip}
\end{aligned}
$$

Shears and shear stresses per stringer:

$$
\begin{aligned}
& f_{v}=\frac{V}{\left(D-2 t_{f}\right) t_{w}} \\
& V_{D L_{-} E 80}=4.33 \mathrm{kips} \\
& f v_{D L}=386 \mathrm{psi} \\
& V_{L_{-} E 80}=\frac{V_{L L_{-} E 80}}{n}=118.28 \mathrm{kips} \\
& f v_{L L}=10542 \mathrm{psi}
\end{aligned}
$$

\section{SHEAR RATINGS}

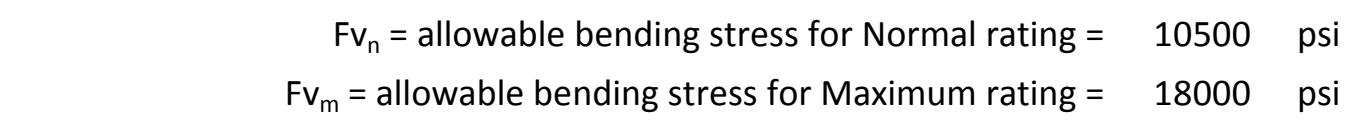

Normal Rating

$$
\begin{aligned}
& \mathrm{RF}_{\mathrm{n}}:=\frac{F v_{n}-f_{D L}}{f_{L L}}=\frac{10500-386}{10542}=\quad 0.96 \quad \text { Cooper } E \text { Rating: } E m_{\mathrm{n}}=\operatorname{round}\left(\mathrm{RF}_{\mathrm{n}} \cdot 80\right)=\quad 80 \\
& \text { Maximum Rating } \\
& \begin{array}{r}
\mathrm{RF}_{\mathrm{m}}:=\frac{F v_{m}-f_{D L}}{f_{L L}}=\frac{18000-386}{10542}=1.671 \quad \text { Cooper } \mathrm{E} \text { Rating: } \mathrm{Em} m=\operatorname{round}\left(\mathrm{RF}_{\mathrm{m}} \cdot 80\right) \\
\text { Cooper E Rating }-\mathbf{1 3 3 . 7}
\end{array}
\end{aligned}
$$

\section{Cooper E Rating - 76.8}

Transverse stiffeners are required if the depth of the web exceeds

$$
\begin{aligned}
& t_{w} 2.12 \sqrt{\frac{E}{F_{y}}}, \text { where } t_{w} \text { equals the thickness of the web } \\
& (0.586) 2.12 \sqrt{\frac{29,000,000}{30,000}}=25.05 \text { in }<\quad d_{\text {web }}=30.5 \text { in }
\end{aligned}
$$

Therefore, Transverse Stiffeners Required.

Actual clear distance, $d_{a}$, between intermediate transverse stiffeners shall not exceed 96 inches, nor the clear distance between flanges or side plates, nor $\mathrm{d}$.

Maximum clear distance, $d$, between intermediate transverse stiffeners: 


$$
\begin{aligned}
d=1.95 t_{w} \sqrt{\frac{E}{S}} \quad, \mathrm{~S} & =\begin{array}{l}
\text { calculated shear stress in gross section of the web at the } \\
\text { point under consideration, psi. }
\end{array} \\
\mathrm{S} & =\quad \begin{array}{r}
8007 \text { psi, generated by a } 286 \text { railcar, heaviest load analyzed } \\
d=1.95(0.375) \sqrt{\frac{29,000,000}{10,056}}=44.60 \text { inches }
\end{array}
\end{aligned}
$$

\section{Equivalent Cooper E Loadings}

\section{Load 1 - Covered Hopper Car}

Gross rail load 286 kips

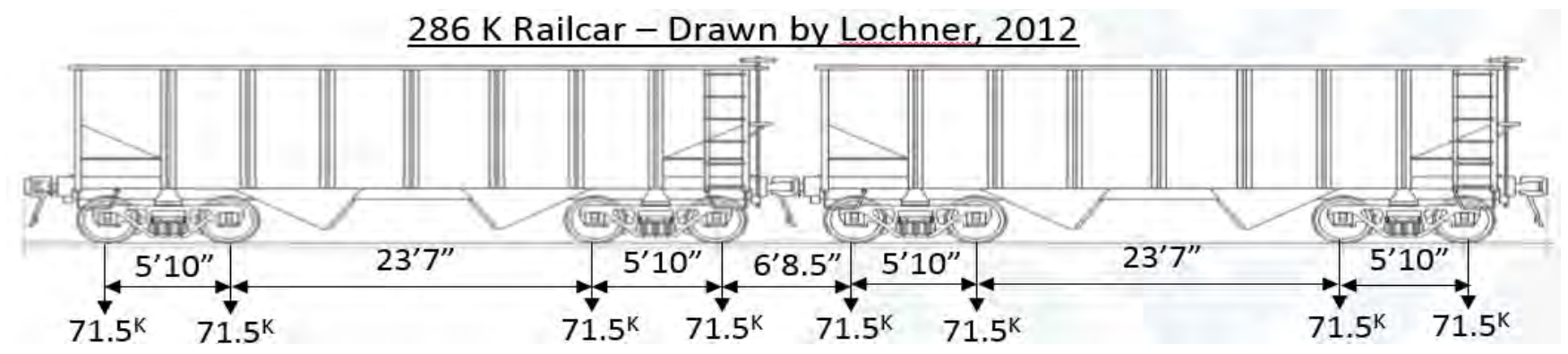

Live Load Moment

All live load beding and shear forces are calculated using a RISA model with moving loads.

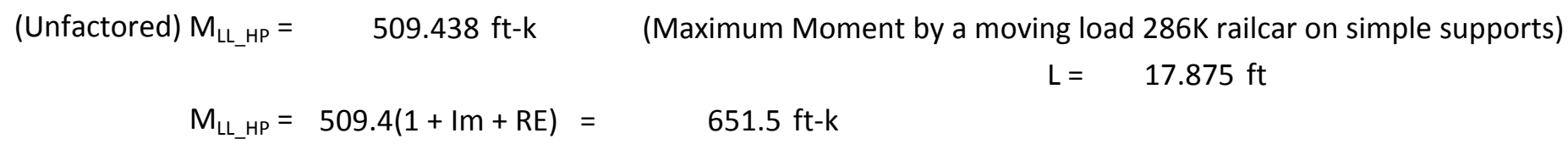

Bending moments and stresses per stringer:

$$
\begin{aligned}
& M_{L L_{-} S t r}=\frac{M_{L L_{-} H P}}{n}=\frac{651.5}{2}=\quad 325.74 \mathrm{ft}-\mathrm{k} \\
& f_{L L_{-} H P}=\frac{M_{L L} S t r}{S_{x}}=12401 \mathrm{psi} \\
& M E_{H P}=\frac{80 * f_{L L \_H P}}{f_{L L_{-} E 10}}=60.68
\end{aligned}
$$

Live Load Shear

All live load beding and shear forces are calculated using a RISA model with moving loads.

$$
\begin{aligned}
& \text { (Unfactored) } \mathrm{V}_{\mathrm{LL}} \mathrm{HP}=\quad 140.5 \mathrm{kips} \quad \text { (Maximum Shear by a moving load 286K railcar on simple supports) } \\
& L=17.875 \mathrm{ft} \\
& \mathrm{V}_{\mathrm{LL} \_H P}=140.5(1+\mathrm{Im}+\mathrm{RE})=\quad 179.7 \mathrm{kips}
\end{aligned}
$$

Shears and shear stresses per stringer:

$$
\begin{array}{r}
V_{L L_{-} S t r}=\frac{V_{L L_{-} H P}}{n}=89.84 \mathrm{kips} \\
f v_{L_{-} H P}=\frac{V_{L L_{-} S t r}}{\left(D-2 t_{f}\right) t_{w}}=8006.573 \mathrm{psi} \\
V E_{H P}=\frac{80 * f v_{L L_{-} H P}}{f v_{L L_{-} E 80}}=
\end{array}
$$$$
b=\text { thickness of the stringer web }=t_{w}=0.38 \text { in }
$$$$
\mathrm{Q}=\text { first moment } \text { of Area }=\mathrm{Q}_{\mathrm{x}}=\quad 180.79 \mathrm{in}^{3}
$$

Equiv. Cooper E Load - E 60.8 


\section{Load 2 - GP38 Locomotive}

General Purpose 38-2 (GP 38-2) - Drawn by Elbv, 2016

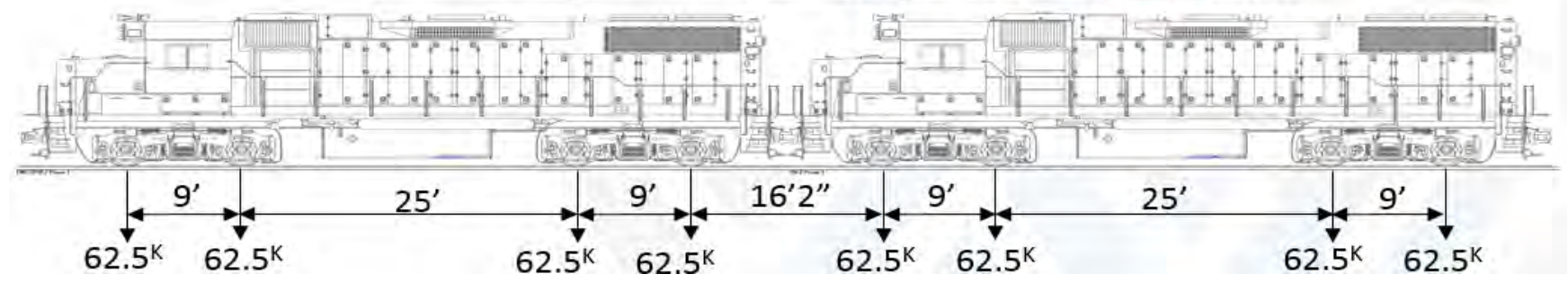

Live Load Moment

All live load beding and shear forces are calculated using a RISA model with moving loads.

(Unfactored) $\mathrm{M}_{\mathrm{LL} \_\mathrm{GP}}=\quad 278.646 \mathrm{ft}-\mathrm{k} \quad$ (Maximum Moment by a moving load GP38 on simple supports)

$$
M_{L_{-} G P}=278.64(1+I m+R E)=356.3 \mathrm{ft}-\mathrm{k}
$$

Bending moments and stresses per stringer:

$$
\begin{aligned}
& M_{L L_{-} S t r}=\frac{M_{L L_{-} G P}}{n}=\frac{356}{2}=\quad 178.17 \mathrm{ft}-\mathrm{k} \\
& f_{L L_{-} G P}=\frac{M_{L L_{-} S t r}}{S_{x}}=6783 \mathrm{psi} \\
& M E_{G P}=\frac{80 * f_{L L \_G P}}{f_{L L \_} E 80}=
\end{aligned}
$$

$\mathrm{n}=$ number of stringers under track $=2$

$$
\mathrm{S}_{\mathrm{x}}=\text { Stringer Section Modulus }=\quad 315.21 \mathrm{in}^{3}
$$

Live Load Shear

All live load beding and shear forces are calculated using a RISA model with moving loads.

$$
\begin{aligned}
& \text { (Unfactored) } V_{\text {LL_GP }}=\quad 93.24 \text { kips } \quad \text { (Maximum Shear by a moving load GP38 on simple supports) } \\
& V_{L L_{-} G P}=93.24(1+I m+R E)=119.2 \text { kips } \\
& L=17.875 \mathrm{ft}
\end{aligned}
$$

Shears and shear stresses per stringer:

$$
\begin{aligned}
& V_{L L_{-} S t r}=\frac{V_{L L_{-} G P}}{n}=\frac{119.2}{2}=\quad 59.62 \mathrm{kips} \\
& f v_{L L_{-} G P}=\frac{V_{L L \_} S t r}{\left(D-2 t_{f}\right) t_{w}}=5313.401 \mathrm{psi} \\
& V E_{G P}=\frac{80 * f v_{L L_{-} G P}}{f v_{L L_{-} E 80}}=\quad 40.32
\end{aligned}
$$

Equiv. Cooper E Load - E 40.3

Load 3 - WM 82 Locomotive

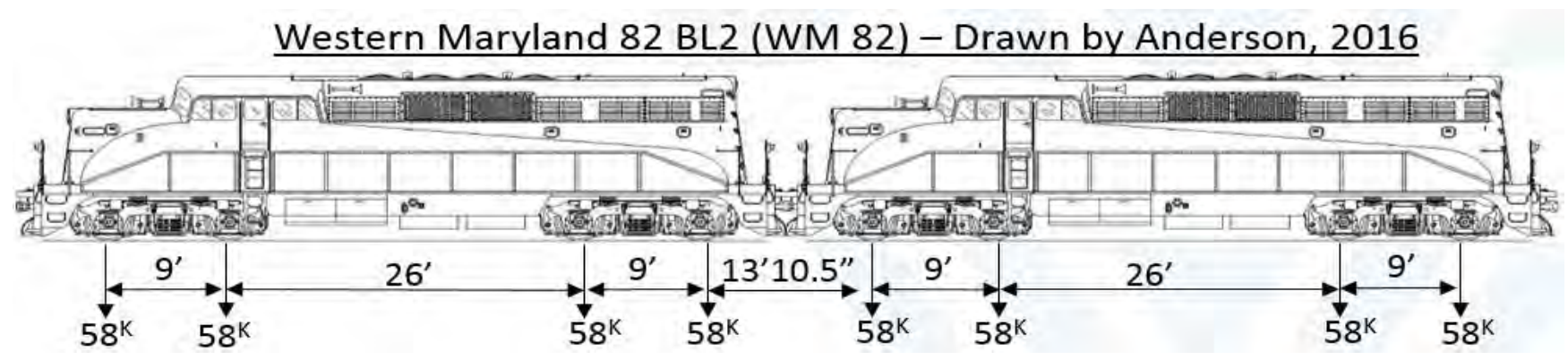


Live Load Moment

All live load beding and shear forces are calculated using a RISA model with moving loads.

(Unfactored) $\mathrm{M}_{\mathrm{LL} \_\mathrm{WM}}=\quad 258.584 \mathrm{ft}-\mathrm{k} \quad$ (Maximum Moment by a moving load WM82 on simple supports)

$M_{\text {LL_WM }}=258.58(1+I m+R E)=\quad 331 \mathrm{ft}-\mathrm{k} \quad 17.875 \mathrm{ft}$

Bending moments and stresses per stringer:

$$
\begin{array}{ccc}
M_{L L_{-} S t r}=\frac{M_{L L_{-} W M}}{n}=\frac{331}{2}= & 165.34 \mathrm{ft}-\mathrm{k} & \mathrm{n}=\text { number of stringers under track = } 2 \\
f_{L L_{-} W M}=\frac{M_{L L_{-} S t r}}{S_{X}}= & 6295 \mathrm{psi} & \\
M E_{W M}=\frac{80 * f_{L L_{-} W M}}{f_{L L_{-} E 80}}= & 30.80 &
\end{array}
$$

Live Load Shear

All live load beding and shear forces are calculated using a RISA model with moving loads.

$$
\begin{aligned}
& \text { (Unfactored) } \mathrm{V}_{\mathrm{LL} \_\mathrm{WM}}=\quad 86.526 \mathrm{kips} \quad \text { (Maximum Shear by a moving load WM82 on simple supports) } \\
& \mathrm{L}=17.875 \mathrm{ft} \\
& \mathrm{V}_{\mathrm{LL} \_\mathrm{WM}}=86.526(1+\mathrm{Im}+\mathrm{RE})=
\end{aligned}
$$

Shears and shear stresses per stringer:

$$
\begin{gathered}
V_{L L_{-} S t r}=\frac{V_{L L_{-} W M}}{n}=\frac{111}{2}=55.32 \mathrm{kips} \\
f v_{L_{-} W M}=\frac{V_{L L_{-} S t r}}{\left(D-2 t_{f}\right) t_{W}}=4930.795 \mathrm{psi} \\
V E_{W M}=\frac{80 * f v_{L L_{-} W M}}{f v_{L L_{-} E 80}}=37.42
\end{gathered}
$$$$
\mathrm{b}=\text { thickness of the stringer web }=t_{w}=0.38 \text { in }
$$$$
Q=\text { first moment of Area }=Q_{x}=\quad 180.79 \text { in }^{3}
$$

Equiv. Cooper E Load - E 37.4

\begin{tabular}{|l|c|c|c|c|c|}
\hline \multicolumn{1}{|c|}{ DB 1.9 } & \multicolumn{2}{|c|}{ Cooper E Rating } & \multicolumn{3}{c|}{ Equivalent Cooper E Load } \\
\hline & & & \multicolumn{2}{c|}{} \\
\cline { 5 - 6 } Load Effect & Normal & Maximum & $286 \mathrm{k}$ & GP38 & WM82 \\
\hline Bending & 73.5 & 113.8 & 60.7 & 33.2 & 30.8 \\
\hline Horz. Shear & 76.8 & 133.7 & 60.8 & 40.3 & 37.4 \\
\hline
\end{tabular}


Appendix 2 


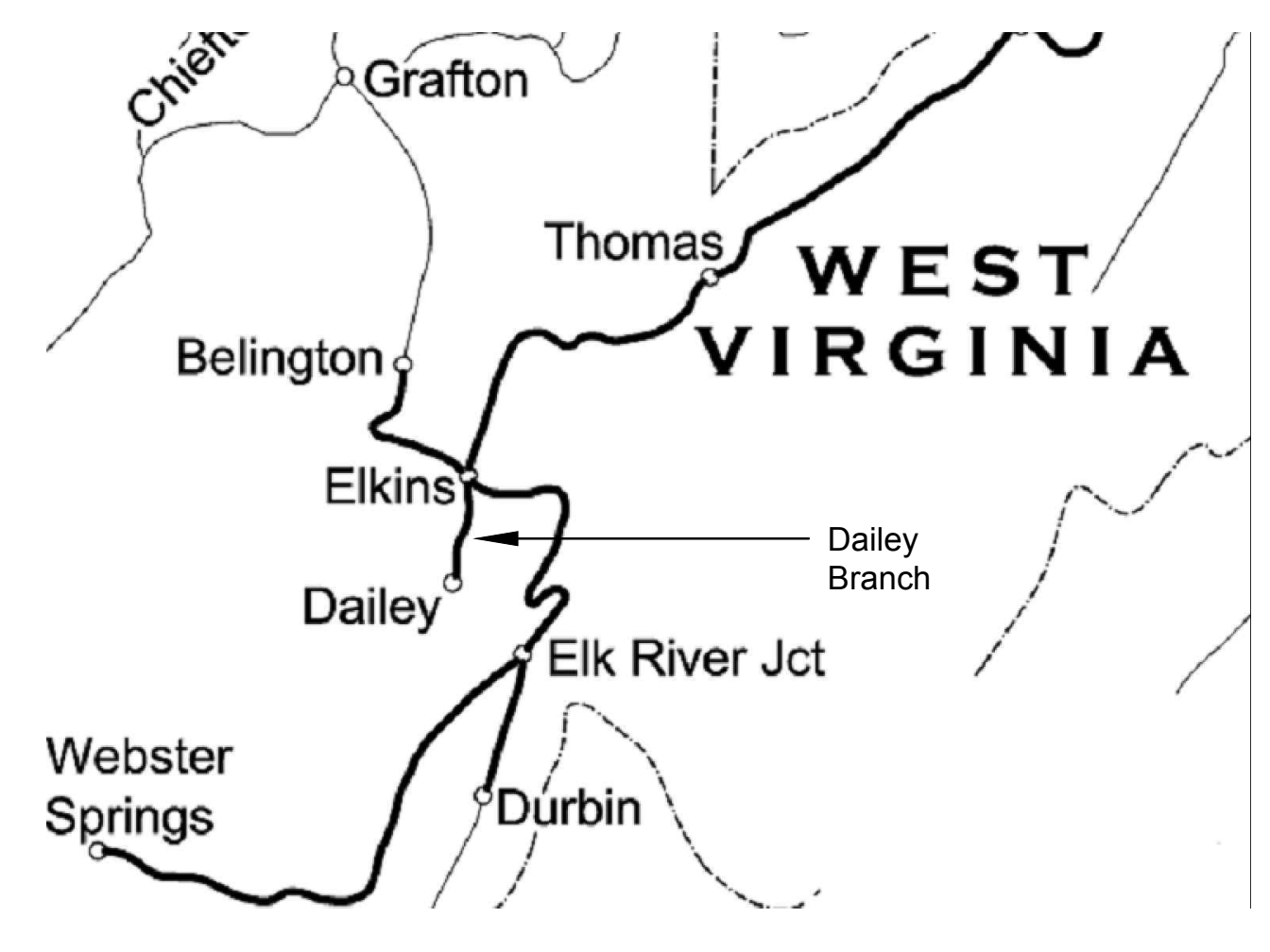

\section{West Virginia \\ Department of Transportation \\ Division of Highways \\ Plans for Construction \\ of \\ State Railroad \\ Fiber Reinforced Polymer Wrap of Dailey Branch Bridges \\ 2 \\ (1) \\ 9 \\ (10)

\begin{tabular}{|c|c|}
\hline \multicolumn{2}{|c|}{ Index to Sheets } \\
\hline No. & Description \\
\hline 1 & Title Sheet \\
\hline $2-4$ & Notes and Quantities \\
\hline 5 & Bridge Locations \\
\hline 6 & Typical Cross Section of a Framed Bent \\
\hline $7-16$ & Bridge 1.9 - Inspection Tables and Drawings \\
\hline $17-25$ & Bridge 4.3 - Inspection Tables and Drawings \\
\hline $26-33$ & Bridge 5.1 - Inspection Tables and Drawings \\
\hline
\end{tabular}

Plans Prepared by: Constructed Facilities Center West Virginia University

\begin{tabular}{|l|l|}
\hline The West Virginia Department of Transportation \\
Division of Highways
\end{tabular}


Governing Specifications:

Eantenance-of-Way Association 2014 Manual for Railway Engineering

Special Provisions:

low ACl 440.2R-08, Guide for the Design and Construction of provision applicable to Systems for Strengthening Concrete Structures. Sections in this system constituent materials, is covered in Chapter 5 . All sections in Chapter 6 , with the exception of the concrete specific surface preparation in section 6.4 , are applicable to different aspects of the installation process of FRP systems.

\section{Scope of Work:}

These set of drawings and specifications are intended for all timber members in the railroad bridges found on the Dailey Branch line meeting the criteria for FRP repair.

Potential members for FRP repair are divided into two groups, the members to be replaced and the members to be wrapped with FRP. This grouping is based solely on the economic feasibility of the two proposed options. Members/material above the stringers fall outside of the scope of the FRP specs and drawings presented in this work i.e. rails, ties, tie spacers, ballast. Retaining wall structures, including timber backwalls and wingwalls, are not considered for FRP repair in this work.

Materials:
(1) Fabric: E-glass
(2) Resin: Phenolic adhesive and Formaldehyde hardener
per manufacturer recommendation
(3) Primer: Phenolic primer (also filler material)

*Manufacturer should provide proper mixing, and curing time.

\section{Surface Preparation for Wrapping:}

ofore wrap can be applied on a post where bracing bstructs the surface area. For members bearing on the ground, excavation to expose the bottom surface of the member to be wrapped might be necessary.

- Any extraneous material on the members to be repaired, such as logged debris,

vegetation, sawdust, mold, and mud, needs to be removed. If heavy mud and dust has collected on surfaces intended for repair, a pressure washer may be used for an effective system and the wood substrate. Heavy duty 60,000 BTU heaters and fans may be used to dry the timber if a pressure washer is needed.

- All members (rectangular cross sections) to be wrapped need to have round edges in order to ensure proper bonding, and reduce stress concentrations. This can be performed with a handheld sander. ACl 440.2R-08 Chapter 13 specifies a minimum corner radius of $\frac{1}{2}$ for wrapping of concrete members, the same concept will apply to the timber members in this repair scheme. The surface of the member to be wrapped should also be sand down if it contains imperfections that could generate voids under the FRP wrap. - A filler material needs to be prepared to fill hollow sections of the members to be wrapped. This is done by mixing the phenolic based adhesive with sawdust. The mixing quantities are $\frac{4}{5}$ phenolic primer, $\frac{1}{5}$ sawdust of the total volume. After being mixed, it can be poured through the holes to allow the filler to flow into the heart rot space. Shrink wrap should be used as form work to seal around the member to be filled until the filler material sets.

- The primer (G-1149A) can then be applied to the surface with a paintbrush, to then let cure. The curing time should be provided by the manufacture, which is dependent on the ambient temperature.
Wrapping of Posts:

- After all the surfaces have been coated with primer and cured, the wet lay-up process begins. The phenolic formaldehyde resin (G-1131A + G-1131B) is mixed in a basin to be used for fabric wetting. A discontinuous wrapping approach is recommended, where 20 rolls of E-glass fabrics are cut to 5 ' lengths to then be applied in sections. 5' sections of fabric allow for easier handling and construction of FRP wrap repair. After the resin has been mixed for the time recommended by the manufacturer, the sections of fabric shall be dipped in the resin. A hand-wringer is then to be used in order to remove/squeeze any excess resin from the fabric.

- The wrapping of the posts will always start from the bottom, by tightly pulling the fabric around the post in a circular manner. The wrap shall not be applied at an angle, it should go around all four sides of the post at a zero degree angle until it comes back around and overlaps for a minimum of $4^{\prime}$. A staple gun should be used to hold the ends of the wrap in place in order to maintain a uniform pulling pressure around the post, thus minimizing any voids from the wrap sagging under its own weight.

- Any additional layers of wrap needed shall be placed up from the previous FRP wrap with an overlap of 3" to 4" all around all 4 side of the post. This allows for water to drain down the outside of the FRP wraps, once they have been placed and cure. If this procedure is not followed, any lower wrap overlapping higher placed wrap on the post, might create a pocket for water collection. The last sheet of wrap for each layer (depending of the number of layers needed) shall be placed to where it extends 6" above the area

- After the final layer of wrap has any future moisture from reaching the damaged area. - Afer the fnallayer of wrap has been applied,

\begin{tabular}{|c|c|c|}
\hline Description & Units & Quantity \\
\hline $\begin{array}{l}\text { Glass Fiber Fabric (per layer) } \\
\text { Bulk Filler }\end{array}$ & $\begin{array}{l}\bar{f} \mathrm{f}^{\wedge} 2 \\
\mathrm{gal}\end{array}$ & $\begin{array}{l}324.12 \\
301.32\end{array}$ \\
\hline
\end{tabular}

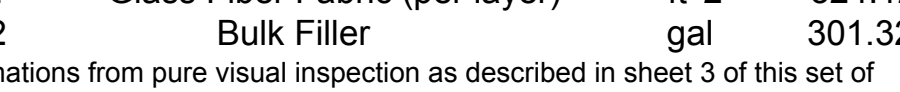

"These quawings.

Summary of Estimated Quantities for Replacement

\begin{tabular}{|c|c|c|c|c|}
\hline Type & Width (in) & $2 \underline{\text { Height (in) }}$ & Length & Quantity \\
\hline Stringer & 8 & 16 & $88^{\prime}-7^{\prime \prime}$ & \\
\hline Stringer & 8 & 16 & $20^{\prime}-11.75^{\prime \prime}$ & 1 \\
\hline Stringer & 8 & 16 & $23^{\prime}-10^{\prime \prime}$ & 2 \\
\hline Stringer & 8 & 16 & $20^{\prime}-11^{\prime \prime}$ & \\
\hline Stringer & 8 & 16 & $23^{\prime}-9^{\prime \prime}$ & 2 \\
\hline Stringer & 8 & 16 & $11^{\prime}-11^{\prime \prime}$ & 2 \\
\hline Stringer & 8 & 16 & $22^{\prime}-7^{\prime \prime}$ & $\frac{2}{1}$ \\
\hline Stringer & 8 & 16 & $10^{\prime}-9^{\prime \prime}$ & 1 \\
\hline Stringer & 8 & 16 & $12^{\prime}-5.88^{\prime \prime}$ & 2 \\
\hline Stringer & 8 & 16 & $23^{\prime}-5.13^{\prime \prime}$ & $\frac{1}{1}$ \\
\hline Stringer & 8 & 16 & $23^{\prime}-7.75^{\prime \prime}$ & 1 \\
\hline Corbel & 12 & 8 & $4^{\prime}-0 "$ & 1 \\
\hline Cap Beam & 12 & 12 & $12^{\prime}-0 "$ & 1 \\
\hline Block & 16 & 8 & $3^{\prime}-0 "$ & 5 \\
\hline Block & 12 & 12 & $3^{\prime}-0 "$ & 4 \\
\hline Block & 12 & 6 & $3^{\prime}-0 "$ & 3 \\
\hline Sway Brace & 8 & 4 & $21^{\prime}-6.5^{\prime \prime}$ & 1 \\
\hline Tower Brace & 12 & 4 & $25^{\prime}-2^{\prime \prime}$ & 1 \\
\hline Tower Brace & 12 & 4 & $25^{\prime}-10.5^{\prime \prime}$ & $\frac{1}{1}$ \\
\hline Tower Brace & 12 & 4 & $25^{\prime}-2.5^{\prime \prime}$ & 1 \\
\hline
\end{tabular}

sportation Division of Highways

PROJECT WV Central Rail Road Dailey Branch Bridges

Notes and Quantities

\begin{tabular}{ll|l|}
\hline Drawn By & Date \\
& LCP & 12-9-2015 \\
\hline \multicolumn{3}{|c|}{$\begin{array}{c}\text { Constructed Facilities Center } \\
\text { West Virginia University }\end{array}$} \\
\hline Scale & None & Sheet 2 \\
& None
\end{tabular}


Surface Preparation

Rounding edges of the cross section of posts and sills

Existing Post/Sil

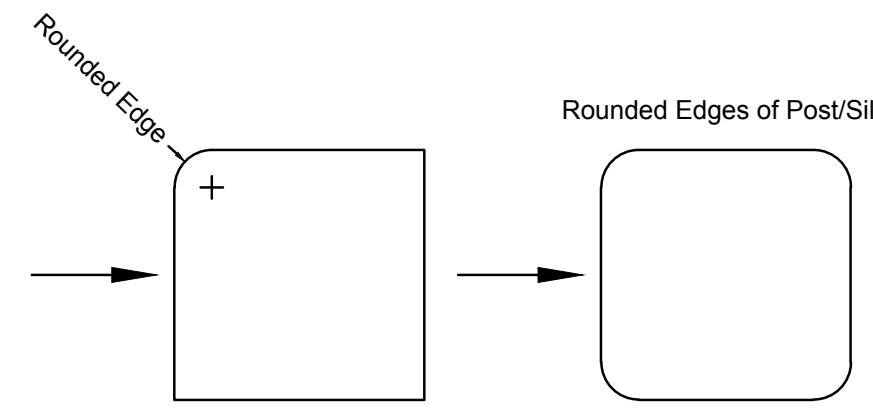

Wrapping of Post:

First cut fabric to $5^{\prime}$ lengths. Next, wet the fabric and remove any excess resin.

The layers of wrap will be placed transversely to the length of the posts, exactly

perpendicular to the length of the post. Make sure to staple the FRP wraps at both ends to

secure the bond during the curing process, Additional layers are to be wrapped in the

same order as the first layer.

Step 1

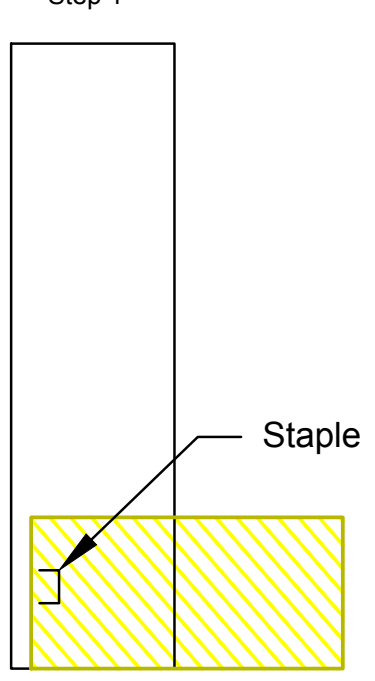

$\square$
Step 2
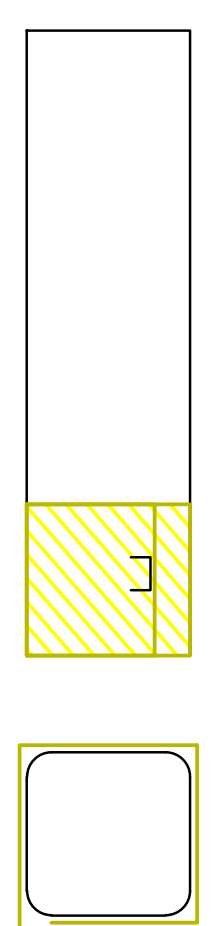

Step 3
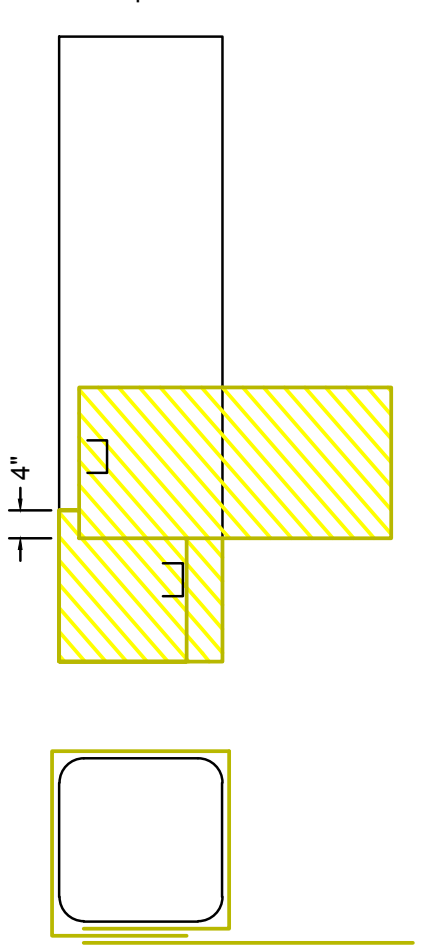

Step 4

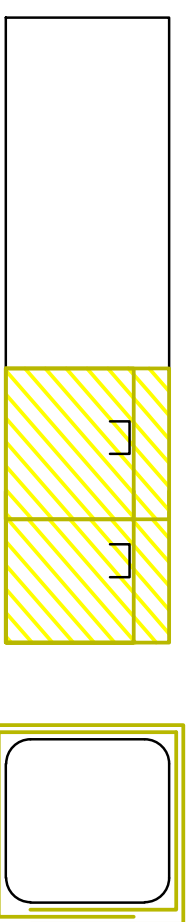

\section{Wrapping of Sill:}

The fabric in step 1 should be cut to the deterioration length of the corresponding sill. Cut the remaining fabric to $5^{\prime}$ lengths. Next, wet the fabric and remove any excess resin. The layers of wa wil be placed transversely to the ang rh of the sill, exacly

perpen the bronds to

e firstlayer. Excavation might be necessary under the sils.

Step 1

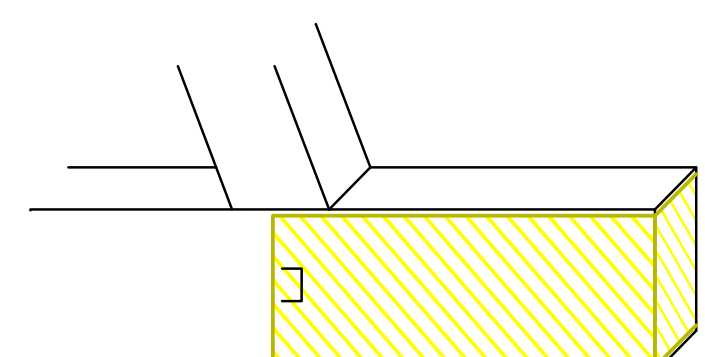

Step 2

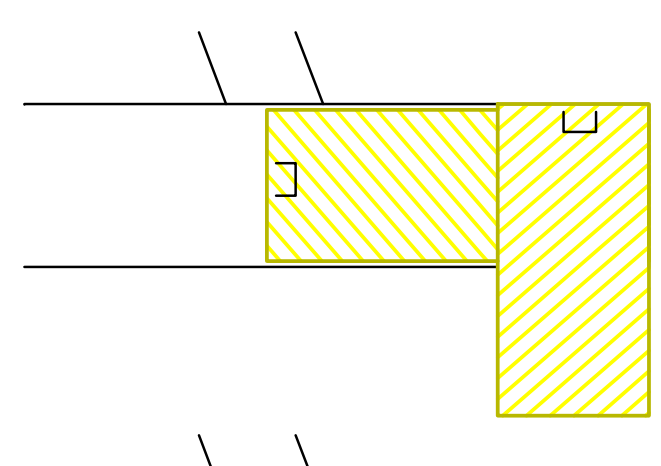

Step 3

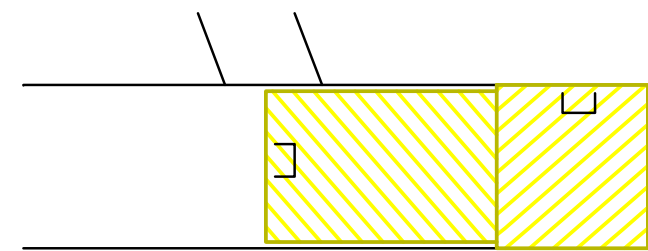

Step 4

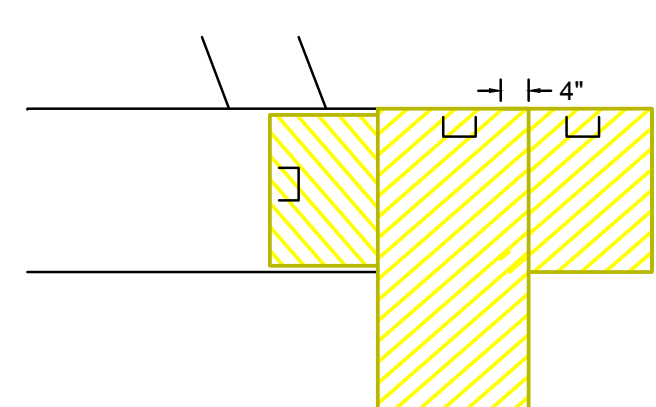

Step 5

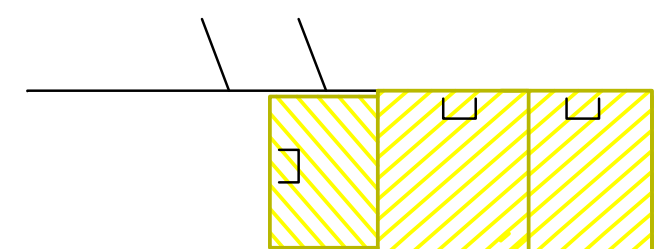

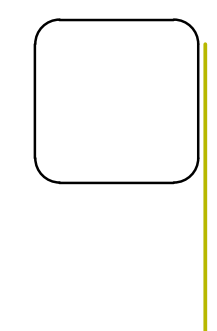
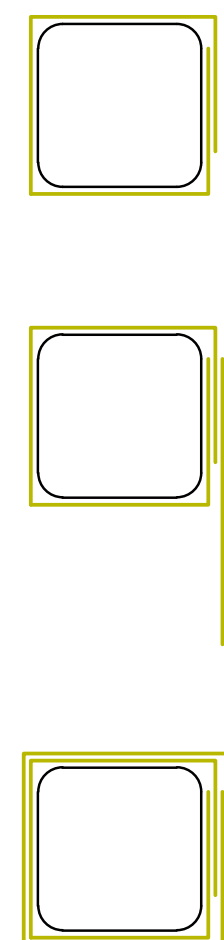

The West Virginia Department of Transportation Division of Highways

WROJECT Central Rail Road
Dailey Branch Bridges

TITLE

Wrapping Scheme

\begin{tabular}{|ll|l|}
\hline Drawn By & Date \\
& LCP & 12-9-2015 \\
\hline \multicolumn{3}{|c|}{$\begin{array}{c}\text { Constructed Facilities Center } \\
\text { West Virginia University }\end{array}$} \\
\hline Scale & None & Sheet 3 \\
&
\end{tabular}


Notes:

1. The superstructure inspection table only covers damage found in the stringers of the timber bridges, undamaged members are not included.

2. The substructure inspection table covers damage found in all members below the stringers of the timber bridges, undamaged members are not included.

3. The following color coding is used:

- RED: Significant deterioration in member, replacement of member is recommended.

- YELLOW: Significant deterioration in member, FRP wrap is

recommended.

- GREEN: Softening noted in member, no repair is needed but monitoring is recommended.

- BROWN: Member in good condition, no repair is needed.

4. Due to the staggered continuity of the stringers, most stringers will span continuously over two spans. The member length noted in the tables

represents the whole length of a stringer, whether it extends over two spans or only one span.

5. Inspection drawings are provided in order to show the dimensions and location of the damage. The damaged area in the drawings is represented with black diagonal staggered continuous-dash lines.

6 . In the drawings, yellow diagonal continuous lines are used to represent the area of a member to be wrapped with FRP.

7. High rot dimensions on members are used to represent high levels of damage. Since many members were checked with a hammer for internal rot, the dimensions are approximate.

\section{FRP Wrap:}

The wrap quantities shown in individual bridge inspection sheets are based on the surface area of the member to be covered with FRP wrap. These quantities are for a single layer of wrap without accounting for overlap.
8. The individual inspection sheets on each bridge show a table where the type of damage is included in one of its columns. The most common type of damage shown is rot. Where rot was not noticeable on the outside surface of a member, heart rot was determine by the use of a hammer being knocked on the visible surfaces of a member. If a member was found to be hollow by this procedure, than it was labeled as rotted (heart rot).

Tables for each bridge indicating the type of damage as follows:

-Rot: Heart rot visible through holes on the surface of the timber (reference sheet number 8 - Bent 4 Post 1) or internal rot found via hammer sounding -Soft or softening: Surface of member showed higher levels of moisture than surrounding members, and hammer taps were muted.

-Splits: Surface splits in the member.

-Fruiting Bodies: Growth of fungi on the surface of the member indicating decay

9. Stringers $1,4,5$, and 8 were inspected on three of their four surfaces; the top and bottom surfaces, and on the side surface not bolted to another stringer. Stringers 2, 3, 6, and 7 could only be inspected on the top and bottom surfaces. The figure below shows the two chord stringer set up.
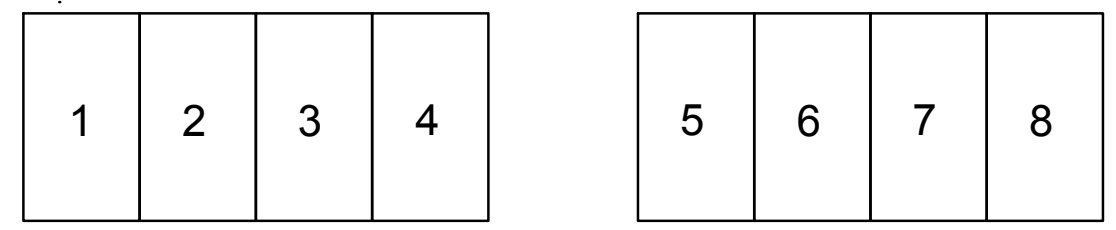

In each 4-stringer chord system, the inner 2 stringers have less exposure, thus visual inspection of these internal members is based on on the top and bottom faces of the stringers.

10. The posts and other members were inspected on all visible surfaces.

11. If a more accurate dimensioning of the damage inside the timber members is needed, it is recommended that 3D Acoustic tomography or drilling/coring be conducted.

\begin{tabular}{|l|l|}
\hline The West Virginia Department of Transportation \\
Division of Highways
\end{tabular}




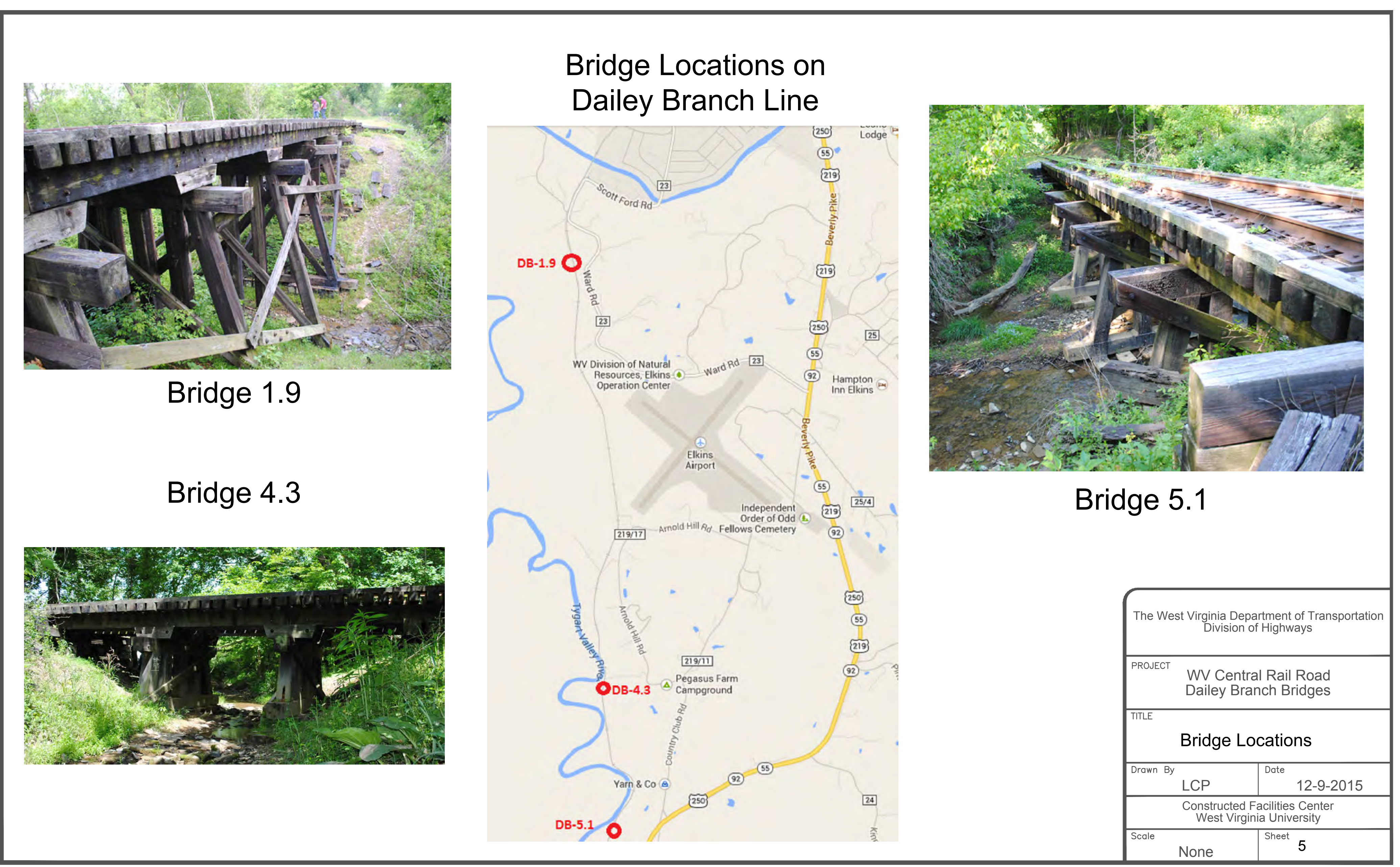




\section{Typical Cross Section and Numbering of an Inner Bent}

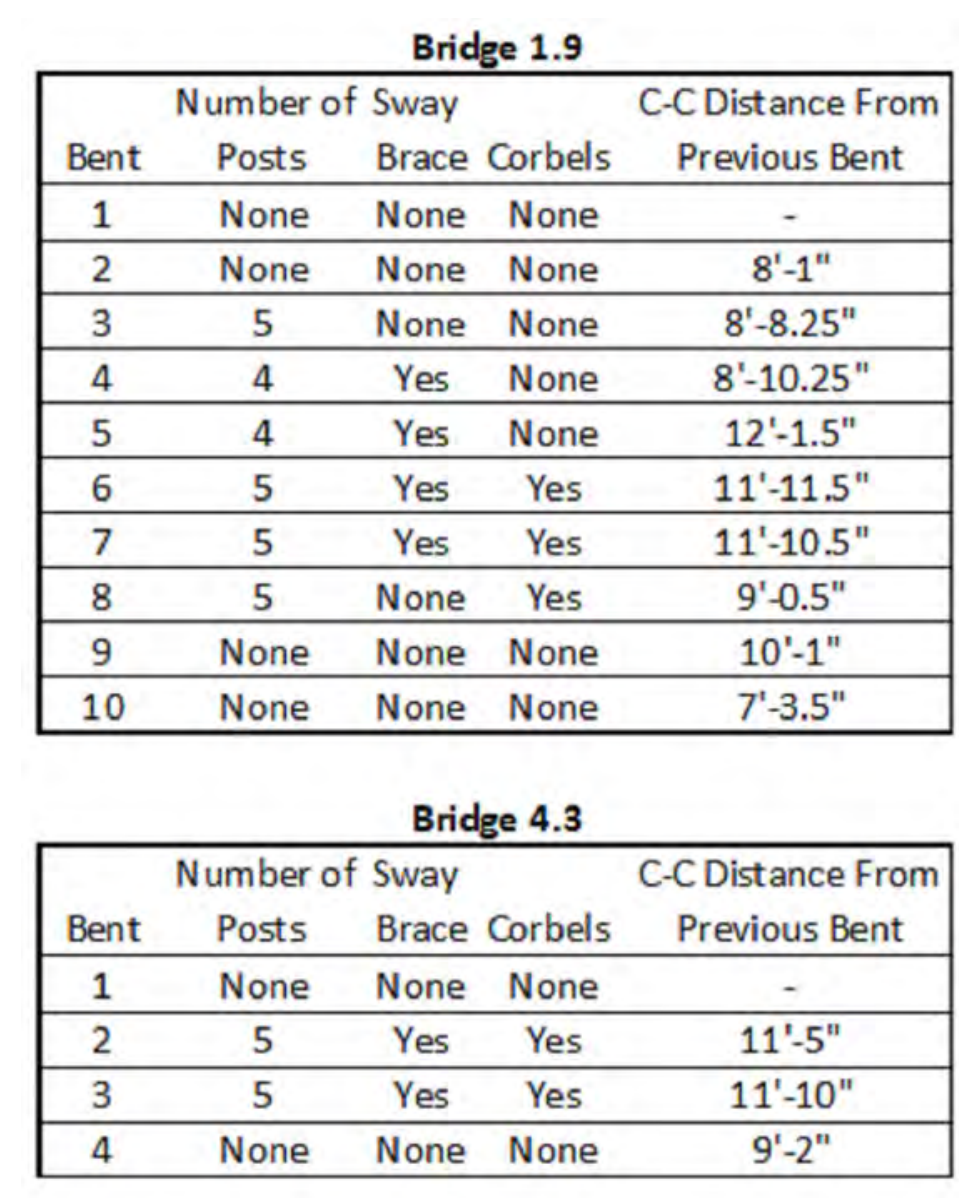

\begin{tabular}{|c|c|c|c|c|}
\hline & Number & Sway & & C-C Distance From \\
\hline Bent & Posts & Brace & Corbels & Previous Bent \\
\hline 1 & None & None & None & - \\
\hline 2 & 5 & Yes & None & $11^{\prime}-6^{\prime \prime}$ \\
\hline 3 & 5 & Yes & None & $10^{\prime}-11.25$ \\
\hline 4 & 5 & Yes & None & $12^{\prime}-1.75^{\prime \prime}$ \\
\hline 5 & 5 & Yes & None & $11^{\prime}-6^{\prime \prime}$ \\
\hline 6 & 5 & Yes & None & $11^{\prime}-10^{\prime \prime}$ \\
\hline 7 & 5 & Yes & None & $11^{\prime}-6.5^{\prime \prime}$ \\
\hline 8 & None & None & None & $10^{\prime}-0.88^{\prime \prime}$ \\
\hline
\end{tabular}

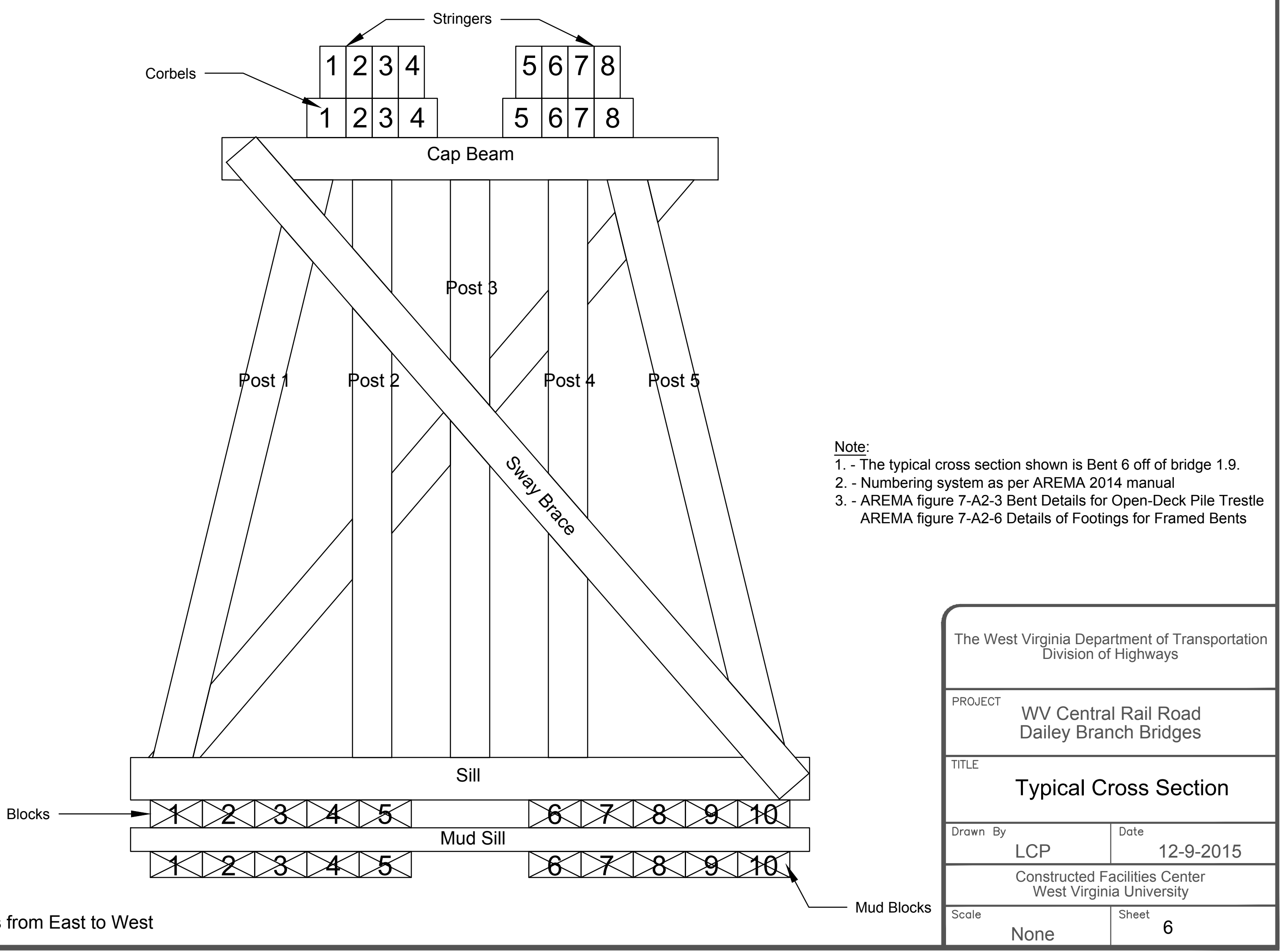

${ }^{*}$ Member numbering increases from East to West 
Bridge 1.9 Superstructure Inspection - Stringers

\begin{tabular}{|c|c|c|c|c|c|c|}
\hline \multirow{2}{*}{ Span } & \multirow{2}{*}{ Stringer } & \multirow{2}{*}{$\begin{array}{l}\text { Member } \\
\text { Length }\end{array}$} & \multicolumn{4}{|c|}{ Damage } \\
\hline & & & Type & Width & Height & Length \\
\hline 1 & 1 & $8^{\prime}-7^{\prime \prime}$ & Rot & $8^{\prime \prime}$ & $2^{\prime \prime}$ & $4^{\prime}$ \\
\hline 3 & 2 & $20-11.75^{n}$ & Rot & $8^{n}$ & $2^{\prime \prime}$ & $18^{\prime}-10^{\prime \prime}$ \\
\hline 4 & 2 & \multicolumn{5}{|c|}{ Same Stringer as Span 3 Stringer 2} \\
\hline \multirow{4}{*}{5} & 2 & $23^{\prime}-10^{\prime \prime}$ & Rot & $8^{\prime \prime}$ & $2^{n}$ & $12^{\prime}$ \\
\hline & 3 & $244^{\prime \prime}$ & Soft & & & \\
\hline & 4 & $23^{\prime}-10^{\prime \prime}$ & Rot & $4^{n}$ & $2^{n}$ & $3^{\prime}$ \\
\hline & 6 & $23^{\prime}-10^{\prime \prime}$ & Soft & & & \\
\hline \multirow{4}{*}{6} & 2 & $23^{\prime}-10^{\prime \prime}$ & Soft & & & \\
\hline & $\underline{3}$ & $20^{\prime}-11^{\prime \prime}$ & Rot & $8^{n}$ & $2^{n}$ & $5^{\prime}$ \\
\hline & 4 & $23^{\prime}-10^{\prime \prime}$ & Soft & & & \\
\hline & 7 & $20-11^{\prime \prime}$ & Soft & & & \\
\hline \multirow{2}{*}{7} & 5 & $20^{\prime}-11^{\prime \prime}$ & Soft & & & \\
\hline & 6 & $19^{\prime}-1.5^{\prime \prime}$ & Soft & & & \\
\hline \multirow{3}{*}{9} & 3 & $17^{\prime}-5^{n}$ & Soft & & & \\
\hline & 4 & $7^{\prime}-9.5^{\prime \prime}$ & Soft & & & \\
\hline & 8 & $7^{\prime}-9.5^{\prime \prime}$ & Soft & & & \\
\hline
\end{tabular}

Notes:

1. The following color coding is used:

- RED: Significant deterioration in member, replacement of member is recommended.

- GREEN: Softening noted in member, no repair is needed but monitoring is recommended.

- BROWN: Member in good condition, no repair is needed.

2. The damage in Span 3-Stringer 2 extends over to Span 4-Stringer 2 (same member).
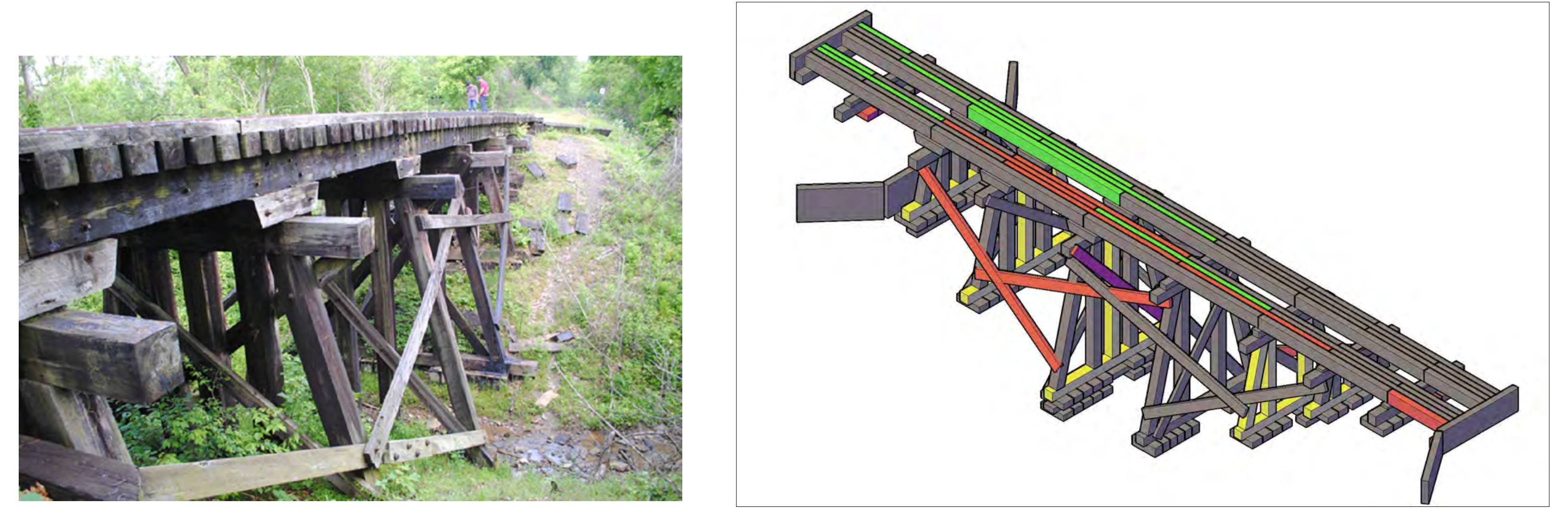

\begin{tabular}{|c|c|c|}
\hline \multicolumn{3}{|c|}{$\begin{array}{l}\text { The West Virginia Department of Transportation } \\
\text { Division of Highways }\end{array}$} \\
\hline ROJECT & \multicolumn{2}{|c|}{$\begin{array}{l}\text { WV Central Rail Road } \\
\text { Dailey Branch Bridges }\end{array}$} \\
\hline ITLE & \multicolumn{2}{|c|}{$\begin{array}{c}\text { Bridge } 1.9 \\
\text { Inspection - Superstructure }\end{array}$} \\
\hline rawn By & & $\begin{array}{ll}\text { Date } & \\
& 12-9-2015\end{array}$ \\
\hline \multicolumn{3}{|c|}{$\begin{array}{l}\text { Constructed Facilities Center } \\
\text { West Virginia University }\end{array}$} \\
\hline cale & & Sheet 7 \\
\hline
\end{tabular}




\section{Bridge 1.9 Substructure Inspection}

\begin{tabular}{|c|c|c|c|c|c|c|c|c|}
\hline \multirow{2}{*}{ Bent } & \multirow{2}{*}{ Member } & \multicolumn{3}{|c|}{ Member } & \multicolumn{4}{|c|}{ Damage } \\
\hline & & Width & Depth & Length & Type & Width & Height & Length \\
\hline 2 & block 5 & $16^{\prime \prime}$ & $8^{\prime \prime}$ & $3^{\prime}$ & Rot & $8^{\prime \prime}$ & $4 "$ & 6" \\
\hline \multirow{2}{*}{3} & sill & $12^{\prime \prime}$ & $12^{\prime \prime}$ & $12^{\prime}$ & End Rot & $10^{\prime \prime}$ & $10 "$ & 1'-6" \\
\hline & block 5 & $16^{\prime \prime}$ & $8^{\prime \prime}$ & $3^{\prime}$ & Rot & $16^{\prime \prime}$ & $8 "$ & $2^{\prime \prime}$ \\
\hline \multirow{4}{*}{4} & sill & $12^{\prime \prime}$ & $12^{\prime \prime}$ & $13^{\prime}-4^{\prime \prime}$ & End Rot & 6" & $6^{\prime}$ & $12^{\prime \prime}$ \\
\hline & post 1 & $12^{\prime \prime}$ & $12^{\prime \prime}$ & 9'-1" & Rot & 6" & $6^{\prime \prime \prime}$ & 9'-1" \\
\hline & post 2 & $12^{\prime \prime}$ & $12^{\prime \prime}$ & $8^{\prime}-10^{\prime \prime}$ & Rot & $5 "$ & 5" & $12^{\prime \prime}$ \\
\hline & post 3 & $12^{\prime \prime}$ & $12^{\prime \prime}$ & $8^{\prime}-10^{\prime \prime}$ & Rot & $10.5^{\prime \prime}$ & $10.5^{\prime \prime}$ & $2^{\prime}$ \\
\hline \multirow{3}{*}{6} & sill & $13^{\prime \prime}$ & $13^{\prime \prime}$ & $17^{\prime}-4^{\prime \prime}$ & Rot & $11^{\prime \prime}$ & $11^{\prime \prime}$ & $5^{\prime}$ \\
\hline & post 3 & $12^{\prime \prime}$ & $13 "$ & 14'-9" & Rot & $10^{\prime \prime}$ & $11 "$ & $12 "$ \\
\hline & North sway & $8^{\prime \prime}$ & 4" & $21^{\prime}-6.5^{\prime \prime}$ & Rot/Split & \multicolumn{3}{|c|}{ Through bottom bolt } \\
\hline \multirow{3}{*}{7} & sill & $13^{\prime \prime}$ & $13^{\prime \prime}$ & $16^{\prime}-8^{\prime \prime}$ & Rot & $10^{\prime \prime}$ & $10^{\prime \prime}$ & 2'-6" \\
\hline & post 3 & $12^{\prime \prime}$ & $13^{\prime \prime}$ & 9'-4.5" & Rot & $8.25 "$ & $9.25 "$ & 1'-4" \\
\hline & post 5 & $12 "$ & $13^{\prime \prime}$ & 9'-7.75" & Rot & $7.25^{\prime \prime}$ & 7" & $2^{\prime}$ \\
\hline 8 & sill & $13^{\prime \prime}$ & $13.5^{\prime \prime}$ & $14^{\prime}-8^{\prime \prime}$ & Rot & $5 "$ & $8 "$ & $2^{\prime}$ \\
\hline \multirow{3}{*}{9} & block 1 & $16^{\prime \prime}$ & $8^{\prime \prime}$ & $3^{\prime}$ & Rot & $16^{\prime \prime}$ & $8 "$ & $3^{\prime}$ \\
\hline & block 2 & $16^{\prime \prime}$ & $8 "$ & $3^{\prime}$ & Rot & $16^{\prime \prime}$ & $8 "$ & $3^{\prime}$ \\
\hline & block 4 & $16 "$ & 8" & $3^{\prime}$ & Rot & $16^{\prime \prime}$ & 8" & $3^{\prime}$ \\
\hline West & ower Brace 1 & $12 "$ & 4" & $25^{\prime}-2 "$ & Split & \multicolumn{3}{|c|}{ Through North Bolt } \\
\hline \multicolumn{2}{|c|}{ East Tower Brace 3} & $12 "$ & $4 "$ & $25^{\prime}-10.5^{\prime \prime}$ & Split/Fruiting & \multicolumn{3}{|c|}{ On South Bolt } \\
\hline \multicolumn{2}{|c|}{ East Tower Brace 4} & $12^{\prime \prime}$ & $4 "$ & $25^{\prime}-2.5^{\prime \prime}$ & Rot/Split & \multicolumn{3}{|c|}{ Through South Bolt } \\
\hline
\end{tabular}

1. The following color coding is used:

- RED: Significant deterioration in member, replacement of member is recommended.

- YELLOW: Significant deterioration in member, FRP wrap is recommended.

- BROWN: Member in good condition, no repair is needed.

2. Tower Braces 3 and 4 have been spliced, but are in good shape.

\section{FRP Wrap Quantities}

\section{To Wrap}

Bent Member Width (in) Depth (in) Length (in) Area $\left(\mathrm{in}^{2}\right.$ )

\begin{tabular}{|c|c|c|c|c|c|}
\hline \multirow{3}{*}{4} & Post 1 & 12 & 12 & 109 & 5232 \\
\hline & Post 2 & 12 & 12 & 18 & 864 \\
\hline & Post 3 & 12 & 12 & 30 & 1440 \\
\hline 6 & Post 3 & 12 & 13 & 18 & 900 \\
\hline \multirow{2}{*}{7} & Post 3 & 12 & 13 & 22 & 1100 \\
\hline & Post 5 & 12 & 13 & 18.25 & 912.5 \\
\hline 3 & Sill & 12 & 12 & 24 & 1152 \\
\hline 4 & Sill & 12 & 12 & 18 & 864 \\
\hline 6 & Sill & 13 & 13 & 66 & 3432 \\
\hline 7 & Sill & 13 & 13 & 36 & 1872 \\
\hline 8 & Sill & 13 & 13.5 & 30 & 1590 \\
\hline
\end{tabular}

FRP Wrap:

The quantities shown are based on the surface area of the member to be covered with FRP wrap. These quantities are for a single layer of wrap without accounting for overlap.

\begin{tabular}{|l|l|}
\hline The West Virginia Department of Transportation \\
Division of Highways
\end{tabular}




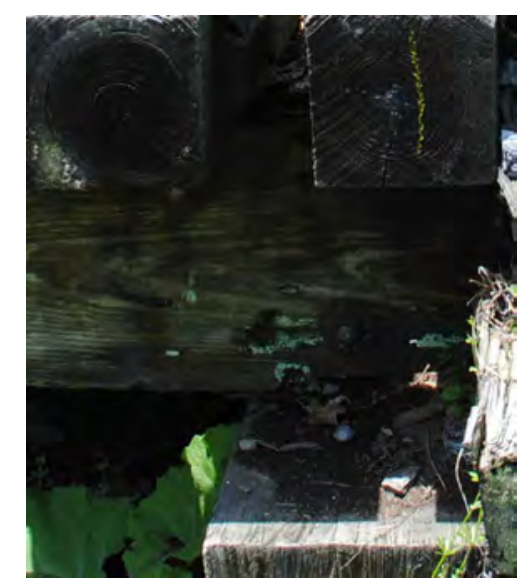

Span 1 - Stringer 1 Rot

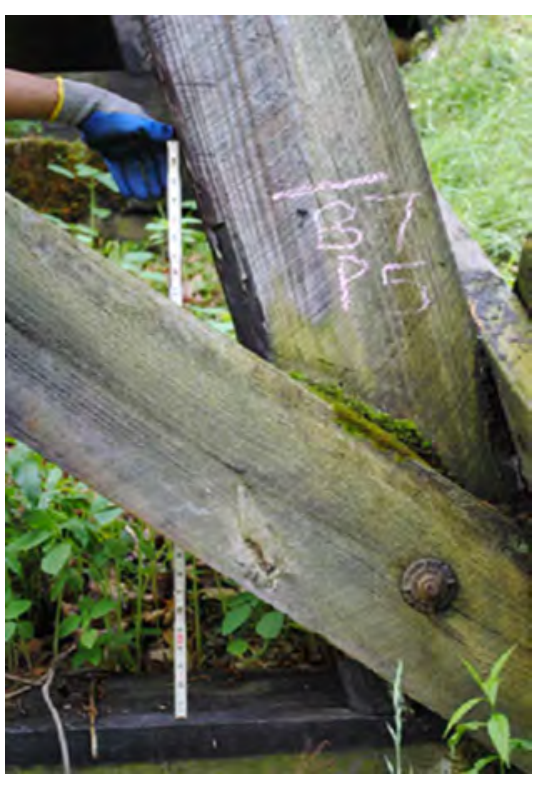

Bent 7 - Post 5 Rot

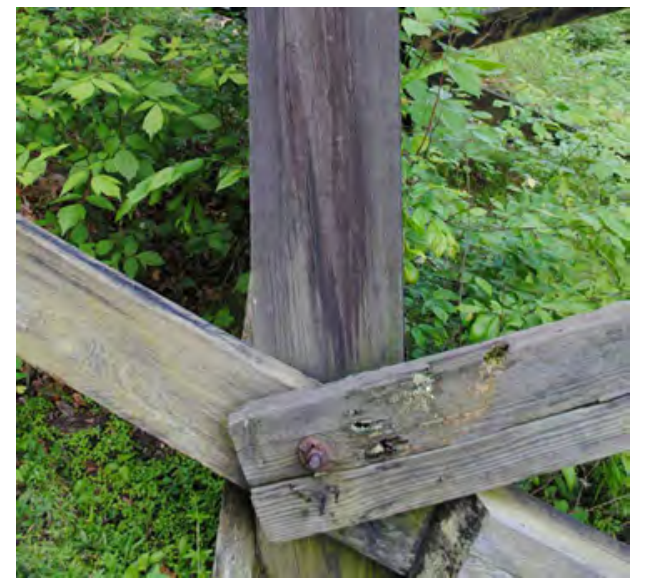

East Tower Brace 3 - Fruiting Bodies

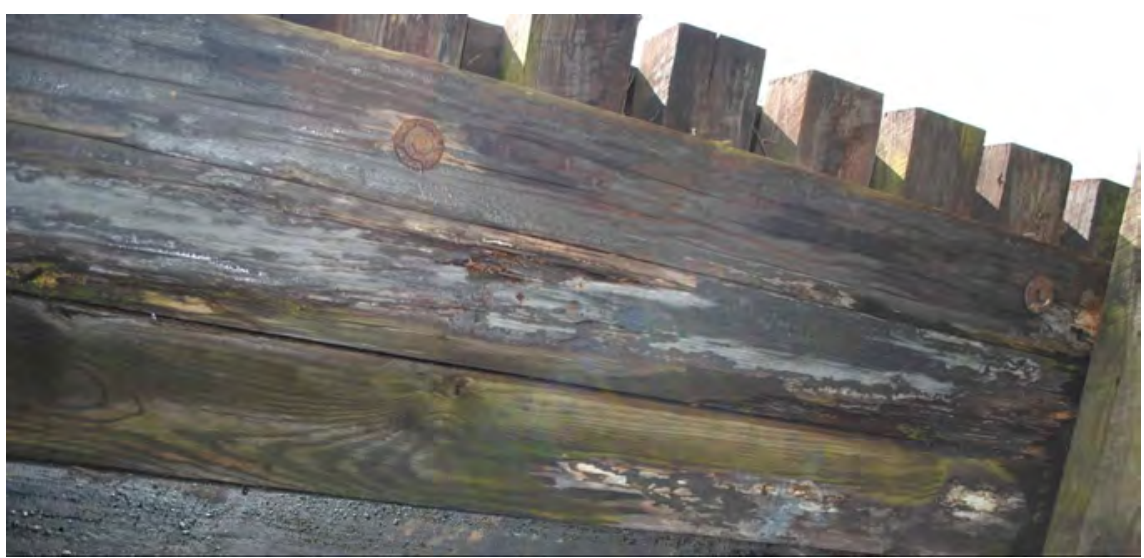

Span 3 - Stringer 2 Rot

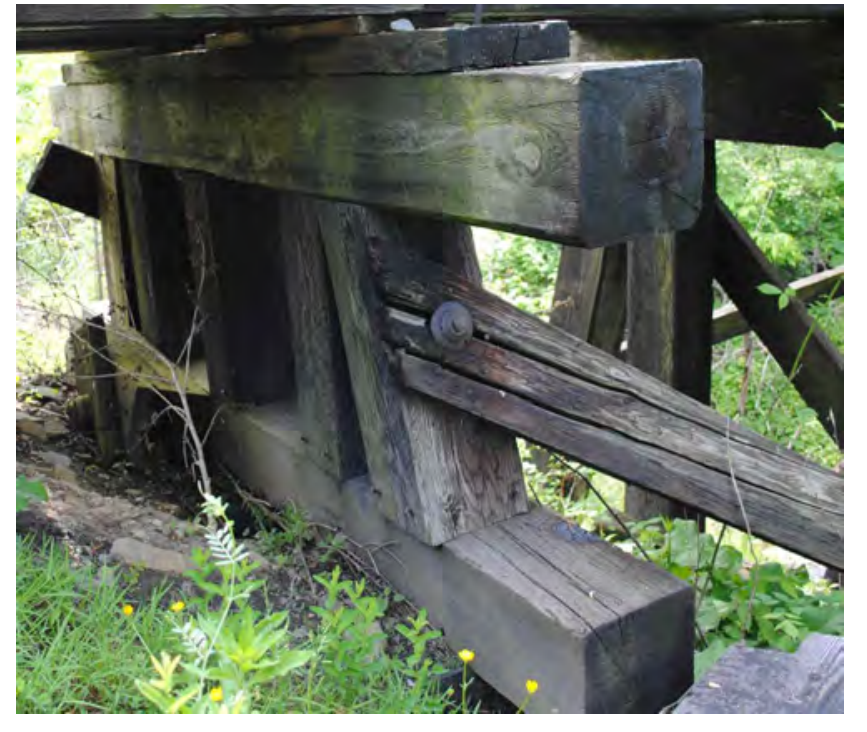

Tower Brace 1 West

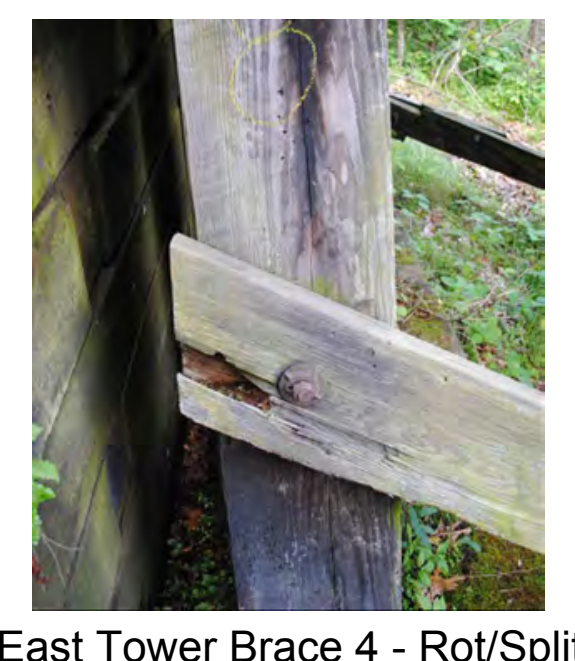

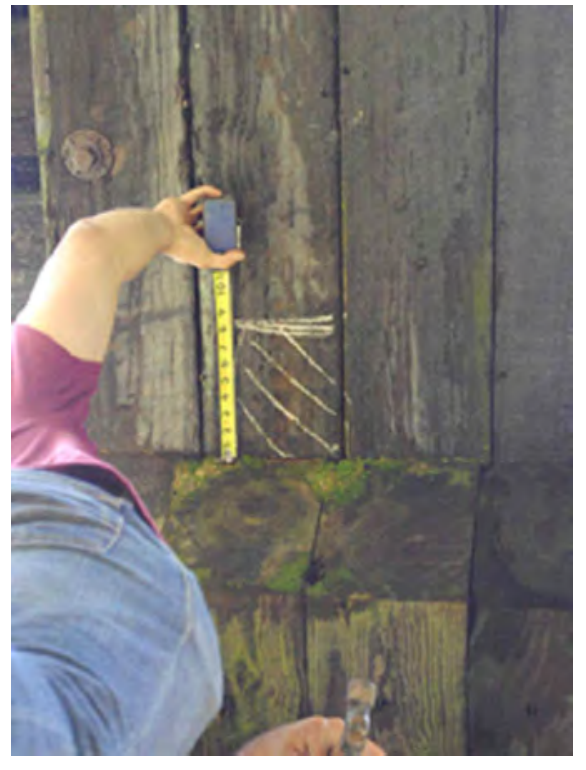

Span 6 - Stringer 7 Softening

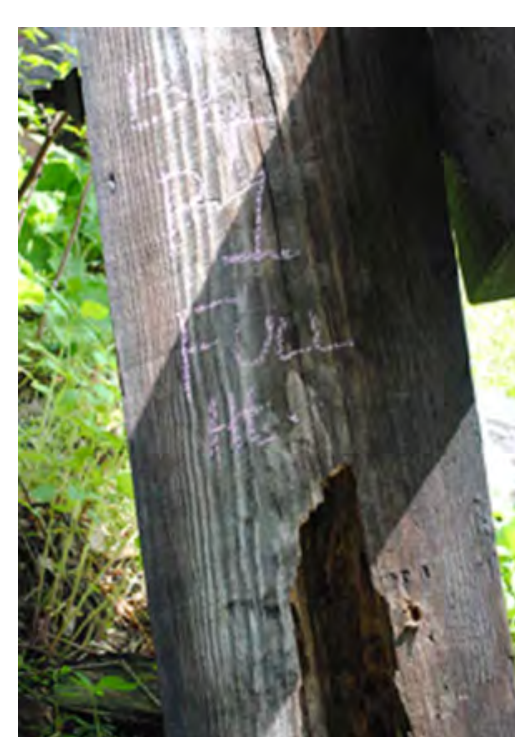

Bent 4 - Post 1 Rot

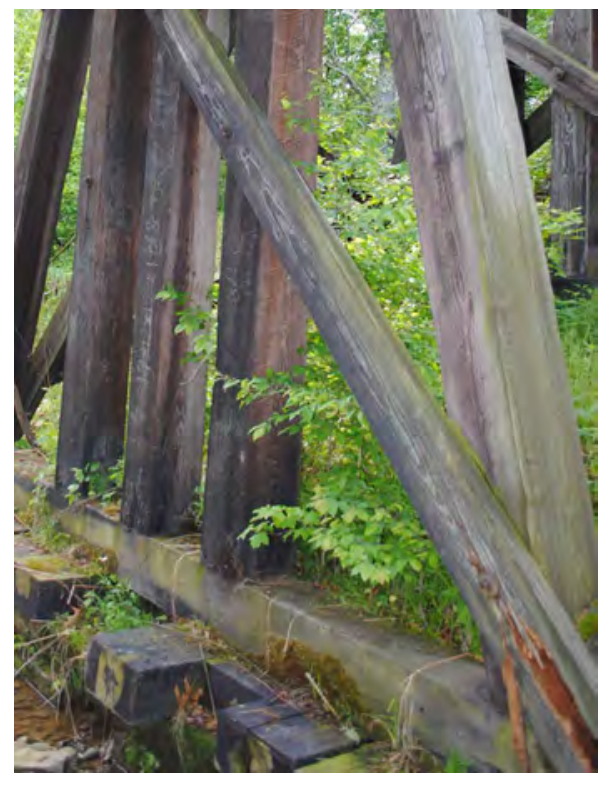

Bent 6 - North Sway Brace

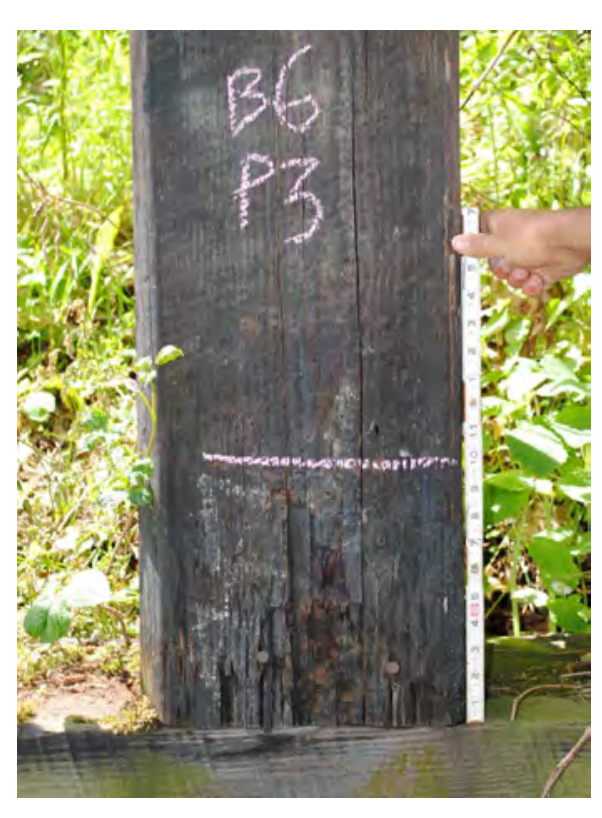

Bent 6 - Post 3 Rot

\begin{tabular}{|l|l|l|}
\hline The West Virginia Department of Transportation \\
Division of Highways
\end{tabular}




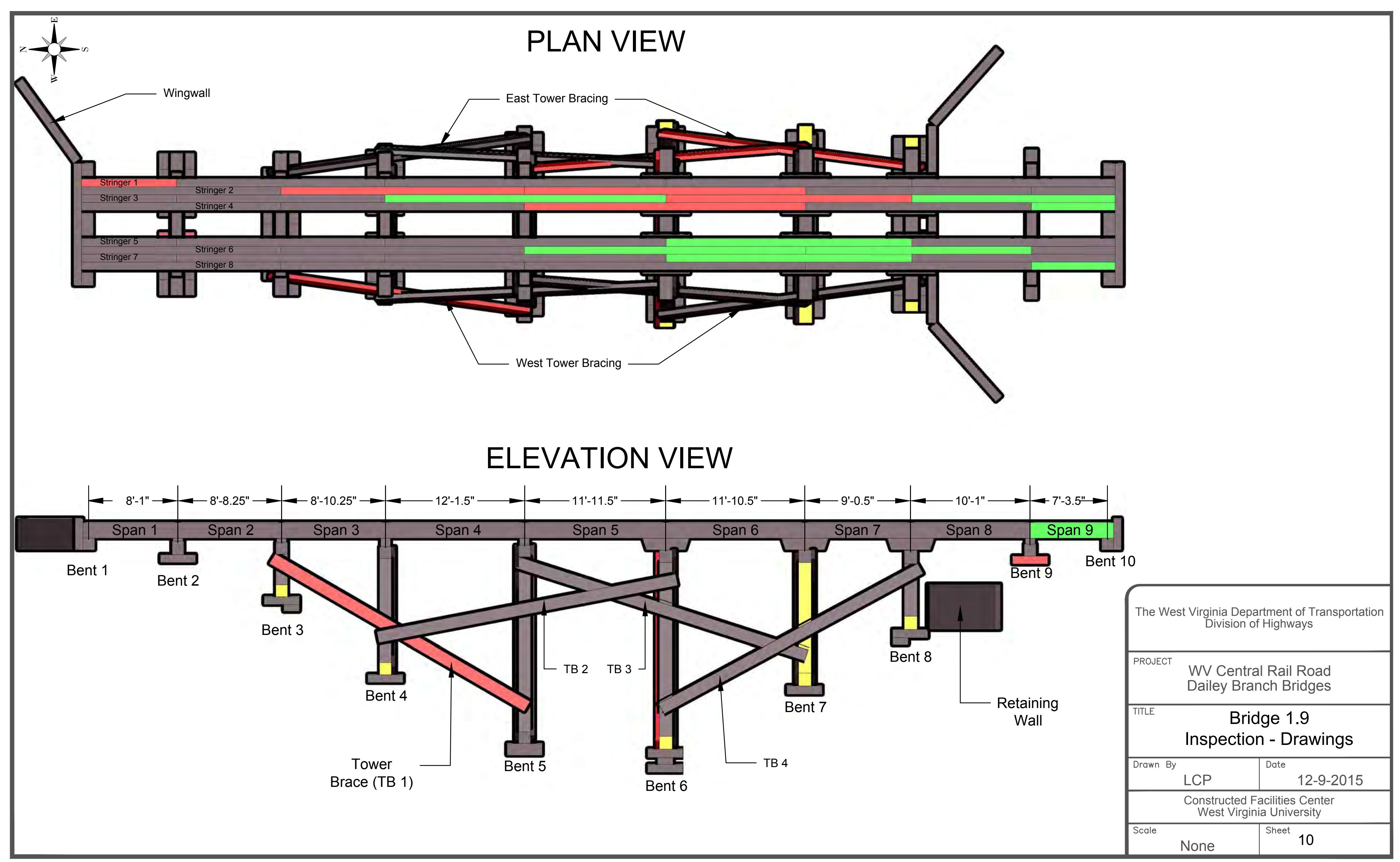




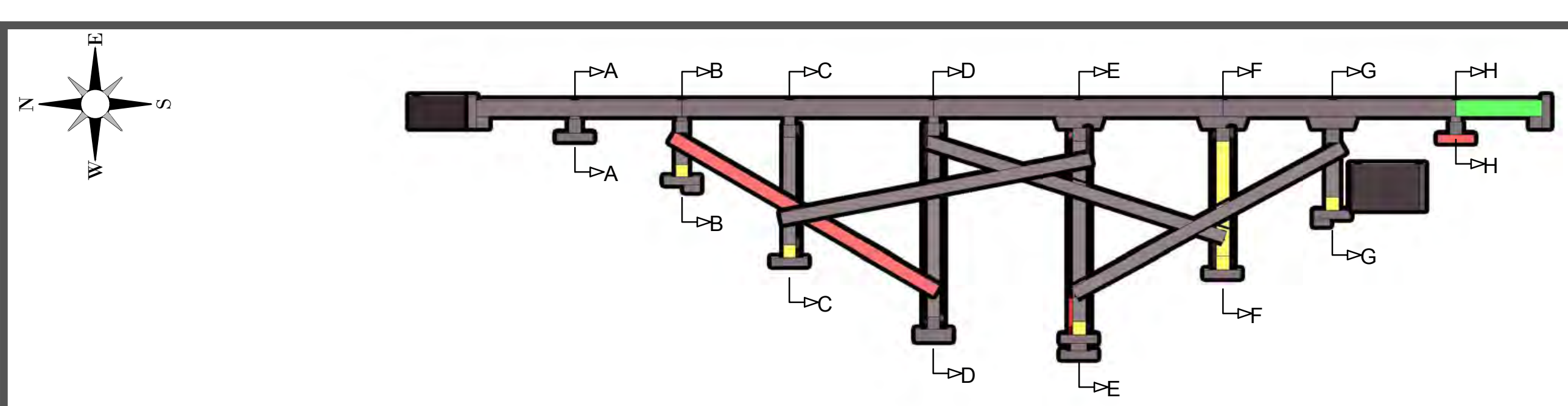

SECTION A-A (Bent 2)

SECTION C-C (Bent 4)

SECTION B-B (Bent 3)

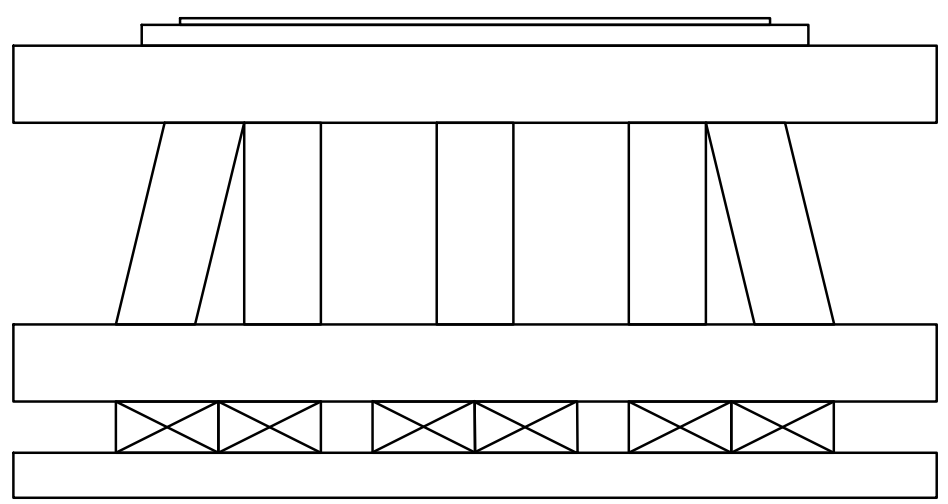

SECTION F-F (Bent 7)

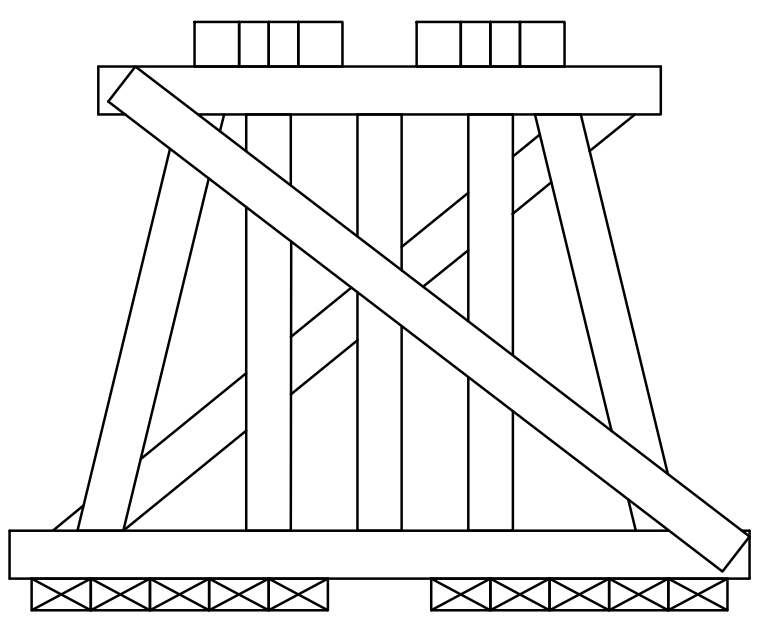

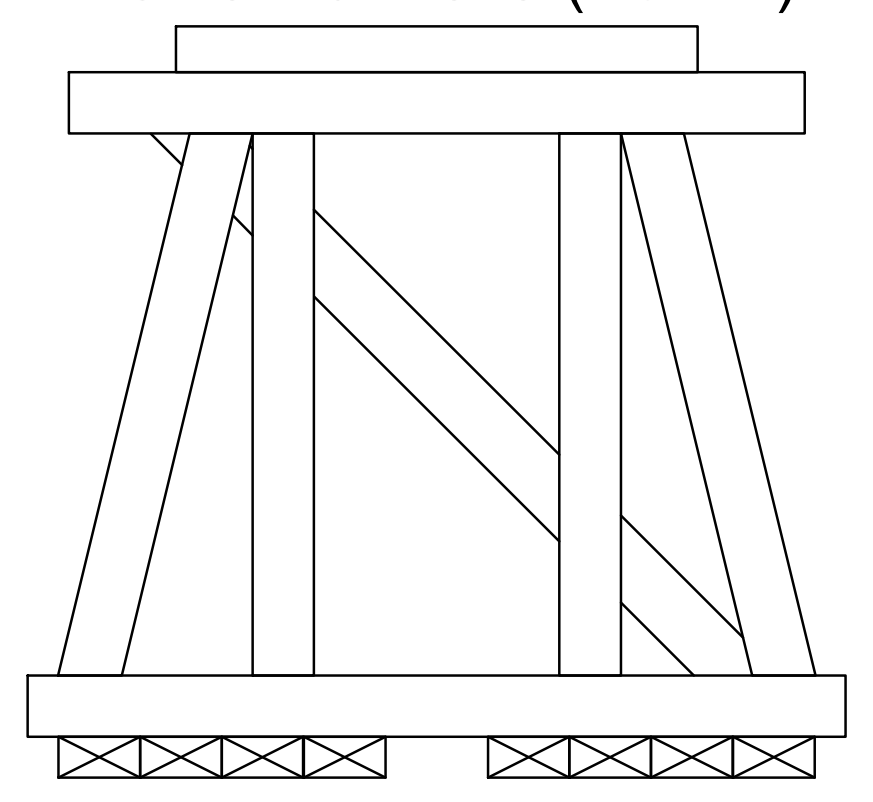

SECTION G-G (Bent 8)

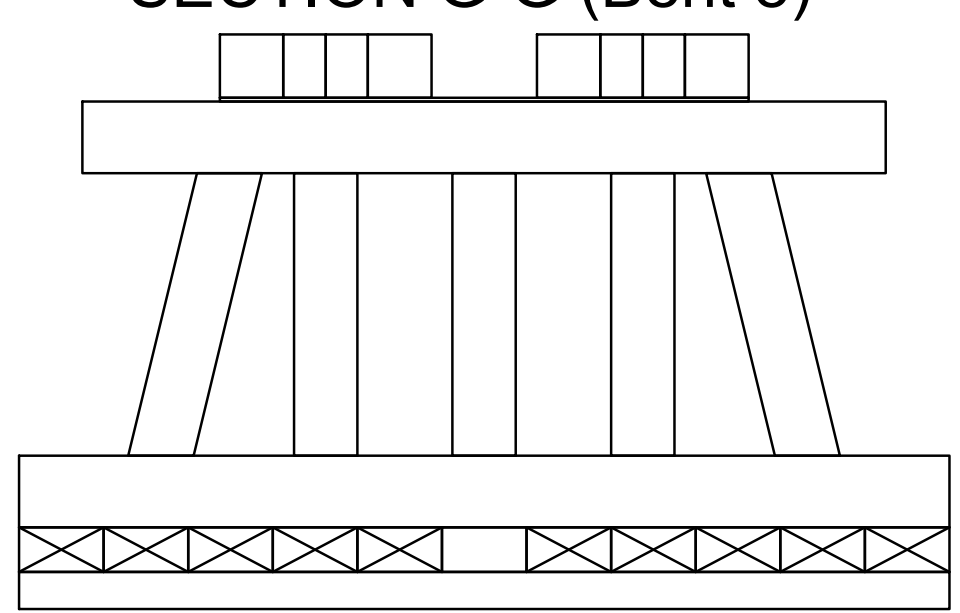

SECTION D-D (Bent 5)

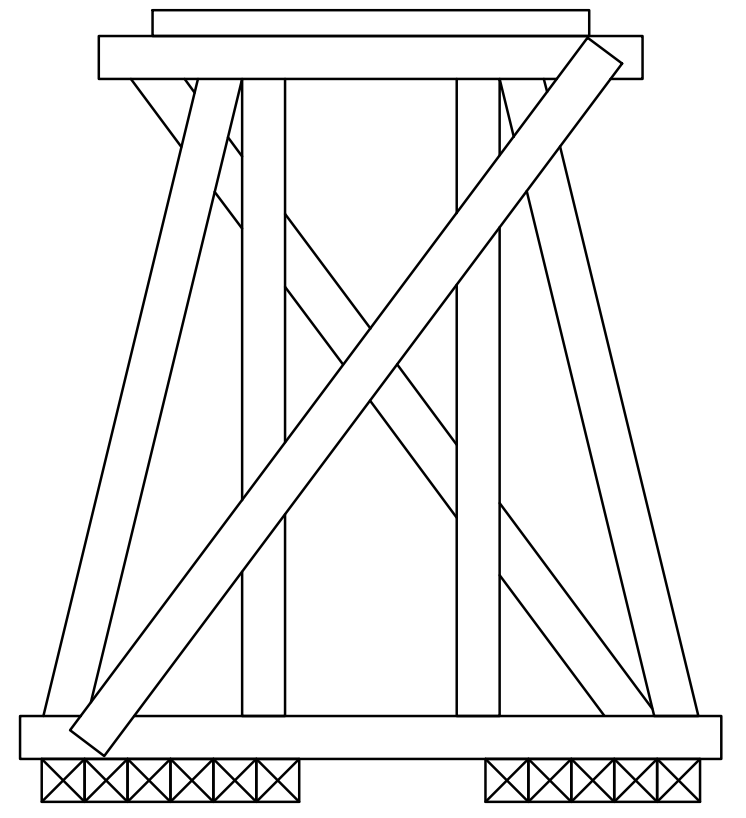

\section{SECTION H-H (Bent 9)}

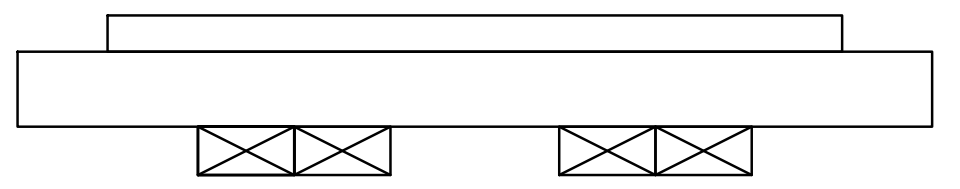

Note:

1. - The cross sections shown do not include stringers since they are located and spaced equally over every bent.

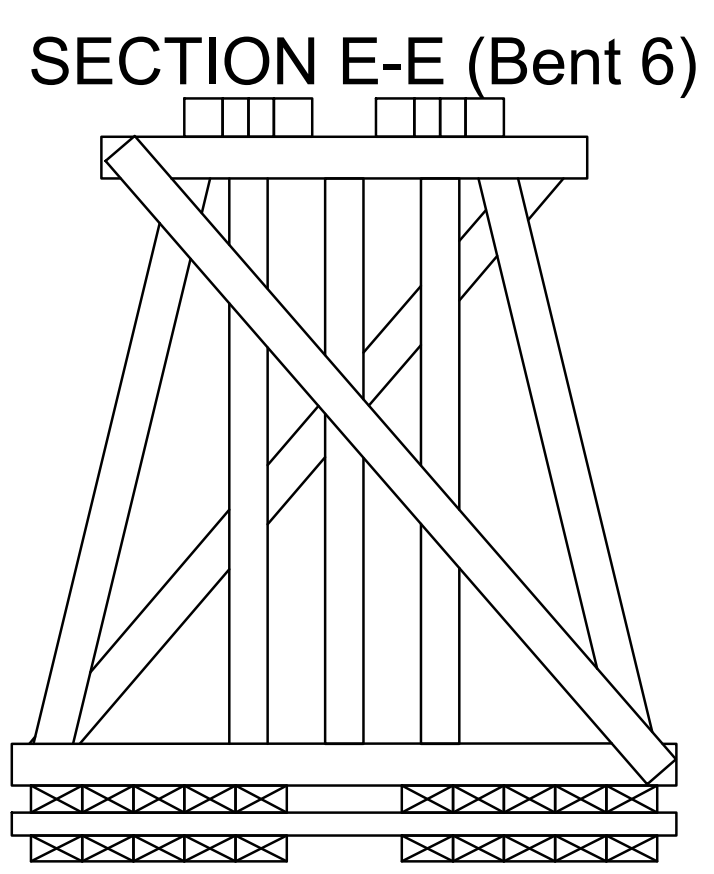

\begin{tabular}{|c|c|}
\hline \multicolumn{2}{|c|}{$\begin{array}{l}\text { The West Virginia Department of Transportation } \\
\text { Division of Highways }\end{array}$} \\
\hline $\begin{array}{l}\text { WV } \\
\text { Dail }\end{array}$ & $\begin{array}{l}\text { WV Central Rail Road } \\
\text { Dailey Branch Bridges }\end{array}$ \\
\hline \multicolumn{2}{|c|}{$\begin{array}{c}\text { Bridge } 1.9 \\
\text { Inspection - Drawings }\end{array}$} \\
\hline $\begin{array}{l}\text { Drawn By } \\
\text { LCP }\end{array}$ & $\begin{array}{l}\text { Date } \\
12-9-2015\end{array}$ \\
\hline \multicolumn{2}{|c|}{$\begin{array}{l}\text { Constructed Facilities Center } \\
\text { West Virginia University }\end{array}$} \\
\hline None & $\begin{array}{l}\text { Sheet } 11 \\
11\end{array}$ \\
\hline
\end{tabular}




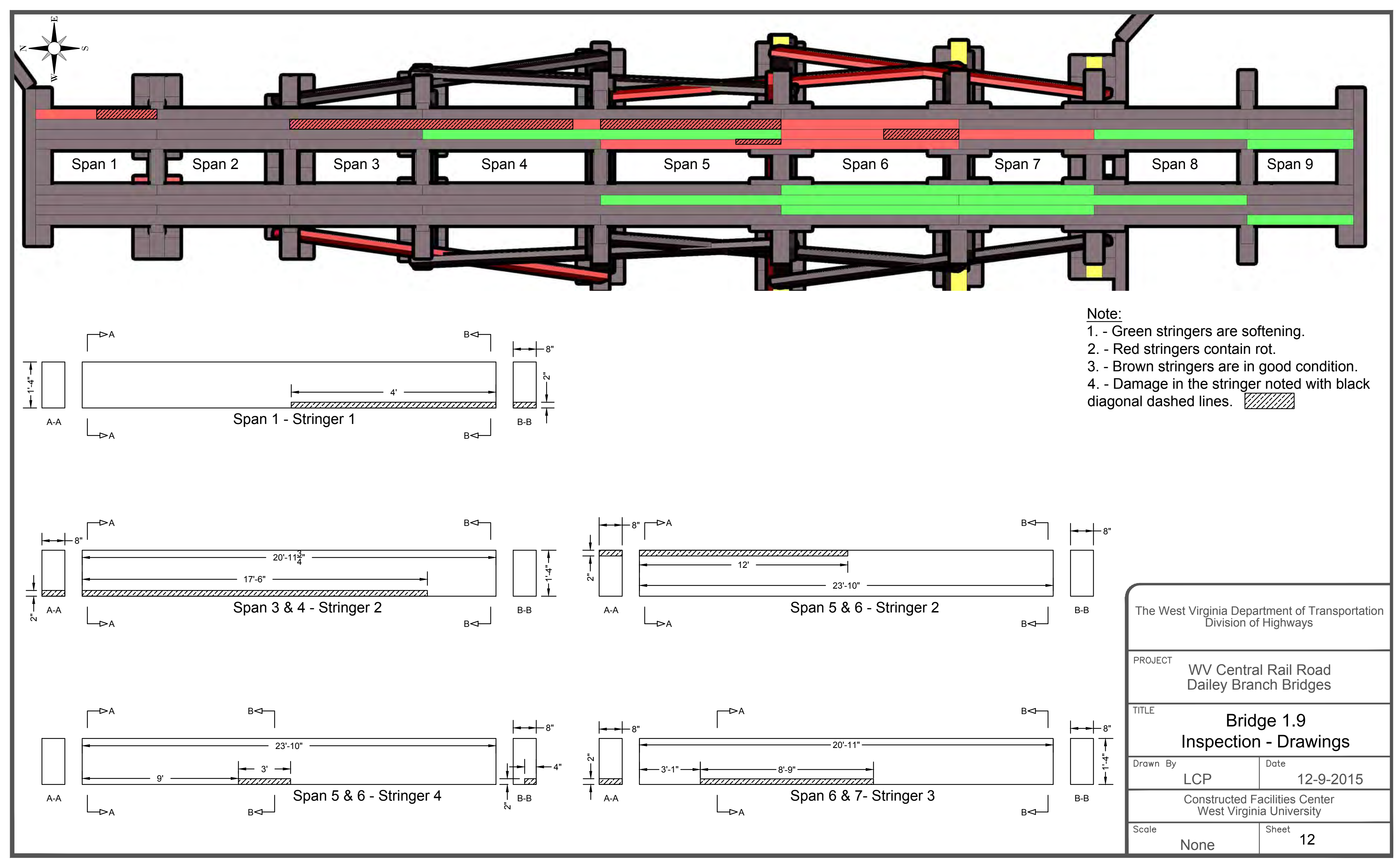




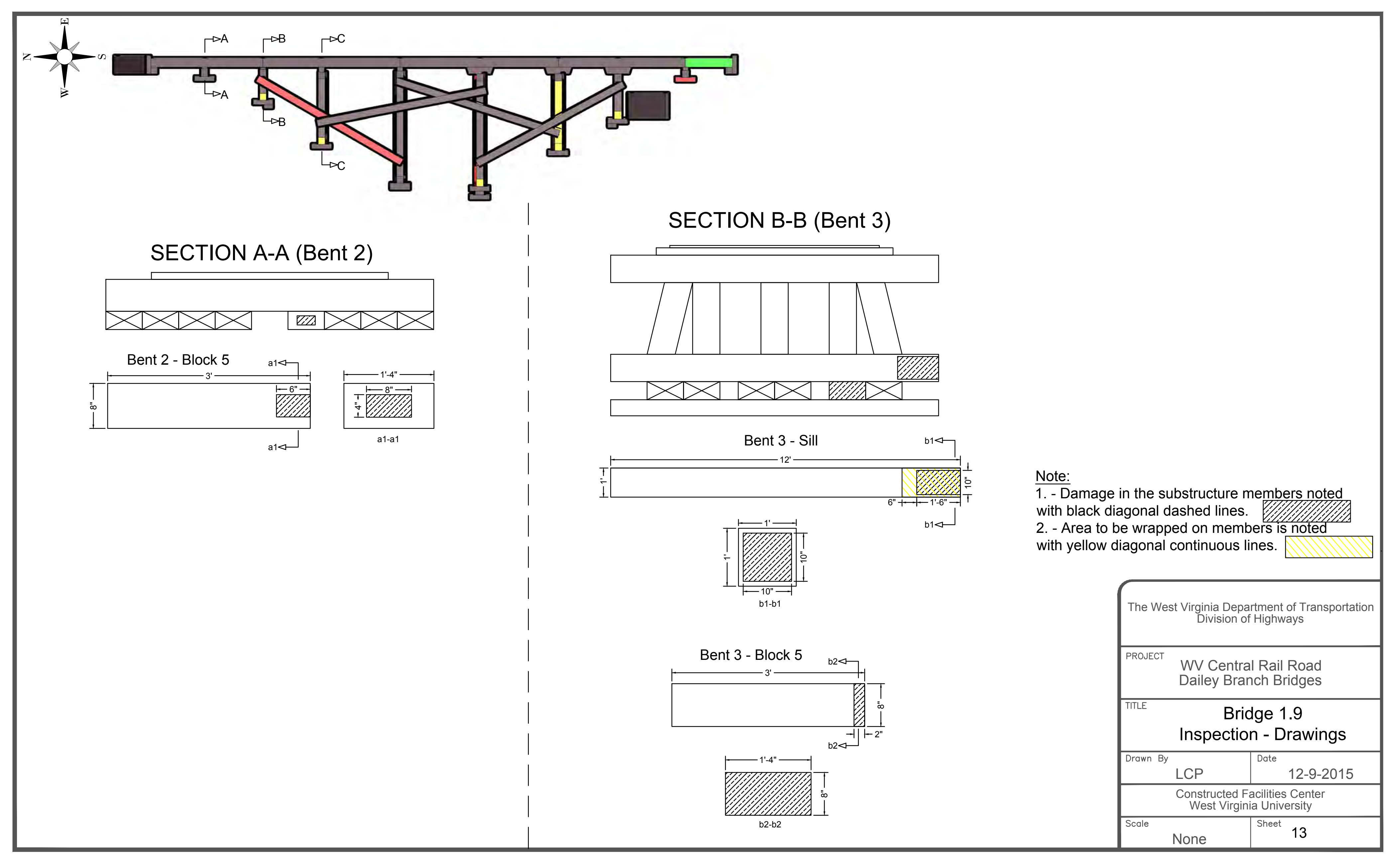




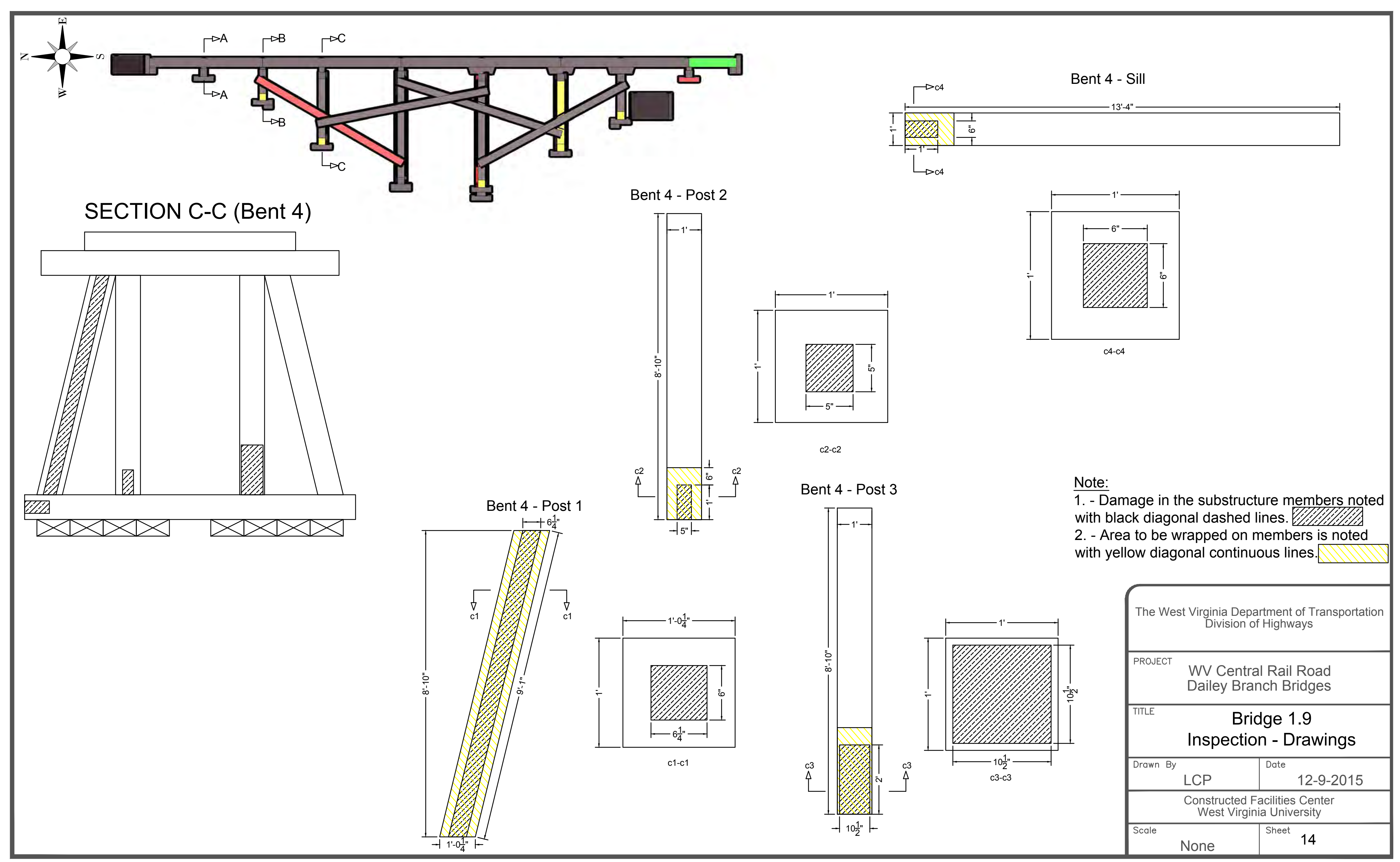




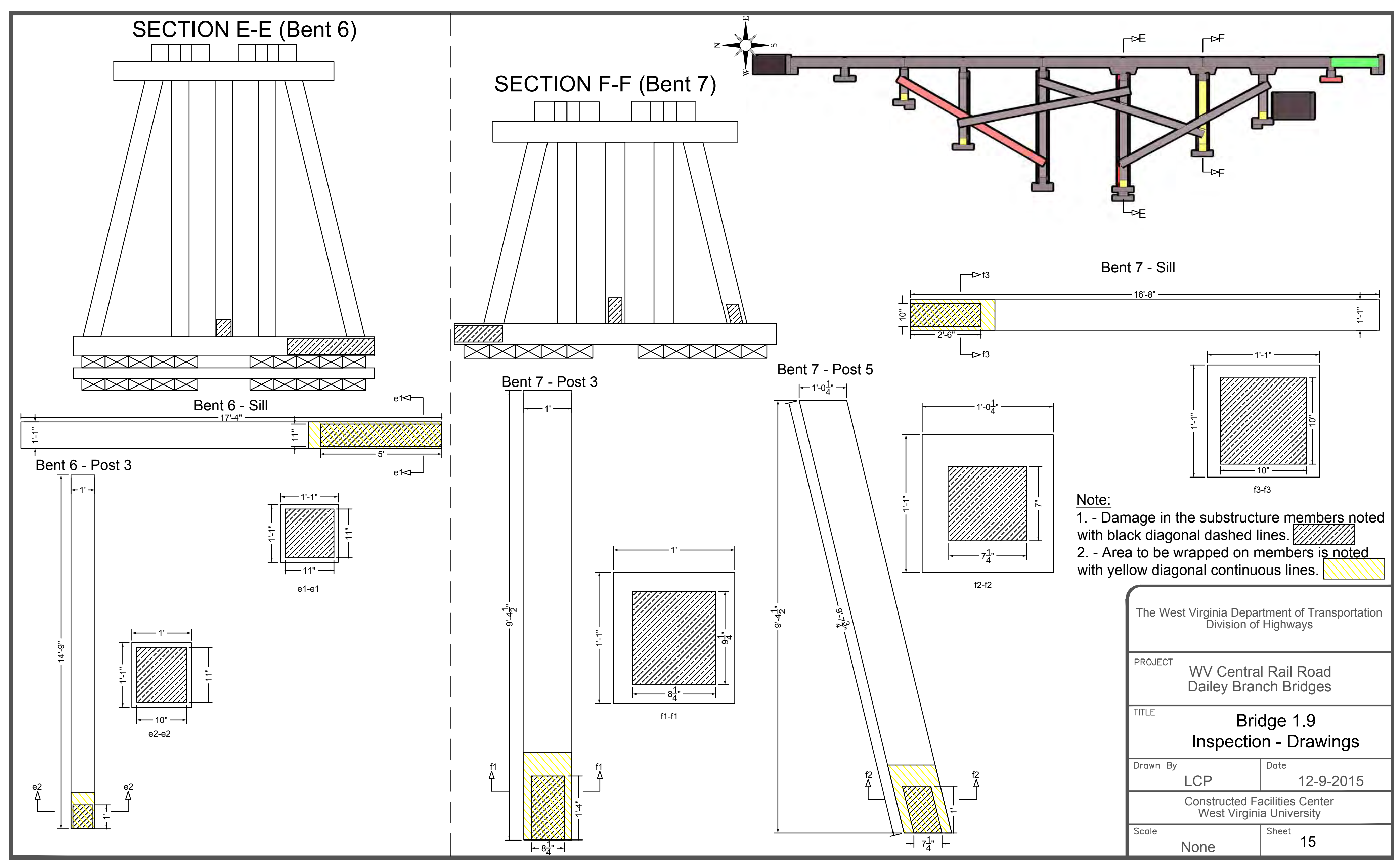



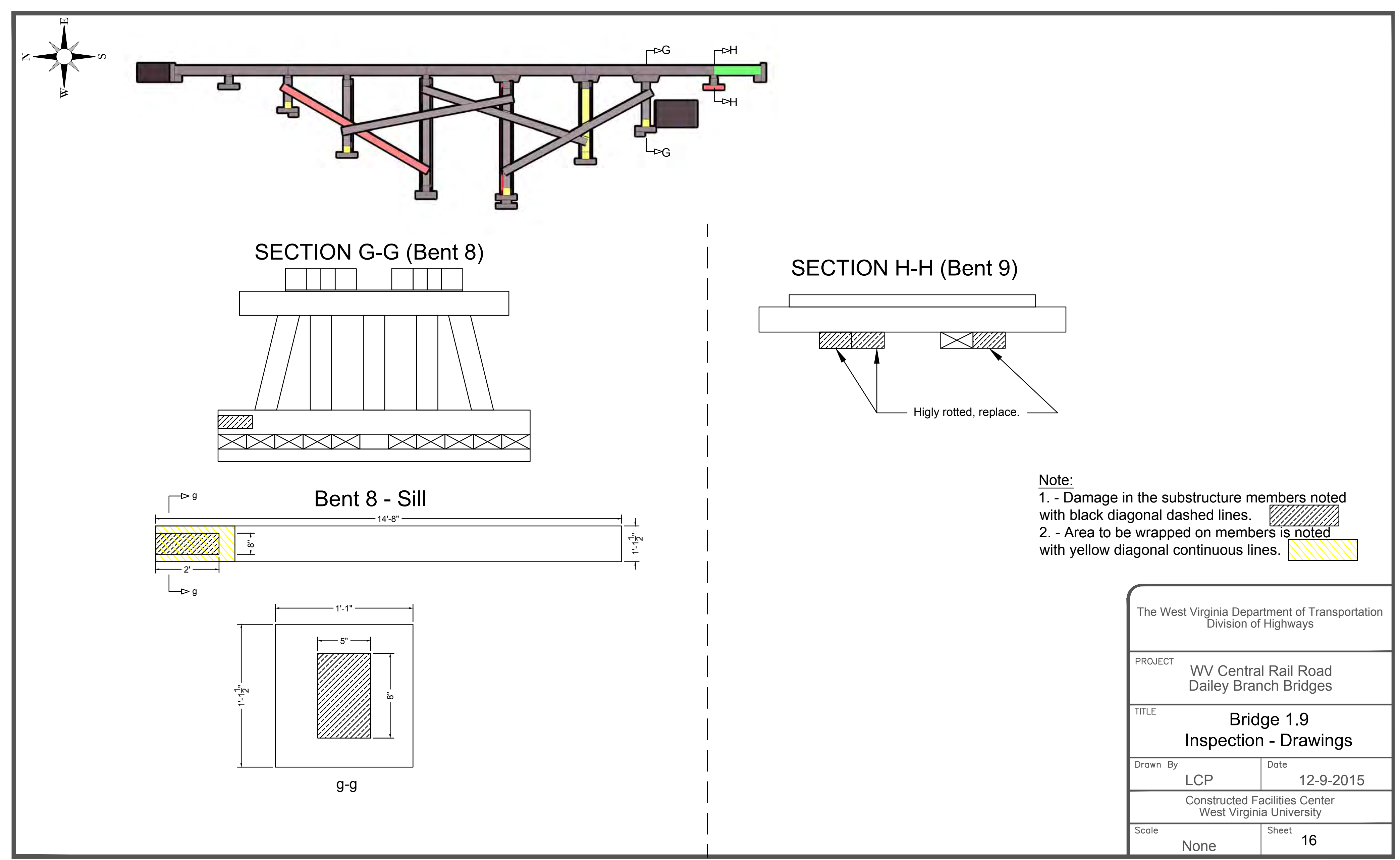
Bridge 4.3 Superstructure Inspection - Stringers

\begin{tabular}{|c|c|c|c|c|c|c|}
\hline \multirow{2}{*}{ Span } & \multirow{2}{*}{ Stringer } & \multirow{2}{*}{$\begin{array}{c}\text { Member } \\
\text { Length }\end{array}$} & \multicolumn{4}{|c|}{ Damage } \\
\cline { 3 - 7 } & & & Type & Width & Height & Length \\
\hline \multirow{3}{*}{1} & 1 & $23^{\prime}-9^{\prime \prime}$ & Rot & $4^{\prime \prime}$ & $8^{\prime \prime}$ & $13^{\prime \prime}$ \\
\cline { 2 - 7 } & 2 & $11^{\prime}-11^{\prime \prime}$ & Rot & $7.25^{\prime \prime}$ & $14.125^{\prime \prime}$ & $14^{\prime \prime}$ \\
\cline { 2 - 7 } & 5 & $11^{\prime}-11^{\prime \prime}$ & Rot & $4^{\prime \prime}$ & $8^{\prime \prime}$ & $13^{\prime \prime}$ \\
\hline 2 & 8 & $23^{\prime}-9^{\prime \prime}$ & Rot & $4^{\prime \prime}$ & $8^{\prime \prime}$ & $4^{\prime \prime}$ \\
\hline \multirow{2}{*}{3} & 3 & $23^{\prime}-9^{\prime \prime}$ & soft & & & \\
\hline & 7 & $22^{\prime}-7^{\prime \prime}$ & Rot & $4^{\prime \prime}$ & $8^{\prime \prime}$ & $4^{\prime \prime}$ \\
\hline
\end{tabular}
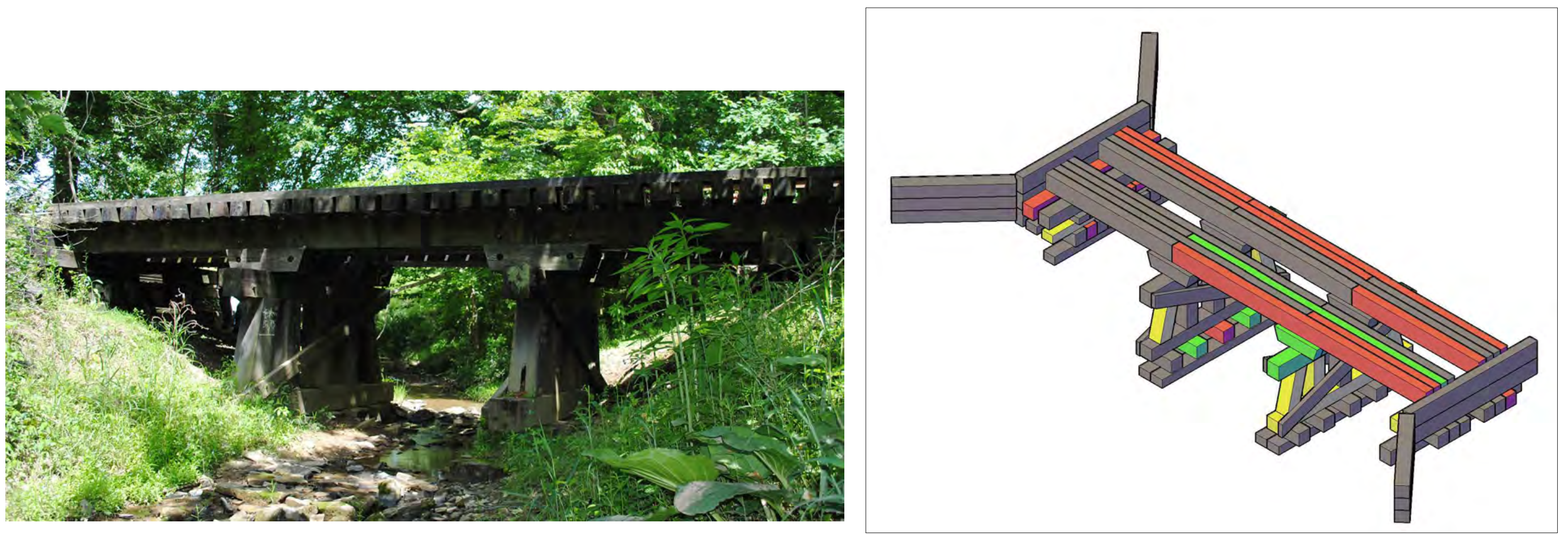

Notes:

1. The following color coding is used:

- RED: Significant deterioration in member, replacement of member is recommended.

- GREEN: Softening noted in member, no repair is needed but monitoring is recommended.

2. Due to the staggered continuity of the stringers, most stringers will span continuously over two spans. The member length column represents the whole length of a stringer,

wether it spans over two spans or only one (i.e. Span 1-Stringer 2 is simply supported).

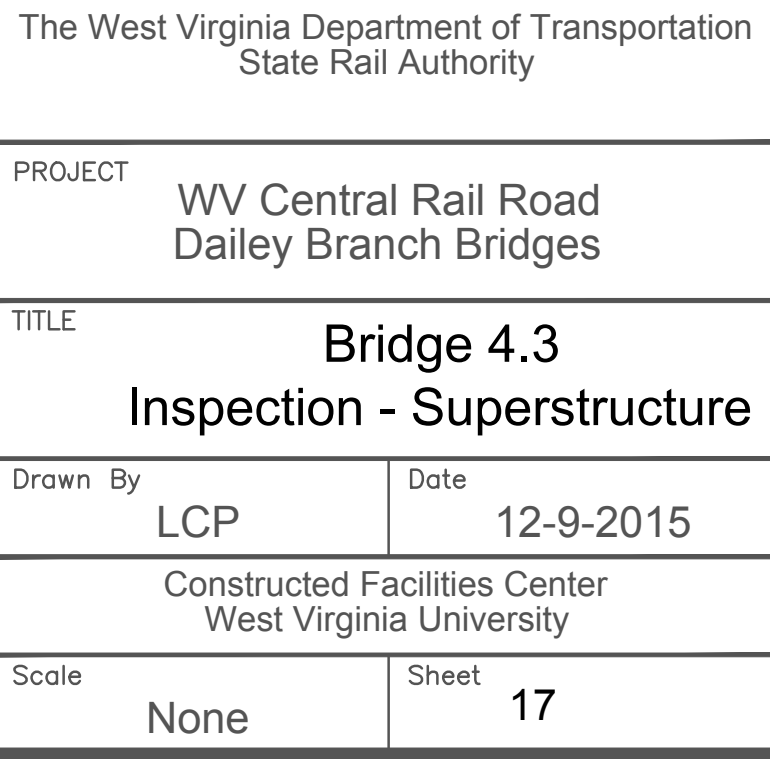


Bridge 4.3 Substructure Inspection

\begin{tabular}{|c|c|c|c|c|c|c|c|c|}
\hline \multirow{2}{*}{ Bent } & \multirow{2}{*}{ Member } & \multicolumn{3}{|c|}{ Member } & \multicolumn{4}{|c|}{ Damage } \\
\hline & & Width & Depth & Length & Type & Width & Height & Length \\
\hline \multirow{2}{*}{1} & sill & $12 "$ & $12^{\prime \prime}$ & $12^{\prime}-4 "$ & rot & $10^{\prime \prime}$ & $10^{\prime \prime}$ & $2^{\prime}$ \\
\hline & block 6 & 12" & $12 "$ & $3^{\prime}$ & rot & 12" & $12^{\prime \prime}$ & $3^{\prime}$ \\
\hline \multirow{9}{*}{2} & post 1 & $12^{\prime \prime}$ & $13^{\prime \prime}$ & $4^{\prime}-1.625^{\prime \prime}$ & rot & $12^{\prime \prime}$ & $13^{\prime \prime}$ & \begin{tabular}{|l|}
$4^{\prime}-1.625^{\prime \prime}$ \\
\end{tabular} \\
\hline & post 2 & $12^{\prime \prime}$ & $13^{\prime \prime}$ & 4'-0.25" & rot & $5.75^{\prime \prime}$ & $6.75^{\prime \prime}$ & 1'-3" \\
\hline & post 5 & $12^{\prime \prime}$ & $13^{\prime \prime}$ & 4'-1.625" & rot & $5.75^{\prime \prime}$ & $6.75^{\prime \prime}$ & 1'-7.5" \\
\hline & corbel 1 & $8 "$ & $12 "$ & $4^{\prime}$ & softening & & & \\
\hline & corbel 2 & $8^{\prime \prime}$ & $12^{\prime \prime}$ & $4^{\prime}$ & softening & & & \\
\hline & corbel 3 & $8 "$ & $12 "$ & $4^{\prime}$ & softening & & & \\
\hline & corbel 7 & $8^{\prime \prime}$ & $12^{\prime \prime}$ & $4^{\prime}$ & softening & & & \\
\hline & sill & $13 "$ & $12^{\prime \prime}$ & $14^{\prime}$ & rot & $6.75^{\prime \prime}$ & $5.75^{\prime \prime}$ & $1^{\prime}-2^{\prime \prime}$ \\
\hline & cap & $13 "$ & $12 "$ & $12^{\prime}-8^{\prime \prime}$ & softening & & & \\
\hline \multirow{7}{*}{3} & block 2 & $12 "$ & $12^{\prime \prime}$ & $3^{\prime}$ & softening & & & \\
\hline & block 3 & $12^{\prime \prime}$ & $12^{\prime \prime}$ & $3^{\prime}$ & softening & & & \\
\hline & block 4 & 12" & 12" & $3^{\prime}$ & rot & 12" & $12 "$ & $3^{\prime}$ \\
\hline & block 5 & $12^{\prime \prime}$ & $12^{\prime \prime}$ & $3^{\prime}$ & softening & & & \\
\hline & post 1 & $12^{\prime \prime}$ & $13 "$ & 3'-7.125" & rot & 10.5" & 11.5" & $3^{\prime}-7.125^{\prime \prime}$ \\
\hline & post 5 & $12^{\prime \prime}$ & $13^{\prime \prime}$ & $3^{\prime}-7.125^{\prime \prime}$ & rot & $10.5^{\prime \prime}$ & 11.5" & $3^{\prime}-7.125^{\prime \prime}$ \\
\hline & corbel 2 & $8^{\prime \prime}$ & $12^{\prime \prime}$ & $4^{\prime}$ & rot & $8 "$ & $12 "$ & $4^{\prime}$ \\
\hline \multirow{7}{*}{4} & cap & $12^{\prime \prime}$ & $12^{\prime \prime}$ & $12^{\prime}$ & rot & $9 "$ & $9 "$ & $2^{\prime}$ \\
\hline & block 2 & $12 "$ & $12 "$ & $3^{\prime}$ & rot & $12 "$ & $12^{\prime \prime}$ & $3^{\prime}$ \\
\hline & block 5 & $12 "$ & 12" & $3^{\prime}$ & rot & $12 "$ & $12^{\prime \prime}$ & $3^{\prime}$ \\
\hline & block 4 & $12^{\prime \prime}$ & $6^{\prime \prime}$ & $3^{\prime}$ & rot & $12^{\prime \prime}$ & $6^{\prime \prime}$ & $3^{\prime}$ \\
\hline & block 5 & $12 "$ & 6" & $3^{\prime}$ & rot & $12^{\prime \prime}$ & 6" & $3^{\prime}$ \\
\hline & block 6 & $12 "$ & 6" & $3^{\prime}$ & rot & $12 "$ & 6" & $3^{\prime}$ \\
\hline & sill & $12 "$ & $8^{\prime \prime}$ & $11^{\prime}-8^{\prime \prime}$ & rot & 9" & 6" & $4^{\prime}$ \\
\hline
\end{tabular}

FRP Wrap Quantities

\section{To Wrap}

Bent Member Width (in) Depth (in) Length (in) Area (in ${ }^{2}$

\begin{tabular}{|c|c|c|c|c|}
\hline & Post 1 & 12 & 13 & 49.625 \\
\hline
\end{tabular}

\begin{tabular}{|c|c|c|c|c|c|}
\multirow{2}{*}{2} & Post 1 & 12 & 13 & 49.625 & 2481.25 \\
\cline { 2 - 6 } & Post 2 & 12 & 13 & 27 & 1350 \\
\cline { 2 - 6 } & Post 5 & 12 & 13 & 25.5 & 1275
\end{tabular}

\begin{tabular}{|c|c|c|c|c|}
\hline Post 2 & 12 & 13 & 27 & 1350 \\
\cline { 1 - 3 } Post 5 & 12 & 13 & 25.5 & 1275 \\
\cline { 1 - 3 }
\end{tabular}

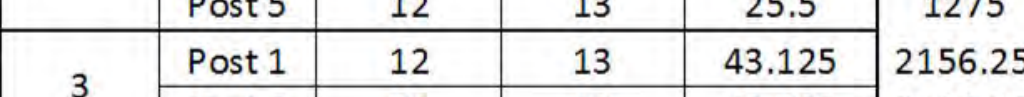

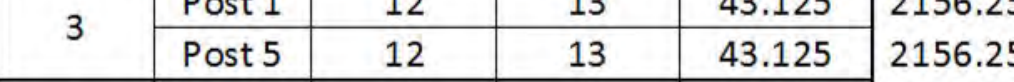

\begin{tabular}{|l|l|l|l|l|}
\hline 1 & Sill & 12 & 12 & 30 \\
\cline { 1 - 3 } 2 & Sill & 12 & 13 & 20 \\
\cline { 1 - 2 }
\end{tabular}

\begin{tabular}{|c|c|c|c|c|r|}
\hline 2 & Sill & 12 & 13 & 20 & 1000 \\
\hline 4 & Sill & 8 & 12 & 54 & 2160 \\
\hline
\end{tabular}

$A_{\text {total }}=14018.8 \mathrm{in}^{2}=97.35 \mathrm{ft}^{2}$

Notes:

1. The following color coding is used:

- RED. Significant deterioration in member, replacement of member is recommended.

- GREEN: Softening noted in member, no repair is needed but monitoring is recommended.

- YELLOW: Significant deterioration in member, FRP wrap is recommended.

FRP Wrap:

The quantities shown are based on the surface area of the member to be covered with FRP wrap. These quantities are for a single layer of wrap without accounting for overlap.

\begin{tabular}{|l|l|}
\hline The West Virginia Department of Transportation \\
State Rail Authority
\end{tabular}




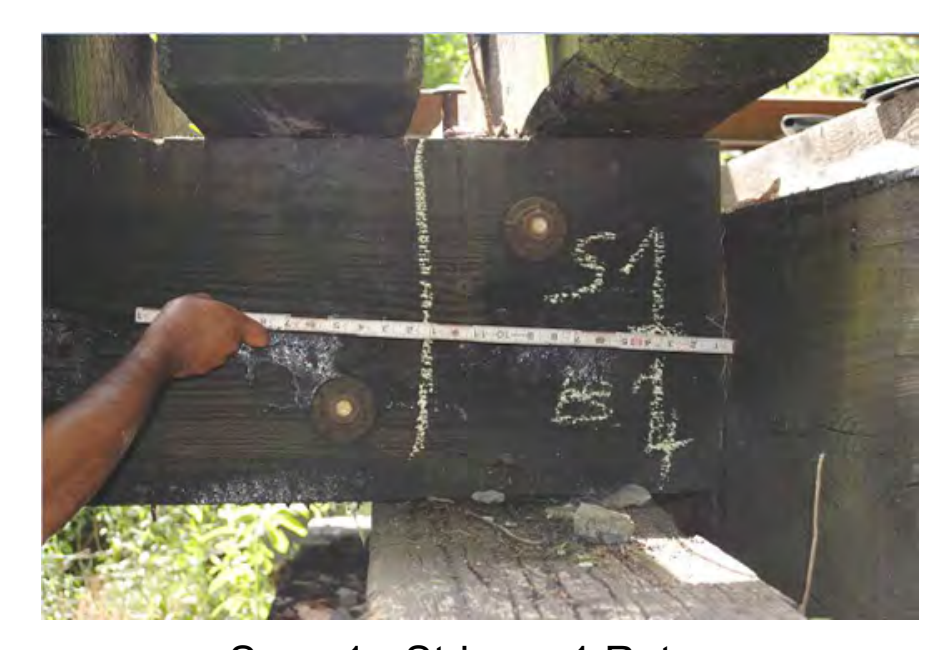

Span 1 - Stringer 1 Rot

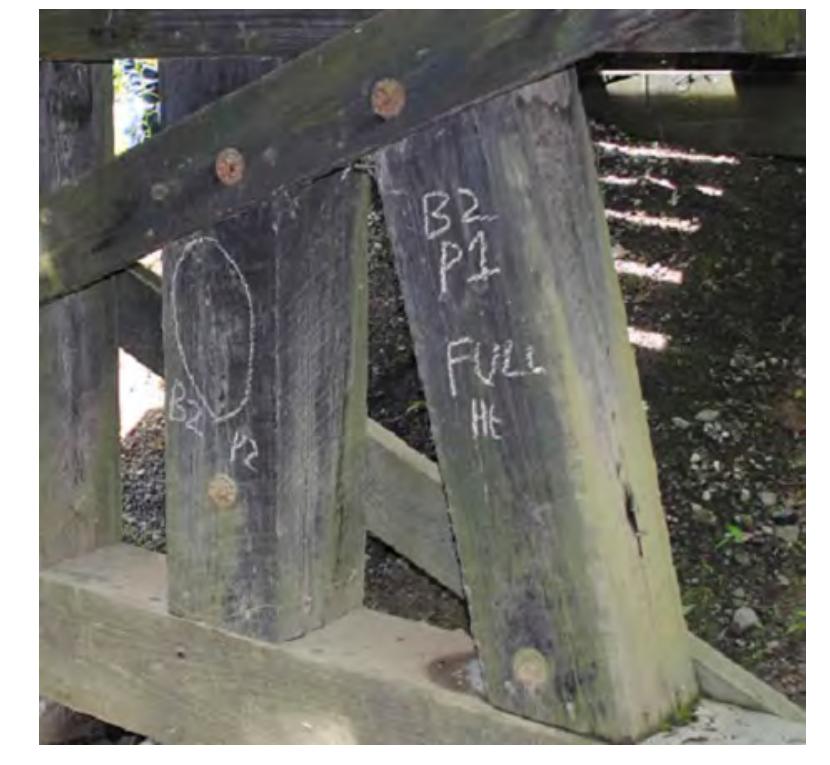

Bent 2 - Posts 1 \& 2 Rot

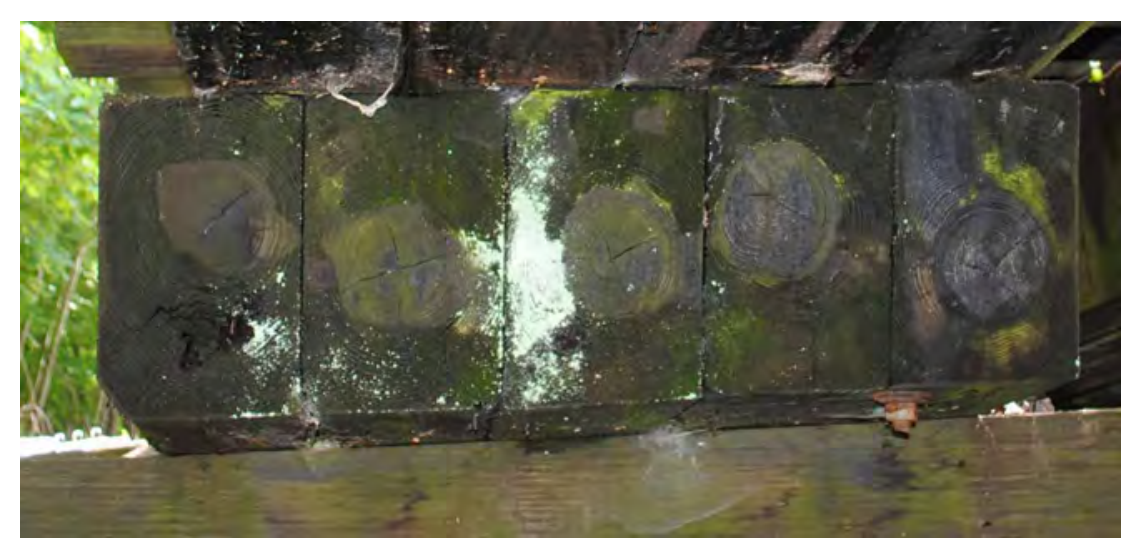

Bent 2 - Corbels 1, 2 \& 3 Rot

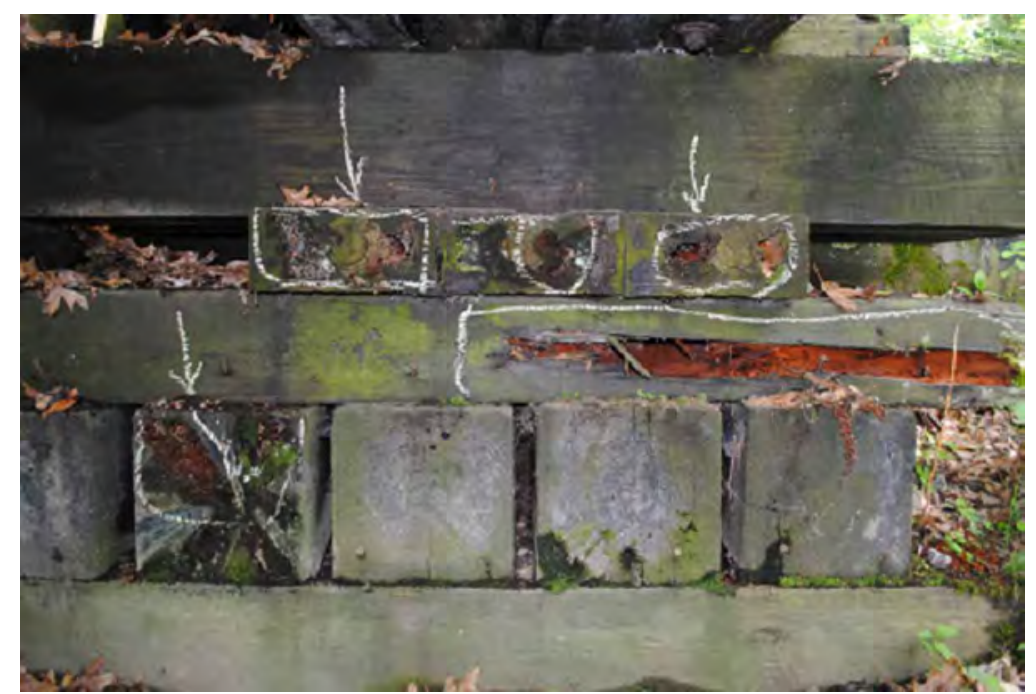

Bent 4 - Rot in Blocks and Sill
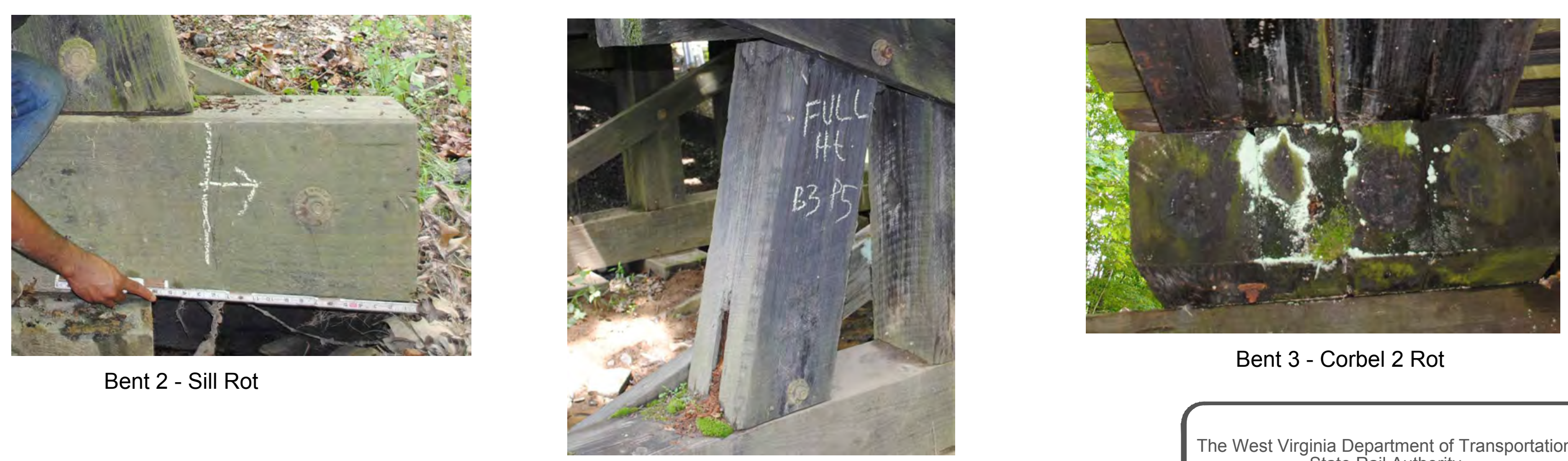

Bent 3 - Corbel 2 Rot

Bent 3 - Post 5 Rot

\begin{tabular}{|l|l|l|}
\hline The West Virginia Department of Transportation \\
State Rail Authority
\end{tabular}




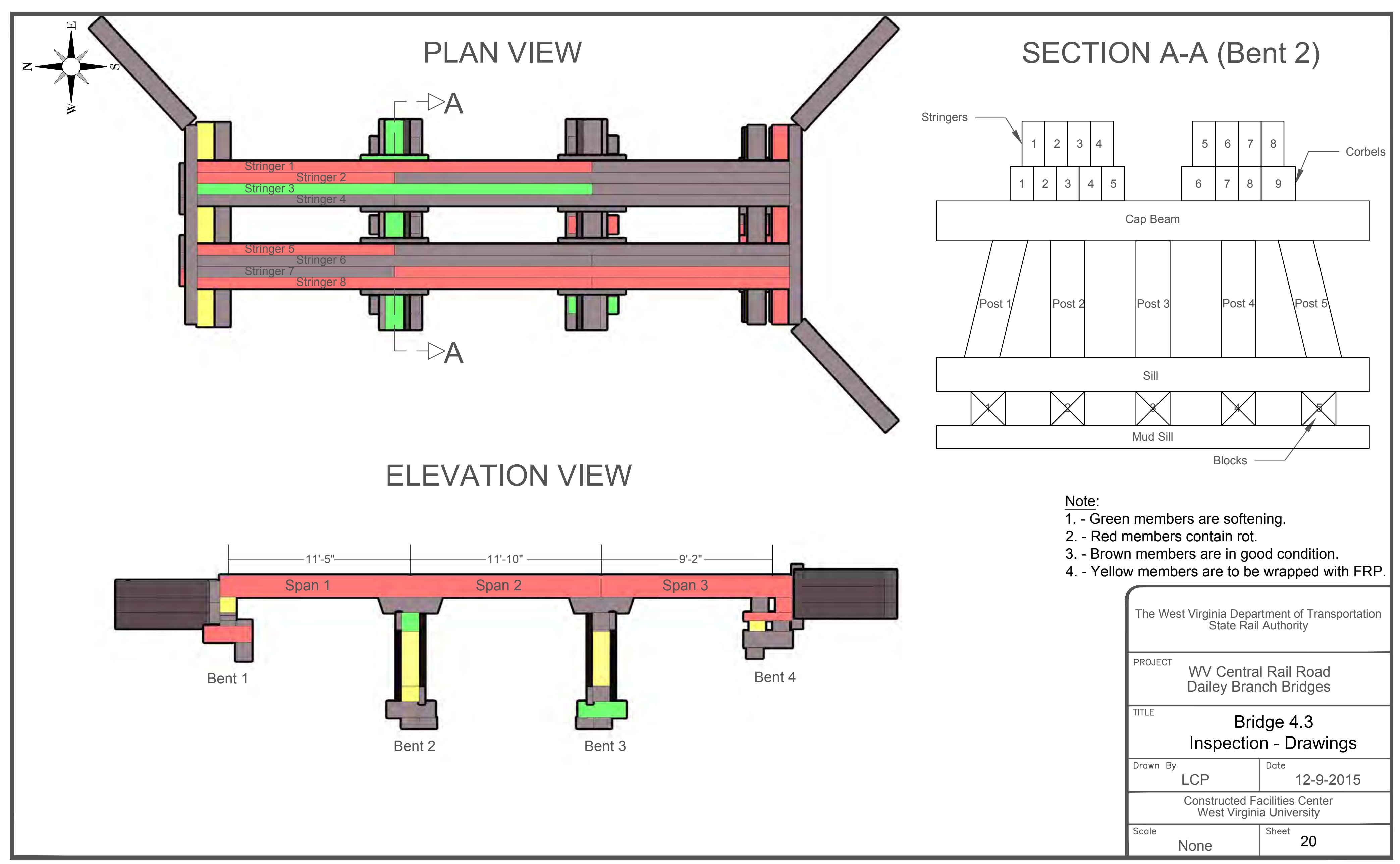




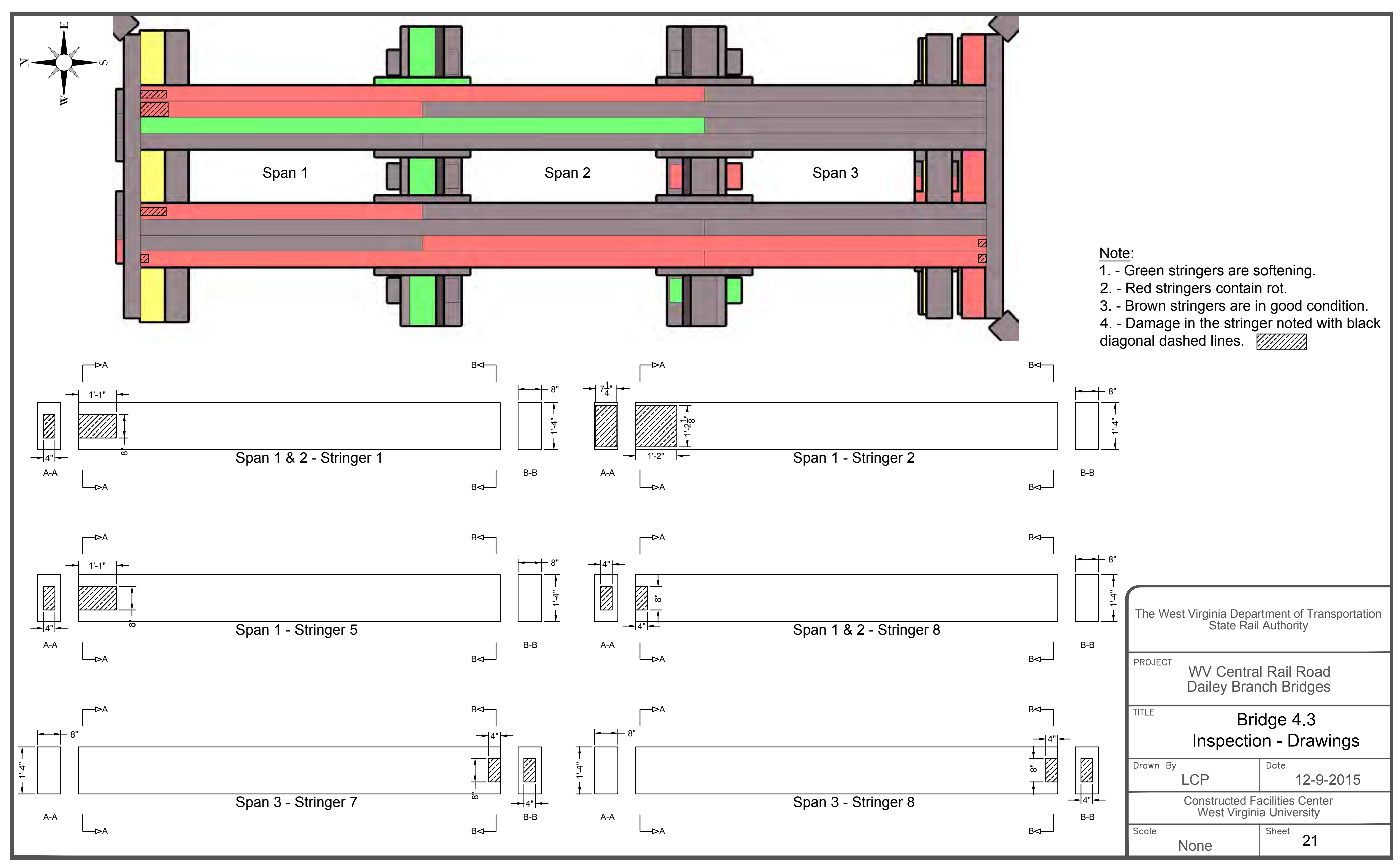




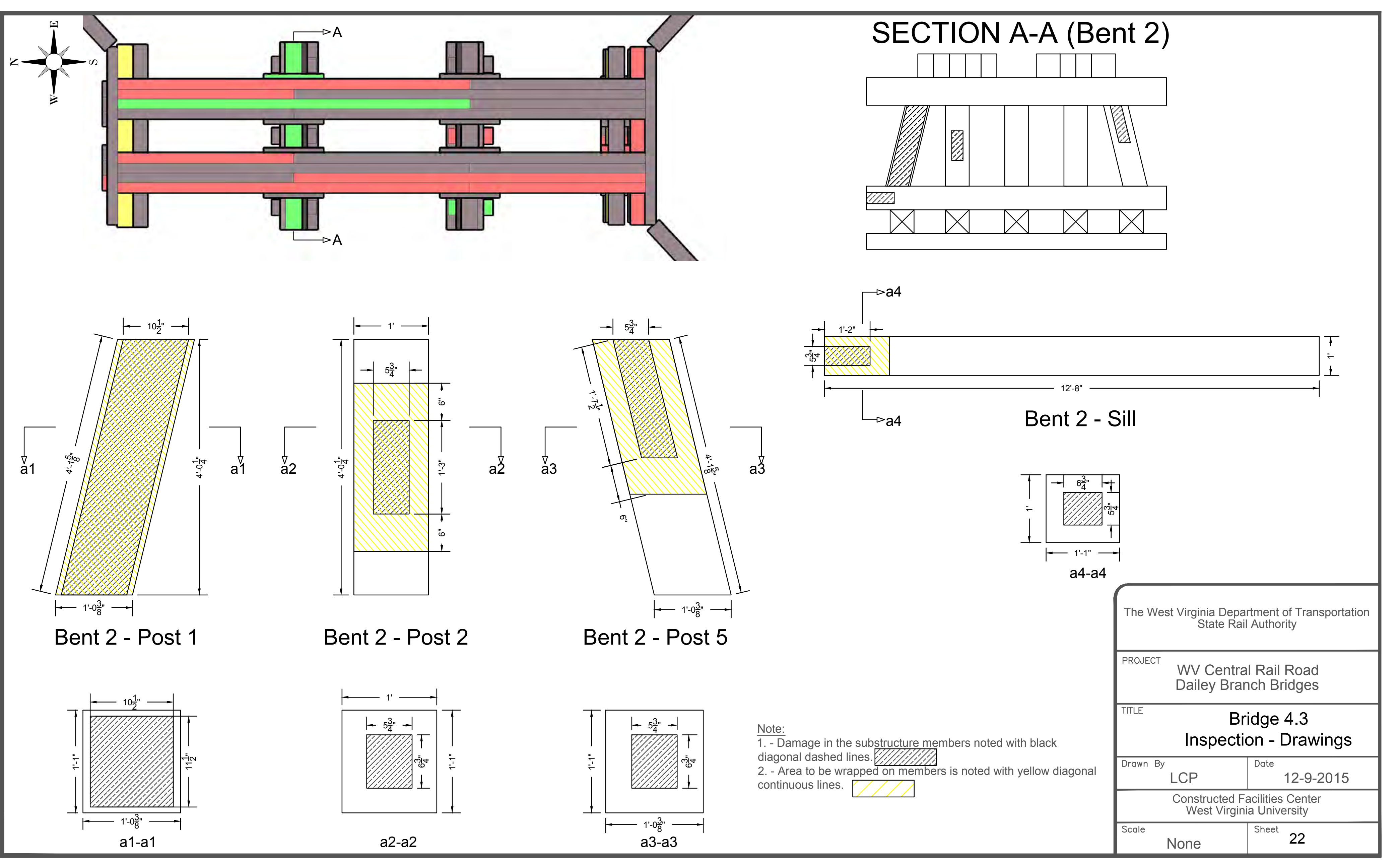




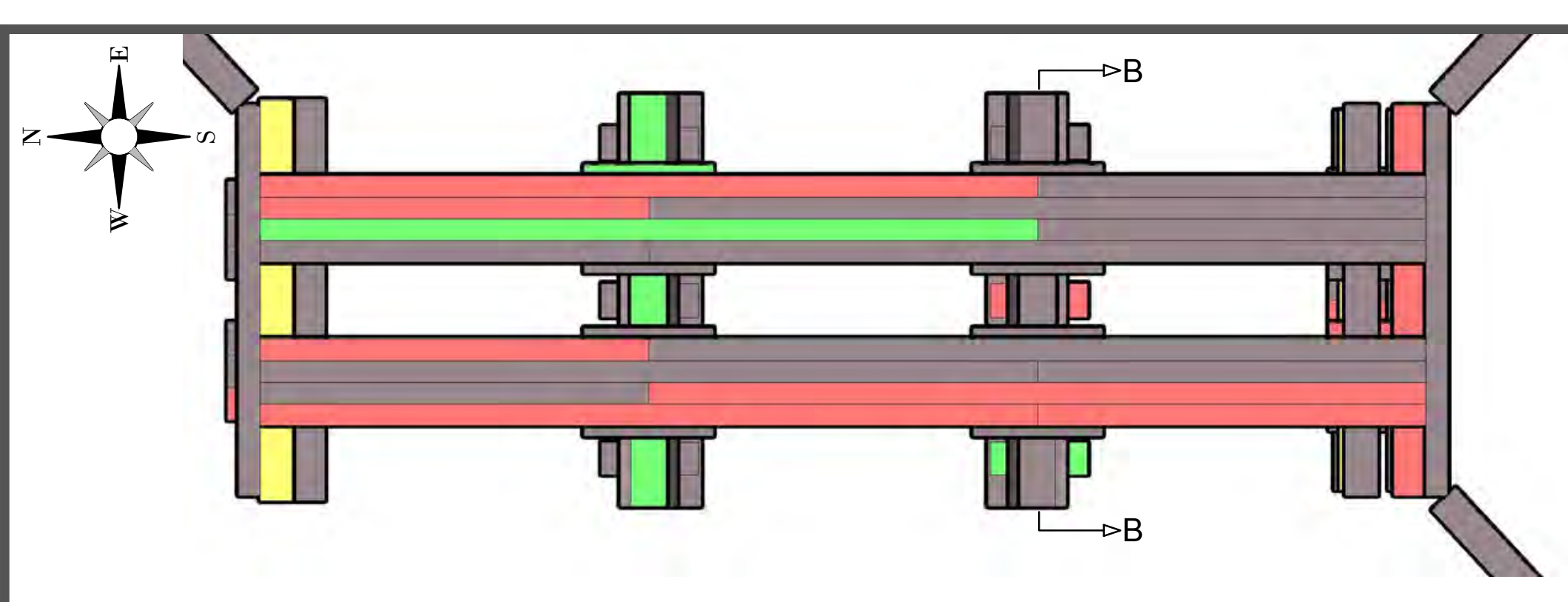

SECTION B-B (Bent 3)

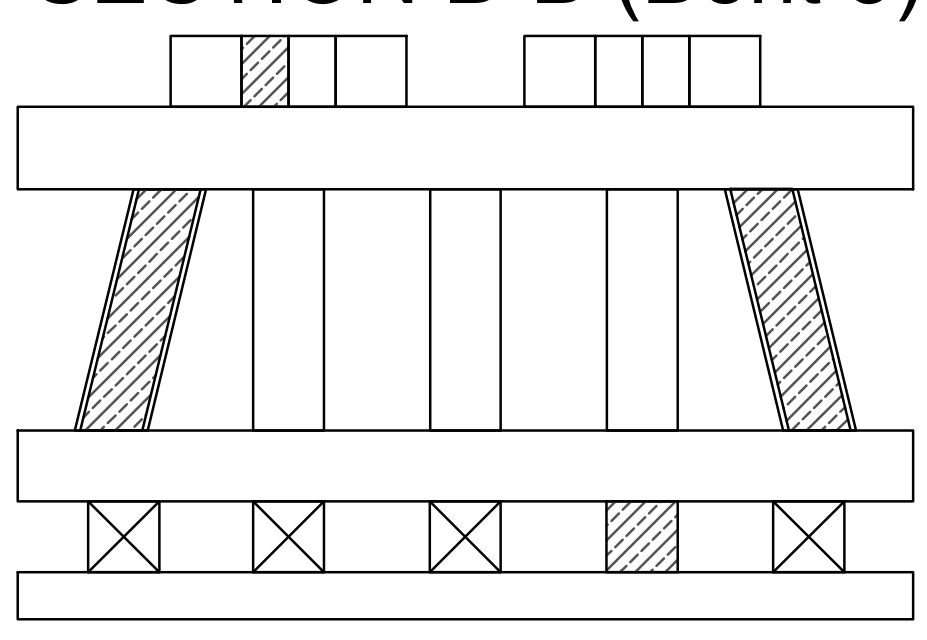

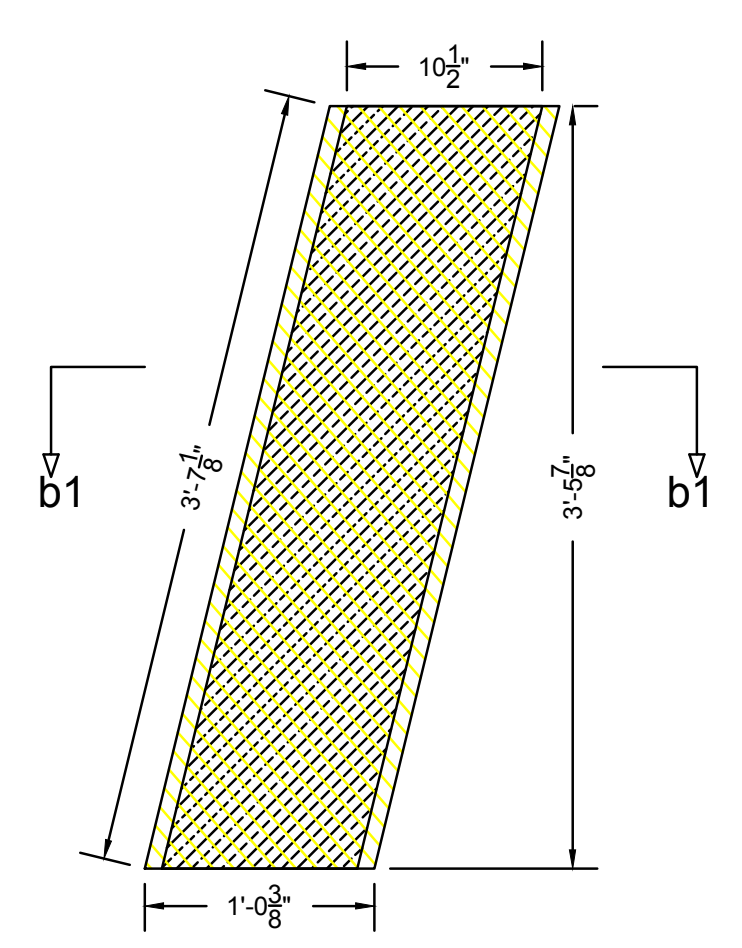

Bent 3 - Post 1

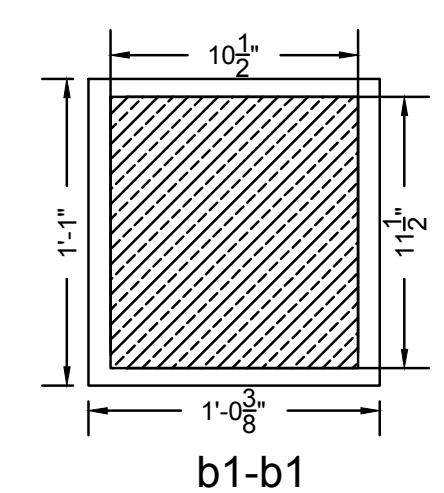

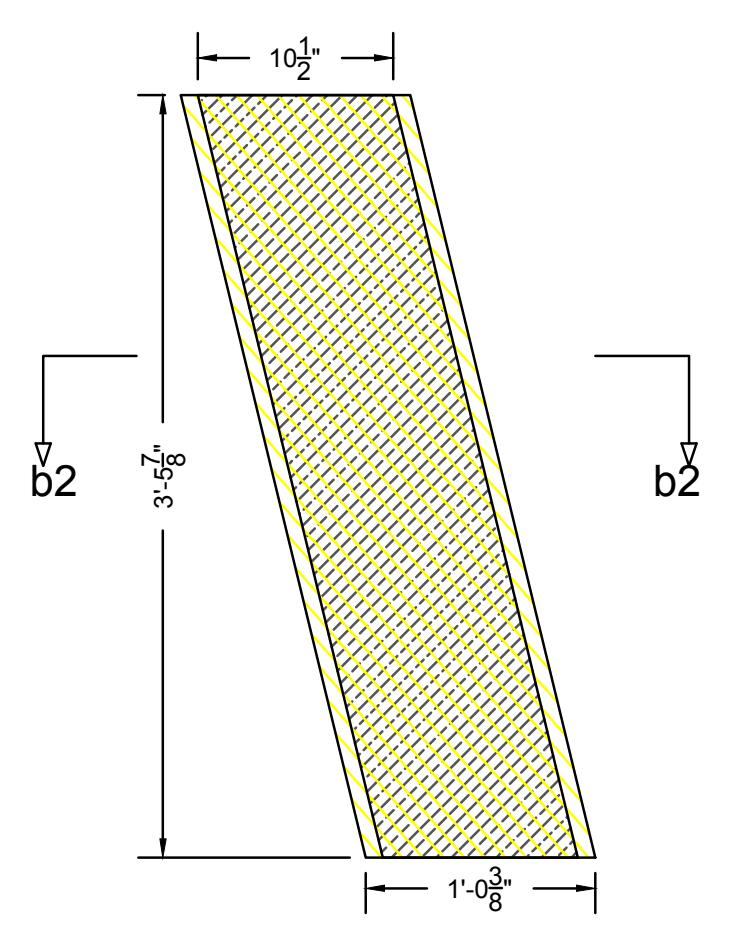

Bent 3 - Post 5

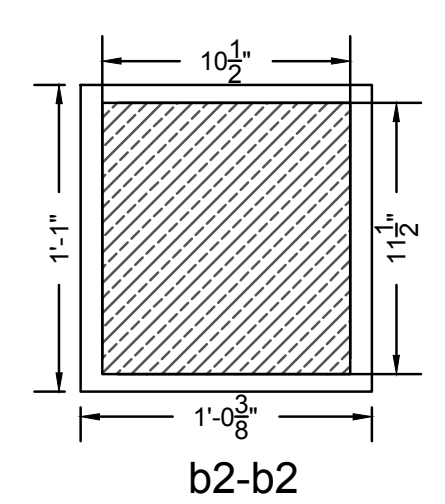

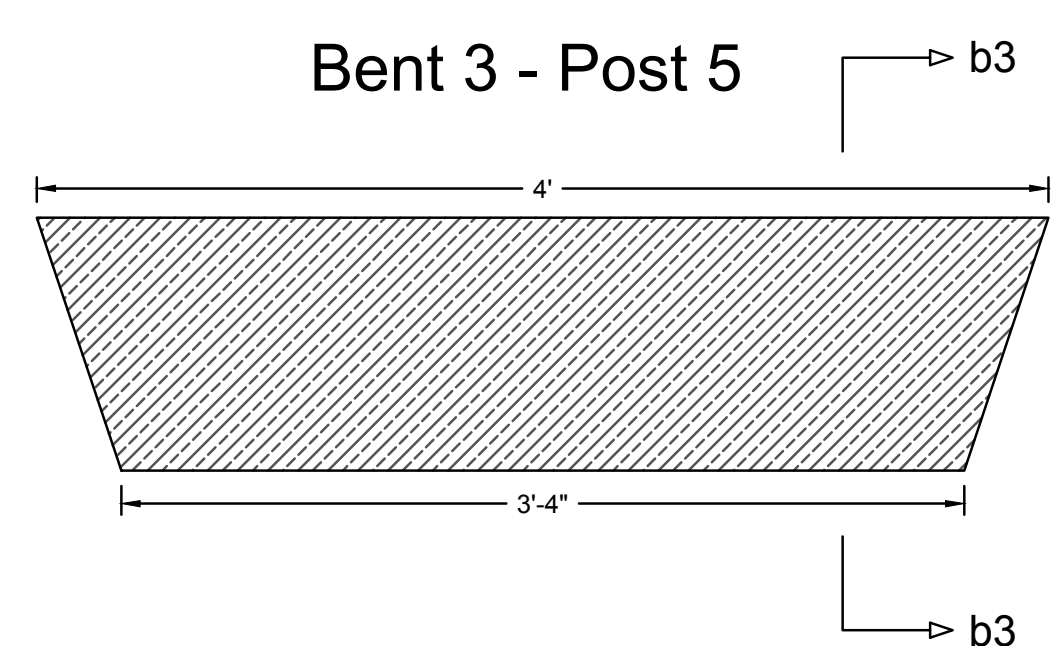
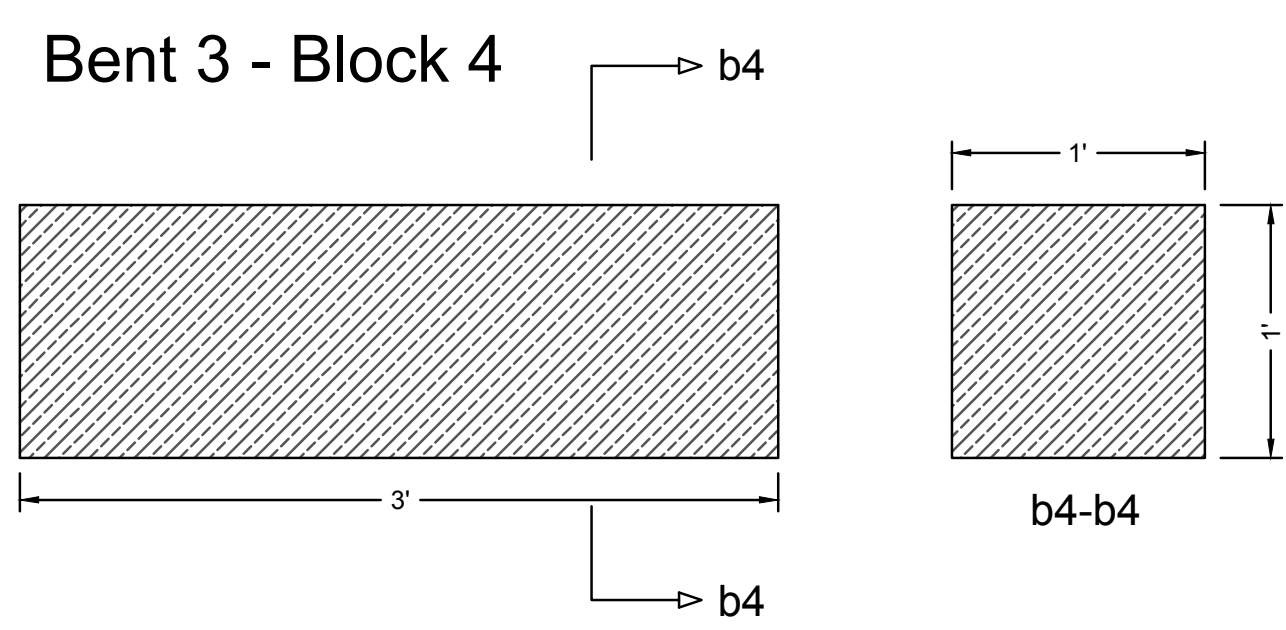

b4-b4

Note:

1. - Damage in the substructure members noted with black diagonal dashed lines. Plifily

2. - Area to be wrapped on members is noted with yellow diagonal continuous lines.

\begin{tabular}{|l|l|}
\hline The West Virginia Department of Transportation \\
State Rail Authority
\end{tabular}




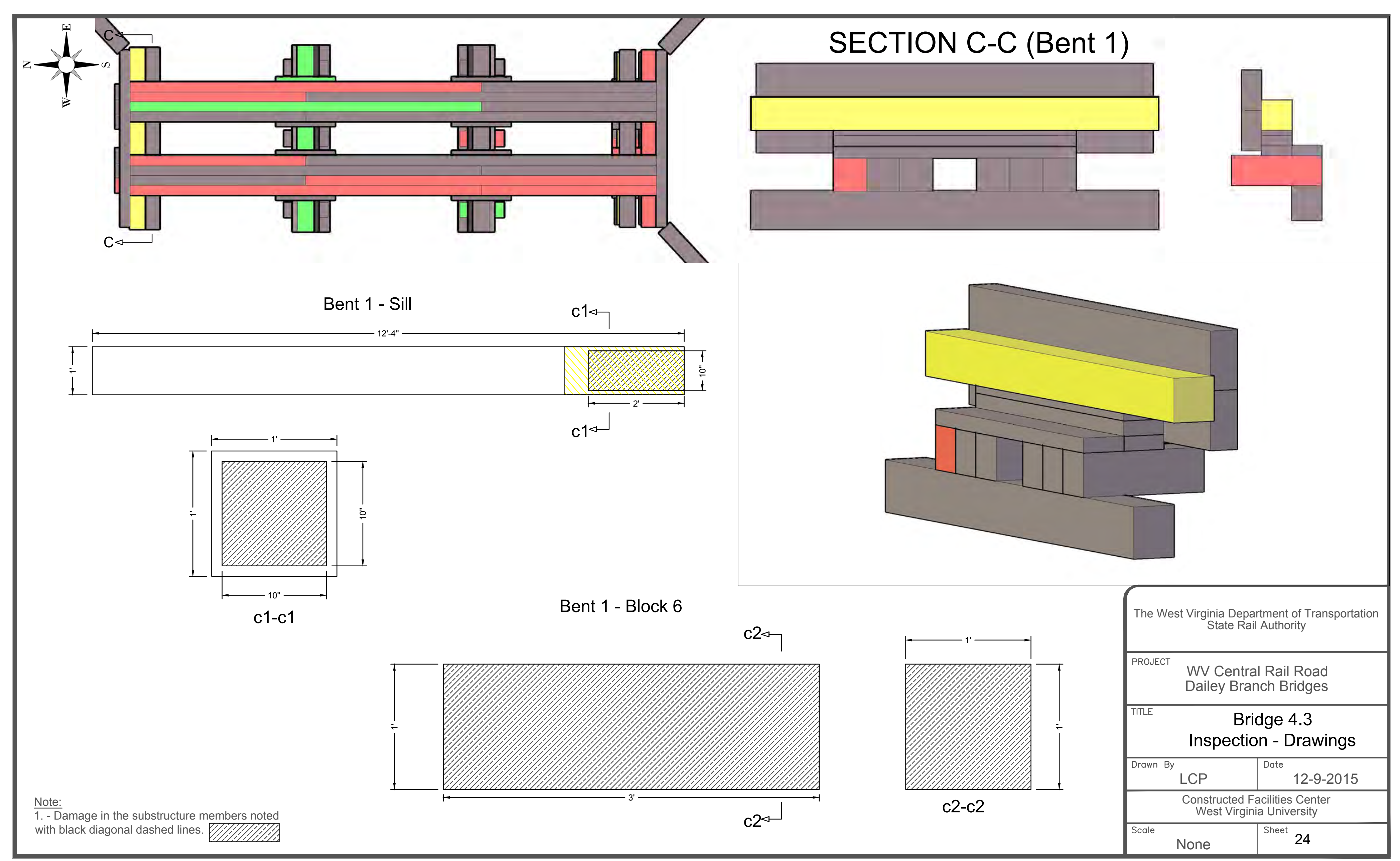




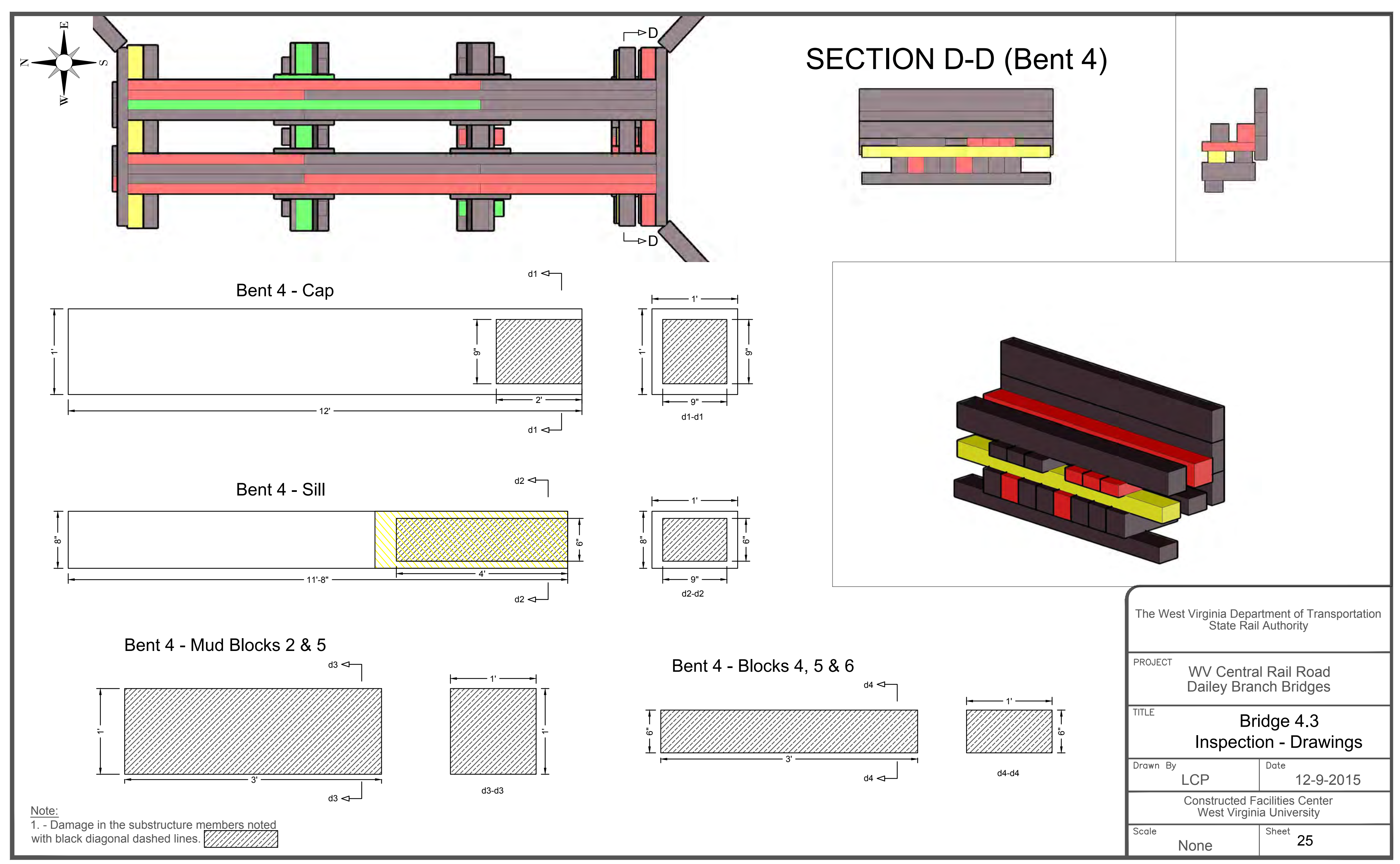




\section{Bridge 5.1 Superstructure Inspection - Stringers}

\begin{tabular}{|c|c|c|c|c|c|c|}
\hline \multirow{2}{*}{ Span } & \multirow{2}{*}{ Stringer } & \multirow{2}{*}{$\begin{array}{c}\text { Member } \\
\text { Length }\end{array}$} & \multicolumn{4}{|c|}{ Damage } \\
\hline & & & Type & Width & Height & Length \\
\hline \multirow{3}{*}{1} & \multirow{2}{*}{1} & $12^{\prime}-5.88^{\prime \prime}$ & Fruiting Bodies & $2^{\prime \prime}$ & $3 "$ & $2^{\prime}$ \\
\hline & & $12^{\prime}-5.88^{\prime \prime}$ & Fruiting Bodies & $2^{\prime \prime}$ & $5 "$ & $2^{\prime}$ \\
\hline & 4 & $23^{\prime}-5.13^{\prime \prime}$ & Rot & $2 "$ & $4 "$ & $3^{\prime}$ \\
\hline \multirow{2}{*}{3} & 6 & 23'-7.75" & Soft & & & \\
\hline & 8 & $23^{\prime}-7.75^{\prime \prime \prime}$ & Rot & $4 "$ & $10 "$ & $11^{\prime}$ \\
\hline 4 & 8 & \multicolumn{5}{|c|}{ Same Stringer as Span 3 Stringer 8} \\
\hline
\end{tabular}

Notes:

1. The following color coding is used:

- RED: Significant deterioration in member, replacement of member is recommended.

- GREEN: Softening noted in member, no repair is needed but monitoring is recommended.

- BROWN: Member in good condition, no repair is needed.

2. The damage in Span 3-Stringer 8 extends over to Span 4-Stringer 8 (same member).

3. Bents 2-7 are skewed up to $9 \%$ right to match the stream flow. This skew is not included in the drawings.
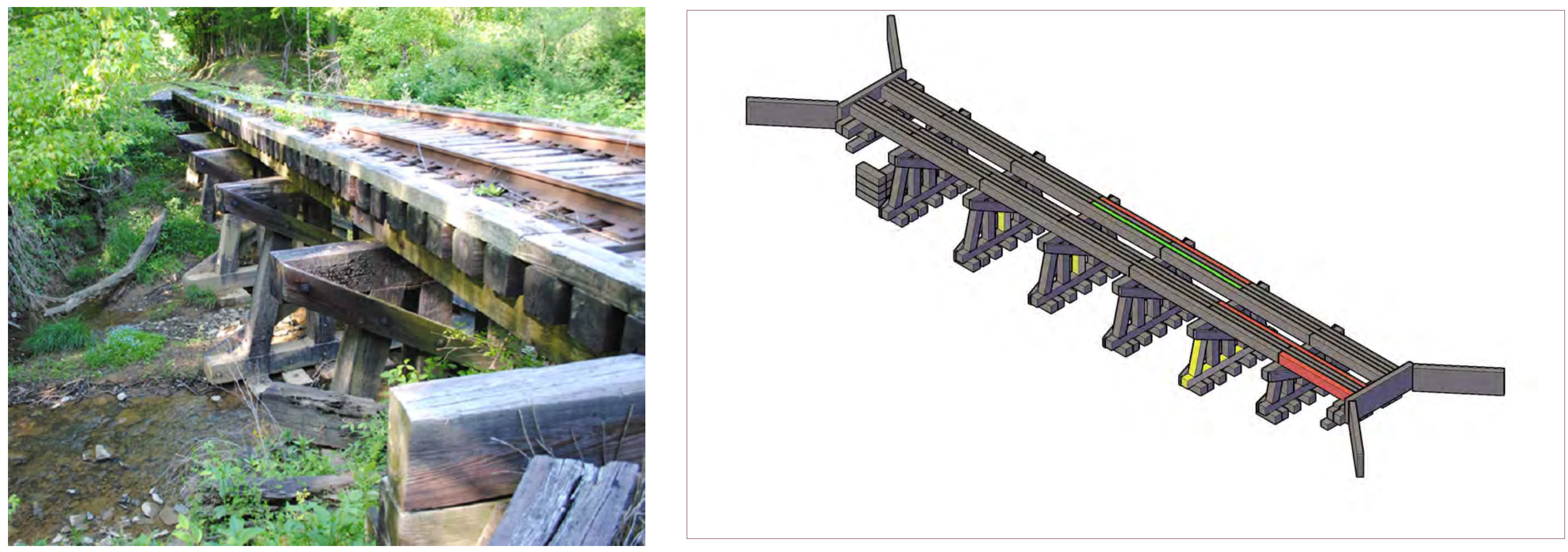

\begin{tabular}{|l|l|l|}
\hline The West Virginia Department of Transportation \\
State Rail Authority
\end{tabular}




\section{Bridge 5.1 Substructure Inspection}

\begin{tabular}{|c|c|c|c|c|c|c|c|c|}
\hline \multirow{2}{*}{ Bent } & \multirow{2}{*}{ Member } & \multicolumn{3}{|c|}{ Member } & \multicolumn{3}{c|}{ Damage } \\
\cline { 3 - 9 } & & Width & Depth & Length & Type & Width & Height & Length \\
\hline \multirow{2}{*}{1} & Block 5 & $12^{\prime \prime}$ & $12^{\prime \prime}$ & $3^{\prime}$ & Soft & & & \\
\cline { 2 - 9 } & Block 6 & $12^{\prime \prime}$ & $12^{\prime \prime}$ & $3^{\prime}$ & Soft & & & \\
\hline \multirow{2}{*}{3} & sill & $12^{\prime \prime}$ & $13^{\prime \prime}$ & $14^{\prime}$ & Rot & $10^{\prime \prime}$ & $11^{\prime \prime}$ & $4^{\prime}$ \\
\cline { 2 - 9 } & post 1 & $12^{\prime \prime}$ & $12^{\prime \prime}$ & $5^{\prime}-7.25^{\prime \prime}$ & Rot & $8.25^{\prime \prime}$ & $8.5^{\prime \prime}$ & $5^{\prime}-7.25^{\prime \prime}$ \\
\hline 5 & post 3 & $12^{\prime \prime}$ & $12^{\prime \prime}$ & $6^{\prime}$ & Rot & $8^{\prime \prime}$ & $8^{\prime \prime}$ & $6^{\prime}$ \\
\hline 6 & post 3 & $12^{\prime \prime}$ & $12^{\prime \prime}$ & $6^{\prime}-9.5^{\prime \prime}$ & Rot & $8.5^{\prime \prime}$ & $8.5^{\prime \prime}$ & $6^{\prime}-9.5^{\prime \prime}$ \\
\hline
\end{tabular}

\section{FRP Wrap Quantities}

To Wrap

\begin{tabular}{|c|c|c|c|c|c|}
\hline Bent & Membel & Width (in) & Depth (in) & Length (in) & Area $\left(\mathrm{in}^{2}\right)$ \\
\hline 3 & 1 & 12 & 12 & 67.25 & 3228 \\
\hline 5 & 3 & 12 & 12 & 72 & 3456 \\
\hline 6 & 3 & 12 & 12 & 81.5 & 3912 \\
\hline 3 & sill & 12 & 13 & 54 & 2700 \\
\hline
\end{tabular}

$A_{\text {total }}=13296 \mathrm{in}^{2}=92.33 \mathrm{ft}^{2}$
Notes:

1. The following color coding is used:

- RED: Significant deterioration in member, replacement of member is

recommended

- GREEN: Softening noted in member, no repair is needed but monitoring is recommended.

- YELLOW: Significant deterioration in member, FRP wrap is recommended. - BROWN: Member in good condition, no repair is needed.

\section{FRP Wrap:}

The quantities shown are based on the surface area of the member to be covered with FRP wrap. These quantities are for a single layer of wrap without accounting for overlap.

\begin{tabular}{|l|l|}
\hline The West Virginia Department of Transportation \\
State Rail Authority
\end{tabular}




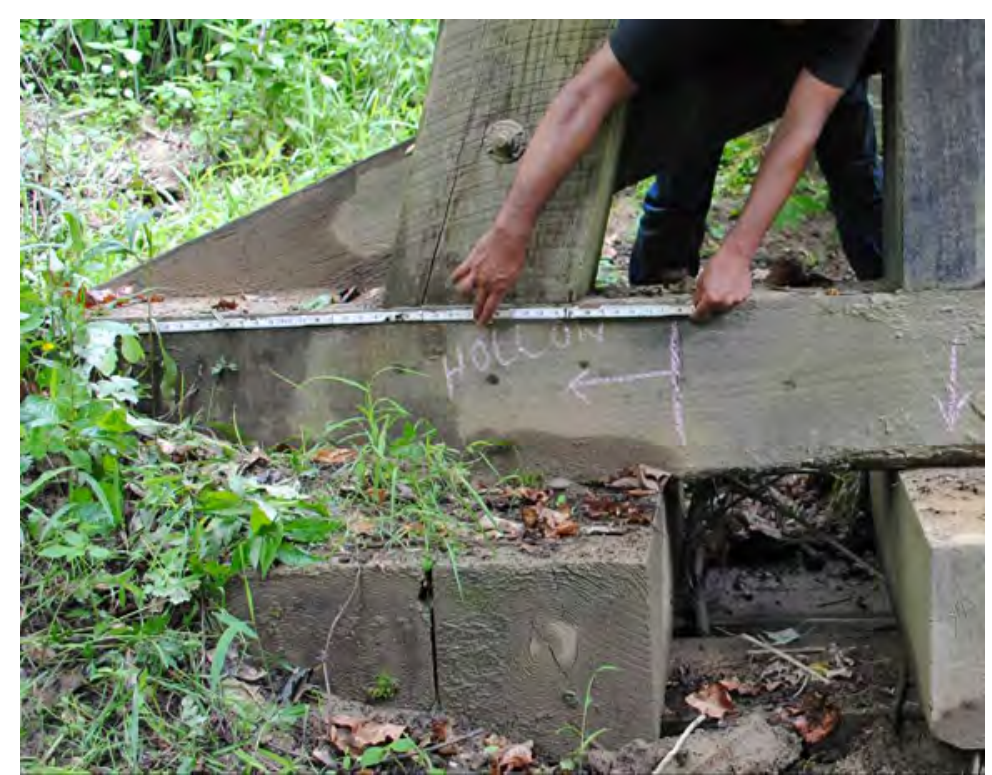

Bent 3 - Sill Rot

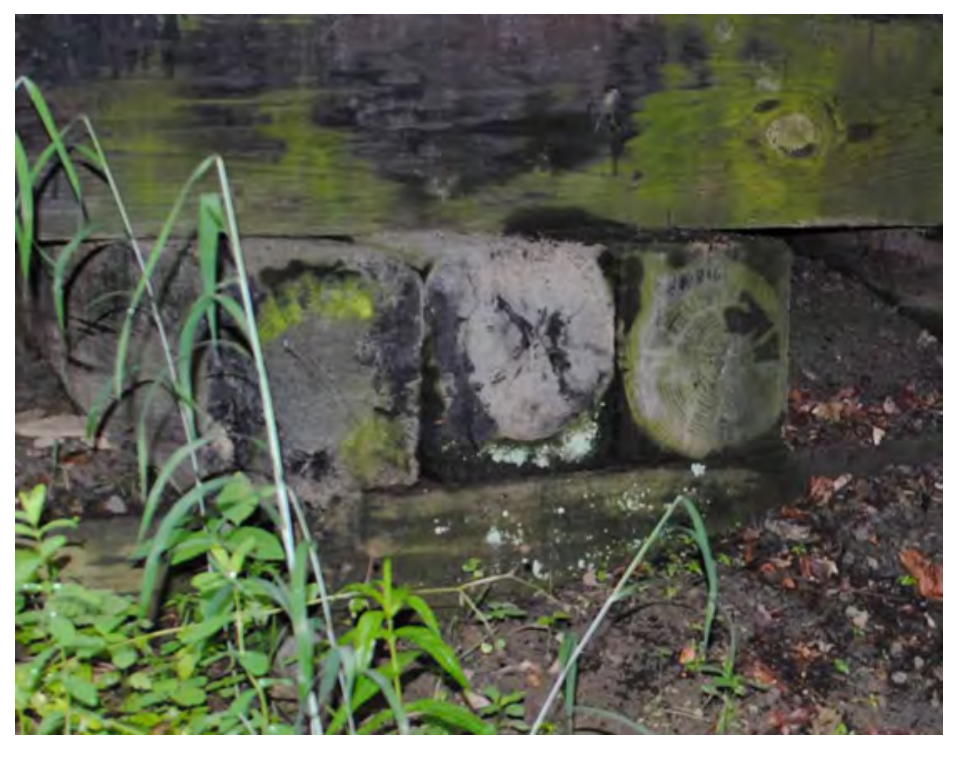

Bent 1 - Blocks 5 \& 6 Softening

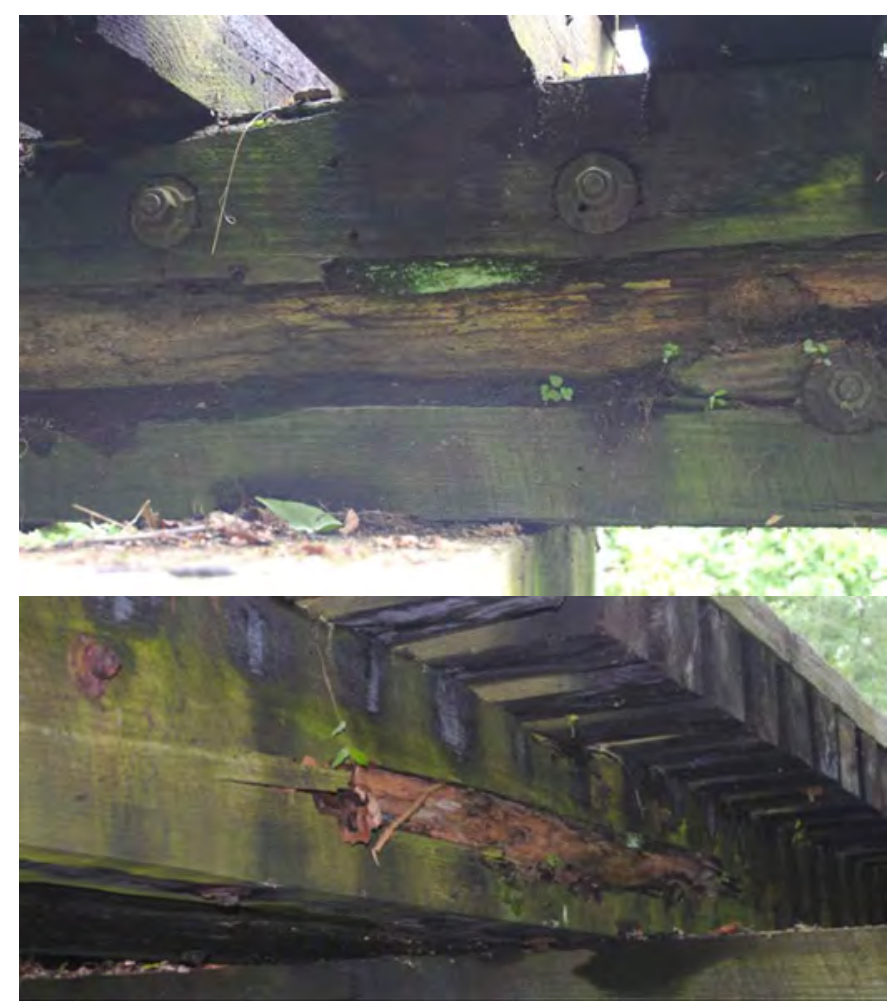

Span $3 \& 4$ - Stringer 8 Rot

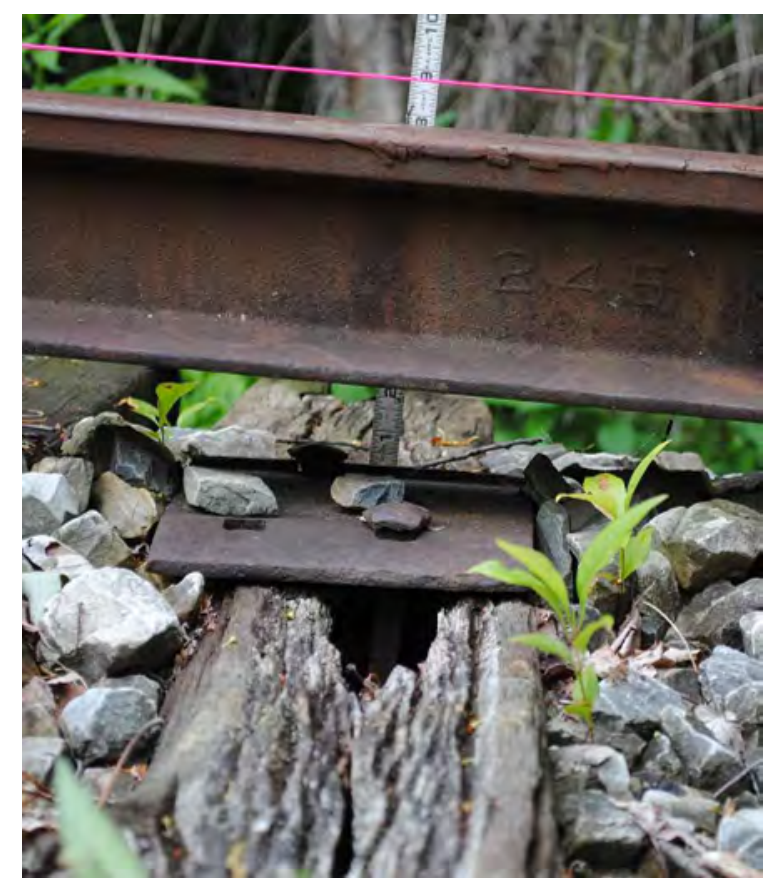

North Approach Low Ballast and Rot Tie

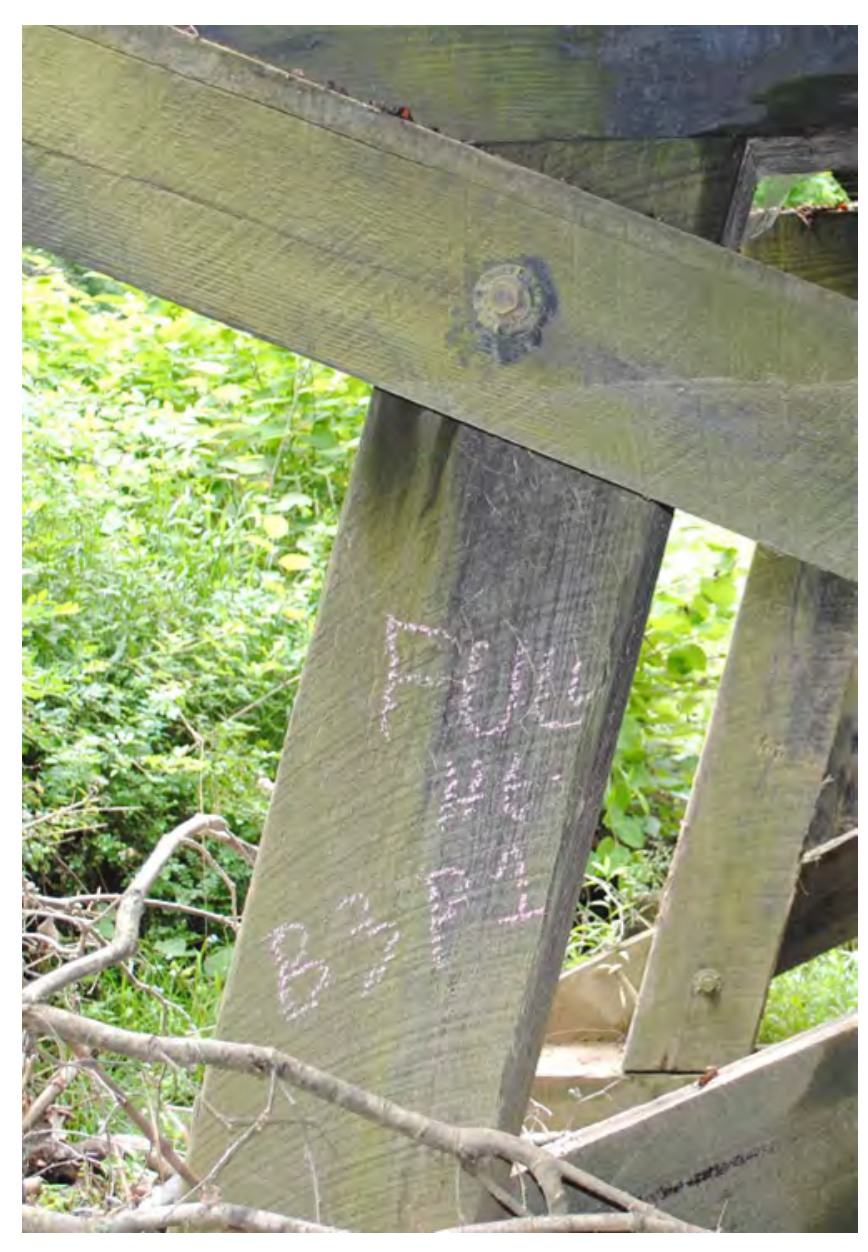

Bent 3 - Post 1 Rot

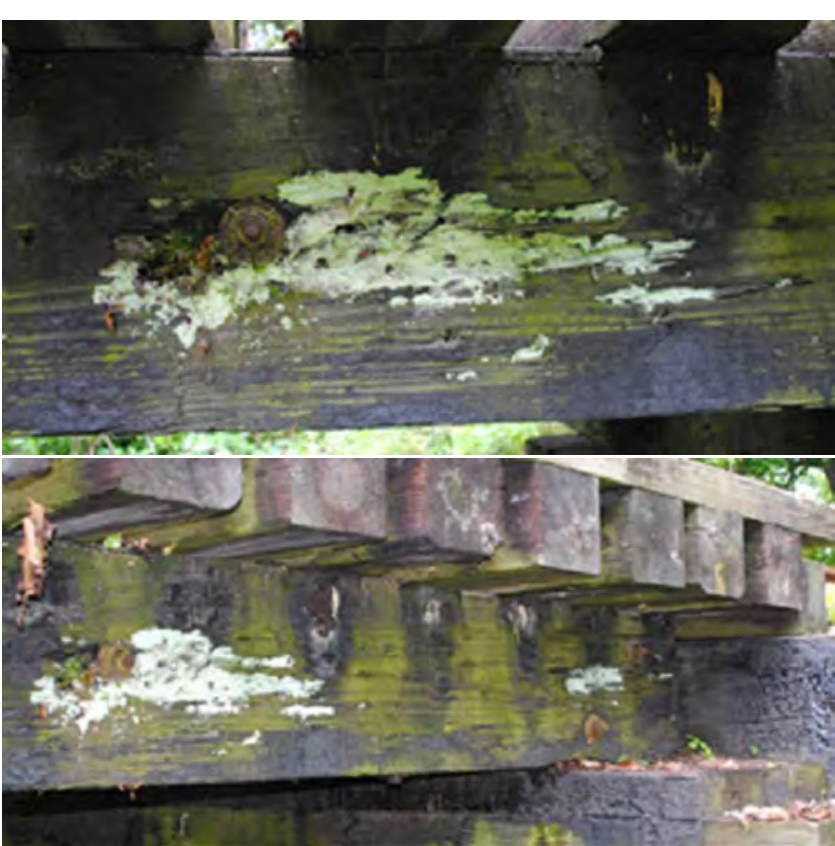

Span 1 - Stringer 1 Fruitng Bodies

\begin{tabular}{|c|c|c|}
\hline \multicolumn{3}{|c|}{$\begin{array}{l}\text { The West Virginia Department of Transportation } \\
\text { State Rail Authority }\end{array}$} \\
\hline PROJECT & \multicolumn{2}{|c|}{$\begin{array}{l}\text { WV Central Rail Road } \\
\text { Dailey Branch Bridges }\end{array}$} \\
\hline TTILE & \multicolumn{2}{|c|}{$\begin{array}{c}\text { Bridge } 5.1 \\
\text { Inspection - Pictures }\end{array}$} \\
\hline Drawn By & $\overline{L C P}$ & $12-9-2015$ \\
\hline \multicolumn{3}{|c|}{$\begin{array}{l}\text { Constructed Facilities Center } \\
\text { West Virginia University }\end{array}$} \\
\hline cole & None & Sheet 28 \\
\hline
\end{tabular}




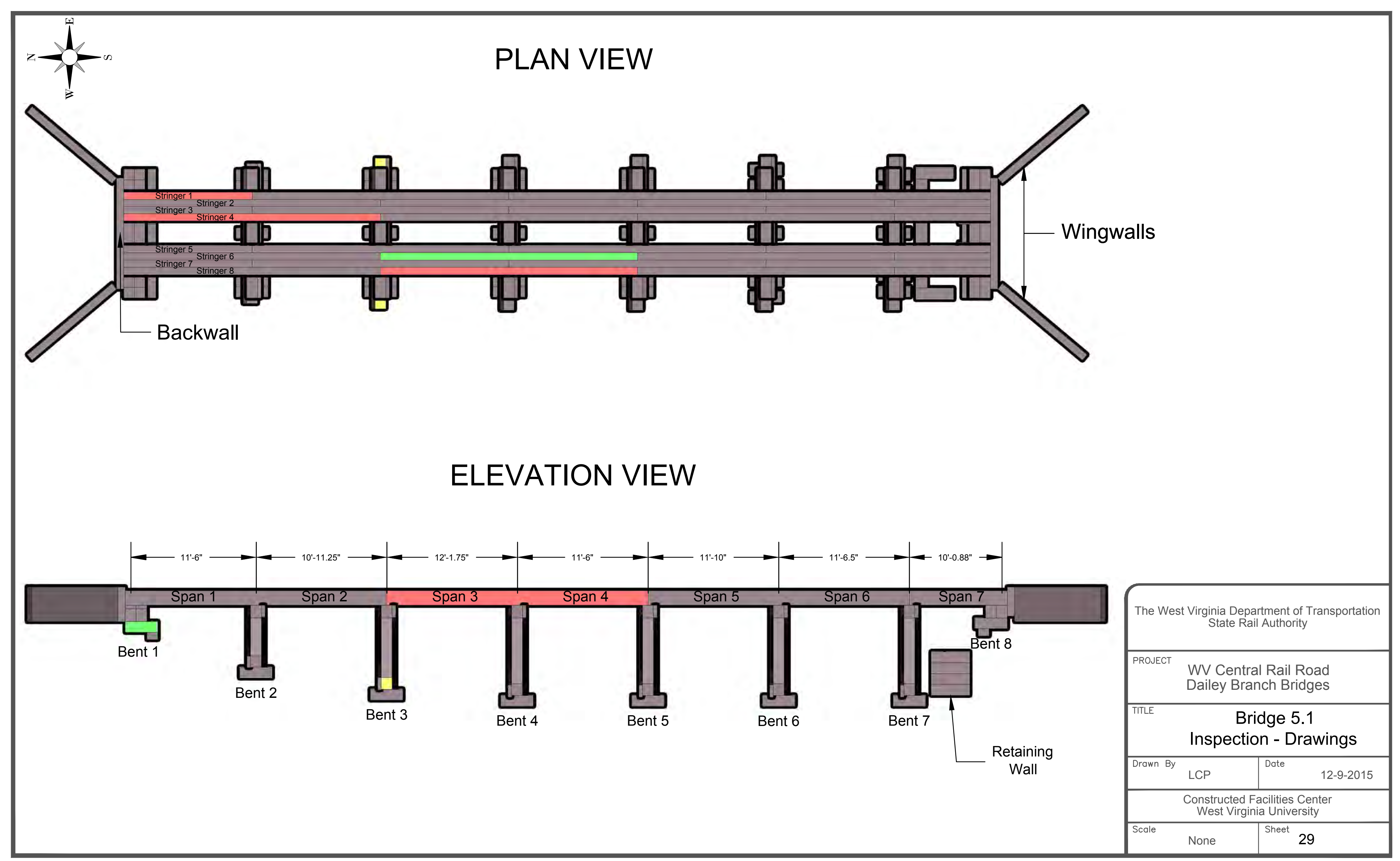



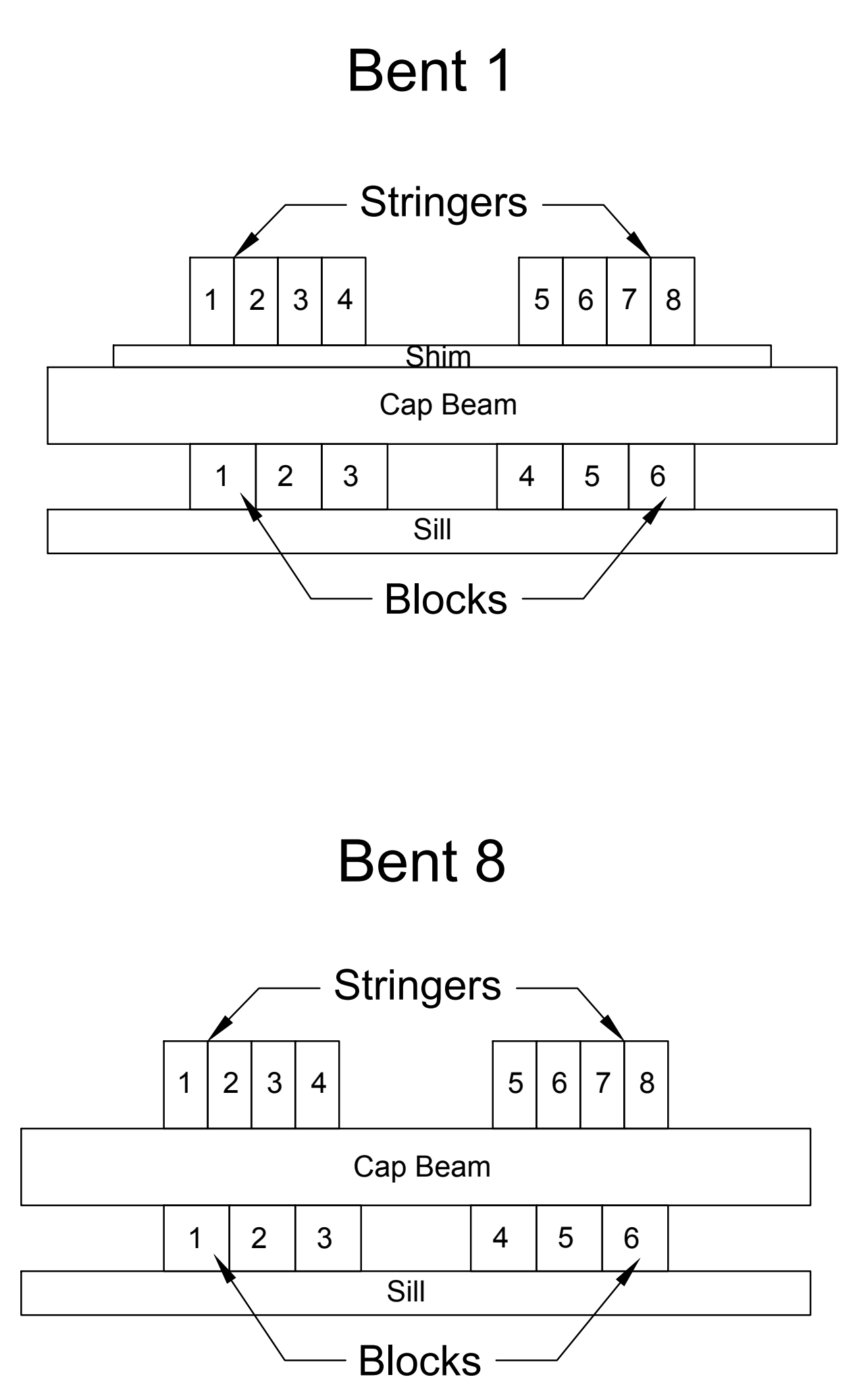

\section{Bent 2 - 7}

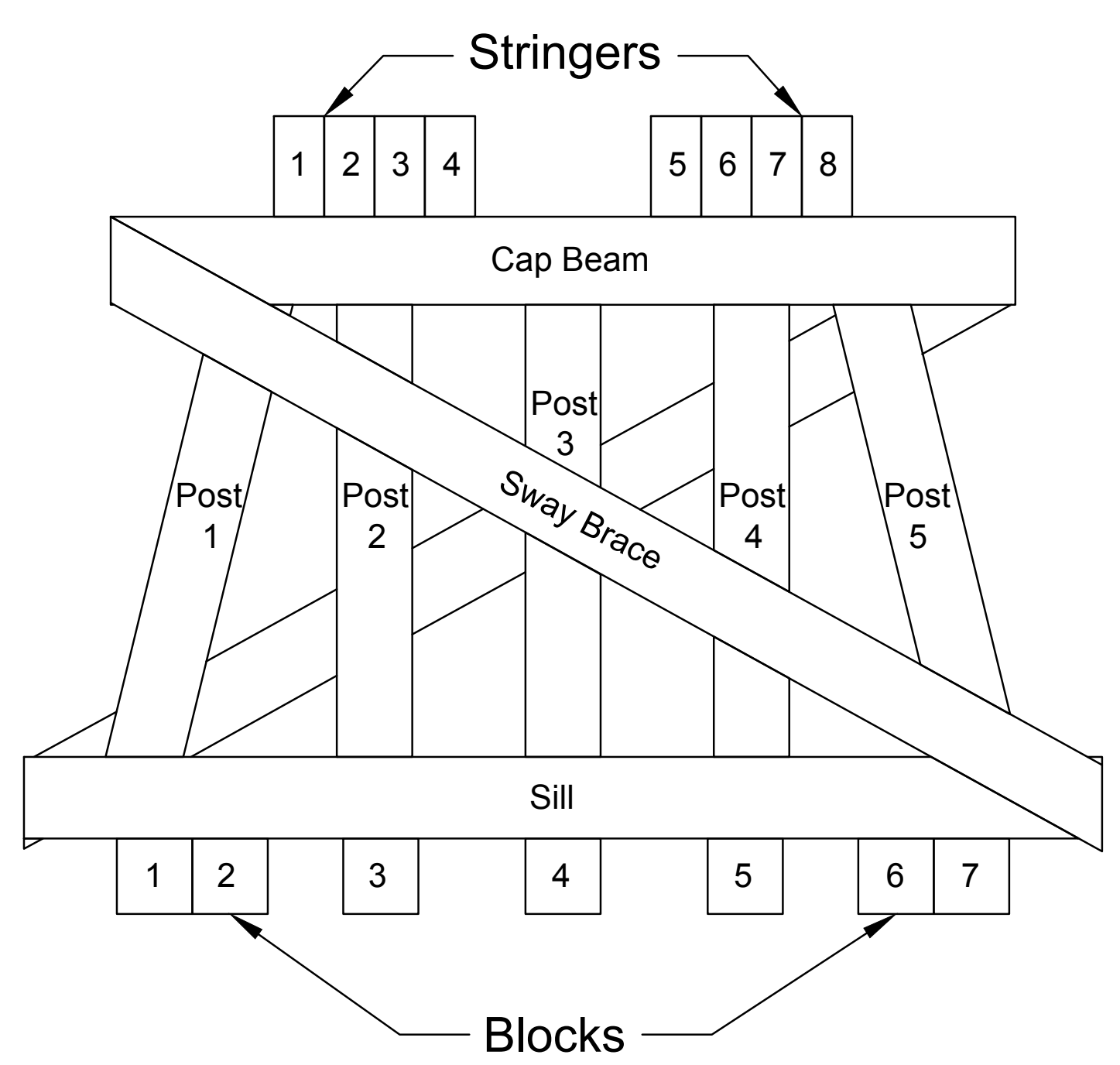




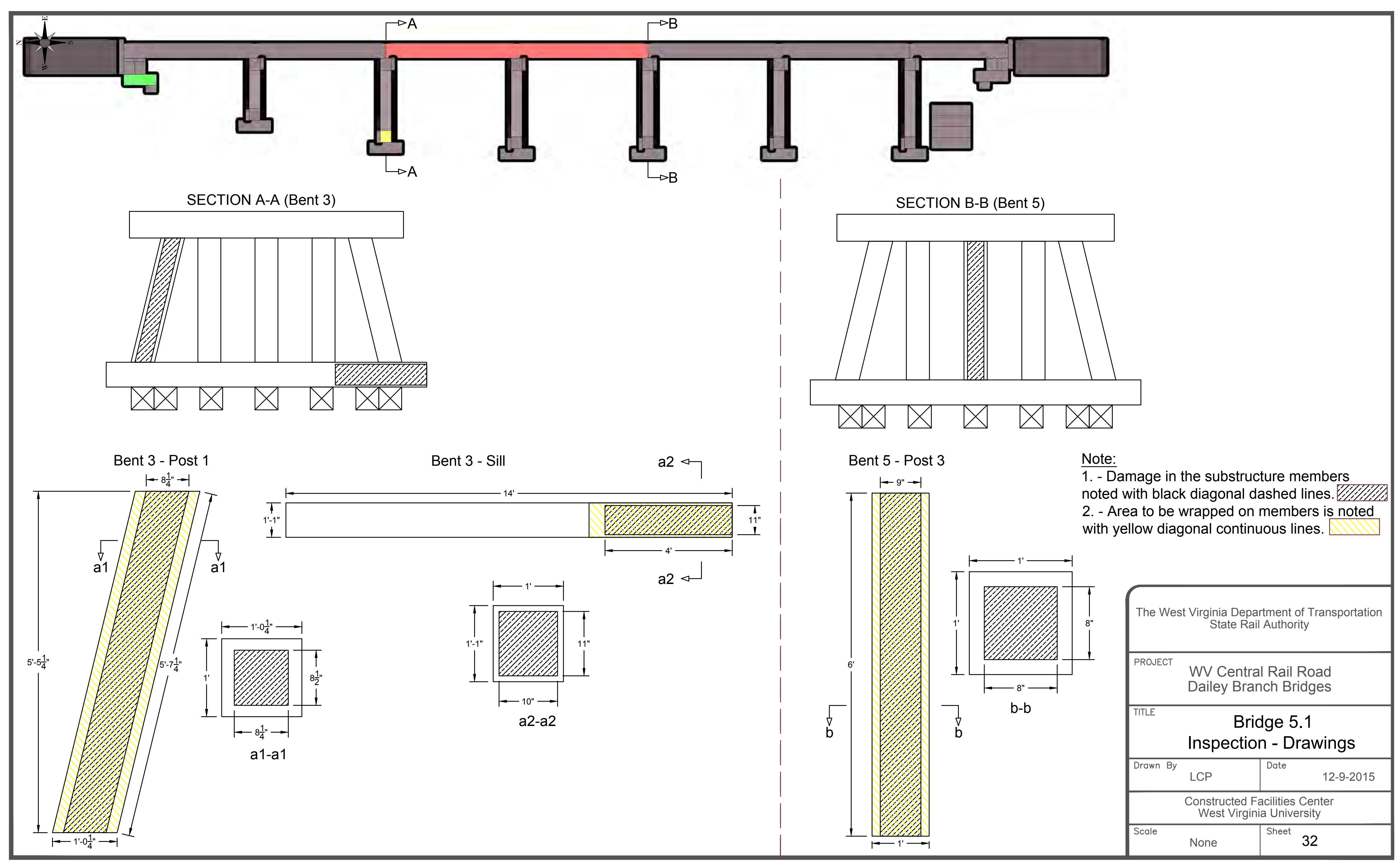




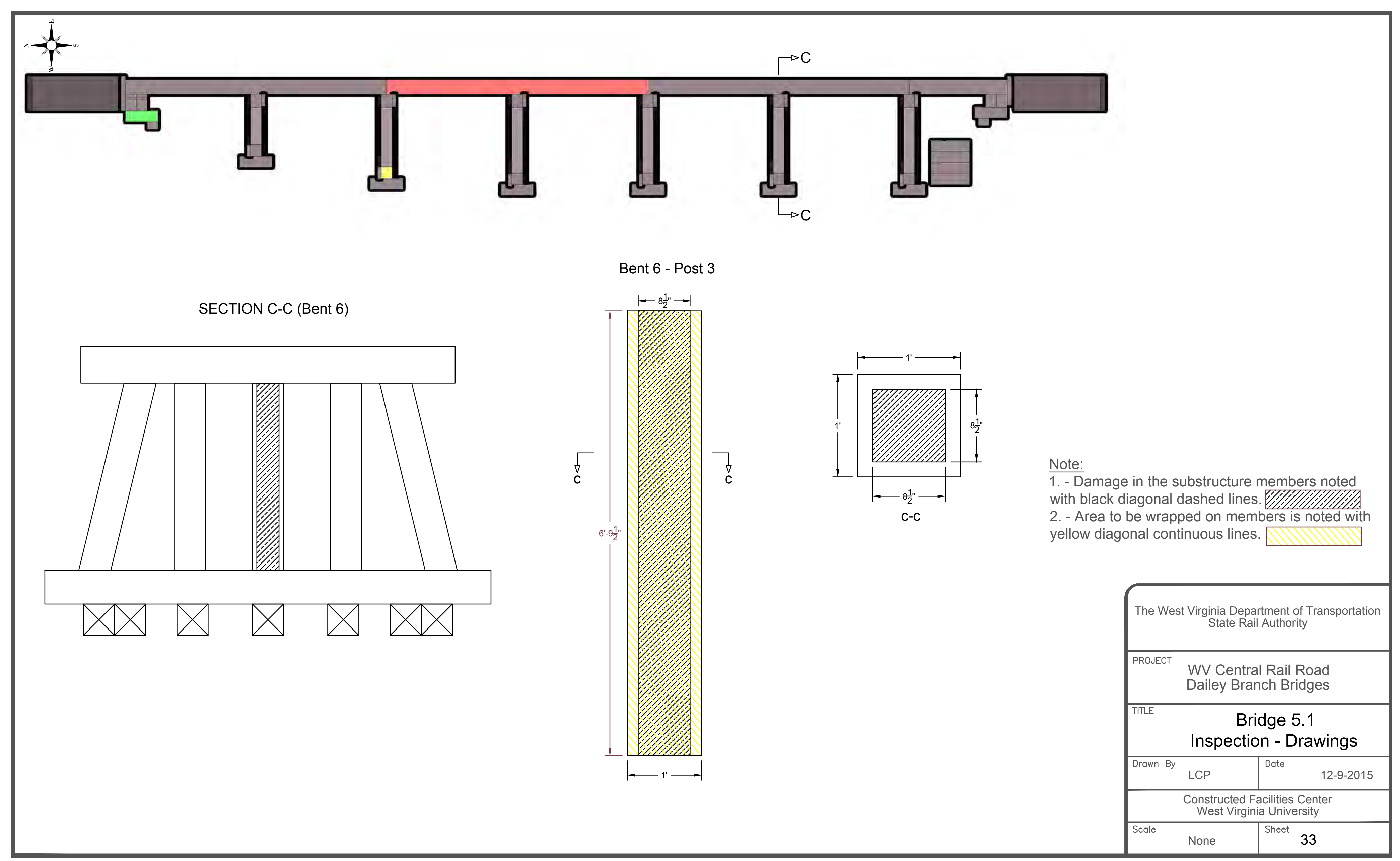




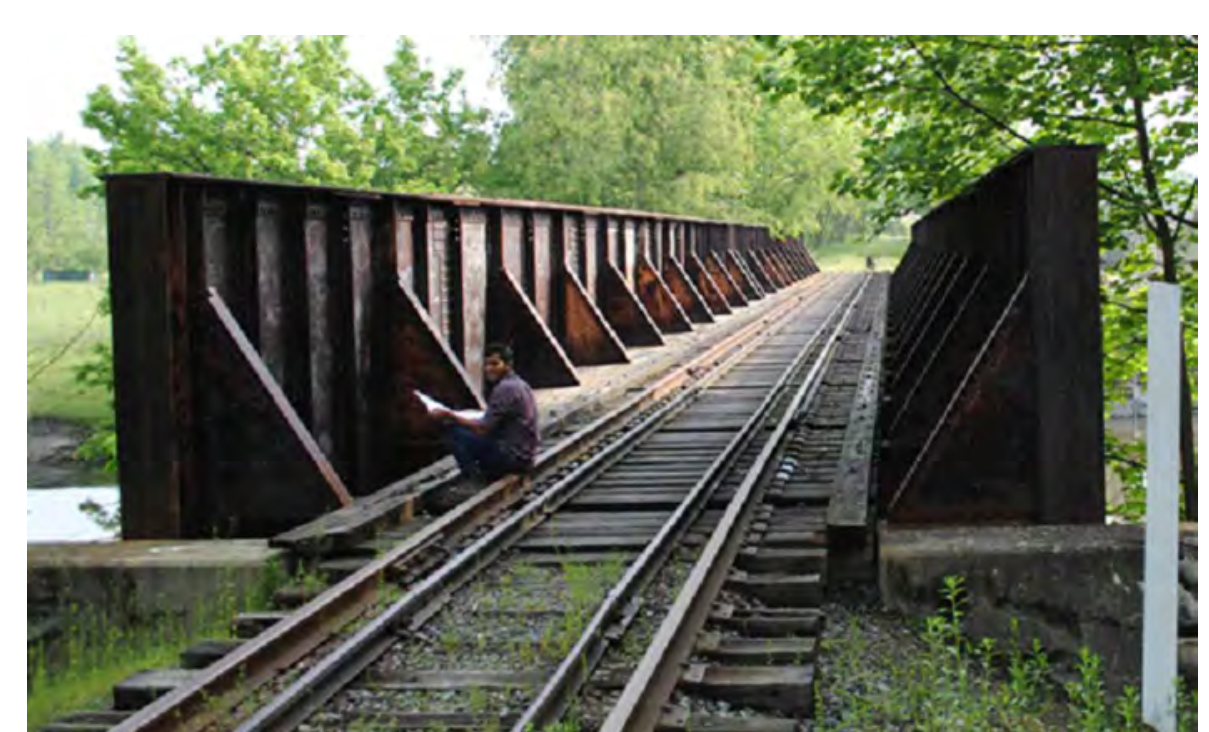

Bridge 1.4

\begin{tabular}{|c|c|}
\hline \multicolumn{2}{|c|}{ Index to Sheets } \\
\hline No. & Description \\
\hline 1 & Title Sheet \\
\hline 2 & Bridge 1.4 - Design \\
\hline 3 & Bridge 1.4 - Typical Cross Section \\
\hline $4-6$ & Bridge 1.4 - Inspection Pictures \\
\hline 7 & Bridge 5.8 - Design \\
\hline 8 & Bridge 5.8 - Typical Cross Section \\
\hline 9 & Bridge 5.8 - Inspection Pictures \\
\hline
\end{tabular}

\section{West Virginia}

Department of Transportation

State Rail Authority

Plans for Construction

State Railroad Inspections and Repair of Dailey Branch Steel Bridges

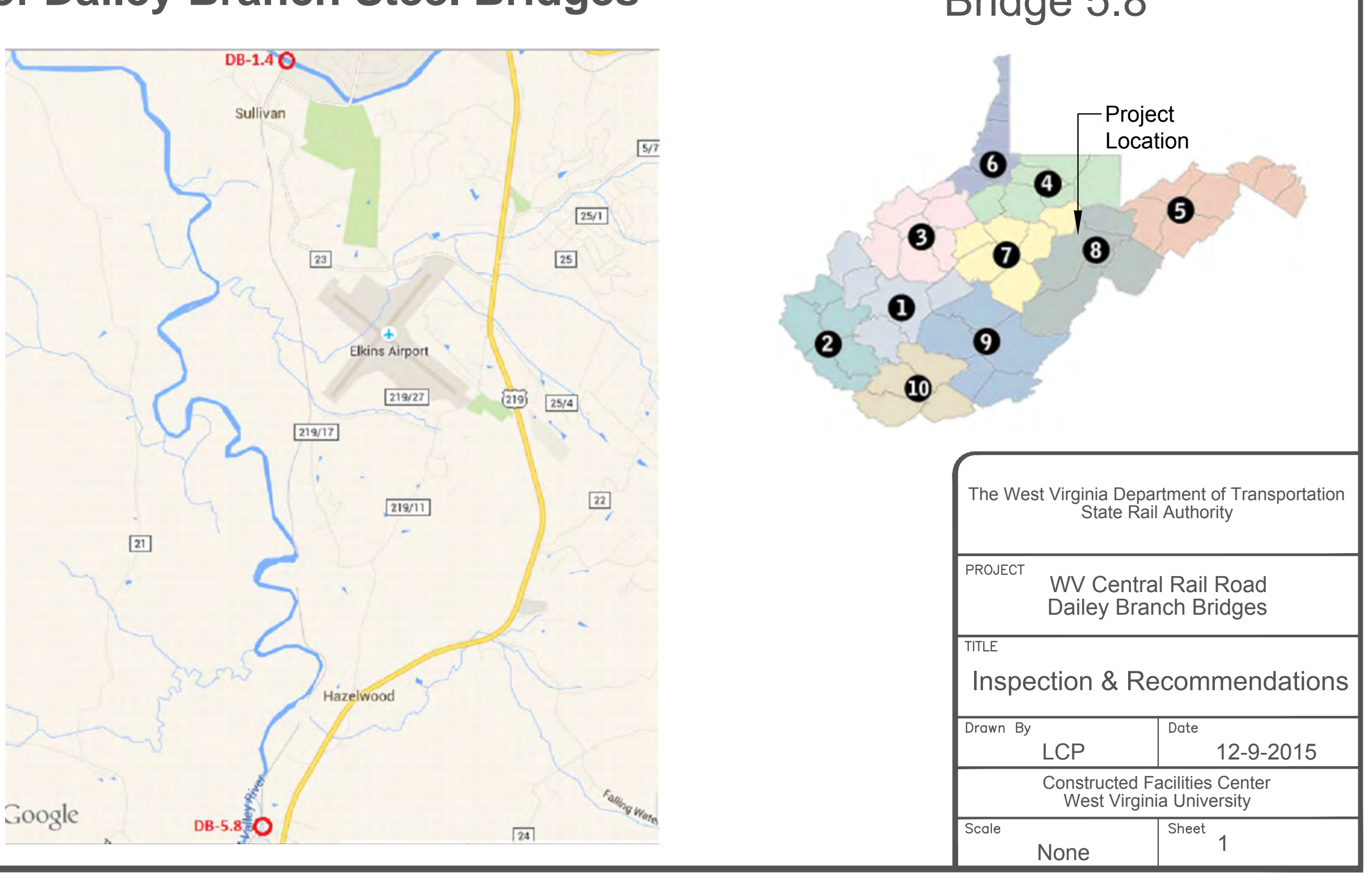

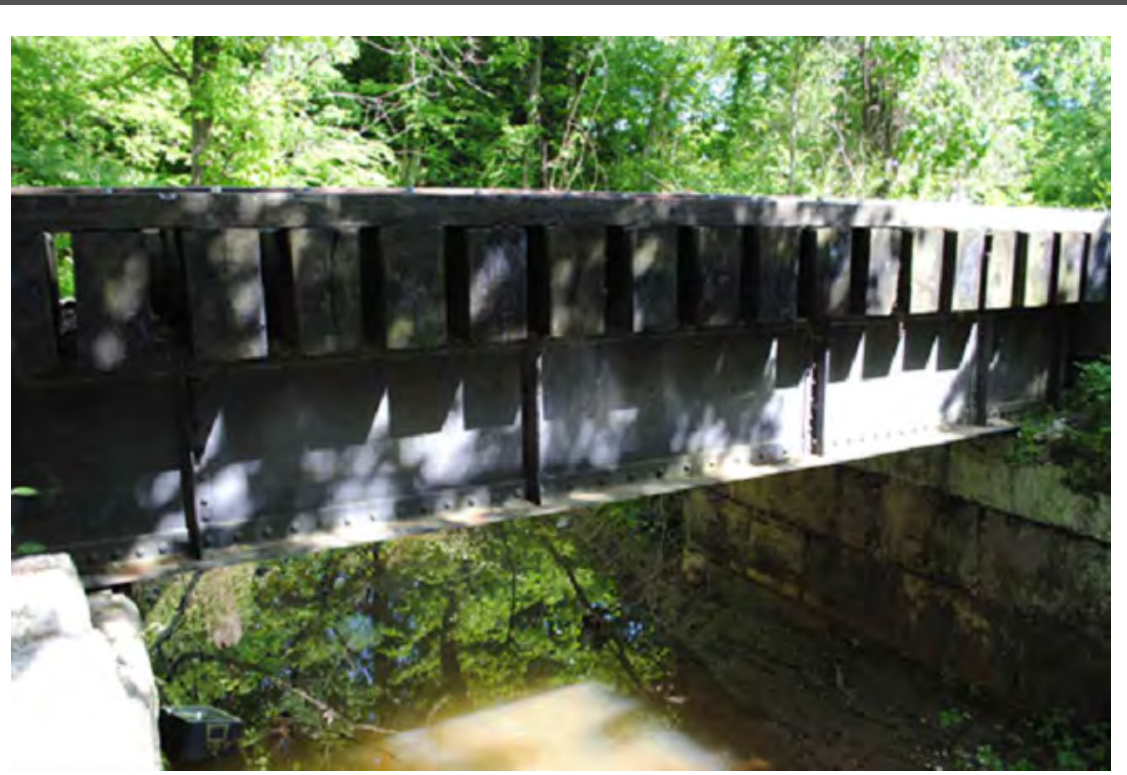

Bridge 5.8 


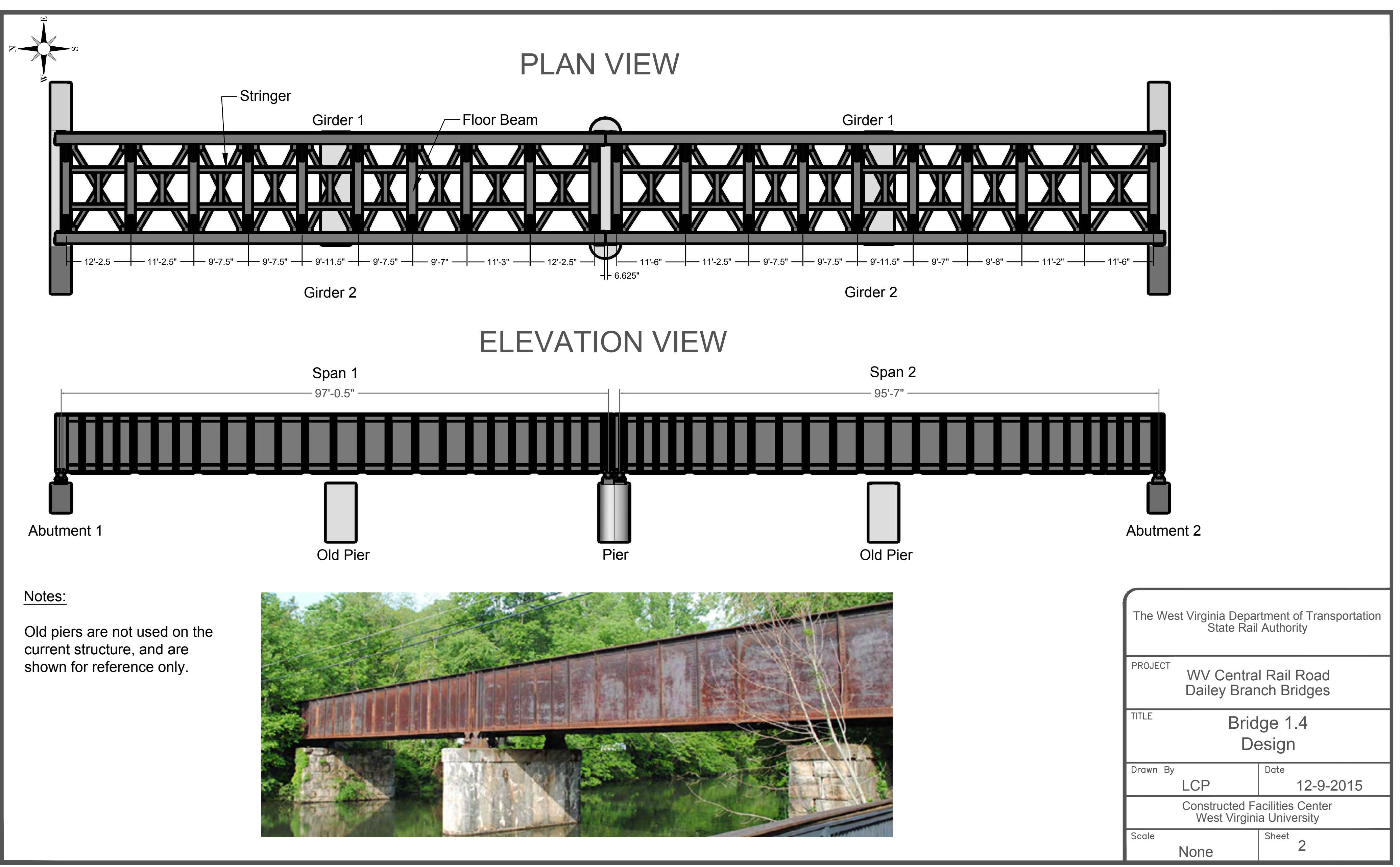




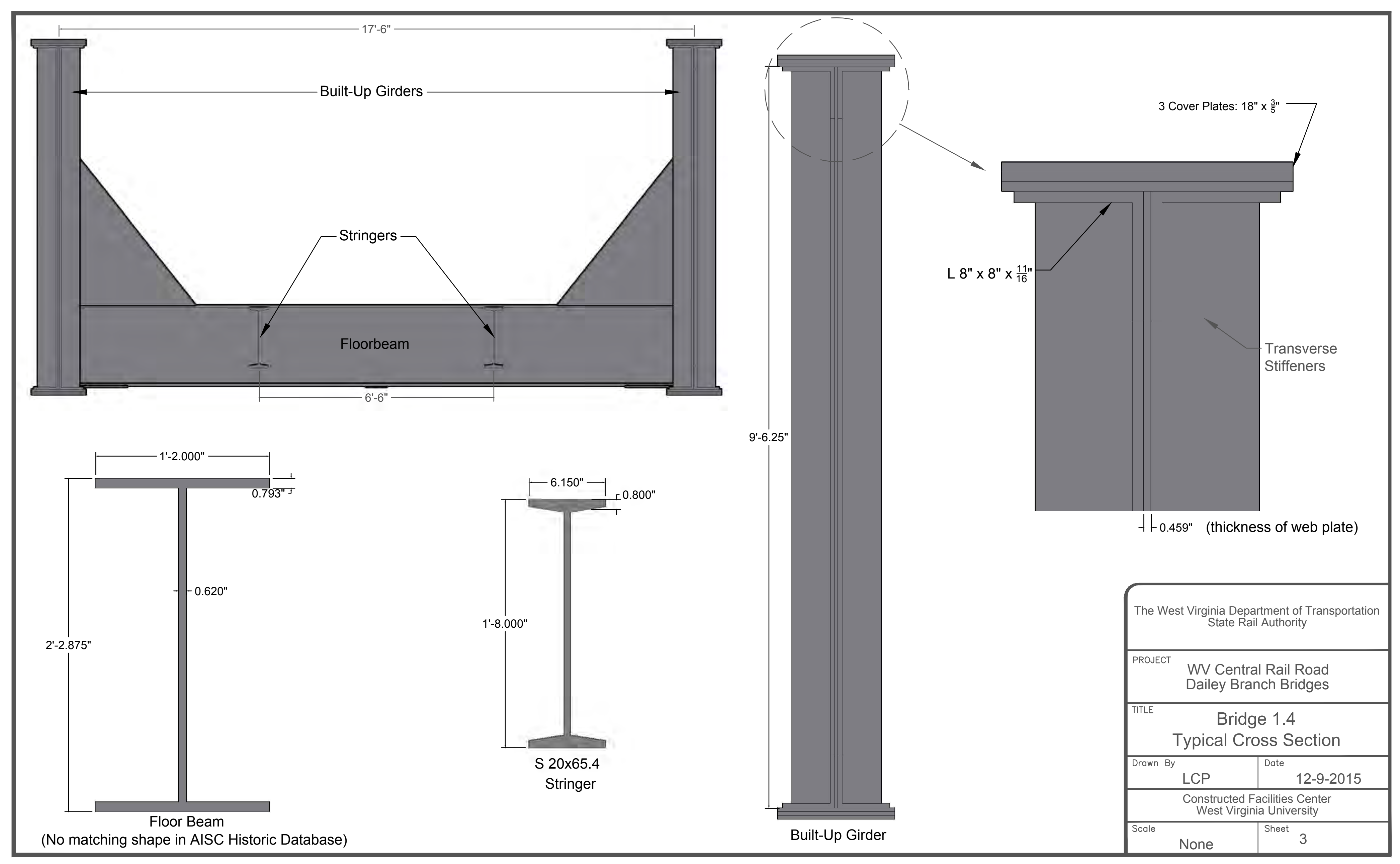




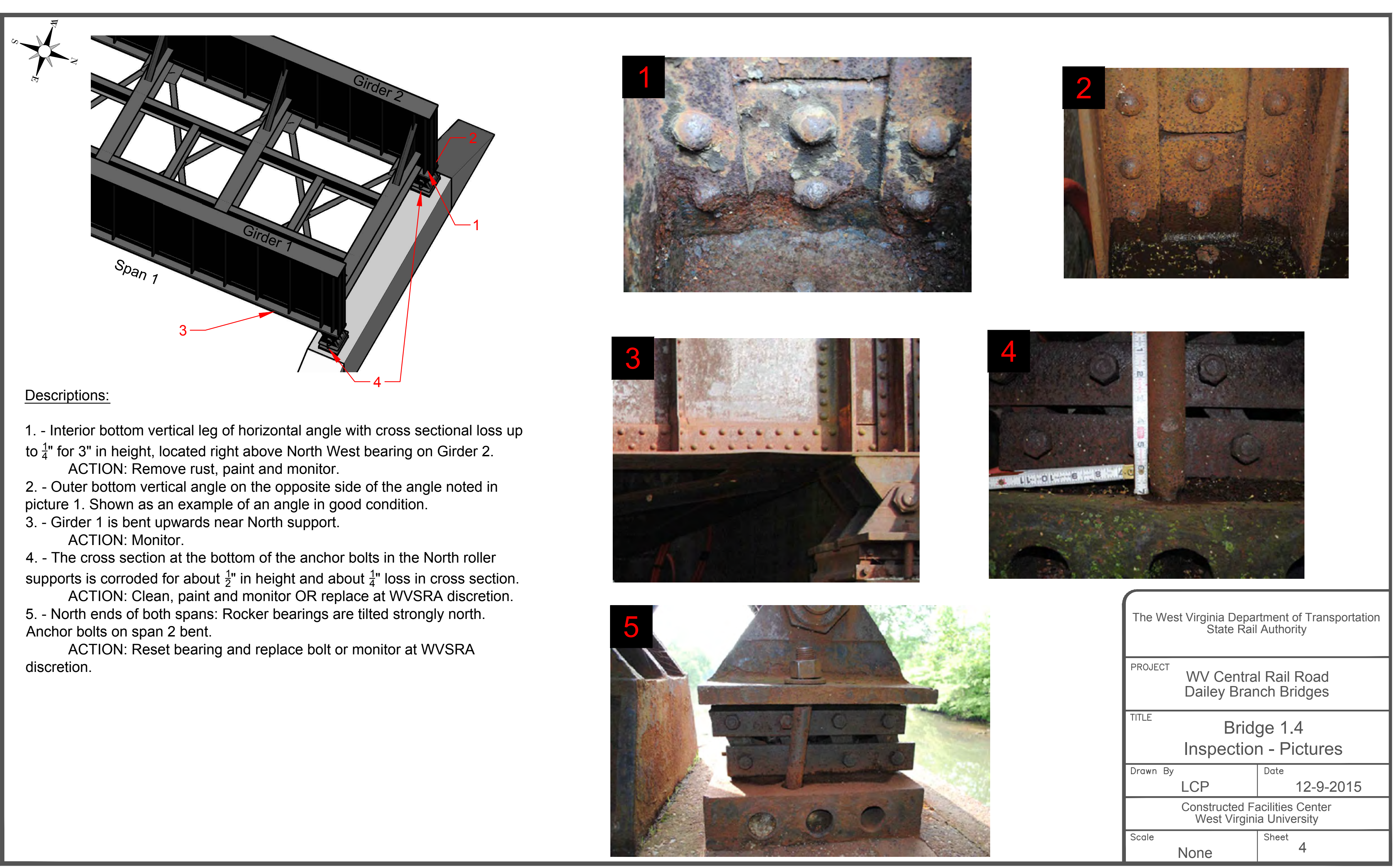




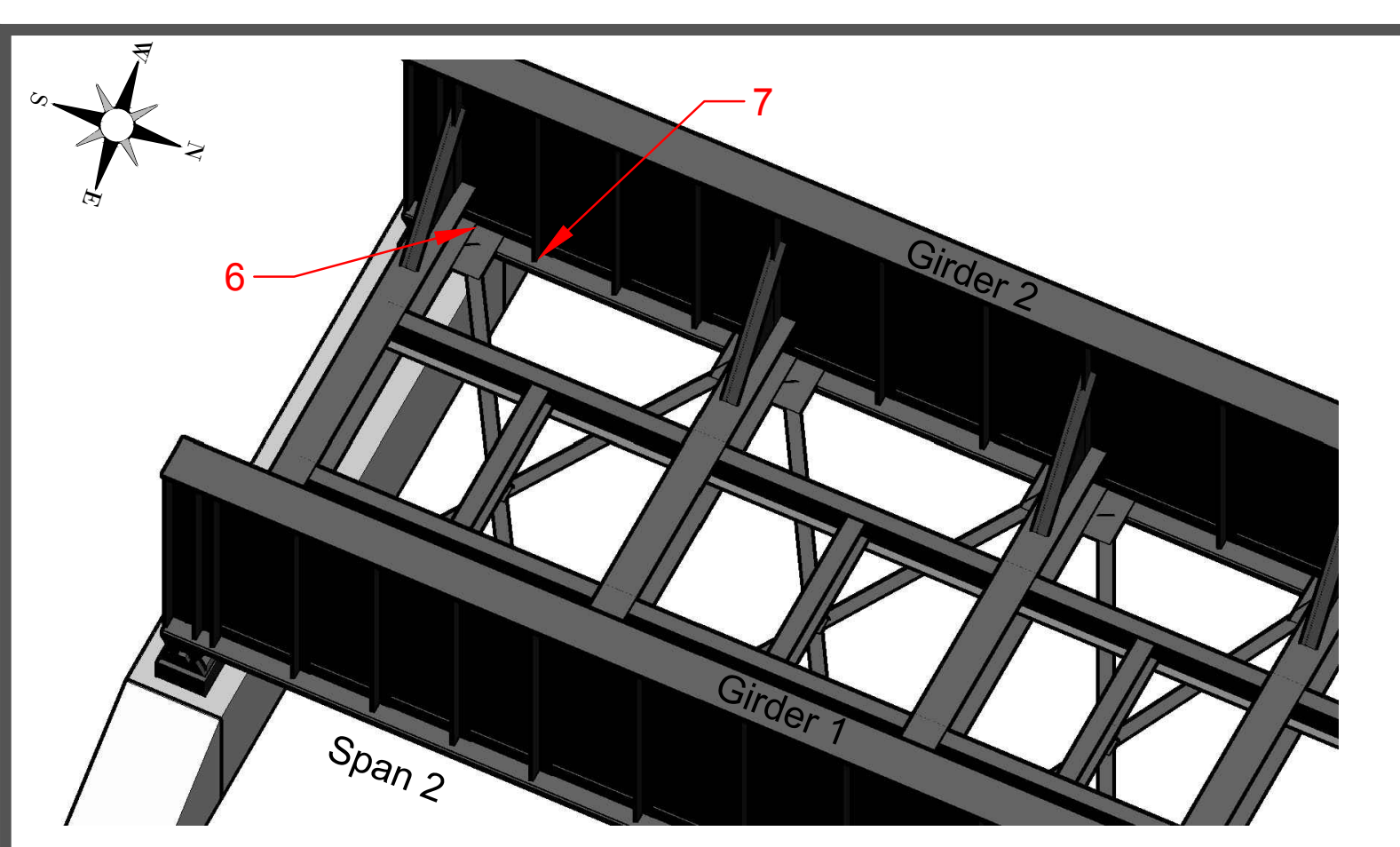

Descriptions:

6. - Gusset plates on multiple locations show corrosion, corner connections of gusset plates corroded away. Many gusset plates connecting floor beam show some corrosion.

ACTION: Clean, paint and monitor.

7. - Stiffener with $100 \%$ section loss at the bottom resting on girder flanges. Since corrosion occurs below the rivets, it does not become a structural

issue. Repetitive issue in many stiffeners. ACTION: Clean, paint and monitor.
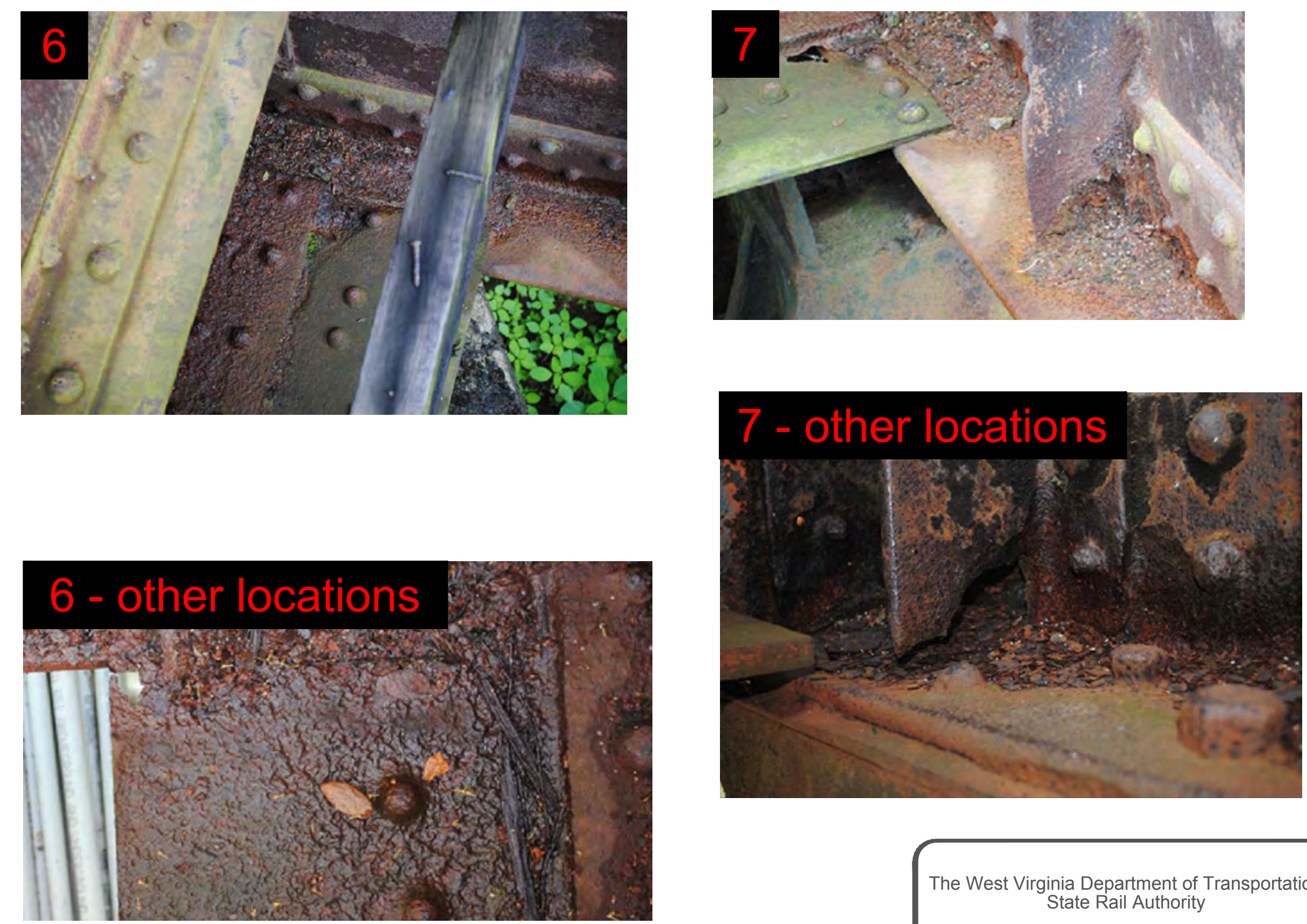

\begin{tabular}{|ll|l|}
\hline The West Virginia Department of Transportation \\
State Rail Authority
\end{tabular}




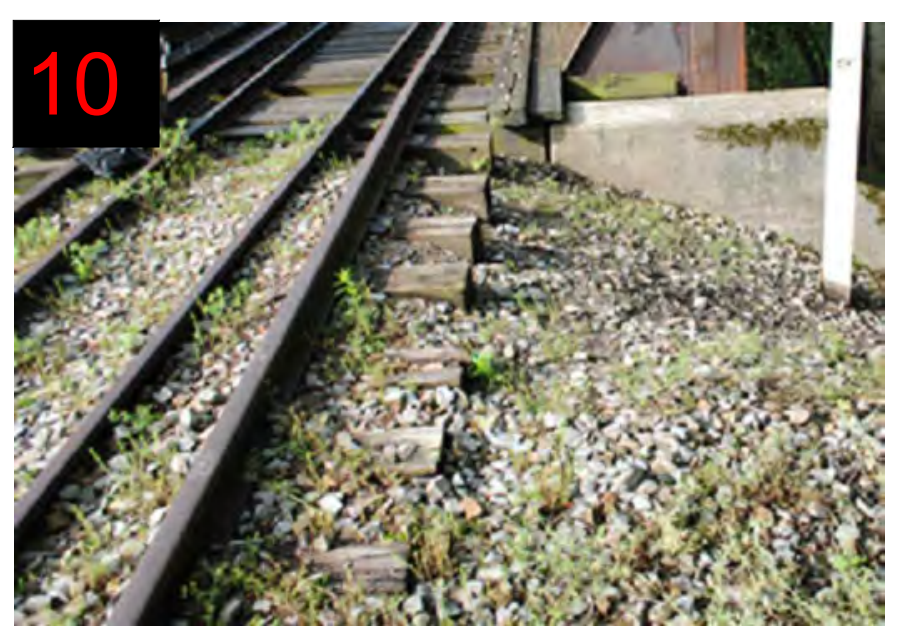

\section{Descriptions:}

Items 10-14 are general observations. Cracks should be monitored.

10. - Ballast is low in North approach.

11. - Ballast is also low in the South approach of the bridge.

12. - North abutment seat, East end, has minor scaling and map cracking.

Structure in good condition.

13. - Pier has heavy efflorescence, rust stains from superstructure. Scaling

visible at the top.

14. - The South East wingwall exhibits minor map cracking
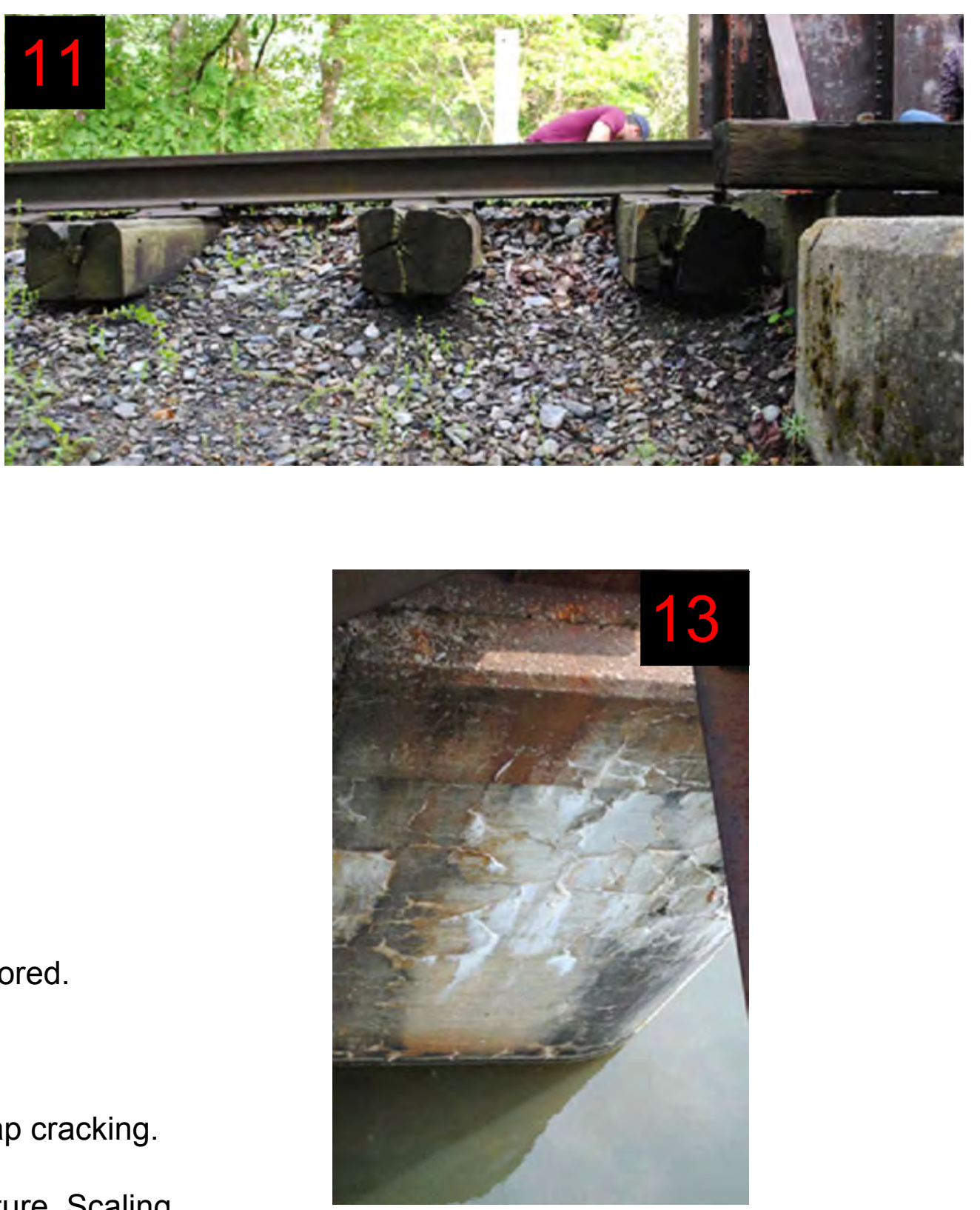
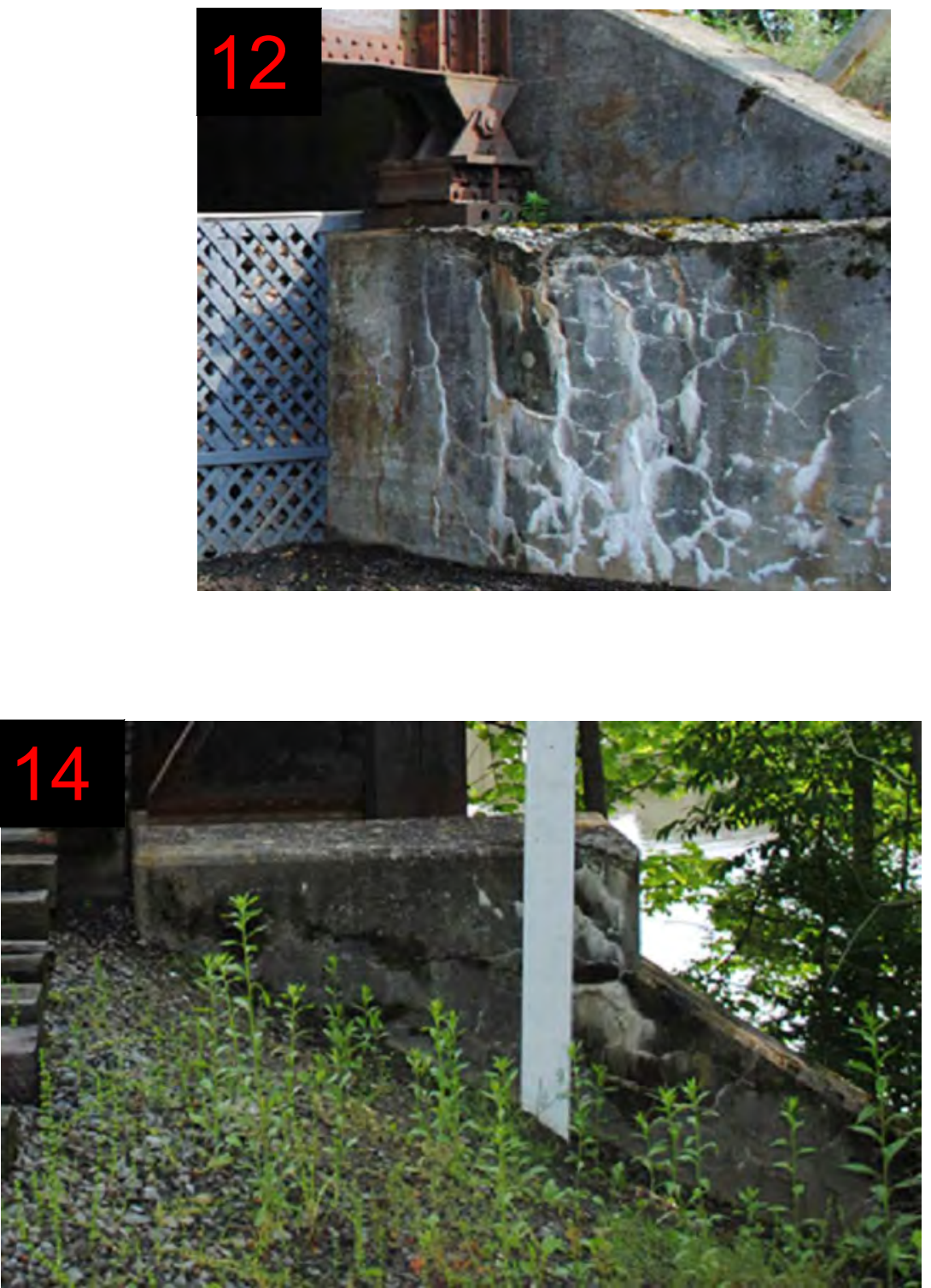

\begin{tabular}{|ll|l|}
\hline The West Virginia Department of Transportation \\
State Rail Authority
\end{tabular}



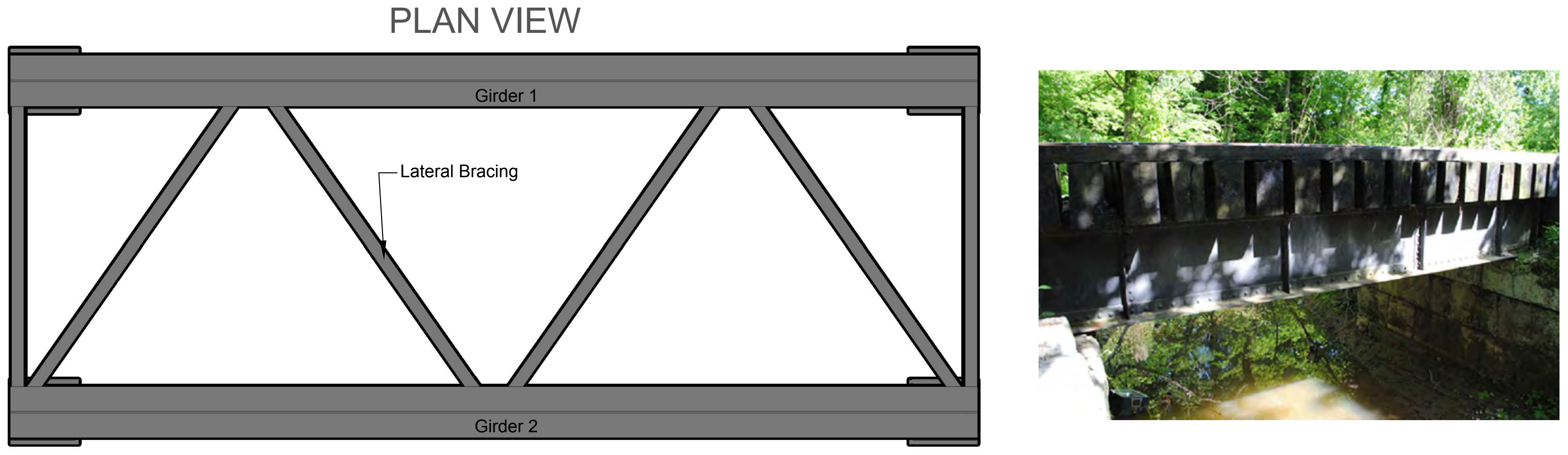

\section{ELEVATION VIEW}

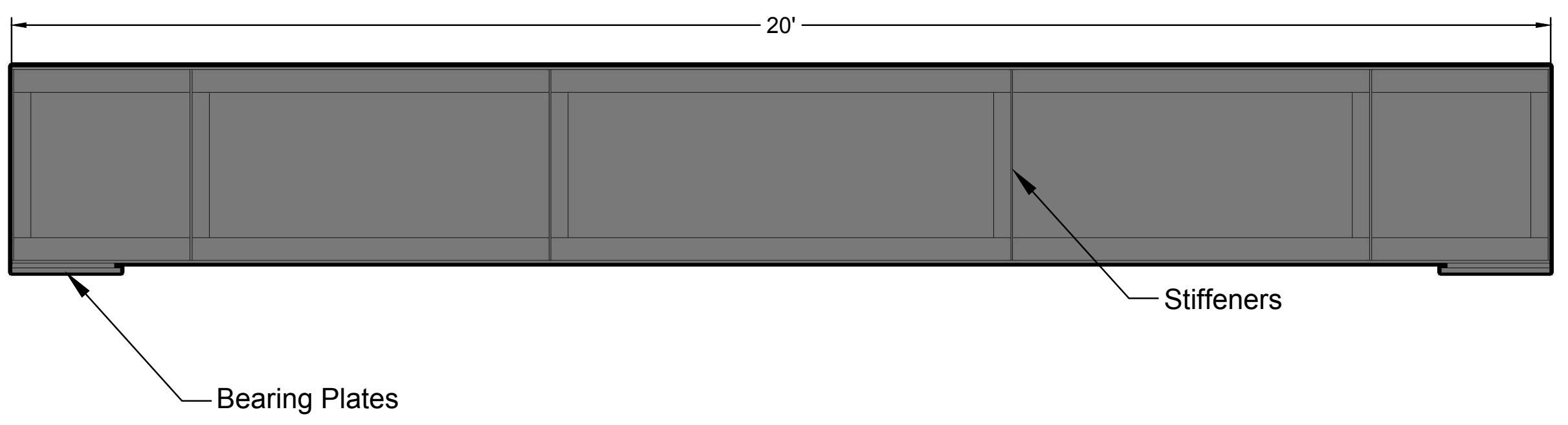

\begin{tabular}{|ll|l|}
\hline The West Virginia Department of Transportation \\
State Rail Authority
\end{tabular}




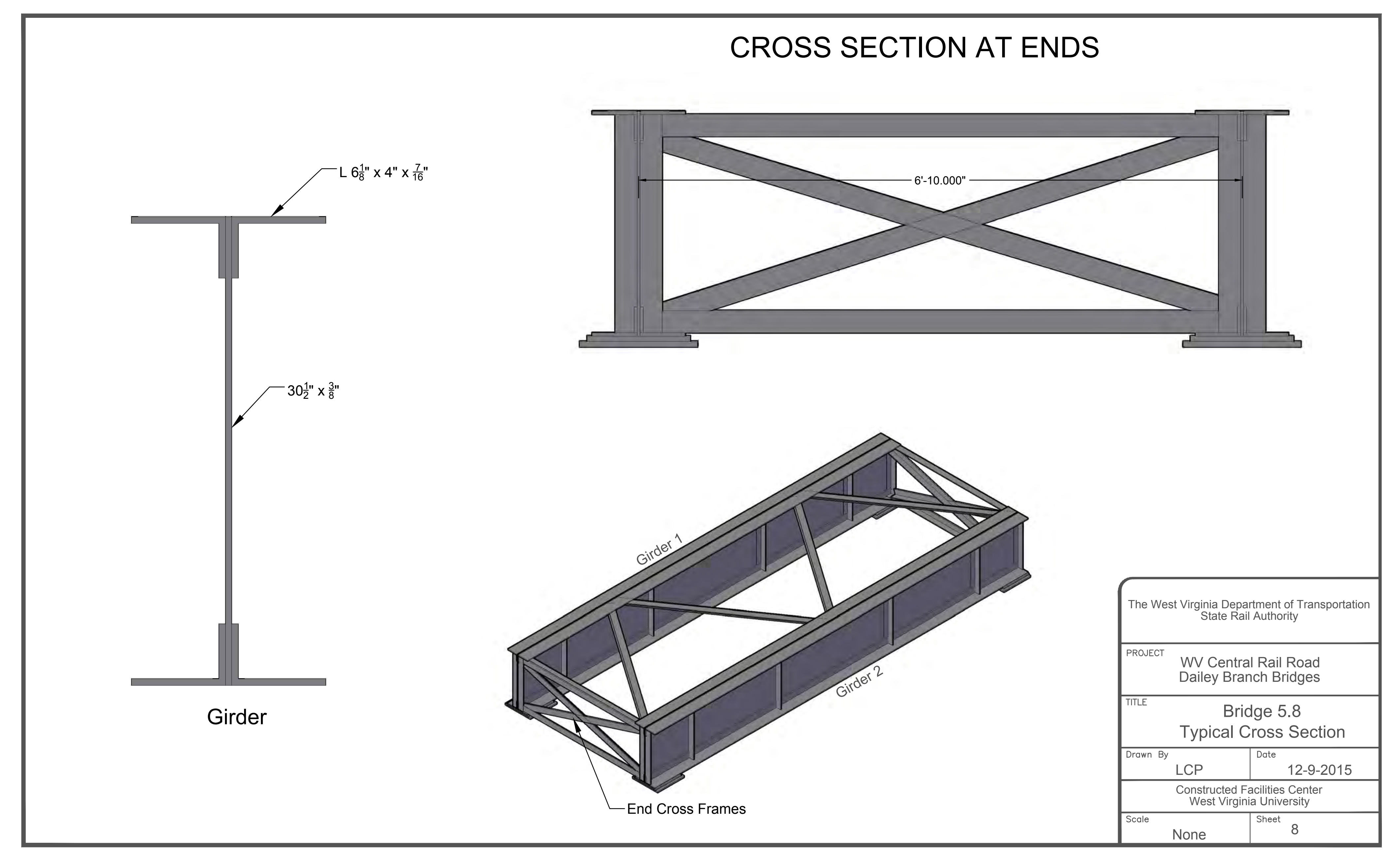



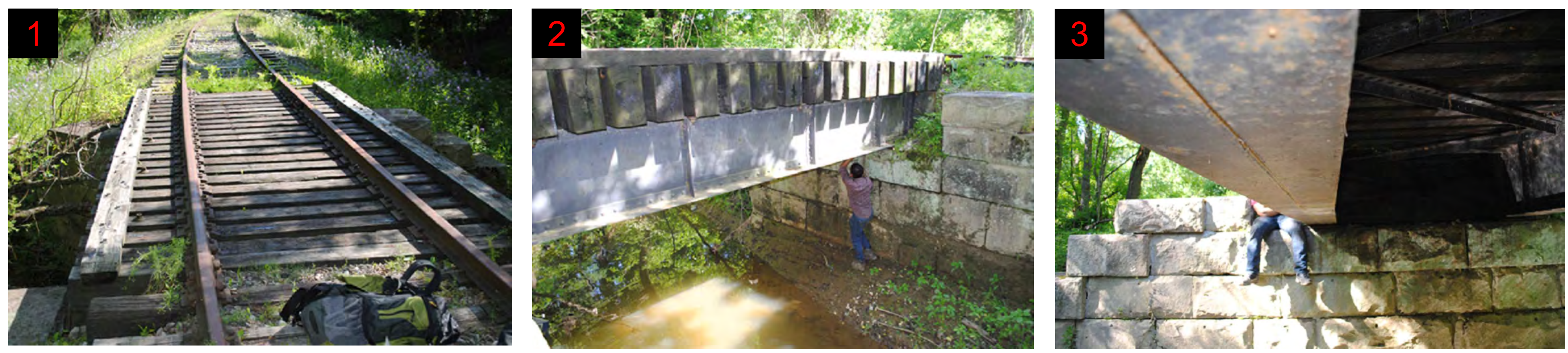

General Notes:

1. - End view of bridge.

2. - Elevation view of bridge.

3. - Abutment stone from West side of North abutment has been

dislodged and is in the creek.

4. - Bent stiffener.

ACTION: Monitor for future changes.

5. - Light corrosion on cross bracing.

ACTION: Monitor and clean/paint as needed.
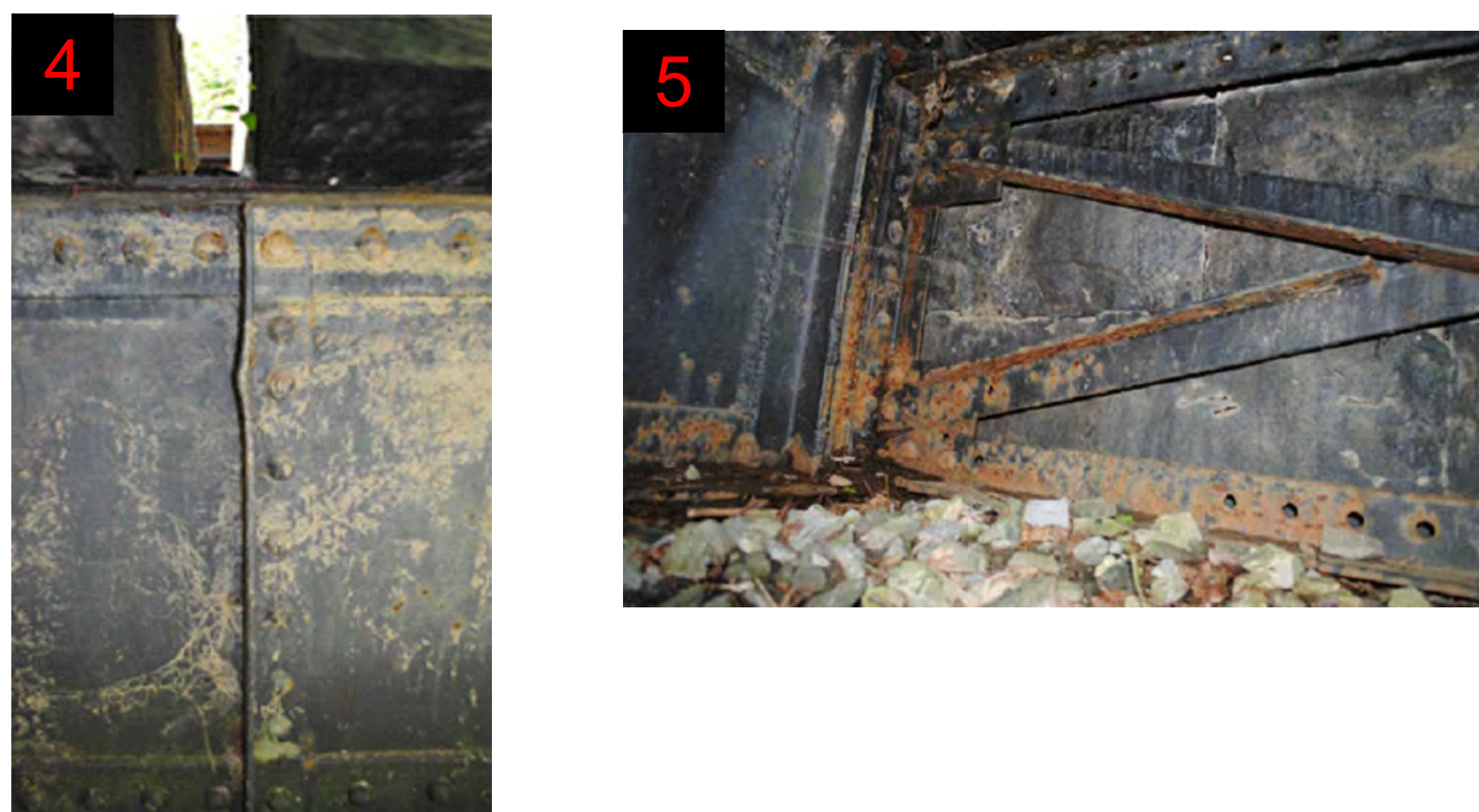

\begin{tabular}{|l|l|l|}
\hline The West Virginia Department of Transportation \\
State Rail Authority
\end{tabular}

